


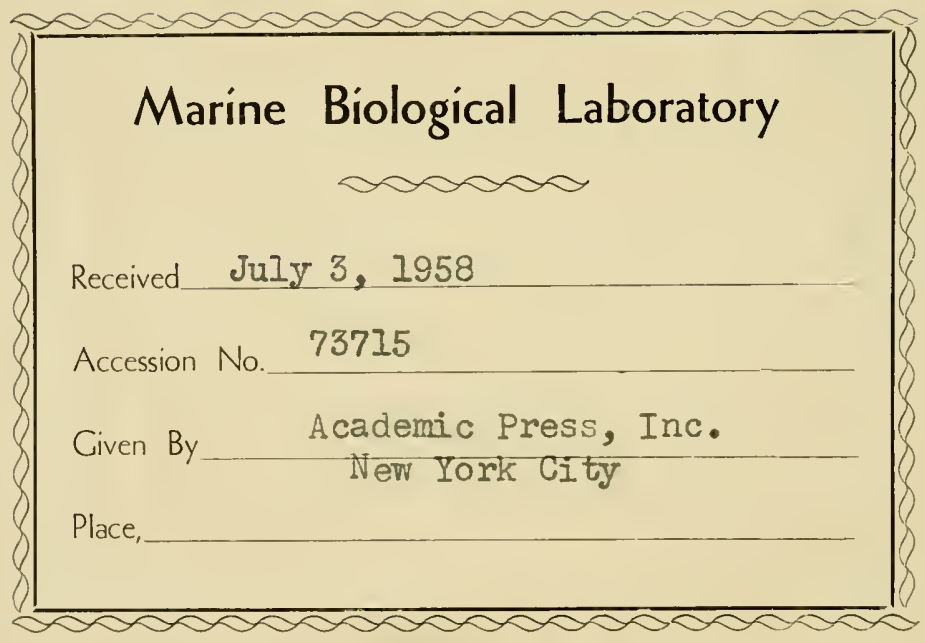




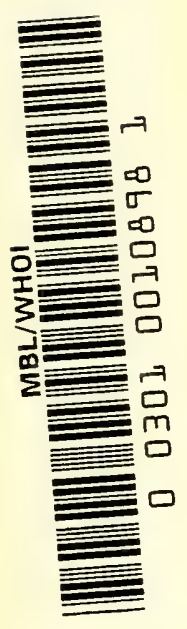



THE ORIGIN OF LIFE

ON THE EARTH 



\title{
THE ORIGIN OF LIFE ON THE EARTH
}

\author{
A. I. OPA R I N \\ ACTIVE MEMBER OF THE ACADEMY OF SCIENCES \\ OF TIHE U.S.S.R. \\ THIRD REVISED AND ENLARGED EDITION
}

Translated from the Russian

by

A N N S Y N G E

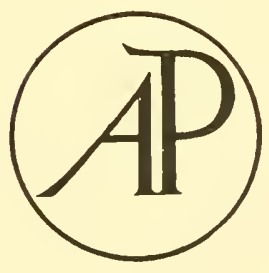

ACADEMIC PRESS ING., PUBLISHERS NEW YORK $\cdot 1957$ 
OLIVER \& BOYD LTD.

Tweeddale Court, High Street

Edinburgh 1, Scotland

Edition for all of the Americas, except Canada

\author{
Published by \\ ACADEMIC PRESS INC. \\ 11 Fifth Avenue \\ New York 3, New York
}

ALL RIGHTS RESERVED

This book may not be reproduced by any means, in whole or part, without the written permission of the Publishers 


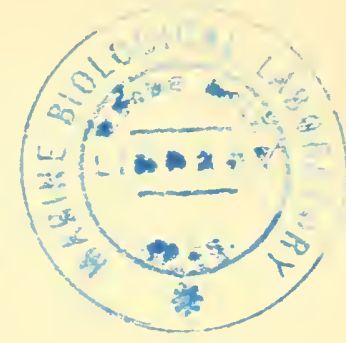

$\mathrm{M}$

$Y$ FIRST WORK on the origin of life was published as a small booklet in 1924 (Proiskhozhdenie zhizni. Moscow: Izd. Moskovskiǐ Rabochiǐ). In it I formulated, though very schematically, the essentials of this problem.

I explained these propositions in an expanded form in my book Vozniknovenie zhizni na zemle (The origin of life on the Earth) (Moscow: Izd. AN SSSR), the first edition of which was published in 1936 . The second edition was published in 1941 without substantial alteration.

After a lapse of 20 years there has accumulated a very large amount of factual material bearing on the origin of life derived from various fields of scientific endeavour. This allows us to draw a considerably more definite picture of the successive stages in the development of matter on the way to the origin of life.

The 1941 edition of the book has, accordingly, been thoroughly revised in the light of this new factual material. The only important features which have been retained from the earlier editions are the fundamental ideas and propositions.

I wish to express my profound thanks to Professors N. M. Sisakyan, A. G. Pasynskǐ̌, A. N. Belozerskiř, V. L. Kretovich and G. A. Deborin for looking over particular chapters of the book and for their valuable criticisms and advice, and also to all my colleagues in the A.N. Bach Institute of Biochemistry of the Academy of Sciences of the U.S.S.R. who have helped me in my work on this edition.

I wish also to make special recognition of the hard and valuable work expended on this task by Candidate in Biological Sciences N. S. Gel'man. 
In connection with the English language edition of the book I should like to extend my hearty thanks to Mrs. Ann Synge for her work in translating it and also to the publishers, Messrs. Oliver and Boyd.

\section{A. Oparin}

16.10 .56 . 


\section{TRANSLATOR'S PREFACE}

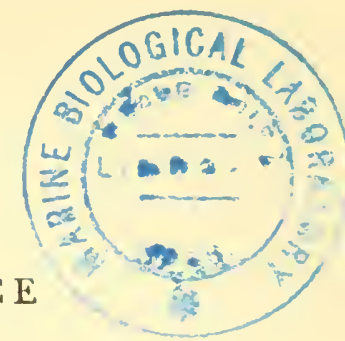

$\mathrm{T}$

His BOoK is a complete translation of the text of the third and completely revised edition of Professor been left out. The Russian and English editions should appear more or less simultaneously. The first edition was translated into English by Professor Sergius Morgulis and was published under the title The origin of life by the Macmillan Company (New York, 1938). It was reprinted by Dover Publications Inc. (New York, 1953).

I could not have undertaken this translation unaided and have received much help from many sources. My husband has helped at all stages. In particular, he has dealt with the bibliography and checked the spelling of all proper names which had to be transliterated from the Russian alphabet. He writes: "Transliteration of Russian names is by the system used in Chemical Abstracts (see annual author index). Titles of periodicals have been abbreviated, in general, as in the World list of scientific periodicals published in the years I900-I950 (London (Butterworth Scientific Publications), 1952). However, for most Russian journals the abbreviations are as in Chemical Abstracts (see indexes for $195^{1}$ and 1956); these will be found as good, or better, for tracing the periodicals in the World list itself. Alternative transliterations of the names of authors are given in brackets where this seems bibliographically helpful. Where the author cites Russian review articles and books I would like to have included supplementary references to works more accessible to English readers, but circumstances have prevented me from doing this in more than a few instances. In connection with verifying the references I am grateful for their unstinted help to many librarians, and especially to the staffs of the Reid Library, Bucksburn, and of the Library of the University of Aberdeen."

I have also received advice and help from Mr. N. W. Pirie, who read the typescript, and from Dr. H. Lees and Mr. 
M. V. Tracey who read the proofs. My technical and terminological advisers are in no way responsible for the views expressed in the book. I hope their, perhaps unconscious, attempts to use it as a platform for their own scientific views have not distracted me from an accurate presentation of Professor Oparin's ideas. He has, in any case, checked the translation in detail from beginning to end.

The following illustrations are reproduced by courtesy of the authors and publishers cited: nos. 4 and 5, McGraw-Hill Book Co. Inc.; no. 10, the Director of Lund Observatory, on behalf of the late Dr. W. Gyllenberg; no. 20, Prof. Linus Pauling and the National Academy of Sciences of the U.S.A.; nos. 23 and 24, Prof. G. Schramm and the Editors of Nature; no. 25 , Dr. F. H. C. Crick and the Editors of Nature; no. 26 , the Publisher of The Scientific American; nos. 31 and 32, the Wistar Institute of Anatomy and Biology; no. 34, Dr. M. Yčas and the National Academy of Sciences of the U.S.A.; no. 35, the Springer-Verlag, Vienna; nos. 38, 39, 41, 42, 43 and 44 , the Academic Press Inc.

My thanks are due to all those I have mentioned and to my teacher, Mrs. Vera Raitt, who has helped me in my struggles with the Russian language, as well as to many others who have helped with typing, illustrations, references and other matters, not forgetting the publishers, Messrs. Oliver and Boyd, who have made strenuous efforts to get the book out in time for the first international Symposium on the Origin of Life, organised by the Academy of Sciences of the U.S.S.R. under the auspices of the International Union of Biochemistry.

ANn Synge

Aberdeen, April 1957 . 


\section{INTRODUCTION}

The question of the emergence of life, of the origin on the Earth of the first living things, raises a number of important and fundamental problems of natural philosophy. Every man, whatever his stage of development, has, consciously or unconsciously, put this question to himself and found some sort of answer to it, for without some such answer one cannot form even the most primitive picture of the world.

History shows that the problem of the emergence of life has fascinated the human mind from time immemorial. There has been no religious or philosophic system and no great thinker that has not devoted serious attention to this problem. In different epochs and at different stages of cultural development the question of the origin of life has been answered in different ways. This problem has however always been the focus of a bitter conflict of ideas between two irreconcilable schools of philosophy-the conflict between idealism and materialism.

At the beginning of our century this conflict did not merely fail to abate but took on a special bitterness because, although science had already achieved glittering and dizzy successes in many fields, it seemed unable to give a rational, scientifically based answer to the question of the origin of life. It appeared that a dead end had been reached as far as this problem was concerned.

Such a state of affairs was by no means fortuitous. It may be explained as follows. About a century ago almost everybody held that the principle of spontaneous generation prevailed so far as the origin of life was concerned. They were convinced that living things could originate, not only from others like themselves, but that they could also come into being spontaneously, appearing all at once, fully formed and organised, among inanimate objects.

Both idealists and materialists held this point of view. The only point of dispute was: what was the cause and what the nature of the forces determining this coming into being. 
According to the idealistic way of thinking all living things, including human beings, originally came into being in more or less the same form in which we now see them, owing to the effect of supernatural spiritual forces, that is to say as the result of a creative act by a deity, formative originating spirit, life force, entelechy or some such concept. In other words, they arose as the result of the influence of a primary spiritual cause which was, itself, according to the idealists, the essence of life.

In opposition to this, the materialistically minded scientists and philosophers set out from the premise that life is material in nature like everything else in the world, and that no spiritual force need be invoked to explain its origin. As most of them accepted spontaneous generation as a fully confirmed 'fact', they had to explain it as the result of the action of natural laws, while denying the intervention of any spiritual force whatever. It seemed to them that the most direct approach to a solution of the problem of the origin of life was to find in nature, or produce in the laboratory, instances of spontaneous generation, and to study the phenomenon by all the available scientific methods.

However, very accurate observations and experiments, especially the researches of Louis Pasteur, demonstrated conclusively the illusory nature of the very 'fact' of the spontaneous generation of even the most primitive organisms from inanimate material. It was established with complete certainty that all previous reports of the occurrence of spontaneous generation had been the fruit of errors of method, incorrect setting up of experiments or superficial interpretation of them.

This removed the ground from under the feet of those students of nature who saw spontaneous generation as the only conceivable way in which life could have arisen. After Pasteur they lost all possibility of an experimental approach to the solution of this problem and this led them to form very pessimistic conclusions and to assert that the problem of the origin or life was 'accursed' and that it was an insoluble question unworthy of the work of any serious investigator and to study it would be simply a waste of his time. 
This led to a serious crisis in the ideas of many scientists of our century concerning the problem with which we are dealing. Some of these scientists tried to get out of the question by suggesting that life never arose on Earth but that the first living things were brought here from somewhere else such as the surface of one of the nearer or more distant planets. Others got round the question of the origin of life by adopting openly idealistic positions and declaring that the problem belonged, not to the province of science but to that of faith.

It was, of course, not the nature of the problem which led to this crisis but the fact that scientists were using faulty methods in their approach to it.

It was the outstanding service of Charles Darwin to biology that he broke with the earlier metaphysical methods for attacking the problem of the origin of the existing forms of animals and plants. He showed, beyond question, that highly organised living creatures can appear on the Earth only as the result of prolonged development, that is, evolution of higher forms from lower ones. In the absence of such evolution it was impossible to maintain that human beings or other highly developed organisms had arisen by natural means without the intervention of any spiritual or supernatural agency.

However, even after Darwin's work, scientists approached the problem of the origin of the very simplest living things, which were the first ancestors of every living thing on Earth, in the same metaphysical way which had prevailed in regard to more highly organised organisms before Darwin's time. We have, however, already seen that, even after the work of Darwin, people tried to explain the origin of life by separating it from the general development of matter. They regarded it as a sudden act of spontaneous generation of organisms which, though themselves primitive, were still endowed with all the complicated attributes of life. This approach to a solution of the question was, however, found to be radically inconsistent with the results of experiment and observation and could therefore lead to nothing but bitter disappointment.

A completely different prospect opens out before us if we try to approach a solution of the problem dialectically rather 
than metaphysically, on the basis of a study of the successive changes in matter which preceded the appearance of life and led to its emergence. Matter never remains at rest, it is constantly moving and developing and in this development it changes over from one form of motion to another and yet another, each more complicated and harmonious than the last. Life thus appears as a particular very complicated form of the motion of matter, arising as a new property at a definite stage in the general development of matter.

As early as the end of last century Frederick Engels indicated that a study of the history of the development of matter is by far the most hopeful line of approach to a solution of the problem of the origin of life. These ideas of Engels were not, however, reflected to a sufficient extent in the scientific thought of his time.

Even in the first decades of this century only a very few of the leading scientists came out in support of the idea that life originated as the result of an evolutionary process. Their pronouncements were, however, still of a very general character and could not overcome the stagnation in the scientific fields concerned with the problem of the origin of life.

Scientists have acquired a large number of facts during the twentieth century and it is only on the basis of these that we have now, at last, been able to draw a schematic picture of the evolutionary development of matter and set out the stages through which it must successively have progressed on the way to the emergence of life. As a result of this, wide possibilities for experimental work on the problem of the origin of life have been opened up. This time, though, interest was not focussed on hopeless attempts to discover instances of spontaneous generation but on the study and experimental reproduction of phenomena which were not merely possibilities but were completely subject to natural laws and took place successively in the evolutionary development of matter.

This situation gave rise to a complete recasting of the ideas of scientists in relation to the problem of the origin of life. During the course of nearly all the first half of the twentieth century this problem was almost entirely excluded from the domain of science and it only received an insignifi- 
cant amount of space in the scientific literature of the world. Now, however, large numbers of books, articles, reviews and experimental papers are already being devoted to it. To-day we are not satisfied by any merely speculative interpretation of the history of the phenomena which have occurred at some time or another on our planet. We must check our knowledge by experiment. We must reproduce experimentally the separate stages in the historical development of matter and finally create life again, synthetically, not by the long and devious route by which this synthesis took place in nature, but by a route based on a thorough understanding of those forms of organisation which we find already in a finished state in existing living things.

This task is certainly exceptionally complicated but contemporary science has indications upon which it can, at least, make an estimate of the work in real terms.

In what follows I shall do my best to make clear the ways in which human minds have tried to solve the problem of the origin of life. I shall give a short account of the numerous doctrines and theories which have been formed during many centuries, but I shall devote the greater part of my attention to drawing a picture of the progressive development of matter which, in my opinion, led up to the emergence of life on our planet.

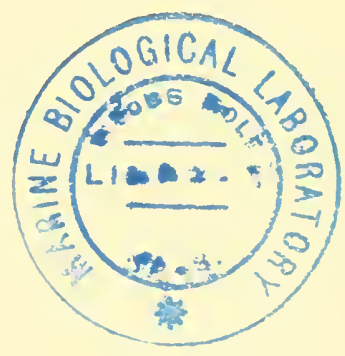





\section{CONTENTS}

\begin{tabular}{|c|c|c|c|}
\hline Preface & $\ldots$ & $\ldots$ & $\ldots$ \\
\hline Translator's Preface & $\ldots$ & $\ldots$ & ... \\
\hline Introduction & & $\ldots$ & \\
\hline
\end{tabular}

\section{Chapter I}

\section{THEORIES OF THE SPONTANEOUS GENERATION}

\section{OF LIFE}

$\begin{array}{lllllll}\text { Ancient and mediaeval beliefs ... } & \ldots & \ldots & \ldots & 1\end{array}$

$\begin{array}{llllllll}\text { Redi's experiments } & \ldots & \ldots & \ldots & \ldots & \ldots & 17\end{array}$

Hypotheses concerning the spontaneous generation of $\begin{array}{llllllll}\text { microbes ... } & \ldots & \ldots & \ldots & \ldots & \ldots & \ldots & 19\end{array}$

$\begin{array}{lllllll}\text { The work of Pasteur } \ldots & \ldots & \ldots & \ldots & \ldots & 28\end{array}$

\section{Chapter II}

\section{THE THEORY OF THE ETERNITY OF LIFE}

The theory of the eternity of life among the ancients $\quad \ldots \quad 43$

The emergence of hypotheses concerning the eternity of life $\begin{array}{llllll}\text { in the nineteenth century } & \ldots & \ldots & \ldots & \ldots & 45\end{array}$

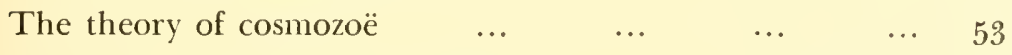

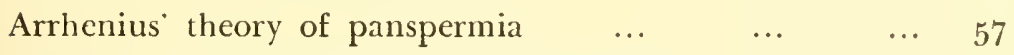

The state of the problem at the present day $\quad \ldots \quad \ldots 66$ 
ATTEMPTS AT A SCIENTIFIC APPROACH TO THE PROBLEM OF THE ORIGIN OF LIFE

The mechanistic concept of the self-formation of living things

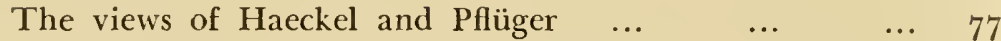

Attempts to construct 'models of living organisms' $\ldots 86$

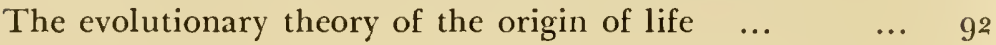

\section{Chapter IV}

THE ORIGINAL FORMATION OF THE SIMPLER ORGANIC SUBSTANCES

The question of the original formation of organic sub-

The distribution of organic substances (hydrocarbons) on

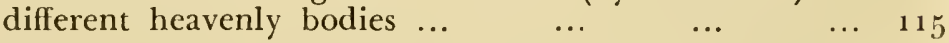

Geological finds of hydrocarbons formed abiogenically on the Earth

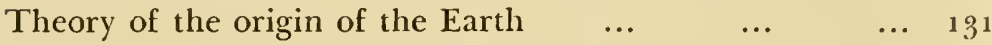

Ways in which organic compounds could have arisen during the formation of the Earth

\section{ChAPTER V}

\section{ABIOGENIC ORGANIC-CHEMICAL EVOLUTION OF CARBON COMPOUNDS}

Thermodynamics and kinetics of the transformation of the simplest hydrocarbons in the lithosphere, atmosphere

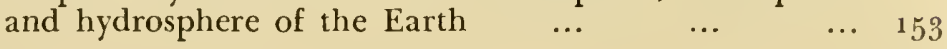
$\begin{array}{lllllll}\text { Reducing conditions ... } & \ldots & \ldots & \ldots & \ldots & 158\end{array}$ 


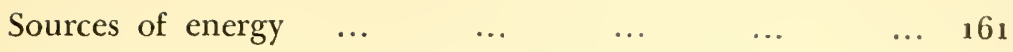

The origin of carbohydrates, lipids, porphyrins, amino acids, nucleotides, polynucleotides and protein-like $\begin{array}{llllllll}\text { polypeptides } & \ldots & \ldots & \ldots & \ldots & \ldots & 189\end{array}$

\section{Chapter VI}

\section{THE STRUCTURE AND BIOLOGICAL FUNCTIONS OF PROTEINS AND NUCLEIC ACIDS AND THE PROBLEM OF THEIR ORIGIN}

Chemical structure and biological functions of polypeptides and proteins

The amino acid composition and sequence in the structure of the macromolecules of proteins $\ldots \quad \ldots \quad \ldots \quad \ldots 236$

Hormones, enzymes, antibiotics and antigens $\quad \ldots \quad \ldots \quad \ldots 243$

$\begin{array}{lllllll}\text { The biosynthesis of proteins } & \ldots & \ldots & \ldots & \ldots & 259\end{array}$

ChAPTER VII

THE DEVELOPMENT OF ORGANIC

MULTIMOLECULAR SYSTEMS: THEIR ORGANISATION IN SPACE AND

IN TIME

Simple and complex coacervates … 301

The structure and properties of complex coacervate drops 307 Points of similarity between complex coacervates and protoplasm

‥ 311

$\begin{array}{lllllll}\text { Stationary open systems } & \ldots & \ldots & \ldots & \ldots & 321\end{array}$

The thermodynamics and kinetics of open systems $\quad \ldots \quad 323$

The initial systems from which living things arose $\quad \ldots \quad 335$ 


\section{THE ORIGIN OF THE FIRST ORGANISMS}

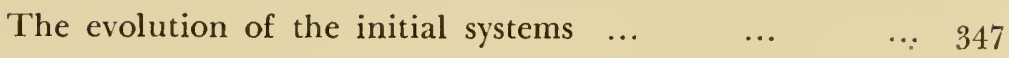

$\begin{array}{lllllll}\text { The principle of selection } & \ldots & \ldots & \ldots & \ldots & 349\end{array}$

Processes of self-renewal of the systems ... $\quad \ldots \quad \ldots \quad \ldots \quad 354$

The origin of the capacity of the systems for self-preserva-

$\begin{array}{lllllll}\text { tion and growth } & \ldots & \ldots & \ldots & \ldots & \ldots & 356\end{array}$

The origin of the highly dynamic state of the systems $\quad \ldots \quad 35^{8}$

The origin of systems capable of reproducing themselves 359

The evolution of metabolism: the origin of enzymes $\quad \ldots \quad 363$

The origin of the co-ordinated networks of reactions: the $\begin{array}{lllll}\text { origin of the first organisms } & \ldots & \ldots & \ldots & 374\end{array}$

\section{Chapter IX}

\section{THE FURTHER EVOLUTION OF}

THE FIRST ORGANISMS

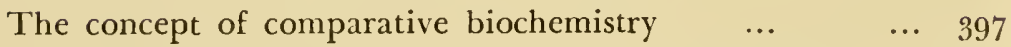

The first living things-heterotrophs and anaerobes $\ldots 399$

$\begin{array}{llllll}\text { Different forms of energy metabolism } \ldots & \ldots & \ldots & 419\end{array}$

$\begin{array}{llllllll}\text { Photochemical reactions } & \ldots & \ldots & \ldots & \ldots & 438\end{array}$

$\begin{array}{lllllll}\text { The formation of free oxygen } \ldots & \ldots & \ldots & \ldots & 448\end{array}$

$\begin{array}{llllllll}\text { Chemosynthesis } & \ldots & \ldots & \ldots & \ldots & \ldots & 450\end{array}$

$\begin{array}{lllllll}\text { Photosynthesis } & \ldots & \ldots & \ldots & \ldots & \ldots & 455\end{array}$

$\begin{array}{lllllll}\text { The origin of respiration } & \ldots & \ldots & \ldots & \ldots & 464\end{array}$

$\begin{array}{llllllll}\text { Conclusion } & \ldots & \ldots & \ldots & \ldots & \ldots & 487\end{array}$

$\begin{array}{lllllll}\text { Index } & \ldots & \ldots & \ldots & \ldots & \ldots & 491\end{array}$





\section{THEORIES OF THE SPONTANEOUS GENERATION OF LIFE}

\section{Ancient and mediaeval beliefs.}

For many centuries people considered that the Earth was flat and inmovable and that the Sun circled round it, rising in the east and hiding itself behind the sea or the mountains in the west. This false belief rested on direct uncritical observation of surrounding nature. Observations of this kind often suggested that living things, for example insects, worms, and sometimes even fish, birds and mice could not only be born from things like themselves but could also arise fully formed by spontaneous generation, out of mud, dung, earth or other inanimate substances.

We may find a belief in the possibility of the spontaneous generation of living things amongst all peoples and at all times; beginning in remote antiquity and finishing in our own days. Even now, in the period of the blossoming of exact science in the culturally advanced nations, it is common for their ordinary inhabitants to be convinced that maggots arise from dung and rotting meat and that various domestic pests arise of their own accord out of rubbish, mud and dirt. These superficial observations miss the fact that dung and filth are to be found in those places where pests lay their eggs from which the new generation of living things develops.

Tremendous significance was attached to these everyday, uncritical observations of creation characteristic of ancient peoples, at a time when nature was still not studied in detail, nor submitted to analysis and dissection but was accepted in its entirety as the immediate perception of the intuition. In his book Urzeugung und Lebenskraft, E. O. v. Lippmann ${ }^{1}$ gives a wide range of material to show how extensively such 
beliefs were held. For example, in China in remote times people believed that aphids would grow by spontaneous generation on bamboos if the young shoots were planted out in warm moist weather. In the Indian holy books there are also references to the sudden appearance of various parasites, flies and beetles from sweat and dung. In the cunciform writings of Babylon one may read that the mud of canals forms worms and other animals from its substance. ${ }^{2}$

In ancient Egypt the view prevailed that the layer of silt left behind after the flooding of the Nile could give rise to living creatures when it was warmed a little by the sun. Frogs, toads, snakes and mice could originate in this way. In this case one might easily convince oneself by direct observation that the front part seemed already finished and alive while the hind part still consisted of undifferentiated damp earth.

We also find a repetition of these tales among the ancient Greeks (e.g. Diogenes Apolloniates) and in the writings of the famous Roman sage, Pliny. Such stories were widely current both in the East and the West, in the Middle Ages and far more recently. Shakespeare's audiences were not surprised when Lepidus, in Antony and Cleopatra, asserted that in Egypt crocodiles are produced from the mud of the Nile under the influence of the warm southern sun. ${ }^{3}$

In general, it appears to be highly characteristic of the history of spontaneous generation that among diverse peoples living at different times and at different cultural stages, we almost always find stories of the spontaneous development of organisms of one kind or another. Here maggots arise from dung and rotting meat, here lice form themselves from human sweat, here fireflies are born from the sparks of a funeral pyre, and finally, frogs and mice originate from dew and damp earth. Wherever man has met with the unexpected and exuberant appearance of living things he has regarded it as an instance of the spontaneous generation of life. Among the ancient peoples the belief in spontaneous generation did not arise as a consequence of any particular philosophy. For them spontaneous generation was simply an obvious, empirically established fact the theoretical basis of which was of secondary importance. 
The ancient teachings of India, Babylon and Egypt bound up the origin of life with various religious legends and traditions. From this point of view spontaneous generation was merely a particular manifestation of the creative will of gods or demons. But at the very source of our European culture in ancient Greece, on the replacement of theogony, a mystical interpretation of nature, cosmogony arises as the beginning of scientific investigation.

Although all the Greek philosophers from the Miletians to Epicurus and the Stoics acknorvledged spontaneous generation as an incontrovertible fact, their philosophical treatment of this fact went far beyond the framework of the previous mystical presentations. ${ }^{4}$ They contained the beginnings of all the concepts which were developed later in connection with the question of the origin of life.

Even the earliest Greek philosopher, Thales, who lived from about 624 to 547 B.C., approached the problem of the essential nature and origin of life from an elementarymaterialist position. Thales and the other philosophers of the Miletian school (Anaximander and Anaximenes) recognised, as a fundamental principle, the objective existence of matter as something which is always living and always changing from the beginning of time. Life is inherent in matter as such. Thus, although the Miletians believed in the spontaneous generation of living things from mud, slime and such materials, they treated this phenomenon as the selfcreation of individual organisms, and not as one requiring the intervention of any special mystical force. This point of view was developed later by Empedocles $^{5}$ (c. $485-425$ B.C.), who held that plants and animals are formed from substances which, although not organised, are already living, either by birth from things like themselves or from things unlike themselves, i.e., by spontaneous generation. A particularly clear enunciation of the idea of the self-creation of living things is to be found in the works of Democritus ${ }^{6}$ (46o-37o B.C.). In this doctrine ancient Greek materialism reached the height of its development although it had also already acquired a somewhat mechanistic character. According to the view of Democritus matter forms the basis of the universe and consists of a multitude of very small particles (atoms) which 
are in constant motion and are separated from one another by empty spaces. This mechanical motion of the atoms is inherent in matter, and on it depends the process of organisation of all individual objects. In particular, life appears, not from an act of divine creation, but as the result of the mechanical forces of nature itself. According to Democritus the primary development of living creatures, or their spontaneous development from water and mud, occurs when minute particles of moist earth come together with atoms of fire in a fortuitous but completely determinate way in the course of their mechanical movement. Another illustrious ancient Greek thinker, Epicurus ${ }^{7}(342-271$ B.C.) took up the same philosophical position a hundred years later. We may find an exposition of his views in the well-known poem of Lucretius Carus, De rerum natura. ${ }^{8}$ According to this source, Epicurus taught that, thanks to the moist heat of the sun and the rain, there arise from earth or manure, worms and a multitude of other creatures. But this happens without the participation of any spiritual influence whatever. Spirits, in the form of non-material forces, do not exist, according to Epicurus. The spirit is material and consists of small, very delicate and smooth atoms. The mechanical juxtaposition of atoms in empty space also leads to the formation of multifarious things, in particular, living beings. According to him, the cause of the motion of the atoms resides in matter itself and does not depend on any 'initial impulse' or other meddling of gods in the affairs of the world.

Thus, even hundreds of years before the beginning of our era, the phenomenon of spontaneous generation was explained materialistically by many schools of philosophers as being the self-creation of living things without the participation of any spiritual forces. The matter may be summed up historically by saying that the later development of the idea of spontaneous generation was bound up, not with the materialistic 'line' of Democritus but with the opposing idealistic 'line ' of Plato.

Plato himself (427-347 B.c.) hardly concerned himself directly with the problem of spontaneous generation. In the Phaedo he only touches superficially on the question of the possibility of the formation of living things under the influence of 
warmth and decay. However, in complete harmony with his general philosophical position, he maintained that life is not inherent in plant and animal matter but this can only be brought to life by the infusion into it of the immortal spirit or Psyche. ${ }^{9}$

This idea of Plato's played a tremendous part in the later development of the problem in which we are interested. It was reflected to some extent in the teaching of Aristotle which later formed the basis of the mediaeval scientific culture and dominated people's minds for nearly 2000 years.

Aristotle ( $38_{4}-322$ B.C.) gave to mankind by far the broadest synthesis of the achievements of ancient science, embracing all the factual material which had been accumulated up till that time. He unfolded his views on the origin of life in a number of biological works concerning the origin of animals: Historia animalium, De partibus animalium, and De generatione animalium. ${ }^{10}$ According to Aristotle animals are born from others like themselves but equally, they arise and always have arisen by spontaneous generation from nonliving matter. He wrote as follows:

Such are the facts, everything comes into being, not only from the mating of animals but from the decay of earth and dung. . . . And among plants the matter proceeds in the same way, some develop from seed, others, as it were, by spontaneous generation by natural forces; they arise from decaying earth or from certain parts of plants.

Ordinary worms, the grubs of bees and wasps and also ticks, greenflies and various other sorts of insects arise, according to Aristotle, from dews in the presence of decaying mud and dung, from dry trees, hair, sweat and meat. All sorts of intestinal worms are formed from decomposing parts of the body and excreta. Midges, flies, moths, mayflies, dung beetles, cantharides, fleas, bugs and lice (partly as such and partly as grubs) arise from the slime of wells, rivers and seas, from the soil of the fields, from mould and dung, from rotting wood and fruit, the dirt of animals, from all sorts of filth, from the sediment of vinegar and also from old wool. ${ }^{11}$ Not only insects and worms but other living things can, according to Aristotle, arise by spontaneous generation. Thus 
crayfish and various molluscs originate from wet earth and decaying slime, eels and some other fishes from marine silt, sand and decaying water weeds. Even frogs, and under certain circumstances salamanders too, can arise from the curdling of slime. Mice arise from damp earth. Some higher animals also arise in a similar way, first manifesting themselves in the form of worms. "For this reason, and concerning human beings and quadrupeds", Aristotle wrote, "if they were sometimes earth-born, as some people maintain, one may postulate two methods of arising, either from worms which form themselves first, or from eggs."

However Aristotle did not merely describe various cases of spontaneous generation. An important feature of his work was that he gave a theoretical analysis of this phenomenon and founded his theory of spontancous generation. In the course of time it seems that his views changed, but in the last analysis they served as the basis of the idealistic hypotheses concerning the origin of life.

Aristotle considered that living things, like all other concrete objects (substances), are formed by the conjunction of some passive principle, 'matter' (by this word Aristotle obviously meant what we now call material), with the active principle of 'form'. The 'form' of living things manifests itself in the 'entelechy of the body'-the soul. This shapes the body and sets it in motion. Thus matter does not possess life but is infused with it. It is adapted and organised by means of a spiritual force ; an orientating internal substance (entelechy) brings matter to life and sustains the living thing. The spirit, however, is already inherent in the actual elements from which living things are formed, it is inherent in a smaller degree in the earth and in a greater degree in water, air and fire. Because of this, that which is created by the spirit depends substantially on the preponderance of this or that element. Earth produces mainly plants; water, aquatic animals; air, the inhabitants of the land; and fire, the supposed inhabitants of the celestial bodies, in particular, the moon. For their 'form' living things which arise from others like themselves depend on 'animal warmth' and when they arise by spontaneous generation on 'solar 
warmth'. Thus, in spontaneous generation, decaying materials do not on their own give rise to life; they are brought to life under the influence of the light of the sun which gives 'psychic warmth'.

The views of Aristotle exerted an enormous influence on the whole subsequent history of the problem of the origin of life. Aristotle, with his undisputed authority, supported the results of direct, naive observation, and for many centuries ahead prejudiced further study of spontancous generation. All the later philosophical schools, both Greek and Roman, completely shared the opinion of Aristotle on the possibility of spontaneous generation of living beings. Moreover, as time went on the theoretical basis of the 'phenomenon' took on a more and more idealistic, indeed even mystical, character.

A whole series of writings, from the 3 rd and and centuries B.C., contain numerous tales and 'miraculous stories' of 'plagues of lice' in which the juices of the human body are changed into parasites, of the appearance of worms and insects from rotting materials, of crocodiles from the mud of the Nile, and so forth. Concerning such matters, the most authoritative philosophical school of that time, the Stoics, taught that animals and plants originate as a result of the activity of 'engendering force' which is a property of pneuma.

From the later Stoics this view obtained a wide circulation in both East and West, through a number of philosophers and writers, particularly the much-travelled Poseidonius. It thus obtained general recognition at the beginning of our own era. In scientific treatises, in political pronouncements and in artistic productions of that period we meet continually with descriptions of various cases of spontaneous generation. We find them in the works of Cicero, of the famous geographer Strabo, of the versatile scholar Philo of Alexandria, of the historian Diodorus Siculus, of such poets as Virgil and Ovid, as well as in the works of the later writers Seneca, Pliny, Plutarch and Apuleius. ${ }^{12}$

The idealistic character of the teachings concerning spontaneous generation was clearly expounded by the neo- 
Platonists (in the third century A.D.). The leader of this philosophical school, Plotinus, taught that living things could originate from earth, and that this method of origin was not confined to the past but also continues now, in the course of decay. He explained this phenomenon as the result of the animation of matter by a life-giving (vivere facit) spirit, and it seems that he was the first to formulate the concept of the 'Life Force' which has persisted even up to the present in the teachings of the contemporary vitalists. ${ }^{13}$

Early Christianity borrowed guiding ideas concerning spontaneous generation from the Bible, which in its turn borrowed its material from the mystical tales of Egypt and Babylon. The theological authorities of the end of the fourth and beginning of the fifth centuries A.D., "the fathers of the Christian Church ', combined these legends with the teachings of the neo-Platonists and elaborated their mystical conception of the origin of life on this basis.

Living in the middle of the fourth century A.D. was St. Basil the Great who was then and still is one of the leading religious authorities of the Eastern Church. It was under his influence that the leaders of the Orthodoxy formulated their beliefs concerning the origin of life. His book Hexaëmeron still retains its place in Church literature, particularly in the Russian language. Discussing the problem in which we are interested, he writes as follows:

For if there are creatures which are successively produced by their predecessors, there are others that, even today, we see born from the earth itself. In wet weather she brings forth grasshoppers and an immense number of insects which fly in the air and have no names because they are so small ; she also produces mice and frogs. In the environs of Thebes in Egypt, after abundant rain in hot weather, the country is covered with field mice. We see mud alone produce eels; they do not proceed from an egg, nor in any other manner; it is the earth alone which gives them birth. ${ }^{14}$

According to Basil the Great all these instances of the spontaneous generation of life (many of which were obviously borrowed from Aristotle) occurred by divine command which has continued to act with undiminished force from the creation of the world to the present day. 
St. Augustine of Hippo is a high authority for the Western Church like St. Basil for the Eastern. He also accepted the spontaneous generation of living things as an unchanging truth and strove in his teachings simply to bring the phenomenon into line with the world philosophy of the Christian Church. Similarly, he wrote "God as a rule creates wine from water and earth through the mediation of grapes and their juice; however sometimes, as in Cana of Galilee, he can create it directly from water. Thus also, in respect of living things, he may cause them to be born from seeds or to emerge from inanimate matter where invisible spiritual seeds (occulta semina) repose."

Thus Augustine saw in the spontaneous generation of living things a manifestation of divine will - the animation of inert matter by the 'life-creating spirit'. In this he affirmed a doctrine concerning spontaneous generation which was in complete agreement with the dogmas of the Christian Church. ${ }^{15}$

Throughout the Middle Ages a belief in spontaneous generation held undivided sway over people's minds. Mediaeval philosophical thought could exist only as theological thought, embodied in one or another doctrine of the Church. Any kind of philosophical question could only obtain a hearing if it was linked with one or another theological problem. Philosophy became the "handmaid of theology', ancilla theologiae. ${ }^{16}$ The problems of science were relegated to a lower plane. People did not use observation and experiment as a guide to an understanding of nature but used instead the teachings of the Bible and of theological treatises. Only a very scanty knowledge of the problems of mathematics, astronomy and medicine penetrated into Europe from the Arab and Hebrew teachers.

It was in this way that the works of Aristotle first reached the European peoples, though often in the form of garbled translations. At first his teachings appeared dangerous, but later, when the Church appreciated the full usefulness of these teachings for many of its purposes, it raised Aristotle to the status of "the forerunner of Christ in the realm of nature' (praecursor Christi in rebus naturalibus). Accordingly, in the apposite words of V. Lenin, "the scholasts 
and clerics seized upon that which was dead in Aristotle and not upon that which was alive". ${ }^{17}$ This teaching was widely accepted by theologians in the Middle Ages, especially insofar as it concerned the origin of life. They held that the animation of lifeless matter by the 'eternal divine spirit' constituted the essence of it.

As an example one may here quote from one of the greatest exponents of scholastic Aristotelianism, the Dominican Albert von Bollstädt, known as Albertus Magnus (1193-1280). According to tradition, Albertus Magnus took a great interest in zoology, botany, alchemy and mineralogy. But in his numerous works he assigns considerably less place to independent observations than to material borrowed by him from ancient authors. On the question of the origin of life Albertus Magnus consistently supported the theory of spontaneous generation, and in his book De mineralibus he specially emphasised the fact that the origin of living things in the presence of decay occurs as a result of the 'animating force' (virtus vivificativa) of the stars.

In his writing on zoology Albertus Magnus gives many accounts of the spontaneous generation of insects, worms, eels, mice, etc., from various sorts of decaying materials, from moist earth, vapours, sweat and various forms of filth. In just the same way vapours of the earth and water give rise, under the influence of warmth and the light of the stars, to numerous plants, not only fungi but even to herbs, bushes and trees which often grow in places where their seed cannot have been carried. ${ }^{18}$

The pupil of Albertus Magnus, Thomas Aquinas (1225${ }_{1274)^{19}}$ also held such opinions. In his chief work, Summa Theologica, he deals with questions concerning the origin of life. In doing so he relies partly. on the views which he ascribed to Aristotle and partly on the teachings of Augustine about the 'anima vegetativa'. He thus freely accepted the possibility of the spontaneous generation of such animals as, for example, worms, frogs and snakes as an effect of the warmth of the sun in the presence of decay. Even those worms which torment sinners in the infernal regions arise, according to the opinion of Thomas Aquinas, in this way from the rotting of their sins. In general Thomas believed 
in and preached a militant demonology. He taught that the Devil really exists as the chief of a whole horde of demons. Hence he conceived the idea that various forms of pest harmful to man can arise as the result of tricks of the Devil and the spirits of evil subservient to him.

The practical results of this hypothesis manifested themselves in the numerous trials of witches who were charged with letting loose mice and other pests on to the fields and thus destroying the sown seed. And it is well known that Catholic bishops also used all sorts of spells and exorcisms in an effort to cast out worms, mice, cockchafers and other harmful creatures from the fields of those who had been confided to their care. According to Uhland, the Swiss and Tyrolese bishops in the sixteenth century laid the curses of the Church on all sorts of agricultural pests and, according to Bodenheimer, ceremonies of this sort persisted until the end of the eighteenth century. ${ }^{20}$

We have dwelt at some length on the views of Thomas Aquinas because, to this day, his teaching is acknowledged by the Catholic Church as the only true philosophy. Thus, the Western Church has retained through all the centuries the principle of the spontaneous generation of living things according to which living things originate from inanimate matter as a result of animation by a spiritual principle.

The standpoint of the theological authorities of the Eastern Churches is similar. In this matter they rely chiefly on the pronouncements of Basil the Great. The opinions on this subject of the outstanding and active participants in the work of the Russian Church, Dimitrir Rostovskir and Theofan Prokopovich, though formulated as late as the eighteenth century, may serve as an illustration. Dimitriř, bishop of Rostov, lived in the time of Peter I and in his works Annals relating shortly the acts from the beginning of the world until the birth of Christ (1708) he wrote that Noah did not take in his ark those animals which are capable of spontaneous generation; they were destroyed on the ground by the flood and then arose anew.

Moreover, from the moisture of the earth, from decay and putrefaction, there arise mice, toads, scorpions and other 
creatures which creep upon the earth, and various worms and even beetles, cockchafers and cockroaches; and also from heavenly dew there are conceived midges and gnats and other such things. These all perished in the Flood and after the flood they arose anew from such beginnings. ${ }^{21}$

In the course of theology which he gave in the Ecclesiastical Academy in Kiev Theofan Prokopovich developed, almost word for word, the same idea.

Furthermore, there is a multitude of animals which arise without copulation of the parents; independently, from rotten things, and there was thus no necessity to give shelter in the ark to creatures such as mice, worms, wasps, bees, flies and scorpions. ${ }^{22}$

Even in the nineteenth century a translation of a book by W. Frantze* was published by Benjamin, archbishop of Nizhegorod, in which it was stated that insects, worms, frogs and mice arise by spontaneous generation "from rotting tree stumps, from the dung of animals, from the sand of the sea, from decaying earth, from corpses . . . etc." ${ }^{23}$

As we have already pointed out, science was at a very low ebb in mediaeval Europe. It was in complete subjection to theology. The natural phenomena observed by the travellers and learned men of those times were not only discussed, but also described, as though scholastic wisdom demanded that they should be in complete conformity with the Church dogmas. The works of the learned men of the Middle Ages therefore abound in those same fantastic descriptions and sometimes even sketches of the spontaneous generation of various insects, worms and fishes from slime and damp earth, of frogs from the dews of May, and even of lions from the stones of the desert. It is specially characteristic of the mediaeval methods of the study of nature that at this time there was a wide diffusion of lore concerning goose trees, vegetable lambs and homunculi.

According to the testimony of very authoritative men of learning of those times, geese and ducks arise from barnacles which in their turn are derived from the fruits of trees. From these latter, birds may also be formed directly.

*Historia animalium sacra etc. Editio sexta. Wittebergae, 1659.-Translator. 
We find this tale of the goose tree as early as the beginning of the eleventh century in the works of Cardinal Peter Damian (1007-1072). The English encyclopaedist Alexander Neckam (1157-1217) considered that birds are formed from the resin of conifers on contact with the salt water of the sea. Furthermore, this story of the vegetable origin of ducks and geese became so widely accepted that their meat was used as lenten fare though this was later forbidden by a special order of Pope Innocent III (1198-1216).

But in spite of this, almost three centuries later, at the end of the fifteenth century, the nobleman Leo von Rozmital described a dinner given in his honour in London by the Duke of Clarence at which, as a hot dish described as fish (for lenten fare), were served ducks, which there generate themselves from 'worms' in the sea. However, Rozmital remarks that the taste of these 'fish' was exactly like that of ducks. ${ }^{24}$

It is interesting that the story of the goose tree persisted until the end of the sixteenth and even the beginning of the screnteenth century. A series of authors describe their personal observations on this subject and even give more or less fantastic drawings showing how the birds are gradually formed from the fruits of the tree.

Evidently this legend was based on the naive interpretation of superficial observations of barnacles of a special kind. In the adult state these marine animals attach themselves by a special kind of stalk to rocks, stones, the bottoms of ships and trees which have accidentally fallen into the water. On the shores of the north of Scotland, Ireland and the neighbouring islands this happens at the time when flocks of young Arctic geese fly there from the north.

These two phenomena were confused and fantasy, not knowing where they came from, drew a picture of the formation of birds from the barnacles found on the branches of trees. It may also be that analogous superficial observations formed the basis for the other stories concerning vegetable lambs. The well-known traveller Odoric di Pordenone (d. 1331) was the first to record this. It was related to him by 'reliable' people that in the Tatar kingdom of Khadli there grew enormous gourds which opened when they were ripe 
to reveal within themselves lambs covered with white wool and having very delicious meat. 'Sir John Mandeville' described his travels in Eastern lands and also told stories of a whole tree, from the melon-shaped fruits of which there arose living sheep..$^{25}$ This story persisted for centuries and as late as the middle of the seventeenth century it was repeated anew by Adam Olearius in his descriptions of his travels in Muscovy and Persia. He wrote:

We were told that there beyond Samara, between the rivers Volga and Don, there grows a rare form of melon or rather pumpkin which is very like an ordinary melon in size and shape but its appearance reminds one of a lamb because it has clearly defined limbs. The Russians therefore call it the 'little ram'. This 'vegetable lamb' feeds on the grass around it but frequently falls a prey to wolves, which are very fond of it.

Later, Olearius writes that he had the good fortune actually to see the wool of such a sheep. ${ }^{26}$

The story of the homunculus developed on the basis of alchemical experiments. It is known to have made its appearance as early as the first century A.D. This story was based on the supposition that by mixing the passive maternal original substance with the active masculine one it is possible to reproduce artificially the phenomenon of birth and to obtain the embryo of a tiny person-homunculus.

Like the legend of the goose tree and the vegetable lamb, stories about the homunculus were current throughout the Middle Ages and are to be met with in many alchemical treatises. A typical exponent of the earlier natural philosophy of the sixteenth century, Theophrastus Bombast von Hohenheim, known as Paracelsus (1498-1541), even gives an 'exact receipt' for the preparation of homunculi. For this it is necessary to obtain human sperm, place it in a sealed gourd inside a horse's stomach and during the course of a certain time to carry out a series of complicated manipulations. In this way there is formed a small person complete in all its parts, like children born of women but on a far smaller scale.

In general, Paracelsus was a convinced supporter of the spontaneous generation of living things. He maintained that there is an active life force, the arche, which governs the 
bodies of animals and men and which can be controlled by means of magic remedies. This force itself determines the formation of the organism and its later conduct. Paracelsus developed a theory of spontaneous generation of life with this philosophical outlook. He even produced a number of personal observations of the sudden formation of mice, frogs. eels and tortoises from water, air, straw, rotten wood and all sorts of rubbish. ${ }^{27}$ The descriptions of the views and beliefs of the learned men of the Middle Ages were excellently portrayed in Goethe's tragedy Faust. Here Mephistopheles refers to himself as "Der Herr der Ratten und der Mäuse, der Fliegen, Frösche, Wanzen, Läuse ", and a swarm of insects fly out from his old doctor's fur cloak and praise him not only as their patron but also as their father, as though he had ac $\_$ually begotten them there and then.

The part played by the homunculus in the second part of Faust is also well known. Wagner takes great pains with the preparation of his alchemical experiments. For this he mixes hundreds of substances, corks them up in a retort and proceeds to purify them by distillation. If the conjunction of the stars were favourable a manikin should develop in the retort. But even in this case the spontaneous generation did not occur without the intervention of Mephistopheles, whom the homunculus greeted as his ' cousin ' ${ }^{28}$

In the second half of the sixteenth century and, in particular, in the seventeenth century, observations of natural phenomena were getting more accurate. Copernicus (14731543), Bruno (1548-160o) and Galileo (1564-1642) destroyed the old Ptolemaic system and drew up sound theories concerning the universe of stars and planets which surround us. ${ }^{29}$ However, this blossoming of exact knowledge did not as yet touch upon biological problems. The idea of the primary spontaneous generation of living things remained unchallenged in the minds of the investigators of that time.

As an example we may here mention the well-known physician of Brussels, van Helmont (1577-1644). He used some methods of exact experiment which enabled him to make substantial progress in the study of the complicated problem of the nutrition of plants. Nevertheless, he was quite convinced that living things could arise by spontaneous 
generation and even went further and carried out a number of observations and experiments to confirm the hypothesis. For example, he gives a well-known receipt for making mice from grains of wheat. He held that human sweat could serve as the life-giving principle. For this it was necessary to place a dirty chemise in some sort of receptacle which contained wheat grains. After 21 days the 'fermentation' was stopped and the exhalations from the shirt together with those of the corn had formed living mice. It was especially surprising to van Helmont that these artificially produced mice were exactly like those born from the seed of their parents. ${ }^{30}$

Neither did Harvey (1578-1657), the originator of the theory of the circulation of the blood, reject the idea of spontaneous generation. However, although the celebrated phrase omne vivum ex ovo (everything alive comes from an egg) belongs to him, he was here giving a very wide meaning to the word egg. He considered generatio aequivoca (spontaneous generation) of worms, insects, etc., to be perfectly possible as a result of the activity of special forces which develop during putrefaction and similar processes. ${ }^{31}$

This also was the view of Harvey's contemporary, the founder of seventeenth century English materialism, Francis Bacon (1561-1626). In his works he expressed the opinion that various plants and animals (such as flies, ants and frogs) could arise spontaneously in the course of the decay of various materials. However, he approached this phenomenon from a materialist position and saw in it only a proof of the absence of an impassable barrier between the inorganic and the organic world. ${ }^{32}$

The materialistic interpretation of spontaneous generation was particularly clearly expressed by Descartes $\left(1596-165^{0}\right){ }^{33}$ This great French philosopher, although he believed the spontaneous development of living things to be beyond dispute, nevertheless categorically denied that this emergence occurred under the influence of the anima vegetativa of the scholasts, the arche of Paracelsus, the 'spirit of life' of van Helmont or any other spiritual principle. In sharp contradistinction to the religious teachings then prevailing and to the anthropocentric tendencies of mediaeval natural philos- 
ophy, Descartes tried to relate the qualitative diversity of natural phenomena to matter and its movement.

Thus, according to Descartes, the living organism does not need to be explained by any special obedience to 'a vital force'. Descartes postulates nothing other than a machine, very complicated certainly, but of completely intelligible construction, whose movements depend exclusively on the pressures and interactions of particles of matter as do the movements of the wheels in a clock. Thus different kinds of living beings can arise spontaneously from the surrounding lifeless matter. In particular, when moist earth is exposed to the rays of the sun or when putrefaction occurs, there develop all kinds of plants and animals such as worms, flies and a variety of insects. But for this to happen there is no need for any intervention whatsoever by any "spiritual principle'. Spontaneous generation consists only of the natural process of self-formation of complicated machines, a process which takes place invariably when certain circumstances, not yet fully investigated by us, are fulfilled.

Thus, down to the middle of the serenteenth century, the actual possibility of spontaneous generation had not been seriously questioned by anyone. The dispute between the mystical doctrines from the Middle Ages and the materialism now in violent spate was only concerned with the theoretical treatment of the phenomenon: was spontaneous generation to be regarded as a manifestation of "a spiritual principle" or as a natural process of self-formation of living beings? However, the study of living nature was all the time becoming both wider and more accurate in its approach, and the assurance of those who had accepted spontaneous generation as a 'fact' now began to be shaken.

\section{Redi's experiments.}

In this matter the experiments of the Tuscan physician Francesco Redi (1626-1697) can justly be counted as the turning point. To Redi fell the honour of being the first to emerge with the support of experiment from the belief in spontaneous generation which had ruled without interruption for so many centuries. In his treatise Esperienze intorno alla generazione degl' insetti (1668) he describes 
a series of his experiments which show that the white maggots in meat are simply the larvae of flies. He kept meat or fish in a large vessel, covered with the finest Neapolitan muslin, and, for still more complete protection, covered the vessel with a frame on which muslin was stre:ched. Although plenty of flies alighted on the muslin, no maggots appeared in the meat. Redi pointed out that he had succeeded in observing how the flies laid their eggs on the muslin, but that only when these eggs fell on to the meat did they develop into meat maggots. From this he concluded that decaying substances are only a place or a nest for the development of insects, but that the laying of eggs is an essential preliminary to their development; without eggs the maggots never appear. ${ }^{34}$

It should not be thought, however, that Redi had succeeded in completely ridding himself of the notion of spontaneous generation. In spite of his brilliant experiments, which he had interpreted correctly, this learned man freely admitted the possibility that spontaneous generation might occur in other cases. Thus he states that worms in the intestines or in timber arise on their own from rotting materials. Moreover, in his opinion, the maggots which are found in oak galls are formed from the juices of the plant. Only later was this opinion refuted by the investigations of the scientific physician Vallisneri (1661-1730).

This example makes it clear that what has been repeated for centuries (though often wrongly) is not easily confuted.

Throughout the eighteenth century, and even in the beginning of the nineteenth century, many scientists and philosophers of different tendencies and schools, and even more writers and poets, often described in their works various fantastic instances of the spontaneous generation of beasts, fishes, insects and worms, or made it clear that they considered that such a phenomenon was quite possible.

As observations of nature became more refined and, in particular, knowledge of the structure of living things became more detailed, so it was admitted, though only very gradually, that the spontaneous generation of such complicated things from structureless filth and decaying matter was impossible. In this way the belief in the spontaneous generation of all 
the more highly organised things ceased to be held among scientists. But this idea as to the primary origin of living things did not disappear. On the contrary, during the eighteenth and nineteenth centuries it reached its fullest development in connection with the simplest living things, the micro-organisms.

\section{Hypotheses concerning the spontaneous generation of microbes.}

Almost at the same time as Redi was carrying out his celebrated experiments, a new world of living creatures invisible to the naked eye was opened up by the Dutch scientist Anthony van Leeuwenhock (1632-1723), with the help of magnifying glasses made with his own hands. In letters to the Royal Society in London he described in detail these small 'living animalcules' discovered by him in rain water which had stood for a long time in the air, in various infusions, in excrement, in the tartar of teeth, etc. With his glass van Leeuwenhoek saw representatives of almost all the classes of micro-organism known to us at the present day. He gave descriptions, which were surprisingly accurate for those times, of infusoria, yeasts, bacteria, etc. ${ }^{35}$

The curious discoveries of the Dutch scientist attracted the most general attention and provoked many similar studies. Micro-organisms were discovered wherever decay or fermentation of organic substances was going on. They were found in different sorts of plant infusions and decoctions, in decaying meat, in stale broth, in sour milk, in fermenting wort etc. Substances which quickly become tainted or which decay easily had only to be kept in a warm place for some time when microscopic living things, which had not been there before, at once began to develop in them. As the belief in the spontaneous generation of living things was current at the time, it was unhesitatingly assumed that it extended to cover the spontancous generation of living microbes from inanimate matter in these decoctions and infusions.

Van Leeuwenhock himself did not propose this idea. He maintained that the micro-organisms fell into his infusions from the air. This opinion was confirmed by the experiments 
of Louis Joblot. ${ }^{36}$ This distinguished follower of van Leeuwenhock used infusions of hay which were swarming with micro-organisms, boiled them for 15 minutes and then poured equal parts into two vessels. One of these he covered closely with parchment before it cooled, the other was allowed to stand uncovered. In the open vessel very small living things (apparently infusoria) grew abundantly, but they did not appear in the closed one. At the end of the experiment the parchment was removed from the closed vessel too, after which the infusion was soon populated with micro-organisms. However, the experiments of Joblot were not convincing enough for his contemporaries and were later completely forgotten.

Philosophical thought at that time could still not renounce the principle of spontaneous generation and, as before, the dispute between the different schools was concerned not with whether or not microbes can develop of their own accord, but only with the spiritual or material basis of this apparently self-evident 'phenomenon' ${ }^{37}$

The discovery of the extremely small germs of life which were to be found everywhere was expressed in the philosophical system of G. Leibnitz $(1646-1716)$. His teachings about monads included metaphysical rehashing of the contemporary data of mathematics and science. According to Leibnitz the monads are primary centres of spiritual force. As the ultimate sources of everything they must be characterised by absolute simplicity and individuality. Matter being inherently passive, the monads constitute the spiritual substance, for only the spirit, in Leibnitz's view, has the capacity for uninterrupted activity. ${ }^{38}$

Starting from these assumptions, Leibnitz considered that life cannot be explained simply on the basis of bodily forces. In particular, he considered the possibility that higher plants and animals could arise by spontaneous generation from decaying material as disproved by direct experiment. The development and disappearance of living things is but the evolution and involution of eternally existing germs. Those substances which we usually consider inorganic contain within themselves a whole world of germs of life. "Even in vinegar and bookbinder's paste," wrote Leibnitz, " these 
germs are present." Thus, all bodies can contain within themselves organic structures, but these are still invisible, incomplete, and only in the form of germs. In these germs there are already present and pre-existing all the conditions for future specific organisation. Thus, living things are formed spontaneously from them by later development.

We find the same ideas concerning spontaneous generation in the works of the French scientist G. L. Buffon (1707$\left.{ }_{17} 788\right) .{ }^{39} \mathrm{He}$ also considered that the whole of nature is full of 'ubiquitous units or germs of life' but, in opposition to Leibnitz, he attributed to them a material character. These material particles endowed with life are capable, according to Buffon, of uniting with one another to form lower plants and animals from which the highly organised creatures later evolve. Conversely, on the decay of the body, individual existence ceases but living particles of matter which were at first scattered and then entered into its composition can now, once more, unite into living bodies. From them microbes originate. In this Buffon saw the explanation of the phenomenon of the spontaneous generation of microscopic organisms in putrefying organic liquids and infusions.

This view was shared by the contemporary and friend of Buffon, the Welsh Roman Catholic priest and naturalist J. T. Needham (1713-1781). He believed that in each microscopic particle of organic matter there was concealed a special 'vital force' which could animate the organic matter in an infusion. Thus Needham developed vitalistic views, which were very common in those days, concerning the essence of life and its begetting. However, Needham's importance in connection with the problem which we are considering depends, not only on his views, but also on the extensive experiments which he carried out in an effort to confirm the spontaneous generation of micro-organisms. He says:

I took a quantity of mutton gravy hot from the fire and shut it up in a phial closed with a cork so well masticated that my precautions amounted to as much as if I had sealed my phial hermetically. I thus excluded the exterior air that it might not be said my moving bodies drew their origin from insects or eggs floating in the atmosphere. I neglected no precaution even so far as to heat violently in hot ashes the body of the phial 
that if anything existed even in that little portion of air which filled up the neck it might be destroyed and lose its productive faculty.

But, in spite of all this, after some days the vessel swarmed with micro-organisms. He made similar investigations on a variety of organic liquors and infusions, always with the same result. This naturally led him to the conclusion that it was completely possible, and indeed inevitable, for micro-organisms to arise spontaneously from putrefying organic substances. ${ }^{40}$

However, these experiments of Needham were subjected to severe criticism by an Italian scientist, the priest Spallanzani (1765). Spallanzani, like Needham, carried out experiments with the object of establishing or refuting the possibility of spontaneous generation, but, on the basis of these experiments, he arrived at exactly the opposite conclusion. He asserted that the experiments of Needham had succeeded because of insufficient heating of the vessels containing the liquid, resulting in their inadequate sterilisation. Spallanzani himself carried out hundreds of experiments in which plant decoctions and other organic liquids were subjected to more or less prolonged boiling, after which the vessel containing them was sealed and thus the access of air to the liquids was prevented. Air, according to Spallanzani, carried the germs of micro-organisms. Whenever the operation was conducted with proper attention the liquids contained in the vessel did not putrefy and living creatures did not appear in them. ${ }^{41}$

Needham objected to this that on prolonged heating of the liquids the air contained in the vessels was spoilt and that this was the chief reason for the failure of microorganisms to develop. Secondly, he asserted that on prolonged heating the 'vital force' of the organic infusions was destroyed. This 'vital force' usually seems to be capricious and inconstant and cannot withstand prolonged and severe. treatments. Thus Needham considered, not that he had heated the liquids too weakly but, on the contrary, that in the experiments of Spallanzani these liquors had been heated 
too strongly and the generative power of the infusions had thus been destroyed.

In order to refute this Spallanzani carried out fresh experiments. In a long series of tests conducted with exceptional care he answered nearly all the criticisms that had been made by Needham. ${ }^{42}$ Nevertheless, he did not succeed in convincing his contemporaries and the controversy remained unsettled for very nearly a hundred years longer.

It is interesting to note that, in parallel with Spallanzani, in the period between the publication of his first and second works, analogous experiments were being carried out by the Russian M. Terekhovskiǔ, who was sent from St. Petersburg to Strasbourg for scientific investigations.

In his dissertation, De chao infusorio Linnaei, ${ }^{43}$ which he published in 1775 in Latin, Terekhovskil recorded the results of his extensive investigations on the 'animalcules of liquors', i.e. the microscopic living creatures which appear in all kinds of organic infusions-the infusoria, flagellates and other primitive organisms. In his opinion it was absurd to suppose that even the very simplest organisms with all the extraordinary complication of their structures which " no mechanic, even the most skilful who ever lived, could understand completely, try as he might, still less reproduce" might "be formed by chance from a chaotic mixture of inanimate particles ". In effect, as S. Sobol' pointed out, the numerous and very carefully performed experiments of Terekhovskir showed that " the spontaneous generation of animalcules does not take place under any conditions". However, these statements and experiments of the Russian scientist, which we now know were completely correct, did not receive recognition in the scientific world of that time and were quickly forgotten.

The doctrine of spontaneous generation was still defended by many scientists and philosophers in the end of the eighteenth century and beginning of the nineteenth century. In particular, it was developed by representatives of the German idealistic philosophy. I. Kant $(1724-1804)^{44}$ himself considered that the primary internal cause of the development of organisms was supernatural (metaphysical) and that therefore the hypothesis of spontaneous generation was merely a 
'bold adventure of the intellect'. However, the later Naturphilosophen, G. Hegel (1770-1831), F. Schelling (1775-1854) and L. Oken $\left(1779^{-1851)}\right.$ extensively developed the idea of generatio aequivoca. Thus, for example, Hegel stated that the earth and the sea had a clear need to be vivified " but in its general form, vivification seems to be generatio aequivoca"; and further, in his Enzyklopädie he wrote that "the earth and, in particular, the sea generate all sorts of lichens, infusoria, innumerable phosphorescent living specks ". ${ }^{45}$

According to Schelling, ${ }^{46}$ there is a complete identity between the earth and the animal and plant world. The earth itself is transformed into plants and animals because that which is called dead matter is merely the 'dormant animal and plant world'.

Oken, ${ }^{47}$ who was a follower of Schelling, developed the idea that the earth, in the course of its metamorphosis, degenerates into carbon and that this, being mixed with water and air, is converted into ' hydrated oxidised carbon' which, as a formless primaeval slime, acts as the basis of all organisms which have a form. Every living thing arises from this slime. At first, like the primaeval planets, it turns into spherical globules (the globules of primaeval slime) or infusoria under the influence of light. These later metamorphose into plants and animals which afterwards, on putrefaction, give rise again to infusoria. Moreover, it is also possible that spontaneous generation of ticks, worms and such creatures occurs by simple direct coagulation of the primaeval slime.

Thus, we find in the works of Oken, along with a banal conception of the spontaneous generation of life, the elements of a specifically scientific prediction. He had already put forward the theory of the development of life by the gradual evolution of matter, although in a very confused form.

While these discussions on natural philosophy were taking place in the first half of the nineteenth century, a whole series of experiments was carried out with the aim of establishing or refuting the possibility of the spontaneous generation of microbes.

An exceptional amount of care and experimental skill was expended on elucidating the significance of air in the appear- 
ance of living things in liquids which had been previously heated.

The well-known French chemist J. L. Gay-Lussac (1778$185^{\circ}$ ) showed, by means of direct analyses, that oxygen, that is the component of the air which sustains burning and breathing, is absent from vessels containing liquid which had been sealed up after boiling. This confirmed Needham's view. To elucidate the part played by oxygen, Gay-Lussac filled with mercury a glass tube which was closed at one end (a eudiometer) and stood it in a vessel of mercury with the closed end uppermost. A grape was then inserted under the mercury into the tube and crushed with a wire which was introduced through the mercury. The juice which ran out of the grape occupied the upper part of the tube. It remained transparent and apparently completely sterile for a long time. However, after the admission of a bubble of air, the juice quickly began to ferment and to be inhabited by microorganisms. ${ }^{48}$

This experiment, which was later made great use of by the adherents of spontaneous generation, is interesting from the point of view that in it the source of infection was, as we know now, the germs of the micro-organisms which were present on the surface of the mercury, to which neither the experimenter himself nor any of his later interpreters had paid any attention.

In 1836 the German naturalist T. Schwann made a new test of the significance of oxygen for the spontaneous generation of microbes. He caused a stream of heated air to pass through a glass tube into a vessel containing sterile meat broth and showed that in these circumstances the broth did not putrefy. Hence spontaneous generation did not proceed in the presence of a constantly renewed stream of sterilised air. However, a repetition of this experiment using a liquid containing sugar gave completely different results. In spite of the fact that, according to the author, the methods used in them were exactly the same as those used in the experiments with the broth, a mass of living micro-organisms often developed. ${ }^{49}$

In the same year F. Schulze carried out analogous experiments differing only in that the air which was admitted into 
the vessel with the sterilised liquid was freed from germs, not by heating but by being passed through strong sulphuric acid. The results were the same. However, numerous repetitions of Schulze's experiments gave inconsistent results and in some cases micro-organisms appeared in the liquids. ${ }^{50}$ This, as we now know, depended on the invasion of the liquid by spores which were present in a resistant state in the bubbles of air passing through the sulphuric acid.

A little later (1853) the Heidelberg professors H. Schröder and $T$. Dusch simplified the experiment still further by purifying the air by passing it through a layer of sterilised cotton wool which served as an excellent filter, removing all germs of micro-organisms. Thus they were able to free the air from germs while not submitting it to any chemical treatment or applying heat to it. In fact, a series of experiments was made by these workers with meat broths, and the wort of beer. These were boiled and then allowed to stand for many weeks without any change occurring. However, milk and meat without water went bad quickly under these conditions and became full of micro-organisms. ${ }^{51}$

Although all the experiments which had been carried out tended to refute the possibility of spontaneous generation, their evidence was not strong enough, in that they were sometimes unsuccessful for no demonstrable reason and microorganisms appeared in the liquid. We now know that this occurred as a result of the accidental introduction of organisms owing to some technical fault; however, contemporary scientists did not see the matter in that light. All these failures, in spite of a known wish to succeed, might easily be interpreted, and were in fact interpreted, as indicating that spontaneous generation, though not universal, could take place under certain circumstances. This opinion was held even by such outstanding investigators as Dumas, Naegeli and a number of other scientists of the middle of the nineteenth century.

The conflict of opinion concerning the possibility of the spontaneous generation of micro-organisms attained its greatest naiveté in 1859 when F. Pouchet ${ }^{52}$ published a paper in which he tried to prove this possibility experimentally. In his voluminous work, comprising about 700 pages, Pouchet ${ }^{53}$ 
developed his theory of spontaneous generation, which is fundamentally very reminiscent of the views of Needham. Fermentation or decay of organic substances precedes each manifestation of spontaneous generation. Only substances forming part of living organisms can give rise to new life. Under the influence of fermentation or decay the organic particles of the corpse disintegrate but, having wandered around for some time independently, they become united once more by virtue of their inherent properties and thus new living things are created. Pouchet considered that a ' life force' was a prerequisite for the development of living things and therefore he never believed that living things could arise de novo in mixtures of mineral substances. In confirmation of his views Pouchet made a large series of experiments in which he repeated the investigations of his predecessors. In these he always got results in agreement with his own ideas; that is to say, micro-organisms always developed in his organic liquids.

Only about a hundred years separate us from the experiments of Pouchet, but when one reads about these experiments now one canno: help noticing how crudely and messily they were carried out. Pouchet, for example, categorically denied the possibility that germs of micro-organisms might have got into his infusions and solutions from outside simply because "Joly and Musset carried out careful chemical analyses of the surrounding air". But what could they find out in this way even if thousands of bacteria and spores were hovering around them? In just the same way Pouchet asserted, without any foundation, that his original hay infusions certainly did not contain the germs of any microorganisms. However, we know that enormous numbers of such germs are always present on the surface of hay and that, on simple infusion of the hay with water, which is what Pouchet did, these germs must certainly fall off into the infusion in a perfectly viable state. This clearly occurred, for when Pouchet placed his hay infusions in a warm place for six days there appeared in them not only bacteria, but also such highly organised creatures as infusoria, in the cells of which there are digestive vacuoles, mouths and other very complicated and specialised organs. It is quite clear to us 
now that under such experimental conditions the appearance of infusoria was simply due to their germs always having reached the original solution from the surface of the hay. This may easily be demonstrated nowadays by direct observation. Pouchet's statement that spontaneous generation of infusoria occurred in his infusions sounds quite unjustified and even ridiculous in the light of present-day knowledge. However, Pouchet's work made a great impression on his contemporaries.

\section{The work of Pasteur.}

The French Academy of Sciences awarded a prize to whoever, by means of accurate and convincing experiments, should cast light on the question of the primary origin of living creatures. This prize was awarded to Louis Pasteur ${ }^{54}$ who, in 1862 , published his work on spontaneous generation in which, by a series of conclusive experiments, he demonstrated the impossibility of the formation of micro-organisms from various infusions and solutions of organic substances. Pasteur was successful in doing this only because he left the beaten track of blind empiricism and approached the whole problem broadly in his experiments. He also gave a rational analysis of all earlier experiments and explained the mistakes of those who carried them out. First of all Pasteur cleared up the question of the presence of micro-organisms in the air which, as we have seen above, was considered to be one of their chief origins. The partisans of spontaneous generation, Pouchet in particular, repeatedly expressed doubts as to whether germs of life were really present in air and demanded a demonstration of the "infinite mass of microorganisms ' which are present in the air.

Pasteur solved this problem by a very simple method. Using an aspirator he drew air through a tube into which a plug of gun cotton had been inserted. As Schröder and Dusch had already shown, all the smallest particles are retained by the cotton and remain in the tube. The current of air was maintained for 24 hours and the plug with the dust which had been caught in it was removed and dissolved in a mixture of alcohol and ether. At this stage all the solid 
particles present sank to the bottom. They were washed with solvent and then studied under the microscope. There were always found thousands of organised bodies which differed in no way from the common micro-organisms and their spores. The presence of large numbers of organised bodies in the ambient atmosphere had thus been demonstrated.

Furthermore, Pasteur showed that these germs which are present in the air can often initiate the growth of organisms. First of all he repeated the experiments of Schwann with some variations and improvements. The boiling of the organic liquids was carried out in a round-bottomed flask with a long drawn-out neck joined to a platinum tube which was heated to red heat with a gas burner. Thus, the air which was drawn into the flask when the liquid in it had finished boiling passed through a red-hot platinum tube in which all the germs present in it were sure to be destroyed. While passing from the tube to the flask the air was cooled by a stream of water. After it had been filled with air the flask was sealed and in this state it could be kept indefinitely. When the experiment was set up in this way the liquid never decomposed and no micro-organisms were formed. However, if the sealed neck of the flask was broken and a cotton plug through which air had been passed was thrown into the liquid contained in it and the neck was quickly sealed again, then the liquid soon became filled with moulds, bacteria and even infusoria. This meant that the liquid had not lost its nutrient capacity for micro-organisms and the germs which had been present in the air and were collected on the cotton plug could, in fact, easily develop in such liquids.

Later Pasteur sterilised the air admitted to the flask without heating it. For this purpose he relied partly on the method of Schröder and Dusch, drawing the air through a cotton-wool plug, and partly brought his own native skill to bear on it. As usual, Pasteur half filled the roundbottomed flask with the experimental liquid and then softened the neck of the flask in a flame and drew it out. The part which was drawn out was bent into the shape of the letter S. The contents of the flask were then boiled without any further precautions. When a strong current of steam issued from the extended neck of the flask the boiling was 
stopped and the flask was allowed to cool. Under this treatment the contents of the flask remained unchanged although, in this case, the solution was directly connected through the curved neck with the surrounding atmosphere. This was due to the fact that all particles of dust, including the germs of the micro-organisms, were retained on the curved surfaces of the S-shaped tube. If the neck was cut off the liquid was soon colonised by micro-organisms. In this experiment the air was submitted to absolutely no treatment and nevertheless decomposition of the liquid did not occur, simply because the organisms floating in the air were denied access to it.

Further investigations by Pasteur showed that the content of viable micro-organisms in the air was far from constant and changed according to conditions such as season and place. The largest number of germs is present in the air of towns and inhabited places. The air of fields and forests is less rich in micro-organisms, and finally in the mountains, especially at great heights, the number of these minute living creatures floating in the air is quite insignificant. One may therefore open flasks containing sterile liquids without their necessarily being exposed to infection. In many cases such flasks remained sterile after resealing, although untreated mountain air had been admitted to them.

Pasteur also demonstrated that the air is far from being the only source of infection of organic liquids. The germs of micro-organisms are present on the surfaces of all the objects which we use in the course of an experiment. Therefore all these objects must be meticulously disinfected. Pasteur showed that the appearance of micro-organisms in the experiments of earlier investigators was always due to the fact that they had not carefully eliminated all sources of infection. Thus, for example, Pasteur showed by direct experiments that the source of infection of Gay-Lussac's grape juice was micro-organisms present on the surface of the mercury. In other cases the organisms were derived from incompletely sterilised utensils. If all sources of error are avoided then, as Pasteur demonstrated brilliantly in numerous experiments, infection will be absent in a hundred per cent of cases. Pasteur also succeeded in showing that it is possible to keep even such easily decomposed liquids as urine 
and blood for an indefinite time without submitting them to heat or any other treatment. It is only necessary to withdraw them from the body of the animal, where they do not contain bacteria, while taking precautions against contamination with germs from outside. Under these circumstances such liquids do not putrefy and may be conserved indefinitely.

Pasteur did not merely aim at getting accurate and uniform results but also at explaining the contradictory data of other authors. He rejected the suggestion that decaying infusions give rise to microbes and showed that, on the contrary, the decay of these liquids itself takes place as a result of the vital activities of micro-organisms which have entered from outside. All attempts to refute this hypothesis and to find a case of spontaneous generation of any particular organism were in vain. From our present point of view this is quite understandable, in that micro-organisms are not simple lumps of organic material as was believed until the time of Pasteur. A detailed study of these very simple living things has shown that they have a very delicate and complicated organisation. It is quite impossible to suppose that complicated structures of this sort could emerge in the course of a short time before our eyes out of structureless solutions of organic substances. This hypothesis is, in essence, just as absurd as the hypothesis that frogs arise from the dews of May or lions from the stones of the desert.

Pasteur's investigations quite understandably attracted tremendous attention among his contemporaries. The complete revolution in biology brought about by Pasteur may be compared with that achieved by Copernicus in astronomy. For, in the one case as in the other, prejudices which had held sway over the minds of men for thousands of years were swept away.

As we have seen above, many generations of scientists and philosophers considered the possibility of spontaneous generation to be an incontrovertible and self-evident truth. The obdurate struggles between idealism and materialism were only concerned with the theoretical explanation of the 'phenomenon'. And now it was suddenly discovered that the 'phenomenon' itself, the very 'fact' of spontaneous 
generation, was illusory and was based on false interpretations of observations and incorrect conduct of experiments. At the end of the last century and the beginning of the present one the two warring philosophical camps redeployed their forces in the light of this discovery.

Vitalism, the idealistic tendency in biology, had already achieved its most exuberant development by the middle of the eighteenth century. At that time our knowledge of life was so limited that it seemed quite impossible to explain physiological and formative processes without recourse to the activity of some special, mysterious 'life force'. However, at the end of the eighteenth century there was a tremendous surge of great discoveries in physics and chemistry, and from that time onwards vitalism suffered one defeat after another. Even by the second quarter of the nineteenth century it had really almost played itself out. The evolutionary theory of Darwin dealt a final crushing blow to vitalism. It showed the way to a scientific, materialistic solution of the problem of the adaptation of form to purpose in the organic world. After this the concept of a 'life force' became quite unnecessary, it explained nothing and was a purely mystical and meaningless word.

However, the end of last century witnessed a resurgence of vitalism, which now chose the problem of the origin of life as one of its main rallying points. In $1894 \mathrm{I}$. Borodin ${ }^{55}$ wrote "Has not the progress of science in the course of centuries furnished the vitalists to some extent with weapons? Yes, they certainly have such weapons, they hold a trump card in their hand." Borodin meant by this "trump' the unsuccessful attempts to discover the phenomenon of spontaneous generation. These failures, in his opinion, indicated the presence of an impenetrable barrier between the animate and the inanimate, the complete autonomy of vital phenomena.

\section{Borodin continued:}

That old woman, the life force, whom we buried with such triumph, at whom we mocked in every way, was only pretending to be dead and now decides to demand some rights to life, prepares herself to start up in a new form.... Our expiring nine- 
teenth century misses fire, it misses fire on the question of the origin of life.

Thus idealism, which, as we have already seen, argued obstinately throughout its whole history in farour of the existence of spontaneous generation, carried out a complete volte face on this question at the beginning of the present century. The triumph of the theory of evolution forced the vitalists to regard the problem of the origin of life as the last refuge of the 'life force'. Darwinism might well give a materialist explanation of the ways in which higher organisms develop from lower ones, but the human mind would never be able to understand how life itself came about, because its essence (' entelechy', the 'life force', the 'cellular spirit', etc.) lay at the limit of the capacity of the intellect. We find this in the writings of most of the neovitalists and other idealistically inclined biologists of our century. Thus H. Driesch ${ }^{56}$ wrote of the insolubility of the problem of the origin of this vital principle which he called 'entelechy'. Uexküll ${ }^{57}$ drew attention to the necessity for a special transcendental factor (structural plan) for the origin of life. L. Bertalanffy ${ }^{58}$ denied the possibility of the self-formation of such a system as, in his opinion, an organism must be. E. Lippmann finishes his book ${ }^{1}$ devoted to the problem of the emergence of life with the words: "The limitations of the intellect prevent us from penetrating into the problem of life. ... We cannot understand its essence which appears to be metaphysical." Thus the idealists try to use the demolition of the theory of spontaneous generation as an occasion for proclaiming the impossibility of solving the question of the origin of life on a materialistic basis.

The leading proponents of materialism rejected this approach to the problem right from its inception in the last years of the nineteenth century. They considered that the fact that microbes do not develop spontaneously in organic solutions and infusions was no argument that life has not a material origin.

One of the first to discuss this problem was F. Engels. ${ }^{59}$ He remarked that all investigations so far made in this field had been quite limited in approach, dealing only with the 
problem of plasmogenesis. Pointing out that spontaneous generation (generatio aequivoca) was contrary to the findings of contemporary science, Engels ironically remarked that it would be absurd to hope to compel nature with the help of some stinking water to do in 24 hours that for which thousands of years had been required. Thus Engels emphasised that it was not sudden spontaneous generation but a prolonged evolution of matter which led up to the emergence of life.

However, most scientists of that period still took up a mechanistic position and held that sudden spontaneous generation was not only the simplest, but even the only conceivable explanation of the origin of life. In this connection E. Haeckel ${ }^{60}$ wrote "To deny spontaneous generation means to accept a miracle, the divine creation of life. Either life arises spontaneously on the basis of some particular laws, or else it has been produced by supernatural forces." This kind of conviction explains the zeal with which many of the exponents of mechanistic materialism flew in the face of the facts to demonstrate the possibility of spontaneous generation. They saw no other way out. As an example one may mention the violent but ill-founded attacks made by the talented Russian publicist D. Pisarev ${ }^{61}$ on the work of Pasteur.

Finally, there was no dearth of experimental effort to show that it was possible for living creatures to come into existence suddenly. However, all these experiments, without exception, were utterly futile. The most serious and interesting were those of Bastian. ${ }^{62} \mathrm{He}$ showed that micro-organisms developed in boiled infusions of hay even when the flasks containing the infusions were opened on mountain tops or after the air entering them had been brought to a red heat. The investigations of Pasteur were consistent with the factual side of these experiments but Pasteur also showed that spontaneous generation of microbes had not occurred in this case either. The spores of the hay bacillus, which was the organism which grew, can withstand prolonged boiling and still remain viable. If the hay infusion is heated in an autoclave to $120^{\circ} \mathrm{C}$ or boiled twice it, like other organic liquids, will retain its sterility on the admission of uninfected air. In such 
cases repeated boiling acts as follows: the first heating destroys all the vegetative forms of the bacteria but the spores remain. After cooling, bacteria develop from the spores but succumb to the second boiling without having succeeded in forming new spores.

The outstanding Russian scientist K. A. Timiryazev, with his usual clarity of scientific exposition, submitted these attempts to demonstrate the possibility of spontaneous generation to devastating criticism. In an address which he delivered at a session of the Society of the Friends of Science in 1894 he spoke as follows:

When Bastian created bacteria from an infusion of turnips with rotten cheese in the nineteenth century he was, in this matter, just as much of an empiricist as was van Helmont in the sixteenth century, when he created mice from flour and dirty rags. At least I know of no physical or chemical laws which might lead one to prefer the stinking mixtures of the nineteenth century empiricists to the sluttish mixtures of the sixteenth century one. Attempts to produce spontaneous generation in the nineteenth century are not necessarily superior to such attempts made in the sixteenth century; in fact, they are equally far from the basic ideas which characterise the scientific thought of our times.

Furthermore, while arguing with Borodin, Timiryazev declared:

So you pick out two or three foolhardy adventurers with the ideas and mentality of the sixteenth century, going astray in the middle of the nineteenth century ; you see in them the representatives of contemporary science and hail their failure as the 'misfiring of the nineteenth century'. Is that quite fair? ${ }^{63}$

This impassioned reply by Timiryazev is also fully applicable to the empiricists of the present day, the adherents of spontaneous generation who, according to their way of thinking, are rushing to the defence of materialism and who only delude themselves and others with their experiments. Having been concerned with the problem of the origin of life for many years, I have received and still receive a large number of letters with descriptions of different instances of spon- 
taneous generation which is said to have occurred in the experiments of one or another of the writers. However, none of these experiments need be taken seriously. They are amateurish and the sources of error can easily be established.

From the works on spontaneous generation which still appear from time to time in the scientific literature, one may be selected by way of an example because it concerns the scientist F. Elfving, who is well known for his investigations in the field of microbiology. It was published in 1938 in the journal of the Finnish Scientific Society. ${ }^{64}$ Elfving sterilised dried peas by placing them in a solution of corrosive sublimate $(3: 1000)$ for half an hour; he then washed them with sterile water and allowed them to germinate under sterile conditions in Erlenmayer flasks containing a little water. When the peas grew and the sprouts had developed considerably he killed them by keeping the flasks at a temperature of $60^{\circ} \mathrm{C}$ for one to two hours. Some days after this treatment by heat he noticed that the water in which the dead plants were lying was swarming with bacteria. From this experiment Elfving came to the conclusion that, in the dispute between Needham and Spallanzani, it was Needham who was right. The substance of the peas which had been killed by gentle heating contained a special 'generative power' which gave rise to new living bacteria. It is easy to detect Elfving's mistake. As was shown by investigations on the production of sterile cultures of higher plants, particularly the experiments of $\mathrm{G}$. Petrov, ${ }^{65}$ one can never successfully sterilise seeds by keeping them for this or that time in a solution of corrosive sublimate. This is better achieved by the action of a solution of bromine. There can be no doubt that completely viable germs remained on the surfaces of Elfving's peas. Elfving himself remarked that on the peas "there grew mycelia which were obviously derived from some spore which had survived the treatment with corrosive sublimate". On repeating Elfving's experiments, using bromine instead of corrosive sublimate to sterilise the peas, we were easily able to convince ourselves that under these conditions, as was only to be expected, no development of microbes occurred. 
We even find an attempt to rehabilitate Pouchet's experiments and thus to resuscitate the theory of spontaneous generation in the much publicised book of O. Lepeshinskaya, The development of cells from living matter. ${ }^{6}{ }^{6}$ However, no such attempts have withstood criticism by experiment and, as Terekhovskir pointed out long ago, they are foredoomed to failure. The organisation of any of the living creatures known to us, even the simplest ones, exhibits not only a very complicated structure in the protoplasm, a particular arrangement in space of those molecular complexes which constitute the protoplasm, but also organisation in time, a particular series of biochemical processes which, together, constitute the metabolism. We now know very well that even relatively slight interference can produce farreaching changes in such a system. On damaging protoplasm mechanically or by heat the balance of the metabolism is disturbed irreversibly. This disturbance upsets the harmonious interaction of the synthetic processes and markedly intensifies the reactions of breakdown which proceed in a disorderly way.

It is interesting to note that the hypothesis of spontaneous generation was always applied to those organisms which had only been studied imperfectly at each stage of the development of science. Before Redi's experiments it was applied to various kinds of worms and parasites. It was the same with bacteria before the time of Pasteur. Finally, in our own times, an attempt has been made to resurrect the theory of spontaneous generation with reference to organisms discovered during this period but still poorly understood, the ultramicrobes and filterable viruses. However, this attempt has been a complete fiasco too.

Summing up all that has been said in this chapter, one must emphasise that the very idea of spontaneous generation has been based on faulty observations, accepted uncritically, of the sudden appearance of living creatures in nature or in the laboratory. The possibility of spontaneous generation was assumed by philosophers of every school and persuasion throughout the course of many centuries. They only quarrelled about the theoretical interpretation of the "phenomenon'. However, as the methods of scientific investigation 
of living nature became more and more precise, spontaneous generation was gradually relegated to simpler and simpler organisms. Finally the sudden appearance of even the most primitive organisms from inanimate material was shown to be impossible. Thus, to-day, the theory of spontaneous generation has no more than a historical interest and cannot serve as an approach to the problem with which we are concerned.

\section{BIBLIOGRAPHY TO CHAPTER I}

1. E. O. v. Lippann, Urzeugung und Lebenskraft. Berlin, 1933 .

2. J. G. Crowther. Science unfolds the future. London, 1956 .

3. William Shakespeare. Antony and Cleopatra. Act 2, Scene 7 .

4. A. Makovel'skiř. Dosokratovskaya filosofiya. Pt. 1, Vol. 1. Kazan, 1918.

5. Paul Tannery. Pour l'histoire de la science hellène. De Thales à Empédocle. Paris, 1930 (2nd edition by A. Diés).

THEODOR GOMPERz. Griechische Denker. Geschichte der antiken Philosophie. 3rd edition. Vol. 1. Leipzig, 1911.

6. A. Deborin. Kniga dlya chteniya po istorii filosofii. Vol. 1. Moscow (Izd. Novaya Moskva), 1924.

Democritus. Fragments.

7. Epicurus. Letter to Herodotus.

8. Lucretius. De rerum natura.

9. Rodemer. Lehre von der Urzeugung bei den Griechen und Römern. Dissert. Giessen, 1928.

10. Aristotle. De generatione animalium.

11. E. Zeller. Die Philosophie der Griechen. Leipzig, 1923.

12. Apuleius. Metamorphoses.

13. H. Meyer. Geschichte der Lehre von den Keimkräften. Bonn, 1914.

14. St. Basil. Hexaëmeron. Cf. A select library of Nicene and Post-Nicene Fathers of the Christian Church. 2nd series. Vol. 8. St. Basil: Letters and select works (trans. Blomfield Jackson), p. 102. Oxford, 1895.

15. Cf. (I.1).

16. Istoriya filosofii (ed. G. F. Aleksandrov, V. E. Bykhovskǐ̌, M. B. Mitin and P. F. Yudin). Vol. 1, p. 413. Moscow (Politizdat), 1940. 
17. V. I. Lenin. Filosofskie tetradi. Moscow (IMEL), 1933.

18. J. Sighart. Albertus Magnus, sein Leben und seine Wissenschaft. Regensburg, 1857 .

19. A. ShтекL'. Istoriya srednevekovor filosofii. Moscow (Izd. Sablina), 1912.

20. F. S. Bodenhemer. Materialien zur Geschichte der Entomologie bis Linné. Berlin, 1928.

21. Dimitriľ Rostovskiľ (D. Tuptalo). Letopis', skazuyushchaya vkrattse deyaniya ot nachala mirobytiya do rozhdestva Khristova, sobrannaya iz bozhestvennogo pisaniya $i$ iz razlichnykh khronografov i istoriografov grecheskikh, slavenskikh, rimskikh, pol'skikh i inekh. Quotation from Sochineniya, Vol. 4, p. 243. Moscow, 1857.

22. Tн. Рвокороwicz. Christianae orthodoxae theologiae in Academia Kiowiensi. Vol. 1, p. 51. Lipsiae, 1782. Quoted by S. Sobol'. Istoriya mikroskopa. Moscow and Leningrad (Izd. AN SSSR), 1949.

23. Quoted by B. Raǐkov. Zhurnal Ministerstıa narodnago Prosveshcheniya, [Nov. ser.] 66 (1916, no. 11) otd. 3, p. 33 .

24. Quoted by E. Lippmann in (I. 1), p. 39.

25. A. Tschirch. Handbuch der Pharmakognosie. Leipzig, 1909 .

26. Adam Olearius. (ed. H. v. Staden.) Die erste deutsche Expedition nach Persien (1635-9). Leipzig, 1927.

27. E. Darmstaedter. Acta Paracels., Mïnch., 1931.

28. J. W. von Goethe. Faust.

29. G. Gurev. Sistemy mira. Moscow and Leningrad (Izd. AN SSSR), $194^{\circ}$.

3o. W. Bulloch. The history of bacteriology. London, $193^{8 .}$

31. T. Meyer-Steineg and K. Sudhoff. Geschichte der Medizin. (2nd edition). Jena, 1922.

32. F. Bacon. Works. Vol. 1, pp. 146, 15 o. London (Reeres and Turner), 1879 .

33. R. Descartes, Oeuvres philosophiques.

34. F. Redi. Esperienze intorno alla generazione degl' insetti. Firenze, 1668. Quoted in (I. 30).

35. A. van Leeuwenhoek. Naturs Verborgentheden Ontdekt. Delft, 1697. Quoted by V. Omelyanskir in Osnovy mikrobiologii. Petrograd (Gosizdat), 1922.

36. L. Joblot. Descriptions et usages de plusieurs nouveaux microscopes. Paris, 1718. 
37. Istoriya filosofii (ed. G. F. Aleksandrov, V. E. Bykhovskiï, M. B. Mitin and P. F. Yudin). Vol. 2, p. 202. Moscow (Gospolitizdat), 1941.

38. G. W. Leibnitz. La Monadologie. Opera philosophica (ed. J. E. Erdmann), p. 705. Berlin, 1840.

39. E. Nordenskiöld. Die Geschichte der Biologie. Jena, 1926. 40. J. T. Needham. Phil. Trans., 1749, No. 490, p. 615 .

Idée sommaire ou vue générale du système physique et métaphysique de M. Needham. Bruxelles, 1776 . Quoted in (I. 30), p. 74 .

41. L. Spallanzani. Saggio di osservazioni microscopiche concernenti il sistema della generazione dei Sig. di Needham e Buffon. Modena, 1765. Quoted in (I. 30), p. 75 .

42. L: Spallanzani- Opuscoli di fisica animale e vegetabile. Modena, 1776.

43. M. Terekhovskǐ (Martinus Terechowsky). De chao infusorio Linnaei. Dissertatio. Argentorati, 1775.

S. SовоL'. Istoriya mikroskopa i mikroskopicheskikh issledovanil v Rossii v XVIII veke. Moscow and Leningrad (Izd. AN SSSR), 1949.

44. I. Kant. Kritik der Urtheilskraft. Berlin, x790.

45. G. W. F. HeGel. Enzyklopädie der philosophischen Wissenschaften. Heidelberg, 1817 .

46. F. V. Schelling. Zeitschrift für spekulative Physik. Jena, $1800-1801$.

47. L. OKEN. Lehrbuch der Naturphilosophie. Zürich, 1843.

48. J. L. Gay-Lussac. Ann. Chim. (Phys.), 76, 245 (1810).

49. T. Schwann. Ann. Phys., Lpz., $4 I, 184$ (1837).

5o. F. Schulze. Ann. Phys., Lpz., 39, 487 (1836).

51. H. Schröder and T. Dusch. Liebigs Ann., 89, 232 (1854).

52. F. Pouchet. C.R. Acad. Sci., Paris, 47, 979 (1858); 48, 148, 546 (1859); 57, 765 (1863).

53. F. Pouchet. Hétérogénie ou traité de la génération spontanée basé sur de nouvelles expériences. Paris, 1859 .

54. L. Pasteur. C.R. Acad. Sci., Paris, 50, 303, 675, 849 (1860); 5I, 348 (1860); 56, 734 (1863). Ann. Sci. nat., I6, 5 (1861). Ann. Chim. (Phys.) [3], 64, 5 (1862). Etudes sur la bière. Paris, 1876 .

55. I. Borodin. Protoplazma i vitalizm. Mir bozhǐ̌ (May p. 1, 1894).

56. H. Driesch. Geschichte des Vitalismus. Leipzig, 1922. 
57. J. v. UexкüLl. Theoretische Biologie. Berlin 1928; Die Lebenslehre. Potsdam, 1930.

58. L. v. Bertalanffy. Theoretische Biologie. Berlin, 1932.

59. F. Engels. Dialectics of nature (trans. C. Dutt). Moscow (Foreign Languages Publishing House), 1954.

6o. E. HaEckel. Natürliche Schöpfungsgeschichte. (2nd edn.) Berlin, 1870.

61. D. Pisarev. Podvigi evropě̌skikh avtoritetov. Sochineniya, Vol. 3. St. Petersburg (F. Pavlenkov), 1909-1913.

62. H. C. Bastian. The beginnings of life. London, 1872 .

63. K. Trmrryazev. Vitalizm i nauka. 'Sochineniya, Vol. 5. Moscow (Sel'khozgiz), 1938.

64. F. Elfuing. Comment. biol., Helsingf., 7, No. 4 (1938).

65. G. Petrov. Usvoenie azola vysshim rasteniem na svetu $i v$ temnote. Moscow (Tipog. Ryabushinskikh), 1917.

66. O. Lepeshinskaya. Proiskhozhdenie kletok iz zhivogo veshchestva. Moscow and Leningrad (Izd. AN SSSR), 1945 . 



\section{THE THEORY OF THE ETERNITY OF LIFE}

\section{The theory of the eternity of life among the ancients.}

It is a necessary and inevitable consequence of all idealistic doctrines that they assume that life is eternal. Idealism sets up, in opposition to the frail material world in which everything has its beginning and its end, the eternal and unchanging spirit. Living creatures are born and die, but life itself, being a non-material principle, the essence of life, is spiritual and hence eternal. Life is never destroyed, nor does it arise afresh; it only changes its external material envelope, as it transforms inert material into living organisms.

From this point of view the principle of the eternity of life is not incompatible with the possibility of spontaneous generation of living creatures. As we have seen in the previous chapter, idealists have, from ancient times, united the two doctrines. This union was specially clearly expressed in the doctrine of 'panspermia'. According to this, the fertilising or life-giving principle takes the form of invisible spiritual germs of life dispersed everywhere.

We first encounter the actual term 'panspermia' in the work of the ancient Greek philosopher Anaxagoras (500-428 B.C.). ${ }^{1}$ In his view, the various living creatures originate from slimy earth when it has been fertilised with "ethereal germs' (spermata) which are present everywhere. Later on, the doctrine of panspermia acquired a markedly idealistic character. We find it in this form in the teachings of Roman philosophers, of 'the fathers of the Christian Church', of the mediaeval schoolmen and of a number of more recent natural philosophers. 
The works of St. Augustine of Hippo may be taken as an example. He held that the earth is full of hidden lifeengendering forces, occulta semina, invisible, mysterious seeds of spiritual origin, which become active under favourable circumstances and produce plants, frogs, birds and insects from water, air and earth. The 'spirit of growth', anima vegetativa of the later scholasts, the arche of Paracelsus and van Helmont, the 'life force' of a number of other authors, etc., were also of this nature.

In the middle of the seventeenth century Athanasius Kircher $^{2}$ developed his theory of panspermia, according to which the germs of life are scattered in chaos and in all the elements, and the various animals and plants arise as a result of their activity. A principle similar to that of panspermia forms the foundation for Leibnitz' teaching concerning the immortal, ubiquitous germs of life which, in the course of their later development, form all living things. According to Needham, the vivifying principle 'life force' is inherent in every particle of organic matter and only under its formative influence can micro-organisms develop in decaying materials.

Pouchet took up an analogous position. He considered that spontaneous generation was only possible as a result of the action of the 'life force' which had previously entered the molecules of organic substances.

When the theory of spontaneous generation was exploded towards the end of the nineteenth century the vitalists and neovitalists quietly abandoned it, bringing to the fore the principle of the eternity of life and emphasising the impossibility that the human mind could ever solve the problem of its origin.

The position was different for those natural philosophers who were working on a materialistic basis. They were trying to use the theory of the eternity of life as a way out from what seemed to be the impasse which had been created by Pasteur's experiments. It is clear that the theory of the eternity of life as something which has a separate existence, divorced from matter, is foreign and hostile to materialism. Mechanistic materialism and, in particular, hylozoism, assume the eternity of life, and regard it as merely a constant 
and inalienable property of matter in general. If we accept this, the spontaneous generation of living creatures follows ex hypothesi. If all matter is endowed with life, if there is, in principle, no qualitative difference between organisms and objects that are inorganic in nature, then living creatures must inevitably arise spontaneously, even in the absence of other living creatures. Hylozoism without spontaneous generation is absurd. It is thus inconsistent for materialists to make use of the theory of the eternity of life to explain the impossibility of spontaneous generation. This leads inevitably to idealism.

\section{The emergence of hypotheses concerning the eternity of life in the nineteenth century.}

Clear examples of this attitude are found in the pronouncements of a number of authoritative scientists of the late nineteenth and early twentieth centuries. Many of these scientists regarded the experiments of Pasteur as proof of the absolute impossibility of the metamorphosis of inorganic materials into living organisms. In 1871 the distinguished British physicist W. Thomson, later Lord Kelvin, wrote in this connection: "Dead matter cannot become living without coming under the influence of matter previously alive. This seems to be as sure a teaching of science as the law of gravitation." 3 Hence followed the complete autonomy of living creatures, and consequently also life must be regarded as eternal.

The famous German physiologist H. Helmholtz said" : "It appears to me to be a fully correct procedure, if all our efforts fail to cause the production of organisms from nonliving matter, to raise the question whether life has ever arisen, whether it is not just as old as matter. ..."

The French botanist van Tieghem wrote in his textbook ${ }^{5}$ : "The vegetation of the earth had a beginning and will have an end, but the vegetation of the universe, like the universe itself, is eternal ".

We meet similar opinions among a number of other scientists who, proceeding from the empirically established fact of the impossibility of spontaneous generation, proclaimed 
that life is in principle eternal while still reckoning that they had based their position on materialistic principles. Thus, for example, the very able Russian plant physiologist and biochemist S. Kostychev ${ }^{6}$ wrote in the conclusion of his book On the appearance of life on the Earth: "When the echoes of the battle about spontaneous generation finally die away, everyone will recognise that life only changes its form, but never arises from dead matter". However, wishing to escape from the justifiable accusation of idealism, he added : "It must be noted that this point of view has nothing in common with the theory of vitalism, which is nebulous and hostile to progress". All the same, this denial is unconvincing, and it is not easy to see how one can combine acceptance of the eternity of life with denial of 'the eternal vital principle' or ' life force'.

As early as the late nineteenth century, F. Engels ${ }^{7}$ gave detailed consideration to the principle of the eternity of life, and showed convincingly that it is incompatible with consistent materialism. He quotes a very characteristic remark made by Liebig to $\mathrm{M}$. Wagner in 1868 :

We may only assume that life is just as old and just as eternal as matter itself, and the whole controversial point about the origin of life seems to me to be disposed of by this simple assumption. In point of fact, why should not organic life be thought of as present from the very beginning just as much as carbon and its compounds (!)* or as the whole of uncreatable and indestructible matter in general, and the forces that are eternally bound up with the motion of matter in space (II. 7 , p. 390).

Engels points out that such views can only be based on recognition of a specific vital force, such as a 'formative principle', and do not at all correspond with a materialist picture of the universe. Engels further wrote in comment:

Liebig's assertion that carbon compounds are just as eternal as carbon itself, is doubtful, if not false. . The compounds of carbon are eternal in the sense that under the same conditions of mixture, temperature, pressure, electric potential, etc., they are always reproduced. But that, for instance, only the simplest

\footnotetext{
* Engels' italics and exclamation mark.
} 
carbon compounds, $\mathrm{CO}_{2}$ or $\mathrm{CH}_{4}$ should be eternal in the sense that they exist at all times and more or less in all places, and not rather that they are continually produced anew and pass out of existence again-in fact out of the elements and into the elements-has hitherto not been asserted. If living protein is eternal in the same sense as other carbon compounds, then it must not only continually be dissolved into its elements, as is well known to happen, but it must also continually be produced anew from the elements and without the collaboration of previously existing protein-and that is the exact opposite of the result at which Liebig arrives (II. 7, p. 394).

The proposition that living beings invariably arise when certain conditions are fulfilled has nothing in common with the concept of the 'eternity of life'. On the contrary, it leads to the idea that organisms invariably originate from inanimate matter.

Against this, those who favour the eternity of life consider that at all times there has existed some element which has been passed in succession from organism to organism. Without this the occurrence of living beings is impossible. "Life," wrote F. J. Cohn (1828-1898), "is like the holy fire of Vesta, which was only kept in being continuously by kindling the new flame from the old." But what is this special principle that is present only in the living organism, and what is its nature? It cannot be an eternal property of matter, as the ancient Greeks supposed, because then the vivification of matter would not require the participation of a living organism already in existence, but life would arise spontaneously of itself. It cannot be a new quality arising in the course of the historical development of matter, because then it would not be eternal. Consequently, this principle cannot be material in nature. And so, as soon as we try to extend or develop the principle of the eternity of life, whether we want it or not. we find we have been trapped into idealistic assumptions. It cannot be said that attempts to resolve this contradiction on the basis of a so-called ' materialistic dualism, have been successful. This recognises the parallel and independent existence of two completely autonomous forms of matter, radically distinct from one another and separated by an impassable gulf. 
The well-known Russian geochemist V. Vernadskiǔ (18631945) presents the clearest example of this tendency. In his works written in the twenties and thirties of this century he puts forward the view that the idea "that logic demands that there should be a beginning of life came into science as a problem of religion and philosophy" and that it is "foreign to the empirical foundations of science". He wrote:

None of the exact relationships between facts which we know will be changed if this problem has a negative solution, that is, if we admit that life always existed and had no beginning, that living organisms never arose at any time or place from inert material, that in the history of the earth there were no geological periods in which life did not exist. ${ }^{8}$

Vernadskir held that the essential feature of the material and energetic characteristics of living bodies which distinguishes them from inert matter is that a special orientation is inherent in the former. ${ }^{9}$ He pointed out that even Pasteur recognised the possibility of different states of cosmic extension and that he used this concept to explain the phenomenon of asymmetry in living things, or, to use the terminology of Vernadskir, ' rightness and leftness'. This orientation which is associated with individual organisms is described by Vernadskir as follows: The mirror-image forms of each chemical compound are acknowledged to be chemically identical in inert matter and different in living organisms.

The chemical dissimilarity is thus conspicuous in the products of biochemical processes, in which either the dextro or laevo isomer predominates. Vernadskir further puts forward the idea that this orientation in space, which is associated with the body of the living organism, is only created in the biosphere from natural living bodies which have existed previously, that is, as a result of reproduction. Thus our lack of success in bringing about the synthesis of a living thing is due to the fact that the special asymmetric spatial conditions required for the purpose are absent from our laboratories.

The question of the 'rightness and leftness' of living substance deserves serious consideration and we shall return to it later, but it must be pointed out here that at present 
a large number of facts are being reported in the scientific literature which suggest the possibility of the production of asymmetric substances independently of living things in the presence of asymmetric factors acting in inorganic nature.

In one of his later works, published in $1944,{ }^{10}$ Vernadskir seems to have taken account of these discoveries and did not refer to this difference between living and inert matter but only emphasised the fact that they differ in isotopic composition. The fact is that as early as 1926 Vernadskir demonstrated that the isotopic composition of the elements present in living organisms differs considerably from that of the elements derived from minerals and rocks. However, biogenic formations which arise in association with living things or after their death, such as soils, the waters of seas, rivers and lakes, petroleums, coals and bitumens, retain the isotopic composition characteristic of living things. Vernadskiǐ therefore held that in this case one cannot a priori deny the possibility of transition of matter from the dead ('bio-inert') to the living state, "for the atomic composition of the living and the inert matter may here be isotopically identical'. On the other hand, the direct transition from materials which have not arisen biogenically to living things would seem to be excluded on account of the profound differences in isotopic composition. However, as these biogenic formations ('bio-inert' substances) only develop in the presence of organisms a closed circle of life is set up.

One might infer from this that Vernadskil continued to believe in the complete impassability of the gulf separating the living from the lifeless, the complete impossibility of the primary origin of life from inert matter. Howerer, such a conclusion would be premature. In the work which we have cited. Vernadskiř shows convincingly, in a number of concrete examples, that a quantitative change in the isotopic composition of the elements "is not only characteristic of living matter but also occurs in processes which have nothing to do with life, as among the products of volcanic eruptions". The whole difference lies in the fact that changes in the isotopic composition of the elements brought about by organisms proceed on the surface of the earth at ordinary temperatures and pressures, whereas analogous changes in 
a lifeless medium only happen at high pressures and temperatures in the depths of metamorphic formations. "The synthesis of life ", Vernadskiř continued, "requires preliminary isotopic modification of the chemical elements ". However, as we have just seen, Vernadskir himself pointed out that changes of this sort may occur in ordinary inert media at high temperatures and pressures and it is therefore quite arguable that life first originated from ordinary inert (not biogenic) matter under conditions where it was subjected to preliminary isotopic modification by the forces of inorganic nature.

Thus we have seen that, as a result of prolonged and varied studies of the question, Vernadskir abandoned the untenable position of 'materialistic dualism' which he previously held. In 1944 he wrote, "In our time the problem can hardly be treated as simply as it could be during last century when, it seemed, the problem of spontaneous generation had been finally solved in a negative sense by the work of Louis Pasteur."

It is hardly necessary nowadays to demonstrate theoretically the complete incompatibility of all kinds of dualistic views with a consistent materialism. We should, however, analyse in detail the factual evidence which has been and still is adduced in support of their attitude by the adherents of the theory of the eternity of life. We should examine how far this evidence agrees with the objective data of contemporary science. The chief difficulty which is always encountered by the materialistically inclined proponents of the eternity of life is the problem of the emergence of life on the Earth and of all those beings which inhabit the Earth. The Earth itself does not seem to be eternal, it originated at some time and it is therefore necessary to explain in some way how the first organisms appeared on it without recourse to the creative act of deity or the formative influence of a 'life force'.

For vegetation to develop on the virgin rocks of volcanic islands the seeds or spores of plants must have been carried there from elsewhere. A similar idea that viable germs from other worlds inhabited by organisms were deposited on the virgin earth during its development was put forward by the 
supporters of the theory under discussion as being the only possible explanation of the appearance of life on our planet. But before this hypothesis is scientifically admissible it must be shown that life is widely distributed throughout the universe, that it is to be found, not only on the Earth or within the solar system, but also in other parts of the universe. Furthermore, it is necessary to explain how the germs of life could be transferred to the Earth through interplanetary and interstellar space while remaining alive and able, under favourable circumstances, to grow and give rise to a new race of living things.

The bold suggestion that there might be a multiplicity of worlds inhabited by living creatures was very clearly stated by the great sixteenth century scientist Giordano Bruno. In his treatise Del' infinito universo e mondi1 he wrote, "There exist innumerable suns and innumerable earths circling round their suns just as our seven planets circle round our Sun. Living things dwell on these worlds."

For a long time this idea did not spread far because it came up against the ancient but very active anthropocentric conviction that there is only one earth supporting life in the universe. It was considered daring and fantastic for a scientist to think that there might be many inhabited worlds. It is only 15-20 years since the authoritative English astronomer Sir James Jeans ${ }^{12}$ stated that

We know of no type of astronomical body in which the conditions can be favourable to life except planets like our own revolving round a sun. . . . Yet exact mathematical analysis shows that planets cannot be born except when two stars pass within about three diameters of one another. ... The calculation shows that even after a star has lived its life of millions and millions of years the chance is still about a hundred thousand to one against its being a sun surrounded by planets. ... All this suggests that only an infinitesimally small corner of the universe can be in the least suited to form an abode of life.

Now, however, we cannot accept Jeans' point of view. On the contrary, contemporary scientific findings definitely confirm the inspired foresight of Bruno. In 1938 the Swedish astronomer E. Holmberg ${ }^{13}$ made careful analyses of a number 
of measurements of the right ascensions of stars the parallax of which had been determined with special accuracy. He demonstrated very small but definite oscillations with periods ranging from one and a half to three years. These oscillations can only be explained as disturbances caused by satellites of comparatively small mass. It would certainly be impossible to observe these satellites directly by means of present-day telescopes, but there is now no doubt that there are many stars which, like our Sun, are surrounded by circulating planets. ${ }^{14}$ Twenty-five per cent of the 240 stars observed by Holmberg give indications of the presence of small, invisible planets. Dark satellites having masses comparable with those of our own planets have already been discovered for many stars, e.g. 7o Ophiuchi and 61 Cygni. ${ }^{15}$

It seems, therefore, that our solar system is not unique. There can be no doubt that planets revolve round other stars too, and very many of these are comparable with our Earth. There is therefore nothing to hinder us from supposing that life exists on some of them, maybe even on many of them.

In his book Life on other worlds $\mathrm{H}$. Spencer Jones ${ }^{16}$ analyses a great deal of factual material relating to our problem and arrives at the conclusion that life is distributed throughout the universe and that the number of worlds where life is possible seems to be very considerable (see also the recent book of A. Oparin and V. Fesenkov, Zhizn'vo vselennor.* Moscow (Izd. AN SSSR), 1956). Thus the first condition mentioned above for the acceptance of the theory under discussion, that is to say the wide dispersal of life in the universe, is not ruled out by the findings of contemporary science. The case is, however, different as regards the passage of the germs of life through space.

The hypotheses concerning this problem may be divided into two groups, (1) the transport of the germs by meteorites ('cosmozoë' or 'lithopanspermia ') and (2) transport of the germs with cosmic dust under the pressure of light ("radiopanspermia ').

* Life in the Universe.-Translator. 


\section{The theory of cosmozoë.}

The idea that fragments of stars bearing the seeds of life might reach the Earth and thus impregnate it was discussed as far back as the beginning of last century by the Frenchman de Montlivault. ${ }^{17}$ It was later developed by H. Richter ${ }^{18}$ in 1865. He started from the hypothesis that when celestial bodies are in rapid motion small pieces or solid particles may become separated or torn off from them. It might be that the viable germs of micro-organisms were attached to the particles at the time when they became separated from the celestial bodies. Furthermore, these particles would wander in interstellar space and might, by chance, arrive on other heavenly bodies. When these germs fell on a planet where the conditions were favourable for life (suitable conditions of moisture and temperature) they would start to develop and, in the course of time, they would establish themselves as the ancestors of all living things on that particular planet. Richter assumed that somewhere in space there are always celestial bodies on which life exists in the form of cells. This idea was later developed by M. Wagner, ${ }^{19}$ who considered that "the atmospheres of the heavenly bodies, and also the swirling cosmic mists may be regarded as eternal repositories of living forms, as perpetual plantations of organic germs". Thus life is scattered throughout the universe and travels in the form of germs within meteorites.

Richter paid special attention to the possibility that viable germs might be carried through interstellar space. He pointed out that the germs of living things can exist for long periods without nutrients and water, remaining in a more or less inanimate state, and may then reawaken to a new life, though only when the necessary conditions are fulfilled. As a result of this capacity they may make very long journeys. The only hazard to which the germs of life are submitted arises from the increase in temperature which occurs as a result of the tremendous friction generated between the meteorites and the atmosphere of the Earth. However. Richter points out that some meteorites contain traces of carbon and other easily combustible substances. If these substances can reach the Earth without being burnt, it is 
perfectly possible that germs might pass through the atmosphere without losing their viability.

Similar views were put forward in Britain by Lord Kelvin, ${ }^{3}$ who wrote in 1871 :

Should the time when this Earth comes into collision with another body, comparable in dimensions to itself, be when it is still clothed, as at present, with vegetation, many great and small fragments carrying seed and living plants and animals would undoubtedly be scattered through space. Hence and because we all confidently believe that there are at present, and have been from time immemorial, many worlds of life besides our own, we must regard it as probable in the highest degree that there are countless seed-bearing meteoric stones moving about through space.

These statements made a very great impression on the scientists of those times. In Germany they were supported by $\mathrm{H}$. Helmholtz, ${ }^{20}$ who considered that the germs of life had reached the Earth by means of meteorites which, in their passage through the atmosphere of the Earth, had been strongly heated on the surface only, while the inner part remained cool. In France this opinion was shared by van Tieghem, who wrote that the Earth received the seeds of life by their being carried on meteorites; henceforth it conserved the life which was derived from these original germs.

The main foundation for all these hypotheses was the fact that many rocky meteorites contain compounds of carbon approaching hydrocarbons in their composition. For example, chemical analyses by $\mathrm{Cloez}^{21}$ of the Orgeuil meteorite revealed the presence of amorphous substances very similar to the humus-like substances found in some fuels dug from the earth. At the time when the presence of hydrocarbons in meteorites was first discovered people were still convinced that organic substances, including hydrocarbons, could only be formed under natural conditions in living cells. Many scientists therefore supposed that the hydrocarbons found in the meteorites had been formed there secondarily as the result of the decomposition of organisms which had lived at some time on these heavenly bodies. This raised the question of the possible existence of living bacteria or their spores inside the meteorites. 
Nowadays, since the comprehensive investigations of D. Mendeleev $^{22}$ and other chemists, we know that hydrocarbons and their derivatives can easily develop inorganically under natural conditions, particularly from cohenites, which are minerals commonly found in meteorites and composed of carbides of iron, nickel and cobalt $-\left(\mathrm{Fe}, \mathrm{N}_{1}, \mathrm{C}_{0}\right)_{3} \mathrm{C}$.

J. L. Smith ${ }^{23}$ showed that the organic substances found in the Orgeuil and other meteorites could have been formed as the result of reactions between iron carbide and iron sulphide. From the Orgueil meteorite Smith even prepared compounds of carbon, hydrogen and sulphur such as $\mathrm{C}_{4} \mathrm{H}_{6} \mathrm{~S}_{5}$. He showed that there is no foundation for the belief that these organic compounds have been formed by organisms.

Berthelot and Schutzenberger independently reached similar conclusions. They demonstrated in meteorites the presence of hydrocarbons completely analogous to those formed during the smelting of iron at temperatures which are certainly incompatible with life. Thus the discovery of compounds of carbon in meteorites cannot now serve as an argument that there are traces of life on these bodies.

Neither have numerous attempts to discover directly the germs of microbes on meteorites given definite positive results. S. Meunier ${ }^{24}$ stated that Pasteur, whom he supplied with specimens of carbon-containing meteorites, also tried to isolate viable bacteria from them. He even constructed a special boring apparatus for the purpose, which enabled him to take specimens from the inner parts of the meteorites. However, Pasteur always got negative results and therefore did not publish them. Later scientists have had no more success in finding living things in meteorites.

The only exception is to be found in a publication by C. B. Lipman ${ }^{25}$ in 1932. Here the author describes his investigations made on many specimens of stony meteorite. He sterilised the outside of the meteorites and took measures to exclude contamination by adventitious bacteria. Nevertheless he was often successful in obtaining living bacteria in the form of rods or cocci by sowing broken-up pieces of the meteorite on a nutrient medium.

This communication attracted much attention in scientific circles and even found its way into some textbooks (e.g. ${ }^{26} /$, 
but unfortunately it has not been confirmed up till now. It is worthy of note that the microbes obtained by Lipman seemed to be identical with the ordinary terrestrial bacteria. In view of the great variability of bacteria and the readiness with which they adapt themselves to external conditions, it is hard to believe that exactly the same forms of microorganisms exist on other heavenly bodies as on our planet. It seems far more probable that, in spite of all his precautions, Lipman failed to prevent terrestrial bacteria from falling on to the meteorites he was studying while he was grinding them. In a letter which he sent to me, Lipman himself did not insist that his results were completely unequivocal.

In the present state of our knowledge it is, in fact, hard to suppose that organisms are present inside meteorites. If life had developed at some time and place on the planet from which the meteorite had become separated, it would undoubtedly have left traces in the shape of biogenic formations. However, even after the most careful searches nobody has been able to find traces of such formations anywhere in meteorites. According to A. Fersman, F. Levinson-Lessing and others there is nothing resembling a sedimentary formation nor anything which might, in general, be ascribed to biological processes. Mineralogical studies of meteorites also show that they were formed under conditions incompatible with life.

That great expert on meteorites Vernadskiǐ wrote as follows ${ }^{27}$ :

Those germs of life, 'microzoa', cannot have any connection with meteorites or any cosmic dust known to us. For nowhere in the structure of the meteorites or dust do we see manifestations or effects of life. If we study them we find that they were formed under conditions similar to those under which our own deepest formations originated (high pressure and high temperature) or else by chemical processes from liquids and gases, also at high temperatures (chondrites, moldavites). Microbes may be associated with them fortuitously but are quite independent and not directly connected with them.

Thus the only possibility would be that the microbes might be picked up by the meteorites in space, but they 
would then certainly be on the surface of the meteorites and would therefore necessarily be destroyed in transit through the Earth's atmosphere.

A very bold and original hypothesis has fairly recently been put forward by L. Berg. ${ }^{28}$ It is directly connected with the meteoritic theory of the transport of life. Berg bases his hypothesis on O. Shmidt's meteoritic theory of the formation of the Earth. ${ }^{29}$ According to this theory, the Earth was never an incandescent sphere but consisted of cold materials from the beginning. "Along with the aggregation of meteorites of which it is formed ", Berg wrote, "the Earth may also have acquired the germs of life or perhaps ready-made complex living organisms."

This hypothesis, however, agrees so badly with the facts so far studied that it is hard to point to a single fact which might support it. On the contrary, all that we know about meteorites and cosmic dust is totally opposed to it.

Summing up all that has been said, we must admit that the theory of cosmozoë or lithopanspermia, the theory that life arrived on Earth inside meteorites, is in direct contradiction to the objective facts of contemporary science.

\section{Arrhenius' theory of panspermia.}

The theory of radiopanspermia was produced at the beginning of the twentieth century to replace that of lithopanspermia. The originator of this theory was the famous Swedish physical chemist S. Arrhenius, ${ }^{30}$ who was an ardent supporter of the idea that life is distributed throughout space. He tried to prove by direct calculations that it is possible for particles of matter to pass from one heavenly body to another. He considered that the main agent in this case would be the pressure of the rays of light.

The phenomenon received its theoretical foundation at the hands of Clerk Maxwell in the second half of the nineteenth century, but the scientists of that time refused to accept it without direct experimental evidence. Only a brilliant experimentalist like the Russian physicist P. Lebedev ${ }^{31}$ could succeed in demonstrating the phenomenon. which he did in 1900. By direct experiment Lebeder showed that 
light exerts pressure on those objects on which it falls and, furthermore, he determined the magnitude of this pressure.

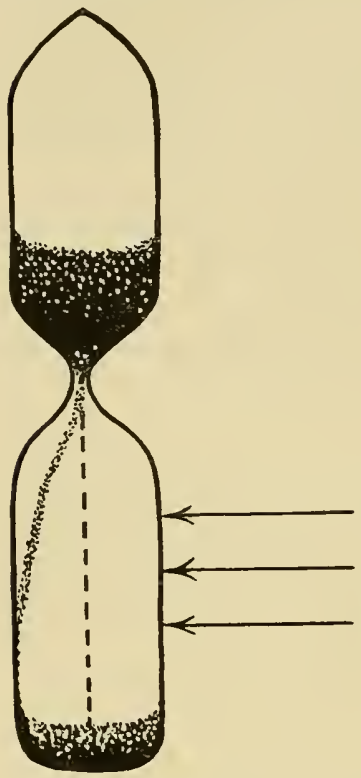

FIG. 1. Diagram of the experiment of Nichols and Hull.

It turned out to be infinitesimal. The sunlight falling on the surface of the Earth only exerts a pressure equivalent to $0.5 \mathrm{mg} / \mathrm{m}^{2}$, but even this is enough to cause minute particles of dust to move through a vacuum at a considerable speed.

Fig. 1 is a diagram illustrating the experiment of Nichols and Hull which demonstrates the theory well. They used a glass vessel shaped like an hour glass. In it they placed a mixture of emery and very fine carbon dust obtained by the carbonisation of fungal spores. The air was evacuated from the vessel. The stream of particles falling through the narrow opening was illuminated by a powerful source of light. The emery fell to the bottom but the carbon particles were diverted on to the walls.

Arrhenius drew a picture of the passage of small particles, among them the spores of micro-organisms, through interplanetary and interstellar space. Upward currents of air, which would be specially strong after volcanic eruptions, might carry particles of matter to very great heights, up to 100 or more kilometres above the surface of the Earth. In the upper layers of the atmosphere there are, for a number of reasons, constant electrical discharges which would be more than enough to drive these particles of matter out of the atmosphere of the Earth into interplanetary space. Here the particles would travel further and further under the one-sided pressure of the rays of the Sun.

As from the surface of the Earth so, in the same way, very small particles must be constantly becoming detached from 
the surfaces of other heavenly bodies. If a planet is inhabited by living organisms, particularly micro-organisms, then their spores would be able to travel through interstellar space in the same way. Arrhenius calculated that bacterial spores having a diameter of $0 \cdot 0002-0 \cdot 00015 \mathrm{~mm}$ could travel through space at a very great speed under the influence of the pressure of sunlight. Fourteen months after having left the Earth such a spore would pass out of our planetary system, but it would be 9,00o years before it reached the nearest star, $\alpha$ Centauri. The migration of spores can, however, take place towards the Sun as well as away from it. While wandering in interstellar space the germ may meet comparatively large particles of cosmic dust. If the spore becomes attached to a particle having a diameter of $0.0015 \mathrm{~mm}$ it will begin to move towards the Sun, as the pressure of the light will not be able to overcome the weight of the particle which will be approaching the Sun under the influence of gravity. Arrhenius thought that the Earth might have been colonised in this way by spores of micro-organisms coming into our solar system from other parts of the universe.

According to the calculations of Arrhenius the particles of cosmic dust falling on the Earth in this way would not necessarily get hot and burn in the atmosphere of the Earth as do meteorites. If the particles were of the size mentioned, the pressure of light would check their motion and the speed at which they fell would be slow enough for them only to be heated through some tens of degrees, which would not prevent the spores from retaining their viability.

Arrhenius' theory received wide attention in the scientific world and found many supporters both among physicists and among biologists. In the U.S.S.R. in particular it was supported by S. Kostychev, P. Lazarev, A. Nemilov ${ }^{32}$ and others. In fact, Arrhenius made careful enough calculations and a good analysis of the mechanical aspect of the passage of particles of matter from one heavenly body to another. There remained, however, the unsolved problem of whether the germs of bacteria could accomplish such an interstellar journey and remain alive. To this aspect of the matter Arrhenius and the other supporters of his theory quite naturally paid special attention. 
The distance separating one planetary system from another is tremendous. Even if the particles were to travel at the speed already mentioned it would still be many thousands of years before they reached the nearest star. Under these circumstances one must take into consideration all the dangers to which the germs of life would be submitted during the whole course of their long journey, the severe cold of interstellar space, the complete absence of moisture, oxygen, etc. Could they endure all these hardships for thousands of years while still retaining the ability to multiply when they fell on a new planet, and to give rise to all the later inhabitants of that planet?

\section{The state of the problem at the present day.}

The adherents of panspermia expended much work and ingenuity to prove the possibility of such a passage of the germs of life from one heavenly body to another in a viable condition. The spores of bacteria are, in fact, extremely stable under all sorts of unfavourable external conditions. Many of them certainly do not need oxygen. It is well known that anaerobic bacteria can not only be conserved without oxygen but can live without it for the whole of their lives.

In the absence of water due to partial, or even more so to complete, drying, living processes are brought to a standstill but the organism is not by any means always killed. It only goes into a state of anabiosis. This is generally known in the case of the seeds of plants and even such lower animals as rotifers, tardigrada and eelworms. The extensive literature concerning this question is collected in P. Shmidt's book Anabiosis. ${ }^{33}$ The spores of bacteria are particularly resistant to drying. At the beginning of the century L. Maquenne ${ }^{34}$ showed that it is even possible to keep absolutely dry seeds in a vacuum for many years and that under this treatment they do not lose their viability. This was later confirmed by P. Becquerel ${ }^{35}$ and a number of other authors.

The resistance of bacteria and their spores to low temperatures appears to be exceptional. R. Pictet ${ }^{36}$ pointed out this peculiarity of bacteria in the nineteenth century. P. 
Becquerel $^{37}$ kept ampoules containing the dried spores of moulds and bacteria in a vacuum at the temperature of liquid air for several weeks. They all remained alive and grew for a year and a half under observation. The articles of C. B. Lipman ${ }^{38}$ and E. Kadisch ${ }^{39}$ may also be referred to.

The studies of B. J. Luyet ${ }^{40}$ and his colleagues are of particular interest. These studies show that if protoplasm is frozen deeply and quickly with liquid air or hydrogen it is possible to avoid crystallisation of ice and the dispersal of molecules and disturbance of structure associated with it. The protoplasm gets into a glassy state (becomes vitrified) and can be kept in that form at low temperatures indefinitely without losing the ability to be brought to life again when transferred to favourable conditions. From this one may conclude that the germs of bacteria which exist in interstellar space, where the temperature is near to absolute zero, could certainly float around for thousands of years without losing their viability. We find in the literature some reports of the survival of viable bacteria for very long periods in the frozen state, but not all of these reports seem completely reliable. We must refer first to the work of $\mathrm{V}$. Omelyanskir. ${ }^{41}$ He found many kinds of micro-organisms (which grew on broth media) in the tissues and mucus of the preserved middle part of the trunk of the Sanga Yurakh mammoth, which was sent to him from the place where the animal was found. The author does not exclude the possibility that some of the bacteria found in the corpse of the mammoth had reached it later. He considers that the evidence in favour of the microflora of the trunk being of contemporary origin with the mammoth is more convincing. If this is true, these bacteria have retained their viability during continuous refrigeration for tens of thousands of years. It must, however, be borne in mind that the remains of the mammoth were sent to Omelyanskiǐ from a distance and were not removed by professional microbiologists. One cannot, therefore, exclude the possibility that they were secondarily infected.

The same applies to the observations of P. Kapterer. ${ }^{42} \mathrm{He}$ has drawn up a complete list of algae, fungi, bacteria and even crustaceans which he has succeeded in bringing to life 
from samples of frozen subsoil obtained from a depth of two to seven metres. This implies growth after 1,000 to 3,000 years of refrigeration. L. Kriss ${ }^{43}$ studied the frozen subsoil of Kolyuchin and Wrangel Islands and made some very cautious inferences. Although he too found viable micrococci at these levels he considered it perfectly possible that these had fallen there from the upper levels where they were also present.

Thus the problem of the possibility of micro-organisms being preserved in a viable state at low temperatures for thousands of years cannot be considered to be conclusively solved. Nevertheless, one cannot reach the opposite conclusion that bacteria and their spores would necessarily be destroyed at temperatures near to absolute zero.

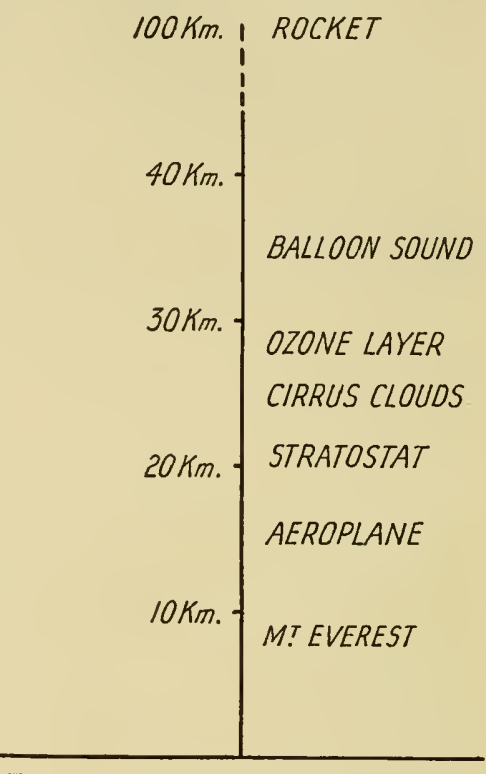

FIG. 2. Diagram of levels of the atmosphere.

It seems, however, that the greatest menace to bacteria and their spores in outer space is not so much the cold as the radiations which pass through it. Even at the end of last century it was established that by no means all the radiations of which sunlight is composed reach the surface of the Earth. Part of the light is absorbed by the atmosphere. This absorption affects particularly the ultraviolet radiations which are invisible to the eye but are very active chemically. Only radiations having a wavelength of not less than $3,000 \AA$ reach the surface of the Earth. It is only by going up high mountains that one can establish the presence of ultraviolet light with a wavelength of $2,900 \AA$. All the short-wave radiation is absorbed by the atmosphere and does not reach the surface of the Earth. However, outside the atmosphere, interplanetary and interstellar space are penetrated by radiations having wavelengths of $1,000-2,000 \AA$. These radiations are 
chemically extremely active. On reaching the outer layers of the atmosphere they are absorbed by molecular oxygen, as a result of which the oxygen is converted into ozone. At a height of about $3^{0}$ kilometres above the surface of the Earth there is a layer of ozone in the atmosphere called the 'ozone screen' which shields us from the short-wave radiations of interplanetary space (Fig. 2). It was noticed as long ago as 1877 that sunshine has a harmful effect on many bacteria. It was later established that this effect is mainly
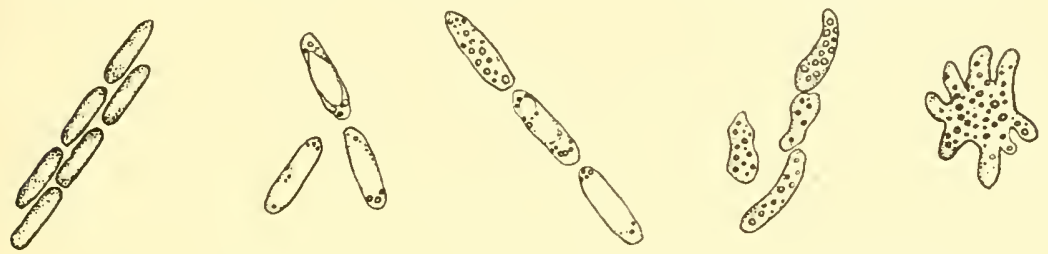

F1G. 3. The action of ultraviolet radiations on bacteria.

Living bacteria on the left.

due to the ultraviolet part of the spectrum which has a wavelength of less than $3,100 \AA$. Using artificial ultraviolet light from a mercury lamp, it was shown that the bactericidal activity of ultraviolet radiations increases as the wavelength decreases. It reaches a maximum at a wavelength of about $2,700-2,800 \AA$, and then falls off somewhat till the wavelength is about 2,600-2,400 $\AA$, after which it again increases strongly on passing to still shorter wavelengths. In the course of a few minutes, or even seconds, light of this sort will destroy not only the bacteria known to us, but also their spores (Fig. 3). ${ }^{44}$

Arrhenius knew about the bactericidal effect of sunlight but he considered that it was not the light itself that killed the bacteria but the oxygen which had been activated by it. This idea seemed to be fully confirmed by the experiments of Roux and Duclos, who kept spores in glass test tubes without oxygen under intense illumination for months. A considerable proportion of the spores retained their viability under this treatment.

These experiments suffered from a technical fault in that all the ultraviolet radiation was absorbed by the glass walls 
of the test tubes. The experiments of $\mathrm{P}$. Becquerel ${ }^{45}$ were technically sounder. He dried the spores of moulds, bacteria and other micro-organisms and collected them on a glass slide which was placed in a wide test tube. This was then hermetically sealed at the top by a plate of quartz, and then evacuated and plunged into a vessel containing liquid air. The

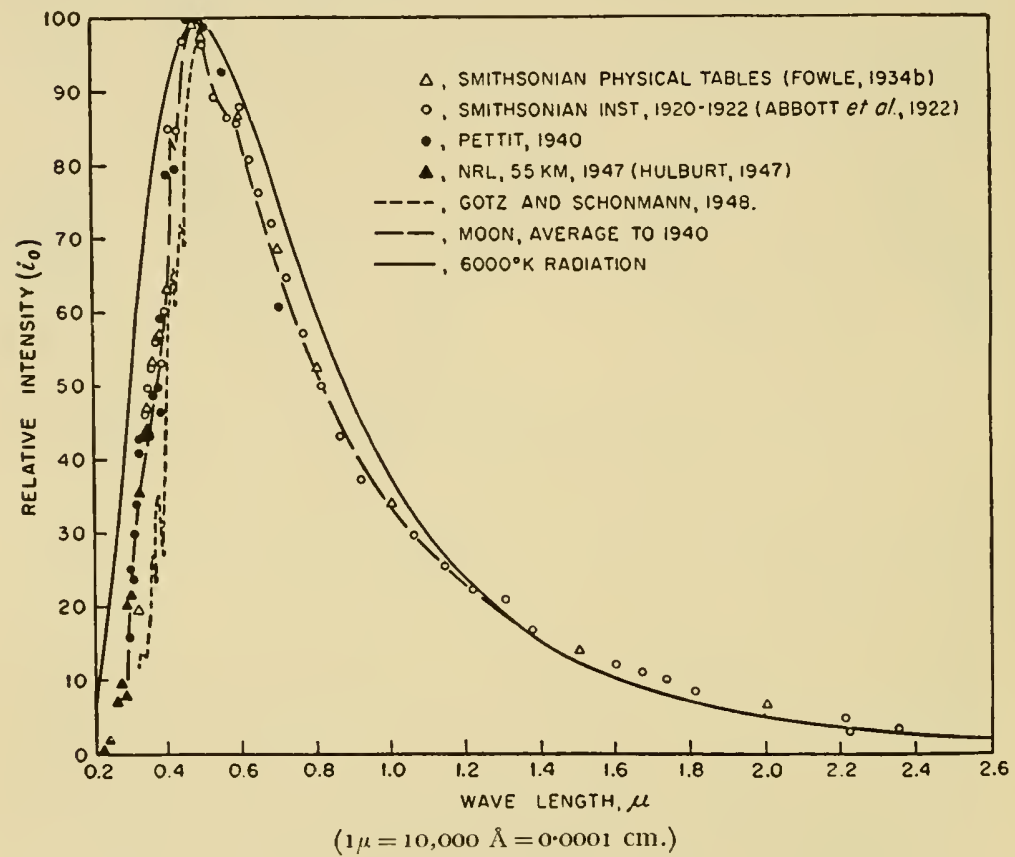

Fig. 4. Solar spectrum curves on top of the atmosphere.

By permission from Radiation Biology, vol. 11 by

A. Hollaender. Copyright 1955, McGraw-Hill Book Company, Inc.

spores were then irradiated with a mercury lamp through the quartz plate. They were all destroyed after fairly short periods of exposure.

The supporters of panspermia brought forward numerous objections to these experiments. It was suggested that there are forms of bacteria which are specially resistant to ultraviolet light; that the bactericidal effect of the ultraviolet light is due to oxidative or other chemical changes so that it can 
only manifest itself in the presence of water and oxygen (these are absent in outer space); that the intensity of the radiations was less in space than in the experiments; that ultraviolet radiation was not effective at temperatures near to absolute zero, etc.

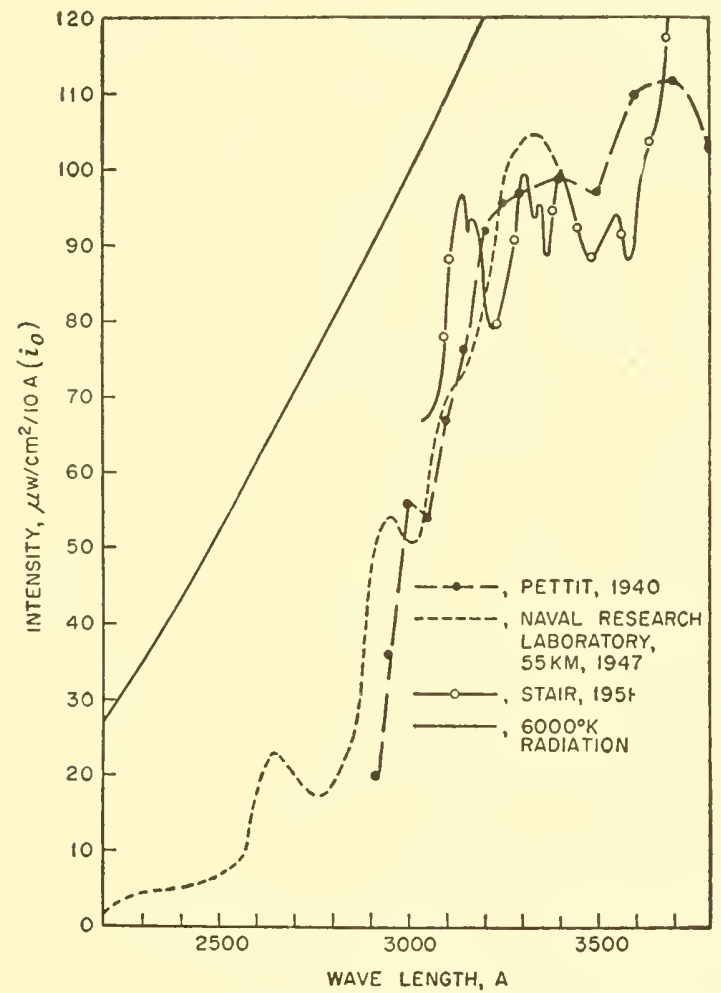

F1G. 5. Ultraviolet portion of the solar spectrum on top of the atmosphere.

By permission from Radiation Biology, vol. 11 by A. Hollaender. Copyright 1955, McGraw-Hill Book Company, Inc.

These objections, however, did not stand up to strict experimental testing. At the present time direct experiments using rockets which are sent up to heights of 100 kilometres, i.e. considerably above the ozone screen, have shown that, at this level, ultraviolet radiation is far more 
intense. We can deduce a curve relating intensity with wavelength for the ultraviolet radiation at the limit of the atmosphere of the Earth (Figs. 4 and 5 ). ${ }^{46}$

In his review D. E. Lea ${ }^{47}$ also presented a wide range of material showing that all forms of microbes and spores which have been investigated in this respect are destroyed by the action of short-wave ultraviolet light. We now possess considerably greater factual material but it completely confirms the earlier work on the destruction by ultraviolet light of all forms of micro-organisms whatever their species. ${ }^{48}$

Thus the earlier findings of $\mathrm{R}$. Wiesner ${ }^{49}$ that there exist forms of bacteria which are resistant to ultraviolet light were not confirmed by later workers. On the contrary, it is now asserted that the various species only differ very slightly from one another in their resistance. This effect of light is quite different from that of temperature, for we know many very thermostable bacteria. This difference is particularly noticeable where spores are concerned. Thus, for example, the spores of Bacillus anthracis and B. subtilis are very resistant to high temperatures and, in contrast to their vegetative forms, can even undergo more or less prolonged boiling. However, the difference in resistance between the vegetative forms and spores does not exist in respect of the effect of ultraviolet light, which destroys both forms of these organisms almost equally easily.

Another difference between the effects of temperature and light is that the presence of water is not necessary for the effect of light. It has now been established that completely dried cultures and spores of various microbes always exhibit considerable radiosensitivity. ${ }^{50}$ Neither does oxygen seem necessary for the bactericidal activity of light. The earlier view that the effect of ultraviolet light depended on an oxidative activity seems to be untenable. It has been shown experimentally that short-wave radiations can have a destructive effect on micro-organisms even in the absence of gaseous oxygen in the surrounding medium. Ultraviolet radiation is bactericidal by virtue of its direct action on the substance of the bacteria. 
Neither does the temperature play a decisive part in the process with which we are concerned. F. Gates ${ }^{51}$ showed that the temperature coefficient does not exceed 1.06 in such processes, which is as expected for photochemical reactions.

As we have seen, the experiments of P. Becquerel demonstrated the bactericidal activity of ultraviolet radiation eren at the temperature of liquid air. This has been confirmed many times since then. In this connection the recent experiments of E. Graevskiı̌s2 are of special interest. This author was studying different forms of bacteria, moulds, yeasts and other such organisms. He showed that when they have been cooled to very low temperatures and the protoplasm is in a glassy state it retains its viability for a long time because, under these conditions, there is no need for metabolic processes to maintain its dynamic structure. However, even under these conditions, micro-organisms and their spores are quickly destroyed by ultraviolet and $\beta$-radiation. Graevskiu writes:

The effect of ultraviolet radiation on a living substrate is the same at room temperature and at $-192^{\circ} \mathrm{C}$ and this completely justifies one in assuming that even the very low temperature prevailing in outer space could not protect living protoplasm from the harmful effects of radiant energy.

The bactericidal effect of short-wave ultraviolet radiation is explained by its extremely strong chemical effects. The energy of this radiation is so great that it can alter or even disrupt any organic molecules which absorb it. It polymerises acetylene, anthracene and many other hydrocarbons. It decomposes acetone and various aldehydes, organic acids, etc. The effects of such radiations on proteins are particularly interesting to us.

A. D. McLaren has summarised the work of a number of authors in his review. ${ }^{53}$ Proteins are denatured under the influence of ultraviolet light and when this happens they lose their solubility in water, they change their viscosity. their optical rotation and their content of amino and other functional groups. In contrast to the denaturation caused by heat, this alteration may occur even on irradiation of the protein in the dry state. Its occurrence is independent of 
the presence of oxygen. ${ }^{54}$ These changes in the physical properties of protein solutions which occur during irradiation (changes in viscosity, solubility, etc.) depend on chemical and structural alterations in the actual molecules of the protein occurring under the influence of the light. These changes are particularly marked at wavelengths where the absorption by proteins is particularly intense. It is specially significant that the curve for the absorption of ultraviolet radiation by proteins corresponds closely with the curve for the destruction of bacteria by radiation in different regions of the ultraviolet spectrum. Thus, in both cases there are maxima at about $2,700 \AA$; below this, the absorption by proteins and the bactericidal activity fall off and then again increase when the wavelength of the radiations becomes still shorter. This correspondence serves as a clear demonstration that the changes in the protein which are brought about by the ultraviolet radiation are the same as those which destroy the bacteria. ${ }^{55}$ It seems significant that direct investigation of irradiated micro-organisms shows that their proteins have been coagulated.

From what has been said it is clear that all micro-organisms which have proteins as the main constituent of their protoplasm (and we know of no living thing which is devoid of protein) must be destroyed by the action of ultraviolet light. As the alteration in the proteins and the associated destruction of the bacteria proceed even in the absence of water and oxygen and at very low temperatures, the probability that viable germs arrived on the Earth from space would seem to be zero. The light of the stars is rich in ultraviolet radiation. On the surface of the Earth we are protected from its harmful effects by the atmosphere surrounding us. On escaping from this atmosphere the germs of life would inevitably be destroyed by the activity of the ultraviolet radiations which traverse interstellar space.

It is true that other 'hypotheses' have been brought forward of recent years in an attempt to redeem the theory under discussion. For example, it has been suggested that life might have been brought here at some time by the landing of astronauts, that is to say, highly developed con- 
scious beings who could undertake interplanetary journeys. This sort of suggestion is, however, more reminiscent of science fiction than of a serious scientific hypothesis. The facts which are at present available to science convince us of the absolute impossibility of viable germs travelling to the Earth through space.

It is interesting to note that, in spite of his ardent belief in the possibility of interplanetary travel, the outstanding Russian scientist and inventor $\mathrm{K}$. Tsiolkovskir ${ }^{56}$ nevertheless categorically denied the possibility of this sort of artificial transport of microbes. When he died in 1919 he left a manuscript entitled The origin of plants on the terrestrial globe and their development. In it we may read "My work has shown that it will be possible to devise means whereby any living thing may be artificially transmitted from the Earth to another planet and back safely, but mankind is not proceeding very fast towards the realisation of this possibility." However, he goes on to say that this form of transport of life 'with the help of reason' could not have occurred, for no traces had been observed suggesting that at any time or place there have been such highly developed beings deliberately visiting the Earth. Tsiolkovskir wrote in conclusion: "This means that life did not reach the Earth from the planets even with the help of reason."

Thus we see that the theory of the eternity of life, like that of spontaneous generation, is in radical contradiction to the observed facts. While travelling through interstellar space with nothing to protect them from the lethal radiations, not only would the germs of life be inevitably destroyed. but even their internal structure would undergo profound alteration in a comparatively short time. We must therefore reject the hypothesis that the germs of life reached the Earth from somewhere else and must seek the source of life within the confines of our own planet. 


\section{BIBLIOGRAPHY TO CHAPTER II}

1. T. Gomperz. (See I. 5).

2. A. Kircher. Mundus subterraneus. Amsterdam, 1665 . Quoted by Lippmann (I. 1).

3. W. Thomson (later Lord Kelvin). Presidential Address, Edinburgh. Rep. Brit. Ass., $187 \mathrm{I}$, ciii.

4. H. v. Helmholtz. Preface to W. Thomson and P. G. Tait: Handbuch der theoretischen Physik. Braunschweig, 1874 .

5. P. van Tieghem. Traité de botanique. (2nd edition), Vol. 1. Paris, 1890.

6. S. Kostychev. O poyavlenii zhizni na zemle. Berlin (Gosizdat), $192 \mathrm{I}$.

7. (I. 59).

8. V. I. Vernadskiľ. Biosfera. Leningrad (Nauchn. khim. tekhn. Izd.), 1926.

9. V. I. Vernadskiľ. Problemy biogeokhimii. Vol. 2. Moscow (Izd. AN SSSR), 1939.

1o. V. I. Vernadskiľ. Pochvovedenie, 1944, (Nos. 4-5), p. 137.

11. Giordano Bruno. Del' infinito universo e mondi. In Opere italiane (ed. G. Gentile). Bari, 1907-9.

12. Sir J. Jeans. The universe around us. Cambridge, 1929.

19. E. Holmberg. Medd. Lunds astr. Obs. Ser. II, no. 92 (1938).

14. N. N. Pariřskiř. Astr. J., Moscow, 16, 77 (1939).

15. N. ReǏn and N. N. PARIǏskiľ. Uspekhi astron. Nauk, 2, 137 (1941). A. N. Deǐch. Priroda, 5-6, 99 (1944).

16. H. Spencer Jones. Life on other worlds. London, 1940.

17. Comte E.-J.-F. DE S. G. de Montlivault. Conjectures sur la réunion de la lune à la terre . . etc. Paris, 1821 .

18. H. Richter. Schmidts Jb., I26, 243 (1865); 148,57 (1870).

19. M. Wagner. Augsburger allgemeine Zeitung, Beilage, 6, 7 and 8 Oct., 1874 . Quoted in (I. 59).

20. H. v. Helminoltz. Über die Entstehung des Planetensystems. In Vorträge und Reden. Braunschweig, 1884.

2 I. S. Cloez. Quoted by H. von Klüber. Das Vorkommen der chemischen Elemente im Kosmos. Leipzig, $193 \mathrm{I}$.

22. D. Mendeleev. Osnory khimii. Vol. 1, p. 379. Moscow (Gosizdat), 1927.

23. J. L. Sмiтн. Amer. J. Sci. [ser. 3], II, 388, 433 (1876).

24. S. Meunier. Quoted by P. Becquerel. Astronomie, 38, 393 (1924) 
25. C. B. Lipman. Amer. Mus. Novit., no. $5^{88}$ (1932).

26. A. Krishtofovich. Paleobotanika. Moscow and Leningrad (Gosgeolizdat), 1941.

27. V. I. Vernadskǐ̌. Nachalo i vechnost' zhizni. Petrograd (Izd.

'Vremya'), 1922.

28. L. Berg. Byull. Moskov. Obshchestva Ispytatelę Prirody, $52(5)$, p. $15(1947)$.

29. O. Shmidt. Priroda, 7,6 (1946).

3o. S. A. Arrhenius. I'erldarnas utveckling. Stockholm, 1906; Das Weltall. Leipzig, 1911; Das Schicksal der Planeten. Leipzig, 1911.

31. P. Lebedev. Sobranie sochinenil. Moscow (Izd. Moskov. Fiz. Obshchestva), 1913 .

32. A. Nemilov. Kak poyavilas' na zemle zhizn'? Leningrad (Izd. ' Obrazovanie '), 1924.

33. P. Shmidt. Anabioz. Moscow and Leningrad (Izd. AN SSSR), 1955 .

34. L. Maquenne. C.R. Acad. Sci., Paris, 135, 208 (1902); I4I, $609(1905)$.

35. P. Becquerel. Ann. Sci. nat. (Botanique, $9^{\circledR}$ série), 5, 193 (1907).

36. R. Pictet. Arch. Sci. phys. nat., 30, 293 (1893).

37. P. Becquerel. C.R. Acad. Sci., Paris, $178,10_{52}^{2}$ (1909); 150 , 1437 (1910).

38. C. B. Lipman. Bull. Torrey bot. Cl., 67, 537 (1937).

39. E. Kadisch. Med. Klinik, 29, ro74 (1931); 30, 1109 (1931).

40. B. J. Luyet. Biodynamica. Vol. 1, no. 29, p. 1 (1937).

B. J. Luyet and P. M. Gehenio. Biodynamica. Vol. 3, no. 60 , p. 33 (1940).

41. V. L. Oméliansky (Omelyanskiñ). Arch. Sci. biol., St. Petersburg, I6, 355 (1911).

42. P. Kapterev. Izvest. Akad. Nauk S.S.S.R. (Ser. biol.), 6, 1073 (1936); Doklady Akad. Nauk S.S.S.R., 20, 315 (1938).

43. L. Kriss. Mikrobiologiya, 9, 789 (1940).

44. Biological effects of radiation (ed. B. M. Duggar). Vols. 1 and 2. New York, 1936.

45. P. Becquerel. C.R. Acad. Sci., Paris, 15 I, 86 (1910).

46. J. A. Sanderson and E. O. Hulburt. Radiation biology (ed. A. Hollaender, et al.). Vol. 2, p. 95. New York, 1955 .

47. D. E. LeA. Actions of radiation on living cells. London, 1946 . 
48. R. Latarjet. Symposium on Radiobiology, Oberlin College, 1950, 241 (1952).

M. R. Zelle and A. Hollaender. Radiation biology (ed. A. Hollaender, et al.). Vol. 2, p. 365. New York, 1955.

49. R. Wiesner. Arch. Hyg., Berl., 6r, 1 (1907).

5o. W. S. Moos. J. Bact., 63, 688 (1952).

51. F. L. Gates. Proc. Soc. exp. Biol., N.Y., 21, 61 (1929); J. gen. Physiol., 13, 231, 249 (1929).

52. E. YA. Graevskir. Doklady Akad. Nauk S.S.S.R., 53, 849 (1946).

53. A. D. Mclaren. Advanc. Enzymol., 9, 75 (1949).

54. H. L. Stedman and L. B. Mendel. Amer. J. Physiol., 77, 199 (1926).

55. C. Sonne. Strahlentherapie, 28, 45 (1928).

T. M. Rivers and F. L. Gates. J. exp. Med., 47, 45 (1928).

$5^{6}$. K. Tsiolkovskiř. Unpublished MSS (1919). 


\section{ATTEMPTS AT A SCIENTIFIC APPROACH TO THE PROBLEM OF THE ORIGIN OF LIFE}

\section{The mechanistic concept of the self-formation of living things.}

As was pointed out in the previous chapters, science, during the second half of the nineteenth century, was in a critical situation as concerns the problem of the origin of life. The old principle of spontaneous generation had been overthrown, and scientists felt that they had been deprived of the possibility of any experimental approach to the problem of the origin of life on the Earth. A period of disillusionment and pessimism set in, which survived from the last years of the nineteenth century well into the twentieth. Very many scientists tried somehow to evade the problem, either by promoting the theory of the eternity of life or by becoming open idealists and relegating the question from the field of science to that of faith. Nevertheless, some advanced and progressive scientists struggled against this kind of attitude right from the beginning. They felt that their chief task, amid the surge of idealism, was to defend the principle of a materialistic approach to the problem of the origin of life.

As an example may be mentioned here the remarkable statements of T. H. Huxley and J. Tyndall at the meetings of the British Association held in the 1860's and 1870's. These meetings served as a forum into which were brought the great controversies of scientific principle of that period. In his presidential address to the British Association, Huxley wrote $^{1}$ :

If it were given to me to look beyond the abyss of geologically recorded time to the still more remote period when the earth was passing through physical and chemical conditions, which it 
can no more see again than a man can recall his infancy, I should expect to be a witness of the evolution of living protoplasm from not living matter. I should expect to see it appear under forms of great simplicity, endowed, like existing Fungi, with the power of determining the formation of new protoplasm from such matters as ammonium carbonates, oxalates and tartrates, alkaline and earthy phosphates, and water, without the aid of light.

In just the same way Tyndall, in his address of $1874,{ }^{2}$ discussed the theory that life originated from lifeless matter. From that time to the present, there have been unceasing efforts to find a scientific solution to the problem of the origin of life, regarding it as an occurrence which could be interpreted on a materialistic basis. This important and extremely difficult task has required, and still requires, not simply an explanation of these wonderful occurrences in time past but also verification of the correctness of such an explanation.

For nearly a century now these efforts have proceeded according to two clearly distinct principles. First, the metaphysical principle, according to which living things were suddenly formed under some special conditions, separating themselves from a lifeless medium in the same way as crystals separate themselves from their mother liquors. Secondly, the evolutionary principle, which considers the origin of life in relation to the general development of matter and sees the emergence of the first organisms as a definite stage in this development.

The evolutionary principle, as it relates to our problem, was first formulated by Lamarck at the beginning of the nineteenth century. Lamarck's ${ }^{3}$ well-known theory of the evolution of organic nature, which was based on the ideas of the French encyclopaedists, ${ }^{4}$ enjoys a wide and wellmerited popularity. His ideas about the development of life are, however, less well known. They are to be found in a work written in 1820 under the title Système analytique des connaissances positives de l'homme restreintes à celles qui previennent de l'observation. ${ }^{5}$ Here Lamarck described the origin of living things from lifeless material as a process of gradual development of matter. On this basis Lamarck 
formed the opinion that " among the inorganic bodies " there must have developed " extremely small, half-liquid bodies of a very diffuse consistency". Then "these small, half-liquid bodies developed further into cellular bodies having an outer envelope with liquid contained in it and acquiring the first rudiments of organisation ..."

There was also a broad development of dialectical methods of thought in classical German Naturphilosophie at the beginning of the nineteenth century. Although, as we have seen in Chapter I, most of the representatives of this school of thought supported the theory of spontaneous generation, we find in the works of L. Oken ${ }^{6}$ a fairly well worked out form of the idea of the gradual evolution of carbon compounds. leading up to the formation of the primaeval slime from which all living things later developed.

In his works Charles Darwin hardly ever made direct reference to the development of the first living things which were to become the first ancestors of everything living on the Earth. It was only in one of his letters to Wallace (written in 1872), in which he was criticising Bastian's experiments and considering them to be completely unconvincing, that he stated that spontaneous generation was quite unproven. Nevertheless he continued, "On the whole it seems to me probable that Archebiosis is true.* I should like to live to see Archebiosis proved true, for it would be a discovery of transcendent importance.' In Darwin's opinion life must have arisen sometime and somehow but we are still completely unaware of the manner in which this took place. ${ }^{7}$

However, these isolated utterances of Darwin are not so important for the solution of our problem as the fact that he applied evolutionary principles to explain the development of higher organisms from lower ones and showed that it was impossible to conceive of living things coming into being without evolutionary development. ${ }^{8}$ Mechanistic concepts of the essential nature of life were, however, still so firmly entrenched in the minds of the scientists of the second

\footnotetext{
* "Perhaps the words archebiosis, or archegenesis, should be reserved for the theory that protoplasm in the remote past has developed from nonliving matter by a series of steps. . . Encyclopaedia Britannica, Vol. 1. p. $4^{8}$. London, $1956 .-$ Translator.
} 
half of the nineteenth century that they overrode the principle of evolution in relation to the problem of the origin of life, although a great deal of preparatory work had already been carried out along evolutionary lines.

The mechanistic conception of life and its origin prevalent in those times was fundamentally this: there is no essential difference between organisms and inorganic bodies. Living things are merely special forms of machines having an exceptionally complicated structure of integrated material particles. Just as the specific function of a machine is determined by the particular circumstances and arrangements of its parts, so the life of an organism depends on the finest details of its internal structure, on the proper interrelation between the atoms and molecules in living protoplasm. From this it follows that the emergence of life is not the emergence of something qualitatively new. The whole question simply comes to this: how did the combinations of material particles characteristic of life arise and how did the peculiar structure of all living things arise?

In the inorganic world we are constantly observing the formation of structures built in an orderly way under the action of definite physical forces; crystals develop from molecules or ions scattered at random throughout the solution. According to the mechanists the problem of the origin of living things is, in the last analysis, nothing but the problem of the crystallisation of organic matter. Thus the primary origin of life seems to be a logically inevitable deduction from the theory already propounded.

In practice, however, the facts prove to be in direct contradiction to this hypothesis. Nowhere in nature do we observe the primary origin of life and all our attempts to reproduce this phenomenon under artificial conditions have been fruitless.

The only way which the mechanistically minded scientists of those times could see out of the blind alley which they had thus created was to suppose that the conditions for the formation of living structures, 'the crystallisation of living matter', were so complicated and specific that this crystallisation could only take place in the remote past and is now impossible because the physical or chemical conditions on 
the Earth are no longer appropriate. This idea was formulated with special precision during the second half of last century by the distinguished German scientist E. Haeckel in his theory of archegony. ${ }^{9}$

\section{The views of Haeckel and Pflüger.}

Haeckel was a convinced and militant supporter of the so-called monistic concept of the world which denied that there was any essential difference between organisms and inorganic bodies. "All natural bodies with which we are acquainted on the Earth," he wrote, "both the animate and the inanimate, are similar to one another in all the essential properties of matter. Life is already present in the atom." Thus, although the primary origin of living things had still not been demonstrated by direct experiment it nevertheless seemed indubitable, 'the logical postulate of natural philosophy'.

The hypothesis that the germs of life travelled through interplanetary space cannot explain the appearance of life on the Earth. However, as there was a time when the Earth was in such a state that living things could not possibly have inhabited it, organisms must have arisen from inert matter at some time since this stage of the development of the Earth. This is not inconsistent with the fact that we cannot, at present, observe the spontaneous generation of microbes. The development of organisms from lifeless matter was perfectly possible at remote periods in the existence of our planet, because special conditions prevailed then which were different from the conditions obtaining now. According to Haeckel it would seem that the primaeval organisms must have been completely homogeneous, structureless, formless lumps of protein. They developed directly by the simple interaction of solutions in the primaeval sea of matter. ${ }^{10}$

Haeckel did not explain how this development took place. He even took the view that

any detailed hypothesis whatever concerning the origin of life must, as yet, be considered worthless, because, up till now, we have not any satisfactory information concerning the ex- 
tremely peculiar conditions which prevailed on the surface of the earth at the time when the first organisms developed.

Thus Haeckel believed that the most primitive organisms must have arisen spontaneously from inorganic matter as a result of the formative action of some special external physical forces. This does not occur now because those forces which were present on the Earth at an earlier stage in its development have now disappeared and cannot be reproduced.

Haeckel's contemporary W. Preyer ${ }^{11}$ laughed rather maliciously at these life-forming forces and the conditions which Haeckel supposed to be necessary for the emergence of life in remote geological epochs. He declared that one could not conceive what these conditions might have been. If they were the same as those now prevailing, it would seem that the emergence of life was impossible because, as Pasteur's work showed, this emergence does not occur at present. If the conditions were substantially different the organisms which had emerged would quickly have been destroyed because they only exist at present under very narrowly circumscribed external conditions.

These ideas of Preyer's seem quite convincing if one adopts a mechanistic position and assumes the sudden emergence of organisms which, though far simpler, already possessed all the organisational characteristics which we find in contemporary living things.

Such objections, however, take on a different aspect if we discard mechanistic principles and adopt the point of view that the primaeval living things arose by stages as the result of a prolonged evolution of organic substances, as a particular stage in the general historical development of matter. In this case we shall not need to invent any special forces or conditions. If it had been accomplished by a process of evolution of organic substances, the emergence of the primaeval living things could have occurred under approximately the conditions of temperature, moisture, pressure, illumination, etc., which now prevail on the surface of the Earth.

There was one condition, necessary for this evolution, which was present then on the surface of the Earth and is 
not present now, and that, though it may at first glance seem paradoxical, was the absence of life. Only in the absence of organisms could life develop. Organic substances arising on the surface of the Earth at present would not be able to undergo prolonged evolution. After a comparatively short time they would be annihilated, devoured by the multitude of organisms, well equipped for the struggle for existence, which inhabit all parts of the earth, water and air. On the other hand, in the remote past when our planet was still sterile, the process of evolution of organic substances could be prolonged indefinitely and this could have led up to the emergence of the primaeval living things in accordance with certain natural laws which we shall discuss later.

This idea, as we now know, was already clear to Darwin, who wrote in a letter dated 1871 as follows:

It is often said that all the conditions for the first production of a living organism are present, which could ever have been present. But if (and oh! what a big if!) we could conceive in some warm little pond, with all sorts of ammonia and phosphoric salts, light, heat, electricity, etc., present, that a protein compound was chemically formed ready to undergo still more complex changes, at the present day such matter would be instantly devoured or absorbed, which would not have been the case before living creatures were formed..$^{12}$

Nevertheless, at the end of last century and the beginning of the present one, the mechanistic concept of the selfformation of life under the influence of some elementary physical forces and effects still prevailed extensively in the minds of scientists. Many of them were so carried away as to make assumptions concerning the nature of these forces and to draw a picture of the emergence of living things from inorganic matter under the circumstances obtaining on the primaeval Earth. Among these forces were included electrical discharges, ultraviolet radiations, the forces of chemical affinity and later even the radioactivity of the elements. As we shall see later, all these factors must certainly have played an important part as sources of energy in the transformation of organic substances in the process of their evolution on the primaeval Earth. However, in themselves they certainly 
could not have brought about the spontaneous generation of organisms in the remote past any more than they can to-day. For this reason all such hypotheses sounded extremely unconvincing and not a single one of them served as a basis for further fruitful investigations.

We may here cite, by way of illustration, only a few of the many investigations referred to above. F. J. Allen ${ }^{13}$ dated the emergence of life at the time when water already formed the primitive ocean on the surface of the Earth. At that time the heavy, stable, insoluble compounds were laid down in the crust of the Earth while the less stable ones, in process of decomposition, were present in gaseous form in the atmosphere and in solution in the water. Nitrogen, oxygen and carbon dioxide were present in the water and atmosphere.

In the presence of electric discharges occurring as flashes of lightning incessantly passing through the warm, moist atmosphere, ammonia and oxides of nitrogen were formed and dissolved in the rain which carried them down into the water. Here they encountered dissolved carbon dioxide, chlorides, sulphates, alkali phosphates and other metallic salts. It was then possible for the compounds of nitrogen, to which Allen attached special importance, to enter into reactions with various other substances. On their combination with carbon dioxide oxygen was liberated and the first living substance was formed and already exhibited essentially the same properties which we find in organisms at the present day.

Allen did not go into much detail about the formation of living matter. He only made the suggestion that, in the transfer of oxygen from or to nitrogen, sunlight might have played a significant part when it was absorbed by iron compounds dissolved or suspended in the water. Taking a general view of all these hypotheses it is impossible to conceive how the forces invoked by Allen could give rise to organised matter.

Similar hypotheses were developed somewhat later by $\mathbf{H}$. F. Osborn. At the beginning of his book, The origin and evolution of life, ${ }^{14}$ he describes the Earth before life was present on it, closely wrapped, as by a blanket, by the atmosphere of that time which contained large amounts of water 
vapour and carbon dioxide. Osborn thought that this carbon dioxide acted as the source of carbon for the formation of those organic compounds from which living organisms later developed. He wrote:

We may advance the hypothesis that an early step in the organization of living matter was the assemblage, one by one, of several of the ten elements now essential to life . . Of these the four most important elements were obtained from their previous combination in water $\left(\mathrm{H}_{2} \mathrm{O}\right)$, from the nitrogen compounds of volcanic emanations or from the atmosphere consisting largely of nitrogen, and from atmospheric carbon dioxide.

However, Osborn did not give any explanation of the way in which this sort of transformation came about. He confined himself to rather vague statements about the 'attractive force ' of oxygen and hydrogen.

Similar views were developed by $W$. Francis, ${ }^{15}$ who attached far greater significance to iron in the process of the formation of life, and by many other authors in the first quarter of this century. It is characteristic of most of these authors that they were convinced that living things developed directly from lifeless matter as a result of the formative activity of some external force.

The practical outcome of all these hypotheses was the carrying out of experiments in which the forces which were supposed to have given rise to life in the past were reproduced in the present under laboratory conditions. However, as was to be expected, these experiments did not meet with success and are now completely forgotten. Only a few of the more typical investigations will be discussed here.

R. Dubois ${ }^{16}$ placed pieces of radium or barium chlorides on the surface of a sterile gelatin broth, and, according to his own account, he obtained microscopic granulations resembling colonies of microbes. They moved actively, grew and divided but could not be subcultured on sterile portions of the broth.

Similar experiments were published somewhat later by M. Kuckuck ${ }^{17}$ under the grandiose title Lösung des Problems der Urzeugung. According to the observations of this author, when radium acted on a mixture of gelatin, glycerine and 
common salt for 24 hours a peculiar culture grew, living cells were formed which grew, divided and manifested other features characteristic of life. This work was obviously very amateurish and is certainly of no real importance. It cannot, however, be regarded as an accidental happening or a mere curiosity. It could only have been done under the influence of the mechanistic outlook which we have already discussed. According to this view, the simplest living things could suddenly crystallise out from lifeless matter. The only requirements for this were various more or less specific unknown forces which effected this sort of transformation of substances into living things. M. Kuckuck attributed such effects to radioactive phenomena, which were still poorly understood at that time.

Another well-known German scientist of the end of last century, E. Pflüger, ${ }^{18}$ approached the subject under discussion in a different way from Haeckel. He sought the cause of the emergence of life in the materials from which the organisms were to emerge as well as in the peculiarities of the external conditions. In his analysis of the problem he started out from the properties of the chemical substance protein, a substance which he associated inextricably with the existence of living processes. Pflüger considered that there are present in organisms two radically different categories of protein, the reserve protein which was 'dead' and the protein of the protoplasm which was 'living'. In the former category he included such substances as the whites of eggs and the protein stores of seeds, etc. These proteins appeared to be very stable, chemically inert substances. In the absence of micro-organisms they may be preserved for an indefinitely long time without undergoing any important changes. The 'living' protein of the protoplasm, on the other hand, seems to be very unstable. Pflüger held that this instability formed the basis for the chemical transformations which proceed within the living cell.

In all living things disintegration of proteins takes place. Pflüger attributed this to various special chemical groups in the composition of 'living' protein. In particular, he thought that 'living' protein must have the power to oxidise itself by using the oxygen of the air. This follows from the 
fact that, when living substances decompose spontaneously, carbon dioxide is always formed, whereas carbon dioxide cannot be formed by direct oxidation of the carbon atoms of proteins. The products obtained by the decomposition of 'dead' proteins and even 'dead' proteins themselves are quite incapable of this sort of oxidation. Consequently there must be present in 'living' proteins some special atomic groupings or radicals which can break themselves down and oxidise themselves.

Pflïger considered that cyanogen represented such a radical in the molecule of 'living' protein. He considered this to be thoroughly demonstrated by a comparison between the nitrogen-containing products of the decomposition of protein obtained as a result of the normal metabolism of living organisms with the corresponding products of the decomposition of 'dead' protein which are formed when it is broken down artificially. There is a radical difference between such products. The products which are characteristic of the breakdown of 'living' protein in the organism such as urea, uric acid, etc., are never obtained from the artificial breakdown of 'dead' protein. However, these characteristic substances can easily be produced from compounds containing cyanogen groups by rearrangement of the elements, as occurred in the synthesis of urea from ammonium cyanate by Wöhler. Pfliiger thus tried to relate the whole metabolism and all the properties of living protoplasm to the presence of definite chemical groupings, the cyanogen radicals, entering into the composition of 'living' proteins.

Contemporary biochemistry has long ago disproved these hypotheses of Pflüger. It has not succeeded in discovering any specific cyanogen-containing radicals which differentiate 'living' from 'dead' protein, and even the separation of proteins into these two categories is now considered to be without any real justification. In particular, it has now been shown that the so-called reserve proteins of the seeds of plants have an enzymic activity similar to that of the proteins of protoplasm. ${ }^{19}$ The end products of nitrogen metabolism in animals, urea and uric acid, arise as a result of secondary synthesis and not by direct oxidation of cyanogen-containing radicals in the molecules of the 'living' protein. It is now 
quite obvious to us that Pfliger oversimplified the complicated phenomenon of the metabolism of living protein. It is, however, of interest in connection with the problem we are studying, that Pfliger built up his original theory of the origin of life on this basis. If the cause of all vital phenomena lies in special groups of atoms, the cyanogen-containing radicals of proteins, then, he argued, it is clear that the whole solution of the problem of the origin of life resolves itself simply into a solution of the question of how these radicals arose. How was cyanogen formed on the primaeval lifeless Earth? Pflüger wrote:

In this connection organic chemistry provided us with a very significant fact, namely that cyanogen and its compounds are formed at incandescent temperatures when the necessary nitrogen-containing compounds are brought into contact with glowing carbon or when mixtures of the substances are raised to white heat. Thus nothing could be clearer than the possibility that cyanogen compounds might be formed at a time when the earth was partly or wholly in a fiery or incandescent state. Life arose from fire and its foundations were laid at the time when the earth was a fiery incandescent globe.

This theory was very progressive for its time and played a positive part in the history of the development of our ideas concerning the origin of life in so far as it included an attempt to explain the primary development of organic substances. However, the hypothesis on which it was based, namely that the vital characteristics of protoplasm could be attributed to the presence of cyanogen or some other radicals in the composition of the proteins, was found to be false and was later refuted.

It must be noted that at the end of last century and the beginning of the present one opinions, which were very widely held, associated life and all its properties, not with protoplasm in its entirety but with particular hypothetical 'living molecules' or molecular complexes the chemical reality of which was far more problematical than that of the cyanogen-containing radicals of Pfliger's 'living protein'.

The biological literature of those times is very rich in different complicated names which were thought out to 
designate the purely speculative, primary structural units of living substances, ' the idioplasm ' of Naegeli and Weismann, 'the biogenes' of Verworn, 'the plastomes' of Wiesner, 'the protomeres' of Heidenhain, 'the gliodes' of Botazzi, 'the vitules' of Meyer, 'the vitaids' of Lepeschkin, 'the moleculobionts' of Alexander and Bridges, etc., etc.

Naturally such authors tried to solve the problem of the origin of these hypothetical units of life, substituting this for a solution of the problem of the origin of life itself. That, however, did not carry them any further forwards, as the one problem presented no less difficulty than the other.

As early as the end of the nineteenth century A. Weismann $^{20,21}$ put forward his theory that every organism contains a special germinal substance which does not change in the course of life ('idioplasm '). In particular, this is regarded as carrying the hereditary endowment and other characteristics of the organism. All the rest of the body of the organism ('soma ') is merely a lifeless receptacle, a nutrient medium for the germinal substance in which alone life is inherent.

The germinal plasm, as Weismann puts it, " never arises anew but grows and reproduces itself uninterruptedly".

Natural philosophy poses the question: How, then, did this substance arise in the first place? Weismann himself only gave a very general and rather vague answer. He stated that in the beginning, under special conditions which are quite unknown to us, there must first have arisen very small living entities, 'biophores', which themselves represented the fundamental active elements of the germ plasm. ${ }^{22}$

This idea of Weismann's was reflected in a number of later pronouncements. In particular, we may take as an example the 'theory of symbiogenesis' of C. Mereschkowsky, ${ }^{23}$ which made a great sensation in its time. According to this theory there are two types of plasm which are not only radically different from one another in their properties, but even have a different historical origin. The first type, that called 'mycoplasm', was essentially the same as the chromatin of the nucleus. The second type-called ' amoeboplasm '-was simply what we now call cytoplasm. The very earliest forms of life, which were formed spontaneously at a time when there were still no organic substances and when 
the original water on the surface of the Earth was near to boiling point, were, according to Mereschkowsky, 'biococci ', minute ultramicroscopic particles of 'mycoplasm'. They were completely structureless but were already able to synthesise proteins and carbohydrates directly from inorganic substances. The first things to be formed from these 'biococci' were bacteria.

Later, when the temperature of the water on the Earth had fallen below $50^{\circ} \mathrm{C}$ and an abundance of organic nutrients had appeared in it as a result of the vital activity of the biococci, there were formed small masses of ' amoeboplasm' which crawled along the bottom of the ocean and devoured the bacteria. The cells with nuclei which we now meet arose as a result of the symbiosis of these two different types of organism when the biococci which had entered the amoeboplasm were not digested but manifested their capacity for symbiosis.

The characteristic feature of this fantastic theory of the emergence of life is that it laid special emphasis on the essential difference between the cytoplasm and the nucleus, giving the first importance to the independent origin of the latter.

Similar ideas were propounded by the well-known English biologist E. Minchin. According to Minchin, ${ }^{24}$ the first living things were minute, ultramicroscopic particles of chromatin. These particles were endowed with the ability to metabolise substances independently and, in particular, to synthesise organic compounds from simpler inorganic salts. It was only later that the protoplasm enveloping them was formed and this, in the last analysis, only acted as a medium for their existence.

We have dwelt in some detail on these hypotheses because they have been reflected to some extent in the views concerning the emergence of life which are now held in certain circles.

\section{Attempts to construct ' models of living organisms'.}

Attempts to solve the problem of the origin of life by producing so-called 'models of living bodies' were crudely 
mechanistic in character. These attempts were made at the beginning of the present century because many biologists of that time considered that the cause of the vital properties of protoplasm resided only in its structure, that is, in its specific spatial configuration, while completely ignoring the metabolism, that form of the motion of matter which is characteristic of life.

At that time they conceived the spatial organisation of protoplasm in terms of a machine; a definite construction formed from some sort of solid and unchanging interrelated 'beams and braces'. From this point of view the structure of protoplasm with the rigidly determined spatial arrangement of its parts was the specific cause of life in the same way as the disposition of the wheels, beams, pistons and other component parts of the mechanism determine the particular function of a machine.

L. Jost ${ }^{25}$ wrote as follows:

The functioning of a machine does not depend primarily on the chemical properties of its components but on their arrangement and interrelationship. We may construct a machine of brass or of steel and this will certainly affect its durability and accuracy but will not affect the nature of the work it does.

Similarly, Jost held, the activity of living cells depends more on the arrangement of their parts than on the composition of the protoplasm. It follows that the direct route to the understanding of life is not through the study of the metabolism and other vital phenomena but through the investigation of the structure of protoplasm and the spatial arrangement of its parts.

The next stage in the historical development of the subject lay in the attempt to see directly, through the microscope. the spatial configuration which formed the basis of life, and the belief that this attempt was only unsuccessful because of the insufficiency of our optical methods. If. we could see the finest details of the structure of protoplasm we should thus understand life itself. The actual working out of this principle, however, only led to bitter disappointments. The simple observation of living cells under the microscope gave very little indication of a machine-like structure of proto- 
plasm. More refined methods of investigation came into use. Before it was examined under the microscope the protoplasin was killed or fixed, and then stained. These methods opened up a whole new world of structures and reawakened the hope of visualising the construction of the mechanism of life. The filamentous, reticular and alveolar theories of the structure of protoplasm followed one another very quickly. By the beginning of the twentieth century, however, it had been shown that all the fine structures which could be seen in fixed preparations were artefacts arising after the death of the cell as a result of reactions between the fixative and the proteins of the protoplasm. ${ }^{26}$ It became quite clear that a study of these structures gives us very little understanding of the organisation of living substance. ${ }^{27}$

At about this time and arising out of such theoretical considerations, some attempts were made to study life by means of artificially produced living structures, by the construction of models of living protoplasm. Even before this M. Traube ${ }^{28}$ had immersed small crystals of potassium ferricyanide in an aqueous solution of copper sulphate and obtained globules surrounded by fine membranes of copper ferricyanide. Under the influence of osmotic pressure these globules grew and, to a certain extent, reproduced the phenomena of the growth of living cells.

O. Bütschli ${ }^{29}$ later made a model which reproduced the movements of a living amoeba. He used drops of olive oil mixed with a solution of potash. As a result of changes in surface tension these drops threw out pseudopodia like amoebae and moved towards solid particles and even engulfed them just as amoebae engulf particles of food. Similar very simple models simulating the movement, feeding and division of cells were also produced by L. Rhumbler ${ }^{30}$ and a number of other workers.

These models had a certain scientific interest only insofar as the phenomena which occurred in them were based on the same physico-chemical causes as those operating in the living cell. Such models enabled the experimenters to study the phenomenon in question in greater detail under circumstances which were simpler than those occurring in protoplasm. This, however, was not what most of these workers 
were aiming at when they constructed their models. They argued that once the essence of life was shown to be associated with a particular structure, it was only necessary to reproduce that structure, albeit with materials unlike those of the organism, to obtain a system endowed with life-_a ' living model'.

Many people were specially attracted to the artificial reproduction of various structures at that particular time because they were looking for some sort of material framework or mechanical structure in protoplasm which would determine all the vital phenomena. It was natural, therefore, to wish to create analogous structures artificially. By mixing and precipitating various substances numerous authors did indeed succeed, on many occasions, in obtaining a microscopic picture which strikingly resembled those structures which may be observed in fixed and stained preparations of plant and animal tissues.

Delighted by the superficial resemblance, these authors enthusiastically proclaimed that they had reproduced living protoplasm artificially. But this was far from being so. Not only were the artificial models lifeless, but even the structures resembling them in the fixed cells were dead. As we have already mentioned, the filamentous, reticular and alveolar structures are artefacts which develop after the death of the cell, as a result of reactions between the proteins and those substances which are used for the fixation and staining of the preparation. The appearance of similar structures in the experiments with models is quite understandable, for here too there takes place just such a precipitation of mixed colloids as occurs during the fixation of protoplasm. This, however, contributes very little to our understanding of life. Scientific interest in this sort of artifical structure, therefore, declined very quickly.

Nevertheless, in a few scattered laboratories, people continued for a long time to try to 'synthesise life' by the construction of analogous structural forms. As an example we may cite the experiments of S. Leduc ${ }^{31}$ in which he produced so-called 'osmotic cells'. Leduc produced just the same sort of phenomena as Traube but under far more complicated conditions. He used small pieces of melted calcium chloride and immersed them in saturated solutions of potash 
or tripotassium phosphate. Semipermeable membranes of calcium carbonate or calcium phosphate were thus produced and these formed osmotic globules (Figs. 6 and 7).

Leduc considered that his experiments might form the basis for a new trend in biology. He called this 'synthetic biology': the science of obtaining living forms from lifeless materials in the laboratory. He set out not so much to elucidate the physical forces underlying the phenomena which were produced, as to attempt to endow his models with a greater superficial resemblance to living organisms by the use of very complicated procedures, some no more than hocus pocus. Certainly his 'osmotic fungi and algae' looked remarkably like the corresponding living objects. But how does this really help us to understand life?

The resemblance between the objects created by Leduc and living things was no greater than the resemblance between a living person and a marble statue of him, and nobody ever set much store by the animation of Galatea or the visit of the 'Stone Guest '.*

The work emanating from the laboratory of the Mexican investigator A. L. Herrera ${ }^{32}$ was of the same nature. In the preparation of his structures, this author used somewhat different materials from those used by Leduc. He mixed solutions of thiocyanates with solutions of formalin. This led to the formation of nitrogen-containing substances of high molecular weight giving colloidal solutions. When these were fixed with formalin or alcohol, precipitation took place and quite complicated structures were formed. In the course of many decades Herrera made thousands of preparations of these structures, some of which showed a remarkable resemblance to those formed on the fixation of cells. (I have been able to satisfy myself personally that this is so by examining preparations sent to me by the author.) Herrera also described his experiments in bulletins specially published by him in which he also gave numerous sketches of the structures which he obtained (Fig. 8). ${ }^{33}$

The interest of these studies lies in the fact that they demonstrate what different forms colloidal substances can

* The reference is to A. S. Pushkin's work of this name: cf. Il Commendatore in the opera Don Giovanni-Author. 


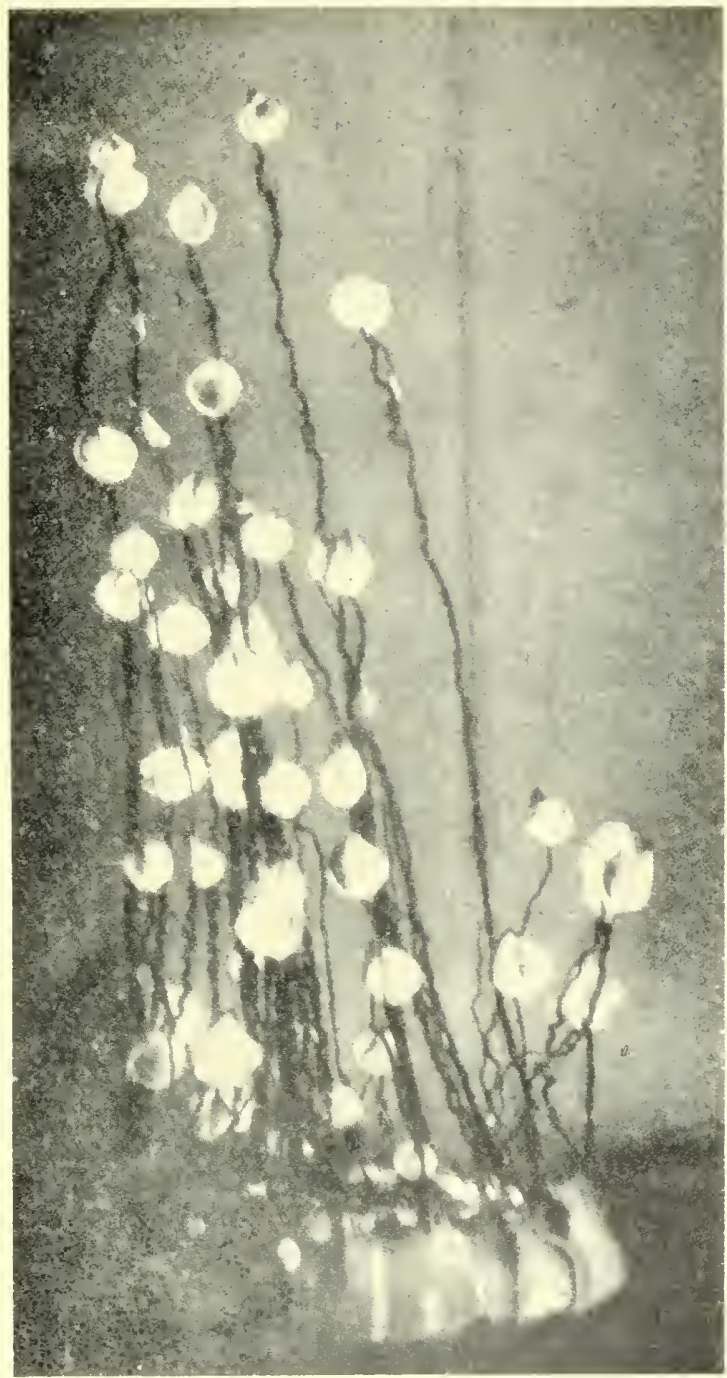

Fic, 6. Leduces antilicial aldeate. 


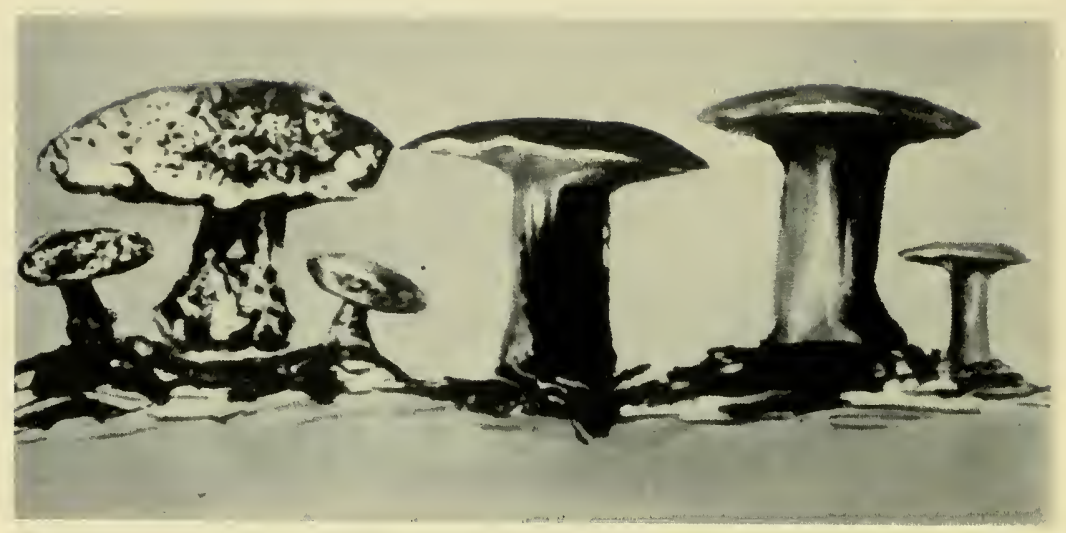

Fic. 7 . Leduc's artificial fungi. 
assume according to the method of their preparation. These experiments can, however, hardly be regarded as "plasmogeny'-a means of obtaining living organisms artificially.

Herrera, however, took just this view in 1942 when he published his New theory of the origin and nature of life. ${ }^{3 \cdot 4}$

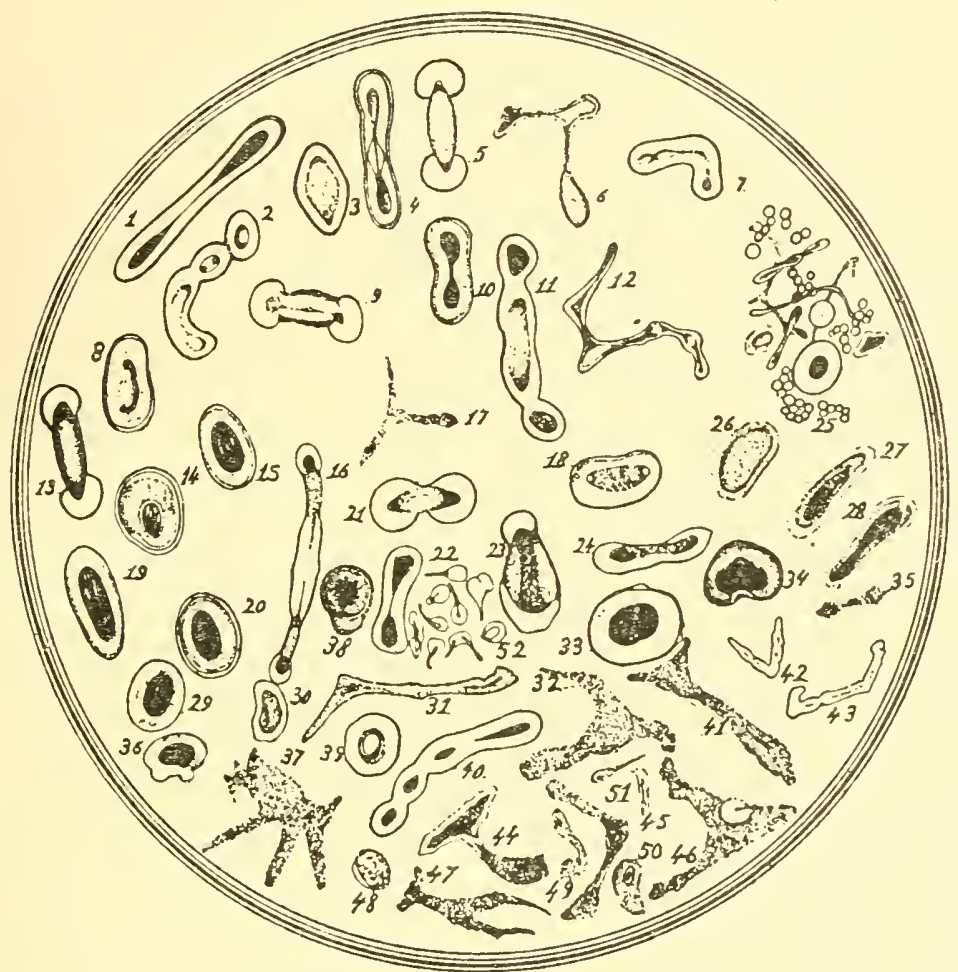

F1G. 8. Herrera's artificial cells.

He based it on his experiments on the structures made out of thiocyanates. Such structures can certainly arise, as Herrera asserts, under natural conditions, but it is doubtful whether any contemporary biologist would admit that these structures are endowed with life. These structures have no organised metabolism and cannot reproduce themselves. The single fact of their resemblance to the structures seen in fixed tissues cannot alone serve as a criterion of life. 
The ideas which we have been discussing are understandable up to a point because a very negative attitude towards the problem of the origin of life prevailed in the biological literature of the twenties and thirties of this century. It was treated as a problem upon which it was not worth while for any serious investigator to waste his time.

\section{The evolutionary theory of the origin of life.}

In spite of the widespread prevalence of mechanistic opinions at the beginning of the twentieth century, the evolutionary approach to the problem of the origin of life was not entirely abandoned. As we have already pointed out, the great minds of the nineteenth century favoured this approach to the problem.

As early as the 1870 os F. Engels indicated that the evolutionary development of matter was the only path by which life could have arisen. According to Engels, life does not arise arbitrarily and is not eternal. It arises by a process of evolution of matter whenever conditions are favourable. ${ }^{35}$

These profoundly significant ideas of Engels were, however, not widely enough reflected in the work of the experimental scientists of those times. Only a very few of them publicly supported an evolutionary solution of the problem of the origin of life. As an example we may point to an address given by V. Belyaev in 1893 in the University of Warsaw. In it this distinguished Russian botanist and cytologist sketched, though still in rather general terms, the gradual development of matter which was achieved "in the great laboratory of nature" on the way to the development of life. In this connection he pointed out that "We are hardly likely to succeed in obtaining quickly that on which nature has spent thousands of years., ${ }^{36}$

An address delivered by E. A. Schäfer ${ }^{37}$ at the annual meeting of the British Association in Dundee was of great importance in the history of the problem under discussion. In dealing with the question of the origin of life Schäfer said :

We are not only justified in believing, but are compelled to believe that living matter must have owed its origin to causes 
similar in character to those which have been instrumental in producing all other forms of matter in the universe; in other words, to a process of gradual evolution. .. .

Looking, therefore, at the evolution of living matter by the light which is shed upon it by the study of the evolution of matter in general, we are led to regard it as having been produced, not by a sudden alteration, whether exerted by a natural or supernatural agency, but by a gradual process of change from material which was lifeless, through material on the borderland between the inanimate and the animate to material which has all the characteristics to which we attach the term 'life'.

The actual process of evolution of organic matter was still only rather roughly sketched by Schäfer. He spoke, though very vaguely, of the formation of organic substances and then of the development of masses of colloidal slime which possessed the power of assimilation. He then spoke of the differentiation of certain phosphorus-rich parts of the living matter, then of the development of enzymes and finally of the differentiation of the nucleus of the cell. Schäfer considered that any more detailed hypothesis as to the direction and causes of this evolution was unwarrantable in the light of the facts known at that time.

K. Timiryazev ${ }^{38}$ thought very highly of these statements by Schäfer. In his article From the scientific chronicle of I 912 he reviewed Schäfer's address in detail and wrote:

We are forced to believe that living matter, like all other material phenomena, was brought into being by evolution. The evolutionary theory now embraces not only biology but all the other natural sciences, astronomy, geology, chemistry and physics. It convinces us that the transition from the inorganic to the organic world was also accomplished by a process of evolution.

More than ten years had passed since Schäfer gave his address when an article on the origin of life on the Earth by P. Becquerel ${ }^{39}$ appeared in a French astronomical journal. The chief interest in this paper lay in the devastating criticism to which its author submitted the theory of panspermia. On the basis of his own experiments he demonstrated most convincingly the impossibility that living things could have reached the Earth from interstellar space. In place of this 
theory he produced one of his own. "On planets like the Earth there must always occur at some stage in their evolution the origin, development and disappearance of life, just as there is always a beginning, transformation and dissolution of worlds, and this continues throughout eternity." Terrestrial life is but a particular instance of this cosmic evolution of matter. However, Becquerel, like Schäfer, only gave a very rough sketch of the actual evolution of organic matter leading up to the origin of living organisms.

Like many of his predecessors, Becquerel considered that carbon dioxide was the first carbon compound existing on the Earth. He based his theory, which he called 'radiobiogenesis', on the experiments of Berthelot and Stoklasa on the synthesis of organic substances from carbon dioxide by the action of ultraviolet and radioactive radiations. According to this theory, organic substances arose directly from carbon dioxide, water and minerals under the influence of the ultraviolet radiation of the Sun and the radioactivity of the rocks at some particular geological period. Some truly colloidal systems were later built up and the germs of life developed from these.

In these hypotheses Becquerel reverts to the possibility which he had explained, that organic substances may develop under the influence of ultraviolet light. However, as concerns the cause of the evolutionary formation of the first living things, which is the most important and interesting point to us, his theory still leaves us in the dark, as the author himself admitted.

In the same year as Becquerel's article appeared, my own little book The origin of life $e^{40}$ was published. In it I expounded for the first time, though still very schematically, the views which the reader will find more fully worked out in the present edition. In particular, I tried to show in it how the simplest carbon compounds, the hydrocarbons, might have been formed on our planet. The evolution of these compounds was held to lead to the formation of protein-like compounds and then colloidal systems which were able to undergo gradual differentiation of their internal organisation as the result of natural selection.

Somewhat later, in 1929 , J. B. S. Haldane published an 
$\operatorname{article}^{41}$ which was very significant in the derelopment of the study of the origin of life. This author also showed that the development of organic compounds took place before the formation of the first living things and took an evolutionary view of this process.

Afterwards, when it was found that the atmosphere of the large planets contained hydrocarbons which can only have been formed there abiogenically, ${ }^{42}$ the hypothesis that organic compounds were formed similarly on the Earth became generally accepted. It must not be supposed, however, that this meant a complete victory for the evolutionary over the metaphysical school of thought in relation to the problem of the origin of life. On the contrary, very many workers on the problem in the thirties and even the forties of this century only applied the evolutionary principle to the origin and development of organic substances. They only accepted organic chemical evolution. They discussed the most important event-the transition from the lifeless to the living state-from a fundamentally metaphysical standpoint, regarding it as the sudden appearance of "living molecules', particles of viruses or genes, which were endowed with all the attributes of life from their very formation.

This approach to the solution of the problem of the origin of life was basically that which is associated with the works of T. H. Morgan ${ }^{43}$ and his followers, on the 'genic' nature of life.

According to Morgan the first organic things which showed signs of life were genes. In his paper The gene as the basis of life H. J. Muller ${ }^{44}$ described this basis as a particle of matter endowed with a definite chemical structure, a giant molecule which is so chemically stable that it has retained its internal, life-determining structure essentially unchanged throughout the whole development of life on the Earth from times 'before green slime bordered the seas' right up to the present. According to Muller, life did not arise before the gene. The first things which were able to grow, from which arose a substance like that which exists at present, probably consisted almost exclusively of the gene or genes already mentioned. Thus, genes formed the basis of the first living things. 
If this is so, the only thing which is required for a solution of the problem of the origin of life is an explanation of the way in which the primary formation of the 'gene molecules' took place.

The followers of Morgan gave what appeared, at first glance, to be a very simple answer to this question. The specific life-determining structure of the original 'gene molecule' arose purely by chance, simply as the result of a 'happy conjunction' of the atomic groups and molecules distributed in solution through the primaeval waters of the oceans. "... The origin of life is identified with the origin of this material [genes] by chance chemical combination" wrote Muller $^{45}$ in 1947 .

Many authors of papers and books on the question of the origin of life published ten to twenty years ago proceeded from this same assumption.

To some extent the conception persists even now. We shall only consider a few examples of this attitude.

As early as 1924 C. B. Lipman ${ }^{46}$ developed the idea of the primary formation of ' a living molecule'. He considered that carbon dioxide, water and nitrates entered into thousands of different combinations with one another in the primitive watery envelope of the Earth as a result of the considerable chemical and electrical activity which existed there. Many different organic molecules of the nature of amino acids and polypeptides were thus formed. The properties of these molecules were determined by the spatial relationships of the atoms. By chance there might even have arisen a molecule of this sort which, orving to a peculiarity of its structure, could multiply like a filterable virus. In its growth and reactions to its environment it might, according to Lipman, be regarded as 'our first living molecule'. Under certain circumstances such a molecule would react with other molecules and would gradually form more and more complicated aggregates until it developed into protoplasm as it exists at present.

In an article published in 1928, J. Alexander and C. Bridges $^{47}$ also wrote about the chance formation of the first molecules of living substances-' moleculobionts '-which had laid the foundations for the origin of life on the Earth. 
Alexander later ${ }^{48}$ gave greater precision to this idea by saying " that life originated by the chance transformation of an autocatalytic unit of molecular dimensions, for the smaller its size, the greater the probability of its formation ".

R. Beutner wrote a number of separate papers $^{49}$ on the problem of the origin of life, as well as a whole book ${ }^{50}$ published in $193^{8}$. He arrived at similar conclusions. In his book Beutner suggests that powerful electric discharges which occurred at some time on the surface of the Earth might have led to the formation of innumerable multitudes of organic substances. Among these substances, which were dissolved in the waters of the primitive ocean, there might chance to have been formed, at first simple enzymes, but later, enzymes which were capable of reproducing themselves-self-regenerating enzymes. These would have been exactly like the filterable viruses of the present day. Through their growth and increase in complexity these original unimolecular forms of living matter would also have served as the basis for the formation of organisms endowed with a definite characteristic structure.

Among French authors A. Dauvillier should be mentioned here. As early as $193^{8}$ and 1939 he brought out papers connected with our problem in the periodical L'Astronomie. ${ }^{51}$ In 1947 he published a whole book on the subject. ${ }^{52}$ Like many previous authors Dauvillier considered that the source of the organic substances on the surface of the Earth was carbon dioxide which was reduced to formaldehyde by ultraviolet radiation. Dauvillier thought that a considerable amount of formaldehyde might have been formed in this way and that nitrogenous substances might have combined with it as a result of electrical discharges. Nitrogen, in the form of ammonia, could also enter into direct combination with carbon dioxide under the influence of ultraviolet radiation. This would also bring about the polymerisation of the developing organic molecules.

Organic compounds of high molecular weight were thus formed in the primaeval ocean. By virtue of their Brownian movement the colloidal particles were able to group themselves together in the most diverse ways. In the course of many thousands of years there could have occurred, by 
chance, juxtapositions of particles which had the structure of the simplest organisms. Dauvillier adduced the crystallisation of glycerine as an example of such configurations arising by chance. Although glycerine had been known since the eighteenth century, for a long time it had only existed in liquid form. The first crystals of glycerine were found in a barrel which was sent from Vienna to London. This sudden crystallisation was due to an unusual combination of movements which occurred, purely by chance, in the barrel. Since that time the spontaneous crystallisation of glycerine has only been observed two or three times in all. It is, however, easy to obtain crystals of glycerine by seeding liquid glycerine with a pre-existing crystal. Dauvillier pointed out that pure chance thus seems to be the most important creative factor. "Here", he wrote, "we see once more the handiwork of a strange creator who is dependent on nothing but time".

According to Dauvillier the first configuration of living material, which arose by chance, must have had the properties of filterable viruses, that is, it must have had the power to reproduce its own structure. As time went on these centres of chemical activity gave rise to the development of mitochondria and then to the formation of bacilli.

The author himself admits that the formation of such a ' living configuration' endowed with the powers of metabolism and self-reproduction, as a result of the chance combination of organic molecules, seems a highly improbable event. He considered that it could only have happened once in the whole time the Earth has existed. After this there occurred only the constant multiplication of this substance which had arisen once and for all and was eternal and unchanging.

G. W. Beadle ${ }^{53}$ subscribed to the same 'molecular' theory when he wrote in 1949:

Somehow, out of this age-long trial and error process there presumably arose molecules with the property of duplicating themselves, that is, capable of catalyzing the process by which they were formed. If such molecules were at the same time sufficiently large and appropriately built to permit chemical modification without loss of the power to multiply their kind 
systematically they would become ancestors of further lines of evolution, now definitely organic.

This attitude was also adopted by H. Blum ${ }^{54}$ in his interesting book Time's arrow and evolution (1951), though he also brought up the question of whether or not the primitive autocatalytic molecules should be regarded as living.

In a recently published article $H$. J. Muller ${ }^{55}$ again affirms his earlier hypothesis, which we hare already discussed, as to the random emergence of one successful gene among myriads of types of molecules.

It is, however, difficult to accept an idea of this kind, in the first place because it completely shuts the door on the scientific study of the most important event in the history of our planet, which was the first emergence of organisms. How can one study a phenomenon which, at best, can only have occurred once in the whole lifetime of the Earth?

Physicists assert, in principle, that it is possible that the table on which I am writing might rise into the air as the result of the chance parallel orientation of the thermal motion of all its molecules. It is, however, hardly likely that anyone will allow for this possibility in his experimental work or general practical activities.

A theory is of special value to the scientist if it opens up practical possibilities for research by verifying the regular occurrence of phenomena, either by observing nature or by setting up suitable experiments in the laboratory. The conception of the chance development of living molecules is quite unproductive practically.

In contradistinction to this, the evolutionary approach to the problem of the origin of life opens up to the scientist wide possibilities for the study and experimental reproduction of the separate stages of the long course of development of matter which led up to the first appearance of living things on the Earth.

During the last few years the evolutionary approach to the solution of the problem in which we are interested has attracted the minds of wider and wider circles of scientists throughout the world. It is expressed in the flow of books and papers, scientific reviews and experimental researches 
which are now appearing in the world literature in greater and greater numbers. It is not only biologists who take part in these investigations but also physicists, astronomers, geologists and chemists having different specialised interests.

In this chapter we can only enumerate briefly a few of these researches and reviews. They are discussed in more detail in the appropriate places in later chapters.

First we must mention the work of $\mathrm{H}$. C. Urey. ${ }^{56}$ Starting from an analysis of the thermodynamic and kinetic laws and the geophysical and geochemical results which can be deduced from them, he drew a picture of the primary formation of organic substances in the course of the development of the Earth, and of their further evolution in the first period of its existence. These studies served as a basis for the very valuable experimental work of S. L. Miller ${ }^{57}$ who synthesised amino acids from those gases which may be presumed to have been present in the original atmosphere of the Earth.

In his well-known book The physical basis of life,,$^{58}$ and in a number of later papers ${ }^{59}$ and pronouncements, ${ }^{60} \mathrm{~J}$. D. Bernal approached the problem of the origin of life from a physical and physico-chemical standpoint. He cast light on many of the stages of the evolution of organic-chemical substances and put forward very interesting ideas about the first development of asymmetry in organic substances and the possibility of their being adsorbed on particles of clay in primaeval pools. In a recently published article V. M. Goldschmidt ${ }^{61}$ threw light on the geological aspects of the problem.

A great deal of work has been done towards explaining the general evolution of matter leading up to the development of living things. According to their own specialities the author's concentrated on the explanation of one or another stage of this historical process. We may mention here the numerous papers by N. W. Pirie, ${ }^{62}$ J. B. S. Haldane, ${ }^{63}$ R. Lemberg, ${ }^{64}$ and the reviews of U. N. Lanham, ${ }^{65} \mathrm{G}$. Wald ${ }^{66} \mathrm{~S}$. Kirkwood, ${ }^{67}$ F. Cedrangolo ${ }^{68}$ and many others. In his experimental work J. J. Scott ${ }^{69}$ pays great attention to the possible way in which porphyrins might have developed. A. Gulick ${ }^{70}$ and L. Roka ${ }^{71}$ consider the formation of high-energy phosphorus compounds and polynucleotides ; while G. Ehrensvärd ${ }^{72}$ and S. Akabori ${ }^{73}$ 
are interested in the primary derelopment of protein-like substances.

The investigation of open systems and the way in which they develop is of great significance for the problem we have been studying. These systems may serve as basis for the development of metabolic activity, which is the form of movement of matter characteristic of life. In this connection the works of C. N. Hinshelwood, ${ }^{74}$ I. Prigogine, ${ }^{75} \mathrm{~J}$. W. S. Pringle $^{i 6}$ and others are of great interest.

The most important, as weil as the least studied, stage of the evolutionary process under consideration would seem to be the transition from the most complicated organic substances to the most primitive living organisms. This is the most serious gap in our knowledge.

When we regard the organisation of any living thing, even the simplest, it strikes us that this organisation is not only very complicated but extraordinarily well adapted to the fulfilment of the functions peculiar to life. It is directed towards the continuous self-preservation and self-reproduction of the whole living system under given external conditions.

The emergence of such internal 'adaptation of form to function' can only be understood on the basis of the same principles which cause the 'adaptation of form to function' in the structure of all the organs of all higher organisms. That is to say, one must study the interactions between the organism and its environment and apply the Darwinian principle of natural selection. This new biological way of behaviour must have been developed in the inorganic world as part of the process of the establishment of life and later played a very important part in the development of all living matter.

A number of authors such as N. H. Horowitz ${ }^{77}$ and $\mathrm{M}$. Calvin ${ }^{78}$ are trying to apply the principles of evolution and even natural selection to individual molecules. However, other workers (N. Kholodny̌r ${ }^{79}$ J. D. Bernal, J. B. S. Haldane. G. Wald and A. Oparin ${ }^{80}$ ) consider that multimolecular systems ('subvital' systems, to use Haldane's terminology) must have been formed before life arose and that these were converted into living things by natural selection. 
Apart from work directly bearing on the problem of the origin of life, general biochemical studies have had tremendous importance in its clarification. This is particularly true of comparative studies of the metabolism of organisms at different stages of evolution.

On the basis of the successive stages in the evolution of metabolism we can put forward certain hypotheses concerning the forms of organisation which preceded the appearance of the first living things. An anatomist who studies and compares the structure and organs of different animals can draw a picture of their evolutionary development. Similarly, a biochemist who studies the processes underlying various vital phenomena can draw a picture of the successive stages in the evolution of matter which led up to the emergence of living beings.

In the rest of this book I try to give a picture of this evolution as it appears in the light of the scientific evidence now available.

\section{BIBLIOGRAPHY TO CHAPTER III}

1. T. H. Huxley. Rep. Brit. Ass., IS 70 , lxxxiii.

K. V. Thimann. The life of bacteria. New York, 1955.

2. J. Tyndall. Rep. Brit. Ass., $I 874$, lxvi.

3. J.-B.-P. Ant. DE Monnet Lamarck. Philosophie zoologique. Paris, 1809 .

4. J. O. DE la MetTrie. Oeuvres philosophiques. Berlin, 1796.

D. Diderot. Pensées sur l'interprétation de la nature. London, 1754 .

5. J.-B.-P. Ant. DE Monnet Lamarck. Système analytique des connaissances positives de l'homme restreintes à celles qui proviennent de l'observation. Paris. 1820 . Cf. A. Studitskir. Uspekhi sovremennol Biol., 39, 3 (1955).

6. (I. 47 ).

7. F. Darwin. Life and letters of Charles Darwin. Vol. 3, p. 168. London, 1887.

8. C. Darwin. On the origin of species by means of natural selection. London, 1859 .

9. E. Haeckel. Generale Morphologie der Organismen. Berlin, 1866.

10. (I. 6o). 
11. W. Preyer. Naturwissenschaftliche Thatsachen und Probleme. Populäre Vorträge. Berlin, 1880.

12. (III. 7). Vol. 3, p. 18 (footnote). Cf. G. Hardin. Sci. Mon. N.Y., $70,178\left(195^{\circ}\right)$.

13. F. J. Allen. What is life? Proc. Bgham nat. Hist. Soc., II, 44 (1899).

14. H. F. Osmonn. The origin and evolution of life. London, 1918.

15. W. Francis. Proc.roy. Soc. Qd., 37, 98 (1925).

16. R. Dubois. C.R. Soc. Biol., Paris, 56,697 (1904).

17. M. Kuckuck. Lösung des Problems der Urzeugung. Leipzig, 1907 .

18. E. Pflüger. Pflïg. Arch. ges. Physiol., Io, 251, 641 (1875).

19. V. L. Kretovich, A. A. Bundel', S. S. Melik-Sarkisyan and K. M. Stepanovich. Biokhimiya, r9, 208 (1954).

A. A. Bundel', M. P. Znamenskaya, and V. L. Kretovich. Doklady Akad. Nauk S.S.S.R., 82, 109 (1952).

20. A. Weismann. Die Continuität des Keimplasmas als Grundlage einer Theorie der Vererbung. Jena, $188_{5}$.

21. A. Weismann. Das Keimplasma. Jena, 1892.

22. A. WeismanN. Vorträge ïber Deszendenztheorie. Jena, 1902.

23. C. Mereschkowsky. Biol. Zbl., 30, 278, 321,353 (1910).

24. E. A. Minchin. Rep. Brit. Ass., I9I5, 437.

25. L. Jost. Vorlesungen über Pflanzenpliysiologie. (and edn.) Jena, 19o8; Lectures on plant physiology (trans. R. J. H. Gibson). Oxford, 1907 (with Supplement. Oxford, 1913).

26. A. Fischer. Fixierung, Färbung und Bau des Protoplasmas. Jena, 1899 .

27. L. Pasonov and V. Aleksandrov. Reaktsiya zhivogo veshchestua na vneshnie vozděstviya. Moscow and Leningrad (Izd. AN SSSR), $194^{\circ}$.

28. M. Traube. Zbl. med. Wiss, 1866, pp. 97, 113 ; Arch. Anat. Physiol., Lpz., I867, pp. 87, 129.

29. O. Bütschu. Untersuchungen ïber mikroskopische Schäume und das Protoplasma. Leipzig, 1892.

30. L. Rhumbler. Ergebn. Anat. EntwGesch., 15, 1 (1905).

31. S. Leduc. Les bases physiques de la vie. Paris, 19o7; Théorie physico-chimique de la vie. Paris, 1910; Solutions and life. Colloid Chemistry, Vol. 2, p. 59 (ed. J. Alexander). New York, 1928.

32. A. L. Herrera. Plasmogeny. Colloid Chemistry, Vol. 2, p. 81 (ed. J. Alexander). New York, 1928. 
33. A. L. Herrera. Bull. Lab. Plasmog. Mex., I, 49, 63, 71 (1934-5).

34. A. L. Herrera. Science, 96, 14 (1942).

35. F. Engels (I. 59).

36. V. Belyaev. O pervichnom zarozhdenii. Warsaw (Izd. Varsh. Universiteta), 1893.

37. E. A. SCHÄFEr. Rep. Brit. Ass., 19I2, 3.

38. K. Timiryazev. Iz nauchnoì letopisi 1912 god. Sobranie Sochinenǐ, Vol. 7, p. 447. Moscow (Sel'khozizdat), 1939 .

39. P. Becquerel. Astronomie, 38, 393 (1924).

40. A. I. Oparin. Proiskhozhdenie zhizni. Moscow (Izd. Moskovskiǐ Rabochiǐ), 1924.

41. J. B. S. Haldane. The origin of life. Rationalist Annual, 1929. Repeated in: The inequality of man. London, 1932; Science and human life. New York and London, 1933 .

42. A. Adel and V. M. Slipher. Phys. Rev., 46, 902 (1934).

43. T. H. Morgan. The theory of the gene. New Haven, Conn., 1926.

44. H. J. Muller. The gene as the basis of life. Proc. 4 th Int. Congr. Plant Sci. (Ithaca, N.Y., 1926), $r, 897$ (ed. B. M. Duggar). Menasha, Wis., 1929.

45. H. J. Muller. Proc. roy. Soc. Lond., I34B, 1 (1947).

46. C. B. Lipanan. Sci. Mon., N.Y., I9, 357 (1924).

47. J. Alexander and C. Bridges. Colloid Chemistry, Vol. 2, p. 9 (ed. J. Alexander). New York, 1928.

48. J. Alexander. Science, 96, 252 (1942).

49. R. Beutner. Biodynamica, Vol. 2, no. 38 , p. 1 (1938).

5o. R. Beutner. Life's beginning on the earth. Baltimore, Md., 1938.

51. A. Dauvillier. Astronomie, 52, 529 (1938).

52. A. Dauvillier. Genèse, nature et évolution des planètes. Paris, 1947 ; Cosmologie et chimie. Paris, 1955.

53. G. W. Beadle. Genes and biological enigmas. Sci. in Progr., 6,184 (1949).

54. H. Blum. Time's arrow and evolution. Princeton, N.J., 1951 .

55. H. J. Muller. Science, I2I, I (1955).

56. H. C. Urey. Proc.nat. Acad.Sci., Wash., 38, $35^{1}$ (1952).

57. S. L. Miller. Science, $I 17,528$ (1953).

58. J. D. Bernal. The physical basis of life. London, $195^{1 .}$

59. J. D. Bernal. The origin of life. New Biol., I6, 28 (1953). 
6o. J. D. Bernal. Sci. o Cult., I9, 228 (1953).

61. V. M. Goldschmid. New Biol., 12, 97 (1952).

62. N. W. Pirie. Discovery, I4, 1 (1953); New Biol., I6, 40 (1953).

63. J. B. S. Haldane. New Biol., I6, 12 (1953).

64. R. Lemberg. Aust. J. Sci., I4, 73 (1951).

65. U. N. Laninam. Amer. N'at., 86, 213 (1952).

66. G. Wald. Sci. Amer., August, p. 44 (1954).

67. S. Kirkwood. Chem. Can., 8 , No. 2, p. 25 (1956).

68. F. Cedrangolo. Nuova Antol., 1956, p. 601.

69. J. J. Sсотт. Biochem.J., 62, $6 \mathrm{P}$ (1956).

70. A. Gulick. Amer. Scient., 43, 479 (1955).

71. L. RокA. Vergleichend biochemische Fragen, p. 1. 6. Colloquium der Gesellschaft fiir physiologische Chemie am 20-22 April 1955 in Mosbach/Baden. Berlin (Springer), 1956 .

72. G. Ehrensvärd. Personal communication.

73. S. Akabori. Communication to Japanese Congress of Biochemists. November 1955 .

74. C. N. Hinshelwood. The chemical kinetics of the bacterial cell. Oxford, 1947.

75. I. PrIgogine. Introduction to thermodynamics of irreversible processes. Springfield, Ill., 1955 .

76. J. W. S. Pringle. Symp. Soc. exp. Biol., 7, 1 (1953); New Biol., 16, 54 (1953).

77. N. H. Horowitz. Proc. nat. Acad. Sci., Wash., 3I, 153 (1945).

78. M. Calvin. Chemical evolution and the origin of life. Transcription of address delivered at Amherst College, 19/11/54. University of California, Berkeley, Calif., 1955 .

79. N. Kholodnyı̆. Uspekhi sovremennol Biol., r9, 65 (1945). 8o. A. I. Oparin. I'ozniknovenie zhizni na zemle. (2nd edn.) Moscow and Leningrad (Izd. AN SSSR), 1941; Vestnik Moskovskogo' Universiteta, 4-5, 193 (1955). 



\section{The question of the original formation of organic substances.}

As a starting point for the study of the stages in the development of matter which led at some time to the emergence of life on the Earth, it seems best to begin by attacking the problem of the original formation on our planet of the simplest organic substances. Without these, life, as we know it, is impossible and inconceivable.* All living beings, without exception, have these substances as their basis. Moreover metabolism, a phenomenon especially characteristic of life, consists essentially of conversions involving organic compounds. The very term 'organic substances' was introduced into the vocabulary of science because it expresses so well the intimate relationship between these substances and living organisms.

The famous Swedish scientist J. J. Berzelius, ${ }^{2}$ when defining organic substances in 1827 , stated that this class of substances can only be formed in living organisms under the influence of the special 'life force' which there prevails. But this incorrect and idealistic view was disproved by Berzelius' contemporary and pupil F. Wöhler ${ }^{3}$ who synthesised first oxalic acid and then urea under laboratory conditions without the participation of living beings.

After Wöhler, syntheses of many diverse and sometimes quite complicated organic compounds were carried out by Kolbe, Butlerov and, especially, by M. Berthelot, who was the first to prepare such compounds starting from their component elements. ${ }^{4}$ These and many other chemists

* There was at one time an exchange of opinions both in scientific and popular writings 1 as to whether organisms formed from silicon compounds could exist. This is no more than speculation, having neither a factual nor a theoretical basis.-Author. 
during the nineteenth and twentieth centuries accomplished artificial syntheses of substances characteristic of living organisms. Among these were the various sugars, amino acids, lipids, numerous pigments derived from plants and animals including alizarin, indigo and substances responsible for the colours of flowers, fruits and berries, also substances responsible for their flavours and scents, numerous acids, terpenes, tanning substances, as well as alkaloids, resins, rubber and many other substances. In recent times some very complicated compounds, having intense biological activities, such as vitamins, antibiotics and hormones, have also been synthesised in the laboratory.

At the same time the organic chemists also synthesised substances which have never been found in any living organism, and thus have no direct relationship with living beings. These, nevertheless, may be strikingly similar in their properties to substances originating from plants or animals. Thus in many works of reference and text books ${ }^{5}$ 'organic chemistry' is defined as the chemistry of compounds of carbon, since this element is present in all natural and artificial substances of this kind without exception.

However, carbon is not only found in nature in the form of its organic compounds. It also enters into the composition of such substances as marble and metal carbides, that is, into the composition of substances that have a manifestly inorganic, mineral character. A much more accurate definition of organic chemistry would appear to be that first given by Carl Schorlemmer ${ }^{6}$ as "the chemistry of hydrocarbons and their derivatives'. This definition not only emphasises the fact that any organic compound can be derived from some hydrocarbon, but has another distinct advantage. It distinguishes the specific quality of organic chemistry, as a branch of science concerned with investigating a higher stage in the organisation of matter than that studied by inorganic chemistry. ${ }^{7}$

From this point of view, organic chemistry is not simply the chemistry of one of the elements from Mendeleev's periodic table. It exhibits special, characteristic regularities which first manifest themselves on passing from the inorganic to the organic compounds of carbon. 
This transition seems, moreover, to have been the first and most important stage in that development of matter which led up to the emergence of life. Therefore, in approaching the problem with which we are concerned, we should first of all clarify our ideas on the following question: What were the natural conditions during the formation of the Earth or in the early stages of its existence which led to the emergence of the hydrocarbons and their simplest derivatives? For these are the carbon compounds from which there could later arise all those other extremely complicated organic substances which form the material basis of life.

Comparatively recently, about twenty or thirty years ago, that first step on the path towards the origin of life scemed to be quite inaccessible to serious study. The majority of scientists of the late nineteenth and early twentieth centuries were firmly convinced that under natural conditions organic substances could only arise by biogenesis, i.e. through the agency of living beings. To some extent they were echoing . early vitalistic views from the time of Berzelius, but their attitude was mainly based on extensive and reliable observations of nature.

These observations show quite definitely that at present the overwhelming bulk of organic substances arises on the surface of the earth as a result of photosynthesis. Green plants, by means of the energy of sunlight, use an inorganic carbon compound (carbon dioxide) to synthesise all the organic substances necessary for their life and growth. Animals obtain these substances from plants, either eating them as such or maintaining themselves on the bodies or residues of planteating creatures. The same sources of nourishment serve for those other macro- and micro-organisms which are classed as parasites and saprophytes.

Almost until the end of the nineteenth century photosynthesis was regarded as the exclusive source of all the organic substances on the Earth. Summing up the extensive factual information on photosynthesis which had already accumulated, K. Timiryazev, in his famous book The life of plants, ${ }^{8}$ pointed out that the green leaf should be regarded as "a unique natural laboratory in which organic substance is prepared for both the plant and animal kingdoms". 
In 1887 and later S. Vinogradskiř ${ }^{9}$ (Winogradsky) discovered another source, likewise biogenic, for formation of organic substances on the Earth. This is the so-called 'chemosynthesis'. Vinogxadskiir established the natural occurrence of a special physiological category of bacteria, which can synthesise the organic substances of their own bodies, using carbon dioxide as their source of carbon, in darkness and quite independently of light. This they do by making use of energy obtained by bringing about the oxidation of various mineral substances-some of the more reduced compounds of sulphur, iron or nitrogen. ${ }^{10}$

Nevertheless, detailed quantitative estimates of the various 'nutritional chains' or attempts at ascertaining overall production of organic substances for the whole surface of the Earth have been made in years gone by ${ }^{11}$ and more recently. ${ }^{12}$ All these lead to the conclusion that photosynthesis by green plants is by far the most important source of organic substances for the living beings which at present inhabit the Earth.

Moreover, photosynthesis has also been responsible for the development of various formations such as coal, which might appear, at first sight, to be mineral in nature. Chemical investigation of organic substances entering into the composition of coal (particularly lignin), geological study of its distribution in the crust of the Earth and palaeontological study of the numerous fossils obtained from it all agree in pointing to a biogenic origin. The various coals are seen to be derived by far-reaching decomposition and alteration of what was originally mainly residues of plants. These became buried in the crust of the Earth, being subjected at first to the action of micro-organisms and later to high temperature and pressure from the surrounding strata. ${ }^{13}$

The biogenic origin of petroleum is more controversial. From the time of M. Berthelot ${ }^{14}$ and D. Mendeleev ${ }^{15}$ up to the present there has been a lively scientific discussion of this problem. However, most of the authoritative chemists and geologists who have been concerned with this problem (see, for example, C. Engler, ${ }^{16}$ A. Arkhangel'skiř, ${ }^{17}$ V. Vernadskiǐ, ${ }^{18}$ N. Zelinskiř, ${ }^{19}$ G. Stadnikov, ${ }^{20}$ I. Gubkin ${ }^{21}$ and others) consider that there is no doubt at all that at least the 
bulk of the organic compounds present in petroleum have been formed secondarily by alteration of the constituent substances of plants or animals which at some time inhabited the Earth.

A proof of this is afforded by the recognition in petroleum of numerous compounds which are characteristic of living organisms. These include porphyrins and quinolines and also a number of other compounds of nitrogen, sulphur, phosphorus and oxygen whose nature suggests that they are biogenic. The optical activity of several of these compounds is also that characteristic for living organisms. The isotopic composition of petroleum suggests the same, for the ${ }^{13} \mathrm{C}:{ }^{12} \mathrm{C}$ ratio is very close to that which we find in living organisms. ${ }^{22}$ Finally, the manner in which petroleum deposits are distributed in sedimentary formations has also convinced many geologists that their origin is biogenic.

Summing up all the evidence at our disposal, we may conclude that, under natural conditions, the conversion of carbon from its inorganic to its organic compounds is only effected by the agency of living beings.

This conclusion set an enormous obstacle in the path of solving the problem with which we are concerned. It appeared necessary to assume that the first organisms to develop on the Earth must have been autotrophs-that is, beings capable of satisfying their own nutritional requirements from inorganic compounds; organic substances were held to have appeared on the Earth only as a result of the activity of living organisms.

We find this point of view expressed by the overwhelming majority of authors around the beginning of the present century when they wrote about the primaeval forms of life which were the original inhabitants of the Earth. The 'biophores' of A. Weismann, ${ }^{23}$ the 'biococci' of S. Mereschkowsky $^{24}$ and $\mathrm{E}$. Minchin, ${ }^{25}$ the primaeval organisms of $\mathrm{F}$. Allen, ${ }^{26} \mathrm{H}$. Osborn, ${ }^{27} \mathrm{~V}$. Omelyanskiı̌, ${ }^{28} \mathrm{~W}$. Francis ${ }^{29}$ and others-all these hypothetical living beings must have arisen all of a sudden, being formed directly from inorganic compounds and have forthwith proved capable of constructing the materials of their bodies out of such compounds.

Many botanists, for example van Tieghem ${ }^{30}$ in France and 
Academician V. Komarov ${ }^{31}$ in the U.S.S.R., have likened the appearance of life on the Earth to a process which occurs nowadays in a number of places, namely the first colonisation of newly exposed rock formations. In his book The origin of plants Komarov very vividly describes the first colonisation of lifeless volcanic deposits in Kamchatka. Here, in the waters of hot springs, which emerge into the light of day among heaps of lava and pumice, can be found bluegreen algae and colonies of thermophilic bacteria, all capable of growth on purely mineral media.

The analogy between such organisms and the hypothetical first living beings to arise on the Earth appears very widely in the literature of science up till comparatively recently. This reflects a deep conviction that the Earth, before the appearance of life, was also completely devoid of organic substances, like these naked lifeless rocks. In fact, this analogy is completely false. For the rocks are known to be continually receiving the spores and seeds of both lower and higher plants. The fact that some of these develop while others do not simply demonstrates the selectivity of the environment. Under these particular conditions only autotrophic organisms can develop. This is easy to understand, since no organic substances are present. Moreover, it is clear that the extremely complicated organisation which makes autotrophy possible among present-day organisms is the result of a prolonged evolution of those living beings which produced the spores and seeds arriving on the bare, lifeless rocks. We are in complete disagreement with the theory of ' panspermia', which implies the transference of ready-made spores to a lifeless Earth. How then, in the absence of such transference, can we imagine the direct formation of autotrophic organisms from inorganic matter, which would imply the sudden development of systems embodying a most complicated organisation of metabolism?

In a recently published and very relevant paper D. D. Woods and J. Lascelles ${ }^{32}$ pointedly remark that if autotrophs are the most primitive living creatures on the Earth, then "something must be imagined analogous to the birth of the Goddess Athené who, you may remember, sprang forth fully armed (in war-gear golden and bright) from the head of 
Zeus ". This implies that the autotrophs must suddenly have appeared in an inorganic medium, completely equipped with the most complicated biochemical systems and morphological structure required for the autotrophic synthesis of organic substances.

The extreme complexity of organisation of those living beings which are capable of photosynthetic assimilation of carbon dioxide is evident not only to the biochemist but also to the morphologist. It long ago forced itself on the attention of the botanical systematists. On purely morphological grounds many of them denied that such organisms could be the prime ancestors of life on the Earth. Others, however, assigned to this role one or another of the more primitive groups of photo-autotrophs because they imagined that the primaeval living beings must have been capable of maintaining themselves on inorganic substances. In this they paid insufficient attention to the facts of comparative morphology, or even flew in the face of these facts (see, for example, the review by A. Pascher ${ }^{33}$ ).

The inherent weakness of this position was very much felt by a number of biologists during the closing years of the nineteenth century. Consequently, when S. Vinogradskir discovered the chemosynthetic bacteria, they were quick and keen to proclaim these as the primaeval organisms. This seemed to resolve the dilemma that, while the primaeval organisms must, according to prevailing views, have been autotrophic in their nutritional requirements, the organisation of cells capable of photosynthesis is manifestly far from primitive.

The hypothesis that the chemoautotrophs were the first organisms to inhabit our planet has remained current up to the present time and is to be found in several widely read reviers (e.g. those of C. H. Werkman and H. G. Wood, ${ }^{34}$ M. Stephenson, ${ }^{35}$ W. O. Kermack and H. Lees ${ }^{36}$ and others). In the light of present-day biochemical knowledge, however, the facts suggest that chemosynthesis, like photosynthesis, requires a far more complicated and specialised biochemical organisation than does heterotrophy (the use of preformed organic substances). Chemoautotrophs can make use of organic substances; this ability is fundamental to the 
biochemical organisation of these and other living things. ${ }^{37}$ Even those few forms of bacteria which are unable to exist at the expense of organic materials derived from the external medium, such as Thiobacillus thio-oxidans, can nevertheless oxidise their intracellular reserves of polysaccharides during the process of respiration. ${ }^{38}$ This breakdown is associated with the same enzymic apparatus, the same metabolites of glycolysis, the same vitamins, adenosine triphosphoric acid, etc., which take part in the metabolism of heterotrophs. ${ }^{39}$ The inability to assimilate organic substances from the surrounding solutions seems, in this case, to be due merely to a peculiar type of permeability of the external membranes of the bacteria in question. The metabolism of all autotrophs is based on a biochemical system for the degradation of organic substances which seems to be extremely primitive and general. The chemosynthetic apparatus would appear to be a secondary, supplementary development which inincreases the complexity of the metabolism. The existence of autotrophic forms within the most systematically diverse groups of micro-organisms also indicates that they have a hereditary relationship to the heterotrophs from which they arose, and that in the course of evolution they have acquired the power to make use of the energy of oxidation of reduced mineral substances. It now seems quite impossible, even from a purely systematic point of view, to suppose that the whole plant and animal kingdoms were derived from the chemosynthetic bacteria. Chemoautotrophy must undoubtedly be regarded as an offshoot of the evolutionary process. ${ }^{40}$

Even among systematists there is, at present, no unanimity as to which of the existing forms of organism are closest to the prime ancestor of life on the Earth. Many workers think the flagellates are the most primitive (e.g. V. Dogel', ${ }^{41}$ L. Kursanov and colleagues, ${ }^{42}$ A. Lwoff $\left.{ }^{43}\right)$; others think the Sarcodina are more primitive (e.g. A. Elenkin, ${ }^{44}$ A. Zakhvatkin, ${ }^{45}$ and A. Markevich ${ }^{46}$ ). All are, however, agreed that the obligate heterotrophic organisms which do not require light are the simplest existing organisms. The controversy is about whether these simpler forms arose by degeneration of more complicated ones or whether they are themselves nearer to 
the original form of life and more complicated forms have evolved from them.

As early as 1922 I expressed the view that all the difficulties and contradictions which have been discussed were only apparent and that the first living things to develop on the Earth were quite able to nourish themselves heterotrophically on organic substances because these compounds must have been formed abiogenically on the Earth long before the appearance of life on it. ${ }^{47}$ The belief that organic substances could only be formed biogenically under natural conditions was based on a preconception of the conditions which prevailed on the Earth at the appropriate epoch in its existence. If, however, we take a broader view of the question and extend our studies beyond the limits of our own planet to include facts concerning other heavenly bodies, then this conception will be rudely shaken.

\section{The distribution of organic substances (hydrocarbons) on different heavenly bodies.}

Spectroscopic studies of the atmosphere of the stars have long ago shown that carbon is very widely distributed throughout the universe. It is to be found everywhere. It has been shown recently that this element plays an extremely important part in the life of stars. It is well known that the source of stellar energy resides in particular reactions taking place within the nuclei of atoms and that these take place in the interior of the stars where temperatures of some tens of millions of degrees prevail. Under these conditions hydrogen is converted into helium with a resulting decrease in mass and consequently with the release of cnormous amounts of intra-atomic energy.

H. A. Bethe ${ }^{48}$ states that reactions of this kind can only take place in the presence of carbon which acts in a peculiar way as a 'catalyst' in this nuclear reaction. In the course of this four hydrogen nuclei (pro:ons) are converted into helium with the liberation of a very large amount of intraatomic energy.

This so-called carbon cycle is the fundamental cause of the shining of the stars which is therefore directly associated 
with the presence of carbon. Any heavenly body having a mass greater than one-twentieth of that of the Sun is very likely to have such a cycle occurring within it, in which case it will be a self-luminous formation, in fact a star.

It is of particular interest to us to enquire as to the form in which carbon exists on stars of different spectral types. On stars of type $\mathrm{O}$, which have a very high temperature on their surfaces, J. Plaskett ${ }^{49}$ found that carbon was present mainly in the singly or doubly ionised form $\left(\mathrm{C}^{+}\right.$or $\left.\mathrm{C}^{++}\right)$. On these stars the temperature is so high that there can be no question of the presence of any sort of chemical combination of carbon. The carbon atoms themselves are substantially altered in that they have lost some of their outer electrons.

On stars of type B, which are cooler, F. Henroteau and J. Henderson ${ }^{50}$ also demonstrated the presence of carbon, though only in the neutral form. However, no carbon compounds could exist on these either. Signs of such compounds appear in the spectra of stars belonging to type A. Traces of $\mathrm{g}$-bands $(\lambda, 4,314 \AA)$ were discovered in the spectra of such stars quite a long while ago, ${ }^{51}$ indicating the possibility of the development there of the most primitive carbon compounds-the hydrocarbons (methyn, $\mathrm{CH}$ ). In the spectra of other types of stars the hydrocarbon bands show up more and more clearly as the temperature of the surface of the star decreases, reaching a maximum clearness in the spectra of types $\mathrm{M}$ and $\mathrm{R}$. These spectra also reveal the presence of compounds of carbon and nitrogen (cyan) in the atmospheres of the stars.

In the spectra of the sun-spots, and even more so in the spectra of stars of types $\mathrm{N}$ and $\mathrm{R}$, there have also been demonstrated the so-called Swan's bands which indicate the presence of molecules consisting of two carbon atoms combined together $\left(\mathrm{C}_{2}\right.$, dicarbon). ${ }^{52}$

The investigations of these bands by G. Shain ${ }^{53}$ and later workers have shown that the carbon in the atmosphere of some so-called carbon stars is ten times richer in the heavy isotope ${ }^{13} \mathrm{C}$ than the carbon in terrestrial objects. It follows that the evolution of the nuclear material itself has followed a somewhat different course on these stars from that which it has followed within the solar system. Nevertheless, hydro- 
carbons form one of the chief types of carbon compounds in the atmospheres of these as of other stars.

Our Sun is classified as a star of type G (yellow stars). The temperature of the atmosphere of the Sun is about $6,000^{\circ} \mathrm{C}$. The temperature of the outer layers is as low as $5,000^{\circ} \mathrm{C}$, while the innermost parts accessible to investigation reach $7,000^{\circ}$ C. Spectroscopic studies show that even here a considerable proportion of the carbon is present in the form of compounds with hydrogen (in the form of methyn, $\mathrm{CH}$ ), and there may also be more complicated compounds containing several atoms of carbon and hydrogen. ${ }^{54}$

We thus see that compounds of carbon and hydrogenhydrocarbons-are very widely distributed in the atmospheres of stars of various types. It is, however, clear that they must have been formed abiogenically as there can be no question of any vital processes taking place at temperatures of some thousands of degrees, such as prevail on the surfaces of stars.

This wide distribution of hydrocarbons is also found at the other extreme of temperature within the universe, at temperatures approaching absolute zero.

It is now well known that by no means all the matter of our galaxy and other analogous systems exists in the form of large aggregates such as stars and planets. A considerable part of its mass (10 per cent or maybe far more) is scattered through space in the form of very finely divided dust or gas. ${ }^{55}$ Clouds of cosmic dust are mainly concentrated in the plane of the galaxy. Some of these are visible to the naked eye, sharply outlined against the light background of the Milky Way by virtue of their absorption of light.

It may be easily shown spectroscopically that atoms and electrons in the interstellar gas in the neighbourhood of stars of types $\mathrm{O}$ and $\mathrm{B}$ can attain very high speeds, corresponding to temperatures of several thousands of degrees. In those parts of interstellar space which are far away from hot stars there are wide areas in which hydrogen exists in the unionised form, the temperature of the gas in these areas being no more than $50^{\circ}-100^{\circ}$ Absolute (about $-200^{\circ} \mathrm{C}$ ). This was established by direct measurement using radio waves. ${ }^{56}$ The temperature of the cosmic dust is even lower. It never rises more than a few degrees above absolute zero. 
Collisions between atoms of gas and particles of dust therefore lead to a cooling of the gas, making it colder in the presence of dust than in the absence of it. ${ }^{57}$

The interstellar gas consists almost entirely of hydrogen which is the most abundant element of the cosmos in general (accounting for 90 per cent of its mass). ${ }^{58}$ The work of $\mathrm{H}$. Kramers and D. ter Haar $^{59}$ has shown that the simplest hydrocarbon radicals, $\mathrm{CH}$ and $\mathrm{CH}^{+}$, are formed in interstellar space. However, H. C. Urey ${ }^{60}$ considers that, as a result of the catalytic activity of the dust and the presence of large amounts of hydrogen in the clouds of gas and dust, all free radicals would be converted into stable molecules. He considers it probable that methane is formed, although more complicated hydrocarbon molecules may also occur. On the basis of their own investigations D. R. Bates and L. Spitzer ${ }^{61}$ suggest that when a cloud of dust of the usual density moves towards a hot star the temperature of the particles of dust will rise and, at a particular distance from the star, the $\mathbf{C H}_{\mathbf{4}}$ will evaporate and will later dissociate to give $\mathbf{C H}$ and $\mathbf{C H}^{+}$.

Thus we may observe the same widespread formation of hydrocarbons, both in the incandescent atmospheres of the stars and in the cold clouds of gas and dust. There can be no possible doubt that the hydrocarbons were formed abiogenically in these situations.

The position is the same within the narrower confines of our own planetary system. Although it is difficult to study the planets spectroscopically, a considerable number of facts as to the chemical constitution of the atmospheres of the planets has now been accumulated. As early as 1935 these facts were brought together by $\mathrm{H}$. N. Russell in his book The solar system and its origin. ${ }^{62}$ The more recent discoveries may be found in H. C. Urey's book The planets, their origin and development, to which reference has already been made, and also in the collection of papers edited by G. Kuiper and published under the title The atmospheres of the Earth and planets. ${ }^{63}$

The planets of the solar system may be divided into two groups according to their chemical composition: the group of large planets, which includes Jupiter, Saturn, Uranus and Neptune, and the group of planets resembling the Earth 
which also includes Venus and Mars. Mercury occupies a somewhat special position, in that it is a naked rocky mass without an atmosphere, similar in some respects to our Moon and Pluto, about the chemical composition of which we still know very little.

When they were formed the large planets retained the quantitative relationship between the various elements which is characteristic of the galaxy as a whole. Thus the elements which predominate in their composition are, first hydrogen, and then the other light elements; this is what causes their characteristically low specific gravity and chemically reduced state.

For a long time spectroscopic studies of these planets led to no definite results. The bands which had been observed in their spectra remained a puzzle and it was not until $193^{2}$ that $\mathrm{R}$. Wildt showed that some of these bands in the spectrum of Jupiter corresponded with the bands of ammonia and others with those of methane. This was soon confirmed by T. Dunham, and then A. Adel and V. M. Slipher ${ }^{64}$ succeeded in identifying all the bands characteristic of methane.

There could thus be no doubt as to the presence of the hydrocarbon, methane, in the atmosphere of Jupiter. H. C. Urey has shown that this methane must be converted photochemically to other higher hydrocarbons, both saturated and unsaturated. In particular, he showed that cuprene, a hydrocarbon of high molecular weight having a red colour, would arise by the polymerisation of acetylene. According to Urey the presence of this substance would account for the colour of the red spot on Jupiter. Owing to the temperature of the surface of Jupiter, which is very low compared to that on the Earth $\left(-140^{\circ} \mathrm{C}\right)$, only methane can exist there in the gaseous state. Even such hydrocarbons as ethane, ethylene and acetylene are liquids under such conditions.

Saturn has an abundant atmosphere which, like that of Jupiter, contains methane and ammonia, but as the distance of this planet from the Sun is far greater, the temperature on its surface is even lower than that on Jupiter. A considerable proportion of the ammonia on Saturn is therefore in the solid state, as may be seen from the spectrum, in which the methane bands stand out very clearly. 
The temperatures are far lower on the surfaces of Uranus and Neptune, which are still further from the Sun. The ammonia is completely solidified but, on the other hand, a very large amount of methane is present in their atmospheres.

Thus we find carbon in combination with hydrogen on all the large planets. The discovery of methane in the atmosphere of Titan, a satellite of Saturn, by G. P. Kuiper in $1944^{65}$ is of very great interest. Titan is one-third of the size of the Earth and has one-fortieth of its mass. It is only the extremely low temperatures which prevail in the neighbourhood of Saturn $\left(-180^{\circ} \mathrm{C}\right)$ which enable Titan to retain its atmosphere of methane. It is clear that there can be no question of biogenic formation of hydrocarbons here any more than on the large planets.

In the atmospheres of the planets belonging to the same group as the Earth the carbon is mostly oxidised and exists in the form of $\mathrm{CO}_{2}$. Thus the proportion of this gas in the atmosphere of Venus is many times greater than in that of the Earth. According to Kuiper, there is reason to believe that a certain quantity of methane and other hydrocarbons of the acetylene and ethylene series are present in the atmospheres of Venus and Mars. Here, however, one cannot completely exclude the possibility that both the carbon dioxide and the organic substances have arisen biogenically.

The study of meteorites is of particular interest in connection with the problem under discussion; in the first place because meteorites which have fallen on to the Earth may be submitted to direct chemical analysis and, further, to mineralogical investigation. These are the only 'non-terrestrial' bodies of which the composition may be established with completeness and certainty. In the second place, a study of meteorites shows us more and more convincingly that their chemical composition is very close to that of the Earth as a whole, and that their formation was related to that of our own planet.

Long ago the attention of scientists was directed towards the origin of the Earth and the meteorites. Many prominent geochemists of the twentieth century, including F. W. Clarke, ${ }^{66} \mathrm{H}$. S. Washington, ${ }^{67} \mathrm{~V}$. M. Goldschmidt, ${ }^{68}$ and I. and W. Noddack, ${ }^{69}$ have studied the structure and composition 
of meteorites from this point of view. In his book Geochemistry A. Fersman ${ }^{70}$ gives an extensive review of these investigations. He indicates the tremendous significance of the study of meteorites in the solution of geochemical problems. He writes:

It may be that we are only now beginning to understand what a very important part a thorough and well worked out analysis of meteorites can play, both in determining the composition of the Earth, and in clarifying the laws governing the difference between the composition of the crust of the Earth and the composition of the Earth as a whole. This is essential to a clear understanding of the quantitative occurrence of the elements in the parts of the crust of the Earth accessible to us.

A. Fersman presented a whole series of comparative analyses of meteorites and of various terrestrial formations. These figures revealed striking correspondence between the over-all composition by weight of the Earth and the average composition of meteorites, a correspondence which cannot be accidental. All this led him to the conclusion

that both in respect of the nature of their elements and in the principle on which their atoms are built, the elements found in meteorites are very similar to those found in the deepest zones of the crust of the Earth, and that, in all probability, they correspond even more closely to the central parts of the Earth.

These data have now been considerably amplified by the inclusion of new analyses and the consideration of a number of new circumstances (e.g. H. Brown and C. Patterson, ${ }^{71}$ H. C. Urey and H. Craig, ${ }^{72}$ and P. Chirvinskiir $\left.{ }^{73}\right)$. The basic conclusions reached by Fersman remain, however, unchanged. The reason for this close correspondence between the chemical composition of the meteorites and that of the Earth is certainly that both the Earth and the meteorites developed from one and the same original material. Nevertheless, different authors have held different views on the way in which meteorites were formed.

Most astronomers and geologists consider that meteorites arose in the solar system by the disintegration of a 'mother' planet, similar in composition to the Earth, but considerably 
smaller in size. This planet is assumed to have been formed somewhere between the orbits of Mars and Jupiter. Its radius is estimated at $2,500-3,000 \mathrm{~km}$. and its mean density at $3 \cdot 8$ (S. Orlov, ${ }^{74}$ V. Fesenkov, ${ }^{75}$ A. Zavaritskiǐ ${ }^{76}$ and others). R. A. Daly ${ }^{77}$ even tried to build a model of this hypothetical planet, analogous to the meteoritic model of the Earth, having a core of iron and nickel enclosed in a geosphere of silicates and basalt.

On the other hand O. Shmidt, B. Levin, ${ }^{78}$ and other workers deny the possibility that meteorites were formed by the disintegration of a 'mother' planet, because they consider such a disintegration physically inexplicable. They see meteorites as splinter bodies like asteroids, formed at remote stages of the evolution of the protoplanetary cloud, formed, perhaps, in the same region as the Earth and therefore having a similar over-all chemical composition.

Whichever hypothesis one supports, it is quite clear that the study of the composition and structure of meteorites can give a great deal of information relevant to the problem of what were the primary compounds which appeared during the formation of the Earth.

All meteorites are commonly allocated to two basic groups, stony and iron. An intermediate group is sometimes recognised, the iron-stony meteorites. ${ }^{79}$

The iron meteorites are composed of so-called nickel iron, which contains more than 90 per cent of iron, 8 per cent of nickel, about 0.5 per cent of cobalt and small amounts of phosphorus, sulphur, copper and chromium. In the stony meteorites, which fall far more frequently on the Earth, the percentage of iron is considerably lower. In these, silicates and oxides of such metals as magnesium, aluminium, calcium, sodium, etc., predominate. The discovery of 9 per cent of constitutive water by $\mathrm{A}$. Zavaritskir and $\mathrm{L}$. Kvasha ${ }^{80}$ in the Staroe Boriskino meteorite is of great interest.

Carbon has been found in meteorites whenever it has been looked for. The amount present is sometimes as low as some hundredths of 1 per cent but some so-called carbon meteorites contain up to 2 or even 4.5 per cent of carbon.

As regards the isotopic composition of the carbon of meteorites, the mean value of the ratio of ${ }^{12} \mathrm{C}$ to ${ }^{13} \mathrm{C}$ is 2 per 
cent higher than that in terrestrial carbonates and 1.3 per cent lower than that in biological objects. ${ }^{81}$ There is reason to suppose that it approximates very closely to the original isotopic composition of carbon on the surface of Earth and that the divergence of the proportions of the isotopes of carbon did not arise until the period in the history of our planet when life had developed and biological processes were taking place.

The forms in which carbon is commonly found on meteorites are carbides and native carbon, either in the amorphous state, or as graphite or diamonds. Graphite, in particular, has been found in iron meteorites in the form of nodules, flakes and granules which sometimes attain a weight of $12 \mathrm{~g}$. Erofeev and Lachinov were able to isolate about 1 per cent of carbon in the form of diamond from the meteorites which fell near the village of Novo-Urer in the province of Penza in 1887. Later A. E. Foote and Koenig obtained diamond dust from the meteorites which fell in the Diablo canyon in Arizona. Weinschenk also found diamonds in the Magura meteorites. ${ }^{82}$

Weinschenk was also the first to find cohenite, a mineral which is very widely distributed in and characteristic of meteorites. It is a carbide of iron, nickel and cobalt and has the general formula $\left(\mathrm{Fe}, \mathrm{N}, \mathrm{C}_{\mathrm{o}}\right)_{3} \mathrm{C}$.

Cohenite is the parent substance of the free carbon and of the hydrocarbons which have been found in a number of meteorites.

As early as $1857 \mathrm{~F}$. Wöhler ${ }^{82 a}$ succeeded in isolating a certain amount of organic material similar to ozocerite from the stony meteorite which fell near Kaba in Hungary. Analysis of this material showed definitely that it was composed of hydrocarbons of high molecular weight. A similar material was isolated from the meteorite which fell in Cold Bokkeveld in Cape Province. This meteorite contained up to 0.25 per cent of hydrocarbons. P. Melikov and V. Krshizhanovskir ${ }^{83}$ found a small amount of hydrocarbons in the silicate meteorite which fell in the village of Migeya near Elizavetgrad in the Khersonese in 1889 . In his book von Klüber $^{54}$ gives a general account of the occasions on which hydrocarbons have been found in meteorites. In particular, 
J. L. Smith ${ }^{84}$ succeeded in isolating a compound having the composition $\mathrm{C}_{4} \mathrm{H}_{6} \mathrm{~S}_{5}$ from the Orgeuil meteorite. Compounds having the formula $\mathrm{C}_{8} \mathrm{H}_{9} \mathrm{O}_{2}$ were found in the Orgeuil and Hessle meteorites. The number of such finds increases from year to year.

At the time when the presence of hydrocarbons in meteorites was first discovered people were, as we have already indicated, still firmly convinced that, under natural conditions, organic substances could only arise biogenically. It was not unusual, therefore, for scientists to put forward the hypothesis that the hydrocarbons of the meteorites had been formed secondarily as the result of the decomposition of organisms which had lived on them at some time. We have shown, however, in Chapter II, that all the numerous attempts to find microbes, their germs, or any other organised remains, have been quite fruitless. On the contrary, all the experts on meteorites, such as A. Fersman, F. LevinsonLessing, V. Vernadskir and others, agree that there is nothing in meteorites which resembles a sedimentary formation or which could, in general, suggest the possibility of the existence of biogenic processes. It follows that the hydrocarbons of the meteorites, like those of the cosmic dust, arose abiogenically, that is to say, without any connection with organic life.

A few words must still be said about comets. These heavenly bodies originate somewhere in the neighbourhood of the orbit of Pluto where the condensation of methane can occur. According to F. L. Whipple ${ }^{85}$ the nucleus of comets consists of finely dispersed dust containing all the elements which are commonly met with in the silicate and metallic phases of meteorites.

There are also present in the nuclei of comets particles of frozen liquids and gases, compounds of carbon, hydrogen, nitrogen and oxygen.

When it approaches the Sun the substance of a comet begins to emit light and can therefore easily be submitted to spectroscopic investigation. The spectrum of the head of a comet shows that it consists of chemical compounds. In particular, hydrocarbon bands may be seen, indicating the presence of $\mathrm{CH}_{2}, \mathrm{CH}$ and $\mathrm{CH}^{+}$. 
Here too, as in other heavenly bodies, we find hydrocarbons, as was to be expected from a theoretical consideration of the circumstances under which comets were formed.

In the light of all that has gone before we see that not only is it perfectly possible that hydrocarbons could have been formed abiogenically under natural conditions but this process seems to be extremely widespread throughout the universe. Hydrocarbons have been found everywhere, on all bodies accessible to investigation ; in the atmosphere of stars of different spectral types, particularly in the atmosphere of the Sun; in the cold clouds of gas and dust in interstellar space; on the surfaces of the large planets and their satellites, in the substance of comets and, finally, in meteorites falling on the surface of the Earth. Is it possible that our planet is an exception to this general rule and that the simplest organic substances could never have arisen abiogenically on it? Is it not more probable that this process took place in the past before the appearance of life on the Earth and perhaps still goes on although we do not notice it?

\section{Geological finds of hydrocarbons formed abiogenically on the Earth.}

Most astronomers and geologists believe that in the centre of the Earth, at a depth of $2.900 \mathrm{~km}$., there is a nucleus which is far denser than the superficial formations and which is similar in chemical composition to the metallic (iron) meteorites. This consists, for the most part, of iron and nickel, with a small admixture of cobalt and other elements. If it is assumed that carbon is present in the core of the Earth, it is present there in the form of carbides of iron and nickel similar to those in the iron meteorites (Fig. 9).

On the other hand, O. Shmidt ${ }^{86}$ and a number of his colleagues at the Geophysical Institute of the Academy of Sciences of the U.S.S.R. Consider that the outer parts of the Earth and its core do not differ from one another in their chemical composition but only in their physical state. According to Shmidt the differences in density, seismic and other phenomena which have led people to postulate a nucleus in the Earth could be due to phase transformations of siliceous material into the metallic state brought about by the high 
pressure, rather than to gravitational layering out leading to a separation of the various substances entering into the composition of the Earth. ${ }^{87}$ However, neither Shmidt nor any other contemporary scientist would deny the presence of iron and nickel carbicles in the composition of the Earth,

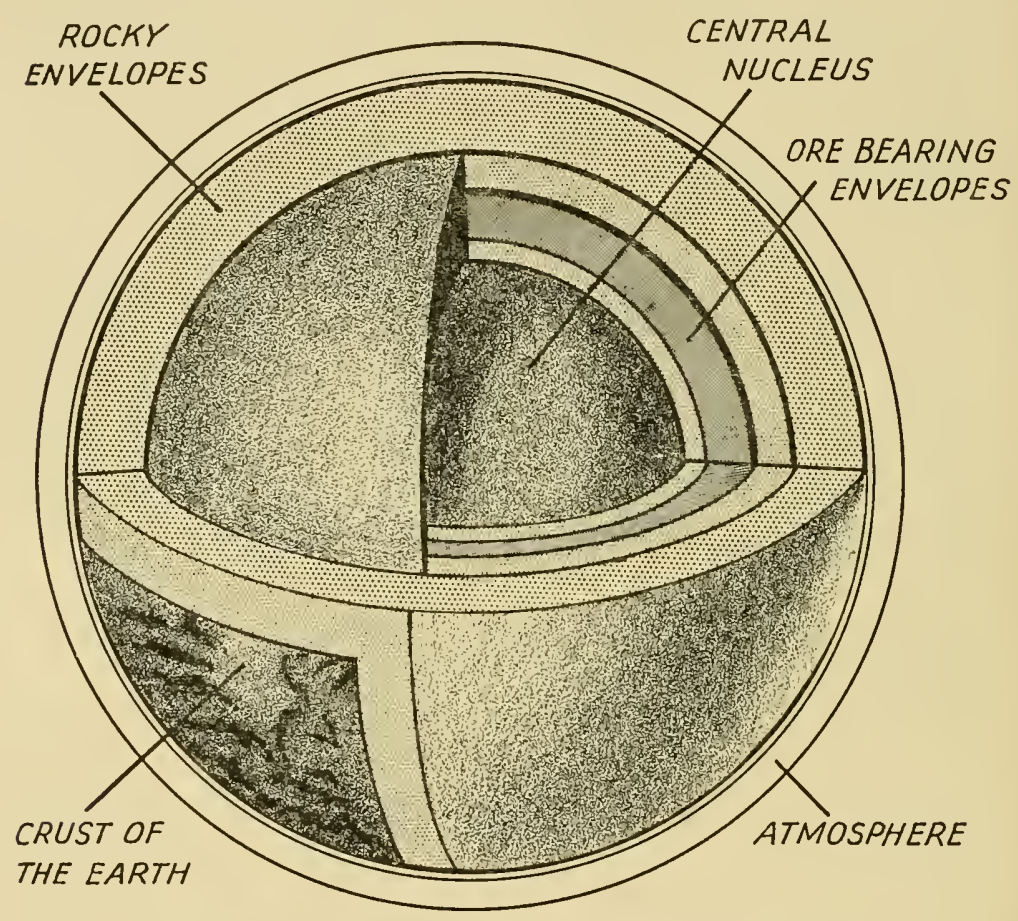

FiG. 9. Diagram of the structure of the Earth.

because their presence is not merely based on theoretical considerations, but is something which has been directly proved by a number of geological findings.

As we have already mentioned, the mineral cohenite, having the general formula $\left(\mathrm{Fe}, \mathrm{N}_{\mathbf{i}}, \mathrm{Co}\right)_{3} \mathrm{C}$ was first found in meteorites. As early as $\mathbf{1 8 5 4}$, however, G. Forchhammer pointed out the presence of carbides of iron and nickel in native iron ores from Niakornak. ${ }^{88}$

In 1870 the Swedish traveller Nordenskjöld found large lumps of iron in the basalt at Ovifak on the island of Disko 
off Greenland. Their chemical composition was similar to that of iron meteorites but later studies have shown that they were undoubtedly of terrestrial origin. ${ }^{89}$

Numerous analyses of the 'Orifak iron', in particular the work of J. L. Smith, ${ }^{90}$ R. T. Chamberlin ${ }^{91}$ and others, have revealed the presence in it of nickel-containing carbides of iron (cohenite). Carbides of this sort have also been found in native iron derived from many different sources; for example, they have been found in native iron ore from Santa Caterina and Kersut, in the basalts of Oregon and Hawaii, in the geological formations of the Transvaal, etc. "It is very probable", wrote Vernadskir.," "that a more detailed study of these minerals will show that they are present everywhere in the deep basalts (the basaltic layer)."

It has already been mentioned that cohenite is the parent substance both of the native forms of carbon (especially graphite) and of the hydrocarbons present in meteorites. The connection between terrestrial cohenites and hydrocarbons can easily be understood from a purely chemical point of view. As long ago as the nineteenth century M. Berthelot, ${ }^{93}$ H. Abich, ${ }^{94}$ and H. Moissan ${ }^{95}$ indicated the possibility that hydrocarbons might be formed directly from the carbon of carbides, and substantiated this by direct chemical experiment. A great deal of work in this direction had been done by $\mathrm{D}$. Mendeleev. ${ }^{96}$ As early as 1877 he described the reaction leading to the formation of hydrocarbons, according to the equation $3 \mathrm{Fe}_{\mathrm{m}} \mathrm{C}_{\mathrm{n}}+4 \mathrm{mH}_{2} \mathrm{O} \rightarrow \mathrm{mFe}_{3} \mathrm{O}_{4}+\mathrm{C}_{3 \mathrm{n}} \mathrm{H}_{8 \mathrm{~m}}$.

Mendeleev wrote as follows:

Cloez studied the hydrocarbons formed by dissolving pig iron in hydrochloric acid and found representatives of the series $\mathrm{C}_{n} \mathrm{H}_{21}$ and other hydrocarbons. I treated crystalline manganese-containing pig iron (containing 8 per cent of carbon) with hydrochloric acid and obtained a liquid mixture of hydrocarbons which, in its smell, appearance and reactions, was just like natural petroleum.

On the basis of these reactions Mendeleev constructed his well-known theory of the mineral origin of petroleum. $\mathrm{He}$ wrote: 
When mountain ranges are raised, cracks opening upwards are formed at the summit while, at the foot of the mountains, the cracks open downwards. In the course of time they are filled up but the younger the rocks ... the fresher are the cracks, and through them water can obtain access to parts of the interior of the earth in a way which cannot normally happen (in plains).

Thus, according to Mendeleev, the water of the sea was able to reach the red-hot central nucleus of the Earth which contained large amounts of iron mixed with carbon; and, by reacting with the carbon, it gave rise to the hydrocarbons of petroleum.

This theory has now been abandoned because it is contradicted by a number of geological observations. It is hard to imagine how the water could have trickled down to reach the carbides of the nucleus of the Earth from which it was separated by a layer of rock formations more than a thousand kilometres thick. Apart from this, all the considerations which we have already put forward about the isotopic composition of petroleum, its optical activity and other physical and chemical properties, as well as the way in which deposits of petroleum are laid down in sedimentary formations, show, without doubt, that the main mass of the organic material of petroleum arose secondarily as the result of alteration of the substances of animals and plants which lived on the Earth at some time. ${ }^{97}$

Mendeleev's main contention that hydrocarbons could be formed abiogenically by the action of water on carbides is completely justified by both earlier and later studies. As early as 1841 Schrötter obtained a liquid similar to petroleum by the action of dilute acids on pig iron. This reaction was later studied by $\mathrm{H}$. Hahn. ${ }^{98}$ By dissolving a large quantity of white iron in acid over several weeks he obtained a very considerable amount of petroleum-like liquid. It is interesting to note that in addition to his work cited by Mendeleev, S. Cloez carried out experiments in which the formation of hydrocarbons occurred during the decomposition of ferromanganese containing 5 per cent of carbon under the action of superheated steam alone. ${ }^{99}$

K. Kharichkov ${ }^{100}$ observed the formation of liquid and gaseous hydrocarbons when aqueous solutions of chlorates 
and sulphates of manganese and sodium acted for a long time in sealed tubes or stoppered bottles on powdered common grey pig iron containing 3 per cent of carbon. Finally, V. Ipat'ev ${ }^{101}$ again repeated the reactions in which hydrocarbons were obtained from iron which contained carbon by the action of dilute hydrochloric acid, salt solutions and plain steam.

A still greater amount of evidence of like character could be adduced, but the facts which have been set out prove conclusively enough that, under the conditions of chemical experiments, treatment of carbides of iron and other metals with dilute acids, solutions of salts or plain water will give rise to the simplest organic substances, hydrocarbons, without any connection with, or participation by, organisms.

Could such phenomena take place under natural conditions on the Earth at the present time? Many leading geologists and geophysicists have considered that this is perfectly possible. For example, V. Vernadskir ${ }^{92}$ in his Outlines of geochemistry wrote: "There are, however, facts which show that metallic carbides, cohenites and perhaps others, may also be thrown up in some volcanic formations under conditions which do not preclude the formation of hydrocarbons on reaction with hot water." Similarly, V. M. Goldschmidt ${ }^{102}$ in his recently published paper on the development of organic substances indicated the possibility that hydrocarbons may be formed by inorganic processes such as the hydrolysis of metallic carbides.

Factual evidence for the possibility that hydrocarbons may be formed abiogenically has been available for a long time in the finding of bitumens in volcanic formations. This is supported by A. Brun's finding of considerable amounts of bitumen in many obsidians and in volcanic pumices and ash. In 1911 D. Edwards drew attention to the fact that the presence of petroleum bitumens in obsidian had been established by C. St. Claire Deville eren before Brun. In $193^{\circ}$ S. Sacco also found bitumens in obsidians and lavas of Vesuvius and Stromboli. ${ }^{103}$

The abiogenic origin of hydrocarbons is also suggested by a number of gaseous formations which are not directly associated with sedimentary deposits. Such, for example, 
are the hydrocarbon gases formed in the crystalline formations of Lake Huron in Canada and in the Ukhta formations in Karelia where very large amounts of hydrocarbons have been found in fissures in the volcanic formations. V. Sokolov, in a personal communication, states that he has found methane, ethane, propane and higher hydrocarbons in volcanic formations in a number of places in the Soviet Union.

Of recent years greater and greater numbers of instances of the presence of petroleum in volcanic and metamorphic formations have been reported. However, as these finds are very seldom of economic importance and, in most cases, only consist of insignificant inclusions, petroleum geologists have paid very little attention to them. Nevertheless, the finds of this kind which have already been made in many countries may be reckoned by hundreds. ${ }^{104}$ In particular, liquid and gaseous hydrocarbons have been found in the form of surface smears and small quantities of separated material in the course of deep boring in the fissures of metamorphic and crystalline formations at levels to which they could hardly have penetrated from the sedimentary formations.

Thus, although petroleum extracted from sedimentary formations shows clear signs of its biogenic origin, in the light of the facts now known one cannot deny that even now the abiogenic formation of hydrocarbons is taking place on the Earth, albeit to a very limited extent.

Until organisms appeared, these processes were the operative ones in the formation of hydrocarbons on the Earth as on the other heavenly bodies. Only after the appearance of life, when new and higher forms of the motion of matter came into existence, did there develop new and extremely highly specialised methods for the transformation of substances and the utilisation of energy for the synthesis of organic compounds. In particular, the development of photosynthesis led to the formation of systems which could use the inexhaustible source of energy of sunlight for this process. As a result of this an enormous amount of the carbon of the surface of the Earth became involved in biological processes and the old, abiogenic mode of formation of hydrocarbons lost its significance, as always happens in the 
development of matter when a new and more effective form of motion makes its appearance.

\section{Theory of the origin of the Earth.}

Unfortunately, we have, as yet, no single comprehensive theory as to the way in which the Earth was formed. However, all the astronomical, geological, physical and chemical facts bearing on the problem which we can assemble and all the generalisations which have been made by contemporary cosmogonists of different outlooks conspire to convince us that large amounts of the simplest organic compounds must have arisen abiogenically on the Earth at the time of its formation and during the first period of its existence, and that these compounds arose by purely chemical, abiogenic means long before life made its appearance.

As early as the end of the eighteenth century W. Herschel ${ }^{105}$ put forward an ingenious idea, which later received the wholehearted support of Laplace, ${ }^{106}$ namely that the stars and constellations are not something unchanging but that they arose at various times (and are still arising) and that they undergo processes of gradual development, the various stages of which can be observed in the sky.

This idea has been thoroughly substantiated by a number of astronomical facts which have since been established, in particular by investigation by $\mathrm{V}$. Ambartsumyan ${ }^{107}$ of stellar associations. These associations seem to be unstable because the attractive forces between the stars of which they are composed are weaker than those of the galaxy as a whole (especially the more central parts of it). The stars comprising these associations are therefore flying apart and, according to Ambartsumyan's calculations, the associations cannot remain in being for long, at most for some tens of millions of years. Judging from what we can now observe of them, these associations and the stars of which they are composed have arisen recently. Thus, the process of the formation of stars is still taking place now. Alongside of this there occurred, and still occurs, the formation of planetary systems analogous to our own solar system. The findings of recent years and, above all, the studies of $\mathrm{E}$. Holmberg ${ }^{108}$ indicate that systems of this kind are widely distributed in the uni- 
verse and that a star with comparatively small cold bodics circling round it is the rule, rather than a rare exception as was thought a few years ago. As a result of these studies there was a withdrawal from the so-called 'catastrophic' theories of the formation of our planetary system which, until recently, prevailed among cosmogonists.

According to such theories, and in particular to that of Sir J. H. Jeans ${ }^{109}$ (which was the only theory of the formation of planets current twenty years ago) the Earth and the other planets of the solar system arose as the result of an exceptional event, a 'catastrophe', namely the close approach of another star to our own Sun. As the result of its gravitational attraction, a stream of incandescent gas was drawn off from the Sun and this provided the material from which the planets were later formed. This theory came in for devastating criticism at the hands of $\mathrm{H}$. N. Russell ${ }^{110}$ who showed that the theory of the origin of the solar system by collision between some other star and the Sun was incompatible with the law of the conservation of momentum.

In 1943 detailed calculations made by N. N. Pariǔskiřrioa demonstrated completely the incorrectness of Jeans' theory and later attempts to revive it in one form or another have not been successful. Furthermore, all the physico-chemical and geological data disagree with the hypothesis that the Earth was formed from gases which were originally incandescent.

Judging by the statements of the cosmogonists, most of the investigations in this field suggest that our planetary system is not the result of some very rare, 'happy' accident or catastrophe but that it, like many other analogous systems, arose as a completely normal phenomenon in the course of the gradual development of matter. According to this hypothesis the material from which the planets were formed was not provided by incandescent gases but by relatively cold substances scattered through interstellar space.

Thus contemporary scientific ideas on the origin of the planets return, in principle, to the hypothesis advanced by I. Kant ${ }^{111}$ more than 200 years ago.

Kant considered that the material which now makes up the planets did not always constitute a system of isolated 
bodies but was scattered throughout the whole of the space now occupied by the solar system. Under the influence of gravitational forces the main mass of this material became aggregated to form a large central body, the Sun. The rest of the material took the form of a cloud of particles moving round this body. Their paths crossed one another at all angles. However, owing to the reactions between the particles, their courses became more and more regular until. finally, there emerged a flat swarm of particles revolving around the Sun, in nearly circular orbits. They approached one another and joined together to form the 'germs' of planets. As these 'germs' grew larger they began to attract particles from more and more distant parts of the swarm and as this went on the speed of their growth increased greatly and the 'germs' turned into planets revolving around the Sun in circular orbits in the same plane and direction.

This so-called nebular theory of the origin of the solar system was, at one time, pushed into the background by the 'catastrophic' hypothesis but came back into currency in Western Europe and America after the appearance of the works of C. F. von Weizsäcker, ${ }^{112}$ D. ter Haar $^{113}$ and S. Chandrasekhar ${ }^{114}$ and in the U.S.S.R. in connection with the studies of O. Shmidt. ${ }^{115}$

It is now the ruling hypothesis among cosmogonists, though it is founded on completely new scientific facts.

In Kant's time nothing was known about the nature of the particles forming the planetary cloud nor about the way in which they interacted. Astronomers now have at their disposal very firmly based factual data concerning the chemical composition of the gases and dust particles which are collected together in vast clouds in a number of parts of our galaxy, and also concerning the temperature which prevails in these clouds, the velocity and size of the particles, the concentrations of the gas and dust in the various clouds, etc. Modern theories of cosmogony make use of all these facts, draw widely on contemporary physics and chemistry and apply the principles of thermodynamics and statistical physics. This makes them more definite and enables them to give a quantitative description of the phenomena which are presumed to have occurred. At the same time the 
demands made on such hypotheses are immeasurably greater. They must give a rational explanation of all aspects of the structure of the solar system, the regularity of the orbits, the distances between the planets, the sizes and masses of the planets, the peculiarity of the distribution of angular momentum according to which the Sun, in which 99 per cent of the matter of the solar system is concentrated, nevertheless has only 2 per cent of the angular momentum of the whole system and so on. Moreover, a contemporary cosmogonic hypothesis must not contradict any of the numerous geological, physical and chemical facts which are now known.

We have, as yet, no such theory of the formation of the solar system which can satisfy all these demands. Therefore, although the overwhelming majority of present-day workers accept the nebular theory (cf. the review of E. Shatsman ${ }^{116}$ ) they frequently disagree with one another on such important questions as the origin and structure of the primaeval cloud of dust and gas, the mechanism of the formation of aggregates within it, and so forth. For example, O. Shmidt considered that the planetary cloud was caught up by the already fully formed Sun; this happened as it passed through an accumulation of gas and dust in the course of its motion round the centre of the galaxy. According to Shmidt this is the only way in which one can explain the peculiar distribution of momentum within the solar system. On the other hand, V. Fesenkov ${ }^{117}$ maintains that one cannot look at the problem of the origin of our planetary system in isolation from the general problem of the origin of stars, and that the Sun was formed simultaneously or nearly simultaneously with the planets which surround it and apparently from the same dust and gases.

In the course of the last ten to fifteen years a number of observations have been made which establish that the interstellar dust is not uniformly distributed but that there are separate aggregations of matter of an average extent of two and a half parsecs though they sometimes attain the colossal dimensions of 200 parsecs or more. The mass of these clouds may be 300 times that of the Sun, though B. Bok and E. Reilly ${ }^{118}$ also discovered small clouds of cosmic dust which are easily visible against a luminous background in the shape 
of more or less circular spots which are exceptionally impermeable to light. These were called 'globules'. The smallest known globule has a diameter of 0.006 parsecs and its mass is $1 / 500$ that of the Sun. Other globules have considerably greater masses, in some cases several times that

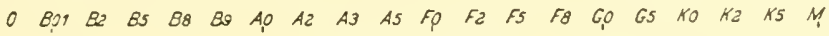

$-12000$
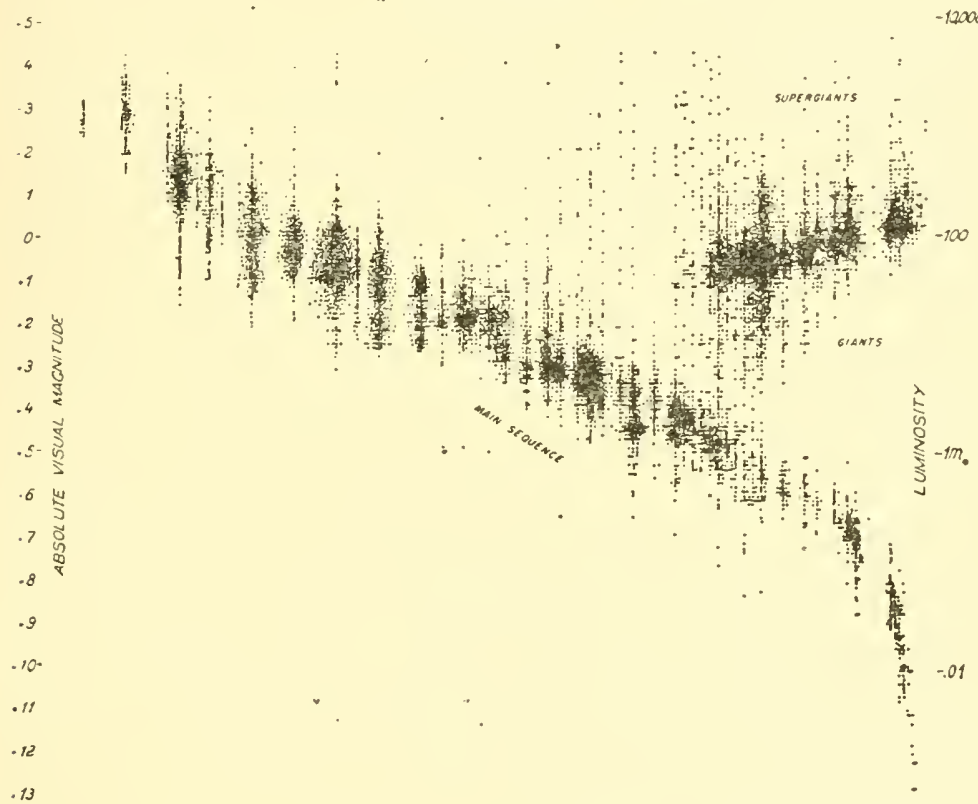

.14

$.15-$

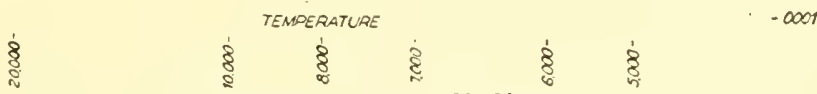

FIG. 10. Hertzsprung-Russell diagram.

of the Sun: i.e. they would be large enough to form one or several stars. In connection with such a possibility one must bear in mind the extremely high density of the globules. This is thousands of times greater than the density of the interstellar medium which surrounds them.

A theory enjoying considerable popularity among contemporary cosmogonists is that one such globule was the "protostar' from which our planetary system was formed. At some stage in the development of this globule there arose a central 
body. When the mass of this body became great enough the necessary conditions were created within it for the setting up of the carbon cycle whereby hydrogen is converted into helium; this resulted in the liberation of enormous amounts of intra-atomic energy so that the body became a star giving off light, the Sun. The further development of the Sun proceeded according to the curve of the main sequence in the Hertzsprung-Russell diagram (Fig. 10). ${ }^{119}$ The remaining matter of the globule which did not enter into the constitution of the Sun formed itself into a discoid cloud of dust and gas from which the protoplanets were formed.

Contemporary cosmogonic literature contains a large number of hypotheses which try to explain the mechanism of the formation of planets.

These are based on the rotary motion, gravitational forces and other physical phenomena which arise when particles of gas and dust collide.

The motion of the particles in the primaeval planetary cloud was chaotic. The particles revolved independently around the central body as very small satellites in different directions and planes. In the course of their motion they inevitably collided with each other. However, because the collisions between the solid particles or between particles of dust and molecules of gas were inelastic, it follows that as the kinetic energy was transformed into other forms of energy the total amount of kinetic energy in the planetary cloud diminished as time went on. Mathematical analysis of the development of the planetary cloud under these conditions shows that this proceeds by the flattening out of the cloud and the gradual amalgamation of the material which was originally scattered through space into relatively small bodies (planetesimals), then into coarser formations made up of centres in which the material is collected together and finally into planets. ${ }^{120}$

\section{Ways in which organic compounds could} have arisen during the formation of the Earth.

Most authors devote themselves almost exclusively to the study of the physical aspects of the subject and try to explain 
the peculiarities of the solar system, which have been mentioned above, in this way. In connection with the solution of the problem of the formation of the first organic compounds, which is our present task, special interest attaches to the chemical processes which went on during the formation of the Earth and in the earliest stages of its existence.

The investigations of G. P. Kuiper and the facts put forward by H. C. Urey in his book The planets, their origin and development ${ }^{60}$ are of special value in this connection.

According to Urey the early chemical history of the Earth and the other planets is determined by the following basic factors (cf. Table 1):-

(1) The distribution of the elements in the cosmos, especially the composition of the primaeval solar nebula; (2) the temperatures which prevailed at the various periods of the formation of the Earth ; (3) the gravitational field of a planet in the course of its formation; (4) the properties of the chemical substances taking part in this formation.

We may judge of the composition of the primaeval solar nebula by studying the clouds of dust and gas which exist at present. The predominant element here, as in the cosmos in general, is hydrogen. Helium and the other inert gases are also present, though in considerably smaller quantities. Such elements as carbon, nitrogen, oxygen, iron, calcium. silicon, etc., are present in proportions of $1: 1,000,1: 10,000$ or even less compared with hydrogen. At the extremely low temperatures (near to absolute zero) which prevail in a nebula, only hydrogen, the inert gases and methane can exist in the gaseous state. Oxygen is present in the form of metallic (iron) oxides and water, and nitrogen in the form of ammonia. All these compounds exist in the nebula in the solid state in the form of fine particles of dust which also contain silicates, metallic iron, iron sulphide, etc.

Urey points out that all the free radicals of carbon, nitrogen and oxygen would be transformed into the stable molecules $\mathrm{CH}_{4}, \mathrm{NH}_{3}$ and $\mathrm{H}_{2} \mathrm{O}$ on account of the catalytic action of the dust and the presence of large amounts of hydrogen in the nebula. There would also be formed from the free radicals compounds of high molecular weight characterised by the linkages C-C, N-N, N-C and C-O. 
TABLE 1

\begin{tabular}{|c|c|c|c|}
\hline $\begin{array}{c}\text { Time and } \\
\text { Process Occurring }\end{array}$ & $\begin{array}{l}\text { Phases and } \\
\text { Objects }\end{array}$ & $\begin{array}{l}\text { Chemical } \\
\text { Composition }\end{array}$ & Temperature \\
\hline 1. Solar dust cloud. & Gas & $\mathrm{H}_{2}$, inert gases, $\mathrm{CH}_{4}$ & \\
\hline $\begin{array}{l}\text { Formation of Sun and } \\
\text { disc of gas and dust. }\end{array}$ & Dust & $\begin{array}{l}\text { Silicates, } \mathrm{FeO}, \mathrm{FeS} \text {, } \\
\text { little metallic iron, } \\
\text { solid } \mathrm{H}_{2} \mathrm{O}, \mathrm{NH}_{3} \text {. }\end{array}$ & $\ll 0^{\circ} \mathrm{C}$ \\
\hline $\begin{array}{l}\text { 2. Preprotoplanet and } \\
\text { early protoplanet. }\end{array}$ & Gas & $\begin{array}{l}\mathrm{H}_{2}, \text { inert gases, } \mathrm{H}_{2} \mathrm{O}, \\
\mathrm{NH}_{3}, \mathrm{CH}_{4} .\end{array}$ & \multirow{3}{*}{$0^{\circ} \mathrm{C}$} \\
\hline \multirow{2}{*}{$\begin{array}{l}\text { Accumulation of } \\
\text { planetesimals and } \\
\text { substance of the } \\
\text { Moon. }\end{array}$} & Dust & Silicates, FeO, FeS. & \\
\hline & Planetesimals & $\begin{array}{l}\text { Silicates, } \mathrm{FeO}, \mathrm{FeS} \text {, } \\
\text { hydrated minerals, } \\
\mathrm{NH}_{4} \mathrm{Cl} \text {, solid } \mathrm{H}_{2} \mathrm{O} \\
\text { and } \mathrm{NH}_{3} \text {. }\end{array}$ & \\
\hline
\end{tabular}

3. High-temperature Gas stage. Reduction of iron oxides. Loss of gases and volatilised silicates.

\section{Large planetesi- $\mathrm{Fe}$ mals}
$\mathrm{H}_{2}$, inert gases, $\mathrm{H}_{2} \mathrm{O}$, $\mathrm{N}_{2}, \mathrm{CH}_{4}, \mathrm{H}_{2} \mathrm{~S}$, vola- tilised silicates.

O, hydrated minerals, $\mathrm{FeS}, \mathrm{NH}_{4} \mathrm{Cl}$, some metallic iron,

$\mathrm{C}, \mathrm{Fe}_{3} \mathrm{C}, \mathrm{TiN}$.

\section{Small planetesi- Silicates, metallic mals iron, $\mathrm{C}, \mathrm{Fe}_{3} \mathrm{C}, \mathrm{TiN}$, some FeS.}

4. Second low-tem- Gas perature stage. Final accumulation of the Earth.
Mostly lost. Small amounts of $\mathrm{H}_{2}$, $\mathrm{H}_{2} \mathrm{O}, \mathrm{N}_{2}, \mathrm{CH}_{4}$, $\mathrm{H}_{2} \mathrm{~S}$, inert gases.
$\sim 0^{\circ} \mathrm{C}$

Planetesimals Same as stage 3 .

5. Final stage. Earth Moon Silicates, a little metal- Space $0^{\circ} \mathrm{C}$ and Moon complete. lic iron.

\begin{tabular}{lcc}
\hline Earth & $\begin{array}{c}45 \% \text { metallic iron; } \\
55 \% \text { silicates. }\end{array}$ & $\begin{array}{c}\text { Earth }<900^{\circ} \mathrm{C} \\
\text { going to } \\
\text { present } \\
\text { temperature }\end{array}$ \\
\hline Atmosphere & $\mathrm{H}_{2} \mathrm{O}, \mathrm{CH}_{4}, \mathrm{H}_{2}$, & \\
& $\mathrm{N}_{2} \rightarrow \mathrm{NH}_{3}$. &
\end{tabular}

(After Urey, IV. 6o, p. 217.) 
After the Sun had become a luminescent star and the discoid protoplanetary cloud had been formed, different conditions of temperature were set up in different regions of the cloud. As a result of the radiations of the Sun the clouds became warmer till the temperatures at various distances from the Sun became roughly what they are now.

Urey considers that the combination of particles with one another which took place during the accumulation of dust composing the protoplanetary cloud and the formation of the planetesimals could only have occurred as a result of the coagulating effect of liquids or damp bodies, as occurs when snowballs are made from wet snow.

In the formation of the planets water, ammonia and methane acted as the sticky material. On the basis of his own calculations Urey determined the distances from the Sun at which these substances would condense. It seemed that the condensation of water vapour would occur in the zone between Jupiter and the asteroids, and that of ammonia in the neighbourhood of Saturn but that methane would remain in the gaseous state right out to the orbit of Pluto. In the region of the Earth and Venus, however, the condensation of water and ammonia (especially in the form of $\mathrm{NH}_{4} \mathrm{OH}$ ) might occur in association with local falls in temperature, and this would create the optimal conditions for the accumulation of particles of dust here, while in the region of Mars and the asteroids the crystals of ice were already so dry that they could not effect coagulation.

The planetesimals which were formed in the neighbourhood of the Earth incorporated all the non-volatile substances of the primaeval cloud of dust, the silicates and their hydrates, the oxides and sulphides of iron and other metals, and also ammonium chloride, water and ammonia. In this stage in the formation of the protoplanet which was the forerunner of the Earth it must already have lost a considerable amount of hydrogen, helium and neon while ammonia and the hydrocarbons only escaped partially. Later there occurred adiabatic compression of the gases of the protoplanet leading to an increase in the temperature of its central parts, which rose to nearly $2,000^{\circ} \mathrm{C}$.

As the planetesimals passed through the strongly heated 
gaseous medium their surfaces were heated. In the course of this heating the oxides of iron and the silicates were reduced and the latter became gaseous. The gases escaped and this increased the proportion of iron in the planetesimals. The smallest ones were completely volatilised, the rather larger ones were converted into alloys of iron and nickel while the still larger ones only formed alloys of iron and nickel on their surfaces, their interiors remaining at low temperatures and retaining their original composition. At this stage the 'proto-Earth' lost a considerable part of its mass. According to Kuiper, the mass of the Earth at present. is only $1 / 1,200$ part of that of the original protoplanet.

A considerable increase in the proportion of iron in the Earth resulted from this loss of silicates and other volatile substances. Some water managed to remain on the protoEarth in the form of hydrates of silicates and as condensed water. Nitrogen was retained in the form of metallic nitrides and salts of ammonia, e.g. ammonium chloride. The most stable forms in which carbon was retained were carbides of iron and graphite, for the primaeval hydrocarbons, methane in particular, must have escaped from the zone in which the Earth-like planets were being formed. Thus, at the end of the third postulated (hot) stage in the formation of planets, large amounts of hydrogen, helium, methane, water and nitrogen disappeared from the proto-Earth and its further development proceeded in the absence of any significant quantities of gas. The temperature of all objects on the protoplanet therefore fell very quickly by radiation. Thus the Earth was evidently formed at comparatively low temperatures approaching those of the present day. It was formed somewhere near to the centre of gravity of the protoplanet and included in itself all the bodies which moved around it as satellites.

In this way our planet was accumulated from the planetesimals, which were iron and siliceous bodies similar to the present-day meteorites. The iron nucleus of the Earth differentiated itself from what was originally a nearly homogeneous mass of iron and siliceous phases considerably later, in geological times. At the same early stage too, the Earth must certainly have lost those gases, above all hydrogen, which its 
gravitational field could not hold at the temperatures then prevailing.

In the final fifth stage of the formation of the planet the primaeval atmosphere of the Earth still kept some remnants of its original hydrogen, water, ammonia, methane and hydrogen sulphide. It was thus highly reducing in character. Only hydrogen and traces of inert gases were continually escaping from the atmosphere of the Earth into interplanetary space while the other gases of the primaeval atmosphere were almost completely held by the gravitational force of the Earth at the temperatures then prevailing. The amount of water on the surface of the Earth at the period under discussion must have been considerably less than it is now. According to Urey the total amount of water present on the primaeval Earth was only 10 per cent of that in the present-day oceans. The rest of the water arose during the development of the lithosphere, being derived from the hydrates of silicates and, in general, from the condensed water of the interior of the Earth. ${ }^{121}$

In just the same way the amount of methane in the primaeval atmosphere of the Earth was very small because the greater part of this gas had escaped during the earlier stages in the development of the planet. As we have seen, carbon was still present on the Earth in the form of metallic carbicles and graphite. During the formation of the lithosphere, however, the carbides reacted with the constitutional water of the interior of the Earth to form methane and other hydrocarbons. These separated out from the lithosphere and accumulated in the atmosphere where they were now retained by the force of gravity. There thus occurred at this time the same reactions leading to the abiogenic formation of hydrocarbons which we can even now see taking place to a small extent.

In just the same way the amount of ammonia in the primaeval atmosphere of the Earth was constantly augmented at the expense of ammonium salts and, even more, of nitrides of metals. The probable formation of nitrides at some period in the formation of the Earth is supported by the geological discovery of nitrides of iron in the deep layers of the crust of the Earth (A. Gautier ${ }^{122}$ ) and in volcanic lavas (A. Brun). 
Goldschmidt has shown that a considerable amount of metallic nitrides must also form part of the iron-nickel core of the Earth. The reaction between metallic nitrides and water gives rise to ammonia according to the equation

$$
\mathrm{FeN}+3 \mathrm{H}_{2} \mathrm{O} \rightarrow \mathrm{Fe}(\mathrm{OH})_{3}+\mathrm{NH}_{3}
$$

Geological findings also point to the presence of ammonium salts in the lithosphere. V. Vernadskiî ${ }^{123}$ wrote as follows:

Chlorides and fluorides of ammonium are undoubtedly produced by volcanoes. These can only be partly attributed to the destruction of nitrogenous residues of living material carried away by the lava. Life can in no way be associated with the production of ammonia together with superheated steam (up to $190^{\circ} \mathrm{C}$ ) in the neighbourhood of geysers which arise from depths of no less than 200 metres, such as those in Tuscany in Italy and Sonoma in California. These gases, of magmatic origin, are formed simultaneously with the steam.

Ammoniacal aluminosilicates similar to kaolin apparently exist as isomorphous mixtures of minerals in volcanic and deep igneous formations, and the derivation of the primaeval nitrogen from these sources seems very likely.

By analogy with the carbides and nitrides, sulphides of metals would seem to be the source from which the hydrogen sulphide of the primaeval atmosphere was formed.

The highly reduced atmosphere which has been described could not remain unchanged on the Earth for ever. Only if a planet is very large or the temperature is very low can it hold all its hydrogen (as happens, for example, on Jupiter and Saturn). The Earth does not seem to be large enough for this so, as we have already pointed out, the hydrogen of its atmosphere was always escaping. However, the ultraviolet radiation of the Sun was constantly decomposing water pho:ochemically in the upper layers of the atmosphere. The hydrogen arising from these reactions escaped but the oxygen oxidised ammonia to molecular nitrogen and converted the primitive hydrocarbons into various oxygen-containing organic compounds such as alcohols, aldehydes, ketones and acids; carbon monoxide and carbon dioxide appeared as the final products of this oxidation, and it was from these 
that the first carbonates were formed. At the same time direct photochemical changes of methane and ammonia were going on, for both of them absorb ultraviolet light, methane at a wavelength below $1,45^{\circ} \AA$ and ammonia at a wavelength below 2,250 $\AA$. Under these conditions methane forms hydrogen, higher saturated hydrocarbons and unsaturated hydrocarbons, particularly ethylene. The ethylene thus formed can be converted photochemically into acetylene and a whole series of liquid hydrocarbons. Ammonia is decomposed photochemically into $\mathrm{NH}_{2}+\mathrm{H}$ with the formation of hydrazine $\mathrm{NH}_{2} \mathrm{NH}_{2}$ and other nitrogenous substances. The radicals which were thus formed in the primitive atmosphere of the Earth such as $-\mathrm{CH}_{3},=\mathrm{CH}_{2}, \equiv \mathrm{CH},-\mathrm{NH}_{2},=\mathrm{NH}$, and $-\mathrm{OH}$ reacted with one another, giving rise to a large number of different sorts of organic compounds, the simplest oxygen- and nitrogen-containing derivatives of hydrocarbons. ${ }^{124}$

The oxygen which was produced by the photolysis of water must have reacted not only with ammonia and hydrocarbons but also with other reduced substances, for example by oxidising hydrogen sulphide and metals, particularly iron. Thus, in spite of the continued photolysis of water and escape of hydrogen, free oxygen did not appear in the atmosphere of the Earth in significant amounts for a long time.

On the basis of a study of the distribution of the isotopes of sulphur in its oxidised and reduced compounds H. G. Thode and colleagues ${ }^{125}$ reached the conclusion that the original transition of the atmosphere of the Earth from the reduced to the oxidised state occurred only 700 or 800 million years ago, that is to say, at a time when, according to all the evidence, life already existed on the Earth and photosynthesis may even have begun.

On the basis of a study of the abundances of isotopes of lead and other elements various authors have given estimates of the age of the Earth ranging from 3.4 to $5.3 \times 10^{9}$ years. ${ }^{126,127}$ It follows that for at least $2-3 \times 10^{9}$ years the atmosphere of the Earth was reduced, or undergoing gradual transition to the oxidised state, and that under these conditions there occurred on the surface of the Earth the abiogenic formation first of the simplest and later of more complicated organic compounds. 
As we shall see later, this primitive way of carrying out organic syntheses abiogenically was very ineffectual, it was slow and circuitous. It occupied thousands of millions of years. This was the first and most primitive epoch of purely chemical synthesis of organic substances on the Earth and it extended throughout the greater part of the history of the planet. It is only 700 or $800 \times 10^{6}$ years since a new and far more efficient method of synthesis of organic materials, photosynthesis, was elaborated on the Earth on the basis of the emergence and later development of a new form of the motion of matter, namely life. This process made use of the enormous resources of energy of the sunlight, and the actual synthesis was not haphazard as it had been before but was carried out by the extremely highly-organised succession of events which we call biological metabolism. As always occurs in the history of the development of matter, this new and efficient method, once it had developed, superseded the old inefficient way of synthesising organic substances abiogenically so that now it is only with difficulty that we can discover even the slightest manifestations of it.

We are now living in the second, biological, epoch of the history of our planet in which green plants almost monopolise the synthesis of organic substances.

When man began to practise cultivation, he achieved great progress in making plants produce larger and larger amounts of organic substances. However, all this progress, which has been extremely important in human history, occurred within the framework of what we have called the second epoch, that of biological synthesis of organic substances. It is all based on the formation of such substances by the green leaf using the energy of sunlight.

The contemporary development of science, however, justifies the belief that we are on the threshold of a new, third, epoch in the history of our planet. The control of nuclear energy opens up to mankind the possibility of using this energy to synthesise organic substances directly from carbon dioxide at any place or time, independently of the season or the weather and without having to use enormous areas of the surface of the Earth and other resources.

In principle this new way of synthesising organic com- 
pounds is a great improvement on the biological method, just as the speed of aeroplanes at present is an improvement on that of the earlier horse-drawn carriages of the time of Dickens.

However, this new and efficient method of synthesis of organic substances can only arise on the basis of a tremendous development in human society; on the basis of new social forms which are far higher and more efficient than the biological ones. It will therefore gradually supersede the old method of photosynthesis which now seems efficient and even the only possible method. Certainly this is still only a dream, but it is already a dream with a scientific foundation and it shows what tremendous vistas of a cosmic nature are opening out before mankind as the result of a wise and progressive use of the achievements of science.

\section{BIBLIOGRAPHY TO CHAPTER IV}

1. C. Sterne. Entwicklung der Erde und des Kosmos, der Pflanzen und der wirbellosen Tiere. Leipzig, 1905.

2. J. J. Berzen.1us. Lehrbuch der Chemie (übers. K. A. Blöde und K. Palmstedt). Vol. 3. Dresden, 1827 .

3. F. Wöhler. Ann. Phys., Lpz., I2, 253 (1828).

4. Quoted by E. HJeLt. Geschichte der organische Chemie von ältester Zeit bis zum Gegenwart. Braunschweig, 1916. A. Arbuzov. Kratkil ocherk razvitiya organischeskol khimii v Rossii. Moscow and Leningrad (Izd. AN SSSR), $194^{8}$.

5. A. Bernthsen. Kurzes Lehrbuch der organische Chemie (8 Aufl.). Braunschweig, 1902.

P. Karrer. Lehrbuch der organischen Chemie (4 Aufl.). Leipzig, 1936.

6. C. Schorleminer. The rise and development of organic chemistry. (Revised edition.) London, 1894.

7. A. Chichubabin. Osnovnye nachala organicheskol khimii. Moscow (Goskhimizdat), 1954 .

8. K. Thiniryazev. Sochineniya. Vol. 4, p. 161. Moscow (Sel'khozgiz), $193^{8}$.

9. S. Winogradsky. Bot. Ztg, 45, 489, 6o6 (1887); 46, 262 (1888).

10. S. Vinogradskiř. O roli mikrobov $\mathrm{v}$ obshchem krugovorote zhizni. Address to General Assembly of Members of Imperial Institute of Experimental Medicine $(8 / 12 / 1896)$. St. Petersburg, 1897 . 
11. J. Liebig. Die organische Chemie in ihrer Anwendung auf Agricultur und Physiologie. Braunschweig, 1840.

12. E. I. Rabinowitch. Photosynthesis and related processes. New York, 1944, 1951, 1955 .

YU. I. Sorokin. Personal communication about work at scientific research station 'Borok'.

13. H. PotoniÉ. Die Entstehung der Steinkohle und der Kaustobiolithe überhaupt. Berlin, 1920.

Yu. Zhemchuzhnikov. Obshchaya geologiya iskopaemykh uglě. (2nd edn.) Moscow (Ugletekhizdat), 1948.

14. M. Bertuelot. Bull. Soc. chim. Paris, II, 278 (1869).

15. D. Mendereev. Neftyanaya promyshlennost' v Sev. Amerikanskom shtate Pensil'vanii i na Kavkaze. St. Petersburg (Izd. 'Obshchestvennaya Pol'za'), 1877.

16. C. Engler and H. H. v. Heimhalt (ed.). Das Erdöl Bd. 1. Leipzig, 1913.

17. A. D. ARkhangeL'skiľ. Usloviya obrazovaniya nefti na Severnom Kavkaze (seriya Neftyanoe Khozyǎstvo). Moscow, 1927.

18. V. I. Vernadskiř. Ocherki geokhimii. Moscow (Gosgorgeoneftizdat), 1934 .

19. N. D. Zelinskir. In the Jubilee Volume: Akademiku V. I. Vernadskomu $k$ 5o-letiyu nauchnoř $i$ pedagogicheskor deyatel'nosti (ed. A. P. Karpinskiǐ and A. E. Fersman), p. 875. Moscow and Leningrad (Izd. AN SSSR), $193^{6 .}$

20. G. Stadnikov. Proiskhozhdenie uglel $i$ nefti. Moscow and Leningrad (Izd. AN SSSR), 1937.

21. I. Gubkin. Uchenie o nefti. Moscow and Leningrad (ONTI), 1937.

22. H. Craig. Geochim. et Cosmochim. Acta, 3, 53 (1953).

23. (III. 22).

24. (III. 23).

25. (III. 24).

26. (III. 13).

27. (III. 14).

28. V. Omelyanskil. Osnovy mikrobiologii. Petrograd (Gosiz-

29. (III. 15). dat), 1922.

30. (II. 5).

31. V. Komarov. Proiskhozhdenie rastenii. Moscow and Lenin$\operatorname{grad}($ Izd. AN SSSR), 1936. 
32. D. D. Woons and J. LAscelles in Autotrophic micro-organisms (ed. B. A. Fry and J. L. Peel), p. 1. Cambridge, 1954 .

33. A. PAscher. Flagellaten und Rhizopoden in ihren gegenseitigen Beziehungen. Jena, 1917.

34. C. H. Werkian and H. G. Wood. Advanc. Enzymol., 2, 135 (1942).

35. M. Stephenson. Bacterial metabolism (3rd edn.). London, 1949.

36. W. O. Kermack and H. Lees. Science Progr., 4o, 44 (1952). 37. A. Lebedev. Issledovanie khemosinteza $u$ Bacillus hydrogenes. Odessa (Tip. Shtaba Okruga), 1910.

W. Ruhland. Jb. wiss. Bot., 63, 321 (1924).

38. K. G. Vogler. J. gen. Physiol., 25, 617 (1942).

39. W. W. Umbreit. Bact. Revs., II, 157 (1947).

40. Yu. I. Sorokin. Mikrobiologiya, 25, 363 (1956).

41. V. Dogel'. Obshchaya protistologiya. Moscow (Izd. 'Sov. Nauka '), $195^{1}$.

42. L. Kursanov, N. Komarnitskiň, K. Meǐer, V. Razdorskiľ and A. Uranov. Botanika, Vol. 2. Moscow (Izd. 'Sov. Nauka '), 1951 .

43. A. Lwoff (ed.). Biochemistry and physiology of Protozoa. Vol. 1. New York, 1951.

44. A. Elenkiv. Notul. syst. Inst. cryptog. Horti bot. petropol., 3, $171(1924)$.

45. A. Zakhvatkin. Sraunitel'naya embriologiya nizshikh bespozvonochnykh. Moscow (Izd. 'Sov. Nauka'), 1949.

46. A. Markevich. Problema proishhozhdeniya prostěshikh Protozoa. Kiev (Izd. Kiev Univ.), 1954.

47. A. I. Oparix. Communication to meeting of Russian Botanical Society. Moscow, 1922.

48. H. A. Bethe. Phys. Rev., 55, 434 (1939); Nature (Lond.), I43, 904 (1939).

49. J. S. Plasketr. Publ. Dom. astrophys. Obs., Ottazia, 2, no. 16, 287 (1924).

5o. F. Henroteau and J. P. Henderson. Publ. Dom. Obs., Ottawa, 5, no. 1, p. 1 (1920).

F. Henroteau. Publ. Dom. Obs., Ottawa, 5, no. 8, p. 331 (1922).

51. E. P. Waterman. Lick Obs. Bull., 8, no. 243, p. 1 (1913).

52. W. C. Rufus. Publ. astr. Obs. Univ. Mich., 2, 103 (1916).

R. F. SANford. Publ. astr. Soc. Pacif., 4I, 271 (1929). 
53. G. Shaǐn. Vestnik Akad. Nauk S.S.S.R., no. 10, p. $5^{2}$ (1940).

G. A. SHAǏN and V. F. GAZE. Doklady Akad. Nauk S.S.S.R., 68,661 (1949).

A. Daudin and C. Fehrenbach. C.R. Acad. Sci., Paris, 222, 1083 (1946).

54. H. V. KLüBeR. Das Vorkommen der chemischen Elemente im Kosmos. Leipzig, 1931.

55. O. Struve. J. Wash. Acad. Sci., 31, 217 (1941).

V. G. Fesenkov. Meteornaya materiya v mezhplanetnom prostranstve. Moscow and Leningrad (Izd. AN SSSR), 1947 .

G. A. Shaǐn and V. F. Gaze (Shajn and Gase). Trans. int. astr. Un., 8, 693 (1952).

56. L. Spitzer and M. P. Savedoff. Astrophys. J., III, 593 (1950).

57. L. Gurevich. In Voprosy kosmogonii (ed. B. V. Kukarkin). Vol. 3, p. 94. Moscow (Izd. AN SSSR), 1954.

58. V. Sofronov. Review in Voprosy kosmogonii (ed. B. V. Kukarkin). Vol. 2, p. 275. Moscow (Izd. AN SSSR), 1954 .

59. H. Kramers and D. Ter HaAR. Bull. astr. Insts Netherlds, Io, 137 (1946).

6o. H. C. UREY. The planets, their origin and development. New Haven, Conn., 1952.

61. D. R. Bates and L. Spitzer. Astrophys. J., II3, $44^{1}$ (1951).

62. H. N. Russell. The solar system and its origin. New York, 1935 .

63. G. P. KuIPER (ed.) The atmospheres of the Earth and planets (revised edition). Chicago, 1952.

64. A. Adel and V. M. Slipher. Phys. Rev., 46, g02 (1934).

65. G. P. Kuiper. Astrophys. J., 100, 378 (1944).

66. F. W. Clarke. Prof. Pap. U.S. geol. Surv., 132D, $5^{1}$ (1924).

67. H. S. Washington. Amer. J. Sci. (ser. 5), 9, 351 (1925).

68. V. M. Goldschmidt. Geochemische Verteilungsgesetze der Elemente. Oslo, 1938.

69. I. Noddack and W. NodDack. Naturwiss., 18,757 (1930).

70. A. Fersman. Geokhimiya. Vols. 1 and 2. Moscow (ONTI), 1934.

71. H. Brown and C. Patterson. J. Geol., 55, 405 (1947).

72. H. C. Urey and H. Craig. Geochim. et Cosmochim. Acta, 4, 36 (1953).

73. P. N. ChirvinskiY. Meteoritika, Io, 67 (1952).

74. S. Orlov. Vestnik Moskov. Univ. Ser. Fiz.-Mat. i Estestven. Nauk, I I, 43 (1949). 
75. V. G. Fesenkov. Meteoritika, $8,3^{8}$ (1950).

76. A. N. Zavaritskiľ. Meteoritika, 8 , 100 (1950).

77. R. A. Daly. Bull. geol. Soc. Amer., 54, 401 (1943).

78. B. Yu. Levin. Meteoritika, II, 47 (1954); Sbornik voprosy unutrennogo stroeniya $i$ rasvitiya Zemli (ed. V. V. Belousov), p. 11. Moscow (Izd. AN SSSR), 1955.

79. I. Astapovich and V. Fedynskiľ. Meteory. Moscow and Leningrad (Izd. AN SSSR), $194^{\circ}$.

8o. L. G. Kvasha. Meteoritika, $4,8_{3}$ (1948).

81. A. V. Trofmov. Meteoritika, 8, 127 (1950).

82. Quoted in (IV. 54, p. 54).

$82^{\text {a }}$. F. Wöhler. S.B. Akad. Wiss. Wien, 33, 205; 34, 7 (1859).

83. P. G. Melikov and V. Krshizinavorskiř. Ammu. géol. min. Russ., 2 (Otd. 3), p. 109 (1897); J. Soc. phys.chim. russe, 28 (Chem.), 651 (1896).

84. J. L. Sмiтh. Original researches in mineralogy and chemistry'. Louisville, Ky., 1884 ; (II. 29).

85. F. L. Whipple. Astrophys. J., III, 375 (1950).

86. O. Sнмnт. Trudy geofizicheskogo Instituta A.N.S.S.S.R., 26, $5(1955)$.

87. V. Lodochnikov. Zapiski Vserossiǔskogo Mineralog. Obshchestva (Ser. 2), Part 68 (no. 2), 207 (1939).

88. G. Forchnammer. Overs. danske Vidensk. Selsk. Forh., I, I $(1854)$.

89. M. Neumayr. Erdgeschichte (2 Aufl.). Leipzig, 1895 .

9o. (J.) L. Suith. Ann. Chim. (Phys.), (Sér. 5), I6, 452 (1879).

91. R. T. Chamberlin. Fubl. Carneg. Instn, no. 106 (1908).

92. V. Vernadskiľ. Ocherki geokhimii. Moscow (Gorgeonefteizdat), 1934 .

93. (IV. 14).

94. H. Aвich. Jb. geol. Reichsanst., Wien, 29, 177 (1879).

95. H. Moissan. C.R. Acad. Sci., Paris, I22, 1462 (1896).

96. D. Mendeleev. Osnoyy khimii. Vol. 1, p. 379. Moscow and Leningrad (Gosizdat), 1927 .

97. Proiskhozhdenie nefti (ed. M. F. Mirchink, A. A. Bakirov, B. F. D'yakov and D. V. Zhabrev). Moscow (Gos.

Nauch. Tekh. Izd. neft. i gorn. topl. Lit.), 1955.

98. H. Hahn. Liebigs Ann., I29, 57 (1864).

99. S. Cloez. C.R. Acad. Sci., Paris, S6, 1248 (1878).

100. K. V. Kharichiov. J. Soc. phys.chem. russ., 28 (Chem.), 825 $(1896) ; 29$ (Chem.), 151 (1897).

101. V. Ipat'ev. Neft' $i$ ee proiskhozhdenie. St. Petersburg (Izdatel'stvo A. Panafidinoí), 1914. 
102. (III. 61).

103. N. Kudryavtsev. Neftyanoe Khoz., 9, 17 (1951).

104. P. Kropotkin. In Sovetskaya geologiya, Part 47, p. 104. Moscow (Gos. nauch. tekh. Izd. vo Geol. Okhrani Nedr), 1955 .

105. W. Herschel. Quoted by A. Berry. A short history of astronomy. London, 1898.

106. P. S. Laplace. Exposition du système du monde. Paris, 1796.

107. V. Ambartsumyan (Ambartsumian). Trans. int. astr. Un., 108. (II. 13). $8,665(1952)$.

109. J. H. Jeans. Astronomy and cosmogony. Cambridge, 1928. 110. (IV. 62).

1 10a. N. N. PARiřskiľ. Astron. Zhur., 20, 9 (1943); 2I, 69 (1944).

111. I. Kant. Allgemeine Naturgeschichte und Theorie des Himmels. Königsberg, 1755 .

112. C. F. V. Weizsäcker. Z. Astrophys., 22, 319 (1944).

113. D. Ter HaAr. Rev. mod. Phys., 22, 19 (1950).

114. S. Chandrasekhar. Rev. mod. Phys., I8, 94 (1946); Introduction to the study of stellar structure. Chicago, 1939 .

115. O. SHMDт. Chetyre lektsii o teorii proiskhozhdeniya Zemli. Moscow (Izd. AN SSSR), $195^{\circ}$.

116. E. Shatsman. In Voprosy kosmogonii (ed. B. V. Kukarkin). Vol. 3, p. 227. Moscow (Izd. AN SSSR), 1954.

117. V. Fesenkov. In Trudy I-go soveshchaniya po voprosam kosmogonii, p. 35. Moscow (Izd. AN SSSR), 1951.

118. B. J. Bok and E. F. Reilly. Astrophys. J., 105, 255 (1947). 119. O. Struve. Stellar evolution: an exploration from the observatory. Princeton, N.J., $195^{\circ}$.

120. L. Gurevich and A. Lebedinskiľ. Izvest. Akad. Nauk S.S.S.R. Ser. Fiz., 14, 765 (1950) ; Astron. Zhur., 27, 273 (1950); also in Voprosy kosmogonii (ed. B. V. Kukarkin), Vols. 2 and 3. Moscow (Izd. AN SSSR), 1954 .

G. Kurl'iı. 200 let nauchnor kosmogonii. Moscow (Izd.

'Znanie'), 1955.

121. W. W. Rubey. Bull. geol. Soc. Amer., 62, 1111 (1951).

122. A. Gautier. Ann. Min., Paris, (sér. 10), 9, 316 (19o6).

123. (IV. 92). 
124. W. A. Noyes (JR.) and P. A. Leighton. The photochemistry of gases. New York, 1941.

G. K. Rollefson and M. Burton. Photochemistry and the mechanism of chemical reactions. New York, 1939. 125. A. Szabo, A. Tudge, A. Macnamara, and H. G. Thode. Science, $x I I, 464\left(195^{\circ}\right)$.

126. A. Holmes. Rep. Smithson. Instn, 1978, p. 227.

127. F. F. Koczy. Nature, Lond., 15I, 24 (1943). 



\section{ABIOGENIG ORGANIC-CHEMICAL EVOLUTION OF GARBON COMPOUNDS}

\section{Thermodynamics and kinetics of the transformation of the simplest hydrocarbons in the lithosphere, atmosphere and hydrosphere of the Earth.}

As was pointed out at the end of Chapter IV, the Earth, during a considerable period of its existence, was devoid of life. During a substantial part of this time, those many millions of years which separate the time of the formation of the Earth from the appearance of life on it, there took place the abiogenic, organic-chemical evolution of carbon compounds. Hydrocarbons and their simplest nitrogen- and oxygen-containing derivatives began to be found on the surface of the Earth, as has been shown above, at the very earliest stage of its existence. Howrever, these compounds were only the starting point, the first link in a long chain of diverse organic-chemical reactions which now began and which led to the formation in the atmosphere and the hydrosphere of the Earth of a large number of varied compounds, some of which were of complicated structure and high molecular weight, similar to the substances entering into the composition of present-day animals and plants.

The basic requirements for this second stage of the development of matter from the simplest hydrocarbons to the most complicated organic compounds were inherent in the original hydrocarbons themselves. Hydrocarbons possess enormous chemical potentialities. It is with good reason that the whole of organic chemistry is today regarded as the chemistry of hydrocarbon derivatives. The diagram (Fig. 11), ${ }^{1}$ showing the free energies of formation of organic compounds, demonstrates clearly the thermodynamic possibility of the passage from hydrocarbons to their oxygen- and nitrogen-containing derivatives. Polymerisation and condensation of these derivatives could then give rise to more 


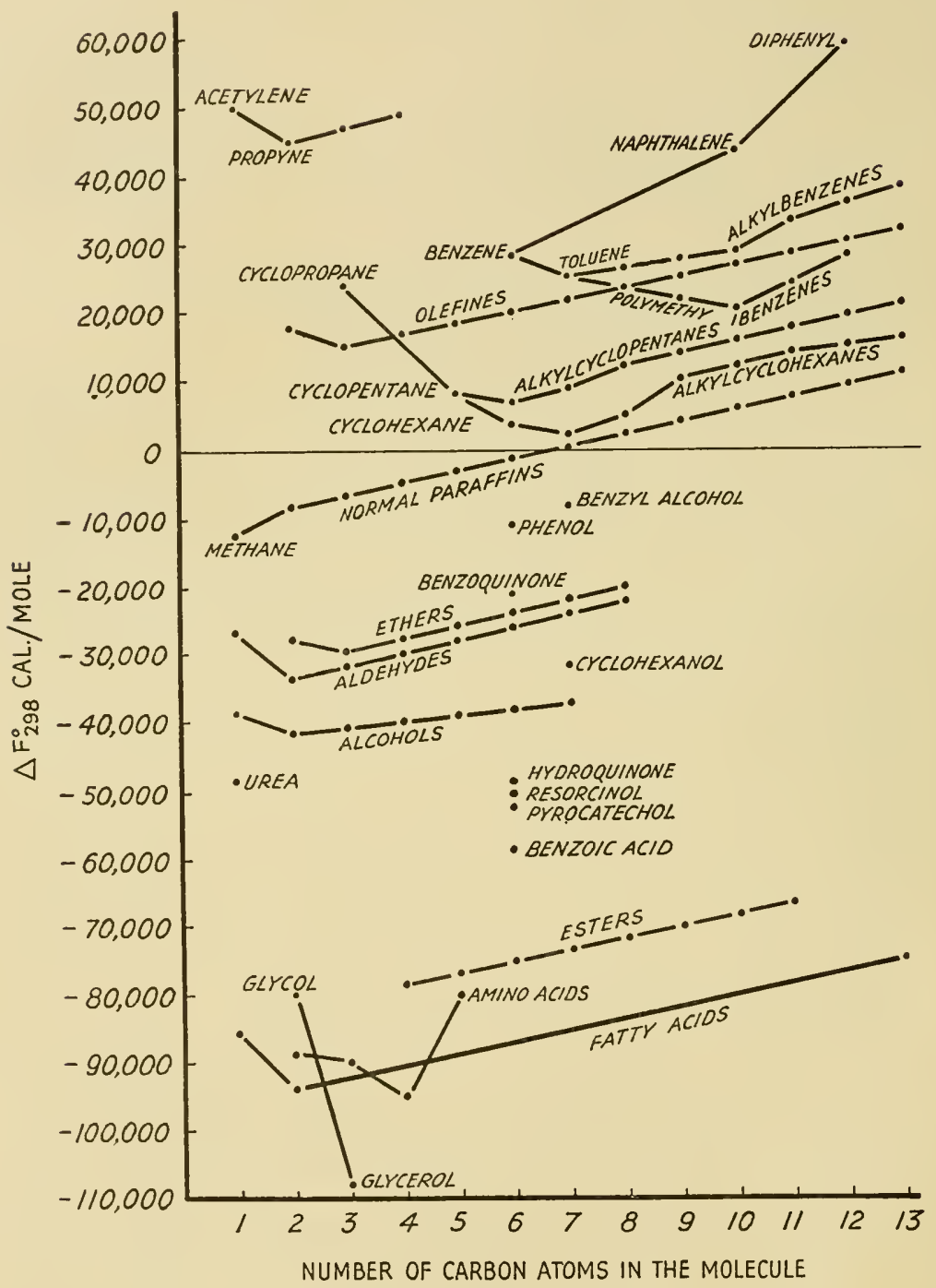

FIG. 11. Diagram of the free energy of organic compounds. 
and more complicated organic compounds on the surface of the Earth when it was still devoid of life. But when one proceeds beyond asserting in principle the possibility of organic-chemical evolution, it is indeed a difficult task to trace the actual paths along which such evolution proceeded during that remote epoch when the Earth was uninhabited by living organisms.

At first sight it might seem that a simple and reliable approach to solving this problem would be through geological and, especially, geochemical study. One could observe, under natural conditions, the changes which carbon compounds today undergo on the surface of the Earth in the absence of living matter, and make detailed chemical study of these changes. Such investigations could, indeed, give valuable results in the long run. However, it must be remembered that the emergence of life and, especially, of photosynthesis, has markedly changed all the conditions which exist on the surface of the Earth. At the present time, under natural conditions, we cannot directly observe many of those phenomena which manifested themselves in the past. Moreover, new processes have now appeared which were absent from the surface of the Earth when it was devoid of life. Consequently we should be wrong to apply, in a simple and mechanical fashion, the data of contemporary geochemistry to the remote early period of the existence of the Earth. We cannot use these data as they stand but must amend them by making free use of laboratory experiments in the attempt to reproduce artificially the various conditions which have been postulated as occurring on the primaeval Earth. We must then investigate the transformation which organic substances undergo when they are exposed to these conditions.

As was pointed out in the previous chapter, the picture of the formation of the Earth which is at present favoured by scientists is that it took place at comparatively low temperatures, of the same order as those at present prevailing here. Even from the earliest period of its existence, the Earth had a firm surface, an aqueous envelope (the hydrosphere) and a gaseous envelope (the atmosphere). The temperature of the firm surface will have depended very much on the radio- 
active decay of the actinouranium and of one of the isotopes of potassium present there; later on, it will have been determined more by that of uranium and thorium. In consequence of this, the interior of the Earth became heated, reaching at some points temperatures of the order of $1,000^{\circ} \mathrm{C}$ or more. At the high pressures which also prevailed, there resulted a redistribution of the substances present-the heavier aggregates, rich in iron, sank inwards, while those that were lighter (silicates) floated towards the surface. This led to the formation of the crust of the Earth, the lithosphere, as a result of the lighter rock formations being squeezed out in a molten state on to the surface of the planet. This process continued throughout geological time and cannot even now be regarded as at an end.

Intimately linked with the formation of the lithosphere is the development of the hydrosphere and of the primaeval atmosphere of the Earth. ${ }^{2}$ The amount of water present on the surface of the Earth was much less than that now present. This was gradually increased by the decomposition of hydrates and the liberation of water of constitution from the interior of the Earth. ${ }^{3,4}$

The hydrosphere was also markedly different in its chemical composition. The waters of the primitive seas and oceans were poorer in inorganic salts than are their present-day counterparts. The migration of the elements which make up these salts only proceeded rather slowly, chiefly as a result of the natural circulation of water. This migration was a very important preliminary stage in the development of life.

The temperature both of the hydrosphere and of the atmosphere was largely determined by the radiation reaching the Earth from the Sun. The strength of this seems scarcely to have changed during the whole period in which the Earth has existed.

The principal qualitative difference from present-day conditions was in the composition of the primaeval atmosphere. The atmosphere to-day has an oxidising character, being very rich in free molecular oxygen. But the overwhelming bulk of this gas was formed, and continues to be formed, biogenically, as a result of the activity of green plants. The total amount of oxygen in the present-day terrestrial atmosphere 
may be taken to be about $2.8 \times 10^{14}$ tons. According to calculations of E. Rabinowitch, ${ }^{5}$ the entire vegetation of the globe prorluces by photosynthesis $1.2 \times 10^{11}$ tons of oxygen in the course of one year. It follows that the entire amount of free oxygen in the atmosphere could be produced by vegetation in roughly 2,000 years-a period which is completely insignificant in relation to the thousands of millions of years during which the Earth has existed. As early as $1856 \mathrm{C}$. Koene ${ }^{6}$ put forward the theory that the entire oxygen of the atmosphere owes its origin to photosynthesis by green plants. This idea was supported by many later authorities. It was, however, handled in a specially detailed way by $\mathrm{V}$. Vernadskir. ${ }^{7}$ Basing his arguments on a whole series of geochemical facts, Vernadskir demonstrated the biogenic origin of the oxygen in the present-day atmosphere.

There is also, in the scientific literature, considerable discussion of the possibility of formation of molecular oxygen by an inorganic mechanism. In particular, G. Tammann ${ }^{8}$ and, later, R. Wildt ${ }^{9}$ pointed out that a certain amount of oxygen might have been formed by thermal dissociation of water. This theory was not, however, sufficiently soundly based, and has met with serious opposition from the majority of geologists and chemists. In any case, such oxygen as might have been formed in this fashion would immediately have been absorbed by mineral formations which were unsaturated in respect of this element.

There is much more in favour of the view that water undergoes photolysis in the uppermost layers of the atmospliere under the influence of ultraviolet radiation. S. Arrhenius $^{10}$ discussed this possibility, and it has since been considered by V. M. Goldschmidt, ${ }^{11}$ W. Groth and H. Suess, ${ }^{12}$ J. H. J. Poole, ${ }^{13}$ N. R. Dhar ${ }^{14}$ and others.

According to $\mathrm{G}$. Rathenau, ${ }^{15}$ water vapour absorbs in the ultraviolet at wavelengths $1,780 \AA, 1,540 \AA$ and $1,34^{\circ} \AA$ (according to R. Mecke. ${ }^{16}{ }_{1,390} \AA$ ). As early as 1910 A. $\operatorname{Coehn}^{17}$ described the direct photochemical decomposition of water into hydrogen and oxygen on ultraviolet irradiation of water vapour. The equation is :

$$
\mathrm{H}_{2} \mathrm{O}+\mathrm{H}_{2} \mathrm{O} \stackrel{\text { light }}{\longrightarrow} 2 \mathrm{H}_{2}+\mathrm{O}_{2}
$$


Later, the ultraviolet photolysis of water under a variety of conditions was observed by A. Tian, ${ }^{18} \mathrm{H}$. Neuǐmin and A. Terenin, ${ }^{19}$ and by several other workers.

P. Harteck and J. H. D. Jensen ${ }^{20}$ tried to calculate the total quantity of oxygen which might have been formed photochemically in the upper layers of the atmosphere during the entire period of existence of the Earth (which they estimated as $3 \times 10^{9}$ years) if hydrogen had been constantly escaping into space. The calculated quantity of oxygen was many tens of times that now present in the atmosphere. If this were so, such extensive abiogenic photochemical production of oxygen would speak against the idea that atmospheric oxygen owes its origin exclusively to photosynthesis by plants.

However, later determinations of the content of water vapour in the cold upper layers of the atmosphere, particularly those by G. M. B. Dobson, ${ }^{21}$ failed to confirm the calculations of Harteck and Jensen. The results of $\mathrm{H}$. E. Moses and $\mathrm{Ta}-\mathrm{You} \mathrm{Wu}^{22}$ on the recombination of oxygen with hydrogen were also in conflict with them. Thus, it appears that, during the entire period of existence of the Earth, there could not have been formed by inorganic, abiogenic means a quantity of free oxygen vastly exceeding that present in the atmosphere of to-day.

\section{Reducing conditions.}

It follows that it was the emergence of life itself and the appearance of biogenic photosynthesis which established on the surface of the Earth the markedly oxidising conditions under which we now live. Up till this time reducing conditions prevailed on the lifeless Earth, under which oxygen can only be supposed to have occurred in the combined state, in the form of water, metallic oxides, silicates, aluminosilicates, etc. The following compounds were of special importance ${ }^{23}$ : $\mathrm{Fe}_{2} \mathrm{~S}_{1} \mathrm{O}_{4}, \mathrm{MgSl}_{3}, \mathrm{Ca}_{3}\left(\mathrm{AlO}_{3}\right)_{2} \cdot \mathrm{H}_{2} \mathrm{O}, \mathrm{Al}(\mathrm{OH})_{3}$. At the same time substantial amounts of metals and other substances existed, in whole or in part, in the reduced state, since no oxygen was available for combination with them.

The comparatively small amounts of free oxygen formed by the photolysis of water in the upper layers of the atmo- 
sphere were now taken up by incompletely oxidised substances. This completely prevented any accumulation of oxygen in the atmosphere of the Earth before life had appeared. Even now, when the reserves of free oxygen in the atmosphere are continually being replenished by green plants, it is only the outermost skin of the crust of the Earth which is oxidised. The deeper formations remained in a strongly reduced state, combining avidly with oxygen. This may be illustrated by the well-known fact that lava and basalt are black, green and grey, showing that they contain iron in an incompletely oxidised state. The sedimentary formations such as clays and sands, on the other hand, are red or yellow in colour. In these the iron is fully oxidised. Thus, oxygen is gradually being taken up before our very eyes in the transformation of igneous into sedimentary formations and it is only the process of photosynthesis which continually replenishes the atmosphere with this gas. According to the calculations of V. M. Goldschmidt, ${ }^{24}$ if all the plants on the Earth were suddenly destroyed the free oxygen of the atmosphere would disappear within a few thousands of years, a very short time on the geological scale; it would be taken up by incompletely oxidised minerals.

However, even in such a case, the Earth, though bereft of life, would not return to its original state. The oxidised conditions brought into being by life would leave indelible traces on its surface in the shape of oxidised rock formations. This applies particularly to carbon compounds. Under the reduced conditions prevailing on the primaeval Earth carbon existed mainly in the form of carbides, graphite and hydrocarbons.

The appearance of free oxygen created the conditions under which hydrocarbons could be oxidised. The final stage in this process was the formation of carbon dioxide, but this could not accumulate in significant amounts in the atmosphere because it reacted with the silicates of the lithosphere and was held there as carbonates ${ }^{25}$ in accordance with such an equation as $\mathrm{MgSiO}_{3}+\mathrm{CO}_{2} \rightarrow \mathrm{MgCO}_{3}+\mathrm{SiO}_{2}$.

The process of the formation of carbonates was greatly intensified after the appearance of life, and the crust of the Earth now contains enormous deposits of carbonate-contain- 
ing formations which serve to replenish the atmosphere with carbon dioxide during all sorts of plutonic processes. It is for this reason that the only carbon compound which is present in quantitatively significant amounts in volcanic gases and the volatile constituents of magma is $\mathrm{CO}_{2}$, while hydrocarbons are present sometimes, but only as traces. It was on the basis of such observations that many authors (e.g. ${ }^{26,27}$ ) who had not taken into account the difference between the conditions formerly present on the surface of the Earth and those which now prevail, accepted carbon dioxide as the primary compound from which all further organic evolution proceeded. For example, H. Borchert ${ }^{28}$ referred directly, in his discussion of the matter, to the composition of the volcanic gases of the Hawaiian islands and also to the considerable preponderance of $\mathrm{CO}_{2}$ over $\mathrm{CO}$ and $\mathrm{CH}_{4}$ in the gases which emerge from the inside of the Earth in molten formations and, when these crystallise, become part of the atmosphere.

But V. Vernadskii ${ }^{29}$ in his Outlines of geochemistry had already pointed out that the carbon dioxide which is formed in enormous amounts at times of volcanic eruption and in quiescent volcanic areas is 'juvenile' only in the sense that it originates from ' juvenile' regions (deep layers of the crust of the Earth or magmatic foci). Its appearance is, however, due to the decomposition of previously formed carbonates, which is brought about at the high temperatures of the deep layers of the crust of the Earth and through the melting of metamorphic formations (Fig. 12).

Urey $^{30}$ was also quite right when, in criticising Poole, he pointed out that one cannot understand how carbon dioxide could have been formed from the graphite, methane or carbides of the interior of the Earth under the reducing conditions which existed on the primaeval Earth.

Only by ignoring the changes which have come about on the surface of the Earth since it became inhabited by organisms, by mechanically transferring present conditions to the remote past, can one explain the fact that many authors writing on the subject of the origin of life based their arguments on the assumption that carbon dioxide was the primary compound of carbon. As a result of this they met with 
unnecessary difficulties such as the need to discover the conditions under which a completely oxidised compound $\left(\mathrm{CO}_{2}\right)$ could be converted into organic compounds of high energy. These investigators devoted the greater part of their attention to resolving these problems although what they should, in fact, have explained first was how carbon dioxide itself could arise under the conditions present on the primaeval Earth.

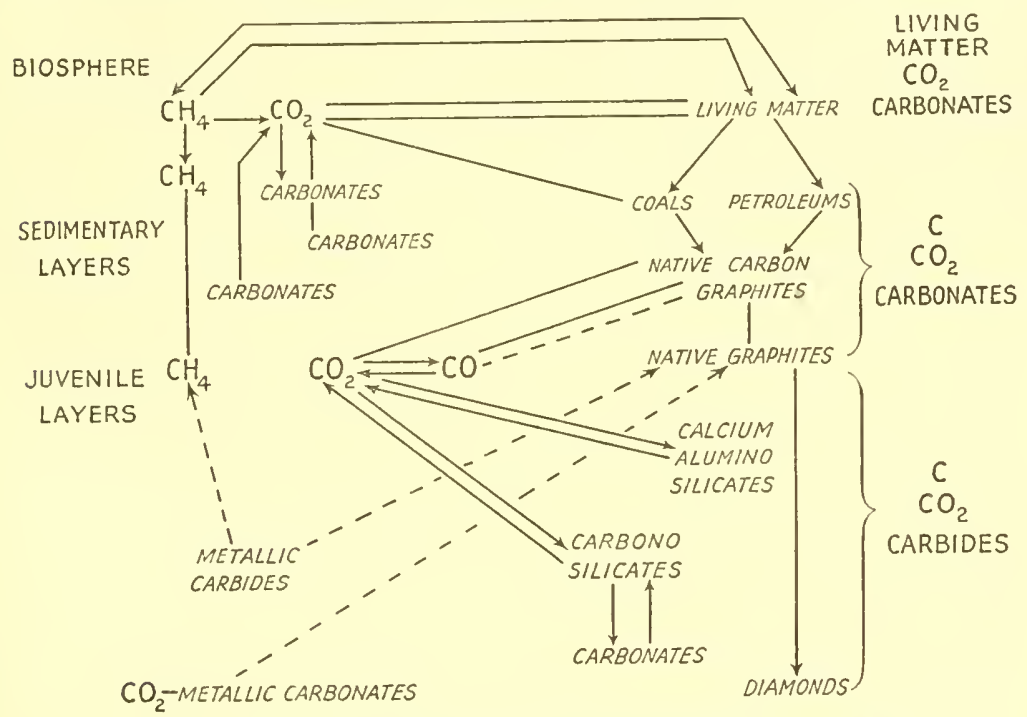

FIG. 12. The circulation of carbon (after Vernadskiǐ).

\section{Sources of energy.}

Nevertheless these investigations are of great interest to us in spite of the false assumptions on which they were based because they revealed the sources of energy which could be used on the primitive Earth, if not for the reduction of carbon dioxide, then for the oxidation and transformation of the primaeval hydrocarbons.

Solar radiation would seem to have been the greatest source of energy on the surface of the Earth. The over-all amount of energy of the solar radiation reaching the outer limits of the atmosphere is $1.2 \times 10^{21} \mathrm{kcal} /$ year. $^{31}$ About 55 per cent of this energy is absorbed by the atmosphere and ground and, after a number of transformations, it leaves the Earth 
in the form of infra-red radiations. The rest is reflected unchanged into space. ${ }^{32}$

According to A. E. H. Meyer and F. O. Seitz, ${ }^{33} 6 \cdot 3$ per cent of all the solar radiation reaching the outermost layers of the atmosphere is in the form of ultraviolet radiation having a wavelength between 4,000 and $3,15^{\circ} \AA$, while that having a wavelength of less than $3,15^{\circ} \AA$ amounts to only about 0.6 per cent. On the basis of direct measurements obtained by sending rockets to great heights, however, J. A. Sanderson and E. O. Hulbert ${ }^{34}$ give the intensity of the ultraviolet radiation (from $4,000 \AA$ downwards) as five times greater, namely $4.8 \times 10^{20} \mathrm{kcal} /$ year.

As early as 1913 B. Moore, ${ }^{35}$ proceeding from A. Baeyer's theory of photosynthesis, put forward the idea that the prerequisite for the development of the organic substances necessary to life was the formation of formaldehyde from the primaeval carbon dioxide as the result of the action of solar ultraviolet radiations. We find this same idea later in the writings of P. Becquerel, ${ }^{36} \mathrm{~J}$. B. S. Haldane, ${ }^{37}$ and, especially, in a number of works by $\mathrm{A}$. Dauvillier ${ }^{38}$ in which he elaborates his photochemical theory of the origin of life. It was shown, long ago, that carbon dioxide gives a series of absorption bands in the ultraviolet region of the spectrum from $1,710 \AA$ downwards. In absorbing these radiations it splits to form co and o (some of which finally appears as ozone). ${ }^{39}$

In the presence of water which is undergoing ultraviolet photolysis we may suppose that $\mathrm{CO}_{2}$ could be reduced by the hydrogen according to the equations:

$$
\begin{aligned}
& 2 \mathrm{H}_{2} \mathrm{O} \rightarrow 2 \mathrm{H}_{2}+\mathrm{O}_{2} \\
& 2 \mathrm{H}_{2}+\mathrm{CO}_{2} \rightarrow \mathrm{CH}_{2} \mathrm{O}+\mathrm{H}_{2} \mathrm{O}
\end{aligned}
$$

$\mathrm{H}$. Thiele, ${ }^{40}$ however, did not find formaldehyde when he submitted mixtures of hydrogen and carbon dioxide to ultraviolet irradiation; on the other hand, D. Berthelot and $\mathrm{H}$. Gaudechon, ${ }^{41}$ and later A. Coehn and G. Sieper, ${ }^{42}$ established that a small amount of formaldehyde is formed under these circumstances. C. Zenghelis ${ }^{43}$ also described experiments in which carbon dioxide gas was reduced by hydrogen under 
ultraviolet irradiation to give formaldehyde which then underwent polymerisation.

E. Rabinowitch has reviered the extensire, though highly contradictory, literature on the subject of the formation of formaldehyde from aqueous solutions of carbon dioxide cluring ultraviolet irradiation. From this literature it appears that such formation, if it occurs at all, does so only to a very limited and sometimes scarcely perceptible extent.

Under natural conditions this reaction could not give rise to large amounts of organic substances, as the oxygen formed in it would very soon set up an ozone screen, preventing the access of short-wave ultraviolet radiations to the lower layers of the atmosphere. This is also the usual explanation for the absence of reactions by which $\mathrm{CO}_{2}$ is reduced under the influence of ultraviolet radiation on the Earth at present.

N. R. Dhar and A. Ram, ${ }^{44}$ however, claim to have found some thousandths of 1 per cent of formaldehyde in rainwater. They suggest that this formaldehyde was formed photochemically in that part of the atmosphere which lies outside the ozone screen. It would, however, be hard to prove that these infinitesimal amounts of formaldehyde were formed in this, rather than in some other way.

The second source of energy in the atmosphere of the Earth is electrical discharges, either silent or in thunder. It is very hard to calculate the amount of this energy. If, as is usually done, we assume that under contemporary conditions one flash of lightning strikes the ground for every square kilometre of the surface of the Earth each year, ${ }^{45}$ and that the mean energy of a flash is $10^{17} \mathrm{ergs}^{46}$ then the whole surface of the Earth receives $5.1 \times 10^{8} \times 10^{17}=5.1 \times 10^{25}$ ergs/year or $1.2 \times 10^{15} \mathrm{kcal} /$ year. It follows that the energy of electrical discharges is several orders lower than that of ultraviolet light. This calculation, however, only takes into account the noisy discharges of thunderstorms and it may be that the energy of silent discharges in the atmosphere is also quite considerable. There is also reason to suppose that thunderstorms were more frequent in primaeval times.

As early as $1899 \mathrm{~F}$. Allen ${ }^{47}$ suggested the possibility that the energy of electrical discharges in the atmosphere might have been used in carrying out many organic syntheses on 
the primaeval Earth. In particular, he disregarded contemporary conditions and considered that lightning was continually striking through the primaeval atmosphere and converting the molecular nitrogen in it into ammonia and oxides which reacted with carbon dioxide and thus produced what Allen regarded as the original carbon compounds on the Earth.

C. B. Lipman ${ }^{48}$ also assumed greater electrical activity in the primaeval atmosphere when he tried to explain the formation there of organic compounds from carbon dioxide, water and nitrates. In his book $\mathrm{R}$. Beutner ${ }^{49}$ also assumes that in the primaeval atmosphere, consisting of carbon dioxide, water vapour and ammonia, complicated organic compounds were formed as the result of powerful electrical discharges.

It is true that these conclusions were arrived at in an a priori way without any profound physico-chemical analysis of the phenomena under discussion. It was, however, already known in M. Berthelot's ${ }^{50}$ time that under the influence of flashing, and in particular, of silent discharges of electricity, carbon dioxide could be reduced by hydrogen to carbon monoxide with the formation of small amounts of organic substances having the general formulae $\left(\mathrm{CH}_{2} \mathrm{O}\right)_{n}$ or $\left(\mathrm{CH}_{4} \mathrm{O}_{2}\right)_{n}$. Later W. Löb, ${ }^{51}$ S. M. Losanitsch, ${ }^{52}$ and others ${ }^{53}$ showed experimentally that in silent electrical discharges a mixture of water and carbon dioxide can form formic acid and formaldehyde, which are further transformed into glycolic aldehyde which then polymerises to form carbohydrates.

On the basis of such observations one may presume that in the atmosphere of the Earth at the present time minimal quantities of organic substances are formed from water and carbon dioxide as the result of flash or silent discharges. This, of course, could also have taken place in the primaeval atmosphere, though it is doubtful whether the reduction of carbon dioxide played any substantial part in view of the very small concentration of carbon dioxide then present.

A far more important effect of electrical discharges was the transformation of the hydrocarbons of the primaeval atmosphere, to which we shall return later.

As the third source of energy on the surface of the Earth 
we must mention the energy of the disintegration of the atoms of the naturally radioactive substances, which were, for the most part, concentrated in the granitic envelope of the lithosphere. The heat passing from the centre of the Earth to its surface amounts to $10^{28} \mathrm{ergs} /$ year or $2.5 \times 10^{17}$ kcal/year. ${ }^{54}$ This is some thousands of times less than the amount of energy received by the surface of the Earth from the Sun.

G. Boĭtkevich ${ }^{55}$ estimates the total amount of radiogenic heat of the crust of the Earth at $4.7 \times 10^{14} \mathrm{kcal} /$ hour or $4.1 \times 10^{18} \mathrm{kcal} /$ year. Even if we assume that the radioactivity of the Earth was several times greater in the remote past than it is now (on account of the breakdown of ${ }^{40} \mathrm{~K}$ and ${ }^{235} \mathrm{U}$ ), amounting to $2 \times 10^{19} \mathrm{kcal} /$ year, the radioactivity of the crust of the Earth must have played a considerably smaller part in the chemical transformation of carbon compounds than the energy of light, the more so as the greater part of the radioactive energy was dissipated as heat. Nevertheless, we certainly cannot discount it. ${ }^{56}$

As early as $1913 \mathrm{~J}$. Stoklasa and colleagues ${ }^{57}$ drew attention to the possibility that the primary synthesis of sugars from $\mathrm{CO}_{2}$ could occur under the influence of radium emanation. We meet with the same idea in the works of many later authors such as Becquerel, who invoked the radioactivity of primaeval rocks (purely speculatively, it is true) as well as ultraviolet radiations as the source of energy for the reduction of carbon dioxide. The possibility that a reduction of this sort might have occurred is, to some extent, confirmed by laboratory investigations. For example, S. C. Lind and D. C. Bardwell ${ }^{58}$ obtained resinous organic substances by allowing $\alpha$-particles to act on mixtures of carbon dioxide or carbon monoxide with hydrogen or methane. V. Sokolov ${ }^{59}$ communicated some very interesting facts to the seventeenth session of the International Geological Congress in Moscow in 1937. On the basis of his own experiments he showed that the water contained in sedimentary formations could be decomposed to hydrogen and oxygen under the influence of the $\alpha$-rays of radioactive elements. If the oxygen is removed in oxidising incompletely oxidised substances, in particular metals and organic compounds, then the hydrogen can reduce 
carbon dioxide to methane, which later polymerises to form ethane and other compounds of higher molecular weight.

W. M. Garrison, D. C. Morrison, J. G. Hamilton, A. A. Benson and M. Calvin ${ }^{60}$ have recently published their studies on the reduction of carbon dioxide in aqueous solutions under the influence of ionising radiations. In their experiments these authors proceeded from the assumption that the formation of organic substances on the primaeval Earth was achieved by the reduction of carbon dioxide under the influence of ionising radiations. To test this assumption they submitted aqueous solutions of carbon dioxide to the action of a stream of helium particles in a cyclotron and were able to show definitely that formic acid and formaldehyde were present among the products of the reaction.

Phenomena of this kind may, of course, occur in the crust of the Earth at present to a very limited extent, but under the reduced conditions of the primaeval Earth they could hardly have been of decisive significance owing to the small amounts of carbon dioxide present there.

All the sources of energy which we have enumerated (ultraviolet and cosmic radiation, electric discharges and radioactive breakdown) must have played important parts in the early history of our planet, not only by bringing about reduction of carbon dioxide (which was scarcely present in large amounts) but by transforming hydrocarbons which were, at that time, the most abundant carbon compounds. The chemical evolution of the hydrocarbons could have been accomplished simply on the basis of their own energy potentials, but the practical realisation of these potentialities was greatly facilitated by the presence of supplementary sources of energy. Short-wave ultraviolet radiation, silent electric discharges and $\alpha$-particles brought about specific transformations of organic molecules by stages, with the formation of a series of intermediate compounds. We must bear in mind that the hydrocarbons and their derivatives which were originally formed in the lithosphere, where the temperature and pressure may have been comparatively high, afterwards migrated, for the most part, into a moist atmosphere, the various layers of which were subjected to cold and the action of light and electric discharges, and that the products which 
made their appearance there could accumulate and be further transformed in the waters of the hydrosphere. Under these circumstances we must expect a considerable variety of organic substances on the surface of the Earth. There might, indeed, have arisen representatives of all such compounds known to us. The difficulty which faces us when we try to give a concrete account of the course of organic evolution on the Earth lies not so much in the absence or insufficiency of chemical possibilities, as in the number of alternative intersecting routes along which any particular organic molecule could have been transformed.

As was shown in Chapter IV, the main source from which the abiogenic hydrocarbons of the surface of the Earth were derived was the lithosphere.

As early as $1889 \mathrm{~V}$. Sokolov ${ }^{61}$ put forward the hypothesis that the primary hydrocarbons of the Earth were taken up by molten magmata and that when these cooled and solidified the hydrocarbons conld once more separate out and that they are still separating out in fissures in the lithosphere. Such a hypothesis, however, seems extremely improbable in the light of present-day astronomical and geological evidence. The main forms in which carbon was retained on the Earth during its formation were, as we have already seen, native carbon and carbides. During the development of the lithosphere they interacted with geological formations incorporating hydrates or other forms of constitutional water. According to R. Goranson ${ }^{62}$ molten magma contains 5 per cent or more of water. The geological formations of the primaeval Earth must have been even richer in water, for the hydrosphere contained only one-tenth as much water then as it does now and the rest of the water was still bound in the lithosphere.

It is well known that, on reaction with water, carbides of calcium, barium, strontium and lithium give rise to acetylene, those of aluminium and beryllium to methane, that of manganese to mixtures of methane and hydrogen, those of the rare metals to mixtures of acetylene and methane, while carbides of uranium give rise to mixtures of methane, hydrogen, ethylene, and liquid and solid hydrocarbons, etc. ${ }^{63}$

Many carbides are not decomposed by water at ordinary 
low temperatures, but yield hydrocarbons when heated to temperatures such as might easily be reached in the lithosphere. Under these conditions the formation of hydrocarbons could also take place by the direct reduction of carbides by hydrogen.

Even now hydrogen is given off by the lithosphere in considerable amounts; it is an important constituent of inflammable volcanic gases. ${ }^{63 a}$ Of course, the hydrogen given off now may be partly of secondary origin, arising as the result of the breakdown of biogenic substances. Its formation by inorganic means is, however, by no means excluded. G. Stadnikov, ${ }^{64}$ for example, put forward the possibility that hydrogen might be formed thermally in the interior of the Earth by the action of water vapour on red-hot solutions of carbides in ferromanganese. A. Gaedicke ${ }^{65}$ invoked the action of the $\alpha$-particles of the radioactive elements on the water of the deep geological formations

$$
(n+1) \mathrm{H}_{2} \mathrm{O} \longrightarrow 2(n+1) \mathrm{H}+(n+1) \mathrm{O}
$$

The hydrogen arising from this reaction might escape directly into the atmosphere or might form hydrocarbons by reacting with carbon (e.g. with graphite) according to the equation:

$$
n \mathrm{C}+2(n+1) \mathrm{H} \longrightarrow \mathrm{C}_{n} \mathrm{H}_{(2 n+2)}
$$

Under the strongly reducing conditions which were present on the primaeval Earth the opportunities for the formation of free hydrogen must have been far greater than they are now.

S. C. Schuman ${ }^{66}$ has calculated the equilibrium constants for the reactions:

$$
\begin{gathered}
\mathrm{Fe}_{2} \mathrm{C}+(2 n-\mathrm{I}) \mathrm{H}_{2}+(n-\mathrm{I}) \mathrm{CO} \longrightarrow \mathrm{C}_{n} \mathrm{H}_{2 n}+2 \mathrm{Fe}+(n-\mathrm{I}) \mathrm{H}_{2} \mathrm{O} \\
\mathrm{Fe}_{2} \mathrm{G}+2 n \mathrm{H}_{2}+(n-\mathrm{I}) \mathrm{CO} \longrightarrow \mathrm{C}_{n} \mathrm{H}_{(2 n+2)}+2 \mathrm{Fe}+(n-\mathrm{I}) \mathrm{H}_{2} \mathrm{O}
\end{gathered}
$$

The results of these calculations showed that the formation of hydrocarbons from iron carbide by direct reduction is perfectly possible thermodynamically, at temperatures of $250^{\circ}-35^{\circ} \mathrm{C}$, that is to say, under conditions which may easily obtain in the lithosphere.

The hydrocarbons which appeared during the formation 
of the crust of the Earth (mainly methane, ethane, acetylene, etc.) were, in part, given off directly into the atmosphere while, in part, they underwent various chemical changes within the lithosphere itself. We will only discuss a few of the many reactions which may have taken place there.

The simple thermal polymerisation of methane to ethane, propane and other higher hydrocarbons would seem to be out of the question, since ethane cannot be formed at temperatures above $227^{\circ} \mathrm{C}$ or propane above $180^{\circ} \mathrm{C}$ and, within the limits of these temperatures, methane is quite stable and has no tendency to dehydrogenation or polymerisation. It has, however, been shown by $\mathrm{V}$. Sokolov that, under the action of $\alpha$-radiation from the radioactive elements of the crust of the Earth, the molecules of methane may become more complicated with the evolution of hydrogen and the formation of ethane and also of the simplest olefines. Further polymerisation takes place, with the formation of gaseous and liquid hydrocarbons of high molecular weight.

Without receiving energy from external sources molecules of methane can undergo conversion according to the equation $^{67}$ :

$$
\mathrm{CH}_{4}+\mathrm{H}_{2} \mathrm{O} \rightarrow \mathrm{CO}+3 \mathrm{H}_{2}
$$

The change in free energy, $\triangle \mathrm{z} \mathrm{cal} / \mathrm{mole}$, in this equation has been calculated by $A$. Pasynskir from the table of $\mathrm{V}$. Korobov and A. Frost: ${ }^{68}$

$$
\triangle \mathrm{Z}=-4927 \mathrm{O}+51 \cdot 3 \mathrm{~T}+11 \cdot 1 \mathrm{f}(\mathrm{T} / 298 \cdot 16)^{*}
$$

It only enters a region of positive values (when the process comes to a standstill spontaneously for thermodynamic reasons) above $65^{\circ}{ }^{\circ} \mathrm{C}$.

At far lower temperatures (of the order of $100-200^{\circ} \mathrm{C}$ ), though under increased pressure, methanol is formed from carbon monoxide and hydrogen according to the equation:

$$
\mathrm{CO}+2 \mathrm{H}_{2} \rightarrow \mathrm{CH}_{3} \mathrm{OH}
$$

\footnotetext{
* In this calculation, as in those which follow, values for $\Delta \mathrm{Z}$ have been calculated for standard conditions and for the gaseous state. $T$ is temperature in degrees Absolute. The function $f(\mathrm{~T} / 298 \cdot 16)=\mathrm{Ln}(\mathrm{T} / 298 \cdot 16)+$ $(298 \cdot 16 / T)-1$. All have been made by A. Pasynskil from the table of korobor and Frost.-A Athor.
} 
For this reaction $\triangle \mathrm{z}=-2168 \mathrm{o}+52 \cdot 7 \mathrm{~T}$, which means that it is thermodynamically possible up to $200^{\circ} \mathrm{C}$.

The next important reaction which methane can undergo is that with ammonia and ammonium salts as follows:

$$
\mathrm{CH}_{4}+\mathrm{NH}_{3} \rightarrow \mathrm{CH}_{3} \mathrm{NH}_{2}+2 \mathrm{H}
$$

According to $\mathrm{V}$. Dolgov ${ }^{69}$ it is thermodynamically possible for this reaction to take place at temperatures of $500^{\circ} \mathrm{C}$ and higher, with the formation of methylamine.

The chemical potentialities of ethylene and acetylene are far wider. We must first discuss the various reactions in which these compounds are hydrogenated and polymerised, leading to the formation of saturated hydrocarbons, of higher members of the olefine series, to ring formation into polymethylenes, and so forth.

All these reactions are possible from a thermodynamic point of view at temperatures below $500^{\circ} \mathrm{C}$.

The polymerisation of the gaseous olefines of low molecular weight is accompanied by a decrease in volume. The increased pressure in the lithosphere would, therefore, favour its occurrence. ${ }^{70}$

The hydration of ethylene and acetylene is easily brought about by their reaction with water. In the presence of specific catalysts such as $\mathrm{Al}_{2} \mathrm{O}_{3}, \mathrm{~W}_{2} \mathrm{O}_{5}$ etc., the reaction $\mathrm{C}_{2} \mathrm{H}_{4}+\mathrm{H}_{2} \mathrm{O} \longrightarrow$ $\mathrm{C}_{2} \mathrm{H}_{5} \mathrm{OH}$ can occur at temperatures of about $100^{\circ} \mathrm{C}$ if the pressure is high. ${ }^{71}$

Acetylene is hydrated by Kucherov's reaction to give acetaldehyde, $\mathrm{C}_{2} \mathrm{H}_{2}+\mathrm{H}_{2} \mathrm{O} \rightarrow \mathrm{CH}_{3} \mathrm{CHO}$. This reaction occurs in the presence of a number of catalysts; even iron ore will bring it about. The equation for its free energy is as follows:

$$
\triangle \mathrm{z}=-35^{890}+29 \cdot 5 \mathrm{~T}+3 \cdot 5 f\left(\mathrm{~T} / 29^{8 \cdot 16}\right)
$$

and shows that it is thermodynamically possible for the reaction to occur at temperatures of $900^{\circ} \mathrm{C}$ and below. Acetylene can also be hydrated to form acetone:

$$
2 \mathrm{C}_{2} \mathrm{H}_{2}+3 \mathrm{H}_{2} \mathrm{O} \longrightarrow \mathrm{CH}_{3} \cdot \mathrm{CO} \cdot \mathrm{CH}_{3}+\mathrm{CO}_{2}+2 \mathrm{H}_{2}
$$

This reaction is usually carried out technically at temperatures of $450-470^{\circ} \mathrm{C}$ with the help of catalysts-oxides of 
iron, manganese, zinc, vanadium, etc. Thermodynamic calculations give the equation

$$
\triangle \mathrm{z}=-80822+47 \cdot 1 \mathrm{~T}+4 f(\mathrm{~T} / 298 \cdot 16)
$$

which means that the reaction could occur at the temperature of the lithosphere.

We may also mention some reactions between acetylene and formaldehyde. One of these in particular gives rise to propargyl alcohol:

$$
\mathrm{C}_{2} \mathrm{H}_{2}+\mathrm{CH}_{2} \mathrm{O} \rightarrow \mathrm{HC} \equiv \mathrm{C} . \mathrm{CH}_{2} \mathrm{OH}
$$

and a large number of more complicated products-glycerol, erythritol, hexamethylolbenzene, etc. Tens of different spontaneously occurring reactions have also been described in which acetylene is condensed with alcohols, ethers, acids, aromatic compounds, etc. ${ }^{72}$

Acetylene can also react with water or hydrogen sulphide to give heterocyclic compounds. For example, A. Chichibabin $^{73}$ obtained a condensate containing furan by passing steam and acetylene over $\mathrm{Al}_{-} \mathrm{O}_{3}$ at $400-425^{\circ} \mathrm{C}$ :

$$
2 \mathrm{C}_{2} \mathrm{H}_{2}+\mathrm{H}_{2} \mathrm{O} \rightarrow \mathrm{C}_{4} \mathrm{H}_{4} \mathrm{O}+\mathrm{H}_{2}
$$

For this process $\triangle \mathrm{z}=-56680+51 \mathrm{~T}$ from which it is clear that, from a thermodynamic point of view, it can occur right up to $800^{\circ} \mathrm{C}$.

The corresponding calculation for the reaction by which thiophene is formed $\left(2 \mathrm{C}_{2} \mathrm{H}_{2}+\mathrm{I}_{2} \mathrm{~S} \rightarrow \mathrm{C}_{4} \mathrm{H}_{4} \mathrm{~S}+\mathrm{H}_{2}\right)$ gives $\triangle \mathrm{Z}=$ $-22760+43.3 \mathrm{~T}$ which suggests that the temperature at which this reaction is thermodynamically possible may be as high as $250^{\circ} \mathrm{C}$.

An interesting possibility for the transformation of the primary hydrocarbons of the lithosphere is provided by the reaction known as the oxo svnthesis. ${ }^{74}$ This consists in the simultaneous condensation of olefines with hydrogen and carbon monoxide (which can here be formed by the conversion of methane), e.g. :

$$
\mathrm{CO}+\mathrm{C}_{2} \mathrm{H}_{4}+\mathrm{H}_{2} \rightarrow \mathrm{CH}_{3} \cdot \mathrm{CH}_{2} \cdot \mathrm{CHO}
$$

Many different aldehydes may arise in this way and then give rise to the corresponding alcohols and acids. Acrylic 
acid formed from acetylene and carbon monoxide at $115^{\circ} \mathrm{C}$ and 100 atmospheres goes on to form succinic acicl according to the equation

$$
\mathrm{CH}_{2}=\mathrm{CH} \cdot \mathrm{COOH} \underset{\mathrm{H}_{2} \mathrm{O}}{\stackrel{\mathrm{CO}}{\longrightarrow}} \mathrm{HOOC} \cdot \mathrm{CH}_{2} \cdot \mathrm{CH}_{2} \cdot \mathrm{COOH}
$$

Oxo syntheses can occur with any unsaturated compounds, including aromatic ones.

Under the conditions prevailing in the primaeval lithosphere many reactions leading to the formation of nitrogenous substances could also occur. In addition to the formation of methylamine as described above, we must now mention the formation of ethylamine and acetonitrile by the catalytic condensation of acetylene and ammonia when they pass over bauxite, permutite or other catalysts at $400^{\circ} \mathrm{C}$.

Long ago Berthelot described the synthesis of pyrrole and other nitrogenous heterocyclic compounds as the result of the action of acetylene on ammonia, diazomethane and hydrocyanic acid. A. Chichibabin ${ }^{75}$ has shown that pyrrole and some pyridine bases are formed from acetylene and ammonia in the presence of $\mathrm{Al}_{2} \mathrm{O}_{3}, \mathrm{Fe}_{2} \mathrm{O}_{3}$, or $\mathrm{Cr}_{2} \mathrm{O}_{3}$ at $300^{\circ} \mathrm{C}$.
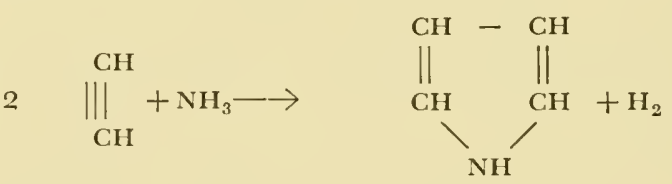

Similar syntheses have been described in detail by A. P. Terent'ev and L. A. Yanovskaya. ${ }^{76}$ T. Ishiguro, S. Kubota, O. Kimura and S. Shimomura ${ }^{77}$ have recently described experiments in which they obtained pyridine $\left(\mathrm{C}_{5} \mathrm{H}_{5} \mathrm{~N}\right)$ and its homologues by condensing acetylene and ammonia in the presence of various catalysts at temperatures of about $300-400^{\circ} \mathrm{C}$.

Most of the reactions which have just been mentioned can easily be carried out in the laboratory or on an industrial scale for the manufacture of one or other of the products. Their occurrence, however, cannot by any means always be observed in nature, as it is now complicated and obscured by the changes taking place in carbon compounds which have 
arisen secondarily and have been laid down in the crust of the Earth as a result of the activities of living organisms. At present we can see in many places the transformation of secondary organic compounds in the lithosphere. A particular example of this is the formation of petroleum. In this, the organic remains of animals and plants which have been heated in the depths of the crust of the Earth undergo reactions involving the breakdown of those large, complicated molecules, rich in oxygen and nitrogen, which have previously been synthesised by living things. On the whole these phenomena are proceeding in the opposite direction from the reactions which have been described above. Compounds of high molecular weight are broken down and new ones are formed in place of them. Compounds containing oxygen, nitrogen, phosphorus and sulphur are almost completely decomposed, their hydrogen content is increased and new cyclic and polycyclic hydrocarbons, etc., emerge. ${ }^{78} \mathrm{It}$ is only on rare and isolated occasions that these phenomena of the degradation of pre-formed organic substances can be used directly to form an estimate of the primitive synthetic processes which occurred on the Earth before the appearance of life.

A study of the formation of petroleum and, in particular, of that of natural gas can, however, make a great contribution towards the solution of the problem before us. It shows that the results which are obtained under artificial conditions in the laboratory are completely confirmed in nature. This applies both to the influence of temperature and pressure on the complicated processes of transformation of organic substances in the crust of the Earth, and also to the effects of various artificial and natural catalysts on these processes. The remarkable geochemical ideas on this subject put forward by $\mathrm{N}$. Zelinskiir ${ }^{9}$ on the basis of his laboratory experiments have been completely confirmed by the investigations of the formation of petroleum by many scientists in Russia and other countries. ${ }^{80}$ According to S. N. Obryadchikov $^{81}$ and A. V. Frost, ${ }^{82}$ petroleum is formed at comparatively low temperatures, about $100-300^{\circ} \mathrm{C}$. V. Porfir'er, ${ }^{83}$ on the other hand, suggests the figure of $5 \mathrm{Oo}^{\circ} \mathrm{C}$. Even higher temperatures may certainly be encountered in different zones 


\section{ABIOGENIC ORGANIC-CHEMICAL EVOLUTION}

of the crust of the Earth but it would seem not to be these which play the decisive part in the formation of petroleum, but rather the catalytic activity of the mineral formations. In particular, A. V. Frost ${ }^{84}$ has shown that those reactions which, in the laboratory, are catalysed by anhydrous aluminium chloride can also take place in the presence of various natural clays (kaolins, bauxites and other aluminosilicates) without any preliminary treatment or activation. ${ }^{85}$

Similarly, the transformations of the primary hydrocarbons which have already been described may take place in the crust of the Earth, being catalysed by oxides of aluminium, iron, chromium and manganese and by other substances which are widely distributed in the lithosphere.

The multiplicity of possible chemical transformations is further considerably increased in the crust of the Earth by the influence of the decay of the radioactive elements which are present there. Under these conditions reactions can occur which would be prohibited by thermodynamic considerations from occurring on their own. Among these we may mention the formation of acetaldehyde by the reaction between methane and carbon monoxide and the dehydrogenation of methane and its polymerisation, which have already been discussed in relation to the work of $\mathrm{V}$. Sokolov, as well as other reactions.

One of the first to point out the possible significance of radioactive substances in the formation of petroleum was N. Zelinskiř. ${ }^{86}$ As early as $1925 \mathrm{~V}$. Sokolov ${ }^{87}$ produced evidence for the occurrence of natural radioactivity in clays and other geological formations. I. A. Breger and W. L. Whitehead, ${ }^{88}$ A. Kozlov, ${ }^{88} \mathrm{M}$. Karasev ${ }^{89}$ and many other workers have also studied the significance of radioactivity in the formation of petroleum.

One can, however, hardly regard (as some authors do) the radioactivity of geological formations as being solely responsible for the origin of the hydrocarbons which were first formed in the crust of the Earth. Direct catalytic transformations must certainly have been more important quantitatively. Radioactive radiations may, however, have been responsible for the occurrence of reactions which would otherwise have been impossible on thermodynamic grounds. 
One must, therefore, take these radiations into consideration if one wishes to picture to oneself the course of the chemical transformation which took place in the primaeval lithosphere.

Only a small proportion of the primary hydrocarbons and their derivatives (mainly compounds of high molecular weight) were retained in the lithosphere and later extracted from it by the waters of the hydrosphere. All the volatile carbon compounds were gradually given off from the crust of the Earth into the atmosphere, just as we may now observe the giving off of natural gases. The most important and most frequently encountered of these gaseous hydrocarbons is methane. ${ }^{90}$ At present, of course, it is partly formed secondarily, by the breakdown of biogenic organic substances or by the reduction of carbon dioxide. According to V. Vernadskil, however. methane occupies an important place among the carbon compounds originating in the depths of the Earth. Hardly anyone will deny the possibility that even now it is formed, at least in part, as the result of inorganic processes, in volcanic gases and emanations.

As well as methane, the primitive atmosphere of the Earth must have contained carbon monoxide which was formed from methane. Ethylene and acetylene were more likely to have undergone reactions of some kind while still in the lithosphere on account of their chemical reactivity, which is far greater than that of methane. The average specific gravity of the gases composing the primitive atmosphere must, therefore, have been relatively low, which is what we now observe in natural gases.

In the atmosphere the primary hydrocarbons and their derivatives encountered new sources of energy which were not present in the lithosphere. Electrical discharges ${ }^{91}$ and ultraviolet radiation ${ }^{92}$ enabled them readily to surmount the barrier of the energy of activation and even to enter into reactions which would be thermodynamically impossible in the absence of external supplies of energy. For this reason new reactions occurred in the atmosphere in addition to those taking place in the absence of the factors just mentioned (electrical discharges and ultraviolet radiations) and the transformation of hydrocarbons was much wider in its scope. In the atmosphere even such a chemically inert gas as 
methane could serve as the basis for the formation of the most varied organic substances. As we have already seen, the direct thermal dehydrogenation of methane requires very high temperatures, at which it cannot polymerise. Under the influence of electrical discharges, on the other hand, mechane polymerises easily with the formation of various gaseous, liquid and solid products, as had already been demonstrated by the end of the nineteenth century. ${ }^{93}$

Acetylene, ethylene, diacetylene, benzene, naphthalene, acetonaphthene, dipropargyl and many other hydrocarbons, some of very high molecular weights, have been identified during the study of the composition of these products. Most of the substances listed arise as the result of the secondary transformation of acetylene, which is to be regarded as one of the fundamental products of the dehydrogenation and polymerisation of methane under the influence of electric discharges. ${ }^{94}$

R. V. de St.-Aunay ${ }^{95}$ submitted methane to the action of silent discharges in a circulating system and this allowed him to form an opinion as to the earliest stages of the process. On the basis of this work he wrote as follows:

At the very beginning of the activity of the discharge the methane was split to hydrogen and a free radical which led to a slight decrease in the volume of the gas on condensing. Ethane was formed from methane without any change in volume,

$$
2 \mathrm{CH}_{4} \rightarrow \mathrm{C}_{2} \mathrm{H}_{6}+\mathrm{H}_{2}
$$

and as it accumulated it was dehydrogenated, which gave an increase in the volume, $\mathrm{C}_{2} \mathrm{H}_{6} \rightarrow \mathrm{C}_{2} \mathrm{H}_{4}+\mathrm{H}_{2}$. The ethylene thus formed was dehydrogenated in its turn. When enough ethylene and acetylene had accumulated a further decrease in volume took place, due to their polymerisation.

The polymerisation in the electric discharge of ethane, ${ }^{96}$ ethylene $^{97}$ and, especially, of acetylene, ${ }^{98}$ leads to the formation of a countless variety of compounds both aliphatic and cyclic. This variety of products is greatly increased when the electric discharges act on mixtures of hydrocarbons, e.g. $\mathrm{C}_{2} \mathrm{H}_{2}+\mathrm{CH}_{4} ; \quad \mathrm{C}_{2} \mathrm{H}_{4}+\mathrm{CH}_{4} ;{ }^{99} \quad \mathrm{C}_{2} \mathrm{H}_{2}+\mathrm{C}_{2} \mathrm{H}_{4} ;^{; 00} \mathrm{C}_{6} \mathrm{H}_{6}+\mathrm{CH}_{4},{ }^{101}$ etc. Unfortunately these reactions have not yet been studied in anything like full detail. 
A large number of oxygen-containing derivatives of hydrocarbons are also easily formed under the influence of electric discharges. The conversion of methane, $\mathrm{CH}_{4}+\mathrm{H}_{2} \mathrm{O} \rightarrow \mathrm{CO}+3 \mathrm{H}_{2}$, which could only take place in the lithosphere at comparatively high temperatures, occurred in the cold in the primitive atmosphere by making use of the energy of electric discharges. The carbon monoxide thus formed reacted, in its turn, with methane, according to the equation:

$$
\mathrm{CH}_{4}+\mathrm{CO} \rightarrow \mathrm{CH}_{3} \text {. } \mathrm{CHO}
$$

Calculations for this reaction give $\Delta \mathrm{z}=4,800+28 \cdot 2 \mathrm{~T}$. This means that, for thermodynamic reasons, the reaction by which acetaldehycle is formed from methane and carbon monoxide cannot occur spontaneously at any temperature. Nevertheless S. M. Losanitsch and M. Z. Jowitschitsch ${ }^{102}$ submitted a mixture of carbon monoxide and methane to the action of silent discharges and obtained an oily condensation product containing acetaldehyde. On continued action of the discharge this polymerised to aldol and more complicated condensation products.

$$
2 \mathrm{CH}_{3} \cdot \mathrm{CHO} \rightarrow \mathrm{CH}_{3} \cdot \mathrm{CHOH} . \mathrm{CH}_{2} \cdot \mathrm{CHO} \rightarrow\left(\mathrm{CH}_{3} \cdot \mathrm{CHOH} \cdot \mathrm{CH}_{2} \cdot \mathrm{CHO}\right)_{n}
$$

The acetaldehyde itself forms a number of gaseous and liquid products when its vapour is mixed with hydrogen and submitted to the action of a silent discharge. The following equations express some of the individual reactions ${ }^{103}$ :

$$
\begin{aligned}
& 2 \mathrm{CH}_{3} \cdot \mathrm{CHO} \rightarrow \mathrm{H}_{2}+\mathrm{CO}+\mathrm{CH}_{3} \cdot \mathrm{CO} \cdot \mathrm{CH}_{3} \text { (acetone) } \\
& 3 \mathrm{CH}_{3} \cdot \mathrm{CHO} \rightarrow 2 \mathrm{H}_{2}+2 \mathrm{CO}+\mathrm{C}_{2} \mathrm{H}_{5} \cdot \mathrm{CO} \cdot \mathrm{CH}_{3} \text { (methyl ethyl ketone) } \\
& 2 \mathrm{CH}_{3} \cdot \mathrm{CHO} \rightarrow \mathrm{H}_{2}+\mathrm{CH}_{3} \cdot \mathrm{CO} \cdot \mathrm{CO} \cdot \mathrm{CH}_{3} \text { (diacetyl) } \\
& 2 \mathrm{CH}_{3} \cdot \mathrm{CHO} \rightarrow \mathrm{C}_{2} \mathrm{H}_{4}+\mathrm{CH}_{3} \cdot \mathrm{COOH} \text { (acetic acid) } \\
& 4 \mathrm{CH}_{3} \cdot \mathrm{CHO} \rightarrow \mathrm{C}_{2} \mathrm{H}_{4}+2 \mathrm{C}_{2} \mathrm{H}_{5} \cdot \mathrm{COOH} \text { (propionic acid) }
\end{aligned}
$$

Reactions by which aldehydes are formed directly from hydrocarbons and carbon monoxide appear to be very general. For example, under action of electric discharges a mixture of ethylene and carbon monoxide gives rise to acrolein, ${ }^{104}$

$$
\mathrm{CH}_{2}: \mathrm{CH}_{2}+\mathrm{CO} \rightarrow \mathrm{CH}_{2}: \mathrm{CH} . \mathrm{CHO}
$$


a mixture of benzene and carbon monoxide to benzaldehyde and so forth.

Acetaldehyde and its condensation products are formed from mixtures of acetylene and water under such conditions. If a mixture of benzene and water is submitted to an electric discharge phenol will be formed.

Carbon monoxide can also react directly with hydrogen to give formaldehyde. This reaction is brought about by electric discharges, though only to a very small extent. ${ }^{105}$

Reactions betreen hydrocarbons and their derivatives and ammonia must also have occurred extensively in the primitive atmosphere. In this connection we must first discuss the reactions by which hydrocyanic acid is formed:

$$
\begin{aligned}
& \mathrm{CH}_{4}+\mathrm{NH}_{3} \rightarrow \mathrm{HCN}+3 \mathrm{H}_{2}-60 \mathrm{kcal} \\
& \mathrm{C}_{2} \mathrm{H}_{4}+2 \mathrm{NH}_{3} \rightarrow 2 \mathrm{HCN}+4 \mathrm{H}_{2}-63 \mathrm{kcal} \\
& \mathrm{C}_{2} \mathrm{H}_{2}+2 \mathrm{NH}_{3} \rightarrow 2 \mathrm{HCN}+3 \mathrm{H}_{2}-28 \mathrm{kcal} \\
& \mathrm{CO}+\mathrm{NH}_{3} \rightarrow \mathrm{HCN}+\mathrm{H}_{2} \mathrm{O}-10 \mathrm{kCal}
\end{aligned}
$$

These reactions are all endothermic but they proceed satisfactorily when an electric discharge passes through a mixture of the gases. ${ }^{106}$ Hydrocyanic acid is also formed in this way in mixtures of hydrocarbons and molecular nitrogen. This latter could have arisen in the primitive atmosphere by the oxidation of ammonia by the free oxygen derived from the photolysis of water. Long ago, Berthelot showed that hydrocyanic acid was synthesised at the expense of molecular nitrogen when this was mixed with acetylene and submitted to $\operatorname{arc}^{107}$ or flash ${ }^{108}$ discharges. $H$. Becker showed later that a similar process may take place with silent discharges. ${ }^{109}$

One of the many products of such discharges in a mixture of nitrogen, carbon monoxide and hydrogen is urea. ${ }^{110}$ This is probably formed by a reaction between carbon monoxide and ammonia, the ammonia having previously been formed from hydrogen and nitrogen.

$$
\begin{gathered}
\mathrm{N}_{2}+3 \mathrm{H}_{2} \rightarrow 2 \mathrm{NH}_{3} \\
2 \mathrm{NH}_{3}+\mathrm{CO} \rightarrow \mathrm{NH}_{2} \cdot \mathrm{CO} \cdot \mathrm{NH}_{2}+\mathrm{H}_{2}
\end{gathered}
$$

Reactions between hydrocarbons and hydrocyanic acid or 
ammonia give rise to a whole series of different, and sometimes very complicated, products including nitriles, amines, amides, etc. For example, the action of a silent discharge on a mixture of ethylene and hydrocyanic acid gives propionitrile ${ }^{111}$

$$
\mathrm{C}_{2} \mathrm{H}_{4}+\mathrm{HCN} \rightarrow \mathrm{C}_{2} \mathrm{H}_{5} \mathrm{CN}
$$

If acetylene is substituted for ethylene the isonitrile and succinodinitrile are formed ${ }^{112}$

$$
2 \mathrm{HCN}+\mathrm{C}_{2} \mathrm{H}_{2} \rightarrow \mathrm{NC} \cdot \mathrm{CH}_{2} \cdot \mathrm{CH}_{2} \cdot \mathrm{CN}
$$

When mixed with ammonia in silent discharges ethylene gives ethylamine

$$
\mathrm{C}_{2} \mathrm{H}_{4}+\mathrm{NH}_{3} \rightarrow \mathrm{C}_{2} \mathrm{H}_{5} \mathrm{NH}_{2}
$$

According to the evidence of S. M. Losanitsch, ${ }^{113}$ when ammonia reacts with ethylene, acetylene, benzene and other hydrocarbons one obtains a large amount of various complicated nitrogen-containing compounds of very high molecular weight.

From our point of view the formation of amino acids under these conditions is of special interest, as they are the fundamental components in the structure of protein-like substances.

Recently the following experiment, based on the evidence now available as to the composition of the atmosphere of the primaeval Earth, was carried out by S. L. Miller. ${ }^{114} \mathrm{He}$ used apparatus specially constructed for the purpose and passed silent electric discharges through a mixture of methane, ammonia, hydrogen and water vapour and obtained a number of amino acids-glycine, DL-alanine, $\beta$ alanine, sarcosine, DL- $\%$-aminobutyric and $\alpha$-aminoisobutyric acids. A considerable amount of other amino acids which have not yet been identified was also shown to be present. As well as these, glycolic, lactic, formic, acetic and propionic acids were found. A considerable amount of hydrocyanic acid and aldehydes was also present and these seem to have been produced directly by the action of the discharges.

According to Miller there are two possible explanations 
for the way in which these higher products of the reaction were formed:

(1) Hydrocyanic acid, amines, aldehydes, alcohols, most of the volatile acids and acrylonitrile were formed in the electric discharge. The amino acids, hydroxy acids, some of the fatty acids and the polymers only arose in solution.

(2) All the substances which were found arose in the silent discharges in the gaseous phase as the result of reactions between free radicals and ions.

Assuming the former hypothesis to be correct, Miller has drawn up the following set of equations for the formation of amino acids:

$$
\begin{aligned}
& \text { R. } \mathrm{CHO}+\mathrm{NH}_{3}+\mathrm{HCN} \rightarrow \text { R. } \mathrm{CHNH}_{2} \cdot \mathrm{CN}+\mathrm{H}_{2} \mathrm{O} \\
& \text { R. } \mathrm{CHNH}_{2} \cdot \mathrm{CN}+2 \mathrm{H}_{2} \mathrm{O} \rightarrow \text { R. } \cdot \mathrm{CHNH}_{2} \cdot \mathrm{COOH}+\mathrm{NH}_{3}
\end{aligned}
$$

and hydroxy acids:

$$
\begin{gathered}
\text { R.CHO }+\mathrm{HCN} \rightarrow \text { R. CHOH.CN } \\
\text { R.CHOH.CN }+2 \mathrm{H}_{2} \mathrm{O} \rightarrow \text { R. CHOH.COOH }+\mathrm{NH}_{3}
\end{gathered}
$$

S. L. Miller's experiments were repeated and completely confirmed by A. Pasynskiř and T. Pavlovskaya. ${ }^{15}$ According to Pasynskiir's calculations the value of $\Delta z$ for the formation of alanine from methane, water and ammonia was $46100+$ $5^{0.8 T}$ from which it may be seen that $\Delta z>0$ at all temperatures. It follows that the reaction carinot occur spontaneously but requires the extra energy of the electrical discharge. If, however, the mixture of gases includes carbon monoxide, $\Delta \mathrm{z}$ for the reaction becomes $-52939+153 \cdot 4^{\mathrm{T}}$ and the reaction is thermodynamically possible at ordinary temperatures. This variant of Miller's reaction was reproduced experimentally by Pasynskiǐ and Pavlovskaya in an electric field but the reaction has, so far, not been accomplished in any other way.

We have already shown that a far more potent source of energy for the synthesis of organic substances on the primaeval Earth than that of electric discharges was provided by solar radiation, in particular by ultraviolet radiation. At present the only chemical processes which are observed to occur under natural conditions on the surface of the 
Earth under the influence of ultraviolet light are on a very limited scale. This is because the short-wave radiations, which are by far the most active, are almost entirely absorbed by the ozone screen. It is, however, appropriate to refer, at this point, to the recently published work of $\mathrm{K}$. Bahadur. ${ }^{116}$ This author claims to have succeeded in synthesising various amino acids from paraformaldehyde and potassium nitrate in the presence of iron chloride by allowing these substances to stand in aqueous solution in direct sunlight for so hours. The formation of amino acids did not take place in the dark or in the absence of iron chloride. Bahadur claims that in his experiments he observed the synthesis of the following amino acids: arginine, valine, histidine, proline, lysine, serine, aspartic acid, glycine, ornithine and asparagine.

According to $\mathrm{K}$. Bahadur and S. Ranganayaki ${ }^{118}$ the process proceeds through the following intermediate reactions:

$$
\begin{aligned}
2 \mathrm{CH}_{2} \mathrm{O}+\mathrm{H}_{2} \mathrm{O} & \rightarrow \mathrm{CH}_{3} \mathrm{OH}+\mathrm{H} . \mathrm{COOH} \\
\mathrm{CH}_{2} \mathrm{O}+\mathrm{H} . \mathrm{COOH} & \rightarrow \mathrm{HOCH}_{2} \cdot \mathrm{COOH} \\
\mathrm{HOCH}_{2} \cdot \mathrm{COOH} & \rightarrow \mathrm{CHO} . \mathrm{COOH}+2 \mathrm{H}
\end{aligned}
$$

The nitrate is reduced to ammonia at the expense of the formaldehyde

$$
\begin{aligned}
& \mathrm{CHO} . \mathrm{COOH}+2 \mathrm{NH}_{3} \rightarrow \mathrm{NH}_{2} \mathrm{CHOH} . \mathrm{COONH}_{4} \\
& \mathrm{NH}_{2} \mathrm{CHOH} . \mathrm{COONH} \mathrm{H}_{4}+\mathrm{H}_{2} \mathrm{O} \rightarrow \mathrm{NH}_{2} \mathrm{CHOH} . \mathrm{COOH}+\mathrm{NH}_{4} \mathrm{OH} \\
& \mathrm{NH}_{2} \mathrm{CHOH} . \mathrm{COOH} \rightarrow \mathrm{NH}: \mathrm{CH} . \mathrm{COOH}+\mathrm{H}_{2} \mathrm{O} \\
& \mathrm{NH}: \mathrm{CH} \cdot \mathrm{COOH}+2 \mathrm{H} \rightarrow \mathrm{NH}_{2} \mathrm{CH}_{2} \cdot \mathrm{COOH} \text { (glycine) } \\
& \mathrm{NH}: \mathrm{CH} . \mathrm{COOH}+\mathrm{CH}_{2} \mathrm{O} \rightarrow \mathrm{CHO} . \mathrm{CHNH}_{2} \text {. COOH } \\
& \mathrm{CHO}_{\mathrm{CHNH}} \cdot \mathrm{COOH}+2 \mathrm{H} \rightarrow \mathrm{CH}_{2} \mathrm{OH} . \mathrm{CHNH}_{2} \cdot \mathrm{COOH} \text { (serine) } \\
& \mathrm{CH}_{2} \mathrm{O}+\mathrm{CH}_{2} \mathrm{OH} . \mathrm{CHNH}_{2} \cdot \mathrm{COOH} \rightarrow \mathrm{CHO} \cdot \mathrm{CH}_{2} \cdot \mathrm{CHNH}_{2} \cdot \mathrm{COOH}+\mathrm{H}_{2} \mathrm{O} \\
& \mathrm{CHO} \mathrm{CH}_{2} \cdot \mathrm{CHNH}_{2} \cdot \mathrm{COOH}+2 \mathrm{H} \rightarrow \mathrm{HOCH}_{2} \cdot \mathrm{CH}_{2} \cdot \mathrm{CHNH}_{2} \cdot \mathrm{COOH} \\
& \mathrm{CH}_{2} \mathrm{O}+\mathrm{HOCH}_{2} \cdot \mathrm{CH}_{2} \cdot \mathrm{CHNH}_{2} \cdot \mathrm{COOH} \rightarrow \mathrm{CHO} \mathrm{CH}_{2} \cdot \mathrm{CH}_{2} \cdot \mathrm{CHNH}_{2} \cdot \mathrm{COOH}+\mathrm{H}_{2} \mathrm{O} \\
& \mathrm{CHO} \cdot \mathrm{CH}_{2} \cdot \mathrm{CH}_{2} \cdot \mathrm{CHNH}_{2} \cdot \mathrm{COOH}+2 \mathrm{H} \rightarrow \mathrm{HOCH}_{2} \cdot \mathrm{CH}_{2} \cdot \mathrm{CH}_{2} \cdot \mathrm{CHNH}_{2} \cdot \mathrm{COOH}
\end{aligned}
$$

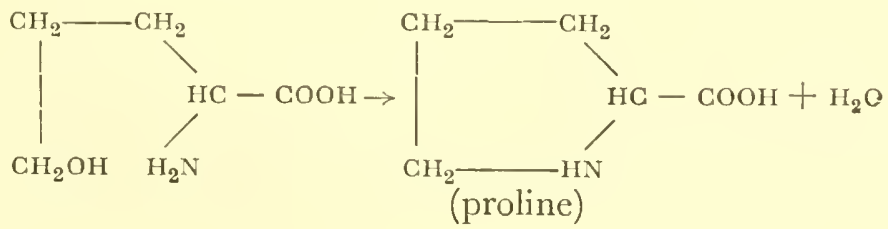


It is, however, not clear from the paper to what extent the authors were able to verify their scheme by direct experiment.

We shall find a sounder experimental basis for our opinions as to the changes which organic compounds must have undergone in the primaeval atmosphere of the Earth under the influence of ultraviolet radiations in the numerous laboratory experiments using artificial sources of light. Like water, ammonia and hydrocarbons are split when they absorb radiations belonging to different parts of the ultraviolet spectrum. This leads to the formation of various radicals such as $-\mathrm{H},-\mathrm{OH},=\mathrm{NH},-\mathrm{NH}_{2}, \equiv \mathrm{CH},=\mathrm{CH}_{2},-\mathrm{CH}_{3},-\mathrm{CN}, \mathrm{C}_{2} \mathrm{H}, \mathrm{C}_{6} \mathrm{H}_{2}$ and $\mathrm{C}_{6} \mathrm{H}_{4}$. When the gas is highly rarefied, as is the case in the outer layers of the atmosphere, these radicals can exist as such for a longer or shorter time. However, as the pressure increases, their life span decreases quickly because they combine with one another to form stable compounds. When this happens, all possible combinations occur and thus there arises a great diversity of substances. ${ }^{118}$ Contemporary scientific literature contains an immense amount of material concerning the transformation of organic substances by ultraviolet radiation. The saturated hydrocarbons only absorb radiation of very short wavelength at the margin of the ultraviolet spectrum but the olefines can also undergo chemical changes under the influence of radiations having a wavelength greater than $2000 \AA$. The action of ultraviolet radiation brings about polymerisation and isomerisation of these hydrocarbons. They are also oxidised, mainiy at the expense of the oxygen arising from the photolysis of water. This oxidation leads to the formation of various alcohols, aldehydes and ketones, which can be further oxidised or broken down photochemically to give $\mathrm{CO}, \mathrm{H}_{2}$ and new derivatives. Under the continued action of ultraviolet radiation the monobasic acids thus formed give rise to $\mathrm{CO}_{2}$, hydrocarbons and small amounts of $\mathrm{CO}$ and $\mathrm{H}_{2}$. The dibasic acids lose $\mathrm{CO}_{2}$ and are transformed into monobasic ones. Various nitrogen-containing derivatives may also easily be formed by reactions with ammonia, hydrazine and such substances. ${ }^{19}$ In this way the great diversity of oxygen- and nitrogen-containing derivatives of hydrocarbons which ap- 
peared in the primaeval atmosphere as a result of the action of electric discharges was markedly augmented both in quantity and quality by the action of ultraviolet radiation. Owing to the selective activity of radiant energy on the surface of the Earth new organic compounds appeared continually, and the complication of their molecular structure was increasing the whole time.

Methane absorbs ultraviolet radiation in the neighbourhood of $1,400 \AA$, and especially strongly in the neighbourhood of $1,295 \AA .{ }^{120}$ When this happens, it is split to methyl radicals and atomic hydrogen. The final products of these transformations of methane are hydrogen and acetylene as well as ethylene, ethane and hydrocarbons with three, five and six carbon atoms. ${ }^{121}$

According to $\mathrm{S}$. Tołłoczko, ${ }^{122}$ when ethane is submitted to ultraviolet irradiation it forms a light, colourless condensate made up of a mixture of hydrocarbons, chiefly hexane, and a gas containing hydrogen and methane. When ethylene is decomposed by ultraviolet radiation having a wavelength shorter than $2,100 \AA$, acetylene and hydrogen are formed..$^{123}$

D. Berthelot and H. Gaudechon ${ }^{124}$ observed a slow polymerisation of ethylene under ultraviolet irradiation. According to H. S. Taylor and D. G. Hill ${ }^{125}$ the polymerisation of ethylene may lead to the formation of saturated hydrocarbons, in particular to those of very high molecular weight such as cuprene.

Acetylene also polymerises very easily and, under the influence of ultraviolet irradiation, it gives rise to many products, including benzene and naphthalene. ${ }^{126}$

Ethylene, acetylene and their derivatives may readily be oxidised photochemically by oxygen to form aldehydes, ketones and acids. For example, on irradiation in the presence of oxygen ethylene gives rise to formic acid ${ }^{127}$ and acetylene to oxalic acid and formaldehyde. ${ }^{128}$ The oxidation products can react with the hydrocarbons and their derivatives to give more and more complicated organic substances such as allyl alcohol, crotonic, maleic and tartaric acids, etc.

Ammonia absorbs ultraviolet light at wavelengths below $2,400 \AA$. The maximum absorption is at $1,910-1,935 \AA .{ }^{129}$ 
The primary photochemical reaction seems to be the breakdown of ammonia according to the equation: $\mathrm{NH}_{3} \rightarrow$ $\mathrm{NH}_{2}+\mathrm{H}^{130}$ A number of derivatives can be formed from $\mathrm{NH}_{2}$, especially hydrazine, $\mathrm{NH}_{2}-\mathrm{NH}_{2}$, which itself absorbs ultraviolet radiation at $2,400 \AA$ and can then take part in chemical reactions with other substances or be broken down according to the equation $2 \mathrm{~N}_{2} \mathrm{H}_{4} \rightarrow 2 \mathrm{NH}_{3}+\mathrm{N}_{2}+\mathrm{H}_{2} \cdot{ }^{131}$ Molecular nitrogen could also have been formed in the primaeval atmosphere by the direct oxidation of ammonia by the oxygen liberated by the photolysis of water and the escape of hydrogen. Reactions between nitrogen and hydrocarbons, particularly methane, give rise to cyanogen derivatives.

When ammonia reacts photochemically with carbon monoxide it gives formamide, with ethylene it gives vinylamine and so forth. As a rule unsaturated hydrocarbons react photochemically with ammonia to give cyclic compounds of the nature of pyrrolidine or pyridine. ${ }^{132}$

In the primaeval atmosphere of the Earth the hydrocarbons could also react with hydrogen sulphide. This gas was evolved during the formation of the lithosphere when metallic sulphides were hydrolysed by the constitutional water of the mineral formations. When it was given off into the atmosphere it was enabled to react with the hydrocarbons present there by the action of both electric discharges and ultraviolet radiations. This mus: have led to the formation of mercaptans and various products of their polymerisation, as was observed by S. M. Losanitsch and M. Z. Jowitschitsch ${ }^{133}$ when they passed silent discharges through a mixture of $\mathrm{H}_{2} \mathrm{~S}$ and ethylene:

$$
\begin{gathered}
\mathrm{C}_{2} \mathrm{H}_{4}+\mathrm{H}_{2} \mathrm{~S} \rightarrow \mathrm{CH}_{3} \cdot \mathrm{CH}_{2} \mathrm{SH} \\
6 \mathrm{CH}_{3} \cdot \mathrm{CH}_{2} \mathrm{SH} \rightarrow\left(\mathrm{C}_{2} \mathrm{H}_{4} \mathrm{~S}\right)_{6}+6 \mathrm{H}_{2}
\end{gathered}
$$

In their book, to which reference has already been made, C. Ellis and A. A. Wells ${ }^{92}$ showed that on ultraviolet irradiation from a quartz mercury lamp mercaptans (RSH) lose their hydrogen and are converted into the corresponding alkyl disulphides (R-S-S-R). Ultraviolet irradiation can also bring about the formation and further alteration of thioglycolic acid, cysteine and other complicated organic compounds of sulphur, particularly heterocyclic ones. 
It is a peculiarity of ultraviolet radiation that its activity is very selective. Sometimes it affects only a very limited part of some particular molecule. Very delicate and specific alterations may therefore be brought about by the action of ultraviolet radiation on substances whose specific absorptive capacity is strictly limited to a particular part of the ultraviolet spectrum. An example of this, which is well known to biologists, is the conversion of ergosterol to vitamin $\mathrm{D}_{2}$ by ultraviolet irradiation. ${ }^{134}$
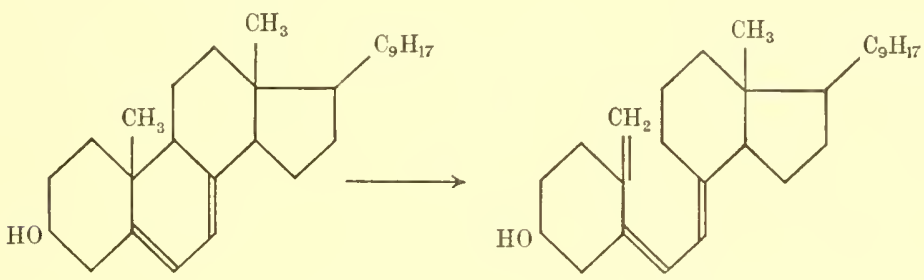

In this reaction the complicated molecule remains unchanged as a whole. It is only in the second ring of the phenanthrene nucleus that one bond is broken, with the formation of a double bond in the side chain. Other very diverse but always highly specific stereoisomeric transformations of organic molecules are well known to occur on irradiation with ultraviolet light of strictly defined wavelength. ${ }^{135}$ In particular we must note the cis-trans isomerisation of very many organic compounds, both simple ${ }^{136}$ and considerably more complicated in structure. ${ }^{137}$ Finally, if ultraviolet light is circularly polarised it can affec: the optical isomerism of the compounds formed, thus creating the conditions for direct asymmetric synthesis. (We shall deal with this subject in more detail somewhat later.)

Taking into account all that has been discussed, we may assume that in the atmosphere of the primaeval Earth many diverse and complicated organic substances were formed from comparatively simple ones, mainly methane, ammonia, water vapour and hydrogen sulphide. under the influence of electric discharges and ultraviolet radiation. With rain and other precipitations these complicated substances fell into the primitive hydrosphere. Having fallen into this new medium they continued to change and become even more compli- 
cated, but in aqueous solution the process took on certain new characteristics.

We must first say a few words as to the concentration of organic substances which could have been attained in the waters of the primaeval Earth. In this connection it is sometimes maintained that the quantity of hydrocarbons and their derivatives formed on the surface of the Earth must have been infinitesimal in comparison with the quantity of water in the primitive ocean and that, consequently, their concentration was quite negligible. For this reason any further transformation of the organic substances in the hydrosphere was almost precluded because, on account of their great dilution, the distances between the molecules were so great that they could hardly come into contact with one another.

In this connection it may not be out of place to recall an example once produced by Lord Kelvin ${ }^{138}$ :

Suppose that you could mark the molecules in a glass of water ; then pour the contents of the glass into the ocean and stir the latter thoroughly so as to distribute the marked molecules uniformly throughout the seven seas; if you then took a glass of water anywhere out of the ocean, you would find in it about a hundred of your marked molecules.

In the case under discussion, however, we are certainly not dealing with a glass of organic substances but with incomparably larger quantities. H. C. Urey has calculated that, if only half the carbon now existing on the surface of the Earth took the form of an aqueous solution of organic substances, then the primaeval ocean would consist of a 10 per cent solution of such substances. (One must, of course, bear in mind that the amount of water on the surface of the Earth at that time was about one-tenth of what it is now.) There is thus no question of such wide dispersal of organic compounds in the waters of the primitive ocean or of such low concentrations as to preclude the possibility of organic molecules reacting with one another. On the contrary, even the mean concentrations were very high, quite sufficient for the later development of more and more complicated and diverse carbon compounds by polymerisation and condensation. 
Furthermore, the hydrosphere of the Earth was no more uniform then than it is now. In isolated parts of it, such as land-locked basins of shallow water, gulfs or lagoons, evaporation of water might have led to even higher concentrations of organic substances. Local increases in concentration could easily have been brought about by the adsorption of organic substances on clays or other inorganic deposits on the bottom and shores of the water as was suggested by J. D. Bernal in his well-known book The physical basis of life. ${ }^{139}$

Some authors, such as V. Vil'yams ${ }^{140}$ and N. Kholodny $\check{1}^{141}$ have even taken the view that the chemical processes leading up to the appearance of life did not take place in the seas and oceans but on the surfaces of particles of marl derived from the primary mineral formations. B. B. Polynov, ${ }^{142}$ who was very interested in questions concerning the migration of the elements within the biosphere, also held this view.

We must, however, emphasise most strongly that it was the actual water of the hydrosphere which formed the necessary medium in which arose the very complicated organic compounds which later provided the material for the formation of the bodies of living things. Even now water forms the predominant, though also the simplest, chemical component of all 'living matter' of the whole range of organisms inhabiting the Earth.

The complicated interactions of organic substances, their synthesis and degradation in living organisms, can only take place in an aqueous medium and the water itself plays a direct part in these processes. Whenever the water content of a living body is substantially decreased there occurs either complete destruction of that body or else anabiosis, the temporary suspension of metabolism.

Even if we adopt the hypothesis of Vil'yams and Kholodnyi that the processes of transformation of organic substances took place on the surfaces of mineral particles, it is still necessary to assume the presence of water on these particles, if not as droplets, at least in the form of a surface film. Only under these conditions could there have taken place the formation of complicated organic compounds such as exist at present. This is to say that the situation on the particles is similar to that in the water of the hydrosphere though, 
on the particles, the water does not exist in large basins but is diffuse or subdivided.

Unlike these authors, we feel that it is far more probable that the formation of complicated organic compounds occurred mainly in the waters of the seas and oceans. These occupied a large part of the surface of the Earth and therefore the bulk of the carbon compounds accumulated in them. The presence of large basins of water also enabled the migration of the non-volatile elements to take place faster and more completely. This led to the formation of a particular mixture of inorganic substances, many of which played an essential part in the transformation of carbon compounds as catalysts and even as components of the material of which 'living matter' is constructed.

Vil'yams and Kholodnyǐ developed their hypotheses mainly because they saw in the marl particles a protection for the developing proteins against the disintegrative action of ultraviolet radiation. However, at the stage of the development of organic substances which we are now considering, the action of the ultraviolet radiation might have played a positive part, just as it did in the atmosphere. In the hydrosphere, however, this activity would be limited to the most superficial layers because the ultraviolet radiations could not penetrate deeper into the water.

Thus there must have accumulated in the primaeval hydrosphere considerable amounts of oxygen-, nitrogen- and sulphur-containing derivatives of hydrocarbons coming partly from the lithosphere, but mostly from the atmosphere. The further transformation of these derivatives was partly brought about by ultraviolet radiations but mainly by catalytic processes.

Among the catalysts taking part in these reactions there may have been both salts in aqueous solution and also insoluble deposits on the surface of which the organic compounds were adsorbed. The compounds which were formed in the hydrosphere became more and more complicated and it is therefore hard to imagine the whole course of the chemical processes which occurred there. 


\section{The origin of carbohydrates, lipids, porphyrins, amino acids, nucleotides, polynucleotides and protein-like polypeptides.}

We shall confine ourselves to an attempt to draw a possible picture of the formation of only some isolated groups of organic substances of the greatest biological significance: carbohydrates, some lipids, organic acids, porphyrins, nucleoticles and, finally, protein-like substances.

However, before turning to this subject we must discuss briefly a phenomenon which is characteristic of many organic substances of biogenic origin, namely their dissymmetry ${ }^{143}$ and the possible ways in which this could have arisen on the Earth before the appearance of life.

The gradual increase in the complexity of organic substances which occurred during their evolution led, at a particular stage in their development, to the emergence of a new property, the dissymmetry of molecules. This property appears whenever an increase in complexity of the molecule leads to at least one of its carbon atoms being united through each of its four valencies to different groups of atoms. For example neither methane, nor carbon monoxide, nor the acetaldehyde which was formed from them, nor even acetic acid possessed this property, in that three of the valencies in their methyl groups were satisfied in the same way, with hydrogen. Neither does dissymmetry arise when glycine is formed by substituting an amino group for one of the hydrogen atoms in acetic acid. However, when another hydrogen atom is replaced by a methyl group with the formation of alanine, dissymmetry arises. This property of molecules is expressed in the existence of two very similar forms of the given organic substance; their molecules contain exactly the same atoms and even exactly the same groups, but these groups are differently disposed in space. If a particular radical is on the right in one of the forms it will be on the left in the other and vice versa. Our two hands serve as a simple model of this dissymmetry. If we lay them side by side with the palms rlown we shall see that, for all their similarity, the right and left hands are radically different in the arrangement of their separate parts. If the thumb is on the left of the right hand, 
the thumb will be on the right of the left hand, etc. Thus each hand is the mirror image of the other (Fig. 13).

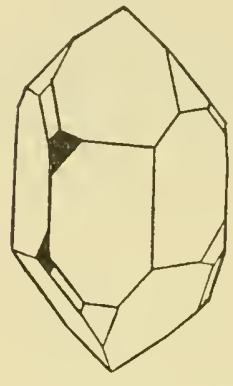

a

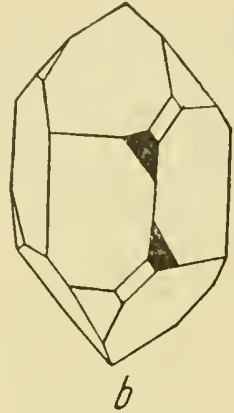

Fig. 13. Crystals of (a) laevo- and (b) dextro-quartz.

In the ordinary laboratory synthesis of organic substances we always obtain mixtures of equal parts of both forms of dissymmetric molecules (a so-called racemate). This is easy to understand, because the formation of one form or the other (the dextro or laevo antipode) in a chemical reaction depends on which of two atoms, placed on one side or the other of the plane of symmetry, will be replaced by a new group of atoms. But the very concept of symmetry implies that both of the atoms in question are subject to identical forces. The probability that one antipode or the other will be formed is therefore exactly the same. Such large numbers of molecules take part in these chemical reactions that statistical laws apply to them and it is very unlikely that an excess of one or other antipode will arise. Indeed we do not usually observe such an excess under natural conditions in the absence of life, or in laboratory syntheses. ${ }^{144}$ In Miller's experiments, for example, when he used silent electric discharges, alanine and the other amino acids always appeared in the racemic form.

In living organisms, on the other hand, the amino acids of which the natural proteins are formed are exclusively in the $\mathrm{L}$ configuration. The $\mathrm{D}$ forms of amino acids are to be found for certain only in some specific bacterial or fungal products, particularly in antibiotics (e.g. D-leucine in grami$\operatorname{cidin}^{145}$ and D-phenylalanine in tyrocidine $\left.{ }^{146}\right)$. In such cases, however, the $\mathrm{L}$ forms of these acids usually are absent.

As a general rule, if a substance having dissymmetric molecules is elaborated by a particular organism, that organism will only produce one of its two forms. The antipode of that substance is either not to be found in living things, or else it is produced by some other organism. This rule applies 
particularly to substances which are of importance for life, such as the amino acids, proteins, carbohydrates, certain lipids, etc.

This capacity of protoplasm to form and store only one antipode of dissymmetric molecules is an indication of the asymmetry of living substance. It is absent from non-living nature but is a characteristic feature of all living things. ${ }^{147}$

The fact was noticed by L. Pasteur ${ }^{148}$ who wrote of it as " this great character which establishes perhaps the only well marked line of demarcation that can, at present, be drawn between the chemistry of dead matter and the chemistry of living matter". The same idea was later emphasised by $\mathrm{V}$. Vernadskir ${ }^{149}$ who thought that the chemical non-identity of the dextro and laevo forms within living bodies was due to the presence of a peculiar 'configuration of cosmic space' in these bodies which cannot be reproduced under laboratory conditions. However, a large body of evidence has since been obtained, which shows conclusively that dissymmetry can arise independently of life. ${ }^{150}$

Pasteur himself ${ }^{151}$ had already pointed out the ways in which the formation of dissymmetric substances might have been achieved in nature. In his opinion this could occur in the presence of some other dissymmetric substance or as a result of the action of some asymmetric physical factor. The first part of this hypothesis was later developed by $\mathrm{E}$. Fischer ${ }^{152}$ in its application to the synthesis of the higher sugars. In increasing the number of carbon atoms in a sugar molecule by the cyanhydrin synthesis, E. Fischer showed that the presence of a particular configuration in the original molecule of sugar affects the form of the derivative, and. of the two possible configurations which could result from the entry of the new carbon atom into the compound, only one actually arises. Fischer put forward the hypothesis that the dissymmetry of carbohydrates and other substances in living cells arises because they are synthesised within organisms under the infuence of optically active substances such as chlorophyll.

IV. Marckwald ${ }^{153}$ confirmed this hypothesis experimentally. He obtained an optically active (dissymmetric) substance by using in its synthesis a substance which is already dissymmet- 
ric, the alkaloid brucine. Marckwald combined the brucine with methylethylmalonic acid, which is not dissymmetric as two of the valencies of its $\alpha$ carbon atom are occupied by carboxyl groups. When the resulting compound was decarboxylated only the free carboxyl group (that which was not combined with brucine) was split off. When the brucine was later removed leaving methylethylacetic acid, this was dissymmetric with a definite preponderance of the laevo isomer.

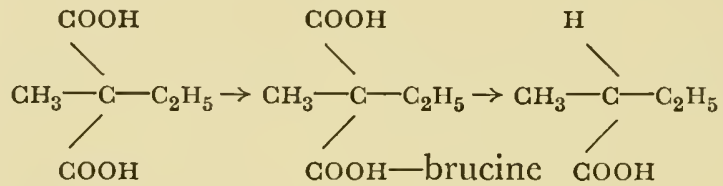

A. McKenzie ${ }^{154}$ later used the same method for carrying out a whole series of dissymmetric syntheses. Thus, if we have dissymmetric substances at our disposal, we can use them to obtain other dissymmetric substances. From this point of view special interest attaches to the work of the school of G. Bredig ${ }^{155}$ on dissymmetric syntheses with the help of catalysts, among them dissymmetric substances.

For example, G. Bredig and M. Minaeff ${ }^{156}$ showed that if the chemical combination of hydrocyanic acid with aldehydes is brought about by the catalytic activity of quinine or quinidine, then, in the one case the dextro and in the other the laevo form of cyanhydrin is obtained. The catalysts of living cells, the enzymes, are dissymmetric. Synthesis brought about by them must, therefore, also lead to the formation of dissymmetric compounds. Such syntheses have, indeed, been carried out by many workers, especially C. Neuberg ${ }^{157}$ in his work on the dehydrases, carboligase, aldehyde mutase and other enzymes of yeast.

In living cells the differential adsorption of the different antipodes on structures composed of dissymmetric materials may play an important part. Under laboratory conditions separations of this kind can be carried out on paper or silica gel containing an optically active substance (camphorsulphonic acid, mandelic acid, etc. $)^{158}$ or in other ways.

Thus it is now to some extent clear in principle in what 
way dissymmetry develops within living organisms. It is true, as W. Kuhn ${ }^{159}$ has already pointed out, that the simple laws of dissymmetric synthesis are not sufficient to explain the extremely high degree of optical purity found in protoplasm and the constancy with which it is maintained throughout innumerable generations of organisms. There can, however, no longer be any doubt that particular antipodes are formed in living things as the result of the presence of pre-formed dissymmetric substances, especially dissymmetric enzymes. Furthermore, this asymmetry is enhanced by the characteristic specific organisation of protoplasm which we shall discuss in more detail later on.

This explanation of the appearance of dissymmetry in protoplasm does not, however, get over the problem of the original dissymmetric synthesis, for all the syntheses discussed so far have depended on the presence of pre-formed dissymmetric compounds which are usually derived from plants (e.g. brucine and quinine).

This question was raised very pointedly by F. R. Japp ${ }^{160}$ at the turn of the century. In his paper Stereochemistry and vitalism Japp categorically denied the possibility of primary dissymmetric synthesis and declared that optical activity could only arise with the help of the 'life force'. Like a living being, an optically active molecule can only arise from another of the same kind. Dissymmetry never arises primarily outside a living organism.

This assertion turned out to be untrue, in that dissymmetric substances can arise, not only in the presence of other dissymmetric substances, but also under the influence of dissymmetric physical factors. As we have already pointed out, Pasteur ${ }^{161}$ had already had this very idea. He considered that the formation of optically active compounds in nature occurred under the influence of 'dissymmetric forces' associated with the movement of the Earth, terrestrial magnetism, etc. With this in mind Pasteur tried to obtain optically active substances by carrying out reactions in rapidly rotating tubes or by allowing racemic mixtures to crystallise in a strong magnetic field. Pasteur did not obtain positive results by these experiments. It was shown later by P. Curie ${ }^{162}$ that this lack of success was due to the fact that the influences applied by 
Pasteur were not, in fact, dissymmetric. Pasteur's experiments were based on a false conception of the asymmetry of motion and magnetic fields. His idea was, however, fundamentally sound.

As early as the end of the nineteenth century J. H. van't Hoff ${ }^{163}$ pointed to the circular polarisation of light as a possible cause of the appearance in nature of dissymmetric substances formed photochemically. For a long time attempts to confirm this idea experimentally did not meet with positive results because those who performed them did not take account of the condition " that one should choose only those reactions which can usually be initiated by the action of the waves of light ". ${ }^{164}$

Success was first obtained in 1929 by W. Kuhn and E. Braun, ${ }^{165}$ who decomposed a racemic ester of $\alpha$-bromoproprionic acid under the influence of circularly-polarised ultraviolet light with a wavelength of $2,800 \AA$. These experiments showed that it is possible to obtain an optically active substance from an inactive one without any participation by organisms or products derived from them. In these experiments, however, as in many later ones (W. Kuhn and E. Knopf,, ${ }^{166}$ S. Mitchell, ${ }^{167}$ J. C. Ghosh, ${ }^{168}$ and others) the optical activity did not, strictly speaking, arise as the result of the synthetic process but was due to the fact that the antipodes making up the racemic mixture decomposed at different rates under the influence of the polarised light.

The direct synthesis of a dissymmetric substance by irradiation with circularly-polarised light was first accomplished by $G$. Karagunis and G. Drikos ${ }^{169}$ and later by a number of other workers.

The synthesis by T. L. Davis and J. Ackermann ${ }^{\mathbf{1 7 0}}$ is specially interesting to us. By irradiating completely optically inactive original materials with right circularly-polarised ultraviolet radiation $(2,535-2,539 \AA)$ these authors obtained a substance, tartaric acid, as the very antipode which is widely distributed among living things.

It may now be held that we have complete proof of the presence of circularly- or elliptically-polarised light under natural conditions. This was already established by A. Byk ${ }^{171}$ and has since been fully confirmed. For example, the light 
of the sky is partly plane polarised but on reflection from water it becomes elliptically polarised. Thus, many causes work together to bring about the presence of right elliptically-polarised light on the surface of the Earth.

Thus we now have some basis for supposing that the action of circularly- or elliptically-polarised light (especially ultraviolet light) must have led to the appearance of dissymmetric substances in the atmosphere and hydrospliere of the Earth even before the emergence of life.

We must point out another possible way in which dissymmetric substances could have been formed without the participation of living things, namely by using dissymmetric crystals as catalysts. The possibility of using this method for the synthesis of dissymmetric substances in the laboratory was noted by I. Ostromisslensky ${ }^{172}$ as early as 1908 . However, it was not until the 193 os that this idea was realised practically in the experiments of G.-M. Schwab and his collaborators $^{173}$ and in the analogous experiments of A. Stankewitch. ${ }^{174}$ G.-M. Schwab succeeded in obtaining an optically active substance by partial destruction of its racemate in a reaction catalysed by metals deposited in a thin coat on dextro- or laevo-quartz crystals.

Such quartz crystals are widely distributed in inorganic nature. J. D. Bernal, ${ }^{175}$ therefore, put forward the hypothesis that the dissymmetry of organic substances might have arisen primarily, before life appeared on the Earth, as a result of the synthesis of these compounds on the surfaces of quartz crystals which adsorbed the starting materials. It is true that in Schwab's experiments it was not synthesis but decomposition which took place. Recently, however, some Soviet chemists, in the first place A. Terent'ev and his colleagues, ${ }^{176}$ have succeeded in carrying out the direct dissymmetric synthesis of a number of organic compounds by using catalysts deposited on powders made from crystals of dextro- or laevoquartz. From our point of view the most interesting reactions are the aldol condensations and the reaction of cyanethylation, which occur by quartz catalysis in the liquid phase and at ordinary room temperatures.

In conclusion, we shall mention a few cases of the spontaneous development of dissymmetry from optically inactive 
starting materials in an enclosed system without the participation of any dissymmetric auxiliary substance whatsoever. C. Neuberg ${ }^{177}$ kept a specimen of the potassium salt of $\beta$ methylvaleric acid for some years. During this time it partially crystallised. When the crystals were separated from it, the mother liquor was found to have considerable optical activity. Another similar case has been described by $\mathrm{E}$. Havinga $^{178}$ who kept a solution of methylethylallylphenylammonium iodide in a sealed tube for two months and found that optically active crystals with a considerable specific rotation had separated out $\left([\alpha]_{\mathrm{D}}+27^{\circ}\right.$ in chloroform). In a later publication Havinga ${ }^{179}$ discussed the idea that even long before the appearance of life there might have occurred on the Earth similar spontaneous dissymmetric syntheses of various organic compounds.

Thus, in contrast to the pessimistic utterances of the turn of the century, we now know of several ways by which optically active carbon compounds might have arisen primarily on the Earth before the appearance of life. In our further discussion we shall try to show what were the causes which led to the fixing in protoplasm of the dissymmetry of organic molecules which had arisen primarily, and what an essential part this played in the general organisation of living things.

Let us now turn to a consideration of what may be said about the primary formation of the groups of compounds most characteristic of life in the waters of the primaeval ocean. We have a wide range of factual material obtained from laboratory experiments relating to this matter. This shows that the immediate oxygen, nitrogen and sulphur derivatives of hydrocarbons, when dissolved in water in the presence of various inorganic catalysts or adsorbed on clay or other precipitates, cannot remain unchanged even at the comparatively low temperatures which are common under present conditions.

By reacting with each other and with molecules of water they undergo many of the reactions which occur by simply allowing the solutions to stand in the laboratory, but which may also be observed occurring as stages in the metabolism of living organisms. There take place in the laboratory the reactions of oxidation and reduction, aldol condensation, 
polymerisation, ring formation and the migration of radicals. In living things, however, these reactions are strictly coordinated in respect of their velocities so that they form a long chain of processes in which one reaction follows the other in a strictly determined sequence. As a result of this, it is a general rule that not all the transformations which are thermodynamically possible in the organism actually occur there. Only strictly determined synthetic pathways are followed and therefore highly specialised compounds are formed. The reactions are also so completely harmonious that they can be combined in such a way that the energy liberated by one reaction can be used for another which could not take place spontaneously without it.

Such co-ordination can, however, only occur in very highly developed and well-organised systems (such as organisms) and not simply in a solution of various carbon compounds. Any co-ordination which may occur in these, if indeed any does, is a purely temporary and fortuitous phenomenon and, as a rule, the only reactions which take place are those in which the compounds participating are themselves rich in free energy or receive supplementary energy from quanta of light, electric discharges, increased pressure, etc. Consequently, in the chaos of different and often mutually independent transformations, there is a predominance (sometimes temporary and short-lived) of those reactions which, under the given physico-chemical conditions and, above all, in the presence of particular catalysts, occur fastest.

Unfortunately we cannot bring direct observation to bear on processes of this sort under natural conditions. This is prevented, not only by the oxidised conditions of the present age, but even more by the ubiquitous distribution of living things on the surface of the Earth. In their presence it is very hard to differentiate between the abiogenic processes which were possible in the primitive hydrosphere and the biogenic ones which only occur at the present time. Organisms confuse the whole issue in this respect. They discharge into the surrounding inorganic medium large amounts of specific substances which can only be formed in the course of highly organised metabolic processes and which are most unlikely to have been formed under primaeval conditions. 
On the other hand, organisms can absorb and consume such substances, and metabolise them to form parts of their own bodies. They radically alter the whole course of the chemical processes in their environment, not merely by their own immediate activities, but also by means of the extremely powerful catalysts which they produce-enzymes.

We can therefore only judge of the transformations accomplished by the more or less complicated organic compounds on the Earth at some time before the appearance of life by analogy with phenomena which have been observed by artificially set up laboratory experiments.

It is very easy to imagine the abiogenic development of sugars and carbohydrates generally in the primaeval hydrosphere. The well-known synthesis carried out by A. Butlerov $^{\mathbf{1 8 0}}$ as early as $\mathbf{1 8 6 1}$ may serve as the starting point for this.

If one simply allows a solution of formaldehyde in lime water to stand under ordinary laboratory conditions, condensation occurs and one obtains a syrup containing a sugarlike substance which Butlerov called 'methylenitan'. The chemical nature of this substance was not elucidated until thirty years later. By similar means E. Fischer and J. Tafel ${ }^{181}$ prepared a syrup containing a mixture of sugars and isolated from it a hexose $\left(\mathrm{C}_{6} \mathrm{H}_{12} \mathrm{O}_{6}\right)$ which they called 'acrose'. This was optically inactive, as was to be expected from a laboratory synthesis. This optical inactivity was, however, merely due to the fact that acrose was a racemic mixture of two antipodal ketoses, natural D-fructose and L-fructose, its antipode which is not met with in living nature. For this condensation reaction $\mathrm{E}$. Fischer gave the following schematic equation:

$$
\begin{array}{r}
\mathrm{CH}_{2} \mathrm{O}+\mathrm{CH}_{2} \mathrm{O}+\mathrm{CH}_{2} \mathrm{O}+\mathrm{CH}_{2} \mathrm{O}+\mathrm{CH}_{2} \mathrm{O}+\mathrm{CH}_{2} \mathrm{O} \rightarrow \\
\mathrm{CH}_{2} \mathrm{OH} . \mathrm{CHOH} . \mathrm{CHOH} . \mathrm{CHOH} . \mathrm{CO} . \mathrm{CH}_{2} \mathrm{OH}
\end{array}
$$

However, it was later shown that the reaction seems to pass through successive stages with the formation of intermediate compounds containing fewer formaldehyde residues, in particular glvceraldehyde and dihydroxyacetone.

By slightly altering the conditions of Butlerov's experiment O. Loew ${ }^{\mathbf{1 8 2}}$ first obtained 'formose', a sweet syrup 
which is not fermented by yeasts, and then 'methose', a syrup which on dilution undergoes fermentation, i.e. it contains a sugar which can provide nourishment for heterotrophic organisms. E. Fischer and F. Passmore ${ }^{183}$ showed that 'formose' and 'methose' contained $\alpha$ and $\beta$ 'acrose' (DL-fructose and DL-sorbose). H. and A. Euler ${ }^{184}$ observed the condensation of formaldehyde in aqueous solution in the presence of calcium carbonate. In this way they obtained, among a number of other products, glycolic aldehyde, which was formed by the aldol condensation of two molecules of formaldehyde

$$
\mathrm{HCHO}+\mathrm{HCHO} \rightarrow \mathrm{CH}_{2} \mathrm{OH} . \mathrm{CHO}
$$

Experiments by Fischer and others ${ }^{185}$ showed that successive aldol condensations of glycolic aldehyde gave rise to tetroses and hexoses. However, in their experiments the Eulers found DL-araboketose, which had evidently been formed by the condensation of glycolic aldehyde and glyceraldehyde.

As E. Schmitz ${ }^{186}$ showed, glyceraldehyde condenses in the presence of calcium or barium hydroxide to give fructose and sorbose. In this reaction part of the glyceraldehyde is first converted into dihydroxyacetone and this then combines with the remaining glyceraldehyde to give a hexose. It was later $^{187}$ established that condensation of glyceraldehyde and dihydroxyacetone leads to the formation of hexoses, whereas condensation of glycolic aldehyde and glyceraldehyde gives rise to pentoses.

There has now accumulated in the scientific literature a very large amount of material concerning the formation of sugars and their derivatives in the way indicated above. ${ }^{188}$ Such reactions have even been used for the production of sugars on a technical scale. ${ }^{189}$

All the conditions necessary for the spontaneous formation of sugars were present in the primaeval hydrosphere-the starting materials in the form of various aldehydes and ketones, the catalysts in the form of lime, chalk, etc.

Thus we have very good reason to suppose that sugars, compounds which play a very important part in metabolism both as sources of energy and as structural materials for living 
things, arose primarily in the waters of the surface of the Earth long before the appearance of life on it.

Like glycolic aldehyde, acetaldehyde can also undergo condensation and we have already shown that acetaldehyde must have been produced in the primaeval atmosphere by the interaction of methane and carbon monoxide. When this condensation occurs, aldol is formed, which can easily isomerise to give butyric acid.

$$
2 \mathrm{CH}_{3} \cdot \mathrm{CHO} \rightarrow \mathrm{CH}_{3} \cdot \mathrm{CHOH} \cdot \mathrm{CH}_{2} \cdot \mathrm{CHO} \rightarrow \mathrm{CH}_{3} \cdot \mathrm{CH}_{2} \cdot \mathrm{CH}_{2} \cdot \mathrm{COOH}
$$

Further condensation of aldol into more complicated products was found by S. M. Losanitsch and M. Z. Jowitschitsch in an oily liquid which they obtained from acetaldehyde:

$$
n \mathrm{CH}_{3} \cdot \mathrm{CHOH} . \mathrm{CH}_{2} \cdot \mathrm{CHO} \rightarrow\left(\mathrm{CH}_{3} \cdot \mathrm{CHOH} \cdot \mathrm{CH}_{2} \cdot \mathrm{CHO}\right)_{n}
$$

and further isomerisation of these products revealed one of the possible methods of formation of the higher fatty acids.

Under somewhat different conditions crotonic condensation of acetaldehyde takes place:

$$
\mathrm{CH}_{3} \cdot \mathrm{CHO}+\mathrm{CH}_{3} \cdot \mathrm{CHO} \rightarrow \mathrm{CH}_{3} \cdot \mathrm{CH}: \mathrm{CH} . \mathrm{CHO}+\mathrm{H}_{2} \mathrm{O}
$$

The crotonaldehyde in its turn can condense with one molecule of acetaldehyde giving rise to sorbic aldehyde:

$$
\mathrm{CH}_{3} . \mathrm{CH}: \mathrm{CH} . \mathrm{CHO}+\mathrm{CH}_{3} \mathrm{CHO} \rightarrow \mathrm{CH}_{3} . \mathrm{CH}: \mathrm{CH} . \mathrm{CH}: \mathrm{CH} . \mathrm{CHO}+\mathrm{H}_{2} \mathrm{O}
$$

This can condense further:

$$
\begin{aligned}
& \mathrm{CH}_{3} \cdot \mathrm{CH}: \mathrm{CH} . \mathrm{CH}: \mathrm{CH} . \mathrm{CHO}+\mathrm{CH}_{3} \cdot \mathrm{CHO} \rightarrow \\
& \quad \mathrm{CH}_{3} \cdot \mathrm{CH}: \mathrm{CH} . \mathrm{CH}: \mathrm{CH} . \mathrm{CH}: \mathrm{CH} . \mathrm{CHO}+\mathrm{H}_{2} \mathrm{O}, \text { etc. }^{190}
\end{aligned}
$$

This is a method of synthesising polyenes, compounds with conjugated double bonds ; that is to say, it is a way of synthesising lipids like carotene, vitamin $\mathrm{A}$ and others which are very important biologically and very widely distributed throughout living nature.

J. D. Bernal ${ }^{191}$ has recently put forward the opinion that the lipids must have arisen at a comparatively late stage in organic chemical evolution. It seems to me that, on the contrary, the reduced conditions on the surface of the primaeval Earth were especially favourable for the formation 
of hydrophobic compounds of high molecular weight which are rich in hydrocarbon groups.

The process of the formation of petroleum, which is going on at present at considerable depths, and therefore under anaerobic conditions, to some extent confirms this idea. Direct experiments on the synthesis of individual lipids analogous to those of Miller with amino acids have, unfortunately, not yet been carried out under conditions which reproduce the state of the primaeval surface of the Earth. Our knowledge of the primary formation of lipids is therefore still very scanty and unreliable. It is considerably more meagre than what we have in respect of carbohydrates.

Most contemporary authors dealing with the problem of the origin of life affirm with complete conviction that at some stage in organic-chemical evolution in the waters of the primaeval ocean there must have occurred the primary development of those biologically important heterocyclic compounds, the porphyrins. These assertions are, however, usually of a very general nature and have but little experimental corroboration.

Only recently, and mainly thanks to the work of $D$. Shemin ${ }^{192}$ and others, has there been a great increase in our knowledge of the biosynthesis of porphyrins in living organisms. Shemin showed that the starting substances in this synthesis were fairly simple compounds, glycine and succinic acids, i.e. substances which could undoubtedly have arisen from the simpler hydrocarbons, ammonia and water. However, the actual process of biosynthesis takes place in many stages and requires for its accomplishment the presence of a very highly organised living system containing numerous enzymes and intact protoplasmic structures.

In this synthesis the succinic acid must first be activated. In the living cell this is brought about by taking it into the succinic acid-glycine metabolic cycle. In this, succinylcoenzyme $\mathrm{A}$ is formed and condenses with the $\alpha$ carbon atom of glycine and in this way $\alpha$-amino- $\beta$-oxoadipic acid is formed. It must be noted that the condensation of succinate with 
glycine is only possible in the presence of intact protoplasmic structures.

By decarboxylation $\alpha$-amino- $\beta$-oxoadipic acid is converted into $\delta$-aminolaevulinic acid:

HOOC. $\mathrm{CH}_{2} \cdot \mathrm{CH}_{2} \cdot \mathrm{CO} \cdot \mathrm{CHNH}_{2} \cdot \mathrm{COOH} \rightarrow \mathrm{HOOC} \cdot \mathrm{CH}_{2} \cdot \mathrm{CH}_{2} \cdot \mathrm{CO} \mathrm{CH}_{2} \mathrm{NH}_{2}+\mathrm{CO}_{2}$

On condensation, two molecules of $\delta$-aminolaevulinic acid form a pyrrole, porphobilinogen. Four molecules of porphobilinogen give a porphyrin structure which, by decarboxylation and dehydrogenation of the side chains forms protoporphyrin.

It must be remarked that each link in this chain of chemical transformations requires a specific enzyme. However J. J. Scott ${ }^{193}$ has recently succeeded in demonstrating the possibility of converting $\delta$-aminolaevulinic acid into porphobilinogen by purely chemical (not biological) means. In the course of this work he established that this reaction is not peculiar to $\delta$-aminolaevulinic acid but can be undergone by $\alpha$-aminoketones in general, with the formation of $\alpha$-aminomethylpyrroles. In addition to this $\mathrm{A}$. Treibs ${ }^{194}$ says that the transformation of porphobilinogen into a mixture of porphyrins can also be achieved abiogenically at high temperatures and acidities.

Certainly it is hard to tell at present to what extent analogous processes could have taken place under natural conditions independently of organisms.

As we have seen above, a number of workers have done many experiments in which pyrrole and pyrrolidine were easily formed from ammonia, acetylene and other unsaturated hydrocarbons by simple catalysis or under the influence of ultraviolet radiations. The development of these heterocyclic compounds in the primaeval atmosphere or hydrosphere can therefore scarcely be doubted. However, the possibility of their combination there to form porphyrin nuclei still needs to be substantiated. The porphyrins of petroleum which have been found under natural conditions are clearly of biogenic origin. They remained in the petroleum after the decomposition of the organisms which had synthesised them when alive. 
The question of the possibility that amino acids might have been formed under conditions similar to those which prevailed in the primitive hydrosphere has recently been studied by S. Fox. ${ }^{195}$ He showed that in a medium resembling a natural hot spring (an aqueous medium containing calcium salts at $p \mathrm{H} 8.0-9^{\circ} \mathrm{O}$ and at a temperature of $100-120^{\circ} \mathrm{C}$ ) the interaction of malic acid and urea gives rise to the formation of aspartic acid and, what is specially interesting, to ureidosuccinic acid.

We must now turn our attention to the question of the possibility of the primary abiogenic formation of nucleosides and nucleotides, in view of the extremely important part played by polynucleotides and, in particular, nucleic acids in the vital processes of organisms. As concerns the possibility of the formation of pyridine from acetylene and hydrocyanic acid Berthelot established the following equation:

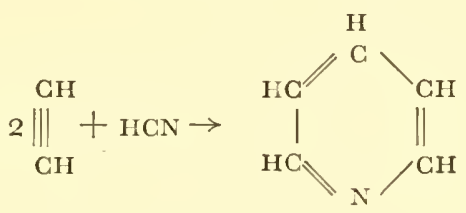

According to the results of Chichibabin, Ishigura, Ellis and others, pyridine and pyrimidine bases can easily arise from ammonia and unsaturated hydrocarbons.

Urea can also serve as the starting substance for the primary formation of pyridine and pyrimidine bases, and the urea itself can arise either from ammonium cyanate (as in Wöhler's synthesis) or, as we have already shown, by the combination of carbon monoxide and ammonia in silent electric discharges.

The first synthesis of uric acid was carried out as early as 1882 by I. Gorbachevskir by heating urea with glycerine. Numerous syntheses of purines and pyrimidine bases have been brought about by the condensation of urea with organic acids. For example, uracil was obtained by D. Davidson and O. Baudisch ${ }^{196}$ by condensing urea with malic acid. An 
204 ABIOGENIC ORGANIC-CHEMICAL EVOLUTION

intermediate compound in this reaction is $\beta$-hydroxyacrylic acid which is formed from the malic acid

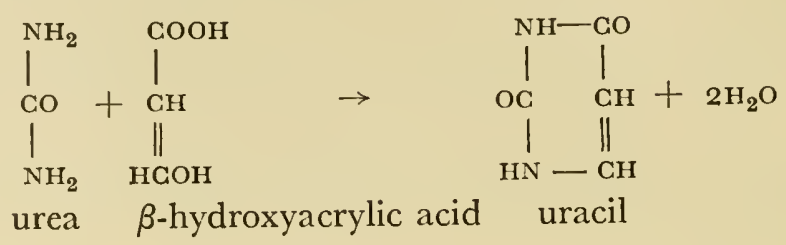

Uric acid can be synthesised by the method of R. Behrend and $\mathrm{O}$. Roosen ${ }^{197}$ from urea and mesoxalic acid:

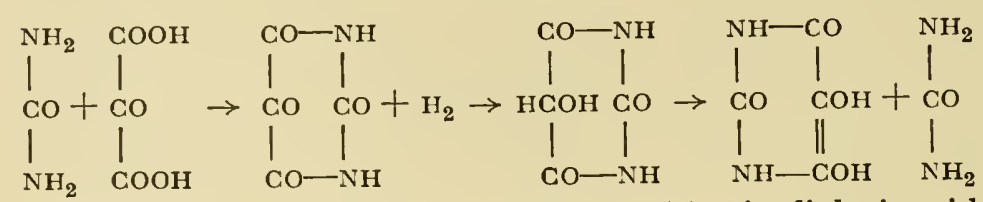

urea mesox- alloxan dialuric acid isodialuric acid alic acid<smiles>CCCCC(=O)NC(C)=O</smiles>

Under reducing conditions, uric acid may be converted to various purine bases. ${ }^{198}$ In connection with the possibility of the primary formation of nitrogen-containing heterocyclic compounds the work of $\mathrm{H}$. Staudinger and K. Wagner ${ }^{199}$ on the products of the condensation of urea with formaldehyde is very interesting.

Recent work using marked atoms has shown, however, that the synthesis of purines and pyrimidines in the living organism occurs in a different way. ${ }^{200}$ It is not based on urea $^{201}$ as was thought earlier, but proceeds by the combination of formyl residues with ammonia and oxaloacetic acid or with glycine. ${ }^{202}$ 
It has also been shown that when nucleosicles are formed in protoplasm it is not pre-formed purines and pyrimidines which combine with the pentoses, but the much simpler compounds which we have already mentioned, which serve as the starting materials for their formation. ${ }^{203}$

Of course one must be very careful here, as in all other cases, in drawing analogies between what happens in the living organism and what might have taken place in the waters of the primaeval ocean. Nevertheless we can construct on this basis hypotheses, though only very rough ones, about the primary formation of nucleosides, as the ribose or desoxyribose required can be produced in the ways which we have described for other carbohydrates.

The possibility of the incorporation of the third component of nucleotides, orthophosphoric acid, at first glance presents no difficulties. The question of the primary, abiogenic formation of compounds of phosphorus with organic substances is, however, extremely complicated and poorly understood.

In the powerfully reducing conditions which prevailed on the surface of the Earth in the earliest epoch of its existence, when carbon, nitrogen and sulphur were present in the forms of methane, ammonia and hydrogen sulphide, phosphorus must also have entered into the primitive atmosphere, though only in part, in the form of hydrogen phosphide, which reacted with the hydrocarbons to form substituted phosphines.

Unfortunately we only have very old and extremely general information to the effect that the action of electric discharges on mixtures of phosphine and ethylene leads to the occurrence of extensive condensation reactions. ${ }^{204}$ Changes of this kind can also come about on ultraviolet irradiation, for phosphines absorb radiations having wavelengths in the region of $2,315-2,290 \AA$. In the outer layers of the atmosphere, however, the phosphines must have been oxidised by the oxygen derived from the photolysis of water with the formation of phosphine oxides and alkylphosphinic acids. ${ }^{205}$ This may be regarded as the formation of phosphorous acid 
in which an alkyl group has been substituted for one of the hydrogen atoms.
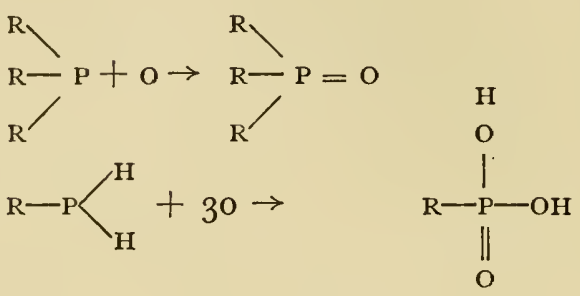

According to N. N. Semenov ${ }^{206}$ hydrogen phosphide can be oxidised directly by oxygen, the reaction proceeding by the following stages

$$
\begin{aligned}
\mathrm{PH}_{3}+\mathrm{O} & \rightarrow \mathrm{PH}+\mathrm{H}_{2} \mathrm{O} \\
\mathrm{PH}+\mathrm{O}_{2} & \rightarrow \mathrm{HPO}+\mathrm{O} \\
\mathrm{HPO}+\mathrm{O}_{2} & \rightarrow \mathrm{HP}>\mathrm{O}
\end{aligned}
$$

Phosphorous acid is formed in this way and gives rise to the corresponding salts, the phosphites.

While studying the physico-chemical environment which was formed by the reducing conditions of the primaeval hydrosphere A. Gulick ${ }^{207}$ recently came to the conclusion that its waters must have contained dissolved phosphites rather than orthophosphates, as had been the commonly accepted belief. Under these conditions orthophosphates would have been almost completely insoluble. Gulick points out that even now the amount of phosphorus dissolved in sea water is only 1.2 parts in $10^{9}$ by weight. By contrast the solubility of phosphite and hypophosphite $\left(\mathrm{CaHPO}_{3}\right.$ and $\left.\mathrm{Ca}\left(\mathrm{H}_{2} \mathrm{PO}_{2}\right)_{2}\right)$ in water is comparatively great. These, however, can only persist under reducing conditions.

Starting from cyanamide (which very probably developed 
in the primaeval atmosphere) and ammonium phosphite, Gulick postulates the following series of reactions<smiles></smiles>

cyanamide

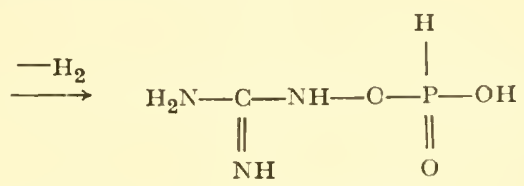

guanidine phosphite

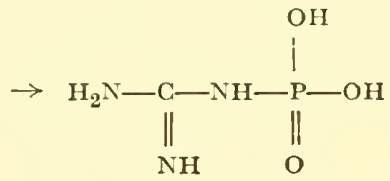

phosphoguanidine

Thus there are obtained high-energy compounds which could have arisen under the conditions of the primaeval ocean. These compounds are similar to phosphocreatine, which plays an important part as a reservoir of free energy in muscle metabolism.

Unfortunately Gulick's paper does not give any experimental support for the possibility of the transformation of guanidine phosphite with an energy of phosphorylation of about 2000-3000 cal. into phosphoguanidine with an energy of phosphorylation of about $12,000 \mathrm{cal}$. The author only points out in a very general way that photochemical energy or the energy of concurrent exothermic reactions could serve for the carrying out of these reactions. But this is just what needs to be proved. It would therefore be very desirable to have direct experiments to substantiate the possibility that phosphoguanidine or some other high-energy compound could be formed under the conditions which existed on the surface of the primaeval Earth, for the formation of substances of this sort in the primitive ocean would have been an extremely important event.

In his well-known book Time's arrow and evolution ${ }^{208} \mathrm{H}$. Blum states explicitly that in his opinion the appearance within the complicated mixture of primary organic sub- 
stances of high-energy phosphorus compounds such as adenosine triphosphoric acid (ATP) was the decisive event determining the transition from the inanimate to the animate state. In this he is starting from the hypothesis that the adenylic acid systems which were developed primarily and which are now widely distributed in living nature would, under the conditions present in the primitive ocean, open up the possibility of the formation of proteins, inasmuch as the energy required for the synthesis of polypeptides is comparatively small and could be provided at the expense of a single high-energy bond. Blum considers that an adenylic system could also have formed the basis for the development of nucleic acids.

The author himself admits that the details of the process which he has put forward are very vague, and he bases his opinion solely on the phenomena which take place in living things. It does, indeed, seem more and more probable that the energy needed for the synthesis of the polypeptide bonds of protein molecules is provided in the living organism through the agency of high-energy phosphorus compounds. ${ }^{209}$ In particular, according to $\mathrm{H}$. Borsoo $\mathrm{k}^{210}$ the first stage in this synthesis is the activation of the carboxyl groups of free amino acids at the expense of ATP, either directly or through coenzyme A. The synthesis of nucleic acids in living protoplasm takes place in just the same way, at the expense of high-energy bonds. In this process, according to $\mathrm{H}$. M. Kalckar $^{211}$ phosphorylated ribose (ribose-1-phosphate) exchanges its phosphate radical for a purine or pyrimidine base with the formation of the corresponding nucleoside. ${ }^{212}$

However, R. Zahn ${ }^{213}$ considers that first there must suddenly have been formed polyphosphoric acid, which is even now present in a number of organisms. ${ }^{214}$

Starting from this assumption and proceeding by analogy with the reactions which occur in living things, L. Roka ${ }^{215}$ has drawn the following hypothetical picture of the formation of nucleic acid in the waters of the primaeval ocean : the macromolecule of polyphosphoric acid which arose there reacted with glyceraldehyde to form polyglyceraldehyde phosphate, which, in later reactions, combined with acetaldehyde. This scheme is based on the observation of the biosynthesis 
of desoxyribose phosphate from acetaldehyde and glyceraldehyde phosphate by Escherischia coli.

The polydesoxyribose phosphate formed in this way combined with ammonia, oxaloacetic acid, glycine and formyl residues. Thus were formed the primaeval desoxyribose nucleic acids (Fig. 14).

Even for the biosynthesis of nucleic acids in living organisms Roka's scheme is certainly no more than a very ingenious hypothesis. We must regard with even greater reserve the analogy between it and the processes which might have taken place in simple aqueous solution of various organic compounds in the primaeval hydrosphere.

Let us suppose that we have demonstrated the possibility that Gulick's phosphoguanidine or some other high-energy compound could have been formed on the surface of the Earth under the influence of ultraviolet irradiation or at the expense of the large amount of energy which is liberated by the oxidation of substituted phosphines by oxygen. Even so, the probability that the energy of the high-energy bonds would be transferred particularly to the carboxyl groups of amino acids or used for the special purpose of phosphorylating ribose or for the formation of polyphosphoric acid is extremely slight under conditions of simple aqueous solution of large numbers of organic compounds. This could only be expected to occur regularly in the presence of pre-formed organisms, which would lead to the strict co-ordination of the different biochemical reactions in space and time. Such organisation is inherent in protoplasm, but it cannot have existed in the waters of the primaeval ocean, where the course of events was solely determined by relatively simple thermodynamic and kinetic laws.

It may be reckoned that we shall succeed in proving the possibility of the formation of complicated polynucleotides in the primaeval hydrosphere in accordance with these laws either in the way described or in some other way. It still does not follow in the least that a similar primary origin was possible for nucleic acids identical with those which are essential for present-day living organisms. These nucleic acids are characterised by a strictly determined sequence of mononucleotides in their polynucleotide chains and this 


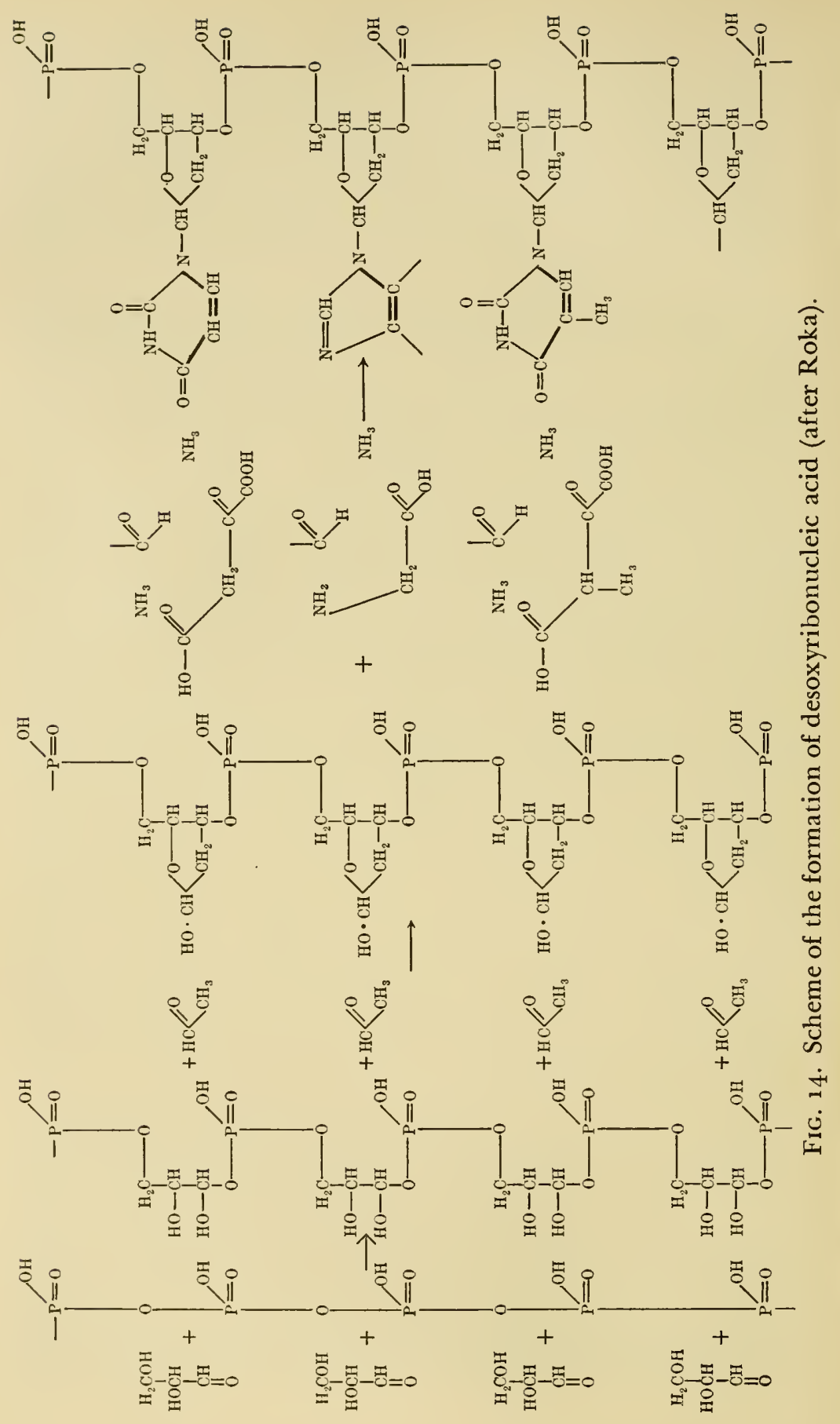


sequence is very thoroughly adapted to the performance of the physiological functions which they carry out in the living cell. Such a sequence is hardly likely to have arisen merely from the action of the simple laws which we have hitherto been discussing.

What has been said about the formation of nucleic acids applies also to the primary synthesis of proteins.

The possibility that amino acids might have been formed on the surface of the Earth before the appearance of life received its theoretical foundation and experimental confirmation in such experiments as those of Miller. The question of the polymerisation of amino acids to form polypeptides is more complicated.

Under laboratory conditions this reaction may be carried out by comparatively simple and extremely diverse methods. For example, $\alpha$-aminocaproic acid may be polymerised simply by heating it. ${ }^{216}$ Polymerised amino acids are obtained by the decarboxylation of $\mathcal{N}$-carboxy anhydrides in the presence of a small amount of water ${ }^{217}$ and in other ways. All these reactions take place in media containing only traces of water. It follows that they could not take place under the conditions prevailing in the primaeval atmosphere and hydrosphere of the Earth. Simply allowing aqueous solutions of amino acids to stand does not lead to any appreciable polymerisation, in contrast to what happens when sugars are synthesised from formaldehyde by Butlerov's method. This has a simple theoretical explanation, in that amino acids cannot polymerise to form polypeptides without taking up free energy. Calculations show that the formation of a single peptide bond requires, on the average, about $3,000 \mathrm{cal} / \mathrm{mole}^{218}$ Thus, in a homogeneous medium containing a suitable catalyst the equilibrium constant for the synthesis of alanylglycine, for example, from alanine and glycine, will only be $0 \cdot 01$.

It has, however, been suggested comparatively recently by K. Linderstrøm-Lang, ${ }^{219}$ that in the synthesis of large peptides from amino acids and other peptides, the change of free energy $\triangle F$ may be considerably less than 3,00o cal. This suggestion has been confirmed experimentally by A. Dobry, J. S. Fruton and J. M. Sturtevant. ${ }^{20}$ 
On the basis of his experiments J. S. Fruton ${ }^{21}$ has concluded that the magnitude of $\triangle F$ depends on the nature of the components taking part in the reaction and is, accordingly, very variable, sometimes falling at low as $400 \mathrm{cal} / \mathrm{mole}$. Most syntheses of peptides are endoergic but in certain cases they may be exoergic. Furthermore, Fruton points out that a very promising way of increasing the yield of peptides is by using reactions which lead to the formation of products which separate out from the general solution by becoming insoluble. This is what happens when, for example, glycinamide is converted to glycine anilide. In this reaction the yield may be as high as $6_{5}$ per cent. Fruton considers that one of the fundamental ways in which the length of polypeptide chains may be further increased is by transpeptidation and transamination reactions which occur without the expenditure of much energy.

In the scientific literature there have already accumulated a number of more or less probable hypotheses as to the sources of the energy needed for the synthesis of polypeptides and the scheme of co-ordination of the energy exchanges in the reactions. We may cite as an example the hypothesis of F. Lipmann ${ }^{22}$ concerning the participation of transphosphorylation of ATP, which is based on experiments on the synthesis of glutathione. However, as we have pointed out above, the co-ordination of these energy-exchange and synthetic reactions presupposes the existence of a certain organisation. It is perfectly applicable to protoplasm but not to the primaeval solution of organic substances. In this case it would seem far more rational to look for the immediate sources of energy in the conditions prevailing in the surrounding medium. The ideas put forward by S. E. Bresler ${ }^{23}$ are particularly interesting in this connection. Bresler considers that the free energy taken up in the formation of peptide bonds in aqueous solution might be provided by the work done by external compression. He therefore carried out his syntheses under pressures of the order of some thousands of atmospheres and, according to his reports, he actually synthesised peptide bonds in the presence of the appropriate enzymes, obtaining polymers of amino acids of 
high molecular weight which were, in many ways, similar to proteins.

If this is true, the depths of the ocean, where quite a high hydrostatic pressure prevails (though not as high as that required by Bresler), may have been a suitable place for the synthesis of polypeptides.

Unfortunately works have recently appeared ${ }^{224}$ which cast doubts on Bresler's results, and we must await the experimental settlement of the argument which has arisen on this score.

In all cases where they have expressed an opinion, those who have worked on the subject hold that it is possible that polypeptides could have been formed in the same way in which they are now produced in living bodies, by the polymerisation of pre-existing amino acids. This, however, is not the sole or necessary way in which primary formation of polypeptides could have taken place in the waters of the primacval ocean.

As a result of his extensive studies of the synthesis of amino acids G. Ehrensvärd ${ }^{25}$ became convinced that in the synthesis of polypeptides in the raters of the primaeval ocean an extremely important part must have been played by polymers of hydrocyanic acid, in particular the tetramer $(\mathrm{HCN})_{4}$ which has the structure of a nitrile

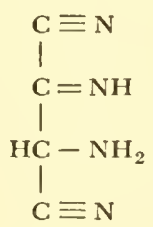

As early as 1911 T. B. Johnson ${ }^{226}$ demonstrated the possibility of the polymerisation of glycinonitrile in simple aqueous solution with hydrogen sulphide

$$
\begin{gathered}
----\mathrm{NH}_{2} \mathrm{CH}_{2} \cdot \mathrm{CN}+\mathrm{H}_{2} \mathrm{~S}+\mathrm{NH}_{2} \mathrm{CH}_{2} \cdot \mathrm{CN}+\mathrm{H}_{2} \mathrm{~S}---- \\
----\mathrm{NH}_{2} \mathrm{CH}_{2} \cdot \mathrm{CSNH}_{2}+\mathrm{NH}_{2} \mathrm{CH}_{2} \cdot \mathrm{CSNH}_{2}---- \\
-\mathrm{NH}_{2} \mathrm{CH}_{2} \cdot \mathrm{CS} \cdot \mathrm{NHCH}_{2} \cdot \mathrm{CS} \cdot \mathrm{NHCH}_{2} \cdot \mathrm{CS}---- \\
+\mathrm{NH}_{3}+\mathrm{NH}_{3}+\mathrm{NH}_{3}
\end{gathered}
$$


On the basis of this reaction Ehrensvärd considers that, in a neutral or slightly alkaline medium in the presence of hydrogen sulphide, $(\mathrm{HCN})_{4}$ should be able to bring about polymerisation, giving

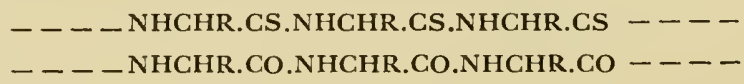

If this were confirmed we should have a very interesting scheme for the primary formation of polypeptides.

Recently the Japanese scientist S. Akabori ${ }^{227}$ has come forward with extremely original and interesting ideas about the problem with which we are concerned.

As has been pointed out above, the synthesis of amino acids in the primaeval atmosphere must have occurred in accordance with the following equation

$$
\begin{aligned}
& \text { R. CHO }+\mathrm{NH}_{3}+\mathrm{HCN} \rightarrow \text { R. } \mathrm{CHNH}_{2} \cdot \mathrm{CN}+\mathrm{H}_{2} \mathrm{O} \\
& \text { R.CHNH } 2 \cdot \mathrm{CN}+2 \mathrm{H}_{2} \mathrm{O} \rightarrow \text { R. } \mathrm{CHNH}_{2} \cdot \mathrm{COOH}+\mathrm{NH}_{3}
\end{aligned}
$$

Akabori put forward the suggestion that polymerisation was not undergone by the amino acids themselves but by intermediate products of the reaction. For example polyglycine might be formed not from glycine but from aminoacetonitrile:

$$
n \mathrm{H}_{2} \mathrm{NCH}_{2} \cdot \mathrm{GN} \rightarrow\left(-\mathrm{NHCH}_{2} \cdot \underset{\mathrm{NH}}{\|}-\right)_{n} \stackrel{\mathrm{H}_{2} \mathrm{O}}{\longrightarrow}\left(-\mathrm{NHCH}_{2} \cdot \mathrm{CO}-\right)_{n}+n \mathrm{NH}_{3}
$$

This gets round the difficulty of the expenditure of energy which stands in the way of the direct synthesis of polypeptides from amino acids. Akabori considers that particles of silicates or clay could have catalysed the polymerisation. As the $\mathbf{C H}_{2}$ groups of the polyglycine chain become more reactive during this process, they are adsorbed on the surfaces of solid bodies. Immediately after the polymerisation there occurs the con- 
densation of polyglycine with various aldehydes analogous to that which occurs with the $\mathrm{CH}_{2}$ groups of diketopiperazines:

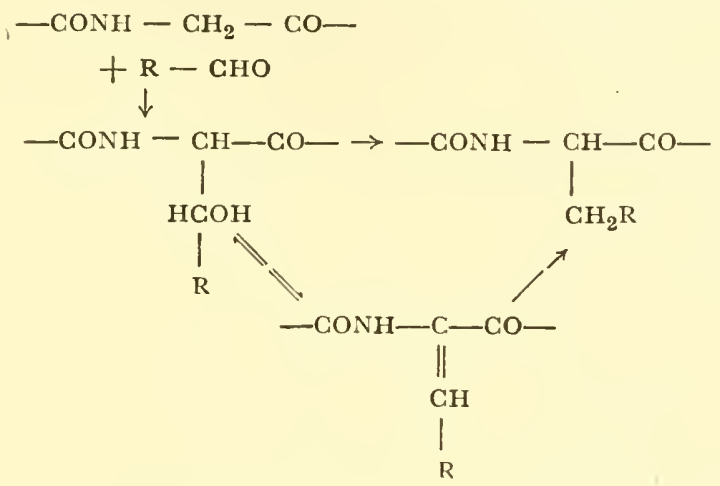

As well as aldehydes, unsaturated hydrocarbons can also combine with the polyglycine chain:

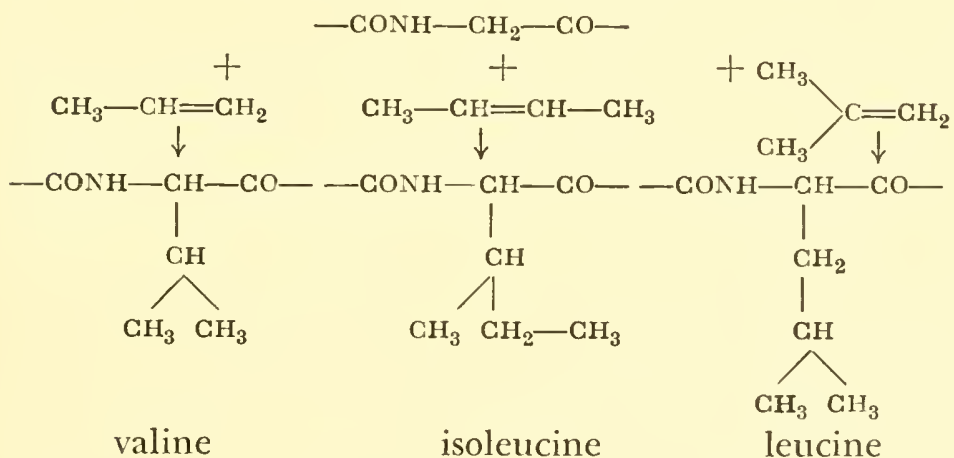

Akabori confirmed his hypothesis by direct experiments which he carried out jointly with Hakabushi and Okawa. In the first of these experiments, in which kaolin or $\mathrm{Al}_{1} \mathrm{O}_{3}$ were used at a temperature of $110^{\circ} \mathrm{C}$, there occurred the polymerisation of $\mathrm{CH}_{2}: \mathrm{NCH}_{2} \cdot \mathrm{CN}$ or $\mathbf{H}_{2} \mathbf{N C H}_{2}$. $\mathrm{CN}$. In this experiment there was formed after five hours a product giving the biuret reaction. Paper chromatography showed that it contained glycine and polypeptides of glycine. In the second experiment polyglycine adsorbed on kaolin reacted at a temperature of $60-80^{\circ} \mathrm{C}$ with $\mathrm{HCHO}$ and $\mathrm{CH}_{3} \mathrm{CHO}$. It was shown that this 
led to the formation of polypeptides containing serine and threonine.

The reaction of aldehydes with polyglycine adsorbed on the surface of solid bodies gives rise to the conditions needed for asymmetric synthesis. It is clear that if polyglycine was adsorbed in its cis forms, so that the side-chains could only react on the outside, the amino acid residues being synthesised would all have the same spatial configuration, at least within each particular polypeptide chain

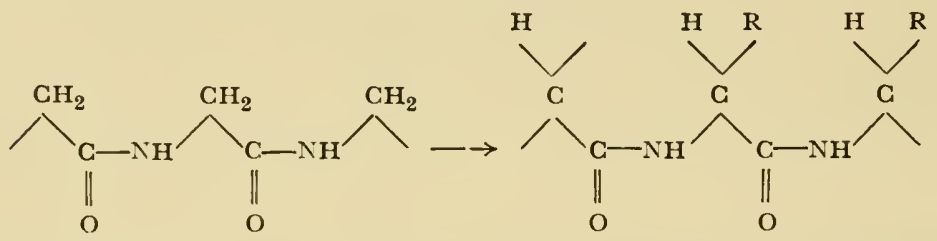

This hypothesis was confirmed by experiments by Akabori and Ikenaka on the asymmetric synthesis of phenylalanine.

According to Akabori there might thus have been formed in the primaeval hydrosphere complicated polymers of amino acid of high molecular weight, rather similar to proteins in their polypeptide structure. This synthesis of protein-like substances followed a completely different path from that which it now follows in living organisms.

It is characteristic of living organisms that in them the synthesis of proteins, like that of nucleic acids, is based on a process which has already been elaborated during the slow evolution of the organism. They arise as the product of this organisation and their specific biologically important peculiarities and properties are the result of this mode of origin.

As we have seen in this chapter, the comparatively simple laws of thermodynamics and chemical kinetics were essentially what determined the course of chemical events in the waters of the primaeval ocean. These principles provide an understandable mechanism for the formation of sugars, amino acids, purine and pyrimidine bases and even their more or less complicated polymers.

Many contemporary authors believe that, on the basis of these same laws, we shall also be able to give an explanation 
of the origin of those compounds which are specific to living things, the proteins with their enzymic activities and the nucleoproteins with their capacity for self reproduction. Such authors also see the primary development of these compounds as the key to the understanding of the origin of life. These arguments do not, however, usually amount to more than individual general declarations and it seems to us that such an approach to the problem which we are considering is wrong.

The origin of proteins, enzymes, nucleoproteins and other substances specific to living things cannot simply be based on those laws which we have been using up till now. There must first have arisen a new specific organisation and afterwards, on the basis of it, the substances appeared, not vice versa. To resolve this vexed question we must now leave, for a while, the approach to the problem which we have hitherto followed. Before studying the further stages in the development of matter on the way to the emergence of life we must learn about the structure and properties of proteins, nucleic acids and other biologically important compounds which constitute the basis of present-day living matter.

\section{BIBLIOGRAPHY TO CHAPTER $V$}

1. M. Dvali and I. Andreev, in Proiskhozhdenie nefti (ed. by M. F. Mirchink, A. A. Bakirov, B. F. D'yarkov and D. V. Zhabrev), p. 83. Moscow (Gosud. nauchnotekhn. Izd. neftyanor i gorno-toplivoř Lit.), 1955 .

H. B. Bull. Physical Biochemistry. New York, 1943.

2. J. L. Kulp. Bull. geol. Soc. Amer., 62, 326 (1951).

3. N. L. Bowen and G. F. Tuttle. Bull. geol. Soc. Amer., 6o, 439 (1949).

4. (IV. 121 ).

5. (IV. 12).

6. C. Koene, quoted by K. Rankama and T. G. Sahama, Geochemistry. Chicago, $195^{\circ}$.

7. V. Vernadskil. Problemy biogeohhimii. (ist edn.) Moscow and Leningrad (Izd. AN SSSR), 1935.

8. G. Tammann. Z. phys. Chem., IIO, 17 (1924).

9. R. WILDT. Rev. mod. Phys., 14, $15^{1}$ (1942).

10. S. Arrhenius. Ann. Nat.- (u. Kultur)phil., 9, 7o (1910). 
11. V. M. Goldschmidt. Fortschr. Min., 17, 112 (1933).

12. W. Groth and H. Suess. Naturwiss., 26, 77 (1938).

13. J. H. J. Poole, as reported in Nature, Lond., I66, 761 $\left(195^{\circ}\right)$.

14. N. R. DhaR. Trans. Faraday Soc., 3o, 142 (1934).

15. G. Rathenau. Z. Phys., 87, 32 (1933).

16. R. Mecke. Trans. Faraday Soc., 27, 359 (1931).

17. A. Coenn. Ber. dtsch. chem. Ges., 43, 880 (1910).

A. Coenn and G. Grote in Nernst Festschrift, p. 136. Halle, 1912.

18. A. Tian. Ann. Phys., Paris, 5, 248 (1916).

19. H. Neuímin and A. Terenin. Acta physicochim. URSS, 5, 465 (1936).

20. P. Harteck and J. H. D. Jensen. Z. Naturf., 3A, 591 (1948).

21. G. M. B. Dobson. Proc. phys. Soc. Lond., 63B, $25^{2}$ (1950).

22. H. E. Moses and TA-You Wu. Phys. Rev., 83, 109 (1951); 84,168 (1951).

23. W. M. LAtimer. Science, $I$ I2, 101 (1950).

24. V. M. Goldschmidt. Skr. norske Vidensk. Akad.

I. Mat.-naturvid. Kl. I937, no. 4 .

25. (IV. 6o).

26. (III. 61).

27. J. H. J. Poole. Sci. Proc. R. Dublin Soc., 25, 201 (1951).

28. H. Borchert. Geochim. Cosmochim. Acta, 2, 62 (1951).

29. (IV. 18).

30. H. C. Urey. Proc. nat. Acad. Sci., Wash., 38, 351 (1952).

31. K. Kondrat'Ev. Luchistaya energiya solntsa. Leningrad, 1954 ; Article, 'Zemlya' (Earth). Vol. 17, Bol'shaya Sovetskaya Entsiklopediya, 1954.

32. L. R. Koller. Ultraviolet radiation. New York, 1952.

33. A. E. H. Meyer and E. O. Seitz. Ultraviolette Strahlen. Berlin, 1943 .

34. J. A. Sanderson and E. O. Hulburt in Radiation biology (ed. A. Hollaender). Vol. 2, p. 95. New York, 1955.

35. B. Moore. The origin and nature of life. London, 1913.

36. P. Becquerel. Astronomie, 38, 393 (1924).

37. (III. 41).

38. A. Dauvillier. Astronomie, 52, 529 (1938); 53, 145 (1939).

A. Dauvillier and E. Desguin. La genèse de la vie. Paris, 1942.

A. Dauvillier. Genèse, nature et évolution des planètes. Paris, 1947 .

39 S. Leifson. Astrophys. J., 63, 73 (1926). 
40. H. Thiele. Ber. dtsch. chem. Ges., 40, 4914 (1908).

41. D. Berthelot and H. Gaudechon. C.R. Acad. Sci., Paris, I5O, 1690 (I 910$)$.

42. A. Coenn and G. Sieper. Z. phys. Chem., gr, 347 (1916).

43. C. Zenghelis. C.R. Acad. Sci., Paris, I7I, 167 (1920).

44. N. R. Dhar and A. Ram. J. phys. Chem., 37, 525 (1933).

45. I. S. Stekol'nikov. Article 'Molniya' (Lightning). Vol. 28, p. 136. Bol'shaya Sovetskaya Entsiklopediya, 1955 .

46. A. I. Bachinskil. Spravochnik po fizike. Moscow, 1951.

I. S. Stekol'nikov. Molniya $i$ zashchita ot ce deřstviya. Moscow and Leningrad (Izd. AN SSSR), 1938.

47. (III. 13).

48. (III. 46 ).

49. (III. $49,5^{\circ}$ ).

5o. M. Berthelot. C.R. Acad. Sci., Paris, 68, 1035 (1869); Ann. Chim. (Phys.), [Sér. 7], 23, 435 (1901).

51. W. Löв. Ber. dtsch. chem. Ges., 37, 3593 (1904); Z. Elektrochem., I2, 282 (1906); Biochem. Z., 46, 121 (1912).

52. S. M. Losanitsch. Ber. dtsch. chem. Ges., 44, 312 (1911).

53. E. Briner and H. Hoefer. Helv. chim. Acta, 23, 800 (1940).

54. V. A. Magnitskiľ, V. V. Belousov, E. I. Lyustikh and S. V. Kolesnik. Article 'Zemlya' (Earth). Vol. 17, p. 3. Bol'shaya Sovetskaya Entsiklopediya, 1954.

55. G. B. Boǐtkevich. Doklady Akad. Nauk S.S.S.R., 74, 771 (1950).

56. R. W. van Bemmelen. Amer. J. Sci., 250, 104 (1952).

57. J. Stoklasa, J. Sebor and V. Zdobxicky. C.R. Acad. Sci., Paris, 156,646 (1913).

58. S. C. Lind and D. C. Bardwell. J. Amer. chem. Soc., 48, 2335 (1926).

59. V. A. Sokolov. I7th Int. geol. Congr., Moscow, 1937. Trudy, Vol. 4, p. 343. Moscow (Gos. nauch.-tekhn. Izd. neft.-top. Lit.), 1940. For English abstract, cf. Abstracts of papers (of above Congress). Moscow and Leningrad, 1937.

6o. W. M. Garrison, D. C. Morrison, J. G. Hamilton, A. A. Benson and M. Calvin. Science, IIf, 416 (1951).

6ı. V. Sokolov (W. Sokoloff). Bull. Soc. Nat. Moscou (nouvelle série), 3, 720 (1889-189o).

62. R. Goranson. Amer. J. Sci. (Ser. 5), 22, 481 (1931).

63. B. Nekrasov. Kurs obshcher khimii. Moscow (Goskhimiz. dat), 1955 .

(IV. 91). 


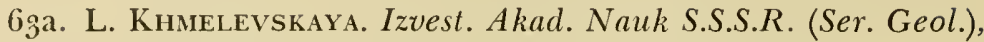
1977 , no. 4 , p. 107.

64. G. Stadnikov. Proiskhozhdenie ugler $i$ nefti. Leningrad (Goskhimtekhizdat), 1933.

65. A. C. Gaedicke. Allgem. österr. Chem. Tech. Ztg., 45, 150 (1927). (Quoted by E. N. Tiratsoo. Petroleum geology, p. 24. London, 1951.)

66. S. C. Schuman. J. chem. Phys., I6, 1175 (1948).

67. M. KaRAPET'yants. Khimicheskaya termodinamika. Moscow and Leningrad (Goskhimizdat), 1953.

68. V. Kоrobov and A. Frost. Svobodnye energii organischeskikh soedinenǐ. Moscow (Vsesoyuzn. Khim. Obshchestvo im. D. I. Mendeleeva), $195^{\circ}$.

69. V. Dolgov. Kataliz v organicheskor khimii. Moscow and Leningrad (Goskhimizdat), 1949.

70. (V.1).

71. S. Berkman, J. C. Morrell and G. Egloff. Catalysis, inorganic and organic. New York, 1940.

72. I. N. Nazarov. Uspekhi Khim., 20, 309 (1951).

73. A. E. Chichibabin. Osnovnye nachala organicheskol khimii. Vol. 1. Moscow (Goskhimizdat), 1954.

74. YA. T. Eǐnus. Uspekhi Khim., 19, 32 (1950).

75. A. E. Chichibabin. J. Russ. phys.-chem. Soc., (Chem.), 47 (Otd. 1), 703 (1915).

76. A. P. Terent'ev and L. A. Yanovskaya. Uspekhi Khim., 23, 697 (1954).

77. T. Ishiguro, S. Kubota, O. Kimura and S. Shimomura. J. pharm. Soc., Japan, 74, 1009 (1954).

78. A. Bogomolov, A. Gorskaya and M. Messineva. (V. 1, p. 280).

79. N. Zelinskiř. Izbrannye trudy (ed. S. S. Nametkin). Vols. 1 and 2. Moscow and Leningrad (Izd. AN SSSR), 1941 .

8o. B. T. Brooks. Industr. engng Chem., 44, 2570 (1952).

81. S. N. Obryadchikov. Neftyanoe Khoz., 24, No. 3/4, 39 (1946).

82. A. V. Frost. Neftyanoe Khoz., 24, No. 3/4, 36 (1946).

83. V. Porfir'ev. Problema nefteobrazovaniya $v$ svete souremennykh dannykh. Moscow and Leningrad (Gostoptekhizdat), 1941 . 
84. A. V. Frost. C.R. Acad. Sci. U.R.S.S. 37, 223 (1942); in Proiskhozhdenie nefti $i$ prirodnykh gazov (ed. A. V. Topchiev et al.). Moscow (Izd. NIMT Nefti), 1947 ; Trudy Instituta goryachikh iskopaemykh Akad. Nauk S.S.S.R., 2, 127 (1944); Uspekhi Khim., 14, 501 (1945).

85. A. I. Bogomolov and A. I. Suirnova. Zhur. priklad. Khim., $27,673(1954)$.

86. N. D. Zelinskĭ̌, in Akademiku $V$. I. Vernadskomu $k$ 50letiyu nanchnor $i$ pedagogicheskor deyatel'nosti (ed. A. P. Karpinskiǐ and A. E. Fersman), p. 875. Leningrad and Moscow (Izd. AN SSSR), 1936.

87. V. Sokolov. Ocherki genezisa nefti. Leningrad and Moscow (Gostoptekhizdat), 1948.

88. I. A. Breger and W. L. Whitehead. Third World Petroleum Congress, The Hague, 195I. Proceedings, Section I, p. 421 . Leiden, 1951.

A. KozLov. Problemy geokhimii prirodnykh gazov. Moscow and Leningrad (Gostoptekhizdat), $195^{\circ}$.

89. M. Karasev. Neftyanoe Khoz., 1,29 (1952).

9o. V. Belousov. Ocherki geokhimii prirodnykh gazov. MosCOW (ONTI), 1937.

9i. D. N. Andreev. Organicheskil sintez elektricheskikh razryadakh. Moscow (Izd. AN SSSR), 1953.

92. C. Eluis and A. A. Wells. The chemical action of ultraviolet rays (revised by F. F. Heyroth). New York, 1941 .

93. M. Berthelot. C.R. Acad. Sci., Paris, 82, 1357 (1876); Ann. Chim. (Phys.), [sér. 5], 10,69 (1877).

94. D. N. Andreev. Uspekhi Khim., 6, 1540 (1937).

95. R. V. de Saint-Aunay. Chimie et Industrie, 29, no. 5, p. IOI 1 (1933).

96. S. C. Lind and G. Glockler. J. Amer. chem. Soc., 5I, 2811 (1929).

S. C. Lind and G. R. Schultze. J. phys. Chem., 42, 547 (1938).

97. M. Z. Jowitschitsch. Mh. Chem., 29, I (1908).

N. Ya. Dem'yanov and N. D. Pryanishnikov. J. Russ. phys.chem. Soc., 58, 462 (1926).

98. M. Berthelot. Amm. Chim. (Phys.), [Sér. 5], io, $5^{1}(1877)$; [Sér. 7], 16, 5 (1899); C. R. Acad. Sci., Paris, IxI, 471 (1890).

S. M. Losanitsch. Mh. Chem., 29, 753 (1908).

99. S. M. Losanitsch. Ber. dtsch. chem. Ges., 42, 4394 (1909). 
100. G. Glockler and C. A. Hollingsworth. Trans. electrochem. Soc., 84, 97 (1943).

101. N. Prilezhaeva and G. Neter. Zhur. fiz. Khim., II, 254 (1938). Cf. Chem. Abstr., 32, 7823 (1938).

102. S. M. Losanitsch and M. Z. Jowitschitsch. Ber. dtsch. chem. Ges., 30, 135 (1897).

103. A. Besson and L. Fournier. C.R. Acad. Sci., Paris, 150, 1238 (1910).

104. J. N. Collie. J. chem. Soc., 87, 1540 (1905).

105. D. Finlayson and J. H. G. Plant. U.S. Pat. 1, 986, 885 (1935). Through Chem. Abstr., 29, 1021 (1935).

R. H. Sahasrabudhey and S. M. Deshpande. J. Indian chem. Soc., 28, 377 (1951).

106. K. Peters and H. Küster. Brennstoff-Chem., 12, 122 (1931). 107. M. Berthelot. Ann. Chim. (Phys.), [Sér. 4], 13, 135 (1868). 108. M. Berthelot. C.R. Acad. Sci., Paris, 67, 1141 (1868). 109. H. Becker. Wiss. Veröff. Siemens-Konzern, 8 , 199 (1929). 110. G. B. Crippa and M. Gallottr. Gazz. chim. ital., 59, 507 (1929).

111. L. Francesconi and A. Ciurlo. Gazz. chim. ital., 53, 327, 470,521 (1923).

112. E. Briner and H. Hoefer. Helv. chim. Acta, 23, 826 (1940). 113. S. M. Losanitsch. Ber. dtsch. chem. Ges., 4I, 2683 (1908). 114. S. L. Miller. J. Amer. chem. Soc., 77, $235^{1}$ (1955).

115. A. Pasynskiř and T. Pavlovskaya. Trudy I Sympoziuma po proiskhozhdeniyu zhizni, Moscow, 1957. (In the press.)

116. K. Bahadur. Nature, Lond., 173, 1141 (1954).

117. K. Bakhadur (Bahadur) and S. Ranganayaki. Zhur. obshchel Khim., 25, 1629 (1955).

118. W. A. Noyes and P. A. Leighton. The photochemistry of gases. New York, 1941.

119. K. P. Bonhoeffer. Z. Elektrochem., 40, 425 (1934).

120. W. Groth and H. Laudenklos. Nalurwiss., 24, 796 (1936).

W. Groth. Z. phys. Chem., B38, 366 (1937).

121. P. A. Leighton and A. B. Steiner. J. Amer. chem. Soc., $58,1823(1936)$.

122. S. ToŁ.

123. R. B. Mooney and E. B. Ludlam. Trans. Faraday Soc., 25, 442 (I929).

124. D. Berthelot and H. Gaudechon. C.R. Acad. Sci., Paris, 155,207 (1912). 
125. H. S. TAylor and D. G. Hill. J. Amer. chem. Soc., 5I, 2922 (1929).

J. C. Jungers and H. S. Taylor. J. chem. Phys., 6, 325 (1938).

126. W. Kemula and S. Mrazek. Z. phys. Chem., B23, $35^{8}$ (1933).

W. Kemula and E. M. Rauchfleisch. Roczniki Chem., 26, 221 (1952).

127. D. Berthelot and H. Gaudechon. C.R. Acad. Sci., Paris, 150, 1327 (1910).

128. R. Livingston. J. Amer. chem. Soc., 53, 3909 (1931).

129. G. Landsberg and A. Predwoditeleff. Z. Phys., 3I, 544 (1925).

130. H. S. TAYlor and H. J. Emeléus. J. Amer. chem. Soc., 53, $562(1931)$.

131. J. C. Elgin and H. S. Taylor. J. Amer. chem. Soc., 5I, 2059 (1929).

132. (V. 92).

133. (V. 99, 102).

134. A. Windaus. Rapp. Cons. Chim. Solvay, 6, 91 (1938).

135. M. L. Sherrill, B. Otto and L. W. Pickett. J. Amer. chem. Soc., 5I, 3023 (1929).

136. J. Errera and V. Henri. C.R. Acad. Sci., Paris, ISo, 2049 $(1925) ; I 8 I, 548(1925)$.

137. R. Kuhn, F. Köhler and L. Köhler. Hoppe-Seyl. Z., 242, 171 (1936).

138. Lord Kelvin. Quoted by E. Schroedinger. What is life? The physical aspect of the living cell. p. 5. Cambridge, 1945 .

139. (III. 58).

140. V. ViL'yams. Izbrannye sochineniya. Vol. 1. Moscow (Izd. AN SSSR), $195^{\circ}$.

141. N. Kholodny̌̌. Izvest. Armyan. Filiala Akad. Nauk S.S.S.R., 9-10, 89 (1942).

142. B. B. Polynov. Pochyovedenie, ro, 594 (1948).

143. G. F. Gauze. Asimmetriya protoplazmy. Moscow (Izd. AN SSSR), $194^{\circ}$.

144. A. Sementsov. Uspekhi Khim., 2, 225 (1933).

145. R. D. Hotchkiss. J. biol. Ghem., I4I, 171 (1941).

146. A. H. Gordon, A. J. P. Martin and R. L. M. Synge. Biochem. J., 37, 86 (1943).

147. M. Schoen. Problèmes d'asymétrie dans les processus biochimiques. Paris, 1936. 
148. L. Pasteur. Researches on the molecular asymmetry of natural organic compounds. Alembic Club Reprints, No. 14. Edinburgh, 1897.

149. V. Vernadskiľ. Problemy biogeoklimiii. (and edn.) Moscow (Izd. AN SSSR), 1939.

150. A. P. Terentev and V. M. Potapov. Priroda, 44, No. 5 , 37 (1955).

151. L. Pasteur. Rev. sci., Paris, (sér. 3), 7, 2 (1884).

152. E. Fischer. Ber. dtsch. chem. Ges., 27, 3189 (1894); HoppeSeyl.Z., 26, 60 (1898).

153. W. Marck Wald. Ber. dtsch. chem. Ges., 37, 349 (1904).

154. A. MaKenzie. J. chem. Soc., 85, 1249 (1904); 87, 1373 $(1905) ; 89,365$ (1906).

A. McKenzie and H. Wren. J. chem. Soc., 9I, 1215 (1907).

155. G. Bredig and F. Gerstner. Biochem. Z., 250, 414 (1932).

156. G. Bredig and M. MinaefF. Biochem. Z., 249, 241 (1932).

157. For a review on asymmetric synthesis, see: A. McKenzie. Ergebn. Enzymforsch., 5, 49 (1936).

158. L. A. Yanovskaya. Priroda, I952, no. 10, p. 95.

R. Curti and U. Colombo. J. Amer. chem. Soc., 74, 3961 (1952).

159. W. Kurn. Ergebn. Enzymforsch., 5, 1 (1936).

16o. F. R. Japp. Nature, Lond., 58, $45^{2}$ (1898).

161. (V. 151).

162. P. Curie. J. Phys. théor. appl. (sér. 3), 3, 393 (1894).

163. J. H. van't Hoff. Die Lagerung der Alome im Raume (Aufl. 3). Braunschweig, 1908.

164. А. Вүк. Ber. dtsch. chem. Ges., 42, 141 (1909).

165. W. Kunn and E. Braun. Naturwiss., 17, 227 (1929).

166. W. Kunn and E. KNopf. Naturwiss., I8, 183 (1930); Z. phys. Chem., 7 B, 292 (1930).

167. S. Mitchell. J. chem. Soc., I930, 1829.

168. J. C. Ghosh. J. Indian chem. Soc., I6, $5^{1}$ (1939).

169. G. Karagunis and G. Drikos. Z. phys. Chem., 26B, 428 (1934).

170. T. L. Davis and J. Ackermann. J. Amer. chem. Soc., 67, $486(1945)$.

171. A. Вук. Z. phys. Chem., 49, 641 (1904); Naturwiss., 13, 17 (1925).

172. I. Ostromisslensky. Ber. dtsch. chem. Ges., 4 I, 3035 (1908).

173. G.-M. Schwab, F. Rost and L. Rudolph. Kolloidzschr., 68, 157 (1934).

G.-M. Schwab and L. Rudolph. Naturwiss,, 20, 363 (1932). 
174. A. Stankewitch. Diss., Königsberg, 1939.

175. J. D. Bernal. Uspekhi Khim., I9, 401 (1950).

176. A. P. Terent'ev, E. I. Klabunovskiľ and V. V. Patrikeev. Doklady Akad. Nauk S.S.S.R., 74, 947 (1950): Uchenye Zapiski Moskov. Gosudarst. Univ., I5I, 145 (1951).

E. I. Klabuvovskiľ and V. V. Patrikeev. Doklady Akad. Nauk S.S.S.R., 78,485 (195I).

A. A. Ponomarev and V. V. Zelenkova. Zhur. obshchel Khim., 23, 1543 (1953).

177. C. Neuberg. Biokhimiya, 2, 383 (1937).

178. E. Havinga. Chem. Weekblad, 38,642 (1941).

179. E. Havinga. Biochim. biophys. Acta, I3, 17 1 (1954).

1 So. A. Butlerov. C.R. Acad. Sci., Paris, 53, 145 (1861) (Boutlerow) ; Liebigs Ann., I20, 295 (1861) (Butlerow).

181. E. Fischer and J. Tafel. Ber. disch. chem. Ges., 22, 97 (1889).

182. O. Loew. J. prakt. Chem. (N.F.), 33, 321 (1886); Ber. dtsch. chem. Ges., 22, 470 (1889).

183. E. Fischer and F. Passiore. Ber. dtsch. chem. Ges., 22, 359 (1889).

184. H. Euler and A. Euler. Ber. dtsch. chem. Ges., 39, 45 (1906.)

185. E. Fischer and K. Landsteiner. Ber. disch. chem. Ges., 25, 2549 (1892).

H. Jackson. J. chem. Soc., 77, 129 (1900).

C. Neuberg. Ber. disch, chem. Ges., 35, 2626 (1902).

186. E. Schimiz. Ber. dtsch. chem. Ges., 46, 2327 (1913).

187. L. Orthner and E. Gerisch. Biochem. Z., 259, 30 (1933).

188. W. W. Pigman and R. M. Goepr. Chemistry of the carbohydrates. New York, 1948.

189. E. J. Lorand. U.S. Pat. 2,272,378 (1942).

190. (V.73).

191. J. D. Bernal. Science and Culture, r9, 228 (1953).

192. D. Shemrs. Conférences et Rapports. zème Congrès international de Biochimie, Bruxelles, I.6 Août I955. p. 197. Liège, 1956 .

193. J. J. Sсотт. Biochem. J., 62, 6P (1956).

194. A. Treibs. Conférences et Rapports. zème Congrès inter national de Biochimie, Bruxelles, I-6 Août I955. p. 207 . Liège, 1956 . 
226 ABIOGENIC ORGANIC-CHEMICAL EVOLUTION

195. S. W. Fox, J. E. Johnson and A. Vegotsky. Science, I24, $9^{23}(1956)$.

S. W. Fox. Amer. Scientist, 44, (no. 4), p. 347 (1956).

196. D. Davidson and O. Baudisch. J. Amer. chem. Soc., 48 , 2379 (1926).

197. R. Behrend and O. Roosen. Liebigs Ann., 25I, 235 (1889). 198. (V: 73).

199. H. Staudinger and K. Wagner. Makromol. Chem., I2, 168 (1954).

200. J. C. Sonne, J. M. Buchanan and A. M. Delluva. J. biol. Chem., I73, 69 (1948).

J. M. Buchanan, J. C. Sonne and A. M. Delluva. J. biol. Chem., I73, 81 (1948).

201. F. W. Barnes and R. Schoenheimer. J. biol. Chem., I5I, 123 (1943).

202. D. Shemin and D. Rittenberg. J. biol. Chem., 167, 875 (1947).

203. J. N. Davidson. The biochemistry of the nucleic acids. London, 1950.

204. P. Thenard and A. Thenard. C.R. Acad. Sci., Paris, 76, 1508 (1873).

205. B. Stepanenko. Kurs organicheskol khimii. Moscow (Medgiz), 1955.

206. N. N. Semenov in Problemy kinetiki i kataliza. Sbornik 4. (ed. M. Neǐman). Moscow, 1940.

207. (III. 70).

208. (III. 54).

209. F. Lipmann. Advanc. Enzymol., 1, 99 (1941).

210. H. Borsook. Conférences et Rapports. zème Congrès international de Biochimie, Bruxelles, I-6 Août 1955. p. 92. Liège, 1956 .

211. H. M. Kalckar. Symp. Soc. exp. Biol., I, 38 (1947); J. biol. Chem., I67, 477 (1947).

212. M. Friedkin, H. M. Kalckar and E. Hoff-Jørgensen. J. biol. Chem., 178,527 (1949).

213. R. ZAHN, quoted in (III. 71 ).

214. G. SснміDт in Phosphorus metabolism. Symposium on the role of phosphorus in the metabolism of plants and animals (ed. W. D. McElroy and B. Glass). Vol. 1, p. 443. Baltimore, Md., $195^{1}$.

F. Winder and J. M. Denneny. Nature, Lond., 174, 353 (1954).

215. (III. 71). 
216. H. Staudinger and H. Schnell. Makromol. Chem., I, 44 (1947).

217. Y. Go and H. TAni. Bull. chem. Soc. Japan, 14, 510 (1939). 218. H. M. Huffian. J. phys. Chem., 46, 885 (1942).

219. K. Linderstrom-Lang. Proc. Sixth International Congress of Experimental Cytology, Stockholm, 1947. Stockholm, 1949.

220. A. Dobry, J. S. Fruton and J. M. Sturtevant. J. biol. Chem., 195, I49 (1952).

221. J. S. Fruton. 2me Congrès international de Biochimie. Chim. Biol. II. Symposium Biogénèse des Protéines. (Paris.) $195^{2}$, p. 5 .

222. F. Lipmann. Fed. Proc., 8, 597 (1949).

223. S. E. Bresler. Uspekhi souremennoi Biol., 3o, 90 (1950); Biokhimiya, 20, 463 (1955).

224. G. Talwar and M. Macheboeuf. Ann. Inst. Pasteur, 86, 169 (1954).

225. G. Ehrensvärd. Personal communication.

226. T. B. Johnson. J. biol. Chem., 9, 439 (1911).

T. B. Johnson and G. Burnham. Amer. chem. J., 47, 232 (1912).

227. (III. 73); cf. Chem. Abs., 5o, 16893 (1956). 

THE STRUGTURE AND BIOLOGICAL FUNCTIONS OF PROTEINS AND NUCLEIC ACIDS AND THE PROBLEM OF THEIR ORIGIN

\section{Chemical structure and biological functions of polypeptides and proteins.}

The problem of the primary development of proteins is extremely perplexing, not only on account of its inherent complexity, but also because there is, at present, no agreed definition of the term protein. Many authors of both the nineteenth and twentieth centuries attached a purely chemical meaning to the term while others regarded it as a specifically biological concept. This is reflected in the terminology currently used. In the Russian language the words belok and protein are used synonymously. The Germans generally use the term Eiweissstoff while British and American authors have gone over entirely to the word protein, the older word 'albumen' having acquired a more specific meaning and being applied only to a particular group of proteins of which egg albumin is one.

In the beginning the word albumen was only applied to the substance in hens' eggs which forms a white coagulum when heated. Later on, other substances similar to the white of eggs were included in the term albumen, but this concept was not given any general biological significance in relation to life. On the contrary, it was considered that egg albumen and other analogous substances were no more than the specific products of a few isolated organisms and, in particular, that they were completely absent from plants. Thus, for example, the gluten which had been isolated from flour as early as the end of the eighteenth century was regarded as a curiosity, a freak of nature, and even called matière végéto-animale. ${ }^{3}$ However, as the study of the chemical substances of living 
nature proceeded, so the idea became stronger and stronger in the minds of scientists that albumens are present in all organisms and that these compounds play an extremely important part in the process of life. This idea received precise expression in the name given to albumens in the 1830 by G. J. Mulder. ${ }^{2}$ He called them protein, from the Greek word $\pi \rho \omega \tau \epsilon i o s$ (first or most important). In using this term Mulder was thus stressing the biological aspect of protein as the most important component of living material. At that time chemical knowledge of proteins was very meagre. Proteins attracted the attention mainly of biologists, who usually regarded them as the main and most important components of the gelatinous material within the cell. This material was called 'protoplasm' by H. v. $\mathrm{Mohl}^{3}$ in the middle of the nineteenth century and the part it plays as the material carrier of life became more and more evident. Some biologists of the latter half of the nineteenth century even identified protoplasm with protein and among them E. Haeckel, ${ }^{4}$ for example, considered that the simplest organisms consisted of nothing but lumps of proteinaceous substances.

F. Engels, ${ }^{5}$ in common with the biologists of his time, often used the terms 'protoplasm' and 'albuminous bodies' (Eiweisskörper). The 'proteins' of Engels must therefore not be identified with the chemically distinct substances which we have now gradually succeeded in isolating from living things, nor with purified protein preparations composed of mixtures of pure proteins. Nevertheless Engels ${ }^{6}$ was considerably in advance of the ideas of his time when, in speaking of proteins, he specially stressed the chemical aspect of the matter and emphasised the significance of proteins in metabolism, that form of the motion of matter which is characteristic of life.*

It is only now that we have begun to be able to appreciate the value of the remarkable scientific perspicacity of Engels. The advances in protein chemistry now going on have enabled us to characterise proteins as individual chemical

\footnotetext{
* Carl Schorlemmer expressed very similar ideas (The rise and development of organic chemistry, pp. 122-3. Manchester and London, 1879). This topic must have been discussed by Engels and Schorlemmer during their years of friendship in Manchester.-Translator.
} 
compounds, as polymers of amino acids having extremely specific structures. As well as this we can to a certain, though admittedly very limited, extent relate this structure to enzymic and other biologically important properties of proteins. This will enable us to understand their extremely great significance in the metabolic process of life. Many organic substances of different kinds entering into the composition of living protoplasm can only readily take part in its metabolism after they have interacted with the proteins of the protoplasm to form extremely active complexes (enzyme-substrate complexes). In the absence of such interaction the chemical reactions of which these substances are capable take place too slowly at ordinary temperatures for them to have any significance in the rapidly moving process of life. Hence the metabolic course followed by any organic compound will depend not only on the peculiarities of its molecular structure, its chemical potentialities, but also on the specific enzymic activity of those proteins of the protoplasm with which the compound is involved in the general metabolism.

Thus, in proteins (enzymes) living material has both powerful catalysts to accelerate chemical processes and an internal chemical apparatus whereby these processes are directed along completely determinate paths co-ordinated with each other in a definite sequence and forming the orderly arrangement of processes characteristic of metabolism. On the basis of this organisation there also takes place, in particular, the constant regeneration of proteins, their self-reproduction, by virtue of which, to use Engels' words, the protein body "while being the result of ordinary chemical processes, is distinguished from all others by being a selfacting. permanent chemical process ".

This presentation is, of course, radically different in principle from those hypotheses formulated at the end of the nineteenth century which identified protoplasm with proteins and referred to the so-called 'living protein molecule'. In these hypotheses, which were discussed more fully in Chapter III of this book, some workers attempted to treat protoplasm as a whole, as a single chemical substance, as a gigantic protein molecule endowed with life (E. Pflüger, $1875^{8}$; F. Bottazzi, $1911^{9}$; N. N. Iwanoff, $1925^{10}$; H. G. 
Doffin, $\left.1953^{11}\right)$. Others regarded protoplasm as no more than a specific medium, a mixture of lifeless compounds containing the hypothetical living particles, the protein molecules, in the chemical structure of which there lie concealed all the causes and mysteries of life. We may refer here to the 'biogens' of M. Verworn, ${ }^{12}$ the 'moleculobionts' of Alexander and Bridges ${ }^{13}$ and other similar hypothetical particles, the chemical reality of which has never been proved by anyone, though references to them are still to be met with in scientific literature.

Thus contemporary chemists and biologists use the word 'protein' in a long series of different senses. At one end of the series we have the purely chemical definition of proteins as highly polymerised organic compounds with very complicated molecules made up of different sorts of amino acids. This definition would, however, seem to be very onesided. It ignores the biologically important properties possessed by all the various proteins which have actually been isolated from organisms, properties which are related to the individual peculiarities of their structure. Such a definition would include all polymers of amino acids, even such possible combinations of amino acids as would not subserve the biological functions proper to naturally occurring proteins. Polymers of amino acids of this sort would naturally be unable to form part of the structure of living matter. This purely chemical definition, therefore, includes among proteins even substances which have no direct biological significance. On the other hand, the definition which we find at the other end of our series, that of the living protein molecule, is completely lacking in any clear-cut chemical meaning. The partisans of this concept attribute to the protein molecule (in most cases they refer to molecules of nucleoproteins) all the properties of life, i.e. the ability to metabolise, reproduce themselves, etc. However, they give absolutely no real explanation of how all these properties could depend on any particular arrangement of the atoms in the hypothetical 'living molecule'.

As a result of this confusion, many contemporary authors studying the origin of life make quite arbitrary and illogical jumps between the concepts of protein implied by the purely 
chemical and the purely biological definitions. For example, they argue as follows: if the process of organic-chemical transformation in the waters of the primaeval occan could have given rise to protein-like polymers of amino acids, then the same processes must have led to the formation of 'living protein molecules'. In what the specific 'life-conferring' structure of these molecules consists and how it could have arisen scems to be something of an inessential detail from this point of view; this structure might even have been formed as a result of purely fortuitous combinations of groups of atoms which remained unchanged during the reproduction and multiplication of these molecules in all succeeding generations. The perpetrators of arguments of this sort do not, however, notice that their approach to a solution of the problem in hand is purely formal and verbal in character and that what they regard as a detail constitutes the very essence of the question.

It seems to us that the problem of the primary development of proteins should be formulated in a different way, as follows: the numerous and varied proteins which we can now isolate from living organisms in crystalline form as individual chemical compounds (various enzymes, hormones, viruses, etc.) have definite structures which are highly specific to each of them and which are extremely well adapted to the fulfilment of those vitally important functions which they subserve in living protoplasm (in metabolism, in reproduction, etc.). Substances of this kind only arise nowadays as components of living bodies and there can be no doubt that the specific structures which they now exhibit reflect the earlier evolution of these bodies and are the result of the prolonged development of living organisms. ${ }^{14}$

The main point of the question is whether compounds of this kind could arise outside living material, primarily, on the basis of the thermodynamic and kinetic laws which were explained in the preceding chapter of this book, or whether this required new laws of a higher order. To give a satisfactory answer to this question it is necessary to give at least a short account of what is now known of the chemical structure of the actual proteins which have been isolated from living things and to try to understand which are the specific 
features of their structure responsible for their biologically important functions. Only after this shall we be in a position to reconstruct for ourselves the ways by which there arose, during the process of the development of matter, those structural peculiarities of the primaeval polymers of amino acids which are required for the vital processes. In discussing the chemical structure of proteins we must first make clear to what extent these 'working mechanisms' of protoplasm which have been isolated from living organisms (various enzymes, hormones, toxins, etc.) exist at the molecular level and to what extent they appear as chemically definable substances, in connection with which the concept of a molecule is the same as for other organic compounds. As early as $194^{\circ}$ N. W. Pirie $^{15}$ expressed doubts as to the validity of this approach and to some extent these doubts still appear in the scientific literature on proteins. ${ }^{16,17}$

In fact, many proteins which were earlier thought to be individual substances have been shown, by more refined methods of separation, to be mixtures. For example, egg albumin has been shown to be a mixture, notwithstanding the fact that it forms beautiful crystals. ${ }^{18}$ The same is true of serum globulins. ${ }^{19}$ For many years purified casein was considered as a single protein. This seemed to be proved by the good agreement of the analytical results obtained by scientists in different countries. However, it has now been established that pure casein consists of a mixture of at least three proteins which have been separated from one another. ${ }^{20}$

In his detailed paper dealing with the isolation of proteins J. F. Taylor ${ }^{21}$ points out what a complicated matter it is to obtain individual proteins from naturally occurring mixtures of them. At the end of his paper he gives a list of those proteins which are now recognised as chemically homogeneous compounds. We cannot be certain, however, that even these proteins are completely uniform.

In connection with the lack of molecular homogeneity of casein, G. R. Tristram ${ }^{22}$ has also pointed out that $\beta$-lactoglobulin $^{23}$ is not a single substance either, and rightly poses the question as to whether the proteins which are now held to be individual substances are not really mixtures of related compounds, among which even the amino acid composition 
varies somewhat. Certainly there are a number of facts which suggest that several pure individual protein-like substances may form, as it were, a family of proteins, being composed of the same amino acids but differing from one another in the amounts of some of the amino acid residues in the peptide chain. This may be demonstrated particularly clearly as regards haemoglobin. ${ }^{24}$

In this connection we must emphasise the fact that proteins having the same biological function may differ markedly from one another chemically. Insulin serves as a good example of this. The hormone was isolated from the pancreas as an individual protein of comparatively low molecular weight, the structure of which is now very well worked out. However, it has been shown that the insulins obtained from oxen, pigs and sheep, though they have the same physiological activity, nevertheless differ from one another chemically. In particular, pig insulin contains threonine at a position in its peptide chain where it is not present in ox insulin. Thus it is evident that the physiological properties of hormonal proteins do not require absolute uniformity of structure. ${ }^{25}$ The same may also be said of enzymes. It now seems quite clear that we include under the same name (pepsin, invertase, phosphomonoesterase, etc.) proteins which have the same enzymic activity though they sometimes differ markedly among themselves in respect of molecular size, isoelectric point and other physico-chemical properties and even in respect of their amino acid compositions. ${ }^{26}$

It follows that the catalytic properties of a given protein are not associated with the whole of its molecule and that this may contain parts which are completely inactive and can easily be altered without destroying the enzymic properties. It follows that some variations in amino acid composition do not necessarily cause noticeable alterations in their biological properties.

It is now well known that different forms of organisms can contain proteins which are identical in their biological functions but which differ in their amino acid composition. It has also been established that changes in the living conditions of organisms bring about variations in the composition and properties of their proteins. 
Having made a thorough review of the facts which we have referred to, Tristram draws from them the following conclusion: "That proteins do appear to remain more or less constant in composition may well be a reflection of the constancy of an environment, rather than evidence that proteins are compounds of unvarying composition."

\section{The amino acid composition and sequence in the structure of the macromolecules of proteins.}

Having made these indispensable remarks about proteins as individual chemical substances we can now proceed to a proper description of the fundamentals of protein chemistry.

It may nor be held to be firmly established, in the first place, that protein molecules are made up of residues of various amino acids and, in the second place, that these residues are linked together in the protein molecule mainly by peptide bonds between the $\alpha$-amino groups and $\alpha$-carboxyl groups of amino acids, as was first suggested by A. Ya. Danilevskiř ${ }^{27}$ and afterwards proved experimentally by E. Fischer $^{28}$ and $\mathrm{F}$. Hofmeister ${ }^{29}$ and a number of later workers.

Thus, as a first rough approximation, a protein molecule may be described schematically as a polypeptide chain:

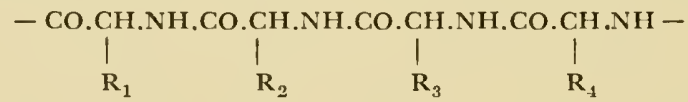

where $R_{1}, R_{2}, R_{3}, R_{4}$, etc., the side chains, represent the free atomic groupings of the amino acid residues, which have very diverse chemical properties (those of hydrocarbons, alcohols, thiols, phenols, acids, bases, etc.).

This sort of structure fundamentally distinguishes proteins from other organic polymers such as cellulose or rubber, in the molecules of which the same atomic grouping (residues of glucose, isoprene, etc.) is repeated over and over again.

Thanks to the variety of amino acid residues entering into their composition, and also to the great chemical variety of their functional groups, proteins have enormous chemical potentialities. They can react with the countless multitude of substances of living protoplasm to form either true com- 
pounds of the nature of conjugated proteins or extremely ephemeral complexes which only have a very transient existence, as happens in the formation of intermediate compounds (enzyme-substrate).

Arising from this, many students of proteins from $H$. Ritthausen ${ }^{30}$ to present-day authors (e.g. H. B. Vickery ${ }^{31}$ and IV. H. Stein ${ }^{32}$ ) have put forward the suggestion that the chemical, and even the physiological, characteristics of any particular protein could be deduced from a detailed and complete knowledge of its amino acid composition and an understanding of the properties of the different amino acids of which it is made up.

Quantitative and qualitative analytical studies on various proteins with a view to determining their amino acid composition have been going on for many years. However, the methods devised in the classical rorks of A. Kossel, E. Fischer and T. B. Osborne ${ }^{33}$ and others depended on the separation of amino acids from hydrolysates and involved the expenditure of enormous amounts of effort, time and starting materials. For this reason such studies were very few and far from complete. However, there have been introduced into protein chemistry in recent years new and satisfactory micromethods based on up-to-date principles of investigation ${ }^{34}$ (isotope dilution ${ }^{35}$ and the isotope-derivative method, ${ }^{36}$ microbiological assay ${ }^{37}$ and chromatography ${ }^{38}$ ). This led to signal advances in the field of amino acid analysis and a very large number of proteins may now be taken to have been fully analysed in this respect. (The extensive factual material is given in the numerous tables in the article by $G$. R. Tristram. ${ }^{22}$ )

Detailed studies have also been made of the chemical properties of the separate amino acids which are found in proteins, those which are common to all carboxylic acids and primary amines and also the specific functional attributes which belong to each separate amino acid and characterise its radical (R). The extensive data on this subject have been recently collated in a review by $P$. Desnuelle. ${ }^{39}$

The results obtained in this way were, however, rather unexpected. In particular, it was found that only a very limited number of different amino acids are to be found in 


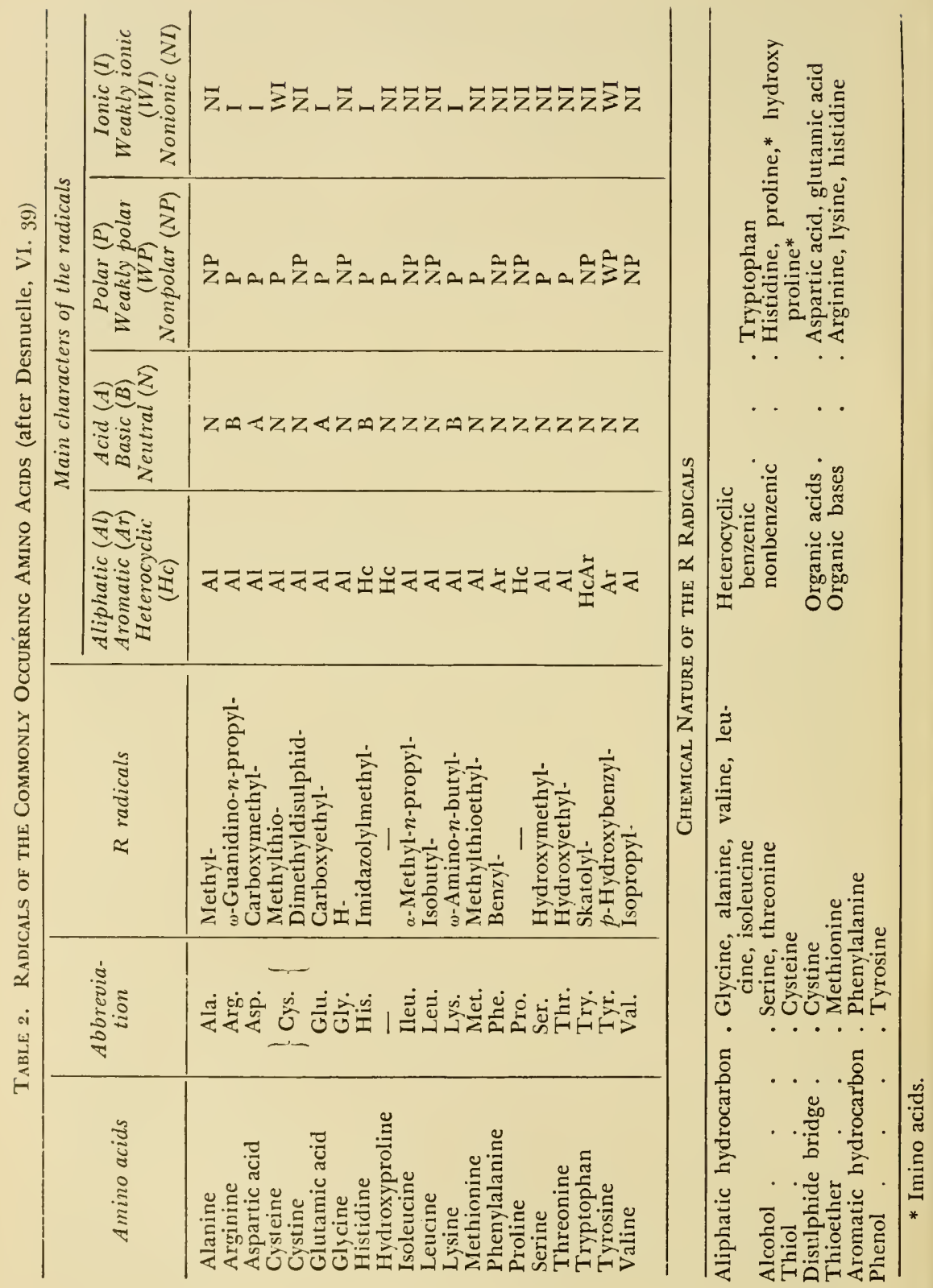


natural proteins, especially in those of higher animals and plants. It is interesting to note in this connection that, as the number of substances studied grows greater and the accuracy of the results improves, the number of so-called 'common' amino acids found in proteins does not increase ; in recent years it has even shown a certain tendency to decrease. Thus H. B. Vickery and C. L. A. Schmidt ${ }^{40}$ considered, in 1931, that there were twenty-two common amino acids, this number later fell to twenty-one, and now, as P. Desnuelle writes, "we shall therefore assume twenty common amino acids only, and this number will probably never be much modified". We give here a table of these amino acids and the chemical characteristics of their radicals, borrowed from Desnuelle's paper (Table 2).

The question inevitably arises as to why the endless variety of proteins which we can isolate from contemporary animals and plants should be made up of such a limited number of structural elements. It is clear that as a result of the physical and chemical laws discussed in the previous chapter there could and must have been formed many, many other amino acids as well as those given in the list. Why, then, do we not find them in contemporary proteins? Obviously, in the formation of these latter, there must have occurred a strict selection of those amino acids indispensable for life. It would seem that the chemical functions which we have just discussed are quite sufficient for the catalysis and co-ordination of all the various metabolic reactions. Combined with one another into protein molecules the twenty amino acids listed form all the enzymes necessary for metabolism and the other important internal chemical mechanisms of living protoplasm. There can be no doubt that in the process of evolution of living matter there took place a rationalisation of these mechanisms and consequently a standardisation of them, analogous to that occurring in technical processes. All those amino acids which were not absolutely necessary to life were eliminated in later generations by natural selection.

R. L. M. Synge ${ }^{14}$ has written very pointedly:

If we assume, on the basis of evolutionary theory, that the proteins of highly organised beings became progressively more 
and more efficient in carrying out their particular functions, then it is reasonable to suppose that their component parts (as it were the nuts and bolts of the mechanism) have been to a great extent standardised, just as in modern engineering the component parts have been standardised so that they can be used to make all kinds of things from sewing machines to motorcar engines.

The idea of the standardisation of the amino acid composition of proteins during the process of evolution of higher organisms finds support in the fact that among organisms at a lower stage in evolutionary development-mainly bacteria and fungi-we find, in addition to the ordinary amino acids which are constantly present in proteins, that there are continually being discovered new, so-called 'peculiar' or 'uncommon' amino acids such as $\beta$-thiolvaline in Penicillium spp. ${ }^{41}$ meso- $\alpha$-diaminopimelic acid $^{42}$ and other amino acids. ${ }^{43}$ There are also found in the proteins and peptides, and particularly in the antibiotics, of lower organisms the ' unstandardised' D-forms of amino acids, among them Dglutamic acid in the capsule of Bacillus anthracis ${ }^{44}$ and related organisms, D-leucine in gramicidin, ${ }^{45}$ D-phenylalanine in gramicidin $S^{46}$ and tyrocidine ${ }^{47}$ (B. brevis), D-alanine in Lactobacillus arabinosus, ${ }^{48}$ etc. In higher organisms, on the other hand, we invariably find only L-forms of amino acids and apparent exceptions to this rule have always been found to be artefacts arising by racemisation, usually during the hydrolysis of the proteins. ${ }^{49}$

Thus we see that during the course of evolution the transition from the lower forms, with their as yet imperfectly organised metabolism, to higher forms in which the metabolism has reached a higher degree of co-ordination, is marked by a standardisation of the amino acid composition of proteins due to natural selection. Thus, one of the essential properties of the animal and vegetable proteins which we have studied, their amino acid composition, is not entirely determined by physical and chemical laws alone but carries the imprint of its biological origin.

Another deduction which can be drawn from a thorough study of the amino acid composition of present-day proteins does not bear out the optimistic expectations, referred to 
above, of many chemists of the past and present centuries beginning with Ritthausen and ending with Vickery. It has been shown that even the most complete amino acid analysis of a particular protein taken by itself is still far from characterising the physical and chemical properties of that protein, let alone its biological functions. As K. Bailey ${ }^{50}$ wrote recently:

One of the most disheartening features of the amino-acid analysis of proteins is that the results have little meaning. To a limited extent they are useful for assessing the nutritional value of a protein, but they do not explain at all the true biological function; why one protein is an enzyme, another a hormone, another a toxin.

This is quite understandable even on purely theoretical grounds. Never in the history of science could it be maintained that the whole is nothing but the sum of its component parts. ("The whole is always somewhat different from the sum of the separate parts," M. Planck, 1935.) In proteins it is the structure which determines this difference. Even a study of the chemical properties of artificially synthesised polypeptides shows that the chemical activities of free amino acid groups (the so-called radicals, $\mathrm{R}$ ) are markedly changed when they are included in peptide chains, and also depend on the order in which they are arranged in the

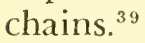

Even by simply comparing the effects of various substances and physical factors on a mixture of amino acids and a polypeptide composed of those same amino acids, it will be found that the amino acid residues of peptides are considerably more labile. For example, they are far easier to racemise than the corresponding free amino acids. In just the same way, the chemical reactivity of particular functional groups such as the hydroxyl group of serine, the phenolic hydroxyl group of tyrosine, the $\omega$-amino group of lysine, etc., is very substantially altered according to which chemical groups are immediately adjacent to them in the polypeptide chain. In a number of cases amino acid radicals, when forming part of a polypeptide chain, can react with compounds to which 
they would be quite indifferent in the form of free amino acids. G. R. Tristram ${ }^{22}$ sums the matter up as follows:

It is now appreciated that the properties of side chains in a protein are not simple functions of the properties of the free amino acids, but are, in fact, highly complex functions dependent on many factors including the relative distribution of side chains in the main peptide chain and in the folded native protein.

The order in which the amino acid residues are arranged in the peptide chains of native proteins or biologically important peptides isolated from organisms has long attracted the attention of scientists. The elucidation of this problem has, however, been attended by a very large number of technical difficulties.*

The first reasonably successful attempt to establish the order in which all the amino acid residues are arranged in a single protein-like substance was made by $\mathrm{K}$. Felix and his colleagues $^{51}$ on the protamine of herring sperm, clupeine. They considered that the molecule of clupeine is made up of no more than 33 amino acid residues, namely, 22 of arginine, 2 of alanine, 2 of serine, 3 of proline, 3 of valine and 1 of hydroxyproline. The unusually small number of amino acid residues and absence of any great diversity, in particular the extreme predominance of arginine, greatly simplified the task of studying this peculiar protein. In Felix' opinion the amino acids in the polypeptide chain of clupeine are arranged in a rather regular way; there are always a series of four arginine radicals in a row along the chain followed by two residues of other amino acids and then again four arginine residues, etc.

M. Bergmann ${ }^{52}$ put forward the hypothesis that the polypeptide chains of other proteins besides clupeine are constructed similarly and that they also contain a definite repetitive sequence of amino acid residues. For example, if there are 54 lysine residues in edestin out of a total of 432 , this means that every eighth amino acid residue in the polypeptide chain of edestin will be lysine. Similarly, in ox globin, each of the 36 lysine residues will be separated from

* The earlier efforts in this direction have been reviewed by $\mathbf{R}$. L. M. Synge, Chem. Rev., 32, 135 (1943).-Translator. 
the next by 15 residues of other amino acids and each of the 12 residues of proline will be separated from the next by 47 other residues, etc. ${ }^{53}$

\section{Hormones, enzymes, antibiotics and antigens.}

However, this hypothesis that the structure is fundamentally related to the ratios between the numbers of different amino acid residues in any particular protein was not confirmed by the direct study of the breakdown products obtained by partial hydrolysis of proteins and polypeptides. On the contrary, the application of this tedious but very reliable method has actually enabled people to elucidate the very complicated arrangement of the amino acid residues in the peptide chains of a number of physiologically important compounds. This applied, in the first place, to toxic substances produced by bacteria (antibiotics), such as gramicidin. By partial hydrolysis of the simplest of these, gramicidin $S_{,}{ }^{54}$ which is a cyclopolypeptide, ${ }^{55}$ it has been possible to isolate numerous dipeptides and tripeptides by paper chromatography. By comparing these, the whole sequence of amino acids in this cyclic peptide has been established. ${ }^{56}$ Furthermore, the use of similar methods has led to the elucidation of the sequence of the amino acid residues in tyrocidines $\mathrm{A}$ and $\mathrm{B}^{57}$ and other polypeptide antibiotics. ${ }^{58}$

Corresponding studies on proteins are naturally of special interest. The one which has now been most thoroughly studied is insulin. This hormone, which is particularly important on account of its physiological activity, has been studied by many workers, both in respect of its amino acid composition and in respect of the arrangement of the amino acid residues in the polypeptide chain. ${ }^{59}$

The work of F. Sanger and his colleagues ${ }^{60}$ has given a clear picture of this structure. Sanger marked the terminal amino groups of the polypeptides present in insulin by condensing them with 2:4-dinitro-1-fluorobenzene; he then submitted this derivative of insulin to partial hydrolysis and studied the breakdown products obtained in this way. On the basis of the results thus obtained Sanger then arrived at 
the structure of insulin as follows: the molecular weight of soluble insulin is about 48,000 . It varies, however, with the concentration and $p \mathrm{H}$ of the solution. When the $p \mathrm{H}$ is less than 4 or more than 7.5 the insulin molecule dissociates into parts with a molecular weight of 12,000 . These parts are each composed of four open polypeptide chains in two of which (the A chains) the terminal amino group belongs to a glycine residue and the terminal carboxyl group to an aspartic acid residue. The corresponding terminal residues in the other two chains (the B chains) are phenylalanine with a free amino group and alanine with a free carboxyl group.

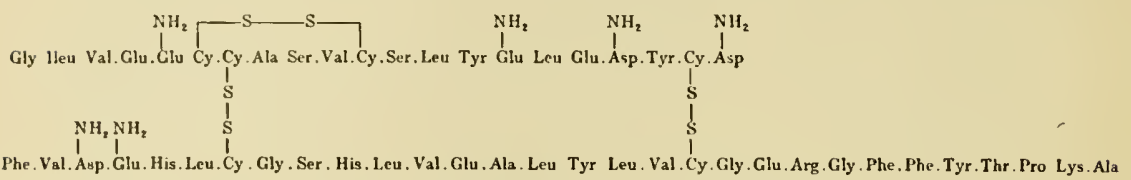

Fig. 15. Formula of ox insulin.

Sanger and colleagues ${ }^{61}$ consider that, strictly speaking, the basic unit of insulin is a particle with a molecular weight of 6 ,ooo consisting of one A chain and one B chain joined together by disulphide bridges. Their complete formula for ox insulin is shown in Fig. 15. According to C. Tanford and J. Epstein, ${ }^{62}$ two such particles are joined together by means of zinc atoms to form a particle with a molecular weight of 12,000 .

These data as to the sequences of amino acid residues in the polypeptide chains of insulin do not show the periodicity in the arrangement of amino acids suggested by Bergmann. The arrangement here is far more complicated. Two identical amino acid radicals may be side by side or may be separated from one another by any number of other residues. There is no obvious regularity or rhythm in these sequences. Moreover, a definite sequence must be present, at least in some part of the molecule, if the protein is to exercise its physiological functions. We still do not know why this is so, we cannot explain the immediate cause of this specificity, but facts which have been obtained recently demonstrate beyond doubt that the specificity exists both for insulin and for other analogous hormones. For example, the two hor- 
mones of the posterior lobe of the pituitary (oxytocin and vasopressin) are very similar in their amino acid composition, ${ }^{63}$ but even the small differences in the details of their structure confer on each its own essential hormonal function which it alone can carry out.

In oxytocin the sequence is Cys. Tyr. Ileu. Glu. Asp. Cys. Pro. Leu. Gly. In vasopressin the sequence is Cys. Tyr. Phe. Glu. Asp. Cys. Pro. Arg. Gly.

Interesting results have been obtained by $\mathrm{P}$. H. Bell and R. G. Shepherd ${ }^{64}$ concerning the structure of the $\beta$-adrenocorticotrophic hormone (ACTH). This is a polypeptide with a molecular weight of 5360 and the following arrangement of amino acid residues: Ser. Tyr. Ser. Met. Glu. His. Phe. Arg. Try. Gly. Lys. Pro. Val. Gly. Lys. Lys. Arg. Arg. Pro. Val. Lys. Val. Tyr. Pro. Asp. Gly. Ala. Glu. Asp. Glu. Leu. Ala. Glu. Ala. Phe. Pro. Leu. Glu. Phe.

It is important that the biological activity of the hormone only depends on the presence in the correct order of the amino acids $1-24$ starting from serine. The rest of the chain is of no importance for its hormonal activity.

Unfortunately we have not yet got the same information concerning the sequences of amino acids in enzymes that we have in hormones. In this case, however, the connection between these sequences and the specific catalytic action of the enzyme in question seems clearer. If the enzyme is to hasten the transformation of the substance which acts as its substrate it must first combine with that substance.

For enzymes with two components which have specific nonprotein (prosthetic) groups as well as proteins in their molecules, it has long been established that the combination of the enzyme with the substrate takes place through the prosthetic groups. ${ }^{65}$

For example, W. Langenbeck ${ }^{66}$ showed in his model experiments that the ability of carboxylase to catalyse the decarboxylation of pyruvic acid is associated with the presence of an amino group in the molecule of the enzyme. Simpler compounds containing this group, such as methylamine, can also accelerate this reaction. The catalytic activity of methylamine is, however, very slight, but can be made many times greater by incorporating, in the molecule of 
methylamine, carboxyl, phenyl and other groups which do not in themselves have carboxylase activity but considerably augment this activity of the amino group.

It has further been shown ${ }^{67}$ that natural carboxylases, that of yeast, for example, have as a prosthetic group a phosphorylated derivative of vitamin $B_{1}$. In this compound the amino group is combined with the heterocyclic pyrimidine and thiazole rings, which confer on it a very high catalytic activity. Not only that, but when the thiamine pyrophosphate is combined with a specific protein the complex acquires a catalytic activity as a decarboxylase ${ }^{68}$ nearly 10,000 times greater than that of the most efficient of Langenbeck's artificial models.

A similar situation is found when we study other enzymes having two components, in particular the oxidising enzymes cytochrome oxidase, ${ }^{69}$ peroxidase,${ }^{70}$ etc.

Catalase, ${ }^{71}$ which catalyses the breakdown of hydrogen peroxide to oxygen and water, is also a compound of a specific protein with a prosthetic group, haem. ${ }^{72}$ The combination of this enzyme with its substrate is brought about through the agency of the iron in the haem. Even ions of inorganic iron have a reak catalytic activity. If, however, the iron is combined with a pyrrole nucleus its catalytic activity is increased several fold. Haem, in which the iron is combined specifically with four pyrrole nuclei, has a specific catalytic activity about 1,000 times greater than that of inorganic iron. In the natural enzyme the haem is combined with a specific protein. As a result of this, its activity is increased ten million times more. One milligramme of iron combined in the catalase complex manifests a catalytic activity which it would require ten tons of inorganic iron to produce.

Thus the presence of a particular group in the prosthetic part of an enzyme with two components seems to be a prerequisite for its activity, because without it the enzyme cannot combine with its substrate. The essential strength and specificity of enzymic catalysis is, nevertheless, associated with the protein component of the enzyme.

We often find the same prosthetic group in a number of different enzymes. Nevertheless, there is a fundamental qualitative difference between them, both as regards the substrates on which they act and the nature of their reactions 



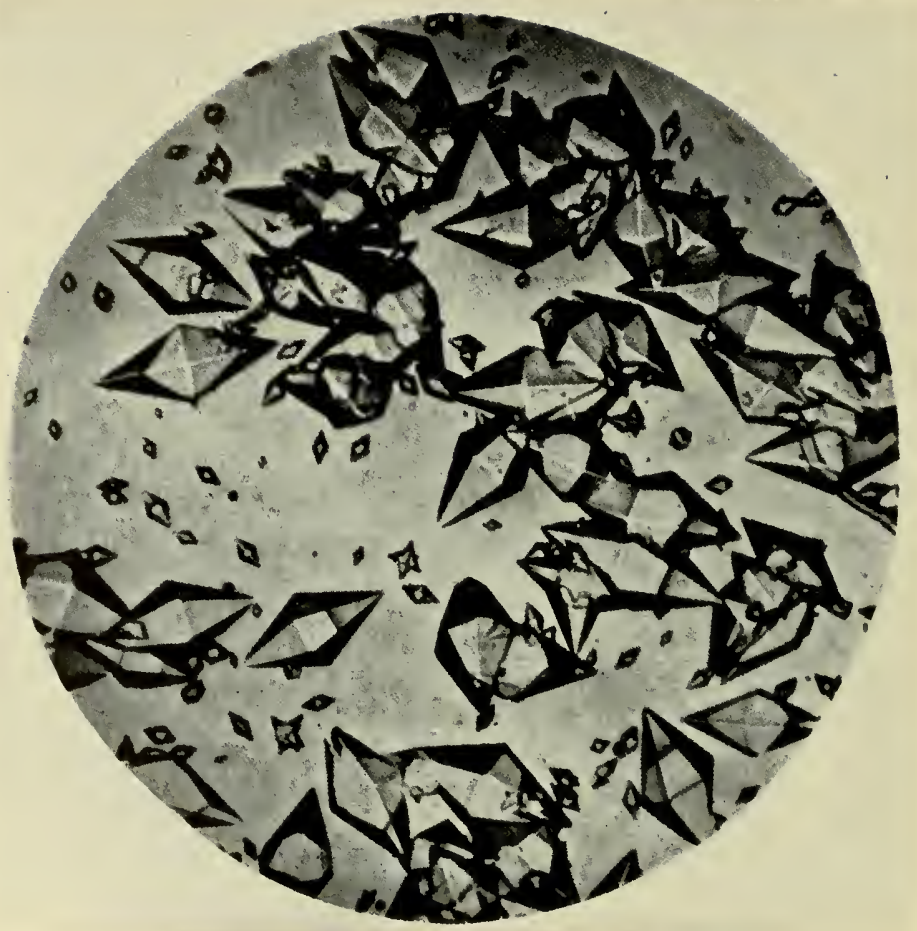

Fig. 16. Crystals of pepsin

(after Northrop, Kunit/ and Herriotı). 
with these substrates. This is due to the fact that the same prosthetic group is combined with proteins which have different compositions and structures. For example, there exist no less than 15 different enzymes which have as their prosthetic group phosphopyridoxal (vitamin $\mathbf{B}_{6}$ ). But, depending on the protein component, one will catalyse the transamination of amino acids, others their decarboxylation, still others the formation of indole from tryptophan, hydrogen sulphide from cysteine, etc. ${ }^{73}$

As well as the enzymes with two components we now know a large number of enzymes which can be prepared in crystalline form and which, on hydrolysis, break down completely to amino acids. They therefore cannot contain prosthetic groups and would appear to be simple proteins. ${ }^{74}$ Enzymes of this kind, having only one component, cannot enter into combination with their substrates otherwise than by means of the free functional groups of the amino acid residues comprising their polypeptide chains (Fig. 16).

Unfortunately, present-day protein chemists only know the complete amino acid composition of a very limited number of crystalline enzymic preparations. We give the facts for four proteins of comparatively low molecular weight which have enzymic actions, and for five with higher molecular weight (Table 3).

A knowledge of these figures for the amino acid composition is, however, of very little help in determining the causes of the activity of any particular enzyme. On the contrary, many contemporary authors emphasise the fact that proteins having similar amino acid compositions may have very dissimilar enzymic activities while, on the other hand, two preparations of the same enzyme isolated from different sources are often very different in amino acid composition. ${ }^{76}$

This should not surprise us. As we have shown above, only a certain number of the amino acid residues in its polypeptide chain play a part in determining the specific biological activity of $\beta$-ACTH, while others are relatively unimportant in this respect. There are a number of facts which suggest that among enzymes, too, their activities are associated with particular parts of the molecule. Centres of activity may be found in them, groups of amino acid radicals 
Table 3. Amino Acid Content of Some

\begin{tabular}{|c|c|c|c|c|c|c|c|c|c|c|c|c|c|}
\hline \multirow[b]{2}{*}{ No. } & \multirow{2}{*}{$\begin{array}{c}\text { Amino } \\
\text { acid }\end{array}$} & \multicolumn{3}{|c|}{$\begin{array}{c}\text { Chymo- } \\
\text { trypsinogen } \\
\text { (ox pancreas) } \\
\text { (mol. wt. } \\
\text { 25,00o) }\end{array}$} & \multicolumn{3}{|c|}{$\begin{array}{c}\text { Ribonuclease } \\
\text { (ox pancreas) } \\
\text { (mol. wt. } \\
15,000)\end{array}$} & \multicolumn{3}{|c|}{$\begin{array}{c}\text { Pepsin } \\
\begin{array}{c}\text { (ox stomach }) \\
\text { (mol. wt. } \\
34,500)\end{array}\end{array}$} & \multicolumn{3}{|c|}{$\begin{array}{c}\text { Lysozyme } \\
\text { (hen's egg) } \\
\text { (mol.wt. } \\
14,700)\end{array}$} \\
\hline & & I & II & III & I & II & III & I & II & III & I & II & III \\
\hline 1 & Alanine & $7 \cdot 6$ & $7 \cdot 4$ & 21 & 一 & - & - & - & - & - & $6 \cdot 0$ & $5 \cdot 1$ & 10 \\
\hline 2 & Arginine & $2 \cdot 8$ & $5 \cdot 6$ & 4 & $5 \cdot 2$ & $10 \cdot 2$ & 5 & $1 \cdot 0$ & $2 \cdot 2$ & 2 & $12 \cdot 9$ & $22 \cdot 5$ & 11 \\
\hline 3 & Aspartic acid & $11 \cdot 3$ & $7 \cdot 3$ & 21 & $14^{-2}$ & $9 \cdot 1$ & 16 & $16 \cdot 0$ & $11 \cdot 5$ & $4^{1}$ & $18 \cdot 2$ & $10 \cdot 3$ & 20 \\
\hline 4 & Glutamic acid & $9 \cdot 0$ & $5 \cdot 3$ & 15 & $13 \cdot 0$ & $7 \cdot 5$ & 13 & $11 \cdot 9$ & $7 \cdot 7$ & 28 & $4 \cdot 3$ & $2 \cdot 2$ & 4 \\
\hline 5 & Cysteine & $1 \cdot 3$ & $0 \cdot 9$ & 3 & 0.6 & $0 \cdot 4$ & $0 \cdot 7$ & $0 \cdot 5$ & $0 \cdot 4$ & 2 & o & o & o \\
\hline 6 & Cystine/2 & $3 \cdot 3$ & $2 \cdot 4$ & 7 & $6 \cdot 5$ & $4 \cdot 6$ & 8 & $1 \cdot 6$ & 1.3 & 4 & $8 \cdot 0$ & $5 \cdot 0$ & 10 \\
\hline 7 & Glycine & $5 \cdot 3$ & $6 \cdot 1$ & 18 & $1 \cdot 3$ & $1 \cdot 5$ & 3 & $6 \cdot 4$ & $8 \cdot 2$ & 29 & $5 \cdot 7$ & $5 \cdot 7$ & 11 \\
\hline 8 & Histidine & $1 \cdot 2$ & $2 \cdot 0$ & 2 & $4 \cdot 2$ & $6 \cdot 9$ & 4 & $0 \cdot 9$ & $1 \cdot 7$ & 2 & $1 \cdot 0$ & 1.5 & 1 \\
\hline 9 & Isoleucine & $5 \cdot 7$ & $3 \cdot 8$ & 11 & $3 \cdot 1$ & $2 \cdot 0$ & 4 & $10 \cdot 8$ & $7 \cdot 9$ & 28 & $5 \cdot 3$ & $3 \cdot 0$ & 6 \\
\hline 10 & Leucine & $10 \cdot 4$ & $6 \cdot 9$ & 20 & o & o & o & $10 \cdot 4$ & $7 \cdot 6$ & 27 & $8 \cdot 4$ & $4^{\cdot 8}$ & 9 \\
\hline 11 & Lysine & $8 \cdot 0$ & $9 \cdot 5$ & 14 & $10 \cdot 4$ & $12 \cdot 1$ & 11 & $0 \cdot 9$ & $1 \cdot 2$ & 2 & $5 \cdot 9$ & $6 \cdot 1$ & 6 \\
\hline 12 & Methionine & $1 \cdot 2$ & $0 \cdot 7$ & 2 & $4 \cdot 4$ & $2 \cdot 5$ & 5 & $1 \cdot 7$ & $1 \cdot 1$ & 4 & $2 \cdot 0$ & $1 \cdot 0$ & 2 \\
\hline 13 & Phenylalanine & $3 \cdot 6$ & $1 \cdot 9$ & 5 & $3 \cdot 6$ & $1 \cdot 8$ & 3 & $6 \cdot 4$ & $3 \cdot 7$ & 13 & $3 \cdot 1$ & $1 \cdot 4$ & 3 \\
\hline 14 & Proline & $5 \cdot 9$ & $4 \cdot 4$ & 13 & $3 \cdot 6$ & $2 \cdot 7$ & 5 & $5^{\cdot 0}$ & $4 \cdot 1$ & 15 & $1 \cdot 4$ & 0.9 & 2 \\
\hline 15 & Serine & $11 \cdot 4$ & $9 \cdot 4$ & 27 & $12 \cdot 0$ & $9 \cdot 7$ & 17 & $12 \cdot 2$ & $11 \cdot 1$ & $4^{0}$ & $7 \cdot 0$ & $5^{\circ} 0$ & 10 \\
\hline 16 & Threonine & $11 \cdot 4$ & $8 \cdot 3$ & 24 & $9^{\cdot 0}$ & $6 \cdot 4$ & 11 & $9 \cdot 6$ & $7 \cdot 7$ & 28 & $5 \cdot 4$ & $3 \cdot 4$ & 7 \\
\hline 17 & Tryptophan & $5 \cdot 6$ & $4 \cdot 7$ & 7 & o & o & o & $2 \cdot 4$ & $2 \cdot 2$ & 4 & $10 \cdot 6$ & $7 \cdot 8$ & 8 \\
\hline 18 & Tyrosine & $3 \cdot 0$ & $1 \cdot 4$ & 4 & $7 \cdot 9$ & $3 \cdot 7$ & 7 & $8 \cdot 5$ & $4 \cdot 5$ & 16 & $3 \cdot 7$ & $1 \cdot 5$ & 3 \\
\hline 19 & Valine & $10 \cdot 1$ & $7 \cdot 4$ & 22 & $7 \cdot 3$ & $5 \cdot 3$ & 9 & $7 \cdot 1$ & $5 \cdot 8$ & 21 & $4 \cdot 7$ & $2 \cdot 2$ & 6 \\
\hline 20 & Amide $\left(\mathrm{NH}_{3}\right)$ & $1 \cdot 86$ & $9 \cdot 5$ & $(27)$ & $2 \cdot 5$ & 12.5 & $(22)$ & 1.6 & $9 \cdot 0$ & (32) & 1.8 & $8 \cdot 0$ & (18) \\
\hline
\end{tabular}

I. g. amino acid/100 g. protein ; II, g. N/100 g. total N ; 
Crystalline Enzymes (after Desnuelle, VI. 75)

\begin{tabular}{|c|c|c|c|c|c|c|c|c|c|c|c|c|c|c|}
\hline \multirow[b]{2}{*}{ No. } & \multicolumn{3}{|c|}{$\begin{array}{l}\text { Aldolase } \\
\text { (rabbit muscle) } \\
\text { (mol. wt. } \\
140,000)\end{array}$} & \multicolumn{3}{|c|}{$\begin{array}{c}\text { Triose- } \\
\text { phosphate } \\
\text { dehydrogenase } \\
\text { (rabbit muscle) } \\
\text { (mol. wt. } \\
\text { 99,ooo) }\end{array}$} & \multicolumn{3}{|c|}{$\begin{array}{l}\text { Phosphorylase } \\
\text { (rabbit muscle) }\end{array}$} & \multicolumn{2}{|c|}{$\begin{array}{l}\text { Lipoxi. } \\
\text { dase } \\
\text { (soya) } \\
\text { (mol.wt. } \\
102,000)\end{array}$} & \multicolumn{3}{|c|}{$\begin{array}{c}\text { Pyro- } \\
\text { phosphatase } \\
\text { (yeast) } \\
\text { (inol. wt. } \\
\text { 10o,ooo) }\end{array}$} \\
\hline & I & II & III & I & II & III & I & II & IV & I & III & I & II & III \\
\hline 1 & $8 \cdot 6$ & $8 \cdot 0$ & 135 & $6 \cdot 7$ & $6 \cdot 4$ & 75 & $4 \cdot 8$ & $4 \cdot 5$ & 54 & - & - & $6 \cdot 4$ & $6 \cdot 2$ & 72 \\
\hline 2 & $6 \cdot 3$ & $12 \cdot 1$ & $5^{1}$ & $5 \cdot 2$ & $10 \cdot 2$ & 30 & $11 \cdot 6$ & $22 \cdot 6$ & 67 & $4 \cdot 7$ & 30 & $3 \cdot 2$ & $7 \cdot 3$ & 18 \\
\hline 3 & $9 \cdot 7$ & $6 \cdot 1$ & 102 & $12 \cdot 4$ & $8 \cdot 0$ & 93 & $9 \cdot 3$ & $5 \cdot 9$ & $7^{\circ}$ & $6 \cdot 2$ & 47 & 14.2 & $9 \cdot 3$ & 107 \\
\hline 4 & $11 \cdot 4$ & $6 \cdot 5$ & 109 & $6 \cdot 8$ & $3 \cdot 9$ & $4^{6}$ & 13.4 & $7 \cdot 8$ & 91 & $10 \cdot 4$ & 73 & $10 \cdot 2$ & $6 \cdot 8$ & 69 \\
\hline $\begin{array}{l}5 \\
6\end{array}$ & $1 \cdot 1$ & 0.8 & 13 & $1 \cdot 1$ & 0.8 & 9 & $0 \cdot 4$ & 0.4 & 3 & 0 & o & - & - & - \\
\hline 7 & $5 \cdot 6$ & $6 \cdot 2$ & 105 & $6 \cdot 0$ & $6 \cdot 9$ & 80 & $3 \cdot 8$ & $4 \cdot 3$ & $5^{1}$ & $6 \cdot 3$ & 82 & 3.7 & $4 \cdot 3$ & 49 \\
\hline 8 & $4 \cdot 2$ & $6 \cdot 8$ & $3^{8}$ & $5^{\circ} 0$ & $8 \cdot 3$ & $3^{2}$ & $3 \cdot 3$ & 5.4 & 21 & $3 \cdot 6$ & 22 & $2 \cdot 6$ & $4 \cdot 3$ & 17 \\
\hline 9 & $7 \cdot 9$ & $5 \cdot 0$ & 84 & $9 \cdot 1$ & $5 \cdot 9$ & 69 & $6 \cdot 5$ & $4 \cdot 2$ & $5^{0}$ & $8 \cdot 1$ & 63 & $10 \cdot 3$ & $6 \cdot 8$ & 79 \\
\hline 10 & 11.5 & $7 \cdot 3$ & 123 & $6 \cdot 8$ & $4 \cdot 4$ & $5^{1}$ & 10.5 & $6 \cdot 8$ & 8o & $11 \cdot 4$ & 89 & $7 \cdot 5$ & 4.9 & 57 \\
\hline 11 & $9 \cdot 5$ & $10 \cdot 9$ & 91 & $9 \cdot 4$ & $11 \cdot 0$ & 64 & $7 \cdot 2$ & $8 \cdot 4$ & 49 & $7 \cdot 8$ & 54 & $12 \cdot 5$ & 14.8 & 85 \\
\hline 12 & $1 \cdot 2$ & 0.6 & 11 & $2 \cdot 7$ & $1 \cdot 7$ & 18 & $2 \cdot 7$ & 1.5 & 18 & 1.6 & 13 & I. 6 & o. 6 & 11 \\
\hline 13 & $3 \cdot 1$ & $1 \cdot 5$ & 26 & 5.5 & $2 \cdot 9$ & 33 & $6 \cdot 2$ & 3.2 & $3^{8}$ & $4 \cdot 9$ & $3^{0}$ & $7 \cdot 1$ & $3 \cdot 7$ & 43 \\
\hline 14 & 5.7 & $4^{\cdot 1}$ & 69 & $3 \cdot 7$ & $2 \cdot 7$ & $3^{2}$ & $4 \cdot 7$ & $3 \cdot 5$ & $4^{1}$ & $5 \cdot 1$ & $4^{6}$ & $7 \cdot 4$ & $5 \cdot 5$ & 64 \\
\hline 15 & $7 \cdot 3$ & $5 \cdot 8$ & 97 & $8 \cdot 5$ & $6 \cdot 9$ & 81 & $3 \cdot 1$ & $2 \cdot 4$ & 30 & - & - & $3 \cdot 7$ & $3 \cdot 1$ & 35 \\
\hline 16 & $7 \cdot 4$ & $4 \cdot 8$ & 87 & $7 \cdot 6$ & 5.5 & 63 & $4^{\cdot 2}$ & $3 \cdot 0$ & 35 & 8.9 & 53 & $5 \cdot 9$ & $4 \cdot 3$ & 49 \\
\hline 17 & $2 \cdot 3$ & $1 \cdot 9$ & 16 & $2 \cdot 0$ & $1 \cdot 7$ & 10 & $2 \cdot 0$ & 1.6 & 10 & 0.4 & 4 & $3 \cdot 6$ & $3 \cdot 1$ & 18 \\
\hline 18 & $5 \cdot 3$ & $2 \cdot 4$ & $4^{1}$ & $4^{\cdot} 6$ & $2 \cdot 2$ & 25 & $5 \cdot 9$ & $2 \cdot 8$ & 33 & $6 \cdot 2$ & 35 & 6.5 & $3 \cdot 1$ & $3^{6}$ \\
\hline 19 & $7 \cdot 4$ & $5 \cdot 3$ & 88 & $12 \cdot 0$ & $9 \cdot 0$ & 105 & $7 \cdot 3$ & $5 \cdot 3$ & 62 & $7 \cdot 8$ & 65 & $5^{\cdot 0}$ & $3 \cdot 7$ & 43 \\
\hline 20 & $1 \cdot 1$ & 5.4 & (91) & $1 \cdot 2$ & $5^{\cdot 8}$ & $(67)$ & 1.5 & $7 \cdot 3$ & 88 & - & - & 1.4 & $7 \cdot 4$ & (82) \\
\hline
\end{tabular}

III, no. of residues/molecule; IV, no. of residues $/ 10^{5} \mathrm{~g}$. 
which also appear to combine directly with the molecules of the substrate, like the prosthetic groups in enzymes which have two components. ${ }^{77}$

In a number of cases it is quite evident that the groups in question are very small in comparison with the size of the whole molecule of the enzyme. The molecular weight of the enzyme ureasc, for example, is almost 10,000 times that of its substrate, urea, and it must have a reactive centre which is, relatively, extremely small. By inhibiting urease with silver ions it has been shown that each molecule of urease must contain three or four such centres. ${ }^{78}$

We can form an opinion as to the chemical nature of the amino acid radicals at these centres by blocking them with some substance which has a specific activity. ${ }^{79}$ By this means it has become clear that it is not just one particular radical which is responsible for the activity of the enzyme, but several amino acids arranged close together in the protein molecule. For example, the catalytic activity of lysozyme depends on the presence of the following free (unblocked) groups: amino, amido, carboxyl, guanidine, hydroxyl and disulphide groups. ${ }^{80}$

R. M. Herriott ${ }^{81}$ gives some interesting facts about the chemical structure of chymotrypsin and pepsin. Comparative study by blocking the free functional groups in active enzymes and their inactive precursors enables one to establish the relationship between the catalytic activity of a given protein and the presence of one or another amino acid radical. For example, it has been shown that di-isopropyl fluorophosphate combines with chymotrypsin but not with its precursor. When this happens, the hydroxyl group of serine is blocked. In the precursor this hydroxyl group forms part of an ester linkage and is only liberated from this by hydrolysis. Besides the hydroxyl group of serine, the imidazole ring of histidine is also necessary for the activity of chymotrypsin. In just the same way the proteolytic activity of pepsin depends on the presence of the free carboxyl and phenolic groups of tyrosine.

I. B. Wilson ${ }^{82}$ has to some extent succeeded in elucidating the structure of the active centres of cholinesterase. One should not, however, suppose that it is only the groups within 
the active centres of the enzyme which are important for its catalytic activities. As with the prosthetic groups of enzymes with two components, they are required only for the initial step, the first stage of the enzymic activity, that is to say, for the combination of the enzyme with its substrate. Thus, if the active centre is absent or blocked no catalytic activity of any sort can occur. However, if the reaction is to be accomplished, the mere combination of the enzyme with the substrate is not enough. A further transformation is necessary, as a result of which the appropriate changes take place in the substrate and the enzyme is regenerated in its original form. If this does not happen, not only is the enzyme unable to accelerate the reaction, but it is itself bound up, immobilised in a stable compound.

It is still not clear which are the details of the structure of the protein molecule associated with these final stages of the catalytic activity of the enzyme. Contemporary scientific literature on this subject consists only of various more or less probable hypotheses (cf. H. Neurath and G. W. Schwert, ${ }^{83}$ P. V. Afanas'ev, ${ }^{84}$ S. E. Bresler ${ }^{85}$ and others). There can, however, be no doubt that the protein molecule as such takes part in the catalytic process, not merely as the active centres which enter into direct combination with the substrate.

It is interesting to compare this suggestion with the results obtained by M. Znamenskaya, P. Agatov and A. N. Belozerskiri $^{86}$ in their work on the mechanism of the biological activity of gramicidin $\mathrm{S}$. These workers showed that the amino group is very important indeed in connection with the activity of this antibiotic. This group should, however, only be regarded as the active centre uniting the antibiotic with the substrate. The nature and specificity of the activity of gramicidin $\mathrm{S}$ depends on the structural features of the molecule as a whole.

Enough has been said to show that the order in which the amino acid residues are arranged is of the first importance in determining the specific biological functioning of enzymes. This order, to some extent, includes both the structure of the active centre and those details of the construction of the protein molecule which are important for its catalytic activity. 
Unfortunately we have, at present, only a very limited amount of information on this subject and what we have is concerned mainly with enzymes of low molecular weight. In particular, C. Fromageot and his colleagues ${ }^{87}$ and later $\mathrm{K}$. Ohno ${ }^{88}$ have established the sequence of the amino acids in some separate fragments of lysozyme (molecular weight 14,700). A. Thompson ${ }^{89}$ obtained from lysozyme a series of penta-, tetra-, tri- and dipeptides and worked out the order in which the amino acids are arranged in them. This order has not, however, been established for lysozyme as a whole. Similar studies with ribonuclease (molecular weight 15,000) are on the way to giving a complete picture of the sequence of amino acids in it. ${ }^{90}$

On the basis of what we know we can already put forward the hypothesis that the sequence of the amino acid residues in the polypeptide chains of various enzymes is not less complicated than that in insulin and other similar hormones and also that, like the biological activity of the hormones, that of the enzymes is determined, in the first place, by this specific structure of the polypeptide chains.

It must not be forgotten that in the protein molecule these chains are disposed in a definite three-dimensional arrangement, the structure of which is of extreme importance in determining the biological characteristics of the protein in question. The chemical potentialities of the side chains and of the polar terminal groups of the amino acid residues are not only realised in external reactions but also in forming internal linkages. This leads to an orderly twisting of the peptide chain and its unification into an extremely well-knit three-dimensional structure with an ordered internal configuration.

A structure of this sort is very characteristic of the protein molecule. Other filamentous molecules, such as rubber, can also curl up into lumps as a result of the thermal motion of their different parts. However, the structure of these lumps seems to be fortuitous. The separate parts are not connected together in any orderly way and the lump may easily be uncurled merely by the application of mechanical tension.

The internal structure of the protein molecules, on the other hand, seems to be perfectly orderly. In them the separ- 
ate parts of the peptide chains and closed rings seem to bear a definite spatial relationship to one another, which is reciprocally strengthened by the drawing together of these parts by means of covalent and ionic bonds, as well as by less stable bonds such as hydrogen bonds. ${ }^{91}$

This sort of structure confers a definite size and shape on the fundamental molecular unit of the protein. These units may combine with one another to give discrete particles of uniform size having a relatively low degree of association, which are usually referred to as molecules of 'globular' or, more accurately, corpuscular proteins, although it would have been more proper to have given them the name of micelles or molecular complexes. ${ }^{92}$ In many cases they may be easily and reversibly dissociated into the fundamental units, which demonstrates the fact that the bonds uniting the fundamental units with one another in their polymers are weaker than those within the fundamental units themselves. It may easily be understood that the three-dimensional architecture of the molecule is of decisive significance in determining the chemical potentialities of a given protein, and thus also its biological properties. Proteins having an identical structure of their peptide chains but with different spatial arrangements of them must obviously also have different enzymic, hormonal or immunological properties.

This is due to the fact that when the chains curl up and form lateral linkages, separate parts of them are necessarily brought into close approximation with one another. As a result of this, amino acid radicals which are widely separated along the peptide chain and even radicals belonging to different chains may be brought together in the protein molecule into the same reactive centre of an enzyme or into the threedimensional 'chemical relief' of the surface of the molecule, which forms the basis for the combination of the antibody with the antigen in immunological reactions. ${ }^{93}$

This type of configuration also means that, while some of the active groups of the amino acid residues find themselves on the surface of the protein molecules and therefore available for chemical activity, others are hidden in the depths of the molecule, protected or 'screened' by the groups which happen to be near them, so that the chemical and even the 
biologically important properties of the protein may change while the composition of its peptide chains and their sequence remain the same.

The correctness of this general picture is confirmed by an immense amount of factual material derived from the fields of both enzymology and immunochemistry. ${ }^{94}$ Experiments on the denaturation of biologically active proteins are specially convincing in this respect. This phenomenon is induced by the action of very diverse physical and chemical factors such as heating, vibration, the action of urea or ultraviolet radiations, etc. It is not accompanied by dissolution or rearrangement of the covalent bonds of the peptide chains of the protein. ${ }^{95}$ The specific three-dimensional architecture of the protein molecule is, however, severely disturbed. ${ }^{96}$ The first more or less satisfactory theory of denaturation was put forward by $\mathrm{H}$. Wu ${ }^{97}$ According to this theory, denaturation occurs as a result of the disruption by the denaturing agent of the weak bonds which subsist between the peptide chains. When this takes place, they arrange themselves in a random and disorderly way corresponding with the most stable thermodynamic state.

According to A. E. Mirsky and L. Pauling ${ }^{98}$ the configuration of the native protein molecule is maintained by hydrogen and salt bonds, which unite the different parts of the peptide chains. When denaturation occurs, these bonds are broken, the chains fall apart and many radicals which were previously hidden within the molecule become available for chemical reactions.

This explains the change in the reactivity of proteins on denaturation. ${ }^{99}$ In particular, it was shown some time ago that the number of sulphydryl and disulphide bonds available for reactions was greater in denatured proteins than in the same proteins in their native state. ${ }^{100}$ Denatured proteins also give stronger reactions for tyrosine $\mathrm{e}^{101}$ and $\operatorname{arginine} \mathrm{e}^{\mathbf{1 0 2}}$ and will combine with larger amounts of iodine. ${ }^{103}$

According to contemporary ideas the structure of native proteins consists of closely packed, coiled or twisted peptide chains which untwist on denaturation to give extended chains without any significant rearrangement which would involve disruption of their covalent bonds. ${ }^{104}$ 
A very characteristic feature of denaturation is the disappearance of the biological properties of the native protein. On denaturation the physiological activities of hormones are destroyed, enzymes lose their catalytic powers and the serological specificity of proteins disappears. The inactivation of enzymes, in particular, seems to be one of the commonest phenomena in laboratory practice and examples in the scientific literature of thermostability among enzymes (e.g. ribonuclease or lysozyme) or of their regeneration after denaturation seem to be the exception rather than the rule. ${ }^{105}$

The same may be said of serological specificity. For instance, it is widely known that denatured egg albumin, like other proteins, does not react nearly so well with the antibody which is formed by the native protein. ${ }^{106} \mathrm{~J}$. O. Erickson and H. Neurath, however, believe that serological activity is associated with structures which are the last to be affected by denaturation. ${ }^{107}$

From all that has been said it follows that the biological specificity of proteins and, in particular, the catalytic activity of enzymes is related not only to a particular sequence of amino acid residues in the polypeptide chains but also to the way in which these chains are arranged inside the molecule of any given protein. Owing to its extreme significance, the structure of the protein molecule has long engaged the attention of scientists. Many of them have tried to construct a schematic representation of this structure on purely theoretical foundations. For example, D. M. Wrinch ${ }^{108}$ once did so, mainly on the basis of geometrical considerations.

A very interesting hypothesis concerning the structure of the molecules of globular proteins has been formulated by D. L. Talmud and S. E. Bresler. ${ }^{109}$ These authors assumed that, as the result of the definite and regular sequence of amino acid radicals, the non-polar (non-ionising) groups such as the hydrocarbon radicals of alanine, leucine, isoleucine, valine, phenylalanine, etc., were mainly arranged on one side of the peptide chain, while the polar (ionising) groups such as the radicals of aspartic and glutamic acids, serine, arginine, lysine and histidine were arranged on the other. This may be represented for the ideal case by the following diagram (Fig. 17). 
A chain constructed in this way would be subject to the action of two opposing forces, the attractive force between the non-polar, predominantly hydrocarbon, side chains, and the repulsive force between the ionising amino acid radicals

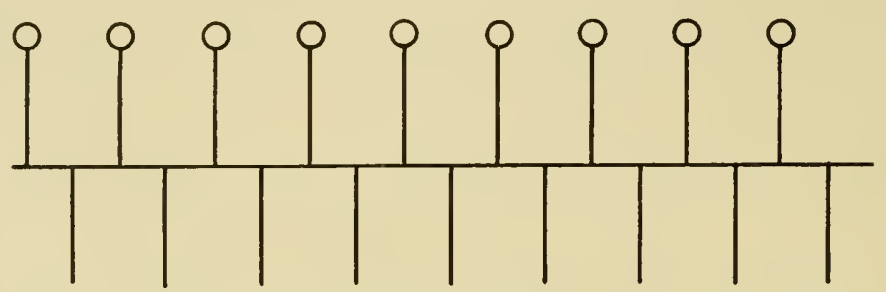

Fig. 17. Diagram of the structure of the polypeptide chain (after Talmud and Bresler).

O- polar (ionising) groups

- non-polar (non-ionising) groups.

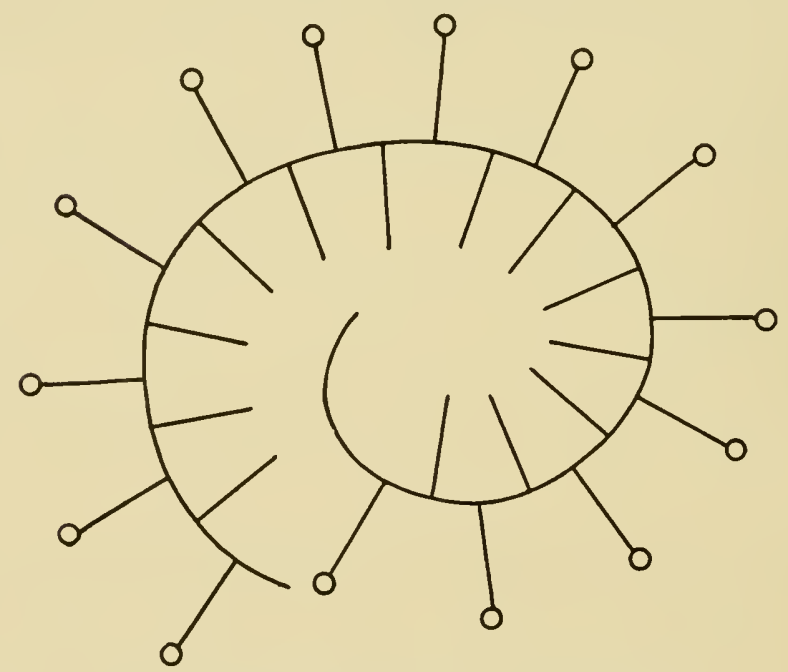

FiG. 18. Diagram of the coiling of the polypeptide chain.

(having similar charges at the given $p \mathrm{H}$ of the surrounding aqueous medium). Owing to this, the chain would twist into a spiral in the middle (nucleus) of which would be the hydrocarbon (hydrophobic) groups while on the outside, which faced the aqueous medium, would be the ionising groups (Fig. 18). 
If this were to happen, additional linkages would arise between adjacent turns of the spiral, in particular hydrogen bonds between the $-\mathrm{NH}-$ and $-\mathrm{CO}-$ groups. The elucidation of the actual arrangement of the amino acid residues in the polypeptide chains of such a typical globular protein as insulin seems to be does not, however, confirm this idea. In this case there is an irregular sequence of polar and non-polar residues (Fig. 19) so that the chain will not be twisted up to form a globule in the way Talmud and Bresler imagined. ${ }^{110}$

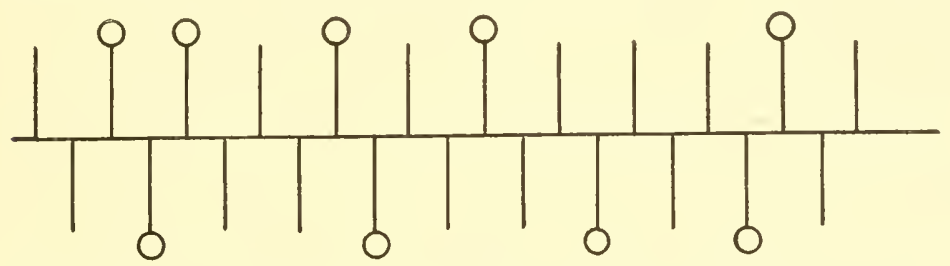

F1G. 19. Polypeptide chain B of the molecule of insulin.

Direct investigation of the structure of corpuscular proteins by the diffraction of $\mathrm{X}$-rays ${ }^{111}$ and infra-red rays ${ }^{112}$ shows that this structure is, in fact, far more complicated than any of the schemes drawn up on the basis of general physicochemical considerations.

In her review B. W. Low ${ }^{113}$ points out that of the whole number of proteins which have been studied in this respect " at best a 'bird's-eye', long distance view of some protein molecules has been derived. It is, however, far from a detailed or precise description of the molecular architecture. ..."

Nevertheless, it may now be held to be established that the essential molecule of corpuscular proteins does not consist of globules but of bundles of polypeptide chains. ${ }^{114}$ A structure of this sort may be made up either of chains which are, in fact, separate (as has been shown in the case of insulin) or of parts of a single polypeptide chain pleated like a ribbon folded back and forth on itself.

In a molecule of native corpuscular protein these chains are twisted or folded in a definite way or curled into helices. It is very likely that in some, though not in all, corpuscular 
proteins there is a structure of the type of the $\alpha$-helix of L. Pauling, R. B. Corey and H. R. Branson, ${ }^{115}$ a diagram of which is here reproduced (Fig. 20).

A helix of this sort is obtained when the chain is twisted

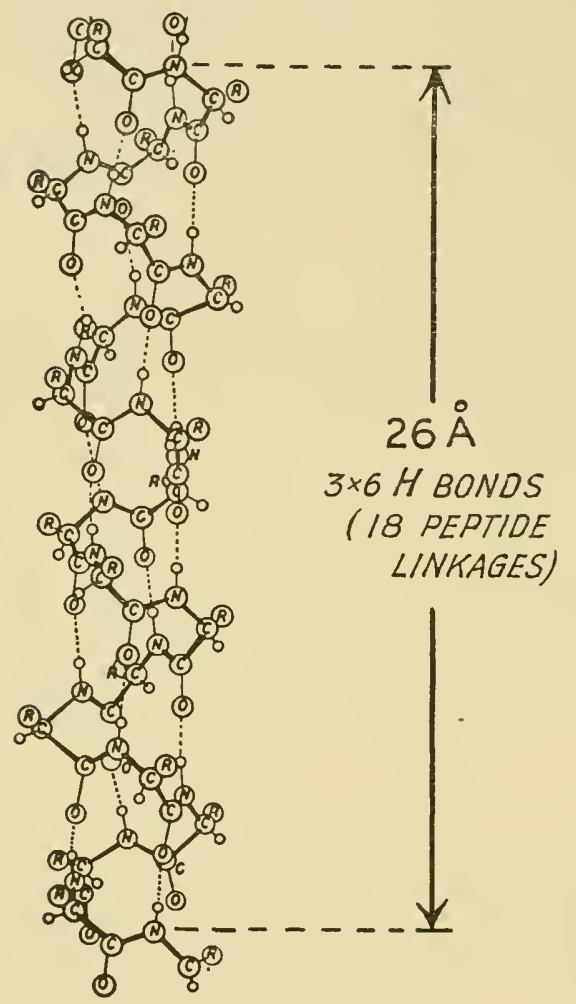
in such a way that each group is united with the third group away from it by means of a hydrogen bond. A complete turn of the helix contains 3.7 amino acid residues. The helix advances $5.44 \AA$ for every turn; each amino acid residue therefore occupies $1.47 \AA$ measured parallel to the axis of the helix. This helix is far more stable in its energy relations than other suggested configura-

FIG. 20.

System of hydrogen bonds in the helical configuration of the polypeptide chain having 3.7 residues per turn (after Pauling, Corey and Branson).

tions of peptide chains and corresponds most nearly to all the theoretical and experimental data.

Nevertheless, B. W. Low ${ }^{113}$ writes:

The problem of protein structure is not simply, however, the problem of polypeptide chain configurations. In all the native protein structures examined in detail there appear to be several chains or lengths of chain arranged in parallel close-packed array. The stability of the molecule as a whole must depend, therefore, upon the nature of the interchain bonding. In the helical structures the side-chain groups are thrown outwards 
towards the perimeter of the coil, and interchain stability must depend, therefore, on side-chain interactions. The reactivity of the molecule is further dependent both upon the sequence of the amino acid residues along a single length of chain and upon the relationships between the residues in adjacent chains.

All these, with other related factors, together determine the complicated three-dimensional surface relief of the molecule of any particular protein which is responsible for its hormonal, enzymic, immunological or other biologically important properties.

\section{The biosynthesis of proteins.}

It now remains for us to answer the question as to whether such an extremely complicated and specific structure as the molecule of a present-day protein with its definite amino acid composition, its particular arrangement of amino acid residues in a polypeptide chain and, finally, its precise internal architecture, so thoroughly and well adapted to the performance of definite biological functions, whether this structure could arise spontaneously, simply in the primaeval aqueous solution of the hydrosphere. Many contemporary authors answer this question in the affirmative, taking the view that there first arose enzymes in this solution of organic substances. These were self-reproducing proteins like viruses, etc., and later combined together. giving rise to the primaeval organisms. It is not, however, so easy to substantiate this sort of general statement. ${ }^{116}$

In the first place, how can one explain the origin of the complicated sequences of amino acids which are found in insulin and other similar proteins? D. L. Talmud and S. E. Bresler once suggested a hypothesis according to which the polypeptide chain was an assemblage of different amino acids, the proportions and sequence of which were statistically determined by their concentrations, but this hypothesis seems to be an oversimplification. The free energies of the polypeptide bonds between the different amino acid residues in a protein are not identical. There is also a correlation between the heat effects of reactions and the energy of their activation. Thus, according to A. G. Pasynskiř, ${ }^{117}$ the incorporation of different amino acids into polypeptide chains 
must proceed at different rates and this must also affect their arrangement. The speed of the reaction whereby amino acid residues are incorporated does not, however, depend entirely on their inherent chemical properties but, in living organisms, it is mainly determined by the presence of a collection of enzymes. It follows that the extremely uneven but strictly determined sequences of amino acid residues in the polypeptide chains, which are to be found in any proteins which have been isolated from living bodies, arise as a result of a pre-existing organisation of their protoplasm. This applies even more forcibly to the three-dimensional structure of corpuscular proteins, which clearly requires for its development a certain spatial organisation. In the absence of such an organisation which had already been elaborated, there could clearly never have arisen simply in an aqueous solution of organic substances such structures as those of present-day proteins with their peculiar properties.

This is also evident because the particles of present-day proteins are not only extremely complicated in structure but are also extremely well adapted to carrying out particular biologically important functions. Enzymes, hormones, etc., seem to be perfectly rationally constructed organs of living protoplasm. Therefore the hypothesis that they arose primarily in some way, and that protoplasm itself was later gradually built up from them, reminds one of the hypothesis of the ancient Greek philosopher Empedocles, concerning the origin of living things.

Empedocles believed that at first there arose separate, independent organs: "Out of it (Earth) many foreheads without necks sprang forth, and arms wandered unattached, bereft of shoulders, and eyes strayed about alone, needing brows."118 Later on these disunited members joined themselves together and in this way there arose various animals and people.

From the present-day Darwinian point of view the falsity and absurdity of hypotheses of this sort are obvious. Any particular organ can arise and become perfected only by the evolutionary development of the organism as a single whole. The definite, complicated structures of eyes and hands are only adapted to the purpose of fulfilling those functions 
which these organs carry out in the whole organism. The effect of natural selection is, therefore, only exerted on them as parts of the whole living thing. It is impossible, unthinkable, to imagine the evolution of isolated organs, the "eyes needing brows" of Empedocles, because for them alone the function to which their structure is adapted has no meaning.

The same applies to the catalytic powers of enzymes. For example, the power of carboxylase to decarboxylate pyruvic acid is of no significance for the enzyme itself, but is only significant for the organism in which the reaction in question occurs. This reaction is only one link in a long chain of energy-yielding transformations of sugar, and if the rate at which it proceeds is co-ordinated with the rates of other metabolic reactions, this will give an advantage to the particular living body in the process of natural selection. It is therefore hard to agree with the recent suggestions of $\mathrm{M}$. Calvin ${ }^{119}$ about the possibility of the primary origin of enzymes by the gradual natural selection, from among a tremendous number of randomly changing organic molecules, of particles with structures which were more and more successfully adapted to the carrying out of particular catalytic functions.

For example, Calvin considers that in the primaeval solution of organic substances there occurred a selection of molecules with a continually increasing amount of carboxylase activity, like that brought about by Langenbeck by artificial selection of his carboxylase models: methylamine, glycine, phenylaminoacetic acid, aminoöxindole, etc.

According to Calvin, the natural selection of molecules having a gradually increasing carboxylase activity in the primaeval hydrosphere took place because this activity was associated with autocatalysis and accordingly the more efficiently the molecule of a catalyst could decompose pyruvic acid. the faster the catalyst itself would be formed.

The models which have so far been constructed by Langenbeck do not, however, bear this out. Their carboxylase activity increases, but no autocatalysis can be observed. The artificial models have no such property nor, it would seem, has the coenzyme of carboxylase, vitamin $\mathbf{B}_{1}$, nor carboxylase itself. One would expect that, if the primary origin of 
enzymes was based on selection for autocatalysis, the proteins of the present time would have that property to the same extent as they have their specific catalytic effects. But this is not so. An example of the formation of enzymes by simple autocatalysis, which caused a great sensation at one time in the scientific literature, is the formation of trypsin from trypsinogen. ${ }^{120}$ In this case there certainly did seem to occur an autocatalytic increase in the number of molecules of the enzyme. If a small amount of trypsin is added to a solution of trypsinogen (which is not proteolytic and may be considered as the nutrient medium in this case) additional amounts of the active enzyme are rapidly formed. One test tube of trypsinogen which has been 'inoculated 'with trypsin may be used for the inoculation of fresh 'media' and the process may be repeated again and again (as is done in the subculturing of bacteria) with the formation of ever more of the enzyme.

However, a more careful study of the mechanism whereby this phenomenon is produced shows that, in this case, we are not, in fact, dealing with the synthesis of trypsin de novo. The enzyme is present in trypsinogen in its entirety, but its activity is blocked by a peptide which is combined with it (just as the ignition key of a car is rendered useless for starting the engine when it is immobilised in the lock of the door). The proteolytic activity of trypsin depends on the activation of trypsinogen simply by the removal of the key from the lock and has nothing to do with the autocatalytic synthesis of fresh enzyme molecules. ${ }^{121}$

The same may be said of the formation of pepsin by analogous means, from pepsinogen. ${ }^{122}$ As regards other enzymes, in particular enzymes such as carboxylase or catalase, they do not even give a semblance of forming themselves autocatalytically. Like the other proteins of protoplasm, they can only come into being there as a result of a very complicated biosynthetic process.

At present biochemists are only beginning to collect the facts in the field of protein synthesis. The scientific literature concerned with this subject, therefore, contains very few firmly established theories but many more or less plausible hypotheses of various sorts and extremely ingenious 
mathematical speculations, which attempt to reduce this complicated biological phenomenon to comparatively simple mathematical terms, just as Wrinch tried to postulate a structure for the globular protein on the basis of purely geometrical considerations. However, we can aheady say with certainty that nowhere in nature can we observe the formation of proteins by the direct 'birth' of one molecule from another identical one, as was imagined even quite recently. The chemically individual proteins which have been isolated do not arise of themselves by the 'division' of molecules nor by simple automatic autocatalysis. We can, in fact, only observe the production of proteins in living bodies, and this process requires the harmonious participation of a series of systems including many different protein-enzymes.

We can nowadays point to at least three categories of such systems, the co-operation of which is indispensable for the biosynthesis of proteins: 1, systems which supply the energy needed for the synthesis of the protein ; 2, catalytic (enzymic) systems which create the kinctic conditions for the synthesis, a definite relationship between the rates of the different reactions; 3 , systems which determine the spatial organisation during the synthesis of the protein molecule.

The method of synthesis of proteins from amino acids seems to be common to the majority of present-day organisms, though one cannot exclude the possibility that some preformed peptides may be incorporated in the chains. ${ }^{123}$ As was pointed out in the previous chapter, this method of synthesis requires a certain expenditure of energy, which must be supplied to any system in which proteins are formed directly.

In all heterotrophic organisms the basic source of the energy required for life seems to be the energy derived from the anaerobic or aerobic breakdown of organic substances, mainly carbohydrates (fermentation, glycolysis, respiration).

The autotrophs also make extensive use of this method, decomposing and oxidising the carbohydrates which they have made by photo- or chemosynthesis. The various fermentations, glycolysis and respiration, seem to be carried through by very highly co-ordinated enzymic reactions. Their realisation requires the presence of a very complicated system 
of enzymes in which, as will be shown later, the more complete the organisation of any particular system the higher its energetic efficiency and the greater the extent to which the energy produced by it can be used for the carrying out of vital processes, in particular for the formation of the proteins of protoplasm. In the course of these metabolic processes there arise many kinds of high-energy compounds and the energy which they yield can be used, in one way or another, for biological syntheses. The best known of these compounds is adenosine triphosphoric acid (ATP), which can hand over the energy of its phosphate linkages by the transphosphorylation of a number of organic compounds.

F. Lipmann ${ }^{124}$ and other authors (e.g. ${ }^{125}$ ) have suggested that the increment of energy required for synthesis of peptide bonds when amino acids combine may be obtained by the phosphorylation of their amino or carboxyl groups at the expense of ATP or some analogous substance. This suggestion is confirmed by various sorts of model experiments in which hippuric acid is synthesised from glycine and benzoic acid, ${ }^{126}$ and also by the synthesis of the tripeptide, glutathione, from its component amino acids in slices and homogenates of various organs ${ }^{127}$ as well as in experiments with yeast. ${ }^{128}$ S. Yanari and his colleagues ${ }^{129}$ have shown recently that an enzyme which they isolated from pigeon's liver can bring about the synthesis of glutathione from its amino acids only when the system contains ATP and glycolytic processes are proceeding.

Lipmann's hypothesis concerning the biosynthesis of proteins is, to some extent, confirmed by the fact that anything which interferes with phosphorus metabolism hinders this synthesis. Thus, in the experiments of E. F. Gale and J. P. Folkes, ${ }^{130}$ fragments of staphylococcal cells were able to incorporate isotopically-labelled amino acids and synthesise proteins from complete collections of amino acids only on the addition of ATP and hexose diphosphate as sources of energy. Analogous phenomena were observed by F. B. Straub $b^{131}$ during the synthesis of amylase by homogenates of the pancreas.

On the other hand, it must be pointed out that nobody has yet succeeded in directly observing the phosphoryla- 
tion of amino acids, while synthetic phosphorylated amino acids which are artificially introduced into an organism do not enter directly into the synthesis of proteins. It must therefore be admitted that the actual mechanism of the transfer of energy during the synthesis of proteins is still not quite clear. H. Borsook ${ }^{132}$ considers that there first occurs the activation of the carboxyl groups of free amino acids by ATP, either directly or through coenzyme A. Afterwards the activated amino acids combine with nucleic acid according to the following scheme:
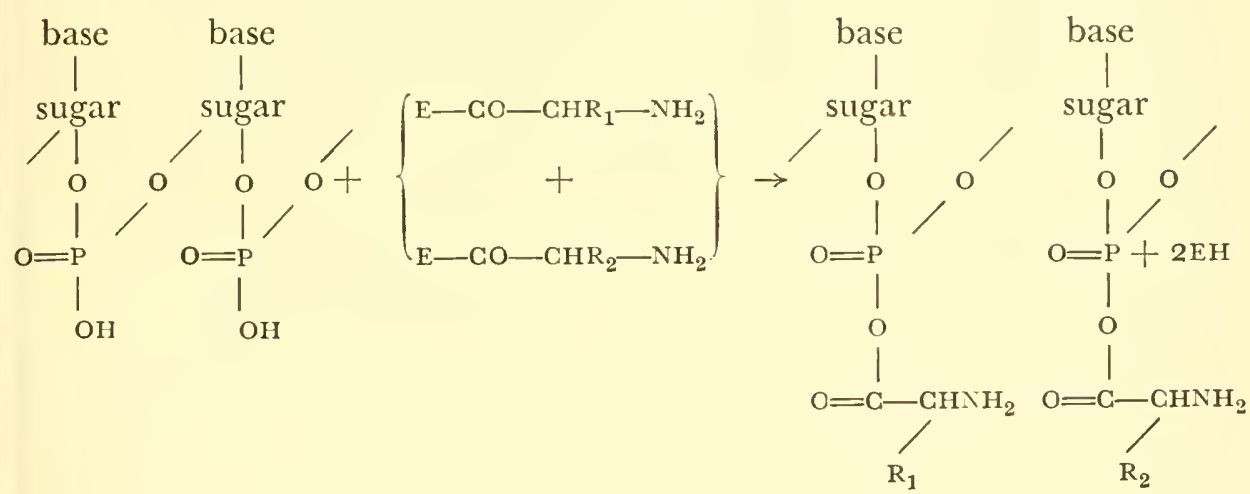

Peptide bonds are then created, after which the finished protein molecule is liberated from the nucleic acid.

On the other hand, according to S. E. Bresler, ${ }^{133}$ energy is necessary for the last stage of the process, the desorption of the polypeptide chain from the surface of the polynucleotide. According to this author, the biosynthesis of proteins is based on the chemosorption of amino acids on the energybearing phosphorylated groups of ribonucleic acid. Under the conditions of the adsorbed layer the equilibrium is shifted towards synthesis. The action of proteolytic enzymes will therefore lead to the joining together of amino acids and the synthesis of protein molecules, which does not require the additional expenditure of energy. Energy is required for desorption of the finished protein molecule and this is derived from high-energy bonds in the phosphorylated nucleic acid. The surface which has been freed from the protein is again phosphorylated and the cycle repeats itself. 
The very interesting experimental results obtained by R. B. Khesin ${ }^{134}$ show that isolated secretory granules of the pancreas cannot make direct use of the energy of ATP for the synthesis of the protein-enzyme amylase. In them the synthesis of the enzyme from free amino acids only occurs as a result of the activity of substances which are elaborated independently by other formed elements in the protoplasm, the mitochondria, in the course of their energy-exchange reactions which take place in the presence of ATP under aerobic conditions. The actual synthesis of protein by the granules can, however, proceed in the absence of oxygen.

The part played by enzymes in the processes supplying the energy required for synthesis is now worked out in great detail but the position is far worse in regard to the part played by enzymic systems directly in the biosynthesis of proteins.

As early as 1886 A. Danilevski ${ }^{135}$ first indicated that synthetic reactions might be brought about with the help of proteolytic enzymes. On digesting dilute solutions of different proteins with pepsin and then concentrating the peptones thus obtained and allowing fresh portions of pepsin to act on them, Danilevskir observed the formation of an insoluble precipitate, which he believed to be protein which had arisen as a result of the enzymic synthesis. Furthermore, it was established that these precipitates, which were called "plasteins", could be obtained from peptic hydrolysates of a very large number of proteins by enzymic synthesis because, owing to the removal of the insoluble products of the reaction by precipitation, the equilibrium was displaced away from hydrolysis and towards the synthesis of peptide bonds. ${ }^{136}$ The plasteins have since been studied in detail by all modern methods. ${ }^{137}$ They seem to be polypeptides, with molecular weights of some thousands, containing a predominance of hydrophobic amino acids and apparently lacking any specific biological properties. ${ }^{138}$

Comparatively recently $H$. Tauber ${ }^{139}$ has succeeded in bringing about the enzymic synthesis of proteins by the action of chymotrypsin on a mixture of peptides. Chymotrypsin also catalyses the formation of peptides from esters of amino acids, in which reaction the energy needed for the 
synthesis is supplied by the simultaneous decomposition of the esters. ${ }^{140}$ M. Bergmann ${ }^{141}$ also brought about the synthesis of peptides. He obtained anilides of acylamino acids from the corresponding amino acid derivatives and various anilides by the action of papain and chymotrypsin on them.

In recent years a number of authors have been laying more and more stress on the part played by transamidation ${ }^{142}$ and transpeptidation $^{143}$ in the process of the biosynthesis of proteins. The enzymic nature of these processes is indubitable and the only question which is not yet quite clear is whether there are specific enzymes for transpeptidation or whether the proteolytic enzymes themselves perform this function. ${ }^{144}$ In particular, I. L. Kaganova and V. N. Orekhovich ${ }^{145}$ have observed a large number of transpeptidations occurring under the influence of chymotrypsin.

It must, however, be admitted that, notwithstanding all this, the direct participation of the enzymic apparatus of the protoplasm in the biosynthesis of proteins has still not received nearly enough study. In particular there remains the vexed question of the part played by enzymes in the creation of the specific structure and properties of the proteins which have been synthesised.

As early as 1939, M. Bergmann put forward the opinion that the sequence in which the amino acids are arranged in the polypeptide chain is determined by the relative rates of the different enzymic reactions co-operating in the synthesis.

This opinion is not widely supported in the world literature at present chiefly because people are distracted by the part played by spatial factors in the determination of the specificity of proteins. For example, F. Haurowitz ${ }^{76}$ states, during the development of his hypothesis concerning the synthesis of proteins on an extensive 'protein template ', ${ }^{146}$ that the amino acids which are arranged in a particular order on this template combine together owing to the action of non-specific proteolytic enzymes such as trypsin or papain. He adds that the specificity of the synthetic processes may now be attributed, not to the specificity of the catalysts, but to the specificity of the organiser or inductor.

A. L. Dounce used to believe that, for amino acids to 
combine with definite parts of the polynucleotide chain during the process of the synthesis of proteins, the participation of a large number (up to 64 ) of specific enzymes was required. He is now inclined to deny the necessity for such far-reaching enzymic specificity. ${ }^{147}$

Unfortunately there is, as yet, very little direct factual evidence on this problem upon which to base a definite conclusion. One should not forget, however, that in all cases where the biosynthesis of any substance has been studied in enough detail, it has been shown to be based on a chain of strictly co-ordinated enzymic reactions. Moreover, the simple consideration of the magnitude of the free energy of the peptide bonds between different amino acid residues and the energy of activation needed for the formation of these bonds shows that the incorporation of different amino acid residues in polypeptide chains must take place at different rates. Thus the kinetic conditions, which are fundamentally regulated by enzymes, must play an essential part in the synthesis of proteins.

Thus, while giving due weight to the importance, for the synthesis of proteins, of spatial factors in the organisation of protoplasm, one must not forget about its organisation in time, the conjunctions of kinetic circumstances which determine a particular type of metabolism. In this connection a very important place is occupied by the catalytic (enzymic) systems.

The significance of spatial localisation in all vital processes and, in particular, in biosynthesis was recognised by the biologist R. Altmann ${ }^{148}$ as long ago as ${ }^{1886}$. In his book Studien $\ddot{u} b e r$ die Zelle he very perspicaciously put forward the idea that the synthetic processes do not occur diffusely throughout the protoplasm but are associated with definite structures in it, which he called 'granules'. This idea of the localisation of the synthetic processes in formed elements of the protoplasm was maintained by G. Lewitsky $y^{149}$ who worked on plant preparations, by A. Guilliermond ${ }^{150}$ on the basis of his observations on mitochondria, and later by $\mathrm{E}$. W. MacBride and H. R. Hewer, ${ }^{151}$ E. S. Horning ${ }^{152}$ and many other authors.

Since then more and more facts have been collected which 
indicate that the bulk of the enzymes are associated with the formed elements of the cell contents, which gives a special character to the activity of these biocatalysts which is substantially different from that observed in simple aqueous solutions of enzymes isolated from cells. It was thus established that even slight changes in the composition of protoplasmic structures occurring under the influence of external factors have a substantial effect on the speed and nature of synthetic reactions within the living cell. ${ }^{153}$

Damage to or disruption of these structures, which occurs under even the mildest conditions, leads to the complete abolition of biosynthesis. For example, the bacterium Micrococcus lysodeikticus may be treated with lysozyme without disturbing the structures in the least, if the lysis is carried out in the presence of sucrose. ${ }^{154}$ When this takes place, the protoplasts retain their ability to incorporate marked molecules of glycine and leucine in their protein. ${ }^{155}$ However, it has been shown in our laboratory that if the concentration of sucrose is gradually lowered, a definite point is reached when the concentration falls below $0.64 \mathrm{~m}$ and the structure of the protoplasts is disrupted. This can easily be checked with the electron microscope. At the same time there is a sharp fall in the respiration of the protoplast, and later, when the concentration of sucrose falls below $0.44 \mathrm{M}$, the protoplast loses its ability to incorporate marked glycine and to synthesise protein in the presence of a complete collection of amino acids. ${ }^{156}$ Obviously there is a limit to the amount of damage which the structure of the protoplast can suffer, beyond which the biosynthesis of protein becomes impossible owing to the loss of that co-ordination of the reactions in time which only occurs when the enzymes are placed in special positions relative to one another in the protoplasm (Fig. 21).

In recent years a large number of papers have appeared showing how particular enzymes are associated with this or that demonstrable structure, whether it be plastids, ${ }^{157}$ mitochondria or microsomes, ${ }^{158}$ and hence which biochemical processes are localised in these formed elements of the protoplasm. Thus it has been established that there are concentrated in the mitochondria the enzymes taking part 
in the Krebs cycle, cytochrome oxidase and also other oxidising enzymes such as succinic, lactic and glycerophosphate dehydrogenases. ${ }^{159}$

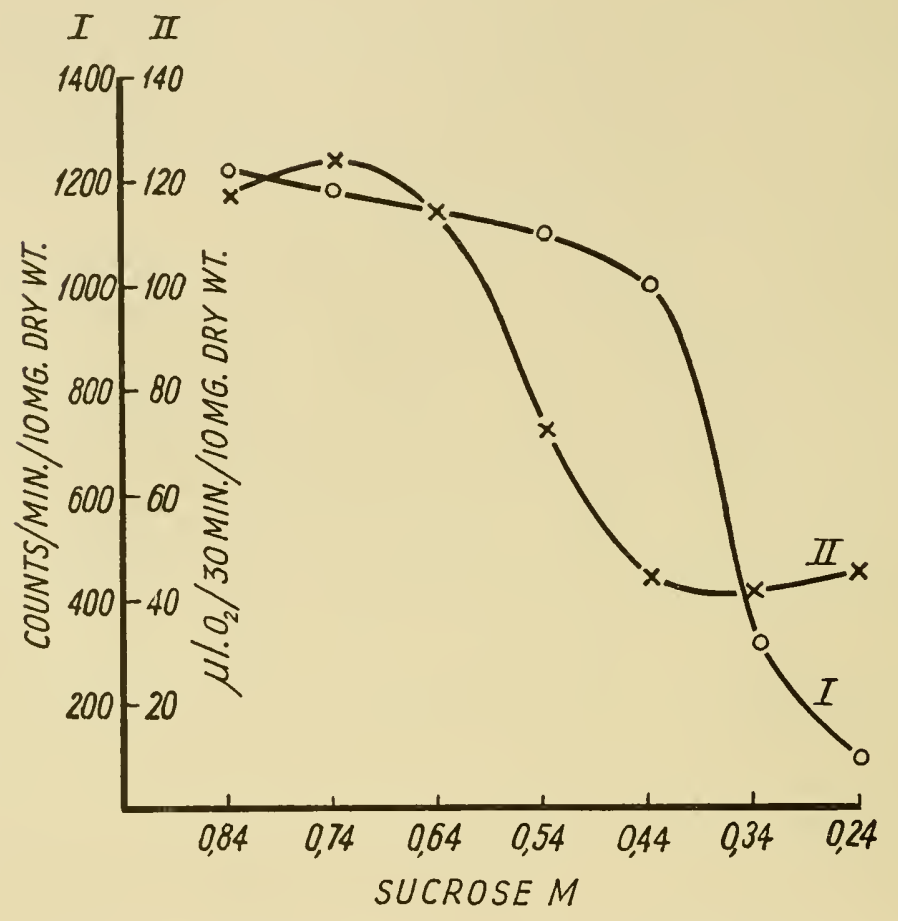

FIG. 21. The respiration of the protoplasts of Micrococcus lysodeikticus and the uptake of labelled glycine.

The enzymes in the mitochondria are not arranged at random but stand in a definite spatial relationship to one another, which is associated with a very precise internal structure of the mitochondria. This reduces the path which must be followed by the substrate or coenzyme to a minimum, which allows a considerable speeding up of long chains of reactions such as the citric acid cycle. K. Lang ${ }^{160}$ showed that anything which destroys the structure of the mitochondria inactivates the so-called cyclophorase system of enzymes discovered in the mitochondria by D. E. Green and his colleagues. ${ }^{161}$ 
The essential energy-exchange processes of the cell are associated with the enzymes which have been found in the mitochondria. It is clear that the main biological function of the mitochondria consists in the formation of energy-rich compounds.

Rather unexpectedly, it was found that the bulk of the enzymes associated with the metabolism of the nucleic acids (ribonucleic acid, RNA, and desoxyribonucleic acid, DNA) was localised in the mitochondria. ${ }^{162}$ This led to the idea that nucleic acid synthesis might be localised in the mitochondria. However, direct experiments did not verify this suggestion. ${ }^{163}$ In the same way all contemporary investigators agree that the actual synthesis of proteins does not occur in the mitochondria.

At one time $T$. Caspersson ${ }^{164}$ suggested that the nucleus is the main centre for the synthesis of proteins, but direct studies of biosynthesis in fragments of algae (Acetabularia) containing no nuclei. carried out by J. Hämmerling ${ }^{165}$ and later by J. Brachet and H. Chantrenne, ${ }^{166}$ disproved this hypothesis. On the contrary, the numerous results obtained by J. Brachet and R. Jeener, ${ }^{167}$ T. Hultin, ${ }^{168}$ E. B. Keller, ${ }^{169}$ P. Siekeritz and P. C. Zamecnik ${ }^{170}$ have shown quite definitely that the proteins of the cytoplasm are synthesised directly in the microsomes. The nucleus only takes part indirectly in the synthesis of proteins, perhaps by controlling the formation of the microsomes themselves.

According to Siekevitz, ${ }^{171}$ however, the incorporation of amino acids into the proteins of the microsomes is only observed when microsomes and mitochondria are incubated together. Under these circumstances the reaction proceeds much faster when the conditions are suitable for oxidative phosphorylation. The mitochondria may also be incubated without the microsomes in a solution containing an oxidisable substrate and co-factors. In this case the mitochondria form a high-energy factor. which enters the solution, and in the presence of this the isolated, incubated microsomes retain their ability to incorporate labelled alanine.

Thus we have here what might be called a division of labour between the two sorts of protoplasmic structures. One system of enzymes is localised in the mitochondria in which, 
so to speak, they are 'assembled' into a single structural aggregate which works up the energy-rich compounds required for the synthesis of proteins. The synthesis itself is, however, carried out in another structural aggregate, the microsome or, as Brachet ${ }^{172}$ calls it, with reference to its high content of ribonucleoproteins, a 'ribonucleopro:ein granule'. A comparison of the evidence concerning the synthesis of peptide bonds in the protoplasmic structures of animal and vegetable cells has revealed some differences in these processes. Thus, according to N. Sisakyan, ${ }^{172 a}$ the incorporation of labelled glycine takes place considerably faster in those fractions of a homogenate of tobacco leaves which contain mitochondria than in those which contain plastids. Nevertheless it is only in the plastids that one can observe an increase in the amount of protein nitrogen derived from mixtures of amino acids.

The idea that RNA plays an important part in the synthesis of proteins arose quite a long while ago on the basis of biological observations and quantitative experiments which showed a close correlation between the rate of synthesis of proteins and the amount of nucleic acids in organs, tissues and the organelles of cells. In growing and secreting organs, i.e. those in which proteins are being synthesised fastest, the amount of ribonucleic acid is found to be greatest. On the other hand the parts of adult organisms which only grow slowly or have stopped growing altogether only contain a relatively small amount of RNA even in cases where the organ is biologically extremely active and carries out a great deal of work in the organism (e.g. the heart or kidneys). ${ }^{173}$

In parallel with this, cytological studies have shown that the synthesis of proteins proceeds with special intensity in just those parts of the cell which are richest in RNA. In particular, in the nucleus the synthesis of proteins is concentrated only in the heterochromatic nucleoli while in the cytoplasm it is concentrated in the mitochondria, which are exceptionally rich in ribonucleic acid. ${ }^{174}$

The association between the intensity of protein formation and the concentration of ribonucleic acid has been confirmed, not only by cytochemical means but also by the use of more accurate methods, ${ }^{175}$ in particular by the use of labelled 
atoms. ${ }^{176}$ In this way it has been possible to find a correlation between the rate of synthesis of proteins and the rate of renewal of phosphorus in RNA, the activity of phosphatase, etc.

Direct evidence of the dependence of protein synthesis on the presence of nucleic acids was obtained by E. F. Gale and J. P. Folkes ${ }^{130}$ in their work on the incorporation of amino acids into proteins by fragments of staphylococci which were obtained by disintegrating the organisms by ultrasonic vibrations. Nucleic acids can be removed from these fragments by washing. When this is done they lose their ability to incorporate amino acids and synthesise protein. This ability is, however, restored by the addition of RNA and DNA isolated from staphylococci to the medium in which the fragments are incubated.

It is very interesting that the ability of disintegrated staphylococcal cells to incorporate separate amino acids into proteins is affected not only by native RNA but also by its breakdown products obtained by splitting it with ribonuclease. When this was done there were isolated from among the products several fractions which could bring about the incorporation of amino acids but the incorporation of each different amino acid was accelerated by a particular fraction. Thus, the incorporation of amino acids into the proteins of the cell fragments does not require RNA as an intact molecular complex but the presence of small fragments of the molecule is enough. Gale therefore considers that the incorporation of each amino acid may be regarded as a separate and independent reaction associated with a special polynucleotide fragment. Recently, howerer, there has arisen some doubt as to whether this action is due to the individual polynucleotide fragments or to some other active compounds contained in the fraction.

The study of viruses is of special importance for an understanding of the part played by nucleic acids in protein synthesis, and especially the study of the simplest viruses pathogenic to plants. The most thoroughly studied of these is tobacco mosaic virus, which was discovered by D. Ivanovskiî ${ }^{177}$ as early as the end of the nineteenth century. The study of tobacco mosaic virus has made great strides forward since 
the end of 1935 when W. M. Stanley ${ }^{178}$ succeeded in isolating it in crystalline form. This virus, as well as a whole series of analogous viruses producing diseases in higher plants, has been studied by Stanley himself and also by F. C. Bawden, N. W. Pirie, R. Wyckoff, J. D. Bernal, R. Markham, H. Fraenkel-Conrat, G. Schramm and, in the Soviet Union, by V. Ryzhkov, K. Sukhov, P. Agatov, A. Vovk, M. Gol'din and many others. There has also been extensive progress in the study of the bacterial viruses or bacteriophages, and especially of the viruses of animals and man which are of medical importance. The scientific literature on viruses has grown to an immense size. We shall only refer here to a limited number of review works which contain extensive references to the literature. ${ }^{179}$

The great advantage of studying tobacco mosaic virus, as an approach to the solution of a number of general biological questions, lies in the relative simplicity of its composition. While the particles of other viruses such as the animal viruses of the smallpox-psittacosis group contains lipids, carbohydrates and other substances as well as nucleoproteins, the crystals of tobacco mosaic virus are composed entirely of nucleoproteins. But, unlike other nucleoproteins which have been isolated from living things, the virus has the specific property that when it is introduced into the living cell of the plant it evokes in the host a turbulent process of biosynthesis of the particular proteins and nucleic acids which are characteristic of the virus but which are absent from the healthy tobacco leaf. In this way the amount of virus in the cells of a large plant may increase many millionfold within a few days. However, nobody has succeeded in producing this so-called 'multiplication' of virus particles under any other conditions or on any artificial medium. Outside the host organism the virus remains just as inert in this respect as any other nucleoprotein. Not only does it show no sign of metabolism but nobody has yet succeeded in establishing that it has even a simple enzymic effect. It is clear that the biosynthesis of virus nucleoproteins, like that of other proteins, is brought about by a complex of energic, catalytic and structural systems of the living cell of the host plant, and that the virus only alters the course of 
the process in some way so as to give specific properties to the final product of the synthesis. Hence one may see what wide vistas are opened up by the study of viruses towards an understanding of the significance of nucleic acid derivatives in the specific synthesis of proteins.

The tobacco mosaic virus, which has been obtained in crystalline form, has been studied in detail by numerous workers using the most diverse and refined apparatus and methods-by X-ray crystallographic analysis, with the electron microscope, with the ultracentrifuge, by the incorporation of labelled atoms, by chromatography, etc. (Fig. 22).

Until very recently indeed it was held that the nucleic acid in tobacco mosaic virus was exclusively RNA, but a communication has just appeared showing that in this virus, as in several other viruses, there is a small amount of DNA. ${ }^{180}$ Thus, even from this point of view, the crystalline virus does not seem to be a single substance.

As the investigations of $\mathrm{R}$. Markham ${ }^{181}$ have shown, the ribonucleic acids of tobacco mosaic virus, tomato bushy stunt virus, turnip yellows mosaic virus, potato $\mathrm{X}$ virus and one of the tobacco necrosis viruses are different from one another in their composition and furthermore each of them differs substantially from the ribonucleic acid of the respective host. In the viruses which have been listed, the differences in proportion of the nucleotides contained in their ribonucleic acids are so great that they can serve as criteria for differentiating between one of these viruses and another. The same is true of the protein parts of the nucleoproteins of these viruses.

The amino acid composition of the protein of tobacco mosaic virus is fairly accurately worked out and is similar to that of a globulin. At present 18 'common' amino acids have been obtained from it; they are without exception L-isomers. ${ }^{182}$ The molecular weight of tobacco mosaic virus particles is very high, about $4^{0}$ million, but the fundamental protein molecules which take part in the structure of the virus have a molecular weight of about 17.000 . This may be demonstrated by destroying the virus with ultrasonic vibrations or detergents. Similar values for the molecular weights of the fundamental proteins have also been obtained by 
determining the numbers of terminal groups of the polypeptide chains. It has thus been established that the amino acid at the carboxyl end of the chain is threonine. ${ }^{183}$

All these data taken together indicate that the protein component of the particle of tobacco mosaic virus consists of about 2,800 separate peptide chains each of which has a threonine residue at one end and is composed of up to $15^{\circ}$ amino acid residues. These polypeptide chains are folded in a definite way to form the fundamental molecule of the protein of the virus.

Proteins of this kind are not only to be obtained from the nucleoproteins of the virus, they may also be isolated from the juices of the infected plant, where they exist in the free state, not combined with nucleic acid. This was done by W. N. Takahashi and M. Ishii. ${ }^{184}$ These authors isolated, by electrophoresis, the same protein from the tissues of tobacco, tomato and phlox plants infected with tobacco mosaic virus and called it X-protein. It was found to be different from the proteins of the plants in question, but to correspond both chemically and serologically with the protein of the virus. In neutral solution the particles of this protein are nearly the same size as the fundamental molecules of the virus proteins but in an acid medium they join together to give rod-shaped formations which look, under the electron microscope, like virus particles and have a diameter of $150 \AA$. This protein is absent from healthy plants.

The suggestion that the X-protein is made up of fragments of normal virus particles arising in the process of disintegration of the plant tissues has not been confirmed. On the contrary, all the data now available indicate that it is the immediate product of biosynthesis which takes place in the living plant in the presence of the virus. The X-protein has no infectivity and, accordingly, no power of self-reproduction even within the living cell.

X-ray crystallographic studies ${ }^{185}$ of the virus particles have shown that the axis of the cylinder or core of the rod is formed by the nucleic acid while the protein is arranged as a covering layer around it. The polypeptide chains of the fundamental protein molecule are curled round the axis of nucleic acid in such a way that the whole virus particle 


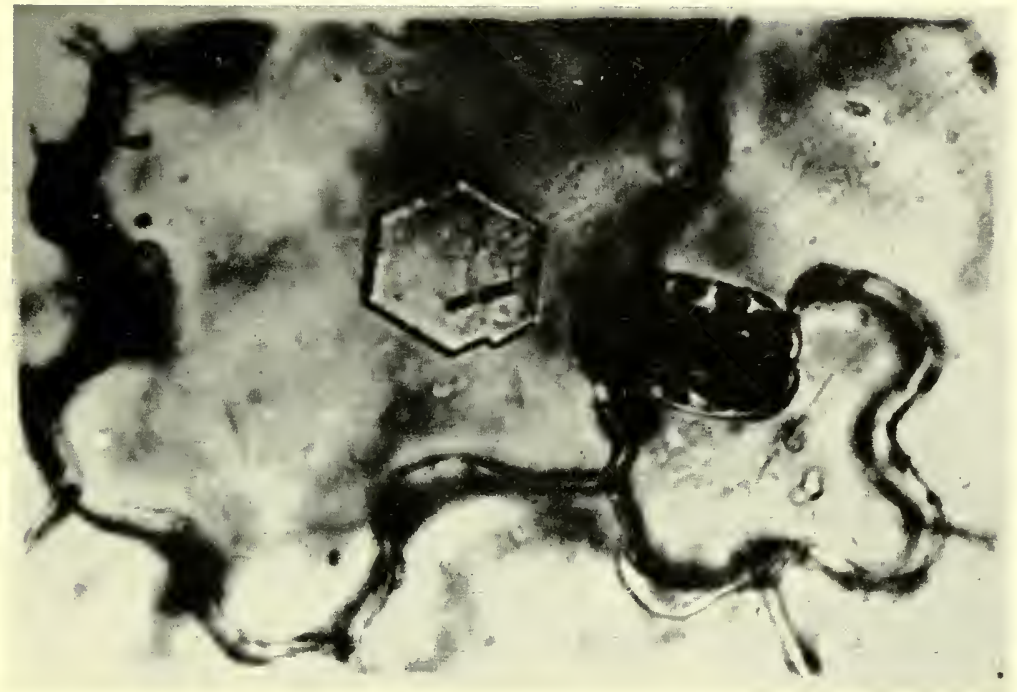

Fro. 22. Comstals of tobacco mosatic vims in a leaf (after Coldin). 


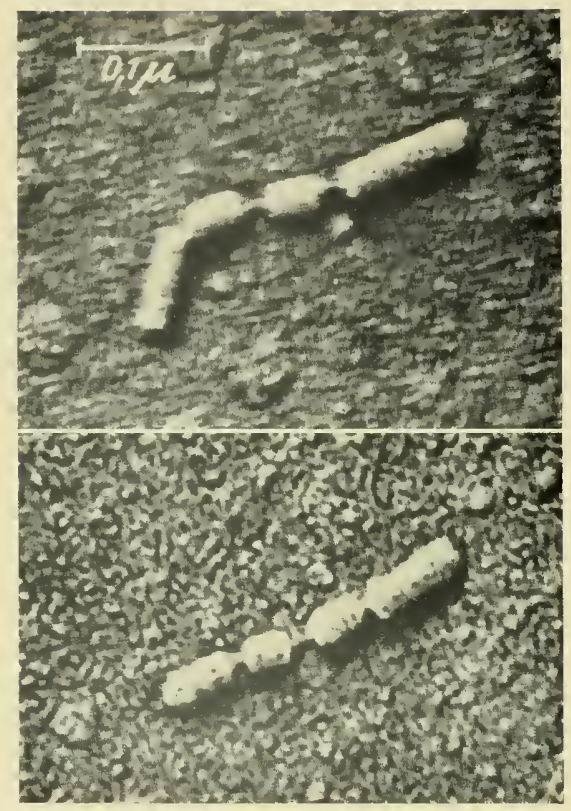

F16. 29. Virus particles from which the protein has been remored in onme places (after Schramm. Schumacher and Zillig).

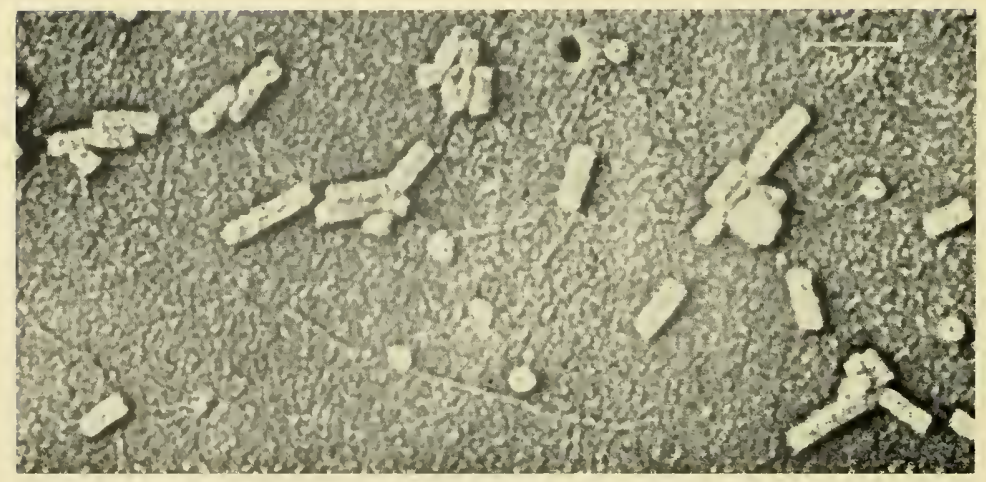

Fic; 2.1. Tobacoo mosaic virus showing moleic acid threach, rod-shaped particles and hises of protein with boles in the midelle (after Schramm. Schumader and lillig). 
may be compared with a necklace, the nucleic acid corresponding with the thread and the fundamental protein molecules with the beads (Fig. 23).

The work of H. Fraenkel-Conrat and R. C. Williams ${ }^{186}$ was a great achievement in the field of virology. These workers succeeded not merely in separating the nucleic acid from the protein components of tobacco mosaic virus, but also in reassembling the virus from these components in a biologically active state. The authors cited lay special stress on the need to retain the separate components absolutely in the native state, if this is to be successful. In particular, it is only by using the unaltered nucleic acid of a virus that positive results can be obtained. When it has been treated with ribonuclease it will no longer serve as material for the assembly of a virus. Equally unsuccessful were attempts to substitute for the RNA of tobacco mosaic virus DNA obtained from the thyroid gland or RNA from the turnip yellows virus.

The protein component which was separated from the nucleic acid was found by electron microscopy to take the form of discoid particles having a thickness of $5^{0}-15^{\circ} \AA$ and a diameter the same as that of the rod of the active virus particle $(150 \AA)$. In the centre of the disc a hole was found having a diameter of about $40 \AA$ (see Fig. 24).

According to the authors quoted, these discs are indistinguishable from $\mathrm{X}$-protein. When the active virus is assembled, the protein discs combine with the nucleic acid, which is concentrated in the central cavity and which enables the fundamental protein molecules to aggregate. As a result of this aggregation particles are formed which are indistinguishable from the particles of the original virus. They are thus about $3,000 \AA$ long.

The action of detergents on a reconstituted virus produces the same deformation of the particles as in the original virus. The rods are broken up into discs and at the site of the fractures there are seen to be centrally disposed cores which disappear on treatment with ribonuclease, thus showing that they are made up of RNA.

According to Fraenkel-Conrat and Williams neither the protein nor the nucleic acid by itself shows any sign of 
infectivity. In a very recent experiment Fraenkel-Conrat ${ }^{187}$ assembled active virus particles from the protein of one strain of virus and the nucleic acid of another. A particularly interesting complex virus of this kind is obtained from the protein of common tobacco mosaic virus and the nucleic acid of the Holmes ribgrass strain of virus. This combination is notable for the fact that the protein of tobacco mosaic virus differs from that of the ribgrass virus both in amino acid composition and in serological properties.

The complex virus thus obtained is inactivated by antitobacco mosaic sera but not by anti-ribgrass. Furthermore, plants infected with this complex, artificial virus form only the nucleic acids and proteins characteristic of the ribgrass virus. In particular, the protein contains methionine and histidine which are characteristic of this virus.

These results are in complete agreement with those of A. Gierer and G. Schramm. ${ }^{188}$ In contradistinction to the findings of Fraenkel-Conrat and Williams which have already been described, Gierer and Schramm showed that the nucleic acid of a virus, completely freed from protein, when introduced into a tobacco plant would evoke the formation of the characteristic nucleoprotein of the virus.

This fact may be compared with earlier observations on the infection of bacteria with the corresponding phages. In their experiments A. D. Hershey and M. Chase ${ }^{189}$ used bacteriophage of group $T$ which had been labelled with phosphorus and sulphur. They showed that only the DNA of the phage enters into the bacterium and evokes there the formation of fresh virus while the protein stays outside the cell of the host and therefore does not play a direct part in the infection.

From the examples which have been given it is quite obvious that in living cells there is no 'multiplication' of protein molecules, nor do they arise as a result of straightforward autocatalysis. In cells there occurs a complicated biosynthetic process whereby new protein is formed, the carrying out of which requires the participation of a large number of complicated energic, catalytic and structural systems which we have remarked on in the living body. Nucleic acids with their definite intramolecular structure 
occupy a very prominent place among these systems in determining the specific structure of any particular protein. In Gale's experiments the addition of nucleic acid to structural fragments of bacterial cells restored their ability to synthesise particular proteins. Similarly, the introduction of the RNA of tobacco mosaic virus into the leaves of tobacco plants creates suitable conditions for the synthesis there by the protoplasmic systems of the cell of the specific X-protein which could not have been formed there before the infection and which seems to be the result of distortions of the process of biosynthesis of protein, distortions determined by the intramolecular structure of the viral nucleic acid.

The specificity of the viral RNA compared with other similar nucleic acids consists simply in the fact that the viral RNA can enter actively into the metabolism of the tobacco plant and, to some extent, overcome the influence of the nucleic acids of the plant itself and enable the leaf to synthesise proteins which are foreign to it and which accumulate there in very large and, therefore. easily detectable amounts. It may be that more careful study would show that many other nucleic acids could also alter, to some extent, the course of biosynthesis in foreign organisms into which they were introduced in the native state. In particular we are convinced that the experiments, which have recently become widely known, in which one strain of bacteria is transformed into another under the influence of DNA prepared from the latter, are cases in point. ${ }^{190}$

An understanding of the part played by the intramolecular structure of nucleic acids in the biosynthesis of proteins with specific structures was made more difficult until very recently by the over-simplified hypotheses concerning the structure of the nucleic acids themselves.

It is still not long since it was accepted, in accordance with the results of $\mathrm{P}$. A. Lerene and $\mathrm{R}$. S. Tipson ${ }^{191}$ that the fundamental units of RNA and DNA consisted of tetranucleotides, i.e. complexes composed of four appropriate mononucleotides united with one another. According to this hypothesis the tetranucleotide complex of RNA is made up of adenine nucleotide. guanine nucleotide, cytosine nucleotide and uracil nucleotide while DNA is composed of adenine 
desoxynucleotide, guanine desoxynucleotide, cytosine desoxynucleotide and thymine desoxynucleotide. Such tetranucleotides would have molecular weights of 1,300 for RNA and $1,25^{\circ}$ for DNA. In fact, however, the values actually found for the molecular weights of various ribonucleic acids ranged from 10,000 to $300,000^{192}$ and for desoxyribonucleic acids from 500,000 to $1,000,000,{ }^{193}$ or, according to later results, up to $8,000,000,{ }^{194}$ which suggested that nucleic acids are high polymers of tetranucleotides. Naturally, in such polymers the quantitative proportions of the various mononucleotides and their spatial relations to one another would remain unchanged. This created a very cramped framework for possible variations in the intramolecular structure of nucleic acids.

However, in the light of recent evidence, which is mainly due to the work of E. Chargaff and his colleagues, ${ }^{195}$ the tetranucleotide theory of the structure of nucleic acids has been overthrown. It is now accepted that RNA and DNA consist of long chains, the individual links of which are mononucleotides joined together by phosphoric acid residues which combine with the hydroxyl groups of the ribose or desoxyribose in the 3 and 5 positions, that is, to give bonds of the type $\mathrm{C}_{3}$.opo.c. $5_{5}{ }^{\prime}$. The proportions of purine and pyrimidine nucleotides and, even more important, their sequence and orientation in the polynucleotide chain may vary, and do in fact vary extremely widely, in nucleic acids of different origins.

The evidence from X-ray crystallographic analyses carried out by J. D. Watson and F. H. C. Crick ${ }^{196}$ suggests a model for DNA which may be represented diagrammatically as in Fig. 25 .

According to this model, the molecule of desoxyribose nucleic acid is composed of two spiral chains wound regularly round a single common axis. Each chain consists of diesterified phosphate residues combined with $\beta$-D-desoxyribofuranoside residues in the 3 and 5 positions. The purine and pyrimidine bases lie within the helix while the phosphoric groups are on the outside. The helical chains which make up the molecule are joined together by the paired interaction of the bases of one chain with those of the other. This pairing 
is brought about by hydrogen bonds and the bases lie in planes perpendicular to the long axis of the molecule.

The three-dimensional structure of RNA is still not completely clear; maybe its molecules have branched chains. A structure of this kind would allow of an unlimited number of isomers, the individual characteristics of which would be determined by the relative arrangement of the nucleotides in the chain. ${ }^{197}$ It is clear that these possibilities must be very widely realised in the world of living things and, in fact, we find there a tremendous variety of nucleic acids with specific structures, just as we do with proteins

Fig. 25. Structural model of the macromolecule of desoxyribonucleic acid. Two spiral chains of desoxyribose; the horizontal lines represent pairs of nitrogenous bases uniting the chains by means of hydrogen bonds (after Watson and Crick).

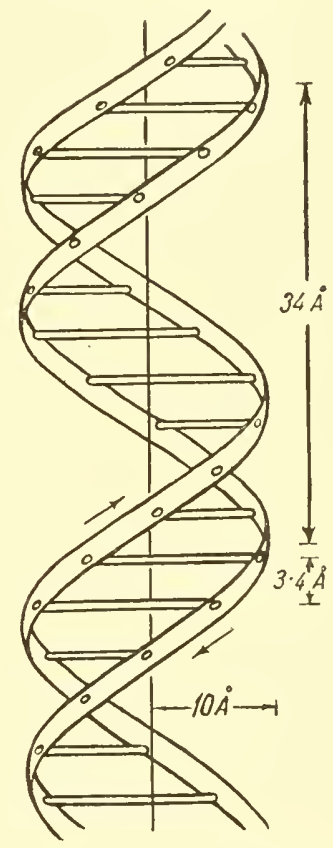

There is a whole series of experimental data demonstrating the species specificity of nucleic acids and showing that the DNA and apparently also the RNA of different species have different over-all compositions. ${ }^{198}$ Furthermore, we may speak of organ specificity or tissue specificity which means that different organs within the same organism have different nucleic acids, and, finally, there is organelle specificity of nucleic acids. This applies specially to RNA, on account of its localisation in the various formed elements of protoplasm. In particular, much evidence has been given in the literature showing that the RNA of the nucleus and that of the cytoplasmic granules are different from one another. ${ }^{199}$

The view is widely maintained in contemporary scientific literature that the molecule of nucleic acid with its specific 
complementary arrangement of purine and pyrimidine mononucleotides and polynucleotide chains is like a matrix in which a particular protein can be synthesised. Each point on the matrix has a specific affinity for a definite amino acid. Thus, according to the hypothesis of P. C. Caldwell and C. Hinshelwood, ${ }^{200}$ the amino acids crystallise, so to speak, on the molecule of nucleic acid in a strictly determined order corresponding with the structure of the matrix.

As the combination of amino acids into a polypeptide chain requires the expenditure of a certain amount of energy, it is generally accepted that the processes leading to the synthesis of proteins on nucleic acids occur in the following order:

Either the separate amino acids are activated by phosphorylation at the expense of adenosine triphosphate, or else the RNA is itself phosphorylated and activated. ${ }^{201}$ The amino acids are then bound to the appropriate points on the nucleic acid. Later, when the full complement of amino acids is present, peptide bonds are formed between them to form 'pro-proteins'. Enzymes play an important part in this process. When the 'pro-proteins' have been formed they become separated from the nucleic acids, a process which may require a further expenditure of energy and the participation of specific catalysts. This is the process which is slowed down by chloramphenicol and aureomycin, substances which have hardly any effect on the incorporation of amino acids. ${ }^{202}$

G. Gamow ${ }^{203}$ has recently tried to use his very ingenious mathematical calculations to show that the specific centres for the combination of particular amino acids on the nucleic acid matrix consist of strictly determined groups of three nucleotides. If four different nucleotides in any nucleic acid are taken in groups of three, the following variants are possible: (1) all three components may be the same, or, to use Gamow's card-playing terminology, they may belong to the same 'suit'; (2) two components may be the same while the third belongs to a different 'suit'; (3) all the components may be different. In this way the number of possible variants will be 20 , which corresponds with the number of amino acids in proteins. As an example, Gamow 
has tried to show that in tobacco mosaic virus there is some correlation between the content of nucleotides of the viral RNA and that of amino acids of the viral protein. For

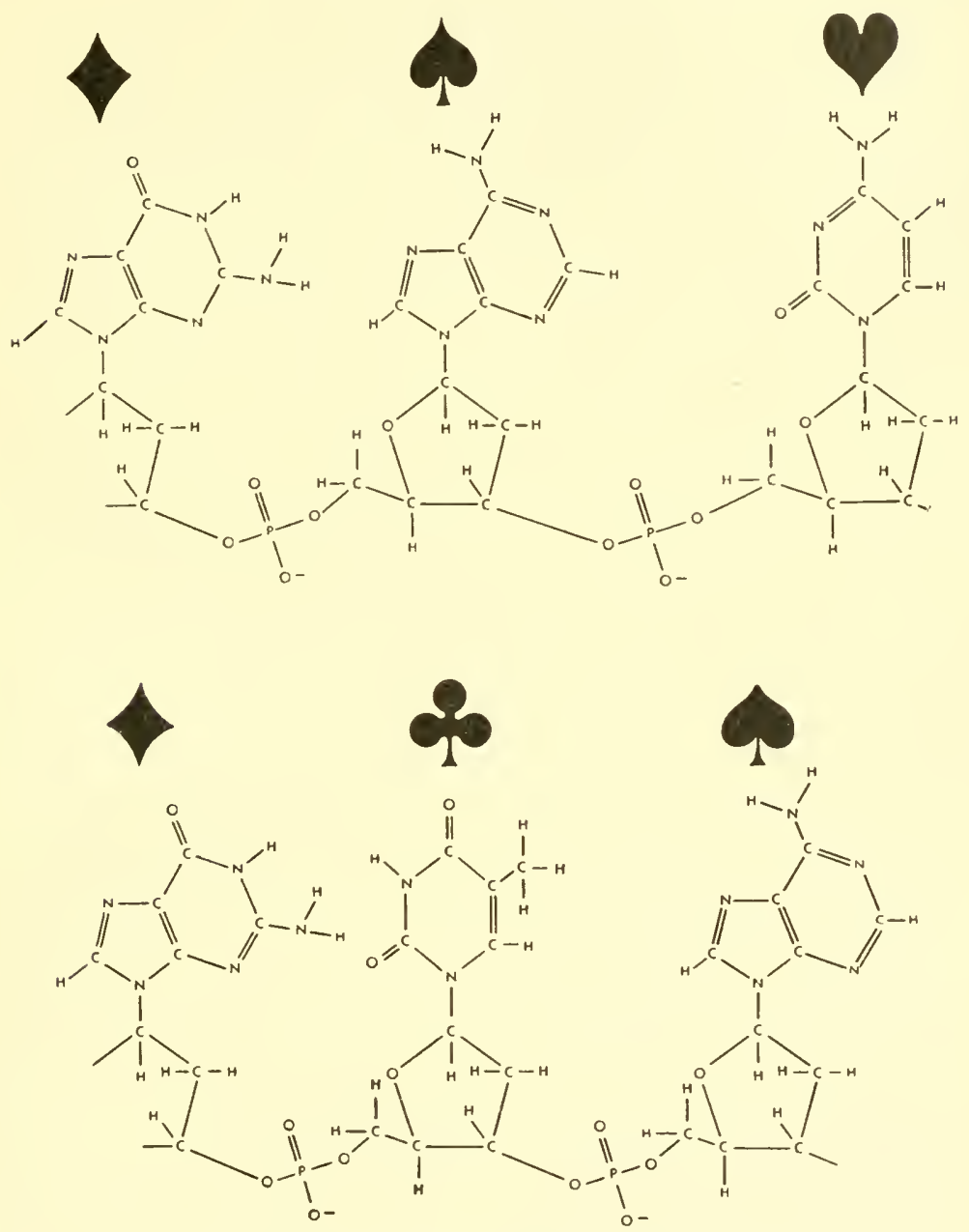

F1G. 26. Triads of nucleotides (after Gamow).

example, valine is supposed to correspond to the combination adenylic acid, cytidylic acid, uridylic acid, tyrosine to adenylic, adenylic, adenylic acid, etc. Horrever, if we do the same calculations for turnip yellows virus, the correspondence 
between the theory and the analytical evidence is less satisfactory. A. L. Dounce considers that the specific arrangement of the amino acids during the formation of a protein is determined, not by triads, but by diads of nucleotides (Fig. 26).

These suggestions certainly still require a lot more experimental work, but many biologists and physicists are now attracted to them. Owing to the attractiveness of the matrix theory some authors are trying to resurrect the earlier theory of the 'living molecule', though it is no longer the protein molecule which plays this part, for it is now quite clear that this needs complicated systems for its biosynthesis. The part has now been assumed by the molecule of nucleic acid, the formation of which has not yet been studied.

In the scientific literature of to-day concerning nucleic acid its individual molecules are endowed with the ability to 'reproduce themselves ', to 'divide' and to 'multiply' just as were the molecules of protein yesterday. However, experience with the latter teaches us that we should regard with caution such a priori and highly simplified ideas.*

It is first necessary to understand clearly that, in the process of the biosynthesis of proteins, nucleic acid (especially RNA) does not act as an independent entity, it is only a part of a complicated apparatus. Without this apparatus nucleic acid cannot synthesise protein on its own. This is indicated by all the facts concerning the biosynthesis of proteins and, in particular, by the experiments which we have already discussed involving the very gentle disruption of the structures of isolated fragments of bacterial protoplasts deprived of their envelopes simply by a slight lowering of the concentration of sucrose in the surrounding solution. When this happens, there is no detectable chemical alteration in the nucleic acids, they remain just as they were but the synthesis of protein is arrested. This is because it requires not merely the intramolecular structure of nucleic acid but also the larger-scale structure of the formed elements of the protoplasm on which are 'assembled' the enzymic systems which determine the order and harmony of the energetic and syn-

\footnotetext{
"For a criticism of these views see C. C. Lindegren.204-Author.
} 
thetic reactions. In fact the kinetic conditions which are very important for any biosynthesis, the relative rates of different processes, the organisation of protoplasm in space as well as in time, give great flexibility to the biosynthesis. This leads to the formation, not of individual proteins, the molecules of which are identical with one another, but of extensive families of proteins which are very like one another.

This would be hard to achieve by rigid synthesis on a matrix. It would be as though the same type could be used to print several newspapers which, although they were of the same political persuasion, nevertheless had a different scope and arrangement of their articles. This suggestion was also discounted by Gamow in his latest paper. Gamoww ${ }^{205}$ regards the variability of the proteins which are synthesised as a possible means of biological evolution, although he gives no explanation of the mechanism of this phenomenon.

To pursue the typographical analogy, set type is needed to form the matrix. What then corresponds to this type in the living cell? How is the rigidly determinate arrangement of nucleotides in the polynucleic matrix set up? As we have seen above, there is a great deal of factual material which indicates that RNA plays a direct part in the synthesis of proteins. Although it is frequently found in the scientific literature, there is less factual evidence for the idea that the specific structure of RNA is in some way determined by the DNA of the nucleus. To use the language now adopted by physicists, the information concentrated in the molecules of DNA is first passed on to the molecules of RNA, after which the synthesis of protein molecules proceeds in accordance with the information which is relayed by the sequence of nucleotides in the RNA chain. ${ }^{206}$

However, even if we assume the truth of this hypothesis, it does not carry us much further forward, for the question now arises as to how the rigidly determinate arrangement of nucleotides in the DNA was brought into being.

One can nowadays hardly take the view that DNA does not take part in metabolic activities, does not undergo any changes in the process of development of the cell, but merely reproduces itself in such a way that each new molecule arises directly by autocatalysis from a pre-existing molecule. This 
is contradicted by numerous observations which show that, during the process of development of cells, their DNA content may diminish markedly until it disappears completely, as occurs in the unfertilised sea-urchin's egg. ${ }^{207}$ On the basis of a study of the development of the mycelium of Actinomyces globisporus streptomycini N. S. Demyanovskaya and A. N. Belozerskiřnos have shown that at a definite developmental stage DNA apparently disappears. In its place there is found in the mycelium another nucleic acid containing not thymine but another base, $\mathrm{X}$. This acid is apparently a precursor of DNA, which is later synthesised from it.

We still know very little about the biosynthesis of nucleic acids but all the facts at our disposal suggest that it is no less complicated a process than the biosynthesis of proteins and is by no means a simple autocatalytic process of self-reproduction.

The studies on the enzymic synthesis of nucleic acid which have recently been started by $M$. Grunberg-Manago and others $^{209}$ in S. Ochoa's laboratory are of very great interest from this point of view. These workers used an enzyme isolated from Azotobacter which catalyses the synthesis of polynucleotides from nucleoside- 5 '-diphosphate with the liberation of inorganic orthophosphate according to the equation:

$$
\begin{aligned}
& n(\mathrm{~A}-\mathrm{R}-\mathrm{P}-\mathrm{P}) \rightleftharpoons(\mathrm{A}-\mathrm{R}-\mathrm{P})_{n}+n \mathrm{P} \\
& \mathrm{A}=\text { the base, } \mathrm{R}=\text { ribose, } \mathrm{P}=\text { phosphoryl radical. }
\end{aligned}
$$

One may thus suppose that the reaction whereby polynucleotides are formed, like that whereby polysaccharides are formed, is a process of reversed phosphorolysis. The authors therefore called their enzyme "polynucleotide phosphorylase'. They showed that it was possible, by using this enzyme, to synthesise a substance similar to ribonucleic acid from separate mononucleotides. From this it follows that the biosynthesis of nucleic acids, like that of the other compounds found in protoplasm, is brought about by means of a complicated enzymic apparatus. Thus, on the one hand, the synthesis of proteins requires the presence of nucleic acids while, on the other, the synthesis of nucleic acids requires the presence of proteins (enzymes). 
J. D. Bernal has recently come to the same conclusion on the basis of his work with viruses. At the end of his address on this subject to the Moscow State University in 1955 Bernal asked me the following question: In this case, which came first, nucleic acids or proteins?

This question reminds one somewhat of the scholastic problem about the hen and the egg. The problem is insoluble if we approach it metaphysically in isolation from the whole previous history of the development of living matter. Nowadays every hen comes from an egg and every hen's egg from a hen. Similarly, nowadays proteins can only arise on the basis of a system containing nucleic acids while nucleic acids are formed only on the basis of a protein-containing system. The hen and its egg developed from less highly organised living things in the course of their evolution. In the same way, both proteins and nucleic acids appeared as the result of the evolution of whole protoplasmic systems which developed from simpler and less well adapted systems, that is to say, from whole systems and not from isolated molecules. It would be quite wrong to imagine the isolated primary origin either of proteins or of nucleic acids.

Many contemporary authors do, however, follow this line of thought. They take the view that in the first place nucleic acids arose in some way and that at once, simply by virtue of their intramolecular structure, they were able both to synthesise proteins and to multiply themselves spontaneously. It is, however, clear from all our previous discussion that a hypothesis of this sort is in direct opposition to the facts as they are at present known.

An interesting attempt to bring these hypotheses into line with contemporary scientific data is to be found in the lecture given by $\mathrm{L}$. Roka at a colloquium on comparative biochemistry in April 1955 in Mosbach-Baden. ${ }^{210}$ He gare a clear account of the fact that the synthesis of nucleic acids requires the presence of a complicated organisation of metabolism and then put forward the suggestion that this metabolism first arose simply in the waters of the primaeval ocean.

The transformation of polyphosphoric acid in these waters also gave rise to the 'original matrix', the molecule of 
nucleic acid. Nucleic acid, reproducing itself and forming proteins in conjunction with the metabolism of the ocean itself, also constitutes, according to Roka, 'living protoplasm'. By degrees more and more 'living protoplasm' was formed while the surrounding medium became more and more "lifeless ' until eventually the process culminated in the formation of the first organisms.

This schematic description is, however, open to a number of objections. In the first place, it is hard to imagine the development of metabolism simply within the aqueous solution of the primaeval ocean. Metabolism is not merely the conjunction of various reactions co-ordinated to some extent in time. In organisms of the present day, metabolism is a definite organisation of processes directed towards the continuous self-preservation and self-reproduction of the living system as a whole. Such an organisation could only have been built up by natural selection and selection requires circumscribed individual formations and could not take place in a homogeneous solution. This is the first point; the second is that although Roka's outline, which we have discussed in Chapter $\mathrm{V}$, demonstrating the possibility that polynucleotides may be formed by the transformation of polyphosphoric acids seems very probable and apposite it still does not solve the question of the origin of nucleic acid itself. This latter is distinguished from simple polynucleotides in that the arrangement of the mononucleotides in its chain is strictly determined and its biological role in the synthesis of proteins depends on its three-dimensional intramolecular structure. This is, of course, the very property which requires explanation and Roka passes it over in silence. Reference to the 'happy chance' that, out of many billions and quadrillions of combinations there could have been formed by chance just that indispensable sequence which is required for the synthesis of proteins is just as irrational in this case as were earlier references to the "chance' formation of proteins (enzymes). Not only is the structure of these proteins very complicated but it is extremely thoroughly adapted to the performance of definite catalytic functions which play an important part in the life of the whole organism, it is inwardly 'constructed for its purpose'. Such 
adaptation to its biological function, such 'purposeful' structure, is also characteristic of the nucleic acids of presentday organisms and its origin by chance is as impossible as the chance assembly from its elements of a factory capable of turning out any particular product.

The third and final point is that, even if we admit for a minute the possibility that in the primaeval soup of the ocean there might have arisen by chance molecular matrices which could reproduce themselves incessantly, even then life could not arise on this basis. In such a case the matrix would continually produce nothing but molecules exactly like itself and the primary organic material would simply be converted into uniform layers of nucleic acids or deposits similar to the 'mineral formations' of crystallised organic materials.

The molecule of nucleic acid in contemporary living organisms is not an independent 'living molecule', it is only a part of living protoplasm, an organ of that protoplasm subserving a function necessary for life. Thus, all that we have already said about the origin of proteins or enzymes applies equally to nucleic acids.

Contemporary scientists are also quite right in supposing that the development of matter proceeded from simpler to more complicated systems. Nevertheless, although the separate organs, such as an arm or an eye, are simpler than the whole organism, we should not assume, like Empedocles, that higher living things dereloped by the aggregation of separate organs. Darwin has shown us the true way in which these living organisms arose. This way is through the evolution of more simply organised things, the evolution of complete systems brought about by natural selection.

Similarly it would be wrong to suppose that there first arose proteins, nucleic acids and the other complicated substances found in protoplasm, which had intramolecular structures which were extremely well and efficiently adapted to the performance of particular biological functions, and that living protoplasm itself arose as the result of a combination of these substances.

All that we can expect from the relatively simple thermodynamic and kinetic laws which prevailed on the surface of the primaeval Earth is that they should explain the formation 
of organic polymers in the shape of polypeptides and polynucleotides, assemblages having, as yet, no orderly arrangement of amino acid and nucleotide residues adapted to the performance of particular functions.

These polymers were, nevertheless, able to form multimolecular systems, though these were undoubtedly incomparably simpler than living protoplasm. It is only by the prolonged evolution of these systems, their interaction with their environment and their natural selection that there developed the forms of organisation characteristic of the living body: metabolism, proteins, nucleic acids and other substances with complicated and 'purposeful' structures which characterise the contemporary living organism.

\section{BIBLIOGRAPHY TO CHAPTER VI}

1. H. M. Rouelle. Recueil périodique d'observations de médecine de chirurgie et de pharmacie, 4o, 59 (1773).

A. F. Fourcroy. Ann. Chim. (Phys.), 3, 252 (1789).

2. G. J. Mulner. J. prakt. Chem., I6, 129 (1839).

M. V. TraceY (Proteins and life. London, 1948) and H. HARTLEy (Nature, Lond., 168, 244 (1951)) cite earlier Netherlands publications by Mulder using this term. Hartley also gives evidence that it had been suggested to Mulder by J. J. Berzelius.

3. H. von MoHL. Grundzïge der Anatomie und Physiologie der vegetabilischen Zelle. Braunschweig, 1851 ; Bot. Zlg, 4, 73, 89 (1846).

4. (I. 6o).

5. F. ENGEls. Herr Eugen Dühring's revolution in science. [Anti-D̈̈hring.] (trans. E. Burns). London, 1934; Ludwig Feuerbach and the outcome of classical German philosophy (ed. C. P. Dutt). London (Martin Lawrence, undated).

6. F. Engels. Herr Eugen Dühring's revolution in science. 7. (I. 59).

[Anti-Dïhring.] (trans. E. Burns). London, 1934.

8. E. Pfü̈ger. Pflïg. Arch. ges. Physiol., Io, $25^{1}$ (1875).

9. F. Bотtazzı in Handbuch der vergleichenden Physiologie (ed. H. Winterstein). Vol. I (1st half), p. 1. Jena, 1911.

10. N. N. Iwanoff. Biochem. Z., 162, $441(1925)$. 
11. H. G. Doffin. Le roman de la molécule: l'explication de la vie. Saint-Germain-en-Laye, 1953.

12. M. Verworn. Allgemeine Physiologie. Jena, 19og.

13. (III. 47).

14. R. L. M. SYNge. Biokhimiya, Io, 179 (1945); Royal Institute of Chemistry: Lectures, Monographs and Reports, 1952, No. 1.

15. N. W. Pirie. Biol. Rev., 15, 377 (1940).

16. E. J. Cohn, D. M. Surgenor and M. J. Hunter in Enzymes and enzyme systems: their state in nature (ed. J. T. Edsall), p. 105. Cambridge, Mass., 1951.

17. R. J. Block in The chemistry of the amino acids and proteins (ed. C. L. A. Schmidt), p. 278. Springfield, Ill., $193^{8 .}$

18. A. Tiselius and I.-B. Eriksson-Quensel. Biochem. J., 33, 1752 (1939).

19. J. T. Edsall. Advanc. Protein Chem., 3, 383 (1947).

20. T. L. McMeekin in The proteins (ed. H. Neurath and K. Bailey). Vol. 2A, p. 389. New York, 1954.

21. J. F. TAYloR in The proteins (ed. H. Neurath and K. Bailey). Vol. IA, p. 1. New York, 1953.

22. G. R. Tristram in The proteins (ed. H. Neurath and K. Bailey). Vol. IA, p. 181. New York, 1953.

23. C. H. Li. J. Amer. chem. Soc., 68, 2746 (1947).

T. L. McMeekin, B. D. Polis, E. S. Dellamonica and J. H. Custer. J. Amer. chem. Soc., 7o, 881 (1948).

24. V. N. Orekhovich. Priroda, I956, no. 5 , p. 35.

25. H. Brown, F. Sanger and R. Kitai. Biochem. J., 6o, 556 (1955).

26. J. B. Sumner and G. F. Somers. Chemistry and methods of enzymes (2nd edn.). New York, 1947.

27. A. Ya. Danilevskil̆. Fiziologicheskǐ Sbornik, I, 289 (1888);

2, 281, 291 (1891). Khar'kov (Tip. Zil’berberga).

28. E. Fischer. Ber. dtsch. chem. Ges., 35, 1095 (1902).

29. F. Hofmeister. Ergebn. Physiol., $x$ (Abt. 1), 759 (1902).

30. H. Ritthausen. Die Eiwesskörper der Getreidearten,

Hïlsenfrïchte und Ölsamen. Bonn, 1872.

31. H. B. Vickery. Ann. N.Y. Acad. Sci., 47, 63 (1946).

32. W. H. Steln. Ann. N.Y.Acad. Sci., 47, 59 (1946).

33. T. B. Osborne. The vegetable proteins. London, 1909.

34. A. J. P. Martin and R. L. M. Srnge. Advanc. Protein Ghem., 2, 1 (1945).

35. D. Shemin. J. biol. Chem., I59, 439 (1945). 
36. A. S. Keston and S. Udenfriend. Cold Spr. Harb. Symp. quant. Biol., I4, 92 (1950).

37. E. E. Snell. Advanc. Protein Chem., 2, 85 (1946).

38. S. Moore and W. H. Stern. J. biol. Chem., 178, 53 (1949); I92, $663\left(195^{1}\right)$.

39. P. Desnuelle in The proteins (ed. H. Neurath and K. Bailey). Vol. IA, p. 87. New York, 1953.

4o. H. B. Vickery and C. L. A. Schmidt. Chem. Rev., 9, 169 (1931).

41. E. Chain. Ann. Rev. Biochem., I7, 657 (1948).

42. E. Work. Biochem. J., 49, 17 (1951).

43. E. Bricas and C. Fromageot. Advanc. Prolein Chem., 8, 1 (1953).

44. E. Bricas and C. Fromageot. Advanc. Protein Chem., 8, 1 (1953).

S. G. Waley. J. chem. Soc., 1955, p. 517.

45. R. D. Hotchkiss. J. biol. Chem., I4I, 171 (1941).

46. R. L. M. Synge. Biochem. J., 39, 363 (1945).

47. A. H. Gordon, A. J. P. Martin and R. L. M. Synge. Biochem. J., 37, 313 (1943).

48. J. T. Holden and E. E. Snell. J. biol. Chem., I 78,799 (1949).

49. D. Rittenberg and D. Shemin. Ann. Rev. Biochem., I5, 247 (1946).

50. K. Bailex. Chem. and Ind., 13, 243 (1950).

51. K. Felix and A. Mager. Hoppe-Seyl.Z., 249, 111 (1937).

52. M. Bergmann. Chem. Rev., 22, 423 (1938).

53. C. Niemann. Cold Spr. Harb. Symp. quant. Biol., 6, 58 (1938).

54. G. F. Gauze and M. G. Brazhnikova in Sovetskil gramitsidin $i$ lechenie ran (ed. P. G. Sergiev), p. 5. Moscow (Medgiz), 1943 .

55. A. N. Belozerskil and T. S. Paskhina. Biokhimiya, io, 344 (1945).

56. R. Consden, A. H. Gordon, A. J. P. Martin and R. L. M. SYNGE. Biochem. J., $4^{I}, 596$ (1947).

R. L. M. Synge. Biochem. J., 42, 99 (1948).

R. Schwyzer and P. Sieber. Angew. Chem., $68,5^{18}$ (1956).

57. A. Paladini and L. C. Craig. J. Amer. chem. Soc., 76, 688 (1954).

T. P. King and L. C. Craig. J. Amer. chem. Soc., 77, 6627 (1955). 
58. L. C. Craig. Conférences et Rapports. 3-ème Congrès international de Biochimie, Bruxelles, I.6 Août 1955, p. 416. Liège, 1956 .

59. C. Fromageot. Cold Spr. Harb. Symp. quant. Biol., If, 49 (1950).

6o. F. Sanger. Nature, Lond., 162, 491 (1948).

F. Sanger and H. Tuppy. Biochem. J., 49, 463, 481 (1948).

F. Sanger and E. O. P. Thompson. Biochem. J., 53, 35̌3, $366(1953)$.

61. A. P. Ryle, F. Sanger, L. F. Siith and R. Kitai. Biochem. $J ., 60,541$ (1955).

62. C. Tanford and J. Epstein. J. Amer. chem. Soc., 76, 2170 (1954).

63. V. Du Vigneaud. Conférences et Rapports. 3-ème Congrès international de Biochimie, Bruxelles, I-6 Aout 1955, p. 49. Liège, 1956 .

64. P. H. Bell and R. G. Shepherd. Ibid., p. 10.

65. O. Hoff mann-Ostenhof. Enzymologie. Vienna, 1954.

66. W. LANGenbeck. Die organischen Katalysatoren und ihre Beziehungen zu den Fermenten (2 Aufl.). Berlin, 1949.

67. K. Lohmann and P. Schuster. Biochem. Z., 294, 188 (1937).

68. D. E. Green, D. Herbert and V. Subramanyan. J. biol. Chem., r $_{3} 8,327$ (1941).

F. Kubowitz and W. Lüttgens. Biochem. Z., 307, 170 (1941).

69. O. Warburg. Naturwiss., 40, 493 (1953).

7o. H. Theorell and A. C. Maehly. Acta chem. scand., 4, $422(1950)$.

A. C. MaEHLY in Enzymes and enzyme systems: their state in nature (ed. J. T. Edsall), p. 77. Cambridge, Mass., 1951 .

71. B. Chance in The enzymes (ed. J. B. Sumner and K. Myrbäck). Vol. 2, Part 1, p. 428. New York, 1951.

72. K. G. STERN. J. biol. Chem., II2, 661 (1936).

73. A. E. BraunshteǏN. Uspekhi biologicheskol Khimii, I, 21 (1950).

74. (VI. 26).

75. P. Desnuelle. Advanc. Enzymol., 14, 261 (1953).

76. F. Haurowitz. Chemistry and biology of proteins. New York, $195^{\circ}$.

77. R. R. Porter in The proteins (ed. H. Neurath and K. Bailey). Vol. $I B$, p. 973 . New York, 1953.

78. J. F. Ambrose, G. B. Kistiakowsky and A. G. Kridl. J. Amer. chem. Soc., 73, 1232 (1951). 
79. R. M. Herriott. Advanc. Protein Chem., 3, 169 (1947).

8o. H. Fraenkel-Conrat. Arch. Biochem., 27, 109 (1950).

81. R. M. Herriott in Symposium on the mechanism of enzyme action. (McCollum-Pratt Inst., Johns Hopkins Univ.) (ed. W. D. McElroy and B. Glass), p. 24. Baltimore; Md., 1953 .

82. I. B. Wilson. Biochim. biophys. Acta, 7, 466 (1951).

83. H. Neurath and G. W. Schwert. Chem. Rev., 46, 69 (1950).

84. P. V. Afanas'ev. O prirode $i$ kinetike fermentativnykh protsessov. Diss. Moscow, 1950 ; Biokhimiya, I4, 259 (1949).

P. V. Afanas'ev. Izvest. Akad. Nauk S.S.S.R., Ser. Biol., 3, 254 (1949).

85. S. E. BRESL.ER. Trudy soveshchaniya po probleme belka, p. 63. Kiev (Izd. Akad. Nauk Ukr. S.S.R.), 1955.

86. M. P. Znamenskaya, P. A. Agatov and A. N. Belozerskiň. Doklady Akad. Nauk S.S.S.R., 59, 95 (1948).

87. R. Agher, M. Jutisz and C. Fromageot. Biochim. biophys. Acta, $8,44^{2}$ (1952).

R. Acher, U. R. Laurila, J. Thaureaux and C. Fromageot. Biochim. biophys. Acta, 14, 151 (1954).

88. K. Onno. J. Biochem., Japan, 4I, 345 (1954).

89. A. R. Thompson. Biochem. J., 6I, 253 (1955).

9o. C. B. Anfinsen, R. R. Redfield, W. L. Choate, J. Page and W. R. Carroll. J. biol. Chem., 207, 201 (1954).

C. H. W. Hirs, S. Moore and W. H. Stein. J. biol. Chem., 219, $613(1956)$.

J. L. Bailey, S. Moore and W. H. Stein. J. biol. Chem., $221,143(1956)$.

C. H. W. Hirs, W. H. Stein and S. Moore. J. biol. Chem., $221,15^{1}\left(195^{6}\right)$.

91. A. G. PAsynskil̆ and V. A. Belitser. Uspekhi sovremennol Biol., 36, 236 (1953).

92. K. Thomas and J. Kapfhammer. Ber. sächs. Akad. Wiss. (Math-phys. Klasse), 77, 181 (1925).

93. L. Pauling. J. Amer. chem. Soc., 62, 2643 (1940).

94. (VI. 76).

95. F. W. Putnam in The proteins (ed. H. Neurath and K. Bailey). Vol. $I B$, p. 807. New York, 1953; Advanc. Protein Chem., 4, 79 (1948).

96. V. A. Belitser. Uspekhi biologicheskol Khimii, r, 53 (1950). 
97. H. Wu. Chinese J. Physiol., 5, 321 (1931).

98. A. E. Mirsky and L. Paulivg. Proc. nat. Acad. Sci., W'ash., 22, $439(1936)$.

99. F. Haurowitz. Kolloidzschr., 71,198 (1935).

100. (VI. 79).

101. F. Haurowitz and S. Tekman. Biochim. biophys. Acta, i, 484 (1947).

102. J. Roche and M. Mourgue. Bull. Soc. Chim. biol., 30, 322 (1948).

103. C. H. Lr. J. Amer. chem. Soc., 67, 1065 (1945).

104. L. Pauling and R. B. Corey. Proc. nat. Acad. Sci., Wash., $37,25^{1}\left(195^{1}\right)$.

105. A. N. BakH and A. I. Oparin in Sbornik rabot po chistol i prikladnol̆ khimii, p. 217 . Moscow (NTO VSNKh), 1925. cf. Chem. Abstr., 20, 2337 (1926).

106. F. Haurowitz and F. Bursa. Rev. Fac. Sci. Univ. Istanbul, $I O B, 283(1945)$.

107. J. O. Erickson and H. Neurath. J. exp. Med., 7s, 1 (1943).

108. D. M. Wrinch. Nature, Lond., I37, 411 (1936).

iog. S. E. Bresier and D. L. Talmud. Doklady Akad. Nauk S.S.S.R., 43, 326 (1944).

D. L. Talmud. Uspekhi biologicheskol Khimii, I, ךo (1950).

110. A. G. PAsynskiľ and V. A. Belitser. Uspekhi sovremennol Biol., 36, 236 (1953).

111. J. D. Bernal, I. Fankuchen and D. P. Riley. Nature, Lond., 142,1075 (1938).

J. D. Bernal and I. Fankuchen. J. gen. Physiol., 25, 111 (1941).

R. B. Corey. Advanc. Protein Chem., 4, 385 (1948).

112. S. E. Darmon and G. B. B. M. Sutherland. J. Amer, chem. Soc., 69, 2074 (1947).

E. J. Ambrose and A. Elliott. Proc. Roy. Soc., Lond., $205 A, 47(1951)$.

113. B. W. Low in The proteins (ed. H. Neurath and K. Bailey).

114. (V. 175). Vol. IA, p. 235. New York, 1953.

115. L. Pauling, R. B. Corey and H. R. Branson. Proc. nat. Acad. Sci., Wash., 37, 205 (1951).

L. Pauling and R. B. Corey. Proc. nat. Acad. Sci., Wash., 116. (III. 5 o). $37,235,729$ (1951).

117 . A. G. Pasynskil̆. Doklady Akad. Nauk S.S.S.R., 77, 863 (1951). 
118. Simplicius on Aristotle's De Caelo, 586, 29 (see H. Diels Die Fragmente der Vorsokratiker. (2 Aufl.), Vol. 1,

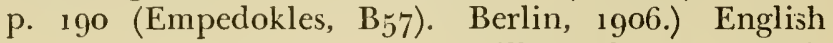
translation by K. Freeman. Ancilla to the pre-Socratic 119. (III. 78). philosophers. Oxford, $195^{2}$.

120. M. Kunitz and J. H. Northrop. J. gen. Physiol., I9, 991 $(1936)$.

121. E. W. Davie and H. Neurath. J. biol. Chem., 212, 515 (1955).

122. R. M. Herriott. J. gen. Physiol., 20, 335 (1937); 21, 501 $(1938) ; 25,185(1941)$.

123. Zir. A. Medvenev. Uspekhi sovremennol Biol., 4o, 159 (1955).

124. F. Lipmann. Advanc. Enzymol., 6, 231 (1946); Fed. Proc., 8,597 (1949).

125. A. E. Braunshtě̃n. Trudy IV Sessii Akad. med. Nauk S.S.S.R., p. 202. Moscow (Izd. AMN SSSR), 1948.

126. H. Chantrenne. Nature, Lond., 160, 603 (1947); Biochim. biophys. Acta, 4, 484 (1950).

127. A. E. Braunshteřn, G. A. Shamshikova and A. L. Ioffe. Biokhimiya, I3, 95 (1948).

128. P. J. Durkin and F. Friedberg. Biochim. biophys. Acta, 9, $105\left(195^{2}\right)$.

129. S. Yanari, J. E. Snoke and K. Bloch. J. biol. Chem., 20t, $5^{61}(1953)$.

130. E. F. Gale and J. P. Folkes. Nature, Lond., r73, 1223 (1954); Biochem. J., 59, 661 (1955).

131. F. B. Shtraub (Straub). Priroda, 1956, no. 2, p. 38.

132. H. Borsook. Conférences et Rapports. 3-ème Congrès international de Biochimie, Bruxelles, I-6 Août 1955, p. 92. Liège, 1956 .

133. S. E. Bresler. Uspekhi sovremennol̆ Biol., 30, 9o (1950).

134. R. B. Khesin. Biokhimiya, 18, 462 (1953); r9, 407 (1954). 135. A. Danilevskir. Organoplasticheskie sily organizma. Kharkov (Tip. Zil'berberga), 1886.

W. W. Sawjalow. Pflüg. Arch. ges. Physiol., 85, 171 (1901). 136. H. Wasteneys and H. Borsook. Physiol. Rev., ro, 110 (1930).

137. P. G. Ecker. J. gen. Physiol., 30, 399 (1947).

A. I. Virtanen. Makromol. Chem., 6, 94 (1951).

198. J. H. Northrop. J. gen. Physiol., 30, 377 (1947).

139. H. TAuber. J. Amer. chem. Soc., 7I, 2952 (1949). 
140. M. Brenner, H. R. Müller and R. W. Pfister. Helv. chim. Acta, 33, 568 (1950).

141. M. Berghann and H. Fraenkel-Conrat. J. biol. Chem., I19, 707 (1937).

J. S. Fruton. Advanc. Protein Chem., 5, 1 (1949).

142. J. Durell and J. S. Fruton. J. biol. Chem., 207, 487 (1954).

143. C. S. Hanes, F. J. R. Hird and F. A. Isherwood. Nature, Lond., I66, 288 (1950).

144. C. S. Hanes, F. J. R. Hird and F. A. Isherwood. Biochem. $J ., 5 I, 25(1952)$.

145. I. L. Kaganova and V. N. Orekhovich. Doklady Akad. Nauk S.S.S.R., 93, 875 (1953) ; 95, 1259 (1954).

146. F. Haurowitz. Quart. Rev. Biol., 24, 93 (1949).

147. A. L. Dounce, M. Morrison and K. J. Monty. Nature, Lond., I76, 597 (1955).

148. R. Altmann. Studien ïber die Zelle. Leipzig, 1886.

149. G. Lewitsky. Ber. disch. bot. Ges., 28, 538 (1910).

15o. A. Gullliermond. C.R. Soc. Biol., Paris, 85, 466 (1921).

151. E. W. MacBride and H. R. Hewer in Recent advances in microscopy : biological applications (ed. A. Piney). London, 1931 .

152. E. S. Horning. Ergebn. Enzymforsch., 2, 336 (1933).

153. A. I. Oparin (Oparine). Variations de l'activité des enzymes dans la cellule végétale sous l'effêt des facteurs extérieurs. Rapport au deuxième Congrès international de Biochimie, Paris, 1952. Moscow (Izd. AN SSSR), 1952 .

154. M. R. J. Salton. Biochim. biophys. Acta, io, $5^{12}$ (1953).

155. M. Beljanski. Biochim. biophys. Acta, 15, 425 (1954).

156 . A. I. Oparin, N. S. Gel'iman and N. G. Zhukova. Doklady Akad. Nauk S.S.S.R., xo5, 1036 (1955).

157. N. M. Sisakyan. Fermentatiunaya aktiunost' protoplazmennykh struktur. Moscow (Izd. AN SSSR), $195^{1 .}$

(Sissakian). Conférences et Rapports. 3-ème Congrès international de Biochimie, Bruxelles, I-6 Aon̂t 1955, p. 18. Liège, 1956.

158. O. LindBerg and L. ERnster. Chemistry and physiology of mitochondria and microsomes. In Protoplasmatologia (ed. L. V. Heilbrumn and F. Weber). Bd. III/A/4. Vienna, 1954 .

159. W. C. Schneider. Conférences et Rapports. 3-ème Congrès international de Biochimie, Bruxelles, I-6 Août I955, p. 305 . Liège, $195^{6}$. 
160. K. LANG. Microskopische und chemische Organisationen der Zelle. 2 Colloquium der deutschen Gesellschaft für physiologische Chemie. Berlin, 1952.

161. D. E. Green, W. F. Loomis and V. H. Auerbach. J. biol. Chem., I72, 389 (1948).

162. W. C. Schneider and G. H. Hogeboom. J. biol. Chem., 198,155 (1952).

J. S. Rотн. J. biol. Chem., 208, 181 (1954).

163. R. M. S. Siellie, W. McIndoe, R. Logan, J. N. Davidson and I. M. Dawson. Biochem. J., 54, 280 (1953).

164. T. Caspersson. Naturwiss., 29, 33 (1941).

165. J. Hämmerling. Roux Arch. EntwMech. Organ., I3I, 1 (1934).

166. J. Brachet and H. Chantrenne. Nalure, Lond., I68, $95^{\circ}$ $(1951)$.

167. J. Brachet and R. Jeener. Enzymologia, $I$, 196 (1944).

168. T. Hultin. Exptl. Cell Research, $I, 376$ (1950).

169. E. B. Keller. Fed. Proc., Io, 206 (1951).

170. P. Siekevitz and P. C. Zamecnik. Fed. Proc., io, 246 (1951).

171. P. Siekevitz. J. biol. Chem., 195, 549 (1952).

172. J. Brachet. Symp. Soc. exp. Biol., 6, 173 (1952); in

Médecine et biologie No. 5 ; Un symposium sur les protéines (general editor, M. Florkin). Liège and Paris, 1947.

172a. N. M. Sisakyan. In Trudy I-go simpoziuma po vozniknoveniyu zhizni. Moscow (Izd. AN SSSR), 1957.

173. R. Jeener and D. Szafarz. Arch. Biochem., 26, 54 (1950).

174. J. BRAchet in The nucleic acids (ed. E. Chargaff and J. N.

Davidson). Vol. 2, p. 475. New York, 1955; (Zh.

Brashe) Uspekhi sovremennol Biol., 29, 140 (1950).

175. M. Steinert. Bull. Soc. Chim. biol., Paris, 33, 549 (1951).

176 . S. Spiegelman and M. D. Kamen. Science, $107,5^{81}$ (1946).

177. D. Ivanovskil. Sel'skoe Khozyalstuo i Lesovodstvo, ISg2,

Feb., Otd. 2, p. 103; Mozaichnaya bolezn' tabaka.

Moscow (Medgiz), 1949.

178. W. M. Stanley. Science, 81,644 (1935).

179. K. Sukhov. Rastitel'nye virusy. Moscow (Izd. AN SSSR), 1956.

L. Zil'ber. Uchenie o virusakh. Moscow (Medgiz), $195^{6}$.

P. Fildes and W. E. van Heyningen (ed.). Nature of virus multiplication. (Symposium of Society for General Microbiology.) London, 1953.

G. Schrami. Advanc. Enzymol., 15, 449 (1954). 
180. M. Holden and N. W. Pirie. Biochem. J., 6o, 46 (1955).

181. R. Markham. Cold Spr. Harb. Symp. quant. Biol., I8, 141 (1953).

182. C. A. Knight. Advances in virus research, 2, 153 (1954).

i 83. H. Fraenkel-Conrat and B. Singer. J. Amer. chem. Soc., $76,180(1954)$.

184. W. N. Takahashi and M. Ishil. Amer. J. Bot., 4o, 85 (1953).

185. J. D. Bernal. Lecture to Moscow State University, 1955 .

186. H. Fraenkel-Conrat and R. C. Williams. Proc. nat. Acad. Sci., Wash., 4I, 690 (1955).

J. A. Lippincott and B. Commoner. Biochim. biophys. Acla, 19, $19^{8}\left(195^{6}\right)$.

R. G. HART. Nature, Lond., I77, $130(1956)$.

187. H. Fraenkel-Conrat. J. Amer. chem. Soc., 78, 882 (1956).

188. A. Gierer and G. Schramm. Z. Naturforsch., IIB, 138 $(1956)$.

189. A. D. Hershey and M. Chase. J. gen. Physiol., 36, 39 (1952).

190. O. T. Avery, C. M. MacLeod and M. McCarty. J. exp. Med., 79, 137 (1944).

A. Boivin, A. Delaunay, R. Vendrely and Y. Lehoult. Experientia, $I$, 334 (1945).

R. D. Hoтchкiss. Cold Spr. Harb. Symp. quant. Biol., I6, $457\left(195^{1}\right)$.

A. N. Belozerskiı̌, A. S. Spirin, D. G. Kudlaǐ and A. G. Skavronskaya. Biokhimiya, 20, 686 (1955).

191. P. A. Levene and R. S. Tipson. J. biol. Chem., iog, 623 (1935).

P. A. Levene. J. biol. Chem., I26,63 (1938).

192. H. S. Loring. J. biol. Chem., I28, lxi (1939); Fed. Proc., 6,487 (1947).

S. S. Cohen and W. M. Stanley. J. biol. Chem., I44, $5^{89}$ (1942).

E. R. M. Kay and A. L. Dounce. J. Amer. chem. Soc., 75, 4041 (1953).

193. R. Signer, T. Caspersson and E. Hammarsten. Nature, Lond., I4I, 122 (1938).

194. S. Katz. J. Amer. chem. Soc., 74, 2238 (1952).

195. E. ChargafF. Symposium sur le métabolisme microbien, p. 41. (2ème Congrès international de Biochimie, Paris, 21-27 Juillet, 1952). Paris, 1952.

196. J. D. Watson and F. H. C. Crick. Nature, Lond., I7I, 737 964 (1953). 
3OO ORIGIN OF STRUCTURES AND FUNCTIONS

197. A. N. Belozerskil and A. S. Spirin. Uspekhi souremennol Biol., 4I, $144\left(195^{6}\right)$.

198. E. Chargaff and R. Lipshitz. J. Amer. chem. Soc., 75, 3658 (1953).

199. A. Marshak. J. biol. Chem., I89, 607 (1951).

200. P. C. Caldwell and C. Hinshelwood. J. chem. Soc., I950, 3156 .

201. S. Spiegelman and M. D. Kamen. Cold Spr. Harb. Symp. quant. Biol., I2, 211 (1947).

202. J.-I. Tomizawa and S. Sunakawa. J. gen. Physiol., 39, 553 $\left(195^{6}\right)$.

203. G. Gamow. Scient. Amer., 193, 70 (1955); Proc. nat. Acad. Sci., Wash., 4I, 7 (1955).

204. C. C. Lindegren. Nature, Lond., I76, 1244 (1955).

205. G. Gamow, A. Rich and M. YčAs. Advances in biological and medical Physics, 4, 23 (1956).

206. G. Gamow. Biol. Medd., Kbh., 22, no. 8 (1955).

207. A. N. Belozerskil. Vestnik Moskov. Univ., 2, 125 (1949).

J. Brachet. Arch. Biol., Paris, 48, 529 (1937).

208. N. S. Demyanovskaya and A. N. Belozerskiř. Biokhimiya, I9, 688 (1954).

209. M. Grunberg-Manago, P. J. Ortiz and S. Ochoa. Science, 210. (III. 71). I2 2, 907 (1955). 


\section{THE DEVELOPMENT OF ORGANIC MULTIMOLECULAR SYSTEMS : THEIR ORGANISATION IN SPACE AND IN TIME}

\section{Simple and complex coacervates.}

It is characteristic of life that it is not scattered diffusely through space but manifests itself in individual, very complicated, multimolecular systems which are delimited from their surroundings, that is, in organisms. In these there takes place a continual succession of strictly ordered physical and chemical processes based on interactions between the organism and its surroundings which, together, constitute its metabolism.

From what has been said in the previous chapter we have seen that it is wrong to suppose that the formation of such highly-developed systems or organisms took place by the combination of molecules of proteins, nucleic acids or other substances which, if not actually endowed with life, were at least fully capable of carrying out vital functions. The development of the organisation peculiar to living things can only have occurred as a result of evolution of systems which, although more primitive, were nevertheless complete. At the moment of their formation these systems did not have the specific attributes of organisms. They were not alive and it was not until later that they assumed these organisational attributes and were transformed into systems which were new in principle and of a higher order, that is to say, into the first living things.

The organisation of any system must be considered both in space and in time. On the one hand the system has a certain size and structure, an ordered relationship between its various parts. On the other hand processes are carried 
out within it in a co-ordinated and consequent way. The comparatively simple and still lifeless systems which must have been elaborated at some time from organic material in the waters of the primaeval ocean, and which formed the starting point on the way to the development of life, must have undergone evolution leading to both the complication and perfection of their three-dimensional structure, and also to improvements in their temporal co-ordination, giving rise to the ordered harmony of the processes occurring within them.

These two aspects of organisation are inseparable from one another and it is only for convenience of exposition that we shall sometimes discuss them separately in what follows.

As we have already seen, the purely abiogenic evolution of organic substances on the surface of the Earth, in the waters of the primaeval ocean, must have led to the formation of very diverse substances which, in some cases, were of extremely high molecular weight, in particular protein-like polypeptides and polynucleotides.

A characteristic feature of these substances, which include individual proteins and even simple protein-like polypeptides, is the readiness with which they form complexes with other organic substances of high molecular weight, among them, with other proteins or polypeptides. Associations of this sort between different protein-like substances give rise to multimolecular formations with physical and chemical properties which differ substantially from those of their separate components. Furthermore, the protein-like polymers arising out of these associations, like natural proteins, could, under certain conditions, form multimolecular swarms which, when they had reached a particular size, would separate out from the solution into a new phase or collection of phases which might be considered to possess a relatively simple 'morphology'. To this category belong, in the first place, precipitates formed by the coagulation of colloids, gels and, finally, materials aggregating in liquid form.

Quite a long time ago, at the turn of the century, many workers (e.g. ${ }^{1}$ ) noticed that in solutions of hydrophilic colloids there occurred another phenomenon as well as coagulation. This was called 'demixing' (Entmischung). ${ }^{2}$ The solution 
separates into two layers, one rich in colloidal substances and another, clearly demarcated from it, which is almost free from colloids.

For many years this phenomenon has been studied in detail by H. G. Bungenberg de Jong ${ }^{3}$ and his collaborators, and recently also by many other scientists in various countries. ${ }^{4}$ To distinguish it from ordinary coagulation, Bungenberg de Jong called this phenomenon 'coacervation'. The colloid-rich liquid was referred to as a 'coacervate' and the colloid-poor liquid in equilibrium with it was referred to as the 'equilibrium liquid'. In many cases the coacervate does not separate out as a continuous layer but appears in the form of very small droplets which are readily seen under the microscope, floating in the equilibrium liquid. In Bungenberg de Jong's experiments with protein coacervates ${ }^{5}$ the diameters of the droplets were between 2 and $670 \mu$.

Moreover, it is not only proteins which form coacervates. they may also be formed by other hydrophilic and even hydrophobic colloids, both organic and inorganic. ${ }^{6}$ For example, they are formed by complex salts of cobalt, ${ }^{7}$ by sodium silicate and ammonia, ${ }^{8}$ by such organic substances as polyvinyl derivatives, by solutions of acetylcellulose in chloroform or benzene, ${ }^{9}$ and so forth.

The phenomenon of coacervation is particularly interesting from our point of view in that, during the process of evolution of organic substances, it must have been a powerful means of concentrating compounds of high molecular weight, in particular protein-like substances, dissolved in the hydrosphere.

It is well known that a coacervate may be obtained experimentally from solutions of as little as 0.001 per cent of gelatin. When this takes place there is a considerable increase in the concentration of the protein in the droplets of coacervate, which is particularly significant at very low concentrations. ${ }^{10}$ For example, if a coacervate is formed from a 1 per cent solution of gelatin, about 93 per cent of the gelatin is to be found in the coacervate layer. but when the concentration is lower the proportion of gelatin in the coacervate to that in the equilibrium liquid is very much greater. It is hardly possible to find any other equally effective means for con- 
centrating protein-like substances and others of high molecular weight, especially at low temperatures. It is true that a considerable concentration might also have been achieved by the adsorption of substances of high molecular weight on particles of clay, as was suggested by J. D. Bernal. ${ }^{11}$ This, however, may lead to irreversible changes in the molecules and, furthermore, they are firmly fixed to the surface of the clay, while in coacervates the molecules of the compounds of high molecular weight retain a considerable amount of their independence and are concentrated without any participation of inorganic precipitates being required.

On the other hand, if we take processes such as gel formation, ${ }^{12}$ this can only occur in the case of gelatin, for example, at concentrations of 1.5 to 2 per cent because gel formation, in general, only fixes the relative positions of the molecules and does not give rise to any concentration of them.

The importance of the formation of coacervates is not confined to their action in concentrating organic compounds of high molecular weight. Of no less importance is the fact that coacervation leads to the formation of a disperse system of coacervate drops with a highly developed surface separating it from the surrounding medium, and a definite internal structure of the droplets. If coacervation merely led to the formation of a continuous colloid-rich layer separated from the rest of the solution, the possible part which it could play in evolution would certainly be far more limited. It is just because coacervation usually leads to the formation of a large number of very small droplets with definite internal structures that it appears to constitute an extremely important stage in the spatial organisation of organic multimolecular systems.

On the basis of many years of work Bungenberg de Jong ${ }^{13}$ has put forward the opinion that the process of coacervation implies either a diminution in the hydration of the colloidal particles, in their ability to retain a layer of water around themselves, or else a diminution of that layer of water owing to the activity of water-removing factors. The colloidal particles do not, however, lose their surrounding water entirely but retain those molecules of it which are firmly 
bound to them and are rigidly orientated relative to the colloidal particles.

Thus, according to Bungenberg de Jong, coacervates form a special class of colloidal sols in which the molecules of water (or other solvent) are, to a certain extent, rigidly orientated with regard to the particles of the colloid and in which, therefore, a real boundary is formed between them and the free molecules of the equilibrium solution.

However, in view of the extreme complication of the phenomenon of coacervation, its theory cannot yet be held to be fully worked out. In order to elucidate the nature of the processes occurring we must turn to a study of some of the simpler cases of coacervation. At present, solutions of organic substances of high molecular weight are generally regarded as thermodynamically stable molecular solutions conforming to the phase rule. ${ }^{14}$ For practical purposes they may be considered as ordinary liquids which contain very large molecules. As early as 1904 G. Galeotti ${ }^{15}$ showed that the phase rule is applicable to protein solutions, and this was later confirmed by H. Chick and C. J. Martin ${ }^{16}$ in 1910-13 and by other later workers. The same applicability was first demonstrated for a number of other substances, including gelatin, by V. Kargin and his collaborators. ${ }^{17}$ If two simple liquids of low molecular weight can be dissolved in one another in all proportions (e.g. benzene and toluene or water and acetone) then, naturally, there will be no layering out. There exists, however, a large number of pairs of liquids which are only soluble in one another to a limited extent (e.g. water and phenol or water and aniline). If we mix two such liquids and shake up the mixture it will quickly separate out into two layers, one of which might consist of a solution of water in phenol and the other of a solution of phenol in water. When this takes place, the difference between the composition of the two layers at room temperature is very great. As a result of this, the surface tension at the boundary between the droplets formed by shaking and the surrounding medium will also be very great and the droplets will coalesce to form a continuous layer, thereby diminishing their surface area and with it the surface energy. As the temperature rises, the mutual solubility of the liquids increases, the difference 
in composition between the two layers decreases, the surface tension of the droplets also decreases and, finally, at a particular temperature, known as the critical temperature of solubility, the boundary between the drops and the surrounding medium disappears and a homogeneous solution is formed. For systems of water and phenol this temperature is $65.9^{\circ} \mathrm{C}$ and for mixtures of methanol and cyclohexane $49^{\circ} 1^{\circ} \mathrm{C}$, etc.

When the temperature falls very slightly below this critical temperature (only $0 \cdot 1-0 \cdot 2^{\circ} \mathrm{C}$ ), statistical variations in density occur and the system begins once more to differentiate. However, as the difference in composition betiveen the phases and the magnitude of the surface tension (some hundredths of a dyne $/ \mathrm{cm}$. at these temperatures) are not so marked as at room temperature, the droplets have no great tendency to coalesce and they form a stable drop-coacervate of a high degree of dispersion. When the temperature falls further the droplets will once more coalesce and the two substances dissolved in one another will separate out into two layers. If we change the relative mutual solubility of the two substances, for example by the addition of salt or naphthalene, this correspondingly alters the temperature relations of their mixtures or drop-coacervates.

Thus, in this simple example of two liquids of low molecular weight which are partially soluble in one another, the formation of drop-coacervates is limited to a narrow region in which the surface tension is very low. If it increases the liquids separate out completely; if it approaches too close to zero they mix completely.

In the systems with which we are concerned, containing protein-like substances and others of high molecular weight, the phenomenon must be more complicated and the 'play' of surface tension will not, by itself, be enough to determine the formation of drop-coacervates. Nevertheless, the essential condition for coacervation, the limited mutual solubility of substances, remains just as important as before.

Bungenberg de Jong obtained simple coacervates from aqueous solutions of gelatin by adding dehydrating agents such as ethanol or sodium sulphate, which decrease the hydration of the particles of gelatin and thereby decrease 
its solubility, so that the solution separates out into two layers and forms a coacervate on warming to $50^{\circ} \mathrm{C}$.

Simple coacervates may also be obtained from other proteins such as amandin (a globulin found in almonds) ${ }^{18}$ by dialysis in cold water, when the coacervate will dissolve again on heating; from alcoholic solutions of prolamines (cereal proteins) by diluting them with water; from alkaline solutions of protamines by adding alcohol and so forth. In all these cases the coacervate is formed under conditions in which the solubility of the protein is diminished. These simple coacervates, however, do not interest us nearly so much as the complex coacervates which are formed on mixing solutions of two or several colloids with different charges ${ }^{19}$ such as gelatin and gum arabic.

\section{The structure and properties of complex coacervate drops.}

Bungenberg de Jong ${ }^{20}$ believes that when such coacervates are formed the electrostatic forces act in the opposite sense to those of hydration. The effect of hydration tends to stabilise the solution while the electrostatic forces are acting to draw together the colloidal particles bearing opposite charges. When the mutual attraction of the oppositely charged particles reaches a certain intensity it can overcome the effect of hydration and the particles combine to form a complex coacervate. Thus such a coacervate is always under the influence of two opposing forces, the electrostatic ones which keep it together and those of hydration which tend to drive the colloid back into solution.

One can, however, treat the formation of complex coacervates from the point of view which has already been discussed, as occurring under conditions of limited mutual solubility of the components of the system. This approach is particularly applicable to such a coacervate as that of gelatin and gum arabic. The isoclectric point of gelatin is at $p \mathrm{H}_{4} \cdot{ }_{2}$ but the coacervate can only exist at $p \mathrm{H}$ levels between 1.23 and 4.82 . Within these $p \mathrm{H}$ limits gelatin is positively and gum arabic negatively charged. Under these conditions the charges can neutralise one another and the solubility is thereby reduced. It is known that at the iso- 
electric point, at which pure proteins carry no net charge, their solubility is at its lowest and therefore they are most easily salted out with neutral salts. At $p \mathrm{H}_{4} \cdot 8_{2}$ the net charge of gelatin disappears and its hydration is least, but, on the other hand, the charges on the gum arabic particles are not neutralised and the mean charge drawing together the particles of gelatin and gum arabic is greater than at lower $p \mathrm{H}$ levels at which the charges can completely neutralise one another. As the $p \mathrm{H}$ falls so the positive charge on the gelatin increases and therefore requires more gum arabic for its neutralisation and for the formation of a coacervate. As the $p \mathrm{H}$ increases, so the negative charge on the gum arabic also increases and it therefore requires the addition of a larger amount of gelatin to form a coacervate. When the $p \mathrm{H}$ becomes higher than the isoelectric point of gelatin and both substances are negatively charged, their charges cannot neutralise one another and coacervation cannot occur. In all these cases the formation of a coacervate depends on the mean net charge of the particles (i.e. on the algebraic sum of the positive and negative charges of the associated particles), and also on the degree of hydration and the solubility of the particles. The same rules govern the formation of coacervates from two proteins with markedly different isoelectric points, and also from proteins and phosphorylated starches and other such substances.

As the system becomes more complicated, when coacervates are formed from three components, for example, the conditions under which they can arise become more complicated also, as the mutual solubility of substances does not merely depend on their charges, but also on many other factors, hydrogen bonds, the hydration of non-ionising polar groups (e.g. OH, CO, etc.), the interaction of hydrophobic groups, etc. We have already indicated that the theory of coacervation is very complicated. This is because the mutual solubility of substances is itself very complicated and we have, as yet, no complete theory of solubility. This, however, does not fundamentally alter our approach to the phenomenon of coacervation, which may be considered as the various manifestations of the limited mutual solubility of substances which 
lead to the layering and separation of their solutions into two liquid phases.

According to $\mathrm{H}$. L. Booij and colleagues, ${ }^{21}$ the stability and the length of time for which coacervate drops can remain unchanged does not only depend on the concentration of $\mathrm{H}^{+}$and $\mathrm{OH}^{-}$ions but also on the presence of other electrolytes.

The particular ratio between univalent and bivalent cations is specially important. This is a manifestation of the pronounced antagonism between cations which has been studied in such detail in biological objects. Non-electrolytes can have a stabilising effect on both simple and more complicated coacervates by removing water from the colloidal particles. For example, coacervate drops of gelatin and gum arabic may be kept in the equilibrium liquid for an indefinite time in the presence of a solution of sucrose. ${ }^{22}$

A coacervate of gelatin and gum arabic is the classical example on which Bungenberg de Jong did most of his work. A number of later workers have also used such coacervates for their experiments, among them D. G. Dervichian, ${ }^{23}$ who confirmed the essential results of Bungenberg de Jong.

Gelatin can, however, form coacervates with other carbohydrates as well as gum arabic, e.g. gum acacia, ${ }^{24}$ araban and agar, and also with starches from various sources. ${ }^{25}$ As the introduction of phosphoric acid into the molecule of starch markedly increases its negative charge, phosphorylated starches very readily form coacervates with gelatin. ${ }^{26}$ Gum arabic also readily forms coacervates with other proteins. Dervichian $^{27}$ obtained a coacervate which was stable between $p \mathrm{H} 3.0$ and $p \mathrm{H}_{3} .8$ from gum arabic and haemoglobin. Gum arabic forms two different coacervates with clupeine, one of which occurs at $p \mathrm{H}_{5}$ and the other at $p \mathrm{H}_{7}$.

We are specially interested in complex coacervates made from two or several proteins. All that is necessary for these to be formed is that, at some particular $p \mathrm{H}$, their particles shall bear charges of opposite signs. This is easily achieved by mixing solutions of acidic and basic proteins. The greater the difference between the isoelectric points of the proteins used in the experiment, the more readily will they form coacervates. For example, good coacervate drops can be made. 
from mixtures of egg albumin with its isoelectric point at about $p \mathrm{H}_{5}$ and clupeine with its isoelectric point at $12 \cdot 1$. It has also been possible to incorporate enzymic proteins in coacervates while retaining their catalytic properties. ${ }^{28}$

Fairly detailed studies have also been made of coacervates containing nucleic acids, for example a coacervate containing three components, gelatin, gum arabic and the sodium salt of a yeast nucleic acid. ${ }^{29}$ By means of studies using ultraviolet light it has been possible to determine the absolute amount of nucleic acid in a single drop of coacervate. ${ }^{30}$ It is often found that a coacervate drop composed mainly of gelatin and gum arabic has droplets within itself composed of gelatin and nucleic acid (Fig. 27).

It is easy to form coacervates by the interaction of proteins with phosphatides, sterols, glycerides and other lipids. In particular, serious study has been given to protein-lipid coacervates $^{31}$ composed of lecithin and various proteins including casein, egg albumin, glycinin, clupeine, gelatin, etc. Gelatin can also form coacervates with other lipids. Bungenberg de Jong has recently paid special attention to the coacervate formed from gelatin and potassium oleate, because this coacervate has a very interesting structural formation and fine bimolecular boundary membranes. ${ }^{32}$ Potassium and sodium oleates can also form coacervates with such proteins as egg albumin, serum albumin, various globulins, etc. Dervichian also obtained protein-lipid coacervates from haemoglobin and the albumin and pseudoglobulin of blood with myristoylcholine.

Basing his opinion mainly on his own work with gelatin, Dervichian naturally arrived at the conclusion that the phenomenon of coacervation is not, in itself, associated with any chemical combination between the substances taking part. But it certainly does not follow that combinations of this kind cannot, in general, occur in coacervates. Thus, in my own laboratory, stable compounds of protein and gum arabic have been found to be present in the corresponding coacervates. $^{33}$ G. A. Deborin and his colleagues ${ }^{34}$ obtained compounds of egg albumin with ergosterol having properties similar to those of natural lipoproteins. Doubtless nucleic 


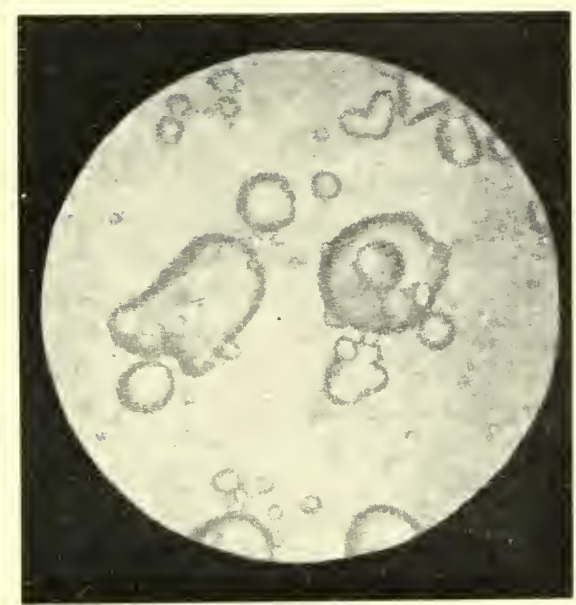

Fis: 27. Coacervate with three componcents: getatin, gimm arabic and ribumaleic acid. $\times 920$ (after Eureinora). 

acid and protein would also combine with one another to some extent in coacervates of which they were components. ${ }^{35}$

The occurrence of such combinations certainly adds considerably to the complication of all the phenomena of coacervation and would seem to favour the stabilisation of the coacervates. Unfortunately this is still but poorly understood.

As well as the simple and complex coacervates, a third group is often formed, the internally complex coacervates. These formations arise when ions of opposite charges are adsorbed on colloidal particles. A clouble layer of ions is formed around the particles. When this happens, the degree of ionisation depends on the chemical nature of both the colloid and the adsorbed ions. Internally complex coacervates may be obtained from solutions of proteins and carbohydrates, sols of phosphatides and fatty acids, with the help of various mineral salts. ${ }^{36}$

\section{Points of similarity between complex coacervates and protoplasm.}

The physico-chemical properties of complex and internally complex coacervates (especially those having many components) are very interesting from a biological point of view as they are similar in many ways to those of protoplasm.

This resemblance has been stressed over and over again by Bungenberg de Jong, ${ }^{37}$ though conflicting opinions have been expressed in the scientific literature. For example, A. Frey-Wissling ${ }^{38}$ insists that protoplasm is based on solid structural elements. He writes as follows: "Thus an extremely fine network is formed, a molecular framework. The meshes of this framework contain the interstitial substances: a solution of salts in water and lipids including phosphatides." This point of riew finds less and less support and even Frey-Wissling himself admits that the structure in question is very labile and can easily be disturbed, when the cytoplasm turns into a typical liquid. ${ }^{39}$

Indeed, as early as $1926 \mathrm{~L}$. V. Heilbrunn ${ }^{40}$ became firmly convinced, on the basis of his extensive investigation of the viscosity of protoplasm, not only that it has no visible struc- 
ture but that neither has it any invisible solid structure made up of 'beams and braces'.

The further such studies proceed the clearer it becomes that living, active protoplasm exists in the liquid state. It is true that parts of it, both internal and external, may at a certain period of life become rigid, when the phenomenon described by Frey-Wissling is reversed.

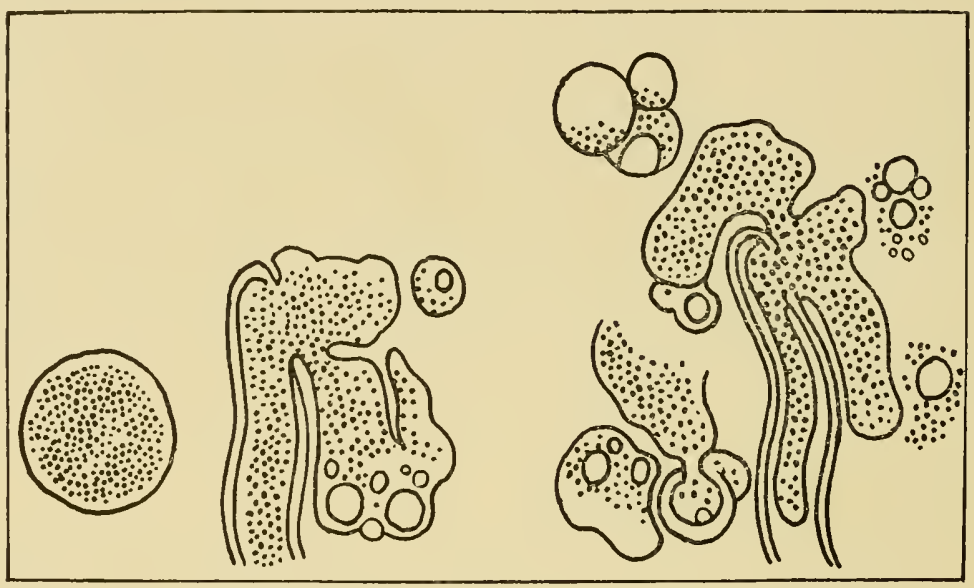

FiG. 28. Protoplasm flowing out from the cut cells of an alga.

However, it is not in these rigid formations that we should look for the key to the structure of the substrate of life. In most cases they play only a secondary part and the general gelatinisation of protoplasm only occurs when the vital processes are diminished, during anabiosis. The essential organisation of actire protoplasm is associated with the liquid state.

What has been said applies equally to the cytoplasm and the nucleus of the cell, and also to a number of formed elements in the prosoplasm, but especially to the mesoplasm of plant cells. ${ }^{41}$ Nevertheless, if the cell membrane is broken and the mesoplasm flows out into the surrounding aqueous medium (Fig. 28), it does not mix with the water but disperses to form a multitude of sharply demarcated droplets which look very like droplets of artificial coacervates but have a 
number of the characteristics of intact protoplasm. This phenomenon has been known ever since the time of Nägeli ${ }^{42}$ and has since been studied in detail by W. Kühne, ${ }^{43} \mathrm{~W}$. Pfeffer, ${ }^{44}$ L. V. Heilbrunn, ${ }^{45}$ W. W. Lepeschkin ${ }^{46}$ and many others with numerous plant and animal materials. ${ }^{47}$ It may be observed by causing the plasmolysis of plant cells even without breaking the cell membrane (Fig. 29). When this

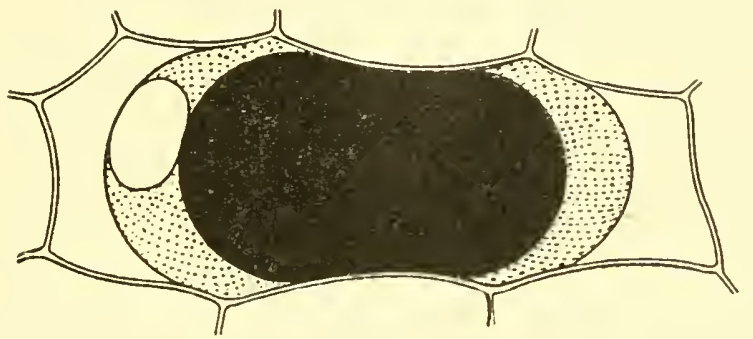

Fig. 29. Domed plasmolysis of a cell of the epidermal scale of an onion. Vacuole stained with an anthocyanin (after Hefler).

occurs, the bulk of the protoplasm becomes separated from the cell wall but is not dissolved in the water which has passed through it. It remains in the form of a sharply demarcated mass. ${ }^{48}$ Similarly, as we have already seen, although artificial coacervates are drops of liquid containing $5^{0}$ to 85 per cent of water, they do not mix with their equilibrium liquids, which are almost colloid-free.

We also find a close similarity between artificial coacervates and protoplasm in regard to the phenomenon of vacuolisation. Under a number of conditions which cause a decrease in the hydration of complex coacervates, clearly defined vacuoles appear in them and these may take the form of separate small bubbles or may coalesce to form a single large vacuole. This phenomenon may be observed under the action of chemical agents and also on changing the temperature, under the influence of electric currents and so forth. When the agent which brought about the racuolisation is removed the phenomenon is reversed and the coacervate returns to its original state. In a similar way the same physical and chemical agencies can induce vacuolisa- 
tion in the protoplasm of very diverse animal and vegetable objects. ${ }^{49}$ It is interesting that this vacuolisation occurs not only in the cytoplasm, but also in the nucleus, nucleolus, chondriosomes and other organelles of the cell. This has led a number of authors to state that these organelles are of the nature of coacervates. ${ }^{50}$

The great similarity between artificial coacervates and protoplasm has been revealed by concurrent studies of such properties as their viscosity, their behaviour with neutral salts, changes of $p \mathrm{H}$ and temperature, their behaviour in an electric field and so forth. In introducing an extensive account of his findings concerning the problem A. S. Troshin ${ }^{51}$ writes as follows:

Thus a number of features which are characteristic of the physico-chemical properties of coacervates seem also to be characteristic of protoplasm. The view of many investigators, that the protoplasm of living cells consists of a system of complex coacervates, is thus fully confirmed by experiment.

The following two characteristic properties of complex coacervates are specially important in relation to the argument which follows: (1) their tendency to form structures ; (2) their ability to adsorb selectively substances from the surrounding equilibrium liquid. It has been indicated above that on the coacervation of organic substances of high molecular weight there is formed a disperse system of coacervate drops with highly developed surfaces and definite internal structures. If the stability of the drops of coacervates of simple liquids is determined by the surface tension of the boundary layer then that of coacervates of proteins and other substances of high molecular weight is determined by far more complicated circumstances. In this case too the surface tension (which amounts to $0 \cdot 2-2$ dyne $/ \mathrm{cm}$. for coacervates) will naturally play some part, but will not be decisive. The work of P. Rebinder and his school ${ }^{52}$ has shown that the stability of disperse systems resembling emulsions depends to a considerable extent on the stabilising effect of the adsorbed layers at the surface which separates the droplet from the continuous phase. This stabilising effect is especially marked when the adsorbed layer with its associated solvent has a 
rather high degree of structural viscosity or, when the solution is highly saturated, even elasticity and mechanical resistance to deformation; in the presence of such rigid layers the stability of disperse systems may be extremely great.

It is very significant that proteins themselves should be among those substances which give rise to differentiated surface layers. The transformation of protein molecules in the surface layers into a laminar state with an increase in their mechanical rigidity is well known; it has been studied in detail, particularly by A. Trapeznikov. However, although in coacervates of simple liquids the elastic surface layers can only arise by the admixture of a third substance, in coacervates of proteins they can arise directly from parts of the protein molecules themselves or other substances associated with them such as lipids, polysaccharides, etc., which migrate to the boundary layer and form molecular layers at the interface, or perhaps only a single layer with changed structural and mechanical properties. This seems to be just the sort of phenomenon which lies at the basis of the formation by protein coacervates and protoplasm (after disintegration of the cell with water) of sharply defined surface films with. fairly rigid mechanical properties. This has nothing to do with surface tension or with the fact that the protoplasm forms a separate phase, but is due to the transformation of the protein molecules and their associated groups in the surface layer into a different structural state.

At the interfaces between the drops of a complex coacervate and its equilibrium liquid, or between a vacuole and the coacervate in which it lies or, finally, between the drops of one coacervate and another in which it is included, one may certainly demonstrate the presence of colloidal films made up of oriented colloidal particles of whichever component is present to excess in the coacervate-equilibrium liquid system. Such films are formed especially readily in protein-lipid coacervates. In particular, Bungenberg de Jong $^{53}$ and his colleagues have recently studied coacervates of gelatin and potassium oleate and concluded that they contain micellar films in the form of a sandwich, molecules 
of oleic acid being arranged in a regular order between two unimolecular layers of protein

The films have definite structures and permeabilities which depend on their chemical composition and electric charge. For example, if the boundary film of the coacervate is negatively charged and the surrounding liquid contains calcium ions, the film is strengthened (forming an internally complex coacervate with the adsorption of calcium ions). Potassium, on the other hand, weakens the film. Thus calcium and potassium act as antagonists in the coacervate. The protoplasmic films dividing the nucleus from the cytoplasm and the nucleolus from the karyoplasm are similar in nature. Many authors claim to have found such films around the chondriosomes, karyosomes, chromosomes and other organelles and inclusions in cells.

The drops of protein coacervates also have an internal structure which distinguishes them fundamentally from simple drops of liquid. This structure manifests itself chiefly as a rather labile state of orientation of the particles of the coacervate. As we have already mentioned, complex coacervates in the aggregated state take the form of more or less freely flowing liquids, but under some circumstances orienting forces may develop within the coacervates so that they cease to behave like ideal liquids. These forces cause the particles of the coacervates to assume a definite orientation with regard to one another. This may, for example, lead to the anisotropy of some coacervates, ${ }^{54}$ although, at first, they remain of a liquid consistency and their capacity for double-refraction is very labile.

According to Bungenberg de Jong, ${ }^{55}$ the colloidal particles in complex coacervates are not, as a rule, oriented in a definite way, because in such coacervates there is no cohesion between the particles. But if, by some means, the positive or negative charge on the micelles of the coacervate is increased or their hydration is decreased, then the micelles approach one another and become oriented in a definite mutual relationship. The so-called 'oriented coacervates' which are thus obtained show many signs of having a structure. For example, if the particles of which it is composed are rod-shaped, the drops of the coacervate will be ellipsoidal. 
In oriented coacervates one may also detect the formation of ' micellar crystals', fibrils and fibrillar structures. Bungenberg de Jong and his colleagues ${ }^{56}$ observed the formation and disappearance of these structures in coacervates of various proteins, lecithin, nucleic acid, polymeric carbohydrates, etc.

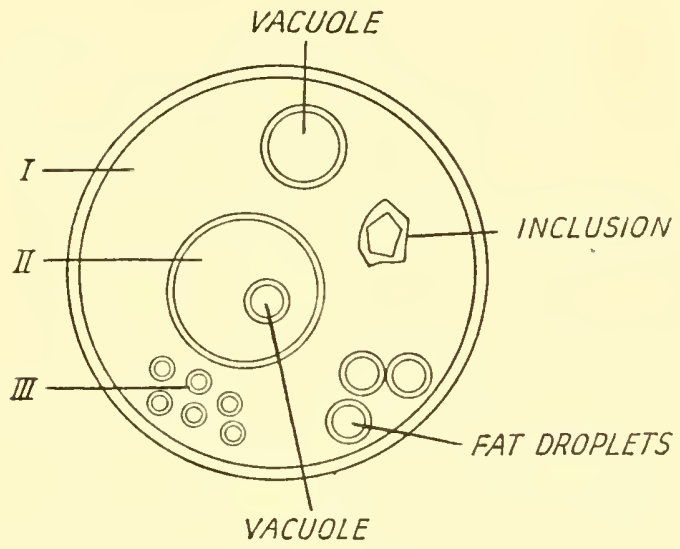

Fig. 3o. Model of a cell (after Bungenberg de Jong).

$I, I I$ and III indicate individual coacervates.

The so-called multiple complex coacervates, ${ }^{57}$ made up of several different components, are of great interest. The coacervate which we have already discussed, made up of gelatin, gum arabic and sodium nucleate, may serve as an example of this class. It may exist as a single complex coacervate or may form two different coacervates which do not mingle; the drops of one coacervate may contain small droplets of the other.

The presence of double coacervates of this sort may readily be demonstrated by staining. For example, the coacervate of gelatin and nucleic acid which lies within the coacervate of gelatin and gum arabic is selectively stained by methylene green. Bungenberg de Jong, along with many cytologists and physiologists, considers that the living cell is, essentially, a very complicated multiple coacervate ${ }^{58}$ (Fig. 30).

From this point of view the nucleus may be regarded as a coacervate lying within another coacervate, the cytoplasm; 
and the nucleolus as a further coacervate included within the nucleus. Guilliermond says that the development of the chondriosomes and their later transformation suggests that they also are coacervates. According to I. N. Sveshnikova ${ }^{59}$ the same may be said of microsomes. Finally, according to P. Makarov, the formation of chromosomes in the resting cell before division suggests that they are coacervate-like in nature.

The process of development of vital-staining granules in protoplasm may serve as an example of the formation of droplets of one coacervate within the substance of another ${ }^{60}$ A. S. Troshin considers that the formation of granules of secretion within glandular cells is generally similar in mechanism to the formation of multiple coacervates.

As we have already mentioned, the process of coacervation leads to the formation of a boundary or surface separating the coacervate from the equilibrium liquid. This is associated with the appearance of new surface phenomena and, in particular, with the adsorption by the coacervate of various substances present in the surrounding medium.

Many organic substances are extracted almost completely by coacervates from their equilibrium liquids. Even when the concentration is as low as 0.001 per cent a coacervate may sorb some substances from the water in which they are dissolved. Some of the molecules which are sorbed by the coacervate pass into its liquid by hydration and some become associated with the colloidal particles themselves, sometimes entering into chemical combination with them so that quite substantial chemical alterations in the composition of the coacervate may take place.

The selective character of the sorption is very important. Coacervates may accumulate large amounts of one substance, collecting it from dilute solutions, while on the other hand they may take up only very limited amounts of another, although this is present in high concentration in the equilibrium liquid. This peculiarity arises from the facts that, on the one hand, the colloidal particles of the coacervate themselves adsorb some particular substances specifically while, on the other hand, the solubility of substances in the 
water of hydration of the coacervate drops is different from their solubility in ordinary water.

A number of workers (D. Sabinin, ${ }^{61}$ D. Nasonov, ${ }^{62}$ A. S. Troshin $^{63}$ and others) who oppose the membrane theory of the permeability of the cell, believe that its ability to take in this or that substance from the surrounding medium and to discharge it again is a manifestation of the sorptive powers of protoplasm, which can only be understood on the assumption that protoplasm is a coacervate system. These authors, therefore, attach very great significance to the study of the mechanism of distribution of substances between a coacervate and its equilibrium liquid in the attempt to work out the theory of the uptake of substances by the living cell.

The multifarious organic compounds of high molecular weight which first arose in the waters of the primaeval ocean, various polymeric carbohydrates, amino acids, nucleotides and so forth, cannot have been fundamentally different in their colloid-chemical properties from the polymeric compounds with which we are familiar.

In solutions of them, as in the solutions, to which we are well accustomed, of proteins, polysaccharides or polynucleotides, there must have been a pronounced tendency to the formation of intermolecular associations. Complex coacervates must have been formed with great readiness. As we have seen above, the essential condition for this is the simultaneous presence in a solution of two or several organic substances of high molecular weight with different charges. The great complexity and diversity of the chemical transformations which took place in the primaeval hydrosphere must, in themselves, have guaranteed that this condition would be fulfilled. Therefore, sooner or later, at some point or another in the primaeval ocean, there must necessarily have come into existence collections of molecules of organic polymers and their separation in particular places from the surrounding medium to form drops of complex coacervates.

This must have been largely facilitated by the relatively very high concentrations of organic substances in the primitive 'terrestrial soup' to which we have already drawn attention. The formation of complex coacervates could, however, have occurred even when the concentration of organic 
polymers was far lower. Under experimental conditions it takes place in solutions containing only a few parts per million of these substances.

The water of the seas and oceans as we know them now only contains negligible traces of organic compounds, which arise secondarily from the decay of dead organisms. In the vast majority of cases these substances are quickly consumed by the organisms of the plankton, for which they provide nourishment. Sometimes, but comparatively seldom, they may remain in the depths of the sea for a relatively long time untouched by micro-organisms. Numerous studies of the slimy bed of the ocean at great depths indicate that, under these conditions, dissolved substances of high molecular weight do, in fact, form aggregates similar to coacervates.

While studying the waters of the seas and oceans at depths of hundreds and thousands of metres, A. Kriss and his colleagues $^{64}$ found submicroscopic formations reminiscent of coacervates which they were able to photograph with an electron microscope. The nature of these formations is still not clear but nevertheless Kriss's observations are of great interest.

Thus, all the evidence now available agrees in indicating that the organic polymers which were originally formed, and in particular the protein-like polypeptides of high molecular weight, must, at some stage in the evolution of carbon compounds, have separated out from a homogeneous solution in the form of multimolecular aggregates similar to the drops of coacervate which are obtained under laboratory conditions.

The formation of coacervates in the waters of the hydrosphere was a very important stage in the evolution of the primary organic substances and in the process of development of life. Until this occurred an organic substance was inextricably merged with its surrounding medium, uniformly distributed throughout the whole extent of the solvent. When coacervates were formed, the molecules of organic polymers became concentrated at particular points and separated from the surrounding medium by a more or less sharp boundary. Thus there were formed entire multimolecular systems, coacervate drops, each of which already had a certain individuality in contrast to all the rest of the external world surrounding 
it. In addition, each such drop had a certain structure peculiar to itself alone. Previously, in the solution, there were only irregularly moving particles of organic substance, all the properties of which were determined simply by their intramolecular structure. In the drops of coacervates these particles were arranged in a definite relationship to one another, giving rise to a certain spatial organisation and there were superimposed on the earlier organic-chemical relationships new colloid-chemical laws which were derived from the interaction of substances of high molecular weight in a multicomponent system.

The primary formation of these coacervate drops is worthy of special attention because the material basis of life at the present day, protoplasm, has a similar structure and, from a purely colloid-chemical point of view, it would seem, as we have shown above, to be a multiple complex coacervate. From this one must not, of course, draw the reverse conclusion that the original coacervate drops, or any which have been produced artificially, are in any way living. The difference is not merely due to the extreme complexity and the far-reaching spatial organisation of protoplasm compared with the great simplicity and lability of coacervate drops. The actual stability of these two systems, their capacity to exist for a long time, is based on completely different principles.

\section{Stationary open systems.}

An artificially produced coacervate, or a drop which arose naturally by separating out from organic solution in the waters of the ocean, is in itself a static system. The longer or shorter duration of its existence, which is associated with maintaining the constancy of the properties of the system in time, depends on its being in a thermodynamically stable or metastable state. The more stable a coacervate drop, regarded from a purely colloidal point of view, the less likely it will be to disappear as an individual formation after any given lapse of time by amalgamating with other drops or by dissipating itself into the surrounding solution. Unlike this, the coacervate structure peculiar to living protoplasm 
can only exist so long as it carries out an unending succession of multitudinous biochemical processes at a great speed, which together make up its metabolism. Thus it is only necessary for these processes to be suspended or radically changed for the protoplasmic system itself to be destroyed. Its continued existence, the maintenance of its form, is associated not with immutability or rest but with continual motion. Thus protoplasm is not a static but a 'stationary' or flowing system.

This characteristic property of living things was already recognised among the ancient Greeks by the great dialectician Heraclitus ${ }^{65}$ who taught that our bodies flow like streams; the material in them is renewed like water in a river. In fact a river or a simple stream of water flowing from a tap enables us to understand, in their simplest form, a number of essential features of the organisation of irreversible or open systems, of which living protoplasm is a particular example. If the tap is not fully open and the pressure in the water system remains constant, the stream of water issuing from the tap will stay almost the same shape, as though it had been congealed. We know, however, that this shape is nothing but the visible manifestation of an unending flow of particles of water which continually enter and leave the system at a particular rate. The very existence of such a system depends on the fact that a constant succession of new molecules of water is passing through it at a steady rate the whole time. If the flow is interrupted the stream ceases to exist as such.

In an analogous way the organisation of protoplasm is based on a stationary state by virtue of the fact that the living organism is constantly exchanging material and energy with the medium which surrounds it; that within it a series of irreversible co-ordinated reactions are being carried out at a definite rate, as a result of which substances which enter the organism from the outside medium undergo a series of transformations within it and the products of their decomposition are again liberated into the outside medium. 


\section{The thermodynamics and kinetics of open systems.}

The mechanistic view of the organisation of living bodies which prevailed among biologists until recently, namely that they were like machines made up of immutable steel components, made such a concept of organisms as open systems very difficult to accept. However, the use of marked atoms in biochemical and physiological investigations ${ }^{66}$ has shown beyond doubt that almost all the substances of the living body, its proteins, nucleic acids, lipids, etc., are completely renewed in the course of a short space of time; that the material substrate of life is constantly being exchanged with the surrounding medium, it is continually being broken down and synthesised again from substances derived from the external world. This provided a complete vindication of Michurin's principle of the unity of the organism and the environment; the contention that a living thing cannot be considered in isolation from its environment, without reference to this unity. ${ }^{67}$

On the other hand, the contemporary wide adoption in industrial practice of technological methods based on continuous irreversible processes has led many physicists and chemists to undertake a complete revision of the theory of open systems, which has introduced many new concepts into the classical thermodynamic and kinetic theories, which are mainly based on the kinetics and equilibrium of reactions in completely isolated systems.

In his very interesting book, An introduction to the thermodynamics of irreversible processes, I. Prigogine ${ }^{68}$ divides all limited systems into three fundamental classes : (1) open, (2) closed and (3) isolated systems. The first group comprises systems in which there is a constant exchange of both matter and energy between them and their surroundings. In closed systems the exchange is only of energy, the exchange of matter being absent. Finally, the third group comprises systems which are completely isolated from their surroundings and do not exchange either matter or energy with them. The latter two groups may be combined under the general term 'enclosed systems' to distinguish them 
from the group of open systems, to which living organisms belong.

In enclosed systems the only things which can react chemically with one another are substances which are present in the system. The constancy of the properties of the system over a period is characterised by a state of equilibrium in which the rate of a reaction in one direction is the same as the rate of the same reaction in the opposite direction. The thermodynamic criterion for this equilibrium is the presence of the minimal amount of free energy and the maximal amount of entropy in the system (in other words the attainment of the most probable state of the system). Processes occurring spontaneously within an enclosed system cannot cause it to reach a less probable state, that is to say, they can only maintain the entropy at its existing level or increase it, according to whether the processes in question are reversible or irreversible. So long as the entropy of a system is increasing, equilibrium has not been reached and, conversely, when equilibrium is set up, the rate of increase of entropy falls to zero.

In contrast to this, in open systems there is a continual accession of substances from the external medium into the system (from which it is separated in some way) and also a discharge of chemical substances, which arise within the system, back into the external medium. The constancy in time of the properties of such an open system is, therefore, not characterised by thermodynamic equilibrium (as is the case in enclosed systems) but by the setting up of a stable condition, the constancy of which is maintained by the rate at which chemical reactions proceed in one direction and bv the diffusion of substances within the system.

Stationary processes may, of course, occur in closed systems though not in isolated ones, ${ }^{69}$ for example, the transfer of heat. The stationary state in which we are interested is that involving chemical reactions and this is peculiar to open systems. We shall therefore direct our attention to these.

Thermodynamic equilibrium and the stationary state resemble one another in that, in both cases, the constancy of the properties of the system is maintained. The essential difference between them is that in thermodynamic equi- 
librium there is, as a rule, no change in free energy, whereas in the stationary state the free energy enters and leaves the system at the same constant rate.

Thus, the stationary state is kept constant, not because the free energy is minimal (as is the case in thermodynamic equilibrium) but because the system is continually receiving free energy from outside in amounts which compensate for its decrease within the system ; it is 'fed' with free energy at the expense of the enrironment.

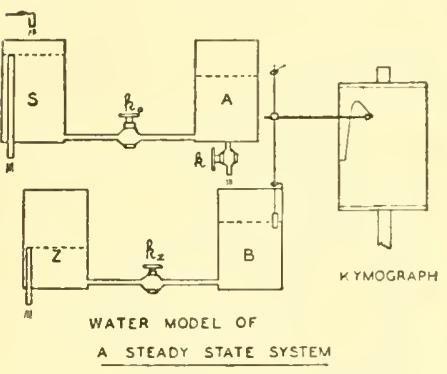

Fig. 31. Water model of the simplest steady state system.
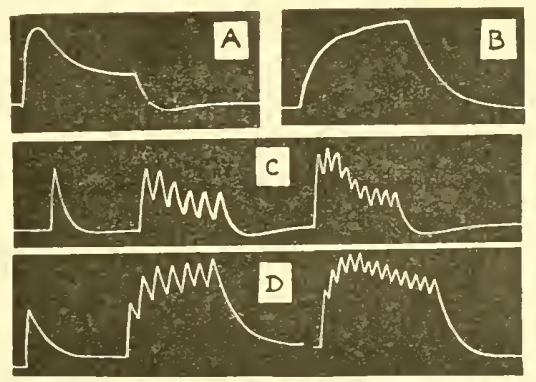

FIG. 32. Records made with the water model of a steady state system. A. Change of $k$ to new level with $k_{0}<k_{z}$. B. Same with $k_{0}>k_{z}$. C. Single and repetitive brief changes of $k$ with $k_{\mathrm{o}}<k_{\mathrm{z}}$. D. Same with $k_{\mathrm{o}}>k_{\mathrm{z}}$.

Reproduced by permission from originals of Figs. 8 and

9. Alan C. Burton, J. cell. comp. Physiol., If, 344 .

Similarly the entropy of a closed system in equilibrium is at a maximum, whereas, in an open system in the stationary state, it is kept constant but not maximal. The chemical thermodynamic theory of irreversible processes occurring in open systems has so far only covered small deviations from thermodynamic equilibrium. From the results of $\mathrm{H}$. Eyring and others ${ }^{70}$ it would seem that it is only applicable where $\Delta \mathrm{z}=$ about $0.2 \mathrm{kcal} /$ mole. However, within these limits thermodynamics has established that, in general, there are linear relationships between the changes in properties of the system (e.g. chemical transformations or the diffusion of substances) and the strength of the forces acting on it (the gradients of free energy, concentration, temperature, etc.) for a number of simultaneous processes. 
The kinetics of processes occurring within open systems are very complicated and peculiar to them. We shall try to explain the kinetic peculiarities of the chemical reactions in open systems by analogy with the simplest hydrodynamic model of stationary systems. A vessel with a liquid flowing through it may serve as such a model. ${ }^{71}$ This is represented diagrammatically in Fig. 31 .

The vessel $S$ in which the liquid stands at a constant level represents the source of substances entering the system (the external medium). The vessel $\mathrm{Z}$ is a sink (this also represents the external medium into which the system discharges the products of the reactions which have occurred within it). The open system itself is represented by the vessels $\mathrm{A}$ and $\mathrm{B}$ which are connected with the 'external medium' by means of the taps $K_{\mathrm{o}}$ and $K_{\mathrm{Z}}$ which represent the diffusion constants of substances into and out of the system. The stationary state of the system is attained when the water is at particular levels in vessels $\mathrm{A}$ and $\mathrm{B}$, which correspond to stationary concentrations of the substances taking part in reactions in the chemical open system. Tap $K$ regulates the flow of water from $A$ to $B$ and represents a constant rate of the reaction with which we are concerned, $\mathrm{A} \rightarrow \mathrm{B}$. There is also shown a kymograph which records, by means of a float, the level of the water in vessel $B$.

When the flow of water through the system has been established, this level will remain constant like the static level of water in an ordinary bucket. In our system, however, there is a continual dissipation of energy due to the flow of the water. This is what maintains a constant level in vessel $B$.

To make it easier to follow the analogy between the hydrodynamic model and the chemical reaction in an open system we may give the following diagram

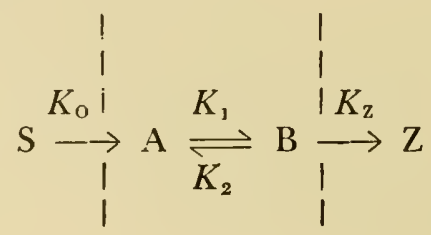


Here the dotted lines represent the boundaries of the open system, such as the cell wall or the surface film of a coacervate drop. $\mathrm{S}$ and $\mathrm{Z}$ represent the external medium, $K_{\mathrm{o}}$ and $K_{\mathrm{Z}}$ the velocity constants for diffusion or penetration of the membrane, $K_{1}$ and $K_{2}$ the velocity constants for the chemical reaction $\mathrm{A} \rightleftharpoons \mathrm{B}$ taking place within the open system. In the hydrodynamic model if we alter the setting of the taps $K_{\mathrm{o}}$ and $K_{\mathrm{Z}}$ (which would be the equivalent of changing the rate of diffusion in the chemical analogy) or turn tap $K$ (which corresponds to a change in the rate of reaction), then a new level will be established in vessel B, i.e. a new stationary state will be set up. Thus it is possible to establish an infinite number of stationary states in an open system, depending, particularly, on changes in the rate of the reaction which is occurring within the system.

It is well known from the classical kinetics of closed systems that the introduction of a catalyst into a system will alter the speed with which it reaches equilibrium, but does not affect the position of the equilibrium because the magnitudes $K_{1}$ and $K_{2}$ are changed in such a way that the ratio between them remains constant $\left(K=\frac{K_{1}}{K_{2}}\right)$. Two ordinary vessels containing water at different levels and connected with one another by a tap may serve as a hydrodynamic model of such a closed system. The amount which this tap is open will affect the rate at which the fluid level becomes the same in both buckets but will not affect its position.

In open systems, on the other hand, the introduction of a catalyst will, as we have already seen, change not only the rate of the reaction but also the position of the 'equilibrium ' (the stationary concentrations of the components of the system) as may be shown by purely mathematical means. A very characteristic feature of the establishment of a new stationary state in open systems is that it does not come about directly but through extreme states (through a maximum or minimum).

Thus, at the beginning it deviates more sharply from the original state and later approaches it again more closely (though not completely) as is shown on the accompanying 
curve obtained by Burton with a hydrodynamic model (Fig. 32).

K. G. Denbigh and his colleagues ${ }^{72}$ gave analogous curves for the chemical reaction of the oxidation of glucose. We must also draw attention to yet another curve obtained by

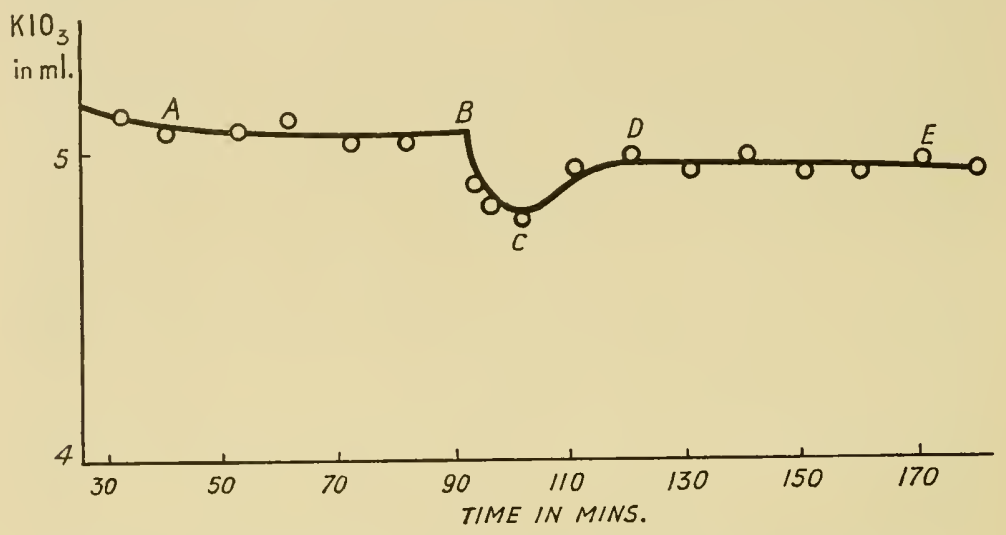

FIG. 33. Changes in the stationary state during the enzymic oxidation of ascorbic acid (after Pasynskii and Blokhina). Explanation in text.

A. Pasynskiř and V. Blokhina ${ }^{73}$ for the reaction of enzymic oxidation of ascorbic acid occurring under the conditions of an open system. The experiment was conducted as follows : a solution of 1.2 per cent of ascorbic acid and 0.2 per cent of hydrogen peroxide was passed through a small cylinder covered at one end by a cellophane membrane. The other side of the membrane was washed with a stream of distilled water. In the diagram (Fig. 33) the ordinate shows the titre of ascorbic acid in the mixture and the abscissa the time in minutes.

When the stationary state had been established (A B), a solution of peroxidase was introduced into the cylinder at the point $\mathrm{B}$, and its titre fell to level $\mathrm{C}$. Owing to the association of the decrease in the concentration of ascorbic acid with a decrease in the rate of its diffusion through the membrane, however, after reaching a minimum BCD, a new stationary state was established at level DE. This experiment 
may serve as an example of the course of an enzymic reaction showing the characteristic features of reactions in open systems: a change in the stationary state, the dynamic stabilisation inherent in the system, and the transition from one stationary state to another through an extreme state (through a minimum). Thus, for every open system there must be an unlimited number of stationary states in which any change, even of only one of the parameters of the system, will, in principle, necessarily lead to the establishment of a new stationary state.

If several reactions are taking place within the system instead of only one, and if these follow one another in a longer or shorter chain of transformations or are, in general, associated with one another in time, then the equation for stationary concentrations in open systems becomes far more complicated. For direct, unbranched, chains of reactions, for example, it may be represented as follows:

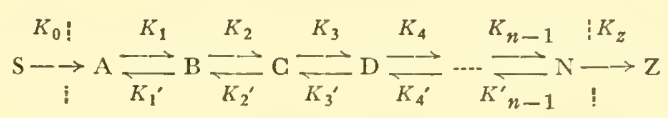

The chains of chemical reactions taking place within open systems may, however, branch, e.g. :

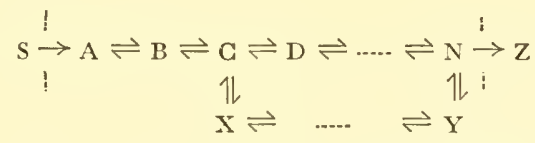

This may lead to the formation of a complicated network of reactions with many branches and internal cycles. It may be compared, in some respects, to a railway network on which a large number of trains are moving in various directions at various speeds. On the basis of his own profound kinetic analysis of these phenomena C. N. Hinshelwood ${ }^{74}$ concluded $^{-}$ that in networks of chemical reactions of this sort the limiting states are not always determined by the slowest individual reaction forming a separate link of the chain but depend on the relationships of a whole series of reaction-velocity constants. In fact, in a complicated network of reactions, the transition between two chemical states may occur, not 
by one, but by several pathways, just as the quickest way of getting from one place to another over a railway system with many branches and loops may involve the use of different routes comprising combinations of different sections of railway line. In chemical kinetics, when alternative routes of this sort are available, special importance naturally attaches to the route along which the reaction can proceed at the greatest speed under the given conditions. But we must not forget that (as all motorists know) the shortest way is not always the fastest, and it is often better to follow a circuitous route which runs over a well-made highway. Similarly in a complicated network of chemical reactions it often happens that a process of transformation comprising a large number of separate links is carried out very quickly to achieve a chemical transformation which is based on but one, or a few, chemical acts.

Thus, in a complicated network of chemical reactions the attainment of the highest speed for a process involves not merely the speeding up of one of its stages, but the establishment of the most effective relationship between all the parameters of the process. In addition, any alteration in the external conditions acting on the process, by speeding up or slowing down any one stage of the chemical transformation, will lead to a rearrangement of the kinetic parameters of the system as a whole.

The establishment of such a network connecting the kinetic parameters under the influence of a change in the external conditions does not, according to A. C. R. Dean and C. N. Hinshelwood, ${ }^{75}$ take place instantaneously but requires a certain time for reconstruction. In its establishment the attainment of the best rate for the process is sometimes even hindered for a period to allow the working of less effective alternative processes which, however, are already in action.

All these processes can not only be worked out theoretically, but can also be demonstrated experimentally, especially by analogy with a hydrostatic model in which there are several stationary systems having common original and final reservoirs.

We may summarise all that has been said about the thermodynamics and kinetics of open systems by stating the 
following essential characteristics of these systems in a form borrowed from the review of Pasynskir. ${ }^{76}$

1. The stationary state of open systems is characterised by a constant minimum rate of dissipation of free energy and a constant minimum rate of development of entropy within the system in contradiction to the state of thermodynamic equilibrium in closed systems in which these functions have a value of zero.

2. In open systems there can occur processes leading to a decrease in entropy owing to their thermodynamic associawith processes leading to an increase in entropy in the external medium.

3. In open systems there can exist an infinite number of stationary states depending on the internal parameters of the system (the original concentration of the components, the diffusion constants, the rates of the reactions and so forth), and on the external conditions (temperature, pressure and so forth). A change in any of the conditions of a stationary state leads to a rearrangement of the kinetic and diffusion parameters of the system and to the establishment of a new stationary state.

4. In open systems where alternative routes are available the directions of chemical changes are determined by the principle of the maximal reaction velocity.

5. In an open system the presence of catalysts affects not only the rate of the reaction, but also the stationary concentrations of the reagents.

6. When the conditions are altered in the stationary state in open systems, processes occur which tend to conserve the properties of the system (the dynamic stabilisation of the stationary state).

7. The transition from one stationary state to another in an open system where the reaction velocities are not very great does not proceed according to a smooth curve but usually passes through an extreme state (through a maximum or minimum).

It is very significant in connection with our problem that the principle according to which protoplasm is organised in time is similar to the principle of organisation of open 
systems. An organism or any one of its cells can only exist so long as there passes through it a continual flow of fresh particles of matter with their associated energy, from the external medium and back into it.

When an organism receives from the external medium compounds which are foreign to it, a whole series of coordinated reactions transmute these compounds into the substances of its own body. This is the ascending branch of metabolism (assimilation). However, assimilation is intimately connected in the organism with the converse process, dissimilation, the decomposition of compounds which form part of the body, the formation of the end products of this decomposition and their discharge into the external medium.

From a purely chemical standpoint assimilation and dissimilation, the whole of metabolism, is a complicated association of an enormous number of extremely simple and relatively uniform reactions. These are well known to chemists and easily carried out outside the living organism under laboratory conditions; they include oxidation, reduction, hydrolysis, phosphorolysis, aldol condensation, the transfer of methyl groups, etc. There is nothing specific to life about any one of these reactions. What is specific about the organisation of biological metabolism seems to be that in protoplasm the reactions are strictly co-ordinated and harmonious, that they follow one another in a definite regular order and not at random, forming long series, branching chains and closed cycles of chemical reactions, just as we have described above with reference to the networks of reactions occurring within open systems. ${ }^{77}$

Thus the simplest abiogenic system which could have served as the starting point for the evolutionary process which led up to the appearance of life must already have had the organisational features characteristic of open systems, in which the separate reactions form a network of chemical transformations which are co-ordinated in time.

How could such an original system have arisen? How could there have arisen at definite points in the primaeval ocean, out of the diverse interlacing reactions, some of that order, that regularly functioning network of reactions which is peculiar to open systems? 
As we have shown above, at a particular stage in the history of the Earth, diverse organic substances were formed and reacted chemically with one another in many different ways. The participation of free radicals, which were formed as a result of the effects of ultraviolet radiations, electric discharges and radioactive radiations, still further increased the number of possible reactions. Over a long period it is probable that almost all the possible chemical reactions between the substances present actually took place to a greater or less extent. However, in the general disorderly association of all conceivable chemical reactions of those times, a single chemical reaction probably predominated at any particular place and others in other places. This was essentially due to the fact that the transformation of any substance entering into a reaction preferentially followed the chemical course which assured the greatest speed of reaction under the given circumstances.

According to the theory of chemical kinetics, if the difference in free energy, $\triangle F$, is the same for all the reactions, the transformation of the bulk of a given substance will follow the course of reaction along which it can proceed most quickly. The attainment of the greatest speed for a given reaction depends, in its turn, both on the chemical nature of the reacting substances and on the local conditions of the medium, temperature, pressure, and particularly the presence of appropriate catalysts, especially when such a catalyst specifically accelerates only one of all the possible reactions.

This may be illustrated by the following elementary scheme. Let us suppose that we have any organic substance A, which can be transformed into substances B, C, D, etc. In our scheme the rates of these reactions are represented by the vectors, the length of which indicates the rate of any reaction.

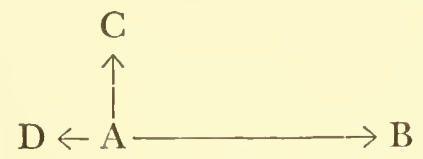

In this diagram we see that the rate of the reaction $A \rightarrow B$ is seven times that of the reaction $A \rightarrow D$ which, in its turn, 
is only half that of the reaction $\mathrm{A} \rightarrow \mathrm{C}$. Naturally, after a certain time, when all of substance $\mathrm{A}$ has disappeared, the resulting mixture will be found to contain $7^{\circ}$ per cent $B$, 20 per cent $\mathrm{C}$ and 10 per cent $\mathrm{D}$. Thus, under the given conditions the bulk of substance $\mathrm{A}$ will have been converted to substance $B$, that is to say, it will have followed the path along which the reaction proceeds fastest.

If we apply to such a system any influence which will increase the rates of all possible reactions equally (e.g., raising the temperature) then the ratio of the end products will not be changed in any way. If, however, we add to the original mixture a catalyst which specifically increases, by perhaps a million times, the rate of the reaction $\mathrm{A} \rightarrow \mathrm{D}$ alone and does not alter the rates of the reactions $A \rightarrow B$ and $A \rightarrow C$, the effect produced will be quite different. Under these circumstances substance $A$ will be converted almost entirely to substance D while B and C will be present in barely perceptible or imperceptible traces.

The substance D which is formed in this way, like substance A or any other organic compound, has many chemical potentialities and also follows the fastest course in its chemical transformations. The compound $\mathrm{N}$ which is formed from it may similarly form the starting point for further chemical transformations. In this way there arises a chain of successive reactions, related to one another in time, the co-ordination of which is based upon the relative reaction velocities.

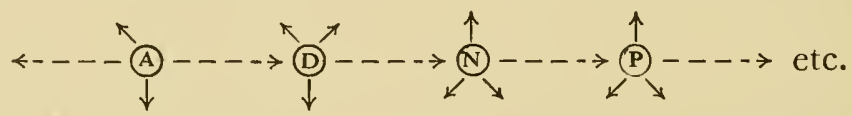

Such chains of successive transformations form the basis of biological metabolism, in particular the synthesis of the most complicated components of protoplasm. For example, as we saw in Chapter $\mathrm{V}$, porphyrin is formed in living cells from the relatively simple compounds glycine and succinic acid. This, however, can only occur as a result of a long series of strictly co-ordinated chemical transformations. First the succinic acid forms succinyl coenzyme A, by means of which it condenses with the $\alpha$-carbon atom of glycine. This reaction gives rise to $\alpha$-amino- $\beta$-oxoadipic acid, which is converted to 
$\delta$-aminolaevulinic acid by decarboxylation. Two molecules of the latter condense to form porphobilinogen and four molecules of porphobilinogen give a porphyrin structure which forms protoporphyrin by decarboxylation and dehydrogenation of the side chains. ${ }^{78}$

Each link in this chain of chemical transformations requires the participation of specific catalysts, enzymes. It is only because of this that each product of a preceding reaction enters into the proper succeeding reaction in the chain and does not wander off into the many other reactions which are thermodynamically possible for it.

\section{The initial systems from which living things arose.}

Something similar to this series of chemical reactions must have taken place in the hydrosphere leading up to the primary syntheses of porphyrins and other complicated organic compounds. The nature of these chains of reactions of complicated organic substances which preceded the appearance of life is therefore very important in connection with our problem.

It may now be taken as an established fact that in such simple reactions occurring in the gaseous phase as the oxidation of the lower hydrocarbons or other similar reactions which took place in the primaeval atmosphere, an essential part was played by the free radicals which were initially brought into being by the action of radiations or electric discharges and perpetuated in the course of chain reactions. For example, the passage of an electric discharge through water vapour leads to the formation of hydroxyl radicals which can oxidise hydrocarbons according to the following scheme $\mathrm{e}^{79}$ :

$\mathrm{H}_{2} \mathrm{O}-\ldots--\rightarrow \mathrm{OH}+\mathrm{H}$ the initiation of the chain $\left.\begin{array}{l}\mathrm{M}_{1}+\mathrm{OH}----\rightarrow \mathrm{H}_{2} \mathrm{O}+\mathrm{R} \\ \mathrm{R}+\mathrm{O}_{2}----\rightarrow \mathrm{M}_{2}+\mathrm{OH} \text { etc. }\end{array}\right\}$ the continuation of the chain a particular example is:

$$
\begin{aligned}
& \mathrm{CH}_{4}+\mathrm{OH}----\rightarrow \mathrm{CH}_{3}+\mathrm{H}_{2} \mathrm{O} \\
& \mathrm{CH}_{3}+\mathrm{O}_{2}-----\rightarrow \mathrm{HCHO}+\mathrm{OH} \text { etc. }
\end{aligned}
$$


Thus, it is a peculiarity of chain reactions that a large number of short cycles of reactions can be carried out by means of alternating active foci, free atoms or elements, when the sequence of cycles is initiated by a reaction giving rise to any of the active particles. At the end of each elementary cycle there are just the same number of free radicals as there were at the beginning, which constitutes the essential conditions for the perpetuation of the chain. If a larger number of radicals is formed at the end of the cycle than were present at the beginning, there will be a branching of the chains, the number of elementary cycles will increase with a coefficient of multiplication of $\mathrm{K}_{\mathrm{m}}$ and the rate of progress will quickly increase. Conversely, if the number of radicals is less at the end of the cycle than at the beginning, the chains will be broken and the reaction will get slower or stop.

Unlike the chain reactions based on ions or radicals, the biologically important elementary cycles based on catalysis arise in another way. According to the most generally accepted theory of contact catalysis the reaction occurs directly between adsorbed molecules and either leads straight to the formation of the final products or first to the formation of an intermediate compound. This then breaks down to form the final product of the reaction, leaving the original molecule of the catalyst (e.g. the enzyme) free.

It is true that $N$. Semenov ${ }^{80}$ has recently suggested that heterogeneous catalytic reactions are also based on an intermediate ionic or radical mechanism, but, however this may be, the elementary cycles of catalysis end with the formation of thermodynamically stable molecules, and not with that of free radicals like chain reactions. We must here lay special stress on the fact that the chain reactions which form the basis for biological metabolism are different in principle from the chain reactions described above, which undoubtedly played an important part in the early stages of the evolution of organic substances. The separate links in biological chains are not free radicals but stable molecules, the transformation of which takes place, in the great majority of cases, without the regeneration of one or more of the original components, while the products arising as a result of one reaction enter into a new chemical transformation, which is different from 
the preceding one. Thus biological chains are formed of different links succeeding one another in a definite sequence of different reactions and do not consist of a continual repetition of one and the same chemical act, as do the chain reactions of free radicals. This may be illustrated by the example of the biosynthesis of porphyrin which we have already adduced, or by alcoholic fermentation, in the course of which a molecule of sugar successively enters into reactions of phosphorylation, enolisation, the breakdown of the carbon chain, oxido-reduction, decarboxylation, etc., giving rise to new products each time, right up to the final products, carbon dioxide and alcohol, which are discharged from the cell into the external medium.

Biological chains of chemical transformations may branch, but this phenomenon is fundamentally different from the branching of chain reactions (of the radical or ionic type) based on an increase in the number of radicals formed and hence an increase in the number of identical cycles of reactions. The branching of biological chains, on the other hand, consists in the occurrence of reactions going in different directions. For example, in a chain of transformations of organic acids, fumaric acid may give rise to succinic acid but it may also be converted to aspartic acid ${ }^{81}$ : Pyruvic acid $\rightarrow$ $\rightarrow{ }^{\nearrow}$ aspartic acid $\searrow$ succinic acid. After a long series of reactions biological chains may join up to form cycles, (e.g. the tricarboxylic acid cycle of Krebs, which we discuss in more detail below) but these cycles have nothing in common with the elementary cycles of chain reactions. They are always associated with irreversible branchings and therefore biological metabolism as a whole always proceeds in the same direction ${ }^{82}$ and is a flowing system such as those described during our discussion of open systems.

This difference in principle between radical chain reactions and biological chains must be kept in mind because there have recently appeared in the scientific literature attempts to explain the origin of the organisation of proto- 
plasm in time on the basis of its derivation from the ordinary chain mechanism.

As an example of this we may cite N. Akulov's book The theory of chain processes, ${ }^{83}$ a quarter of which is devoted to our problem. The theoretical merit of this part of the book lies in the adoption of a kinetic approach to the problems of the evolution of chemical forms of the movement of matter rather than a simplified explanation of this evolution in terms of increasing complexity of structure. Akulov's factual working out of the problem cannot, however, be held to be successful for, instead of the chains of chemical transformations of different molecules, each of which is thermodynamically stable, such as are characteristic of metabolism, he refers to the chain reactions of radicals which are different in principle, in which there is a 'multiplication' of identical cycles such as is found in chain reactions in gases. Also, in Akulov's scheme, the co-ordination of reactions in time and space is supposed to be able to exist, in principle, even in a homogeneous solution, whereas the organisation of protoplasm corresponds more nearly to the sequence of chemical reactions which takes place in an open stationary system. This requires heterogeneity and the presence of a structure which secures a definite distribution of the components of the system and demarcation of the system from the external medium.

A more reasonable outlook on the course of development of 'prebiological' organic chemical processes has been suggested by J. W. S. Pringle. ${ }^{34}$ Like Akulov, Pringle starts from chain reactions of radicals. But as it is quite evident to him that such chain reactions do not occur in contemporary organisms, he assigns a part to them only in the early stages of the evolutionary process. He considers that what characterises living things is a series of reactions in which the entropy of the system is decreased at the expense of an increase of entropy in the external medium.

According to Pringle such a localised decrease in entropy depends on the carrying out of autocatalytic reactions in living systems. However, he uses the term 'autocatalysis' (only for lack of a better one) not in the usual sense (meaning that each molecule of protein or nucleic acid gives rise directly to another just like itself) but to refer to a dynamic 
continuity in the evolution of the whole living system. In this connection it is easy to understand Hinshelwood's point of view on our problem. He states that the processes of autosynthesis do not occur by the isolated self-reproduction of cellular structures but arise as a result of the co-ordinated interaction of all the cellular processes. Hinshelwood therefore refers very sceptically to the theory that the gene is endorved with a 'mystical ability to reproduce itself'.

Concentrating on the dynamic aspect of the problem, Pringle devotes his paper essentially only to a study of the possibility of the development of organisation in time in open systems. Pringle discusses their organisation in space very vaguely. He bases his ideas on the materialistic approach of A. M. Turing ${ }^{85}$ whose computations showed that some kinds of dynamic systems which were originally homogeneous could undergo such progressive modification that they became heterogeneous, the dissolved substances being concentrated locally without invoking adsorption on pre-existing particles.

Hence, in a completely homogeneous system it is hard to predict the site where local concentrations will occur, because this is determined by random oscillations and the rates of different reactions. Such a system would be unstable in respect of these local concentrations and would tend to stabilise itself, and this offers a mechanism for the formation of structures where there were none before. If there is any initial heterogeneity it may provide a focus for morphogenesis. However, according to Pringle such a morphogenetic process demands the complete absence of turbulence in the waters of the ocean and can therefore only take place at great depths.

Thus, in Pringle's view, the open system as it first arose had no real boundaries and merely consisted of local increases in the concentration of reacting substances at some points in the primaeval ocean.

M. Yčas ${ }^{86}$ goes even further in this direction in his observations on the origin of life. He gives a rather interesting diagram of the interaction of catalytic cycles, according to which a product of a reaction in cycle $\mathrm{A}$ increases the limiting rate of a reaction in cycle $\mathrm{B}$ and, conversely, a product 
of a reaction in cycle $B$ increases a particular rate of a reaction in cycle $\mathrm{A}$ (Fig. 34 ).

As we see from the diagram, the boundaries of such an open system are no less than the surface separating the ocean from the atmosphere all over the world. And the author does indeed consider that in the first stage of evolution there were no discrete systems, there was only one living thing, the 'metabolising ocean'. If the problem is formulated in this way, however, one can hardly speak (as the author does) of any ' natural selection' of systems.

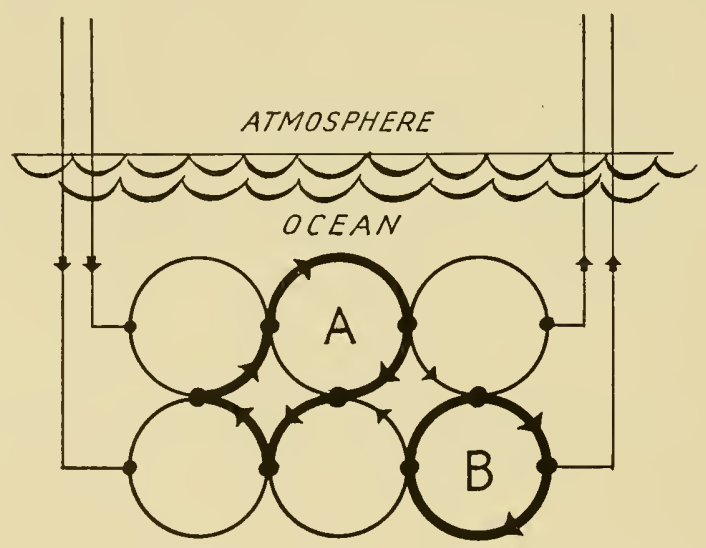

FiG. 34. Diagram of the interaction of catalytic cycles (after Yčas). Explanation in text.

The Japanese scientist M. Sugita ${ }^{87}$ takes an opposing view. He bases his approach to the problem of the origin of life on a study of thermodynamically irreversible reactions in open systems and holds that it is on the basis of these very processes that there must have occurred the formation of molecular swarms and fluctuations leading to the development of coacervate structures.

As we saw on p. 326 , any open system must have definite boundaries separating it from the external medium, which are represented in the scheme given by dotted lines. This is necessary because if any form of energy is to be made to do useful work there must be a spatial separation of the components of the system, and this is determined by its structural 
organisation. Without any such organisation, within a simple homogeneous solution, the free chemical energy which is liberated by the reacting substances could only be distributed in the form of heat and would be dissipated uselessly. Therefore an open system which can do work can only exist when the components are separated from one another in space within the framework of a definite structure.

Any system which could serve as a starting point for the evolution of matter on the way to the origin of life must have been based on the principles of organisation in space and time which characterise all living things without exception. As we saw above, this condition is fulfilled by a drop of a complex coacervate formed of polypeptides, polynucleotides and other substances of high molecular weight and having the properties of an open system with its characteristic network of reactions which are interdependent in time.

We cannot, however, rightly regard a system of this kind as being already alive. Only by a process of progressive evolution could the simplest living bodies arise from it.

\section{BIBLIOGRAPHY TO CHAPTER VII}

1. A. Kossel. Hoppe-Seyl. Z., 22, 176 (1896).

F. W. Tiebackx. Kolloidzschr., 8, 198 (1911).

2. W. Ostwald and R. KöhLER. Kolloidzschr., 43, 131 (1927).

3. H. G. Bungenberg de Jong. Protoplasma, 15, 110 (1932).

4. G. Gavoret and J. Duclaux. J. Chim. phys., 42, 41 (1945).

H. R. Kruyt (ed.). Colloid Science, Vol. 2. Amsterdam, 1949.

Sadhan Basu and Gurucharan Bhattacharia. Science, il 5 , 544 (1952).

5. H. G. Bungenberg de Jong and J. M. F. Landsmeer. Rec. Trav. chim. Pays-Bas, 65, 6o6 (1946); Proc. Acad. Sci., Amst., 5I, 295 (1948).

6. H. Pirenne. Rev. univ. Min., I3, 227 (1937). Through Chem. Abstr., 3I, 4872 (1937).

7. H. G. Bungenberg De Jong and K. C. Winkler. Z. anorg. Chem., 232, 119 (1937).

8. N. E. Prikhid'ko and V. S. Molchanov. Kolloid. Zhur., r3, $45^{\circ}\left(195^{1}\right)$. 
9. Z. A. Rogovin and N. A. Tsaplina. Kolloid. Zhur., 6, 449 (1940).

10. H. G. Bungenberg de Jong. Proc. Acad. Sci., Amst., 50, 707

11. (III. $5^{8)}$. (1947).

12. S. PAPkov. Kolloid. Zhur., 18, 72 (1956).

13. H. G. Bungenberg DE Jong. La coacervation, les coacervats et leur importance en biologie. (Actualités sci. industr., no. 398). Paris, 1936.

14. A. TAGER. Rastvory vysokomolekulyarnykh soedineniž. Moscow (Goskhimizdat), 1951.

15. G. Galeotti. Hoppe-Seyl.Z., 40, 492 (1904).

16. H. Chick and C. J. Martin. J. Physiol., 40, 404 (1910); 43, 1 (1911); 45, 61, 261 (1912); Biochem. J., 7, 380 (1913).

17. S. Papkov, Z. A. Rogovin and V. A. Kargin. Zhur. fiz. Khim., Io, 156 (1937).

S. Papkov, V. A. Kargin and Z. A. Rogovin. Zhur. fiz. Khim., I0, 607 (1937).

Z. A. Rogovin, V. A. Kargin and S. Papkov. Zhur. fiz. Khim., Io, 793 (1937).

V. A. Kargin, S. Papkov and Z. A. Rogovin. Zhur. fiz. Khim., I3, 206 (1939).

A. TAger and V. A. Kargin. Zhur. fiz. Khim., I5, 1029 (1941).

18. T. B. Osborne and E. Strauss in Handbuch der biologischen Arbeitsmethoden (ed. E. Abderhalden). Abt. I, Teil 8, p. 383 . Berlin and Vienna, 1922.

19. W. Bladergroen. Physikalische Chemie in Medizin und Biologie. Basel, 1945 .

20. H. G. BungenberG DE Jong. Kolloidzschr., 8o, 221 (1937).

21. H. L. Booij, C. J. Vogelsang and J. C. Lycklama. Proc. Acad. Sci., Amst., 53, 59 (1950).

H. L. Booij and D. VReugdenhil. Proc. Acad. Sci., Amst., 53, 299 (1950).

H. L. Booij, J. C. Lycklama and C. J. Vogelsang. Proc. Acad. Sci., Amst., 53, 407 (1950).

H. L. Booij, C. J. Vogelsang and J. C. Lycklama. Proc. Acad. Sci., Amst., 53, 882 (1950).

H. L. Boolj and E. S. van Calcar. Proc. Acad. Sci., Amst., 53, $1169(1950)$.

H. L. Booij, J. C. Lycklama and C. J. Vogelsang. Proc. Acad. Sci., Amst., 53, 1413 (1950). 
22. A. S. Troshin. Byull. eksp. Biol. Med., 3I, 180 (1951).

23. D. G. Dervichian. Research, Lond., 2, 210 (1949).

24. D. Dervichian and C. Magnant. Bull. Soc. Chim. biol., Paris, 27, 10 I (1945).

25. W. Ostwald and R. H. Hertel. Kolloidzschr., 47, 258, 357 (1929).

W. Ostwald. Kolloidzschr., 49,60 (1929).

26. P. Koets. J. phys. Ghem., 4o, 1191 (1936).

27. (VII. 23).

28. A. I. Oparin, T. N. Evreinova, T. A. Shubert and M. N. Nestyuk. Doklady Akad. Nauk S.S.S.R., Iof, 581 (1955).

T. N. Evreinova, T. A. Shubert and M. N. Nestyuk. Doklady Akad. Nauk S.S.S.R., 105, 137 (1955).

29. A. I. Oparin and T. N. Evreinova in Noyye dannye po probleme razvitiya kletochnykh i nekletochnykh form zhivogo veshchestva. Trudy Konferentsii Akad. med. Nauk S.S.S.R., p. 231. Moscow (Medgiz), 1954.

3o. T. N. Evreinova and N. V. Korolev. Doklady Akad. Nauk S.S.S.R., 87, $105\left(195^{2}\right)$.

T. N. Evreinova. Biofizika, $I, 167$ (1956).

31. A. A. Horvath. Chem. \& Ind., 1937, 735.

32. H. G. Bungenberg de Jong and A. de Bakker. Proc. Acad. Sci., Amst., 58B, 331 (1955).

33. A. I. Oparin, M. S. Bardinskaya, S. S. Melik-Sarkisyan and K. B. Serebrovskaya. Doklady Akad. Nauk S.S.S.R., IOS, $1125\left(195^{6}\right)$.

34. G. A. Deborin and L. B. Gorbacheva. Biokhimiya, is, 618 (1953).

35. T. N. Evreinova, Uspekhi sovremennol Biol., 37, 177 (1954). 36. H. L. Boorj. Rec. Trav. bot. néerl., 37, 1 (1940).

K. G. A. Pankhurst in Surface chemistry, p. 109. Special supplement to Research. London, 1949 .

37. (VII. 13).

38. A. Frey-Wissling. Submicroscopic morphology of protoplasm and its derivatives (trans. J. J. Hermans and M. Hollander). Amsterdam, $194^{8}$.

39. A. Frey-Wissling. Die submikroskopische Struktur des Cytoplasmas. Protoplasmatologia (ed. L. V. Heilbrunn and F. Weber). Vol. II/A/2. Vienna, 1955.

40. L. V. Heilbrunn. Amer. Nat., 60, 143 (1926). 
41. D. Sabinin. Fiziologischeskie osnovy pitaniya rastenir. Moscow (Izd. AN SSSR), 1955.

42. C. Nägeli and C. Kramer. Pflanzenphysiologische Untersuchungen. Zürich, 1855 .

43. W. KüHNE. Untersuchungen über das Protoplasma und die Contractilität. Leipzig, 1864.

44. W. Pfeffer. Osmotische Untersuchungen. Leipzig, 1877.

45. L. V. Heilbrunn. The colloid chemistry of protoplasm in Protoplasma-Monographien, Vol. 1. Berlin, 1928.

46. W. W. Lepeschinin. Protoplasma, 33, 1 (1939).

47. W. Seifriz. Advanc. Enzymol., 7, 35 (1947).

48. D. Sabinin. Mineral'noe pitanie rastenit. Moscow and Leningrad (Izd. AN SSSR), 1940.

49. D. Nasonov and V. Aleksandrov. Reaktsiya zhivogo veshchestva na vneshnie vozdeřstviya. Moscow and Leningrad (Izd. AN SSSR), 1940.

50. A. Guilliermond. The cytoplasm of the plant cell (trans. L. R. Atkinson). Waltham, Mass., 1941.

P. Makarov. Preface to Tsitologiya rastenil $i$ obshchaya tsitologiya by P. Danzhar (Pierre Dangeard). Moscow (IL), $195^{\circ}$.

51. A. S. Troshin. Problema kletochnol pronitsaemosti. Moscow and Leningrad (Izd. AN SSSR), $195^{6}$.

52. P. Rebinder and K. Pospelova. Introductory paper in Emulsii by V. Kley̌ton (W. Clayton). Moscow (IL), $195^{\circ}$.

53. H. G. Bungenberg de Jong and C. Mallee. Proc. Acad. Sci., Amst., 56B, 203 (1953).

H. G. Bungenberg de Jong, C. R. van Someren and F. Klein. Proc. Acad.Sci., Amst., 57B, 1 (1954).

54. M. A. Lauffer and W. M. Stanley. J. biol. Chem., I23, 507 (1938).

55. H. G. Bungenberg de Jong. Proc. Acad. Sci., Amst., $3^{8,}$ 426 (1935).

56. H. G. Bungenberg de Jong and H. J. C. Sengers. Rec. Trav. chim. Pays-Bas, 53, 171 (1934).

57. H. G. Bungenberg de Jong and J. L. L. F. Hartkamp. Rec. Trav. chim. Pays-Bas, 53, 622 (1934).

H. G. Bungenberg de Jong and O. Bank. Protoplasma, 33 , 321,512 (1939); 34, 1 (1940).

H. G. Bungenberg de Jong and A. de HaAn. Biochem. Z., 263, 33 (1933).

58. H. G. Bungenberg de Jong, O. Bank and E. G. Hoskam. Protoplasma, 34, 30 (1940). 
59. I. N. Sveshnikova. Doklady Akad. Nauk S.S.S.R., 84, 797 $\left(195^{2}\right)$.

6o. N. L. Fel'dian. Doklady Akad. Nauk S.S.S.R., 74, 1139 (1950); 89, 343 (1953).

61. D. Sabinin. Tezisy dokladov soveshchaniya po fiziologii rastenit. Noscow and Leningrad (Izd. AN SSSR), 1940.

62. D. Nasonov. Foreword to (VII. 51).

63. A. S. Troshin. (VII. 22).

64. A. Kriss. Personal communication.

65. Heraclitus of Ephesus. Fragments. See books cited in (VI. 118 ).

66. R. Schoenheiner. The dynamic state of body constituents. Cambridge, Mass., 1942.

67. I. Michurin. Sochineniya (and edn.). Moscow (Sel'khozgiz), 1948.

T. Lysenko. Agrobiologiya (5 th edn.). Moscow (Sel'khozgiz), 1948.

68. (III. 75).

69. K. G. Denbigh. The thermodynamics of the steady state. London and New York, $195^{1 .}$

7o. R. B. Parlin, R. J. Marcus and H. Eyring. Proc. nat. Acad. Sci., Wash., fI, goo (1955).

71. A. C. Burton. J. cell. comp. Physiol., If, 327 (1939).

72. K. G. Denbigh, M. Hicks and F. M. Page. Trans. Farad. Soc., 44, 479 (1948).

73. A. G. Pasynskil and V. P. Blokhina. Biokhimiya, 2I, 826 $(1956)$.

74. (III. 74).

75. A. C. R. Dean and C. N. Hinshelwood. Progress in Biophysics, 5, 1 (1955).

76. A. G. Pasrinskil̆. Uspekhi souremennol Biol. (In press.)

77. A. I. Oparin. Article 'Zhizn' (Life) in Bol'shaya Sovetskaya Entsiklopediya (and edn.). Vol. 16, p. 139.

78. D. Shemin. Conférences et Rapports. 3-ème Congrès international de Biochimie, Bruxelles, I-6 Août 1955, p. 197. Liège, 1956 .

79. A. B. Nalbanyan and N. M. Emanuel (ed.). Kinetika tsepnykh reakstir okisleniya (Collection of papers). Moscow and Leningrad (Izd. AN SSSR), $195^{\circ}$.

8o. N. Semenov. O nekotorykh problemakh khimicheskol kinetiki i reaktsionnol sposobnosti. Chapter 9. Moscow (Izd. AN SSSR), 1954.

81. V. L. Kretovich. Osnovy biokhimii rasteniu. Moscow (Sovetskaya Nauka), $195^{6}$. 
82. N. Sisakyan. Biokhimiya obmena veshchestv. Moscow (Izd. AN SSSR), 1954.

83. N. Akulov. Teoriya tsepnykh protsessov. Moscow (Gos. Izd. tekhnoteoreticheskoì Literatury), 1951.

84. J. W. S. Pringle. Symp. Soc. exp. Biol., 7, 1 (1953).

85. A. M. Turing. Phil. Trans., 237B, 37 (1952).

86. M. YčAs. Proc. nat. Acad. Sci., Wash., 4I, 714 (1955).

87. M. Sugita. Kobayasi Institute of Physical Research : Bulletin, 5, 171 (1955). 
THE ORIGIN OF THE FIRST ORGANISMS

\section{The evolution of the initial systems.}

Anyone looking at nature around him will, almost unerringly, divide it into the world of the lifeless and inorganic, and the world of living things. The world of living things is made up of a tremendous variety of animals, plants and microbes which are widely different from one another. Nevertheless, among all this diversity, even a person without scientific experience will notice something common to all living things, something which relates them to one another and distinguishes even the very simplest organism from objects belonging to the inorganic world. This direct, and sometimes even unconscious, assumption of the ordinary man concerning the world around him itself contains the most primitive as well as the most general definition of life.

The age-long philosophical quarrels and acrimonious differences of opinion on this subject are fundamentally simply concerned with the question as to what is the essence of this 'something'-the essence of life. The idealists see it as something spiritual, the essential nature of which is inaccessible to experimental study, while, according to the materialists, life, like everything else in the world, is material in nature and an explanation of it does not call for the acknowledgement of anything supernatural.

Quite large numbers of scientists now take the view that an understanding of life in general involves no more than a very thorough knowledge of physics and chemistry and a very thorough explanation of all vital phenomena in terms of physical and chemical processes. According to this view there are no specifically biological laws, and the rules which prevail in the inorganic world also govern all the phenomena 
taking place in living organisms. But this amounts to denying all the essential differences between organisms and the objects of the inorganic world, which is fundamentally unsound. Certainly life is material in nature, but it is not inherent in every sort of material. It is a manifestation of a special form of motion which we only find in organisms and which is absent from the objects of the inorganic world. This form of the motion of matter, in addition to obeying the general physical and chemical laws, also has its own specific laws. If one is to understand life it is therefore important to take into account these qualitative differences from other forms of motion.

Outstanding scientists and thinkers of past centuries and of the present time have formulated numerous definitions of life which, to a greater or lesser extent, indicate what is specific to it.

We cannot discuss all these definitions in any detail and shall here confine ourselves to one which was given by $\mathrm{F}$. Engels as early as the end of the nineteenth century but which still remains extremely pertinent. "Life is the mode of existence of albuminous substances and this mode of existence essentially consists in the constant self-renewal of the chemical constituents of these substances."

Thus Engels characterises albuminous substances as the material bearers of life, and metabolism as their essential function; from this all the rest of the most general attributes of life may be derived. In doing so we must not, as was pointed out in Chapter VI, identify the "albuminous substances' referred to by Engels with the individual proteins which can now be isolated from living organisms.

Nevertheless, such unjustifiable identification has formed the basis of several attempts in the recent literature ${ }^{2}$ to interpret as metabolism the reactions observed by a number of authors, ${ }^{3}$ in which amino acids containing isotopically labelled atoms are incorporated into isolated proteins, sometimes involving the substitution of amino acid radicals within the protein molecule. Such an interpretation clearly derives from a confusion between two completely different concepts : (1) biological metabolism in the sense which was described in the previous chapter, i.e. the orderly sequence of processes 
which seems to be the prerequisite for the existence of any living thing, and (2) 'exchange reactions' or substitution reactions in the purely chemical sense, i.e. phenomena in the course of which two molecules of organic substances or even inorganic salts exchange their atomic groups, e.g.:

$$
\mathrm{CH}_{3} \mathrm{COOC}_{2} \mathrm{H}_{5}+\mathrm{HOC}_{5} \mathrm{H}_{11} \rightleftharpoons \mathrm{CH}_{3} \mathrm{COOC}_{5} \mathrm{H}_{11}+\mathrm{HOC}_{2} \mathrm{H}_{5}
$$

Undoubtedly the molecules of any protein, with their extensive chemical potentialities, can take part in such substitution reactions, but, unlike biological metabolism, these reactions are certainly not absolutely necessary to the existence of the protein molecule. It is well known that individual proteins isolated from living things can be kept under suitable conditions in the native state without any such reactions taking place, while an increase in their ability to enter into such reactions may be an indication of denaturation of the protein. ${ }^{4}$

In contrast to this, metabolism is certainly a necessary condition for the existence of protoplasm or "albuminous substances' in the sense in which Engels understood the term.

Engels wrote ${ }^{5}$ :

From the moment when this uninterrupted metamorphosis of its constituents, this constant alternation of nutrition and excretion, no longer takes place in an albuminous body, from that moment the albuminous body itself comes to an end and decomposes, that is, dies.

As we said in the preceding chapter, it follows from the very theory of open systems ${ }^{6}$ that the continuous renewal of the component parts is a necessary condition for the existence of such systems; that as soon as the flow of water from the tap, or, in the hydrodynamic model, the admission of water, ceases then the system itself immediately ceases to exist as such. Similar considerations apply to any chemical open system.

\section{The principle of selection.}

However, living things differ fundamentally from all such open systems in the orderly regulation of their metabolism 
and the 'purposefulness' of their internal structure. Not only are the many tens and hundreds of thousands of chemical reactions which occur in protoplasm, and which together constitute its metabolism, strictly co-ordinated with one another in time, harmoniously composed into a single series of processes which constantly repeat themselves, but the whole series is directed towards a single goal, towards the uninterrupted self-preservation and self-reproduction of the living system as a whole in accordance with the conditions of the surrounding medium.

Here the term 'purposefulness' should, of course, not be taken in an idealist sense as the "fulfilment of some higher design '. The word is used to denote the appropriateness of the organisation of the whole system to its self-preservation and self-reproduction, and also to denote adaptation of the structure of its separate parts to the most efficient and co-ordinated fulfilment of those functions necessary to life which these parts subserve in the system as a whole.

The high degree of adaptation of the separate organs to the carrying out of their functions and the general " purposefulness' of the whole organisation are extremely evident even from a superficial knowledge of higher living things. They were noticed by mankind a very long time ago and were expressed by the 'entelechy' of Aristotle. The essential nature of this purposefulness appeared to be mystical and supernatural until Darwin gave a rational and materialistic explanation of the way in which this 'purposefulness' could arise as a result of natural selection.

However, 'purposefulness ' of structure is not confined to higher beings, it extends downwards through the whole world of living things, right to the bottom, to the most elementary forms of life. It is essential for any living body but is absent from the objects of the inorganic world. The only exceptions are machines, but the purposefulness of their structure, their adaptation to the performance of particular tasks, is determined by the creative intention of those who build them. Machines cannot arise of their own accord by purely physical and chemical means. It is therefore pointless to seek an explanation of them in purely physical and chemical terms. The origin of the organisation of protoplasm 
which characterises living organisms, biological metabolism, is understandable only on the basis of the same principles which govern the origin of the 'purposefulness' of the structure of higher organisms, that is to say, on the basis of the interaction between the organism and the environment and on the basis of the Darwinian principle of natural selection. This new biological law arose during the actual process of the establishment of life and later took a leading part in the development of all living matter.

But can this law be applied to any system other than the living organism? As we have already seen (cf. p. 261) the attempt to apply the principle of natural selection to the evolution of separate molecules cannot be held to be satisfactory. However, we shall adopt a different approach if we try to imagine the possibility of the evolution of those systems which we postulated in the previous chapter as being the starting point on the road to the development of living systems, that is, to the evolution of the drops of complex coacervates which have the properties of open systems and the network of interdependent reactions characteristic of such systems.

In the very origin of such individual multimolecular formations there was already inherent the necessity for their further progressive development. During the time when organic material was completely merged with its environment, while it was dissolved in the waters of the primaeval seas and oceans, its evolution could be considered as a whole. However, as soon as it became concentrated at definite points, in colloidal multimolecular systems, as soon as these formations became separated from the surrounding medium by a more or less clearly defined boundary and attained a certain individuality, new and more complicated conditions were at once created. The later history of any individual coacervate drop might differ substantially from that of another coexistent system. The fate of such a drop depended not only on the general conditions of the external medium, but also on the specific internal organisation in space and time of the system in question. The details of this organisation were peculiar to the particular drop and may have been somewhat different 
in other drops, each system having its own characteristic peculiarities.

What were the conditions which determined the existence of any coacervate drop in the waters of the primaeval hydrosphere? Complex coacervates obtained artificially, by simply mixing solutions of two differently charged colloids, are, as we have seen, formations with a static stability. The greater or less duration of their existence is determined by the conditions of solubility or the presence of surface membranes and is associated with the maintenance of the constancy of the properties of the system in time.

Thus, in such a coacervate drop, the slower any particular change takes place and the more constant the surrounding medium remains, the greater will be the stability of the system and the less its chance of disappearing as an individual formation during the time it is under observation under the conditions of a laboratory experiment.

This, however, was not the sort of stability manifested by the systems which played the decisive part in the evolution of matter on the way to the origin of life. This evolution could only proceed on the basis of interaction between the systems and the external medium in contact with them, i.e. on the basis of the formation of open systems. We must remember that the coacervate drops, which arose somehow in the primaeval hydrosphere, were immersed, not simply in water, but in a solution of various organic compounds and inorganic salts which were certainly capable of entering into the coacervate drop and interacting chemically with the substances of which it was composed. If we do so it will be clear to us that under these conditions the stability of the drop could not retain its static nature. The drop would, to some extent, assume the character of an open system.

This would occur specially readily when the actual formation of the drop was based on a previous chemical organisation in time like that postulated by M. Sugita. ${ }^{7}$ However, let us suppose that the drop arose under purely colloidal conditions, that the whole process of its formation resulted simply from the concentration of protein-like substances and others of high molecular weight at a definite place, and from the formation of a surface membrane separating 
the collection of these substances from the external medium. Even so the molecules of the external medium must have passed selectively through the surface membrane of the drop or been adsorbed selectively by the compounds contained in it and reacted with them in one way or another, the products of the reaction either being retained within the drop or passing out of it back into the external medium. Although these reactions took place very slowly and did not form an interacting network of processes, and although the conditions necessary for the prolonged existence and stability of the coacervate drop were still not present, nevertheless, even at this primitive stage of evolution of our original systems two circumstances were manifest which were of great importance for the further development of matter.

On the one hand the individual peculiarities of the physico-chemical organisation of each separate coacervate drop imposed a definite pattern on the chemical reactions which took place within that drop. The presence in a given drop of this or that compound or radical, the presence or absence of simple inorganic catalysts such as salts of iron, copper, calcium, etc., the degree of concentration of protein-like substances and other substances of high molecular weight forming the coacervate, its particular structure, all these affected the rate and direction of the various chemical reactions which occurred within the given drop, all these imparted a specific character to the chemical processes which took place within it. Thus there appeared a certain connection between the individual structure and organisation of a given drop and the character of the chemical transformation carried out within it. In other drops these transformations occurred and were co-ordinated in different ways, depending on the peculiarities of each particular drop.

On the other hand, any chemical processes, even uncoordinated ones, occurring within a drop, and, even more, any connected group of processes, could not be without effect on its future. Some of them led to greater stability, to a more prolonged existence of the coacervate system under the conditions prevailing in the external medium.

From this point of view they were advantageous, they were of positive significance. On the other hand, other processes 
and groups of processes were of a negative character, they were inimical to the particular individual formation, leading to its dissolution, to the disappearance of the drop in which they arose.

However, such coacervate systems cannot have played any essential part in the further evolution of organic formations as their individual history was short and quickly brought to a close. The only systems which maintained themselves in existence for a more or less prolonged period under the conditions prevailing in the external medium were those which had an individual organisation based on chemical reactions which were favourable for their existence.

Thus, even at this stage of the evolution of matter there appeared a certain 'selection' of organised colloidal systems on the basis of the suitability of their organisation to the function of preserving the uninterrupted interaction of the system and the surrounding medium under given circumstances. This 'selection' was, of course, of a very primitive kind and not directly to be compared with fully developed 'natural selection' in the strictly biological sense of the term. Nevertheless the further evolution of organic systems was controlled by 'selection' of this sort and thus acquired a definite direction.

\section{Processes of self-renewal of the systems.}

In the first place this directed evolution led to an essential alteration in the character of the stability of the original colloidal systems. The stability of the coacervate drops which first arose in the waters of the hydrosphere may originally have been governed by the same static principles which govern the stability of coacervates of gelatin and gum arabic produced artificially in the laboratory.

The coacervate state and the organisation of the processes taking place within the drop may, to some extent, exist independently of one another. However, for reasons which have already been indicated, during the course of directed evolution these two aspects of the organisation must afterwards have become more and more unified within the single system, because the existence of the system depended on a 
network of reactions carried out within it while, conversely, the network was determined by the organisation of the system as a whole. If the system was not co-ordinated but, nevertheless, interacted with the external medium, it would very quickly disintegrate and disappear as an individual formation. If the interaction between the system and the medium stopped for any reason, then the system would become static and, as such, cease to take part in the general process of evolution.

For example, if the stability of the drop depended on the formation of strong surface layers and if these disintegrated spontaneously at a definite rate but could be built up again in the course of chemical reactions within the drop, then the stability of the drop would depend on the relative rates of disintegration and reconstruction of the surface layers. If the chemical reactions took place fast enough in the drop, with a corresponding fast rate of formation of the firm surface layers, then the dynamic stability of the drop might also be very great. In this case an increase in the rate of the chemical reactions within the drop would have favoured its stability. The increased rate of reaction within a drop would increase its stability, and prolong its survival under such conditions. If the rate of formation of the surface layers became less than the rate of their destruction such a drop would soon disintegrate. Finally, if the surface layers themselves were very strong and stable but not associated with any chemical reactions within the drop, then such static colloidal systems would be excluded from the course of the erolutionary process.

Accordingly, as a result of the clirected evolution of the original systems, their stability took on a more and more dynamic character. The coacervate drops were gradually transformed into open systems the very existence of which, under the given conditions of the external medium, depended on the organisation of the processes taking place within them. In other words, there arose systems in which there was a background of continuous processes of self-renewal and which could preserve themselves and exist for a long period on the basis of constant interaction with the external medium. The origin of this capacity for self-preservation may be regarded 
as the first result of the directed evolution of our original systems.

The origin of the capacity of the systems for self-preservation and growth.

The second step forward in the same direction was the emergence of systems which could not merely preserve themselves, but could also grow, increasing their mass by drawing substances from the external medium. As was pointed out in the previous chapter, the stationary state of open systems is maintained constant, not because the free energy of the system is at a minimum as in thermodynamic equilibrium, but because the system is continually receiving free energy from the surrounding medium in an amount which compensates for the expenditure of free energy within the system. In such chemical open systems as the coacervate drops of the primaeval ocean would seem to have been, the intake of free energy was mainly due to the entry into the drop of organic compounds which were relatively rich in energy and which underwent some sort of chemical reaction within the drop. When chemical reactions are taking place, however, closed and open systems differ from one another in that in the former equilibrium is characterised by the reaction occurring at the same rate in both directions so that, in the nature of things, there can be no increase in mass. In open systems in the stationary state, on the other hand, the rate of the reaction is considerably greater in one direction than in the other, and it follows that there may exist in them a coordination of processes leading to an increase in the mass of the system. Such systems enjoyed an undoubted advantage in the process of directed evolution and therefore, owing to the action of 'selection', they came to occupy a predominant position in the general extension of organised formations.

In the absence of any appropriate experiments, even with molels one cannot say anything definite about the nature of such growth in our original systems. They might have become larger in the form of uniform layers of coacervate, but they might also have become divided into separate drops. 
Drops of liquid having a limited mutual solubility or artificial static coacervates cannot divide themselves spontaneously. The forces of surface tension are always tending to make them coalesce and it is only the presence of surface membranes which, to some extent, prevents this from happening. However, as we know, dispersion of this sort may be achieved, even in such static systems, by means of external influences such as simple shaking, which may lead to emulsification.

The dispersion of the primaeval growing coacervate may also have occurred in this way. However, as these were of the nature of dynamic stationary systems the existence of which was bound up with the occurrence of processes within them, their dispersion may have been evoked by internal factors. It may, for instance, have occurred when the osmotic pressure, which was increasing rapidly owing to the hydrolysis of compounds of high molecular weight, became too great for the strength of the surface layer of the drop.

Thus, owing to the constant interaction of our original systems with their environment, there must have occurred a gradual increase in the amount of material organised in the systems. But as this increase always occurred under the influence of 'selection' the only systems which were preserved for further evolution were those which were most highly developed, so that the quality of this organisation was always changing in a particular direction. The systems did not merely become more dynamically stable, they also became more dynamic. We may regard this phenomenon as the third important step in the directed evolution of our original systems on the way to the development of life.

In the first stages of the evolution under consideration, when one could study the fate of isolated coacervate drops without taking into account their relation to other such drops, the factors which were of paramount importance for the prolonged existence of the drop in question as an open system, for its self-preservation under conditions of constant interchange with the surrounding medium, were the relative rates of the processes taking place within it and not the absolute values of these rates. 


\section{The origin of the highly dynamic state of the systems.}

The position is radically altered if we include in the field of our investigations not merely one, but several open systems, existing simultaneously within a particular medium. This may be shown even by working with relatively simple models. For example, when there are several hydrodynamic stationary systems with common initial and final reservoirs, ${ }^{8}$ the greater part of the water will proceed through the system which enables it to pass through most quickly. In the case of several parallel, chemical open systems with a common external medium it is obvious that the main flow of substances will pass through the system which, by virtue of its internal organisation (c.g. the presence of more efficient catalysts, etc.), provides the greatest over-all rate of chemical transformation. In this sense the chemical stationary system in which chemical processes occur fastest will have an advantage over other parallel chemical stationary systems so long as the increased rate of occurrence of the processes does not disturb the relationship of rates necessary for the selfpreservation of the system ; that is to say, if it is compatible with the prolonged existence of the particular open system. In this connection we must bear in mind what was pointed out in the previous chapter, namely that, where there is a complicated network of chemical reactions, the attainment of the maximal rate by a process involves not merely the acceleration of one of the stages of the transformation but the establishment of a more effective relationship between all the parameters of the process. ${ }^{9}$

From what has been said it is clear that a dynamically stable coacervate drop capable of self-preservation and growth, which had acquired the ability to transform substances more quickly during its interaction with the external medium, would have a significant advantage over other drops which were immersed in the same solution of inorganic and organic compounds but in which the characteristic chemical processes proceeded considerably more slowly. In the general mass of coacervates the relative proportion of such more dynamic drops would become greater and greater. There 
arose a special kind of competition among the drops, based on the speed with which reactions were accomplished within them and the rate of their growth. For this reason the principle of the greatest speed (which must, nevertheless, be compatible with the existence of the stationary system as such) was a very important factor in the directed evolution of organised formations.

\section{The origin of systems capable of reproducing themselves.}

It must, however, be pointed out that the capacity for self-preservation, and even for rapid growth, of the whole dynamic system did not imply the complete immutability of the system. On the contrary, the stationary drop of a coacervate, or any other open system, may be preserved as a whole for a certain time while changing continually in regard to both its composition and the network of processes taking place within it, always assuming that these changes do not disturb its dynamic stability.

Changes of this sort were, in fact, a necessary part of the process of the emergence of life for they guaranteed the evolution of the initial systems. Without these changes no new material would have been provided for selection and the further development of the systems would have been frozen and brought to a standstill at some point.

Naturally, it was of the utmost importance that these changes should not overstep the bounds of the dynamic stability of the systems. Otherwise any markedly unstable compounds which arose would be in constant danger of passing out of equilibrium and disappearing. Therefore, when there was rapid and massive growth of the original systems, selection took place, the only ones which were preserved for further evolution being those in which the network of reactions was so co-ordinated that there arose stationary chains of reactions which were constantly repeated or, even better, closed cycles of reactions* in which the reactions always followed the same

* Of course these cycles must not, as we have already mentioned in Chapter VII, be confused with the elementary cycles of chain reactions.-Author. 
circle and branching only occurred at definite points on the circle leading to the constantly repeated formation of this or that metabolic product. This constant repetition of connected reactions, co-ordinated in a single network, also led to the emergence of a property characteristic of living things, that of self-reproduction. This may be taken as the origin of life. At this stage in the evolution of matter natural selection assumed its full biological meaning and formed the basis for the faster elaboration of higher and higher degrees of adaptation of living organisms to the conditions under which they existed, of the exact correspondence of all the details of their internal structure to their vital functions. In other words, there appeared that striking 'purposefulness' of the structure of living bodies upon which we have already remarked.

The opinion is fairly widely held in contemporary scientific literature that the capacity for self-reproduction is to be found even in the chemical form of the motion of matter, that it can be a property of isolated molecules. Until comparatively recently many biologists regarded the constant formation of particular substances within the organism as being the result of the presence in the organism of readymade moulds for those particular substances. These moulds were supposed to 'multiply' in some way and thus be responsible for the constancy of the composition and structure of the organism and for its reproduction.

In particular this opinion was once very clearly expounded by $\mathrm{N}$. Kol'tsov. ${ }^{10} \mathrm{He}$ believed that the formation, not only of proteins, but also of other components of the living cell, such as chlorophyll and the anthocyanins, occurred because the protoplasm already contained corresponding molecules which acted as templates for their formation. These molecules 'multiplied' and thus exactly reproduced their own structures.

The factual evidence of contemporary biochemistry was, however, radically opposed to this opinion and revealed a completely different mechanism of biosynthesis based on the constancy of certain sequences of biochemical reactions. For example, butyric acid is formed by some species of bacteria, not because it was present in them beforehand, but because 
the sugar which is taken up from the surrounding medium by the bacterial cells is broken down to acetic acid by means of a series of strictly co-ordinated reactions. The acetic acid then combines with coenzyme A and is thus enabled to condense to form aceto-acetic acid which is then reduced to butyric acid. ${ }^{11}$

If the sequence of these reactions were somewhat different, the end products might be alcohol and carbon dioxide, as in yeast, or lactic acid, as in some bacteria. The same principle of the constancy of a definite sequence of reactions is also responsible for the synthesis of the higher fatty acids, amino acids $^{12}$ and a whole series of other compounds.

The chemical studies carried out 20 years ago by $R$. Robinson ${ }^{13}$ and the biological work of $\mathrm{R}$. Scott-Moncrieff ${ }^{14}$ showed that the anthocyanins mentioned above arise in the same way in plants as a result of the occurrence in them of a definite sequence of reactions of condensation, oxidoreduction, methylation, acetylation, etc. According to the order in which these reactions occur in the petals of different flowers, various derivatives of flavones and anthocyanins are formed, and the particular combinations in which these substances are present give the petals their characteristic colours.

A similar mechanism has also been discovered for the formation of various terpenes in plants from which essential oils are obtained. ${ }^{15}$ The terpenes appear in them as a result of sequences of reactions which are specifically determinate for each plant and include polymerisation, hydration, oxidation and ring formation. The same is true for the synthesis of tannins, ${ }^{16}$ alkaloids, ${ }^{17}$ vitamins ${ }^{18}$ and various porphyrin derivatives, chlorophyll in particular. ${ }^{19}$ Very detailed evidence has also been obtained recently concerning the biosynthesis of such extremely complicated and specific substances as antibiotics. ${ }^{20}$ Here also a definite sequence of chemical transformations is involved.

Thus lactic or butyric acids are formed in particular species of bacteria, nicotine in tobacco plants, tannin in tea leaves, vitamins in yeast cells and streptomycin in actinomycetes. not because pre-formed molecules of these substances were already present in the objects in question, but because, 
at a given stage in their life cycles, chemical transformations are carried out within them in a definite, co-ordinated sequence. The constancy of the formation of the substances is simply a manifestation of the constancy of the sequences of the reactions. Here there is no 'self-reproduction' of molecules in the literal sense of the term, no multiplication of them; here new molecules of exactly the same kind are repeatedly produced. The sequence of reactions on which this phenomenon is based does not depend on any single individual factor but is a manifestation of the whole organisation of the protoplasm in its relationship to its environment.

As we saw in Chapter VI, the biosynthesis of proteins constitutes no exception in this respect. Attempts to treat it as an autocatalytic process, in which one molecule of a given substance arises as a result of the catalytic activity of another of exactly the same sort which was already present, have recently proved a complete fiasco. The experiments of $\mathrm{A}$. Gierer and G. Schramm ${ }^{21}$ are particularly convincing in this connection. They showed that a single nucleic acid of tobacco mosaic virus completely freed from protein, when introduced into the plant, will evoke the formation in it of a specific protein which was not previously present in the plant. In this case there could be no question of any autocatalysis in the strictly chemical sense of the term. There was only definite co-ordinated interaction of all the processes of the cells of the tobacco leaf, which were somewhat altered in character by the introduction of a new factor, the viral nucleic acid. The nucleic acid as an individual substance, a compound considered in isolation, could certainly not synthesise a protein by itself. It is only effective against the general background of the whole metabolism of the tobacco plant, as is confirmed by all the evidence at present available. The harmonious participation of a long series of catalytic systems is required for the biosynthesis of proteins, some providing the energy needed for the synthesis, some determining the strictly regular and constant relationship between the rates of the different reactions and, finally, some systems which control the spatial organisation of the protein molecule in the process of its synthesis. Among these systems which determine the specific structure of the protein, nucleic acid plays 
a very important part, but it does not seem to be the sole determinant, it simply constitutes a part of the general organisation of the living system.

As has been pointed out above, nucleic acid itself also arises in the living organism in accordance with the same rules as the other components of the protoplasm, that is to say, on the basis of strictly co-ordinated, constantly repeated, catalytically induced exchange reactions. ${ }^{22}$

It is clear that no substance which forms a major component of protoplasm can be reproduced by a chance or easily attained relationship between the rates of reactions. It requires the absolutely constant, continually repeated chains and cycles of reactions which together comprise the network of the self-reproducing, living, open system. As we have seen above, the origin of such a system may be regarded, theoretically, as a result of the directed evolution of our original, dynamically stable, colloidal formations.

The living systems which were first formed already had all the features needed for their selection to be of the nature of purposeful 'natural selection' in the biological sense of the expression. Further improvements in their internal organisation, rationalisation of their metabolism, therefore, went forward at a faster pace. As a direct result of this, all intermediate forms of organisation were destroyed, swept from the face of the Earth by natural selection. This is why we have now no possibility of studying these forms directly and filling in, with factual material, the abyss which exists between the organisation of the original systems and the organisation of even the simplest of present-day organisms.

\section{The evolution of metabolism : the origin of enzymes.}

Experiments with models which reproduce the phenomena in dynamically stable colloidal formations may, perhaps, play an important part in this connection. Studies of this sort are, however, still only beginning to be made* and the

\footnotetext{
* In particular in the form of attempts to incorporate active preparations of enzymes in the coacervate drops with a view to conferring some dynamic character on the drops.-A Athor.
} 
results obtained from them are still very modest. Therefore, if we wish to formulate any sort of idea concerning the actual forms which developed during the course of evolution from the original systems to the first organisms, we must make as much use as possible of the data of comparative biochemistry (this is done more fully in the next chapter) and the results obtained from a study of the metabolism, or separate aspects of the metabolism, of isolated protoplasmic structures and collections of enzymic systems. In this way we may be able to reveal various features common to all living organisms and may try to form a mental picture of how these features could have arisen during the process of directed evolution of our original systems or in the earliest stages of the development of life.

As we have remarked again and again, the fundamental organisation of living matter is its organisation in time. The phenomena which take place in it in a definite, regular order together constitute its metabolism.

The individual reactions which occur in protoplasm are rather simple and uniform. They are the reactions, familiar to chemists, of oxidation, reduction, hydrolysis, phosphorolysis, aldol condensation, the breaking of carbon-carbon bonds, etc. Any of these may be brought about outside the organism and there is nothing specifically vital about them. What would seem to be specific to living bodies is the definite organisation in time of these reactions in them, to form a single complete system, an abundantly branching network of reactions. In living bodies these reactions do not take place chaotically but bear a strictly determined relationship to one another. The colossal diversity of organic compounds which is to be found in the world of living things does not depend on diversity and complication of the separate individual reactions but on the diversity of their combinations, the variations in the order in which they occur in the different cells of the organism at particular stages of development. This sequence of chemical reactions forms the basis of both the synthesis and the breakdown of the substances of protoplasm. It forms the basis of such vital phenomena as the synthesis of proteins, fermentation, respiration, photosynthesis, etc. In the respiratory and photosynthetic processes 
sugar and oxygen, carbon dioxide and water, are only the first and last links; between them there are long chains of chemical transformations. In these chains the intermediate product which is produced by one reaction immediately enters into the next reaction, which is strictly determinate for the vital process in question. If these sequences are changed. if any single link in the chain of transformations is removed or altered, then the whole process will become quite different or even be thrown right out of action. As we have seen, these organisational features, which are characteristic of everything living, are exactly analogous, in principle, to the network of chemical transformations which forms the basis of any more or less complicated chemical open system. As in these systems, so in living things, the characteristic order of phenomena which has been described is based on a close co-ordination of the rates of the chemical reactions which form the individual links of the long and labyrinthine chain of metabolism.

Organic substances, which are the essential components of living systems, seem to be the only material which can form the basis of such chains of reactions. It is characteristic of these substances that they can react in the most diverse ways. Although they have tremendous chemical potentialities, these are only realised extremely slowly under ordinary conditions and in isolation. This very slow rate of reaction depends essentially on the great amount of energy of activation, i.e. the high energy-barrier which molecules of organic substances must surmount before they can participate in any chemical reaction. However, depending on all the combinations of circumstances under which any given reaction takes place, its velocity may vary within very wide limits.

If the conditions are such that only one of the reactions possible for any particular organic substance occurs very fast while all the rest of the possible reactions proceed comparatively slowly then, naturally, the practical significance of the latter will be quite negligible in the over-all result. In other words, there lie before each organic substance in protoplasm many routes of chemical transformation which are thermodynamically open to it. In fact, however, each compound which enters the protoplasm from the environment, and any 
intermediate product which may be formed within the protoplasm, will be changed during metabolism only in the direction in which it can react most quickly. All the rest of the reactions, which take place more slowly, will simply not have time to occur to any significant extent. It is in this way that there are formed those strictly determined chains and cycles of successive quick reactions which together constitute the more or less ramifying network of metabolism.

A simple homogeneous mixture of organic substances, or even a newly formed coacervate drop which has not yet been transformed into a well-organised open system, presents, from this point of view, a very wide but completely untrammelled field of chemical possibilities. The same great difficulties and obstacles hinder movement in any direction in this field. In contrast to this, selection has led to the presence in protoplasm of definite paths of biochemical processes, a whole network of ' rationally built roads' along which there proceeds at a great rate and in 'orderly columns' the chemical transformation of substances and the associated conversion of energy.

This highly-developed order, which depends on the definite relationships between the velocities of the reactions, is regulated in the living body by many factors. The most important of these is the catalytic activity of the enzymes.

Nowadays the study of enzymes, enzymology, has grown into an extensive and independent field of knowledge in which an immeasurable amount of work is being done. ${ }^{24}$ Many enzymes have now been isolated from living organisms in the form of highly purified crystalline preparations ${ }^{25}$ which have been studied in detail as regards both their chemical nature and the mechanism of their catalytic activity. ${ }^{26}$

These enzymes have been found, without exception, to be simple or conjugated proteins. The prosthetic groups of the latter consist, in most cases, of organometallic compounds or various vitamins. There can now be no doubt that each cell contains a whole collection of diverse enzymes and that the majority of the proteins of the living body have enzymic activity. Thus enzymes would seem to constitute the bulk of the proteins of protoplasm. ${ }^{27}$ 
The fact that enzymes seem to be chemically proteins, having a definite sequence of amino acid residues in their polypeptide chains and a definite internal structure of their molecules, determines a number of the peculiarities which distinguish enzymes from all other catalysts known to us. The most important of these is their intense catalytic activity.

There are known to be a large number of inorganic and organic substances which can hasten the same reactions as those affected by enzymes, but there is no comparison between the strengths of their catalytic activities. For example, hydrogen ions can catalyse the hydrolytic reaction whereby sucrose is hydrolysed to glucose and fructose, a reaction which is also catalysed by the invertase of yeast, but the enzyme is at least ten million times as effective. The very simple nitrogencontaining organic compound, methylamine, increases the rate of breakdown of pyruvic acid. So does the enzyme carboxylase, but the catalytic activity of the enzyme is about thirty million times as great as that of methylamine. The ferric ion appreciably facilitates the breakdown of hydrogen peroxide into water and oxygen. The enzyme catalase, which is a combination of an iron-porphyrin complex with a specific protein ${ }^{28}$ has the same effect but brings about the reaction about $10^{10}$ times as fast as inorganic iron.

The complicated structure of the protein molecule is also responsible for the second important peculiarity of enzymes, the high specificity of their action. Inorganic catalysts are rather indiscriminate in their action. For example sucrose, maltose, starch, proteins and many other substances may all be hydrolysed equally well by hydrogen ions. But enzymes act in a highly specific way, only catalysing particular reactions. They only break the bonds between certain definite groups of atoms and leave others quite intact, although these may be very similar to those of their substrates. If, therefore, we have any organic substance which is capable of a number of chemical changes, then, in the presence of any one enzyme it will react with remarkable speed, but only in one particular direction. For example, pyruvic acid in the yeast cell, where the enzyme carboxylase is present, is almost entirely broken down to carbon dioxide and acetaldehyde and it is only the acetaldehyde which is reduced to alcohol 
by the action of a specific dehydrogenase. In the lactic acid bacillus, on the other hand, where there is no carboxylase, pyruvic acid is reduced directly to lactic acid and is not decarboxylated to any considerable extent. Thus the highly specific action of enzymes is a very important factor in the organisation of protoplasm. Less specific catalysts would not have this capacity to determine the direction in which any particular organic substance in the protoplasm would undergo chemical change.

The mechanism of enzymic reactions has now been studied from various points of view by many authors but, so far, the problem cannot be considered to have been solved. In its most general form, the participation of enzymes in metabolism may be presented as follows: The substance which is undergoing the reaction in question (the substrate) first forms a very short-lived intermediate compound with the enzymic protein. This requires a certain corresponderce of structure between the enzyme and the substrate. If this is absent no catalysis whatsoever can take place. When this correspondence exists the reaction between the enzyme and the substrate requires considerably less energy of activation and therefore takes place very fast at ordinary temperatures. However, owing to the specific properties of the enzyme molecule, the intermediate, enzyme-substrate, compound is very unstable. It very soon undergoes a further alteration, in the course of which the substrate is changed in the appropriate way and the enzyme is regenerated and can once more form an intermediate compound with a fresh portion of the substrate.

Reactions whereby the substrate is transformed without the help of an enzyme usually require a high energy of activation and therefore take place so slowly that they cannot play a decisive part in metabolism, which is rapid. When the enzyme is present, the high energy barrier seems to be broken down and the route via the intermediate compound seems to be considerably easier and faster.

Thus, in order that any chemical ingredient may actually take part in metabolism, it must first interact with a protein to form a definite intermediate compound. If not, its chemical potentialities will be realised so slowly as to be of no 
significance in the rapidly flowing process of life. Thus the direction in which any compound is altered in the course of metabolism depends not only on the molecular structure of the compound, but also on the enzymic activity of the protoplasmic proteins with which it becomes involved in the course of metabolism.

Thus, in enzymes, living bodies not only have powerful accelerators of chemical processes, but also an extremely efficient chemical apparatus which can direct these processes along strictly determined channels. This is, in fact, the essential function of enzymes in living bodies, and it must be said that enzymes are extremely efficient 'instruments' for the performance of this function. Their structure is amazingly precisely adapted to the carrying out of this function in the organisms. One has but to make a slight change in the structure of the enzyme complex, to rearrange or block one or other of the chemical groups of its prosthetic part or to disturb the structure of its protein component, and the catalytic activity and specificity of the enzyme are markedly diminished. Thus, even in enzymes, we can already see the suitability of structure to function, the internal " purposefulness' which is so characteristic of living matter in general.

The study of the formation of enzymes in living bodies, their biosynthesis, is, as yet, really only just beginning ; most attention has so far been paid to the question of the "adaptive' origin of enzymes. ${ }^{30}$ We know very little about this matter ; it is only clear that the biosynthesis of enzymes, like that of proteins and the other components of protoplasm, must occur by many stages. It is quite unnecessary that, in the course of this biosynthesis, all the elements out of which the enzvme complex is 'assembled' should have been synthesised by one and the same organism. They are very often taken in ready-made from the environment in the form of vitamins or parts of vitamins, essential amino acids, etc.

How could such a highly developed catalytic apparatus have arisen in the first place in the process of the clirected evolution of our original systems?

In Chapter VI it was shown that the ability of enzymes to carry out their functions in the organism, their great catalytic activity and specificity, was primarily based on the strictly 
ordered arrangement of atomic groups in their complicatedly constructed molecules. As a result of this, the catalytic activity of each of the groups and radicals is extremely 'advantageously' combined with activating groups which considerably augment their catalytic effects or facilitate the combination of the enzyme with the substrate. This takes place in enzyme proteins, in which such a structure is associated with a definite arrangement of amino acid residues in the polypeptide chain and a definite internal structure of the protein particle as a whole. This is just what may be seen, for example, in the structure of the prosthetic groups of the conjugated-protein enzymes.

We have already mentioned the work of W. Langenbeck ${ }^{31}$ on the construction of artificial models of the enzyme carboxylase. In this work the author started from the observation that such a simple compound as methylamine can catalyse the reaction of decarboxylation of pyruvic acid, this catalytic activity being a property of the amino group. But methylamine itself catalyses this reaction very weakly. The inclusion of a carboxyl group in the methylamine molecule increases its catalytic activity 19 -fold, although the carboxyl group itself has no catalytic activity. The catalytic activity of methylamine derivatives may again be increased by the further addition of aromatic and heterocyclic rings. Following this up, Langenbeck finally got a compound (hydroxyaminonaphthoxindole) which had a carboxylase activity 4,000 times as great as that of the original methylamine.

Vitamin $\mathbf{B}_{1}$ forms the prosthetic group of natural carboxylase from yeast. ${ }^{32}$ Its molecule, like Langenbeck's models, contains a catalytically active amino group which is combined with two complicated heterocyclic rings. The combination seems to be more effective here than in the artificial model. But it is only when vitamin $B_{1}$ is combined with a specific protein through a phosphoric group that it acquires the extremely powerful catalytic activity characteristic of the enzyme. Neither the vitamin itself, nor the carboxylase protein, taken alone, have this power and it is only their combination in a special way which gives the enzyme its great activity and specificity. 
This sort of structure of carboxylase is a demonstrable instance of one case of the internal organisation of protoplasm. So long as only the separate parts of the enzyme are present or these parts are not combined with one another in a special way, their catalytic activity is small and they carry out their function in the living body badly. If the enzyme is to have its characteristic efficiency in this respect its separate components must be combined together in a special way, but this cannot occur by chance.

Catalase may serve as another analogous example. As we have already pointed out, even ferric ions can catalyse the breakdown of hydrogen peroxide to water and oxygen, but this is only a weak effect. If the iron is combined with a porphyrin nucleus to form haemin, the catalytic activity is increased about a thousand fold. In the natural enzyme, catalase, the haemin is combined with a specific protein and this further increases its catalytic activity many million fold.

In the systems which we postulated as being the starting point for the process of evolution on the way to the origin of life, in coacervate drops having the properties of open systems, the chemical reactions which formed the network of the system must, at first, have occurred very slowly. A certain speeding up of isolated reactions may have been achieved, mainly by means of the catalytic effect of such inorganic salts (e.g. those of calcium, iron, copper and vanadium) as may have been present in large enough quantities in the waters of the primaeval ocean.

Certainly even such a very slight increase in rate must have played a decisive part in the establishment of a definite sequence of reactions, in the organisation of the network of chemical processes in our open systems.

In particular, orving to the catalytic activity of inorganic iron, the breakdown of hydrogen peroxide into water and oxygen might thus have occupied a place in the network if it somehow favoured the dynamic stability of the drop, its preservation for a long time or even its growth under the conditions of its interaction with the external medium.

Now, let us suppose that some of these coacervate drops, owing to their adsorptive powers or for other reasons, could 
take in from the surrounding medium the porphyrins which were formed there by purely abiogenic means, just as some contemporary organisms extract from their environment vitamins which they need for the synthesis of enzymes. On combining with the iron, the porphyrin would markedly increase its catalytic activity, and if such a speeding up of the reaction under discussion was favourable to the dynamic stability of the drops in which it occurred, then these drops would enjoy a considerable advantage in the process of selection compared with other similar systems. Thus the drops which were preserved for further evolution would be just those which had a structure enabling them to adsorb porphyrins selectively.

Analogous considerations also apply to the formation of other specific catalysts and enzymes. Even such comparatively simple substances as, for example, methylamine, glycine, aldehydes, sugars, etc., have a weak catalytic activity for some reactions. These compounds could enter into the original systems or even, to some extent, be synthesised there. In the various coacervate drops they could combine with one another and with the inorganic catalysts present there in hundreds and thousands of different ways. Among all these combinations there must certainly have been some in which the catalytic activity was greatly increased owing to a favourable disposition of active and activating groups. A particular case might be the successful combination of amino acid residues in the polypeptide chains of the protein-like substances. This might give marked advantages to the systems in which there were formed combinations which had a powerful catalytic activity favourable to their dynamic stability and general activity.

This internal chemical rationalisation of the systems was reinforced by their selection. This destroyed those in which there had arisen, by chance, 'unsuccessful' combinations which diminished the catalytic activity. It preserved for further evolution only the more efficient catalysts which were more capable of performing their functions. 
We have pointed out above that the very highly developed structures of catalase, carboxylase or any other enzyme could not have arisen by the action of selection on their separate isolated molecules, because the reactions which they carry out are of no significance to the catalase or carboxylase themselves. Their hastening or slowing of reactions cannot be reflected in the length of the existence or an increase in the amount of the enzymes as such. This activity may, however, have a decisive effect on the existence of the system in which any particular catalyst acts. Thus these systems must have been selected for the characteristic in question, and thus there could have arisen that extreme 'purposefulness' of structure, that correspondence between structure and function, by which enzymes may be recognised as biological formations.

Indeed, although we are now very rapidly approaching a full understanding of the chemical nature of enzymes, and even the solution of the problem of their synthesis by artificial means, these catalysts still bear all the marks of their biological origin. In nature they are only to be found in organisms and can only be formed naturally there. Such a 'fortunate' combination of atomic groups as we find in enzymes, such an intimate association between their structures and their biological functions, could not have arisen by chance or simply as a result of the action of the laws of physics and chemistry. The formation of enzymes required a definite orientation of the process of the evolution of matter, it required selection, the destruction of all 'unsuccessful ' combinations and the retention for further evolution of only those systems in which the catalytic apparatus fulfilled its biological function most rationally.

This evolution of enzymes is still taking place to some extent. It must, however, be pointed out that the basic forms of construction of catalytic systems were already elaborated at what, comparatively speaking, was a very early stage in the establishment of life and its further development. Nowadays, therefore, even in the most poorly organised of contemporary living things, the individual enzymes are present as fairly highly-developed formations. 


\section{The origin of the co-ordinated networks of reactions: the origin of the first organisms.}

Enzymes are, however, only the elementary and simplest form of organisation of protoplasm, its separate working mechanisms.

The extreme specificity of protein enzymes means that each of them can only form intermediate compounds with a definite very narrow group of substances and can only catalyse strictly determinate individual reactions. However, the separate reactions catalysed by the different enzymes cannot of themselves, in isolation, serve as a basis for the process of life. Their biological significance becomes manifest and well defined only by virtue of their strict co-ordination with all the other chemical processes of the living body ; their place in the general network of reactions in open systems is only maintained when they are included as essential links in a long chain of metabolic processes.

Hundreds and thousands of enzyme proteins play their parts in each vital process, let alone metabolism as a whole. Each can catalyse only one or a very limited number of reactions, and it is only when taken together, when their actions are unified in a definite way, that they constitute the orderly sequence of phenomena which forms the foundation for the process of life.

By using chemically individual enzymes isolated from living organisms one may produce, under laboratory conditions and in isolation, separate biochemical reactions which are links in the metabolic chain. This enables us to unravel the complicated skein of chemical reactions which make up metabolism, in which thousands of individual chemical reactions are carried out; to dismember metabolism into its constituent stages; to analyse not only the composition of living bodies, but also the chemical processes which are carried out in them and on which vital phenomena depend.

The great service of A. N. Bach (Bakh) ${ }^{33}$ to biochemistry was that, as early as the end of the nineteenth century, he showed, in his study of the chemistry of respiration, for example, that this phenomenon could not depend on the 
effect of any single enzyme (e.g. laccase or some other oxidase) but consisted of a chain of enzymic reactions which followed one after the other and were co-ordinated in an orderly fashion.

The same thing was established somewhat later for another important vital phenomenon, that of fermentation.

L. Pasteur ${ }^{34}$ in his day said that:

The chemical act of fermentation is essentially a phenomenon associated with a vital activity, beginning and ending with that activity; there is no fermentation without simultaneous organisation, development, multiplication of globules or the continuation of life by globules which are already formed.

This supposition was refuted experimentally at the turn of the century by E. Buchner. ${ }^{35}$ By using a high pressure, he expressed a juice from yeast which did not contain any living cells but which could nevertheless ferment sugar. Buchner believed that his juice contained a specific enzyme, 'zymase', which broke the sugar down to alcohol and carbon dioxide by a single chemical act, just as, for example, invertase breaks sucrose down into glucose and fructose. However, the work which continued to be carried out for many years afterwards by a whole constellation of the outstanding biochemists of the first half of the present century, in particular by S. Kostychev, A. Lebedev, C. Neuberg and O. Meyerhof, showed that Buchner's juice contains, not one single enzyme, but a whole complex of such catalysts. ${ }^{36}$ Each of these accelerates its own specific reaction. All these reactions are combined together to form a long chain of transformations following one another successively in such a way that the end product of the preceding reaction serves as the starting substance for a rigidly determinate succeeding reaction. Sugar, on the one hand, and carbon dioxide and alcohol, on the other, are merely the first and last links of this chain. The reaction catalysed by each separate enzyme of the zymase complex occupies its orwn essential place in the chain of transformations, and forms an indispensable part of the chain as a whole. By poisoning or blocking, one may inactivate selectively any single enzyme of the zymase complex and thus exclude the reaction which it catalyses from the general 
sequence. The whole chain is then immediately disturbed and fermentation ceases or is distorted.

By now most of the enzymes of the zymase complex have been studied in great detail. Many of them have been isolated and obtained in a pure state; their chemical nature, the character of their specific action and their dependence on a number of physico-chemical conditions have been established. Alongside this analytical work a number of extremely interesting studies have been made, reproducing not merely individual enzymic reactions, isolated links in the chain of fermentation, but whole concatenations of these links, combinations of successive reactions catalysed by several enzymes of the zymase complex. Thus it seems to be possible to reproduce alcoholic fermentation artificially by the simultaneous action of all the enzymes and co-enzymes isolated from Buchner's juice.

During the interaction of our original colloidal systems with the medium surrounding them, and in the process of their later development, there must have been formed within them, not a single individual enzyme, but many specific catalysts. Their simultaneous activity determined the occurrence of some particular chain of chemical reactions or a whole network of reactions. On the nature of the organisation of this chain or network depended the greater or less dynamic stability conferred by the network on the open system. The selection of systems was based on this stability, destroying those which had an 'unsuccessful' combination of reactions and preserving for further evolution only systems with chains and networks which enabled them to survive for a long while under conditions of constant interaction with the external medium. It is obvious that it required a very prolonged and rigorous selection of a colossal variety of such systems for there to arise, at last, a chain consisting of more than 20 rationally concordant reactions such as take place in alcoholic fermentation. In principle, however, the origin of such a harmony between different catalytic reactions could quite well have occurred during the process of directed evolution and it seems that it must have come about at a comparatively early stage in the origin and development of life since the same basic collection of chains is common to, 
literally, all representatives of the living world which have been studied in this respect.

However, the form of organisation of the chain of processes on which extracellular fermentation is based is still relatively primitive. It is only based on a certain qualitative composition of the mixtures of enzymes, i.e. the obligatory presence in it of the whole collection of enzymes of the zymase complex. The sequence of reactions in extracellular fermentation simply depends on each intermediate product having its own specific enzyme. Other transformations of the product are excluded because, in the absence of the corresponding catalyst, they would proceed incomparably more slowly than the reaction which is accelerated by the enzyme. For this reason the whole process of extracellular fermentation is of the nature of a straight, unbranched chain. In the living cell it is of great importance not only what enzymes are present but also what are the quantitative relations between the various catalysts acting there ; there must always be a certain correspondence between their activities. This is specially important when one and the same substrate can interact with several of the enzymes present in the cell. As a result of this the substrate is, in fact, altered in different directions. The chain of reactions then becomes branched, and the relationship between the rates at which reactions occur in the different branches has sometimes been found to determine whether or not some vital process can take place. A small change in this relationship may cause not merely the cessation of a process, but even the disruption of the whole system.

As an example of this we may cite the phenomenon of respiration in the plant cell. It only takes place normally when the process of oxidation of the chromogens into respiratory pigments by the oxygen of the air and the reverse process of their reduction at the expense of the hydrogen of the appropriate donors, correspond very closely with one another, when their rates bear a precisely determined relationship to each other. If, as happens on mechanical injury to the cell, the rate of oxidation is increased disproportionately to that of reduction, the respiratory pigment will not be able to be reduced and will undergo further oxidation into a stable 
brown pigment which cannot serve as a hydrogen acceptor. In this way all the chromogen of the cell is very quickly converted into an inactive state and the process of respiration ceases as a result of the disturbance of the mechanism on which it is based. ${ }^{37}$

There is a great variety of substances in protoplasm by means of which the accurate regulation of the catalytic activities of the enzyme complex is accomplished. In addition to the new formation and irreversible destruction of the protoplasmic enzymes, there also occurs a widespread reverse activation or inhibition of these catalysts. The protein nature of enzymes not only determines their exceptional activity and the specificity of their effects, it also determines their great lability, their extreme sensitivity to different kinds of physical and chemical factors. Any rough treatment will cause the denaturation of proteins and their catalytic activity will be irreversibly lost. But by treatment which does not lead to denaturation the activities of enzymes may be altered reversibly over a very wide range. In fact there is no physical or chemical factor, no organic compound or inorganic salt, which cannot affect the course of enzymic reactions in one way or another. Any raising or lowering of the temperature, any change in the acidity of the medium, its oxidationreduction potential, its salt content or its osmotic pressure, interferes with the relationship between the rates of the different enzymic reactions and thus changes their interconnections in the network of metabolism. Of great importance in this connection is the development among the components of protoplasm of various activators and inhibitors with specific activities, which selectively speed up or slow down any one or several enzymic reactions. ${ }^{38}$

Owing to the action of all these supplementary chemical mechanisms which are intimately associated with the physicochemical state prevailing at any given moment within the protoplasm, very precise quantitative relationships are established between the rates of the enzymic reactions. These relationships may, however, vary greatly both as between different organisms and even in a single cell at different periods of its existence, and owing to the effects of different external and internal conditions. This gives a form of organ- 
isation which is very labile and adaptable, but at the same time very efficient. The process of extracellular fermentation is not associated with any protoplasmic structure; the whole process simply takes place in a solution of the enzymes of the zymase complex. In the cells of contemporary organisms, on the other hand, the spatial organisation of their protoplasm exercises a great, and sometimes decisive, influence on the rate and direction of the enzymic reactions on which its metabolism is based. We now know that the enzymes of cells are present, for the most part, in an associated state on protoplasmic surfaces and various cellular structures. ${ }^{39}$

The investigations carried out in the Institute of Biochemistry of the Academy of Sciences of the U.S.S.R. (A. Kursanov, ${ }^{40}$ N. Sisakyan, B. Rubin and A. I. Oparin ${ }^{41}$ ) have shown that the degree of association of the enzymes with the structures mentioned has a decisive effect not only in determining changes in the rates of the reactions catalysed by the enzymes, but also in displacing the dynamic equilibrium of the chemical processes towards a predominance of breakdown or synthesis. This, naturally, is of paramount importance for the self-preservation and growth of the whole living system. Phenomena of this sort cannot be explained on the basis of the laws which have been established for closed systems. As was shown in the previous chapter, however, in open systems (as distinct from enclosed ones) a catalyst may alter the stationary concentrations of the reacting substances, i.e. it may displace the experimentally determined, dynamic 'equilibrium 'of the process.

This sort of influence of the protoplasmic structures on the rate and direction of the enzymic reactions of the metabolic network leads to a very intimate and critical connection between the metabolism and the conditions of the external medium. It very often happens that a factor which has a very weak or hardly noticeable effect on the activity of isolated enzymes will produce a radical displacement of the equilibrium between breakdown and synthesis, by altering the associated power of the protein structures of protoplasm, which are very sensitive in this respect.

According to contemporary cytological evidence ${ }^{42}$ a very considerable part of the cytoplasm, up to $5^{\circ}$ per cent of its 
weight, is composed of different formed structures, particles of various sizes, for the most part mitochondria and microsomes. The mitochondria are rod-shaped formations visible under the microscope. Their internal structure has been fairly well studied both as to its morphology and its physical chemistry. They have an envelope consisting of two protein layers with a lipid layer between them. The internal core has a complicated structure and is also made up of proteins and lipids. ${ }^{43}$ The microsomes are submicroscopic and can only be discerned with the electron microscope. Their structure has still only been very poorly studied. According to J. D. Bernal ${ }^{44}$ the arrangement of the molecules of protein and nucleic acid in them is reminiscent of the structure of globular virus particles.

Both the mitochondria and the microsomes are very rich in lipids. ${ }^{45}$ The mitochondria contain the iron-porphyrin systems of the cell ${ }^{46}$ while the bulk of the nucleic acid is situated in the microsomes. ${ }^{47}$ The mitochondria contain large amounts of various enzymes. They seem to embody the catalytic mechanism required by the cell for the processes of oxidation and decomposition which lead to the liberation of energy from the multifarious substrates entering the cell, and also for the processes of transformation of this energy into forms in which it can be used in synthetic processes and for carrying out work in general. In particular, in the cells of highly developed organisms capable of respiration, this is carried out by means of the tricarboxylic cycle of Krebs (a diagram of which is given in Fig. 40 on p. 466). This is the most widespread system of oxidation of intermediate products of the breakdown of various organic substrates. ${ }^{48}$ The Krebs cycle comprises a strictly ordered concatenation of a large number of enzymic reactions, especially the hydration, dehydrogenation and decarboxylation of organic acids. At particular points in the cycle there branch off side reactions leading to the formation of substances which can serve as material for the synthetic processes of the cell. For example, $\alpha$-oxoglutaric acid is one of the links in the Krebs cycle. It is formed from oxalosuccinic acid and later, in the course of the transformations of the cycle, it is converted, by oxidative decarboxylation, into succinic acid. This in its 
turn is transformed into fumaric and then into malic acid, etc. The $\alpha$-oxoglutaric acid may, however, be transaminated and part of it may leave the cycle by a side route and be converted into glutamic acid which later serves as a material for the synthesis of proteins. In this way part of the -oxoglutaric acid is always leaving the cycle irreversibly. In just the same way other keto acids (pyruvic and oxaloacetic acids) react with ammonia, i.e. are aminated directly, ${ }^{49}$ or are transaminated ${ }^{50}$ to form alanine and aspartic acid respectively. These are later transaminated to form other amino acids.

The acetic acid arising in the cycle may later take part in the formation of the citric acid of the cycle. ${ }^{51}$ Alternatively it may leave the cycle to serve as the starting material for the formation of fatty acids and other lipids. Oxaloacetic acid and glycine are essential materials for the biosynthesis of purine and pyrimidine bases, and glycine and succinic acid for the construction of porphyrins. Thus, all these biosynthetic processes which form the basis for the synthesis of living protoplasm are intimately associated with catabolism, from which they obtain their structural starting materials.

At certain definite points on the cycle there is also liberation of energy which is derived from high-energy bonds. ${ }^{52}$ The energy of the substances in which these bonds were originally present is transferred to ATP in the mitochondrial system. This, in its turn, activates substances taking a direct part in synthetic reactions.

Owing to the extremely efficient spatial disposition of the enzymes and coenzymes of the respiratory and energetic complex, their orderly assembly in the mitochondria, the cell achieves a maximal effect in the oxidation of substrates and the transformation of energy. The energy made available in this way is intimately associated with the formation of fragments of molecules which serve as materials for the synthesis of the substances of which the cell is made. ${ }^{53}$ The intensity of the oxidative processes in the mitochondria is, therefore, regulated by factors responsible for maintaining the balance between the liberation of energy and the supply of materials required for synthesis.

The direct synthesis of proteins from amino acids takes 
place in the nucleic acid-rich microsomes, as has been shown by experiments using labelled atoms. ${ }^{54}$ The energy needed for this reaction is made available in the mitochondria. It has been supposed that it enters the microsomes in the form of high-energy bonds of activated peptides containing the $\gamma$-glutamyl group. ${ }^{55}$ The microsomes themselves seem to be

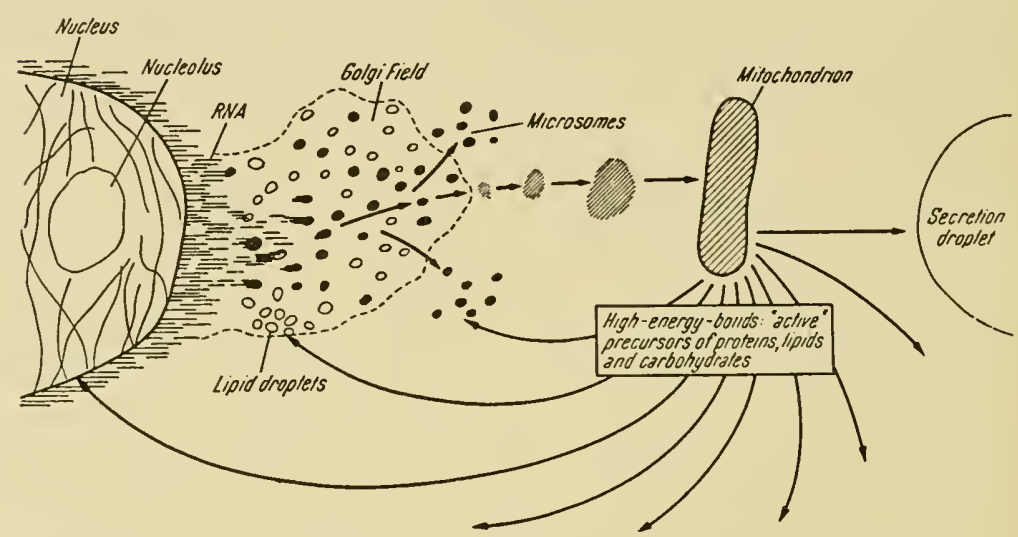

Fig. 35. Diagram of the formation of cytoplasmic particles and their interaction with other elements (after Lindberg and Ernster).

formed from proteins, ribonucleic acids synthesised under the control of the nucleus and lipids which are formed in the mitochondria and stored in the Golgi apparatus. ${ }^{56}$

We give a diagram of these interactions of the formed elements of the cell as it is given by Lindberg and Ernster ${ }^{42}$ (Fig. 35).

The form of organisation of protoplasm which we have described is extremely efficient. With an organisation of this sort, owing to its definite spatial localisation, complete independent blocks of well 'assembled' enzymes interact in the performance of certain vital functions. Thus we have here a well-organised 'division of labour' between the various structures of the cell operating to achieve the maximum effect in the transformation of energy and the synthesis of living material.

Naturally this sort of organisation could only arise as a result of the prolonged development of living matter and it 
is, therefore, only to be found in organisms which have already reached a comparatively high level on the evolutionary ladder. Even in the comparatively poorly organised living things of the present time it is far more primitive. It must be supposed that the organisation of the primaeval organisms was even more primitive, although such a form of spatial localisation of the various enzymes and the reactions which they catalyse must have existed even at this stage of evolution.

Even the reactions of alcoholic fermentation take place far less harmoniously in Buchner's juice, where the spatial localisation of the enzymes is largely destroyed, than in yeasts or bacteria. But, most important of all, in Buchner's juice the process of fermentation follows, as it were, a lone trail. Here none of the energy liberated during the breakdown of sucrose to carbonic acid and alcohol is used rationally in any way. In the living cell, on the other hand, owing to the strict co-ordination of the chemical reactions, this energy participates to a greater or lesser degree in the process of synthesis of living material.

Of course, it is still very hard to answer the question as to what was the spatial organisation of the earliest living things. Considerable light might be shed on this problem by a comparative study of this organisation among the more primitive contemporary organisms. The study of multiple coacervates might also give some indication of the possible means whereby the simplest internal structure of the original colloid systems could have arisen. In multiple coacervates formed of several components there is an internal separation of the individual components in space, in that small droplets of one coacervate arise within the drops of another. For example, on mixing solutions of gelatin, gum arabic and sodium nucleate, drops are formed, composed of gelatin and gum arabic. Within these drops there are formed small droplets containing gelatin and nucleic acid. ${ }^{57}$ This can easily be demonstrated by selective staining or by the use of the ultraviolet microscope. ${ }^{58}$ Various substances and catalysts may become localised on the internal surfaces which are formed in this way.

In summarising what has been said one must emphasise 
the extreme complexity and diversity of the factors which determine the organisation of contemporary living bodies in time, the causes on which the structure of the network of chemical transformations of their metabolism depends. The formation of this network was determined by the chemical properties of the compounds of which living bodies were composed. The great diversity of these compounds and their extreme chemical reactivity carried with them the possibility of numerous chemical transformations and unlimited combinations of the compounds. But, in this extremely wide field of chemical possibilities the process of directed evolution, by the gradually increasing organisation of living systems, led to the emergence of ever more clearly defined pathways of biochemical processes which formed a more and more efficient network of metabolic reactions.

In contemporary organisms this network has reached a very high efficiency. Its organisation is determined, as we have seen, by a whole complex of concordant factors: the presence of a particular collection of enzymes, their quantitative relationships, the physico-chemical conditions prevailing in the protoplasm, its colloidal properties and, finally, its structure, the definite localisation of chemically and biologically active compounds and the irreversible nature of the biochemical processes. The original systems, and even the earliest living things, did not have to the full such a complicated and efficient form of organisation. However, both before and after the emergence of life, there took place a directed evolution, not of isolated factors or parts of the system, but of the metabolic network as a whole, leading towards its improvement. In the course of this evolution there continually arose new pathways, some of which became predominant in metabolism at the same time as old pathways disappeared or merely remained in reserve. During all these changes, however, there was always maintained a network which, to some extent, provided for constant self-preservation and self-reproduction of the system as a whole. The improvement of the metabolic network only implied the more and more rational performance of this task under more and more diverse and varying environmental conditions.

As the metabolic network improved so there arose and 
developed those properties of the system which may be regarded as the characteristic features of life, which are fundamental to the organisation of this form of the motion of matter.

The interaction with the external medium of such systems as coacervate droplets, which have no organised network of chemical reactions, can only be based on the permeability of surface membranes or the adsorptive properties of colloids. In this case, however, the entry of substances into the system by such means soon ceases and the system enters into equilibrium. Only when the substances entering the system in one way or another can be changed and accumulated within the system in the form of some particular compounds, or cast out into the surrounding medium as breakdown products, can the phenomenon of interaction between the system and its environment continue for a long time. This must have occurred when coacervate drops were transformed into open systems at a comparatively early stage in the erolution of the original colloidal formations. But, in this case, the entry of substances into the system or their expulsion into the external medium must already have ceased to depend on the simple laws of permeability and adsorption and have depended on the state of development of the organisation of the network of reactions into which the substances derived from the external medium entered, or in which the breakdown products which were expelled were formed.

It is precisely this sort of interaction with the external medium, though in a considerably more highly developed form, which is characteristic of all contemporary living things. According to the evidence of contemporary cytology and cellular physiology, ${ }^{59}$ the entry of substances from the environment into the cell is not a passive process determined by the greater or lesser mobility of these substances through a hypothetical semi-permeable membrane, or by their selective adsorption on protoplasmic surfaces, as had earlier been supposed. This entry is brought about by the active participation of the whole cellular metabolism. It occurs because the substances which enter are drawn into the network of metabolic reactions. For this reason any disturbance of metabolism, such as a decrease in cellular respiration, has an 
immediate and decisive effect on the entry of substances into the cell.

In an analogous way the characteristic features of cellular energetics depend on the high degree of organisation of the metabolism of protoplasm. ${ }^{60}$ In the engines which are widely used in industrial processes, the chemical energy which is liberated by burning the fuel is usually first converted into heat and only later transformed into other forms of energy. In protoplasm the energy liberated by the decomposition of organic substances (in the process of fermentation or by their oxidation during respiration) is converted directly into the forms of energy required for life. Owing to this an extremely high coefficient of utilisation of energy is achieved in living bodies such as is not approached by our technology. In the engines of the present time this coefficient reaches, at best, $4^{\circ}$ per cent, and this requires considerable temperature differences, of the order of hundreds of degrees. If the transformation took place in living bodies in the same way as in heat engines, then, at the temperature differences which are possible for organisms, the coefficient of energy utilisation would only be a fraction of 1 per cent. Nevertheless it in fact reaches $5^{\circ}$ per cent or even more. This is explained by the fact that the breakdown and oxidation of sugar or other energy-yielding material does not take place as an isolated process in the living cell, but through a series of separate reactions which are strictly co-ordinated in time and which form the chains and cycles which constitute metabolism. The chain of alcoholic fermentation and the oxidative cycle of Krebs may serve as examples.

It must be pointed out that if the oxidation of organic molecules were to take place all at once in protoplasm, the living body would not be able to make rational use of the energy thus liberated. The oxidation of only one gram-molecule of sugar to carbonic acid and water liberates about $700 \mathrm{kcal}$. The instantaneous release of this amount of energy would be associated with a sharp rise of temperature, the denaturation of proteins and the destruction of protoplasm. The energetic effect achieved by protoplasm at ordinary low temperatures depends on the fact that, in the process of biological 
oxidation or degradation of sugar, this substance is not converted into its end products all at once, but by gradual stages.

This sort of organisation not only gives rise to the possibility of overcoming the high barrier of the energy of activation of the reaction of the oxidation of sugar by atmospheric oxygen at ordinary temperatures; it also allows the living cell to make rational use of the energy, which is not liberated all at once but gradually in separate small portions. We have already seen from the example of the Krebs cycle that this is what actually takes place. At definite points on this cycle energy is liberated, whereupon it is immediately taken up to form ATP, or some other compound with high-energy bonds, which may be used for carrying out syntheses or for performing work necessary for life. ${ }^{61}$

The more highly organised the metabolism and the better the co-ordination between the separate reactions of which it is made up, the higher will be the coefficient of useful work. Direct observations on various representatives of the living world show that in poorly organised living things, standing at the bottom of the evolutionary scale, the reactions of the energetic network are not always strictly co-ordinated. A considerable amount of the energy liberated in them is therefore dispersed aimlessly and cannot be used for vital processes, in particular for the formation of new living material and the growth of cells. ${ }^{62}$ When, on the contrary, the rates of the reactions are strictly co-ordinated, when they are, so to speak, accurately adjusted to one another, this waste of energy is cut down substantially. In such a case a relatively small access of the organic materials serving as the source of nourishment leads to considerable growth of the living thing.

This may be seen in moulds, for example, where the metabolism is very highly organised. H. Tamiya ${ }^{63}$ in particular obtained the following data for Aspergillus oryzae: for the formation of $1 \mathrm{~g}$. of mycelium the mould assimilated $1 \cdot 467 \mathrm{~g}$. of glucose. The efficiency of the utilisation of energy was thus $\frac{4 \cdot 8 \mathrm{kcal}}{1 \cdot 4^{6} 7 \times 3 \cdot 76 \mathrm{kcal}} \times 100=87$ per cent. This efficiency is exceptionally high and other authors ${ }^{64}$ assign a lower percentage value to it, but even they obtain very high values 
in moulds. In some bacteria, on the other hand, this efficiency is incomparably less and this is associated with incomplete co-ordination of the various links of their chains of energy metabolism.

The energy metabolism of the primaeval organisms must certainly have been at a still lower level of development. The commencement of this metabolism must, however, have taken place in the very early stages of the evolution of our original systems as the only easily mobilised sources of energy available to them were organic compounds which entered the system from outside. However, if the energy contained in these substances was to be released, they had to be broken down in some way. At first this breaking down took many forms and followed various paths and its efficiency must therefore have been very low.

Later, however, selection led to the formation of several standard paths which formed the basis of the energy exchange of all living things without exception. The earliest reactions in the process of glycolysis, in particular, seem to constitute such paths. They have been found in all organisms where they have been looked for.

As we saw above, the definite organisation of the network of metabolic reactions also forms the basis for the synthesis of all the substances formed in living matter. This may be demonstrated above all by the origin of the property which first Pasteur ${ }^{65}$ and then Vernadskii ${ }^{66}$ considered to be one of the most characteristic features of life, namely, the asymmetry of protoplasm.

What is the cause of this asymmetry? Why is there only formed in living protoplasm one particular optical configuration of amino acids and other similar compounds?

In Chapter $\mathrm{V}$ we indicated that in the original solution of organic substances the action of circularly polarised light or selective synthesis on the surfaces of quartz crystals could have led to the appearance of a certain dissymmetry, some predominance of the dextro or laevo antipodes of particular compounds. This original asymmetry may have formed the basis for the asymmetry of all later organic formations.

It is generally supposed that one molecule with a particular optical configuration gave rise to another exactly similar 
molecule, 'multiplied' so to speak more and more, so that there was a steady increase on the surface of the Earth in the amount of the compounds which belonged to the series of optical isomers in question. A detailed examination of the subject shows, however, that the matter is considerably more complicated.

W. Kuhn ${ }^{67}$ in his day undertook a detailed analysis of all the evidence then available concerning asymmetric synthesis. He showed, in the first place, that a racemic mixture is thermodynamically more stable than its separate optically active components because the free energy is less in the racemic mixture. Any mixture of optically active substances will, therefore, tend to racemise and lose its optical activity. In any synthesis mediated by an asymmetric catalyst (e.g. an enzyme) at first only one optical antipode will be formed quickly. However, the other antipode is formed too, but in an amount which is as many times smaller than that of the first as the rate of the synthesis in the presence of the catalyst is greater than the rate without the catalyst. This will lead to the appearance of a certain asymmetry, a certain inequality between the amounts of the dextro and laevo antipodes. But as a true catalyst increases the rate of a reaction and of the reverse reaction, after equilibrium has been reached some of the product of the synthesis will be converted into the starting substance giving rise, though very slowly, to fresh amounts of the antipode which is synthesised without the catalyst. Thus the whole system will tend towards the racemic state and the optical activity which arose as a result of the action of the asymmetric catalyst will gradually get weaker as may, in fact, be demonstrated by experiment. ${ }^{68}$

Thus the asymmetry which arose in an enclosed system owing to the activity of any isolated reaction must have been a temporary phenomenon and could not have served as a basis for the formation of the very complete and constant asvmmetry of protoplasm.

The continual formation of only one optical antipode can only occur in open systems on the basis of a definitely organised network of reactions, the rates of which are very accurately related to one another. Under such conditions, when there is a definite sequence of processes, racemisation 
or the appearance of the opposite antipode may be avoided altogether and the system may retain its asymmetry indefinitely. ${ }^{69}$

Thus the asymmetry of protoplasm is due to its definite organisation in time, the co-ordination of the reactions occurring in it. This co-ordination certainly did not arise by chance. It was enabled to arise by selection of the original systems, for, according to W. H. Mills, ${ }^{70}$ everything else being equal, reactions proceed at a significantly slower rate in racemic mixtures than in optically active mixtures. Systems made up of asymmetric material must therefore have been more effective in the struggle for existence than their competitors made up of racemic mixtures.

Systems, in which a definite co-ordination of reactions had led to the formation of asymmetry, carried out their syntheses more quickly than otherwise identical systems based on racemic mixtures. The growth of the former must therefore have been significantly faster and their dynamic stability must have been greater. As a result of all this the action of selection must have tended to increase the asymmetry of the substances entering into the composition of our original colloidal systems from the first stages of their evolution. In contemporary protoplasm this asymmetry has reached a very high level ; there is an extremely high degree of optical purity which can only be present as a result of a very close coordination of the rates of the reactions contributing to the synthesis of the substances in question. ${ }^{71}$

In order to renew and preserve themselves continually in a state of uninterrupted interaction with the external medium, our original systems could extract the ingredients which they needed ready-made from the medium, sometimes in the form of very complicated organic molecules. However, even at the earliest stages of the evolution of our original systems, the substances entering them must have undergone some sort of chemical transformation, otherwise the properties which characterise open systems could not have arisen. As we saw above, this did not involve any direct 'multiplication' of the individual molecules, they could not ' reproduce themselves' directly. What did occur was only a more or less constantly repeated formation of new material based on 
chemical reactions taking place in a certain sequence. Thus, for the progressive evolution of our original systems the important thing was not the chance entry or development of any particular compound, but the appearance of a definite co-ordination of the reactions which provide the constant synthesis of this compound in the system in continuous interaction with the external medium.

The more closely the chemical substances entering it from the external medium resembled ingredients of the system itself, the less complicated were the chains of reactions leading to its synthesis and the simpler was the metabolic organisation. However, the system was correspondingly more dependent on the constancy of the external medium and on its high content of complicated organic compounds.

Clearly the selection of our original systems and the emergence of the first organisms from among them must have been directed towards a lessening of this clependence and the formation of networks of synthetic reactions by which the complicated ingredients of the system could be synthesised unerringly from the somewhat diverse compounds which entered it from the external medium. For this purpose the compounds in question had to be 'standardised', that is to say, broken down to relatively simple and uniform fragments from which any specific ingredients of the system could be built up by standard methods, though using complicated chains of transformations with many links.

We do, in fact, find such a form of organisation in the constructive metabolism of contemporary organisms. In them, as we have pointed out several times, very simple compounds of low molecular weight such as oxalic acid, glycine, succinic acid, keto acids, etc., serve as starting points for the synthesis of proteins, nucleic acids, lipids, porphyrins and the other complicated ingredients of protoplasm. These simple compounds arise as fragments split off in the course of the destructive metabolism of the sugars and other substances which enter the cell from its surrounding medium and serve as its nutrients. In the course of this destructive metabolism the energy needed for synthesis is liberated and stored in ATP and other compounds with high-energy bonds. We have already explained this with reference to glycolysis 
and the tricarboxylic acid cycle of Krebs. These examples show that the biosynthetic processes, which form the basis for the formation of the living material of organisms, are intimately associated with destructive metabolism, from which they obtain their original structural materials and the energy needed for synthesis.

The route by which the fragments under discussion are built up into proteins, nucleic acids or porphyrins is, of course, very complicated and consists of a series of successive reactions. Such syntheses can, therefore, only take place by means of a very precise and absolutely constant co-ordination of these successive reactions, by means of a very highly developed organisation of the metabolic network. This was also essential for the appearance of the most characteristic feature of life, the capacity for self-reproduction.

Thus, we can now already give an indication, though still only a very rough and speculative one, of the actual course of development leading from the initial systems to the simplest organisms during the emergence of life on our planet. This development involved successive improvements in the networks of reactions within individual colloidal systems which were reacting with the external environment. Owing to continual changes in these systems, within the limits of their dynamic stability, they underwent the following transformations. First there was the formation of individual catalysts of great reactivity and specificity. Later the activity of these catalysts was co-ordinated and there arose the whole chains and cycles of enzymic reactions which form the basis for the separate departments of metabolism. Still later came the spatial organisation of the system and the localisation of processes and the rationalisation of the interacting energic and structural branches of metabolism. This guaranteed, within limits, the continual self-preservation and selfreproduction of living systems.

The nature of this organisation may, naturally, vary within limits in different representatives of the living world, but it is always an expression of the degree of integration attained by the organism in the course of its evolutionary development. A comparative study of contemporary living things will enable us to form an opinion as to the course of the 
successive integration of this remarkable form of the motion of matter which came into being at some time on the Earth.

BIBLIOGRAPHY TO CHAPTER VIII

1. (VI. 6).

2. A. S. Konikova and M. G. Kritsman. Voprosy Filosofii, I954, no. 1, p. 210.

R. Brunish and J. M. Luck. J. biol. Chem., 197, 869 (1952).

3. M. G. Kritsian, A. S. Konikova and Ts. D. Osipenko. Biokhimiya, 17,488 (1952).

4. T. E. Pavlovskaya, M. S. Volkova and A. G. Pasinskily. Doklady Akad. Nauk S.S.S.R., IOI, 723 (1955).

5. (VI. 6).

6. (III. 75).

7. (VII. 87).

8. (VII. 71).

9. A. G. Pasynskir. Uspekhi sovremennol Biologii (in Press).

10. N. Kol'tsov. Organizatsiya kletki. Moscow and Leningrad (Biomedgiz), 1936.

11. H. G. Wood, R. W. Brown and G. H. Werkman. Arch. Biochem., 6, 243 (1945).

12. G. Ehrensvärd. Ann. Rev. Biochem., 24, 275 (1955).

13. R. Robinson. Nature, Lond., 137, 172 (1936).

14. R. Scotт-MoncriefF. Ergebn. Enzymforsch., 8, 277 (1939). 15. V. I. Nılov. Izvest. Akad. Nauk S.S.S.R. (Ser. biol.), 6, 1709 (1937).

K. Paech. Biochemie und Physiologie der sekundären Pflanzenstoffe. Berlin, 1950 .

16. A. Kursanov. 7-oe Bakhouskoe chtenie. Moscow (Izd. AN SSSR), 1952 .

17. K. Мотнes. Ann. Rev. Plant Physiol., 6, 393 (1955).

18. W. H. Sebrell and R. S. Harris (ed.). The l'itamins. New York, 1954.

19. T. N. Godney and A. A. Shlyk. Priroda, 1955 , no. 5 , p. 48. 20. D. W. Woolley. A study of antimetabolites. New York, 1952.

21. (VI. 188).

22. (VI. 209).

23. A. I. Oparin, T. N. Evreinova, T. A. Shubert and M. N. Nestyuk. Doklady Akad. Nauk S.S.S.R., ro4, 581 (1955). 
24. K. Oppenheimer. Die Fermente und ihre Wirkungen. Leipzig, $1925^{-1929 .}$

F. F. Nord and R. Weidenhagen (ed.). Handbuch der Enzymologie. Leipzig, 1940.

25. J. H. Northrop, M. Kunitz and R. M. Herriott. Crystalline enzymes (2nd edn.). New York, 1948.

J. B. Sumner and G. F. Somers. Chemistry and methods of enzymes (2nd edn.). New York, 1947.

26. E. A. Moelwyn-Hughes in The Enzymes (ed. J. B. Sumner and K. Myrbäck). Vol. 1, Part 1, p. 28. New York, $195^{\circ}$.

27. V. L. Kretovich, A. A. Bundel', S. S. Melik-Sarkisyan and K. M. Stepanovich. Biokhimiya, 19, 208 (1954).

28. K. Zeile and H. Hellström. Hoppe-Seyl. Z., I92, 171 (1930). K. ZeIle. Hoppe-Seyl.Z., I95, 39 (1931).

29. P. V. Afanas'ev. Biokhimiya, If, 259 (1949).

B. Chance. Advanc. Enzymol., I2, 153 (1951).

30. S. Spiegelman. Conférences et Rapports. 3-ème Congrès international de Biochimie, Bruxelles, I-6 Août 1955, p. 185 . Liège, 1956 .

31. W. Langenbeck. (VI. 66) ; Adyanc. Enzymol., 14, 163 (1953). 32. K. Lohmann and P. Schuster. Biochem. Z., 294, 188 (1937). 33. A. N. Bakн. J. Russ. phys.chem. Soc. (Chem. section), 29 (div. 1), 373 (1897); 44 (div. 2), 1 (1912).

34. L. Pasteur. C.R. Acad. Sci., Paris, 8o, $45^{2}$ (1875).

35. E. Buchner, H. Buchner and M. Hahn. Die Zymasegärung. Munich, 1903.

E. Buchner and R. Rapp. Ber. dtsch. chem. Ges., 32, 127 (1899).

36. S. Kostychev. Izbrannye trudy po fiziologii $i$ biokhimii mikroorganizmov. Moscow (Izd. AN SSSR), 1956.

A. LEBEDEV. Khimicheskie issledovaniya nad vnekletochnym spirtovym brozheniem. Novocherkassk (Tip. Mamontova), 1913 .

F. F. NORD in Handbuch der Enzymologie (ed. F. F. Nord and R. Weidenhagen), p. 968. Leipzig, 1940.

37. A. Oparin. Biochem. Z., I82, 155 (1927).

38. T. Bersin in Handbuch der Enzymologie (ed. F. F. Nord (VI. 65). and R. Weidenhagen), p. 154 . Leipzig, 1940.

39. N. M. Sisakyan. Fermentatiunaya aktiunost' protoplazmennykh struktur. Moscow (Izd. AN SSSR), $195^{1 .}$ 
40. A. Kunsanov. Obratimoe derstvie fermentov v zhivol rastitel'nol kletke. Moscow (Izd. AN SSSR), 1940.

41. A. I. Oparin. Uspekhi Khim., 3, 200 (1934); Ergebn. Enzymforsch., 3, 57 (1934); Bull. Soc. Chim. biol., Paris, 32, 306 (1950); (VI. 153).

42. (VI. $15^{8}$ ).

43. H. U. Zollinger. Amer. J. Path., 27, 545 (1948).

F. SJöstrand. Nature, Lond., I68, 646 (1951).

K. W. Clela ND. Nature, Lond., I7o, 497 (1952).

44. J. D. Bernal. Lectures to Moscow State University, September $195^{6}$.

45. A. Claude. J. exp. Med., $\mathcal{S}_{4}, 51$ (1946).

46. W. C. Schneider and G. H. Hogeboom. Cancer Res., II, 1 (1951).

47. A. Claude. J. exp. Med., So, 19 (1944).

48. D. E. Green. Symposium sur le cycle tricarboxylique. zème Congrès international de Biochimie, p. 5. Paris, $195^{2}$.

49. V. L. Kretovich and A. A. Bundel'. Doklady Akad. Nauk S.S.S.R., 59, 1595 (1948).

V. L. Kretovich, A. A. Bundel' and K. B. Aseeva. Doklady Akad. Nauk S.S.S.R., So, 225 (1951).

5o. A. Braunshteǐn. Biokhimiya aminokislotnogo obmena. Moscow (Izd. AMN SSSR), 1949; I2-oe Bakhorskoe chtenie. Moscow (Izd. AN SSSR), 1956.

51. S. Oснол. Symposium sur le cycle tricarboxylique. 2ème Congrès international de Biochimie, p. 73. Paris, 1952 .

52. B. Chance and L. Sinth. Ann. Rev. Biochem., 21,687 (1952).

53. F. Lipmann, M. E. Jones and S. Black. Symposium sur le cycle tricarboxylique. 2-ème Congrès international de Biochimie, p. 55 . Paris, 1952.

54. J. Brachet. Enzymologia, 10, 87 (1941).

P. C. Zaniecnik. Ann. Rev. Biochem., 21, 411 (1952).

P. Siekevitz. J. biol. Chem., I95, 549 (1952).

55. J. E. SNoke and F. Rothman. Fed. Proc., Io, 249 (1951).

56. C. Veninely. Arch. Anat., Strasbourg, 33, 113 (1950).

57. (VII. 35).

5 8. T. N. Evreinova. Biofizika, $I, 167(1956)$.

59. (VII. 41); (VII. 51).

60. (VII. 82).

61. H. A. Krebs. Symposium sur le cycle tricarboxylique. zème Congrès international de Biochimie, p. 42. Paris, $195^{2}$. 
62. (IV. 35).

63. H. Tamiya. Acta phylochim. Tokyo, 6, 265 (1932); 7, 27 (1933).

64. J. W. Foster. Chemical activities of fungi. New York, 1949. 65. (V. 151 ).

66. (II. 9).

67. (V. 159).

68. (V. 167).

69. P. D. Ritchie. Asymmetric synthesis and asymmetric induction. Oxford, 1933 .

7o. W. H. Mills. J. Soc. chem. Ind., 5 I, $75^{0}$ (1932).

71. (V. 143). 


\section{THE FURTHER EVOLUTION OF} THE FIRST ORGANISMS

\section{The concept of comparative biochemistry.}

Strictly speaking, the origin of the first organisms should conclude an exposition of the origin of life on the Earth. When this had taken place matter entered into a new, biological stage of its development. There began the evolution of living things from the most primitive original organisms to the highly-developed plants and animals which now live on our planet.

Careful study of this already purely biological evolution may, however, be very helpful towards understanding the actual origin of life, the way in which it came into being. At the present time we cannot observe this process directly in nature because all the intermediate links, the more primitive and incomplete forms of organisation of living matter, would appear to have been destroyed long ago, swept from the face of the Earth by natural selection. However, a study of the organisation of protoplasm in contemporary organisms at different levels on the evolutionary scale provides us with some objective evidence as to the nature of the earliest forms in which life existed on the Earth.

Especially valuable in this respect is the study of metabolism, that ordered series of biochemical processes which forms the basis of the organisation of protoplasm in time and in space. As we saw above, metabolism occurred even in the very earliest organisms, but was altered and brought to a higher degree of integration during the process of their evolutionary development. This involved the repeated appearance of new conjunctions of biochemical reactions and new chemical mechanisms within the protoplasm on which these reactions depended. These enabled organisms to make better 
use of a wider variety of sources of energy and starting materials required for life, for constant self-renewal and selfreproduction. A comparative study of metabolism in primitive and highly-developed organisms enables us to understand the characteristic features of the organisation of chemical processes which is the very foundation of life and which arose by the same process which brought life into being.

As a comparative study of the structure of the organs of individual animals enables an anatomist to piece together a picture of their evolutionary development and allows us to look into their remote past, so also a comparative study of the metabolism of different organisms enables a biochemist to approach the actual origin of life and to understand the more primitive forms of its organisation.

Comparative biochemistry, in this sense, is still a very young subject. It is only very recently that any significant factual material has been collected to enable us to compare the organisation of metabolism, its individual links, in different representatives of the living world. Even now this material is far from comprehensive and permits few generalisations.

The great obstacle to the interpretation of the evidence of comparative biochemistry is that the evolution of metabolism is not a single process proceeding in a straight line. It follows paths which are winding and confusing, very varied, often intersecting and sometimes even reversing themselves.

However, a comparative study of the chemistry of protein synthesis, fermentation, respiration, chemo- and photosynthesis and other vital processes in different micro- and macro-organisms shows that the new concatenations of biochemical reactions which arise during evolution do not by any means always supplant the old metabolic chains of metabolism but merely supplement them, forming, as it were, an auxiliary 'superstructure' on the existing chemical mechanisms of the protoplasm. In certain sections of metabolism we may even sometimes see two parallel chains of chemical transformations, of which the newer one is used extensively in metabolism while the older one is, essentially, only a reserve. It is, nevertheless, preserved intact, and when 
the conditions of existence are radically changed, the organism possessing such a chain can easily fall back on it.

This may, to some extent, serve as a guicling thread in the complicated labyrinth of intersecting paths of metabolic evolution. If we establish that a given system of biochemical reactions is peculiar to the metabolism of a definite, more or less well-defined group of organisms and is absent from all other living things; and if it only forms an accessory superstructure in the metabolism of these organisms while the chemical changes in which it participates are based on a more generally-used catalytic mechanism; and if, finally, under certain conditions, this superstructure may be displaced or superseded by the other mechanism; then we are justified in regarding such a set of reactions as a supplementary system of metabolism which only arose at a later stage in the phylogenetic development of the organisms in question.

In contrast to this, in the study of the metabolism of different sorts of organism we also meet with chemical systems and catalytic mechanisms which seem to be extremely widely distributed, to be present in all groups of living things without exception, in protozoa, bacteria, algae, fungi, terrestrial green plants and all the various categories of the animal world. We are justified in considering such metabolic systems as being of more ancient origin and as forming the very basis of the organisation of living things.

\section{The first living things-heterotrophs and anaerobes.}

Working in this way, trying to detect the points of similarity among the tremendous variety of metabolic systems in different organisms, the features of organisation which are most widespread among all living things and which are therefore most ancient, we can put forward two cardinal theses.

In the first place, the metabolism of all living things is based on the ability to use ready-made organic substances as the starting materials for the construction of proteins, nucleic acids and other components of protoplasm and also as the immediate source of energy for these biosyntheses. This ability is characteristic even of those organisms which 
have a chemical organisation enabling them to synthesise organic compounds directly from carbon dioxide, water and mineral salts and which can use such sources of energy as sunlight and the oxidation of inorganic substances for the purpose.

In the second place, the general method whereby all organisms obtain energy from organic substances is by decomposing them anaerobically. Many contemporary living things have chemical mechanisms which enable them to use the energy of organic substances far more fully and efficiently by their complete oxidation by the oxygen of the air in the process of respiration, but their metabolism is also based on the same system of anaerobic decomposition which is common to all organisms.

These generalisations have been established by means of a comparative study of the metabolism of all sorts of contemporary organisms. They provide a solid confirmation of the hypothesis concerning the way in which the first living things arose which we propounded in the previous chapters. The taking in of organic substances dissolved in the surrounding aqueous medium and their transformation into parts of its own body is, obviously, the absolutely indispensable form of metabolism in a living body which arises by the incorporation of polymeric organic compounds into multimolecular systems. Even the coacervate drops which were first formed in the waters of the primaeval ocean must have been able to incorporate in themselves the organic substances of the surrounding medium. All their subsequent evolution was based on the natural selection of those systems which could assimilate these substances most quickly and efficiently.

The first organisms which arose in this way needed readymade organic substances primarily for keeping the balance of their metabolism constantly positive and for the fastest possible synthesis of the proteins, nucleic acids, enzymes and other components of the living system. The more primitive the organisation of such a system the greater the demands it will make on the starting structural material and the more similar this material must be to the components of the living body which are to be synthesised from it. Many contemporary organisms can synthesise quite complicated organic 
compounds from very small original molecules; the carbon skeletons of the various amino acids, including the aromatic and heterocyclic ones, are built up by contemporary organisms from acetic acid and other simple breakdown products of monosaccharides. ${ }^{1}$

Ammonia, oxaloacetic acid, glycine and formyl residues serve as the material for the synthesis of purine and pyrimidine bases, ${ }^{2}$ while glycine and succinic acids serve for porphyrins, ${ }^{3}$ etc. However, as we have mentioned above, such syntheses require the presence of a very highly developed organisation of protoplasm. If the very simple starting ma. terials are to be transformed into complicated organic compounds the biosynthesis must occur by means of a long series of intermediate stages. These must be very well co-ordinated in time so that the intermediate product which is formed as a result of one reaction will be completely transformed by the next reaction into a new and more complicated compound. The greater the number of links in a metabolic chain the more its realisation will depend on specific enzymes or even on whole complexes of enzymes, and the more accurate must be the co-ordination of the velocities of the separate reactions, both those whereby the small molecules are converted into larger formations and those supplying the energy required for these syntheses.

In $1945 \mathrm{~N}$. H. Horowitz. ${ }^{4}$ on the basis of studies of the fungus Neurospora, gave a very interesting schematic account of the way in which the synthetic abilities of the primary living things became more complicated during their evolution, though this scheme still requires some biochemical particularisation. The gist of Horowitz' scheme is as follows : Let us assume that some very simple organism required the rather complicated compound $\mathrm{A}$ for its vital processes. If this compound were present, ready-made, in the surrounding medium the organism could assimilate it directly without possessing any chemical ability to synthesise the substance. However, if there should arise a deficiency of the material in the outside medium, or if it should vanish altogether, the only organisms which could continue to exist would be those in which there had somehow arisen a new chemical mechanism enabling them to synthesise substance A from 
the simpler substances $\mathrm{B}, \mathrm{C}$ or $\mathrm{D}$ which were present in sufficient amounts in the surrounding medium. This would then be repeated for substance $B$ when it disappeared from the external medium, and so forth.

Thus, the ability to synthesise any particular complicated component of protoplasm must depend on each separate link in the process having arisen successively in the course of the prolonged evolution of organisms. According to Horowitz, the first living things must have been completely heterotrophic in the sense that they needed ready-made, complicated, organic compounds for the building up of their bodies.

Even for such building up, however, energy was needed and the source of energy most readily available when the organisation of the living bodies was still primitive was, once again, organic substances. They contain large, hidden stores of potential energy which can be mobilised comparatively easily in the course of their degradation and used for biosynthesis either by means of linked reactions or by the formation of high-energy compounds. The exploitation of any of the other kinds of sources of energy in the external medium would have required the presence in the organism of accessory systems which could only have arisen in the course of very prolonged evolution.

It is quite clear that the mobilisation of energy by the first organisms could only have been brought about by the anaerobic degradation of organic substances, as there was no molecular oxygen in the atmosphere of the Earth under the reducing conditions which prevailed at the time when these organisms existed. Only when free gaseous oxygen appeared in the atmosphere did there arise the theoretical possibility of oxidising organic substances completely, in order to use the energy locked up in them. In order to realise this possibility, however, the organisms must, in addition to their primary, anaerobic, energy metabolism, have created in the course of their evolution, under the new conditions of the external medium, new oxidative enzymes and new systems of reactions which certainly could not have arisen at earlier periods in the history of life when the atmosphere was of a reducing nature.

The gradual complication and integration of both the 
synthetic and energy-yiclding reactions of metabolism could not occur as a single process following a direct course. It followed different and very divergent paths in different representatives of the living world. As this went on, some organisms were quicker to acquire the power to synthesise complicated organic compounds, while others set up mechanisms which enabled them to use a greater variety of sources of energy. Owing to this, the heterotrophic nature of contemporary organisms, their dependence on organic nutriment, is very diverse. For example, some representatives of the genus Hydrogenomonas do not require organic nutrients for their energy metabolism and can use $\mathrm{CO}_{2}$ as the sole source of carbon for the construction of their substance, though they cannot synthesise the prosthetic groups of some of the enzymes which they need. They have to obtain these readymade from the environment, as vitamins, otherwise they cannot exist. ${ }^{5}$

Moulds, on the other hand, have a very highly developed ability to synthesise various very complicated organic compounds, vitamins, antibiotics, etc., but they are typical heterotrophs in the sense that they can only grow on organic substrates (e.g. on sugar solutions) which act as non-specific sources of energy and carbon for the construction of the components of their protoplasm. ${ }^{6}$

In view of this, the concept of heterotrophy itself is far less simple than it might seem at first glance. The classification of various organisms according to their nutrient requirements which are current in scientific literature at present (e.g. those of R. Hall ${ }^{7}$ and $\mathrm{A}$. Lwoff ${ }^{8}$ ) are very complicated and often rather confusing as well. Attempts to form a picture of the progress of the evolution of organisms in this respect are even more contradictory, 10 because, in some cases, an obligatory requirement for some particular organic substance may also arise secondarily owing to the dropping out of some chemical, metabolic mechanisms which had been elaborated a: a preceding evolutionary stage.

It is, nevertheless, a self-evident and generally accepted fact that the overwhelming majority of biological forms now living on our planet can only exist in the presence of readymade organic substances. 
This includes all animals, both higher and lower, among them most of the protozoa, the vast majority of bacteria and all fungi. This fact by itself is very significant. It is, in fact, hardly possible to imagine the evolution of all these multifarious living things, entirely in accordance with the simplified scheme suggested by Bateson, as the complete loss of that ability to nourish themselves autotrophically which they once possessed.* This is also contradicted by intensive biochemical studies of the whole metabolic system of these organisms. In the heterotrophs we do not find the specific enzymic complexes and concatenations of reactions which are characteristic of autotrophs. On the other hand, the metabolism of autotrophs is based on the same internal chemical mechanisms as that of all other organisms which can only exist by consuming organic substances. This is what allows autotrophs under some conditions to revert so easily to heterotrophy. This can be confirmed, not only by rather intricate biochemical analyses of the metabolism of different organisms, but even by comparatively simple physiological observations on their nutrition.

The colossal amount of factual material at the disposal of contemporary students of vitamins and essential amino acids shows clearly how widely the requirements for specific, readymade, organic compounds are distributed among all the inhabitants of the world. Of course, these requirements may arise secondarily in a number of individual cases, as a result of a certain regression, the dropping out of particular synthetic mechanisms which had previously been built up in the organism. For example, it is possible by certain procedures to cause some particular bacteria, which were previously able to synthesise all the essential amino acids which they required, to lose this ability. ${ }^{12}$ The relative ease with which 'mutants' of this sort can be obtained indicates that the synthetic mechanism in question is not fundamental to the metabolism which enables the organisms to remain alive. The mechanism can be destroyed or removed but the organism continues to exist so long as the surrounding medium contains the amino acids or vitamins which it needs. * An extended critique of hypotheses of this sort is given in V. Polyanskiì's
interesting article.11-Author. 
This sort of requirement for ready-made, specific, organic substances may be met with under natural conditions in organisms at the most varied levels of the evolutionary scale, not only among obligate heterotrophs, but even in organisms which in all other respects can dispense with organic nutrients.

As we have already seen in the case of Hydrogenomonas, even chemoautotrophs sometimes require specific organic nutrients such as vitamins, although in general they may serve as examples of organisms in which there have been set up, during the course of evolution, extremely thoroughgoing mechanisms for the carrying out of diverse syntheses.

This is true to an even greater extent among the photoautotrophs, many of which, either during the whole of their life cycle, or at particular stages of it, require exogenous organic substances such as vitamins, growth factors, essential amino acids, etc. This concerns the lower chlorophyll-containing organisms in particular. Thus, for example, some species of green flagellates like Euglena, even when growing in light, cannot do without amino acids or peptones for building up their bodies, while other species, although they can use mineral nitrogen, can equally well use amino acids as nutrients. ${ }^{13}$

The requirement for vitamins, in particular for vitamin $B_{1}$ and various growth factors, is very widespread among most of the algae, among the blue-green algae and diatoms as well as among the green forms. ${ }^{14}$

E. G. Pringsheim ${ }^{15}$ has already pointed out that exogenous organic substances must be added to pure cultures of algae, and now various organic extracts are always added when growing such cultures (except, of course, when special investigations are being carried out).

The situation in regard to vitamin $B_{12}$ in various algae is extremely interesting. Although algae contain a large amount of this vitamin they cannot synthesise it but obtain it from symbiotic bacteria. ${ }^{16}$

Intensive investigations have shown that, in other cases too, the extremely widespread occurrence of the parasitic mode of life among many algae is associated with their requirement for specific organic substances. This applies, in particular, to the symbiosis established in lichens ${ }^{17}$ and the 
constant presence of algae within the bodies of some infusoria and other kinds of animals. The scientific literature also contains references to large numbers of cases of parasitism, not only among green algae, but also among blue-green, diatomaceous and brown and purple forms. ${ }^{18}$

In this, as in other forms of parasitism, regression undoubtedly takes place, the loss of the internal chemical abilities which the original organism possessed and which enabled it to build up the necessary organic substances autotrophically. However, this return to the past could not occur so readily unless there were already present some phylogenetically earlier mechanism for heterotrophic nutrition.

The higher green plants which have a very highly developed apparatus for the synthesis of different substances have, to a large extent, freed themselves from dependence on preformed vitamins, if we consider the organism as a whole. Nevertheless, separate parts of such plants grown in isolation in tissue cultures are absolutely dependent on an exogenous supply of vitamins and other organic substances. ${ }^{19}$

Not only do many green photoautotrophs need specific organic substances but, in general, they can all very easily be induced to nourish themselves on ready-made exogenous organic compounds, notwithstanding the fact that during the process of evolution, they long ago acquired the ability to synthesise these substances for themselves from mineral salts at the expense of energy derived from sunlight. Such an easy transition to ordinary heterotrophism demonstrates once more that the metabolism of photoautotrophs is based on chemical mechanisms which can derive energy from readymade organic substances.

It is understandable that the less highly organised photoautotrophs are specially liable to manifest their tendency to heterotrophism and revert to it with particular readiness under both laboratory and natural conditions.

As an example of complete transition from autotrophic to heterotrophic nutrition we may mention the experiments of C. Ternetz ${ }^{20}$ and a number of later authors on Euglena. Starting from the green forms of this organism it is possible to obtain completely colourless forms which can only nourish themselves heterotrophically. This is done by cultivating 
the Euglena on organic substrates in the dark, or even in the light when the medium is very rich in organic substances. The colourless cultures obtained in this way can live and grow for many years because they can nourish themselves by purely heterotrophic means.

As early as the beginning of the twentieth century it was shown that if algae were supplied artificially with organic substances it had a very favourable effect on their growth and development. ${ }^{21}$ The direct experiments of A. Artari ${ }^{22}$ on the utilisation of organic substances by pure cultures of algae showed that glucose, fructose, maltose, sucrose, peptones, asparagine, lysine, glycerol, mannitol, inulin and many salts of organic acids formed excellent nutrients for many unicellular forms of green algae. When supplied with these substances the algae develop equally well in the light and in the dark.

Later experiments ${ }^{23}$ established beyond doubt that when organic substances are introduced in to cultures of green algae they are assimilated directly. This may occur alongside the process of assimilation of $\mathrm{CO}_{2}$, but in some cases this process may be put out of action and the algae turn over to an entirely saprophytic way of life. Under these conditions blue-green algae such as Nostoc, ${ }^{24}$ diatoms and such green algae as Spirogyra flourish luxuriantly.

Working with soil algae (Scenedesmus costulatus) B. M. B. Roach $^{25}$ established that they could grow in the clark on media to which glucose had been added as a carbon-containing nutrient. C. B. Skinner and C. G. Gardner ${ }^{26}$ showed that, in pure cultures of green algae, casein, albumin and glucose could serve as nutrients for the organisms. Nowadays media composed of potatoes, meat peptones or wort are successfully used for the culture of various algae. ${ }^{27}$

It would appear that many blue-green and other algae can use the organic materials found in mud under natural conditions too. This is indicated by the very fact that they develop specially luxuriantly in stagnant waters and in other similar places which are rich in organic substances.

The view that heterotrophy is the primary mode of nutrition is also supported by the results of investigations on higher green plants (i.e. organisms which have long been 
adapted to the autotrophic way of life). Only those cells in them which contain chlorophyll possess the chemical mechanism for photosynthesis. It is in them alone that there occurs that primary synthesis of organic substances which are used as nutrients by all the rest of the colourless tissues of the plant. These are nourished in a purely heterotrophic way just as fungi are nourished by the addition of sugar to the culture medium. The leaves, too, are nourished in this same way in the absence of light.

Thus, the metabolism of the plant as a whole is based on a heterotrophic mechanism using organic substances as nutrients although, in its green tissues, this mechanism is combined with an additional specific apparatus whose function is to supply the whole organism with ready-made organic substances. If the plant is supplied in some way with such substances from without, it can exist even without its photosynthetic apparatus. This takes place under normal natural conditions, in particular during the germination of seeds. It can be demonstrated experimentally by, for example, raising a whole adult plant of the sugar beet in the dark from a one-year-old root. Finally, it may also be observed in cases where higher plants have lost their ability to synthesise owing to having become parasitic, e.g. in broomrapes. ${ }^{28}$

In all these cases the plant lives and nourishes itself on exogenous organic substances while its photosynthetic autotrophic apparatus is completely inactive. But if even one link of the enzymic chain of heterotrophic metabolism is disrupted, all the vital activities of the plant cease and it is destroyed. This may be observed, in particular, during the specific poisoning of phosphoglyceraldehyde dehydrogenase with monoiodoacetic acid or of enolase with sodium fluoride. ${ }^{29}$

Hence it is quite clear that the vital processes of photoautotrophs, including the higher plants, are based on the primary and ancient heterotrophic form of metabolism while the ability to synthesise organic substances by using the energy of light only arose in them as an accessory apparatus on this basis.

The situation is less clear in regard to the chemoautotrophs, mainly because their metabolism is, as yet, very little studied in comparison with that of other organisms. Even 
in the time of $\mathrm{S}$. Vinogradski ${ }^{30}$ it was suggested in regard to these organisms (as well as to the more pronounced autotrophs which can develop in purely mineral media) that organic substances not only were not assimilated by them but actually hindered their growth, i.e. were toxic to them.

This idea had its theoretical basis in the preconceived conviction, which was referred to in Chapter IV, that the first organisms must have been able to make organic materials for themselves because none were present on the Earth before the origin of life.

For this reason the chemoautotrophs were also regarded as extremely primitive organisms, the organisation of which lacked the chemical mechanisms which enabled all other living things to use organic substances as sources of energy and as immediate structural materials for the synthesis of the components of their protoplasm.

This idea of the primitiveness of the metabolism of chemoautotrophs was due to the fact that our knowledge of it was, and to some extent still is, very limited. But the further the study of this field progresses the clearer it becomes that the organisation of the metabolism of chemoautotrophs is very complicated in comparison with that of many other living things. ${ }^{31}$ Their ability to use energy derived from the oxidation of inorganic substances for the synthesis of the components of their protoplasm is not due to the simplicity of their organisation. On the contrary, they manifest a high degree of complexity and integration which could not, by any means, be primary but must have arisen as a result of prolonged evolution. This is indicated by the fact that the overwhelming majority of chemoautotrophs are markedly or, so to speak, 'essentially' aerobic. The characteristic reactions on which their autotrophy is based take the form of the oxidation of reduced inorganic compounds by molecular oxygen. The catalytic mechanisms underlying these reactions could obviously not have arisen during the period when reducing conditions prevailed on the Earth. They could only have been elaborated secondarily, when the atmosphere of our planet had been considerably enriched with free oxygen.

It is very characteristic of chemoautotrophs that a more searching investigation of their complicated metabolism 
reveals the presence, alongside these oxidative mechanisms, of the same enzymic complexes which form the basis of the heterotrophic and anaerobic metabolism of all other living things. This is what allows many chemoautotrophs to go over readily to a heterotrophic way of life under certain circumstances.

Actually, facts have been assembled in the scientific literature for a comparatively long time indicating that many organisms which can exist as pure chemoautotrophs can, at the same time, assimilate organic substances very well. This was established for hydrogen bacteria as early as 1910 by A. Lebedev ${ }^{32}$ and was later confirmed by W. Ruhland. ${ }^{33} \mathrm{~K}$. Trautwein ${ }^{34}$ and R. L. Starkey ${ }^{35}$ working with Thiobacillus trautweinii, and P. A. Roelofsen ${ }^{36}$ and M. S. Cataldi ${ }^{37}$ working with other sulphur bacteria, showed that these can grow heterotrophically in the absence of oxidisable inorganic substrates and in the presence of the organic substances which they require. The same was established for many iron bacteria by the experiments of $\mathrm{H}$. Molisch, ${ }^{38} \mathrm{R}$. Lieske, ${ }^{39}$ M. S. Cataldi, ${ }^{40}$ V. O. Kalinenko $0^{41}$ and others.

In presenting an account of the extensive experimental evidence which has now been collected, C. B. van $\mathrm{Niel}^{42}$ reaches the conclusion that organic substances have a less deleterious effect on most chemosynthetic bacteria than is commonly supposed. Only Nitrosomonas, Nitrobacter, four species of Thiobacillus (in particular $T$. thiooxidans and $T$. thioparus) and forms related to these species can be considered as 'strict' autotrophs (and this only in a somewhat provisional sense). All the other chemoautotrophs, according to van Niel, are not obligate autotrophs but can make extensive use of the energy of organic compounds.

However, it has recently been established that even those few species of chemoautotrophs (Thiobacillus thiooxidans and the nitrifiers) which, for reasons which are still unknown, cannot assimilate the organic substances contained in the surrounding medium, can nevertheless carry out internal respiration which proceeds by the oxidation of polysaccharides which they have accumulated within their cells. These transformations are brought about by the same glycolytic mechanisms which operate in typical heterotrophs. ${ }^{43}, 44$ This 
was shown for $T$. thiooxidans in particular by the experiments of K. G. Vogler, W. W. Umbreit and other authors who have collaborated with them. ${ }^{45}$ According to Umbreit, when sulphur is oxidised by this organism there occurs a phosphorylation analogous to that which takes place during the oxidation of organic compounds by heterotrophs. During this process the energy derived from the oxidation is fixed in high-energy organic compounds of phosphorus, such as ATP, so that it can be used later when $\mathrm{CO}_{2}$ is assimilated under anaerobic conditions. Doubt has been cast on these conclusions by a number of authors (K. Baalsrud and K. S. Baalsrud, ${ }^{46}$ R. W. Newburgh ${ }^{47}$ and others). However, Umbreit completely confirmed his ideas by further experiments using more refined isotopic methods. ${ }^{48}$ Studies of the phosphorus compounds which accumulate in the cells of T. thiooxidans during the oxidation of sulphur, carried out by G. A. LePage and W. W. Umbreit ${ }^{49}$ and later by H. A. Barker and A. Kornberg, ${ }^{50}$ revealed the presence of labile polyphosphates, ATP and such typical metabolites of glycolysis as phosphohexoses and phosphotrioses. During a period of intensive oxidation of sulphur and assimilation of $\mathrm{CO}_{2} T$. thiooxidans synthesises a store of polysaccharides ; the endogenous destruction of this is carried out by means of a glycolytic mechanism which is present in these bacteria.

Thus, even in regard to such typical 'strict chemoautotrophs' as T. thiooxidans, the position is analogous to that which we have discussed above in regard to green plants. The metabolism of both groups of organisms is based on the heterotrophic utilisation of organic materials while the autotrophic mechanisms which are superimposed on this basis enable the organism which possesses them to exist under a greater diversity of external conditions. ${ }^{51}$

Umbreit's results have also been confirmed by work with other chemoautotrophs. For example, it has been shown that in hydrogen bacteria there is an accumulation of organic phosphorus (mainly in the form of ATP) when hydrogen is oxidised in the absence of $\mathrm{CO}_{2}$, while the amount of such compounds present decreases rapidly during the process of assimilation of $\mathrm{CO}_{2}$. Analogous results have been obtained 
by $\mathrm{Yu}$. I. Sorokin ${ }^{52}$ for one of the chemoautotrophs, Vibrio desulfuricans.

According to $\mathrm{H}$. Lees, ${ }^{53}$ who has recently done a lot of work on the metabolism of Nitrosomonas, this organism, like other chemoautotrophs, uses the energy derived from the oxidation of inorganic substrates for the assimilation of $\mathrm{CO}_{2}$. In satisfying the internal requirements of the cell, it may use another source of energy, heterotrophic respiration based on the carbohydrates which have been formed. However, this suggestion still requires further experimental amplification. ${ }^{54}$

It remains obscure why typical 'strict' chemoautotrophs which have the appropriate catalytic mechanisms cannot work up the exogenous organic substances present in the surrounding medium. Some authors ascribe this to peculiarities of the permeability of the cell membranes of these organisms ${ }^{55}$ but it must be pointed out that very little factual material bearing on this has been collected. In particular, experiments on the nutrition of chemoautotrophs on organic substances have only been carried out for a very limited number of such substances, chiefly glucose, other sugars, amino acids and their polymers. However, this does not show that the organisms tested are absolutely unable to nourish themselves on organic matter.

In this connection we may note the following interesting fact. We now know that there are organisms which are quite unable to assimilate sugar and other analogous compounds, but which can make good use of such sources of carbon for their nutrition as toluene, phenol, salicylic acid and other typical antiseptics which are very poisonous to all other living things. The literature contains accounts of curious situations in which attempts to sterilise soil with toluene, which is commonly used for this purpose, did not bring about destruction of the microflora, but, instead, the greater proliferation of some members of it. ${ }^{56}$ These so-called 'cyclists' have been studied in detail by V. O. Tauson in particular. ${ }^{57}$ He isolated them from the soil of petroleum-bearing regions which contained a considerable number of bacteria and other organisms which could break down both petroleum and various fractions of it, kerosene, fuel oil, paraffin, lubricating oil, etc. The 
organisms use the hydrocarbons obtained from these mixtures as their sole sources of carbon and of energy. From a study of these organisms Tauson ${ }^{58}$ came to the conclusion that their inability to use glucose, fructose, mannitol, glycerol, tartaric acid and other similar compounds, which serve as satisfactory sources of carbon for most living things, was due to their inability to transform the primary alcohol groups into methyl groups. Thus the 'cyclists' (like other hydrocarbon-using organisms) cannot form acetaldehyde from carbohydrates and this prevents them from being able to synthesise fatty acids and the carbon skeletons of amino acids. They use another means to this end, namely the breakdown of the benzene nucleus of cyclic compounds, and thus obtain only partly hydroxylated carbon chains which then serve as material for the building of the proteins and lipids of protoplasm. This suggestion of Tauson's certainly still requires further study and biochemical confirmation.

However, even if we accept Tauson's views, it is still hard to decide whether this metabolic peculiarity is, as Tauson thought, an expression of the primitiveness of the 'cyclists', or whether it arose secondarily as an adaptation to circumstances in which hydrocarbons were the most readily available nutrients. The latter is the more probable. In the first place this is suggested by the extensive material put forward by C. E. Zobell, ${ }^{59}$ which shows that among hydrocarbonusing organisms there are living things belonging to very diverse systematic groups including bacteria, yeasts and moulds. Another fact which suggests that the ability of these organisms to use hydrocarbons as nutrients is of secondary origin is their pronounced aerobic habit, though some of them can also exist without free oxygen. As an example we may here cite Tauson's work on Microspira spp. ${ }^{60}$ Under strictly anaerobic conditions (in the deep layers of the crust of the Earth) these organisms can oxidise paraffins as well as naphthalene, phenanthrene and other polycyclic compounds while simultaneously reducing sulphates to hydrogen sulphide.

Although the metabolism of hydrocarbon-using organisms has received very little study as yet, one can nevertheless find in them the general methods of transformation of organic 
compounds, common to all living things. In particular, dehydrogenase systems ${ }^{61}$ and enzymes catalysing the rupture of carbon-carbon bonds (aldolases) have been shown to be present. Another piece of evidence tending in the same direction is the fact that we find, as intermediate products in these organisms, the organic acids, aldehydes, alcohols, etc., which are common to all other organisms. ${ }^{62}$

The relationship between the metabolism of the hydrocarbon-using organisms and that of typical heterotrophs is also confirmed by the ability of some living things, which can oxidise hydrocarbons, also to thrive in glucose solutions. Pseudomonas fluorescens may serve as an example; it is well able to oxidise hydrocarbons ${ }^{63}$ but, at the same time, it is a classical subject for the study of the glycolytic and oxidative degradation of sugars.

Thus, whichever group of microbes, plants or animals we consider in detail, we can establish that their metabolism is based on an ability to use organic substances as sources of energy and of structural materials for the formation of the components of protoplasm. This ability is common to all living things. This process is characteristic, not only of clearly-defined heterotrophs, but also of autotrophs, in which it may always be found alongside the specific mechanisms which enable them to build up organic from inorganic substances. In contrast to this, heterotrophs show no traces of autotrophic mechanisms though some odd vestiges of these must surely have been retained if the heterotrophs had arisen by regression from autotrophic ancestral forms.

In 1914 , A. Lebedev's experiments with moulds ${ }^{64}$ indicated that these typical heterotrophs could fix carbon dioxide, and this was later established for other analogous microbes, in particular for heterotrophic bacteria. ${ }^{65}$ Some authors naturally took this fixation to be a vestige of autotrophy in these organisms. Such a view was only to be expected at that time, when the assimilation of $\mathrm{CO}_{2}$ was held to be the exclusive prerogative of autotrophs and the ability to assimilate it was recognised as the criterion for distinguishing between them and heterotrophs.

However, as studies of this subject developed further, so the circle of living things which had been shown to be able 
to fix carbon dioxide became wider and wider, ${ }^{66}$ although the biological significance of the phenomenon remained obscure. The fact is that fixation of any kind needs energy. Taking it over all, photosynthetic organisms use the energy of light for this purpose while chemosynthetic organisms use energy derived from the oxidation of hydrogen sulphide, ammonia, ferrous oxide, etc. By these means the amount of organic substances is increased at the expense of the carbon of $\mathrm{CO}_{2}$ and the stored potential energy of the living cells. When heterotrophs fix $\mathrm{CO}_{2}$, on the other hand, they use the energy which they obtain from the degradation or oxidation of ready-made organic substances and thus the process is not accompanied by any increase in either their stored organic carbon or their stored energy. Their over-all balance is negative in both respects, as may easily be shown by direct determinations.

In view of this, the widespread occurrence of heterotrophic fixation of carbon seemed incomprehensible. Furthermore, later studies, especially those involving the use of $\mathrm{CO}_{2}$ containing labelled carbon atoms, showed beyond doubt that the ability to fix carbon heterotrophically was in fact possessed by all known living cells, ${ }^{67}$ not only by microbes ${ }^{68}$ but also by animals ${ }^{69}$ and even by the colourless cells of higher plants which can only live heterotrophically, e.g. the cells of roots. ${ }^{70}$

As we now know, the fundamental protoplasmic mechanism taking part in the initial stage of the fixation of $\mathrm{CO}_{2}$ in both autotrophs and heterotrophs is coenzyme A. This was discovered by F. Lipmann ${ }^{71}$ during a study of processes of acetylation in living tissues and also studied simultaneously in several other laboratories (D. Nachmansohn and M. Berman, ${ }^{72} \mathrm{~W}$. Feldberg and T. Mann ${ }^{73}$ and others).

The significance of coenzyme A is, essentially, as follows. Acetic acid plays a very important part in the metabolism of every living organism. It seems to be a connecting link between the metabolism of carbohydrates, fats and proteins. By itself, however, it is chemically inert and before it can enter into reactions of acetylation or condensation it must be activated in some way. This is clone by the formation of an acetyl derivative of coenzyme $\mathrm{A}$, which was first isolated in the pure state from yeast by F. Lynen, E. Reichert and L. 
Rueff. ${ }^{74}$ This 'active acetate' is a thioester of acetic acid with coenzyme A:

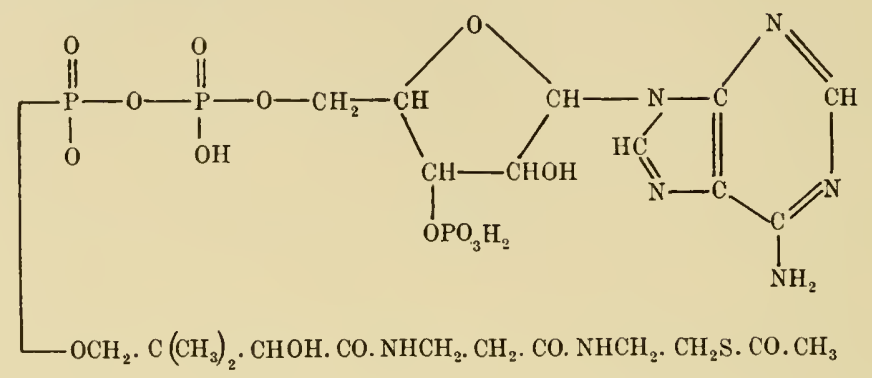

The thioester bond of coenzyme $\mathrm{A}$ is associated with a large supply of energy and when it is broken by hydrolysis 8,200 $\mathrm{cal} /$ mole are liberated..$^{75}$ Thus acetyl coenzyme $\mathrm{A}$ may be described as a 'macroergic' compound. It must arise during metabolism at the expense of energy derived from the phosphate bonds of ATP or from a simultaneous oxidation according to the equation ${ }^{76}$

$$
\mathrm{CH}_{3} \mathrm{CO} \cdot \mathrm{COOH}+\text { coenzyme } \mathrm{A}+\frac{1}{2} \mathrm{O}_{2} \rightarrow \text { acetyl coenzyme } \mathrm{A}+\mathrm{CO}_{2}+\mathrm{H}_{2} \mathrm{O}
$$

However, this oxidation does not require the presence of free oxygen, it can also occur anaerobically with the transfer of hydrogen to other organic substances through the mediation of diphosphopyridine nucleotide. When it has been activated in this way by coenzyme $\mathrm{A}$, the acetyl residue can enter into the most diverse condensation reactions leading to the formation of new carbon-carbon bonds and the lengthening of the carbon chain.

It later appeared that coenzyme A can activate, not merely acetic acid, but also other organic acids of both the aliphatic and aromatic series which also form thioesters with coenzyme $\mathrm{A}$, e.g. succinyl coenzyme $\mathrm{A}^{77}$ and isovaleryl coenzyme $\mathrm{A}^{.78}$

The tremendous biological importance of coenzyme A rests on the fact that only through its mediation can small organic molecules combine together by carbon-carbon bonds to form complicated organic substances. That is to say, this is the only way in which one of the most important processes in the synthesis of the carbon skeletons of the components of protoplasm can take place. It is quite clear that a process 
of this sort must have occurred in even the very earliest living things, it must have arisen concurrently with life. It is, therefore, to be found in all organisms without exception, in particular in such typical heterotrophs as the bacteria responsible for butyric acid fermentation, in which the actual formation of butyric acid results from the reductive condensation of two acetyl residues.

What has been said accounts for the extremely widespread occurrence, not to say universality, of coenzyme A, which has been found in all organisms in which it has been looked for.

'Active acetyl", however, is not used only for the condensation of two molecules of acetic or analogous acids, it can also be used for bringing about the combination of these acids with $\mathrm{CO}_{2}$. The very presence of acetyl derivatives of coenzyme A therefore necessarily implies the possibility of the fixation of $\mathrm{CO}_{2}$.

Studies in this field do indeed show that when $\mathrm{CO}_{2}$ is fixed its labelled carbon atoms always appear in carboxyl groups combined with pre-formed organic molecules containing not less than two carbon atoms. In particular we may indicate the following types of reaction whereby $\mathrm{CO}_{2}$ is fixed by some heterotrophs. ${ }^{79}$

$$
\begin{array}{lc}
\left(\mathrm{C}_{2}+\mathrm{C}_{1}\right) & \text { Clost. butylicum } \\
\text { Acetate } & +\mathrm{CO}_{2}+\mathrm{H}_{2} \longrightarrow \text { pyruvate }+\mathrm{H}_{2} \mathrm{O} \\
\left(\mathrm{C}_{3}+\mathrm{C}_{1}\right) & \text { M. lysodeikticus } \\
\text { Pyruvate } & +\mathrm{CO}_{2} \longrightarrow \text { oxaloacetate } \\
\left(\mathrm{C}_{4}+\mathrm{C}_{1}\right) \quad \text { Esch. coli }
\end{array}
$$

Succinate $+\mathrm{CO}_{2}+\mathrm{H}_{2} \longrightarrow x$-oxoglutarate $+\mathrm{H}_{2} \mathrm{O}$

As a rule, heterotrophs cannot synthesise substances in which two neighbouring carbon atoms are derived from $\mathrm{CO}_{2}$, the ability to do this being peculiar to autotrophs, which build the whole of the carbon skeletons of the components of their protoplasm out of carbon dioxide which they have fixed.

However, K. T. Wieringa, ${ }^{80}$ and later H. A. Barker and his colleagues, ${ }^{81}$ have succeeded in isolating bacteria which require organic nutrients for their growth and development 
but at the same time can synthesise acetic acid in such a way that both carbon atoms are derived from $\mathrm{CO}_{2}$, as may be shown by studies using labelled carbon atoms. This relates these bacteria to the typical autotrophs which have an analogous method of fixing $\mathrm{CO}_{2}$.

It follows from all that has been said that the fixation of $\mathrm{CO}_{2}$ is a universal process and thus also very ancient, forming the very foundation of the organisation of the metabolism of all living things.

In heterotrophs it does not itself play a significant part, but only accompanies more important synthetic reactions. However, in the transition to autotrophy, the ability of the primaeval organisms to carry out this reaction was of the utmost importance. It was only on this basis that, in the course of their further evolution, organisms were able to free themselves from dependence on organic nutrients, derived from the external medium.

Thus the heterotrophic fixation of $\mathrm{CO}_{2}$ would not appear to be a vestigial form of autotrophy. On the contrary, it constitutes an extremely ancient and universal mechanism, present in even the most primitive organisms, a mechanism which formed the basis for the later development of autotrophy in the course of progressive evolution.

Summing up all that we have discussed, it must be admitted that the metabolism of all the multifarious organisms now living on our planet is based on processes involving the use of ready-made organic substances as starting materials for building the components of protoplasm and as sources of the energy required for life. This process is extremely ancient, it is primary, whereas the chemical mechanisms used by some living things to synthesise organic substances from inorganic materials and supplies of energy arose alongside of it during the course of the further evolution of organisms.

In full agreement with this, we find that the overwhelming majority of organic forms can still only nourish themselves heterotrophically, while those special groups of living organisms which have acquired autotrophic mechanisms during their evolution can comparatively easily revert to their earlier nutritional habit. 


\section{Different forms of energy metabolism.}

It would seem, at first glance, that the position is reversed with the second cardinal thesis which we enunciated earlier, that is, the primary nature of the anaerobic degradation of organic substances. Only a very limited number of species of bacteria and other lower organisms are obligate anaerobes, living out the whole of their life cycles in the absence of molecular oxygen. Other micro-organisms, such as yeasts, are facultative anaerobes. But the overwhelming majority of contemporary living things, especially all higher plants and animals, cannot do without the free oxygen of the atmosphere.

This state of affairs is highly significant because, under the oxidising conditions of the present time, it is quite possible to oxidise organic substances completely to carbon dioxide and water, which mobilises a far greater amount of energy than the simple anaerobic degradation of these substances. It is therefore quite natural that contemporary living things should, during the course of their prolonged evolution, have become widely adapted to the most extensive use of the conditions which prevailed on the surface of the Earth after a considerable amount of free oxygen had been formed, i.e. from about 700 million years ago.

It must, none the less, be admitted that anaerobiosis is the primary way of life ; for a careful study of the energetics of metabolism in the most diverse organisms, both lower and higher, has shown convincingly that everywhere (even among aerobes) this metabolism is based on strikingly similar and completely universal anaerobic reactions of degradation of organic substances, while the very variegated mechanisms which catalyse the combination of molecular oxygen with the products of this degradation in different living things are only superimposed on this basis.

This state of affairs was noticed as early as the end of last century as a result of purely physiological investigations. It was E. Pflüger ${ }^{82}$ who first discovered the so-called anaerobic respiration of higher animals and put forward the view that this process was not pathological and that it was not a minor biological adaptation to enable organisms to survive a short 
period of lack of oxygen. In Pflüger's opinion the ability to degrade carbohydrates anaerobically formed the basis of the whole of the normal respiratory process. Somewhat later a similar state of affairs was shown by W. Pfeffer ${ }^{83}$ to exist in higher plants. He showed that, in the absence of atmospheric oxygen, plants can carry out so-called intramolecular respiration which is, chemically, completely analogous with alcoholic fermentation. The much more recent studies of V. Palladin ${ }^{84}$ and, especially, S. Kostychev ${ }^{85}$ showed that, in the great majority of cases, the process of normal respiration also begins with the anaerobic degradation of carbohydrates. If air is available, however, the intermediate products of alcoholic fermentation are oxidised to $\mathrm{CO}_{2}$ and water by means of specific oxidative mechanisms. If free oxygen is artificially excluded the process will usually lead to the formation of small quantities of ethyl alcohol and carbon dioxide.

S. Kostychev ${ }^{86}$ gives the following diagram of the relationship of the processes just referred to:

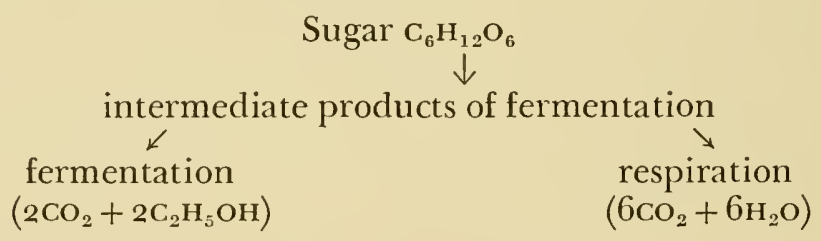

A very similar mechanism was described by Pflüger in animals and was later confirmed by the profound researches of O. Meyerhof, ${ }^{87}$ G. Embden ${ }^{88}$ and J. K. Parnas ${ }^{89}$ who showed that the tissue respiration of animals was based on an anaerobic glycolytic process completely comparable with lactic fermentation.

The primary nature of anaerobiosis is specially clearly illuminated by a comparative study of the chemical nature of the energy metabolism of the most diverse groups of contemporary living things. The essence of the biological concept of energy metabolism is the mobilisation of the energy locked up in organic compounds (of which carbohydrates are a particular example) and its direction into the synthesis of the components of protoplasm and into other processes necessary for life. However, many obstacles lie in the way of this 
transformation. In the first place the molecule of sugar, or any other carbohydrate, does not break down spontaneously at ordinary, comparatively low temperatures and it is therefore difficult to liberate the energy locked up in it. For this to occur, a very high energy barrier must be surmounted. In the second place, if the molecule of sugar were broken down or oxidised completely and suddenly, there would be something like an explosion, which would be associated with such heating of the protoplasm at the point of the occurrence that its existence rould be rendered impossible. In the course of their evolution, therefore, organisms have elaborated chemical mechanisms of energy metabolism in which sugar is broken down gradually, by stages, rather than suddenly.

This gave the possibility, not only of surmounting the barrier of the energy of activation of the separate reactions at ordinary temperatures, but also of making rational use of the energy, which is then not liberated explosively, but step by step in separate portions.

The energy of organic compounds liberated in this way can usually be accumulated in high-energy compounds which can then be used, by means of specific mechanisms, for the synthesis of proteins, for muscular contraction, etc.

It must not, however, be supposed that energy exchange takes place in the living cell as an isolated mechanism, serving merely for the production of high-energy molecules. In all processes of the biological destruction of organic substances (during fermentation, respiration, etc.) the straightforward task of storing energy is achieved, but the transfer of electrons and hydrogen also takes place continually, as well as the formation of those small fragments of the original organic molecules which arise as intermediate breakdown products and from which, in fact, the important components of living material are directly synthesised. In this way organisms are enabled to synthesise the tremendous variety of extremely complicated substances which make up their bodies, by the degradation of a small number of non-specific substrates.

By virtue of all this, the energy metabolism of any organism consists of a long chain (or even many chains) of well 


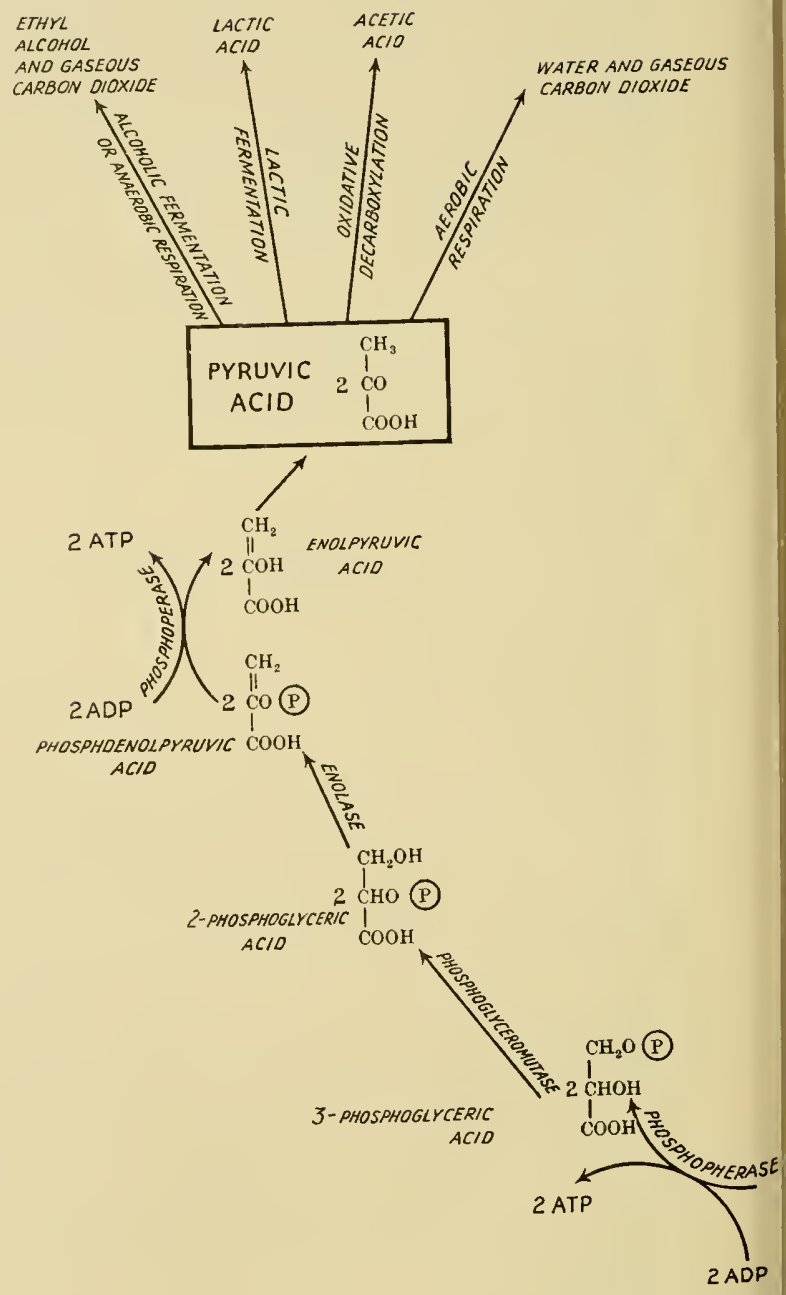

Fig. $3^{6 .}$ Scheme of the reaction: 

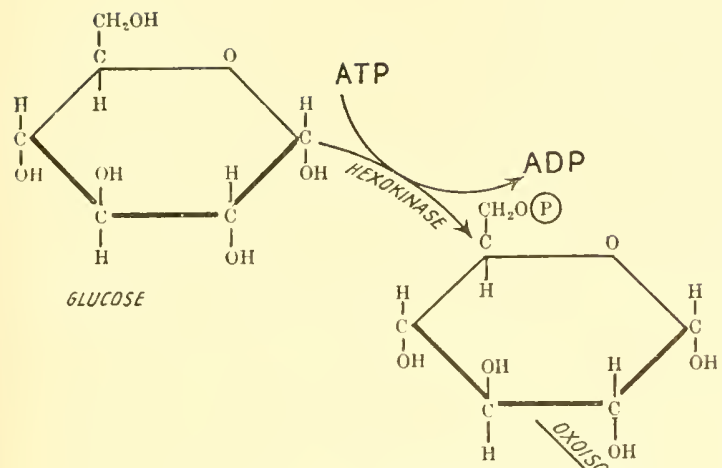

GLUCOSE
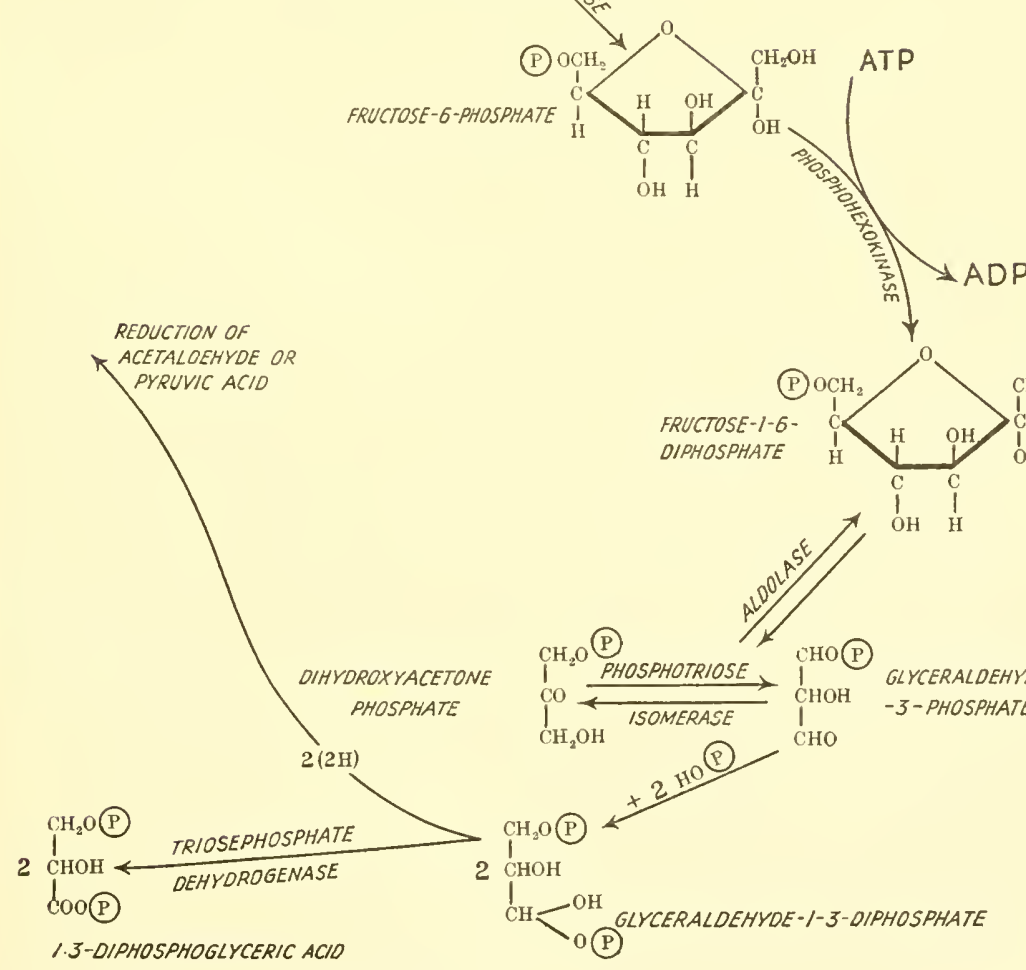

GLUCOSE-6-PHOSPHATE

ACETALOEHYDE OR

PYRUVIC ACID
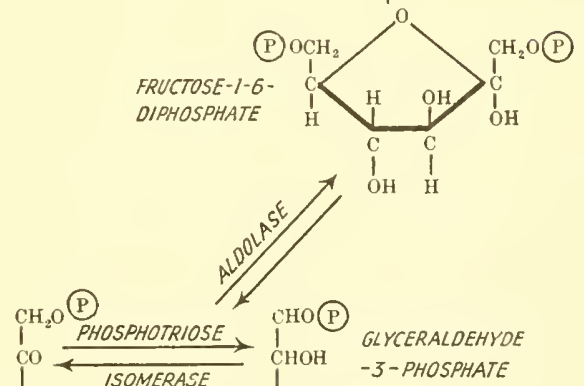

$\left.\int_{\mathrm{CH}_{2} \mathrm{OH}}^{\mathrm{CO}}{ }_{\text {ISOMERASE }}\right|_{\mathrm{CHO}} ^{\mathrm{CHOH}}-3$-PHOSPHATE

involved in alcoholic fermentation. 
co-ordinated reactions, each of which is catalysed by its own specific enzyme. Thus, this exchange of energy demands a rather highly developed internal chemical mechanism, and, the longer the chain of reactions, the more co-ordinated the mechanism must be.

It would be theoretically possible to imagine an infinitely large number of such chains of energy exchange, each different in principle from the others both as regards the individual reaction-links and as regards the general structure of the whole chain. It is therefore very remarkable that extensive biochemical researches have established the fact that in all organisms which have yet been studied in this respect, the energy metabolism is based on extremely similar, almost identical, systems of reactions, catalysed by identical enzymes. The system may vary from organism to organism, but only in detail; if one enzyme is absent another takes its place, but, as a whole, it seems to be the same throughout all the stages of evolutionary development of all the inhabitants of the Earth, both anaerobes and aerobes. Among aerobes new catalytic mechanisms have been added to the original system, enabling them to use molecular oxygen.

To familiarise ourselves with the actual working of the basic system we may consider the chemical mechanism of alcoholic fermentation, which has now been thoroughly studied. It takes place in a number of micro-organisms, of which yeast would seem to be the most typical. The general scheme of the reactions of fermentation as given by $\mathrm{V}$. L. Kretovich in his book, ${ }^{90}$ is shown in Fig. $3^{6}$. The diagram shows that glucose is transformed into ethyl alcohol and carbon dioxide, without the participation of molecular oxygen, by means of a series of strictly co-ordinated enzymic reactions.

The process starts with the phosphorylation of glucose with the help of the enzyme hexokinase. This involves the transfer by hexokinase of a phosphate residue with a highenergy bond $(\triangle F$ approx. $8,000 \mathrm{cal} / \mathrm{mole}$ ) from ATP to a glucose molecule. It leads to the formation of glucose-6phosphate and adenosine diphosphate (ADP). The glucose-6phosphate is then transformed into fructose-6-phosphate by the enzyme oxoisomerase. The fructose-6-phosphate combines 
with another high-energy phosphate residue from another molecule of ATP, the reaction being catalysed by the enzyme phosphohexokinase.

These preparatory reactions, involving the expenditure of two high-energy bonds on each glucose molecule, lead to the formation of fructose-1:6-diphosphate. This is followed by a reaction catalysed by aldolase, the disruption of the six-membered carbon chain into two trioses (glyceraldehyde3-phosphate and dihydroxyacetone phosphate) which can undergo a mutual transformation, catalysed by the enzyme phosphotriose isomerase.

In the process of fermentation glyceraldehyde-3-phosphate undergoes a further transformation, being continually replaced at the expense of dihydroxyacetone phosphate. The molecule of glyceraldehyde-3-phosphate undergoes dehydrogenation while simultaneously combining with a phosphate residue (derived from mineral phosphate) and a new highenergy bond is thus formed in which is stored the energy liberated by the removal of hydrogen from the glyceraldehyde-3-phosphate. The hydrogen thus liberated combines with coenzyme I (DPN) which constitutes the active group of the enzyme triosephosphate dehydrogenase which catalyses this reaction. This hydrogen can be used further for a number of reducing transformations in the living cell; in particular, in alcoholic fermentation, it reduces acetaldehyde to ethyl alcohol.

The 1:3-diphosphoglyceric acid formed from the glyceraldehyde-3-phosphate gives its high-energy phosphate residue to ADP. This reaction thus brings about the regeneration of one of the two molecules of ATP which had earlier been used for the phosphorylation of glucose. It is catalysed by phosphopherase (phosphoglyceric phosphokinase).

The 3-phosphoglyceric acid formed from 1:3-diphosphoglyceric acid is converted, by the action of phosphoglyceromutase, into 2-phosphoglyceric acid which is transformed, with the help of enolase, into phosphoenolpyruvic acid. In this reaction 2-phosphoglyceric acid gives up water, which leads to a rearrangement of the internal energy of the molecule and the formation of a second high-energy bond at the 
expense of the alteration of the whole of that half of the glucose molecule.

The high-energy phosphate residue thus formed is transferred to ADP and the second molecule of ATP is regenerated. The enolpyruvic acid then goes over to its more stable form, pyruvic acid. The enzyme carboxylase splits off a molecule of $\mathrm{CO}_{2}$ from the pyruvic acid and the acetaldehyde so formed is reduced to ethyl alcohol by combining with the hydrogen from coenzyme I.

How great is the amount of energy obtained by the fermentation of a whole molecule of glucose?

As we have seen, the transformation of half a glucose molecule (glyceraldehyde-3-phosphate) gives two high-energy bonds which serve for the regeneration of the two molecules of ATP which were used to phosphorylate the glucose. The high-energy bonds derived from the second half of the glucose molecule are a pure energy 'profit' to the cell and can be used for the synthesis of living matter or for other purposes.

Thus alcoholic fermentation is a process of anaerobic breakdown of the glucose molecule, in which the energy liberated by dehydrogenation accumulates in the form of the high-energy bonds of phosphate residues and is carried over in this form into the general metabolic system of the cell through the agency of derivatives of adenylic acid, ADP and ATP, with the help of the appropriate enzymes.

On considering the mechanism of alcoholic fermentation one is struck by the large number of stages involved. The reason for this is that it allows more effective use to be made of the energy liberated by the breakdown of the sugar molecule and also allows the formation of those fragments of molecules from which the organism builds the carbon skeleton of its living material.

We find this ability to acquire energy by the anaerobic degradation of organic substances by many stages in all the different systematic groups of organisms, from the most primitive bacteria to the highest mammals. Hence the energy metabolism is based on anaerobic dissimilation of carbohydrates similar to the process of alcoholic fermentation which has just been expounded. Individual links in the chain may vary and accessory superstructures may be elabor- 
ated, but the basis always remains unchanged. In particular, we find everywhere the same catalytic mechanisms and methods of obtaining energy and accumulating it in highenergy bonds. The differences, as we shall see below, only represent different ways of using the hydrogen liberated by the process of dehydrogenation and different ways of further transforming the breakdown products which are used for building the protoplasm of the living cells.

In the diagram of alcoholic fermentation given above, all the hydrogen which is formed by the dehydrogenation of glyceraldehyde-1:3-diphosphate to the corresponding acid is used, with the help of coenzyme I, for the reduction of acetaldehyde to ethanol. In other cases the hydrogen may be taken up by other intermediate products of metabolism and used for reducing processes in the course of the biosynthesis of components of protoplasm, or oxidised to water by the oxygen of the air in the course of respiration.

In all forms of anaerobic degradation of carbohydrates, and in all organisms which have been studied in this respect, pyruvic acid and its immediate derivatives occupy a key position in the processes of biosynthesis of important components of protoplasm, proteins, lipids, nucleic acids, etc. The nature of the organisation of these synthetic processes may, however, vary to some extent as between different representatives of the living world. The processes of breakdown and synthesis may be co-ordinated to a greater or lesser degree. During evolution this internal co-ordination therefore increases and at the same time there is an increase in the coefficient of useful activity, the completeness with which the nutrient substances entering the living things from the outside medium are used.

The anaerobic dissimilation of carbohydrates into alcohol and $\mathrm{CO}_{2}$ is usually brought about by a number of different sorts of bacteria in the way which has been described above for yeasts. In some species of these micro-organisms, however, the individual links in the chain of fermentative reactions may vary to a certain extent. We may cite, as an example, Pseudomonas lindneri which, according to A. J. Kluyver and W. J. Hoppenbrouwers, ${ }^{91}$ can form a larger amount of alcohol. The general features of its metabolism 
agree with the scheme which has been given, but recently M. Gibbs and R. D. DeMoss ${ }^{92}$ have shown that the initial stages of its metabolism deviate from the scheme in some details. As soon as hexose-6-phosphate is formed it is dehydrogenated anaerobically to form 6-phosphogluconic acid. This is then decarboxylated to give a pentose. The pentose is broken down by the disruption of a carbon-carbon bond to form alcohol and phosphoglyceraldehyde-3-phosphate which is converted to alcohol in the same way as in ordinary alcoholic fermentation by yeast.

In a group of typical obligately anaerobic bacteria, the clostridia, which can carry out butyric and acetone-butyl alcohol fermentation, this takes place by essentially the same method of glycolytic transformation of sugars as is found in alcoholic fermentation. For example, the experiments of $\mathrm{B}$. Rosenfeld and E. Simon ${ }^{93}$ showed that phosphoenolpyruvic acid is formed during the process of acetone-butyl alcohol fermentation. Pyruvic acid seems to be a necessary intermediate product in other forms of butyric acid fermentation but its further transformation in other bacteria of this group gives rise to a whole range of different organic substances: butyric acid, butyl alcohol, isopropyl alcohol, acetone, ethyl alcohol, acetic acid, formic acid, hydrogen and carbon dioxide.

For example, Clostridium acetobutylicum ferments glucose with the formation of butyl alcohol, acetone, ethyl alcohol and hydrogen. Another organism, Cl. saccharobutyricum, forms butyric and acetic acids, carbon dioxide and hydrogen. Zymosarcina maxima forms butyric, acetic and lactic acids, carbon dioxide and hydrogen. ${ }^{94}$

The work of H. G. Wood and his colleagues, ${ }^{95}$ and of H. A. Barker, ${ }^{96}$ has established that the 4 -carbon compounds which are produced during various types of butyric acid fermentation are formed by the condensation of active residues of acetic acid, in the form of acetyl-coenzyme $\mathrm{A}$, with the formation of acetoacetic acid and its subsequent reduction to butyric acid. Acetyl-coenzyme A is either formed directly from acetic acid or from pyruvic acid by anaerobic dehydrogenation and decarboxylation.

Acetone is formed by the decarboxylation of acetoacetic 
acid. According to the results of $\mathrm{H}$. J. Koepsell and his colleagues, ${ }^{97}$ cell-free extracts of $\mathrm{Cl}$. butylicum transform pyruvic acid into acetyl phosphate, $\mathrm{CO}_{2}$ and hydrogen. Butyl alcohol is produced by the reduction of butyryl-coenzyme A.

Thus we see that the anaerobic breakdown of sugar by the various butyric acid bacteria is based on the same catalytic mechanisms and the same sequence of reactions with which we are familiar in alcoholic fermentation. The 4 - and 3-carbon compounds characteristic of butyric acid fermentation are formed by the further anaerobic transformation of pyruvic acid, that is to say, by the formation, transfer and condensation of acetyl residues.

Another well-known example of anaerobic decomposition of carbohydrates is provided by lactic acid fermentation which is brought about by various species of facultative anaerobes, e.g. Lactobacillus spp. and Streptococcus spp. The main product of this fermentation is lactic acid, which is formed by the dissimilation of sugar. In its initial stages this process passes through the same intermediate reactions as ordinary alcoholic fermentation, right up to the formation of pyruvic acid. However, owing to the absence of carboxylase, in lactic acid bacteria the pyruvic acid is not transformed into acetaldehyde and $\mathrm{CO}_{2}$, but is reduced directly to lactic acid.

In some lactic acid-producing bacteria such as Escherischia coli or Strep. faecalis large amounts of acetic acid and ethyl alcohol are formed as well as lactic acid. Here this process can only take place anaerobically, by the anaerobic dehydrogenation and decarboxylation of pyruvic acid. In the course of this acetyl-coenzyme $\mathrm{A}$ is formed. At the same time the hydrogen liberated by means of diphosphopyridine nucleotide may be transferred to another molecule of pyruvic acid, reducing it to lactic acid, or may react with one of the two molecules of acetyl-coenzyme A which had been formed, so that, in addition to acetic acid. ethyl alcohol is also formed. Thus we see, here too, the same reactions and catalytic mechanisms as are found in strictly anaerobic butyric acid fermentation. ${ }^{98}$, 99 Unlike the bacteria which carry out this fermentation, however, lactic acid bacteria are facultative anaerobes and the organisation of their metabolism shows 
supplementary structural features which, to some extent, enable us to understand the mechanism of the transition from primary anaerobiosis to the aerobic way of life.

As we have shown, the reaction whereby acetyl-coenzyme A is formed from pyruvic acid can take place, not only anaerobically, but also with the participation of free oxygen. The difference in this case is simply that the hydrogen set free by dehydrogenation is not accepted by pyruvic acid or acetaldehyde but is oxidised by oxygen.

This oxidative process does not occur spontaneously, it requires special catalytic mechanisms which are completely absent from obligate anaerobes because, in them, the reaction can only follow the first path via the transformation of pyruvic acid.

In facultative anaerobes, by contrast, there have been found, alongside the ordinary glycolytic mechanisms, specific catalysts promoting the oxidative decarboxylation of pyruvic acid. Thus, according to the studies of I. C. Gunsalus and his colleagues, ${ }^{100}$ and L. J. Reed and colleagues, ${ }^{101}$ in Esch. coli and $L$. delbrückii and other bacteria this reaction is catalysed by a complex compound of the amide of lipoic acid and cocarboxylase which has been called lipothiamide pyrophosphate.

When facultative anaerobes are cultivated in the absence of free oxygen these supplementary mechanisms are of no significance. They can easily be excluded from metabolism ; they remain 'unemployed' but the bacterial cell continues to exist satisfactorily on the basis of the old organisation. On the other hand, in the presence of oxygen, the oxidative catalysts give a great advantage because they enable the organisms in which they are present to make considerably more rational use of the organic materials at their disposal.

It is obvious that, under the reducing conditions of the primaeval atmosphere, only mechanisms subserving anaerobic metabolism could develop, while oxidative catalysts were only formed as supplementary, and sometimes very unimportant, accessories, after a considerable amount of free oxygen had appeared on the surface of the Earth. This is reflected in the organisation of present-day facultative anaerobes. 
The bacteria which carry out propionic fermentation may serve as a further example. Under anaerobic conditions their metabolism is in complete accord with the scheme for alcoholic fermentation; sugar is broken down to pyruvic acid by means of the same enzymes and with the formation of the same intermediate products as in yeast. The peculiarity of these bacteria is that in them the pyruvic acid, which is formed in the ordinary way, is not decarboxylated but, on the contrary, combines with $\mathrm{CO}_{2}$ and is transformed into oxaloacetic acid, which is first reduced to succinic acid and then decarboxylated to propionic acid according to the scheme:

$$
\begin{aligned}
& 2 \mathrm{H}_{2} \\
& \mathrm{CH}_{3} \cdot \mathrm{CO} \cdot \mathrm{COOH}+\mathrm{CO}_{2} \rightarrow \mathrm{HOOC} \cdot \mathrm{CH}_{2} \cdot \mathrm{CO} \cdot \mathrm{COOH} \rightarrow \\
& \mathrm{HOOC} \cdot \mathrm{CH}_{2} \cdot \mathrm{CH}_{2} \cdot \mathrm{COOH} \rightarrow \mathrm{CH}_{3} \cdot \mathrm{CH}_{2} \cdot \mathrm{COOH}+\mathrm{CO}_{2} \text {. }
\end{aligned}
$$

All these reactions take place with the help of the mechanisms with which we have become familiar, in particular coenzyme A and codehydrogenase. In the air, however, these same bacteria can carry out the typical aerobic oxidation of various organic acids, among them pyruvic acid. ${ }^{102}$ Accordingly they, unlike obligate anaerobes, are often found to contain such oxidative mechanisms as cytochrome $a^{103}$ and the enzyme catalase. ${ }^{104}$

Like alcoholic fermentation, the anaerobic breakdown of sugar is the basis not only of the energy metabolism of facultative and obligate anaerobes; the same glycolytic mechanisms may also be found in typical aerobic bacteria which, when living under natural conditions, absolutely require molecular oxygen.

For example, in the strictly obligate aerobe Streptomyces coelicolor, V. W. Cochrane ${ }^{105}$ found the following enzymes: phosphofructokinase, aldolase, triosephosphate isomerase, triosephosphate dehydrogenase, phosphopherase, enolase and ethanol dehydrogenase, i.e. the typical catalysts with which we have become familiar in the scheme of alcoholic fermentation.

The acetic acid bacterium Acetobacter suboxydans carries out its energy metabolism by the aerobic oxidation of hexoses. According to E. Simon ${ }^{106}$ it transforms hexose di- 
phosphate into trioses and then, via pyruvic acid and acetaldehyde, into acetic acid. If it is short of oxygen, however, it begins to carry out ordinary alcoholic fermentation as it has all the necessary enzymes.

When grown on a mineral medium with the addition of glucose, Bacillus subtilis cannot carry out alcoholic fermentation and is obliged to exist aerobically. However, as N. D. Gary and R. C. Bard ${ }^{107}$ showed, a culture of these bacteria, grown on a medium containing glucose, tryptone and yeast extract, grows under anaerobic conditions by carrying out lactic acid fermentation. In such a culture one may find a collection of the most important glycolytic enzymes.

Even in such well-defined aerobes as the obligate chemoautotrophs, in which the whole mechanism is directed towards the oxidation of an inorganic substrate by oxygen, there have been found, as we saw above, such typical glycolytic mechanisms and intermediate products as diphosphopyridine nucleotide, ATP, phosphohexoses and phosphotrioses.

Thus we see that among bacteria, which are the organisms manifesting the greatest metabolic variety, we find everywhere that their metabolism is based on anaerobic degradation which follows the scheme for alcoholic fermentation. This seems to be completely universal among these microorganisms. Only isolated groups of bacteria possess the supplementary oxidative mechanisms, which must, obviously, have arisen after the appearance of free oxygen in the atmosphere of the Earth. The oxidative decarboxylation of pyruvic acid by lactic acid bacteria may serve as an example of such an original primitive mechanism. Later these mechanisms became more complicated and were transformed into whole cycles of orderly oxidative reactions which will be analysed in more detail later, in connection with the problem of the origin of respiration.

The glycolytic breakdown of carbohydrates also underlies the energy metabolism of other primitive living things, in particular protozoa. A. Lwoff and his colleagues ${ }^{108}$ found a starch phosphorylase in Polytoma caeca. Adenosine mono-, diand triphosphates, glucose-1-phosphate, fructose-6-phosphate, fructose-1:6-disphosphate and phosphoglyceric acid have all 
been found in Euglena gracilis. ${ }^{109}$ S. C. Harvey ${ }^{110}$ found a series of glycolytic enzymes in cell-free extracts of Trypanosoma equiperdum. The work of R. W. Mckee ${ }^{111}$ established that Plasmodium gallinaceum contains enzymic systems which catalyse the phosphorylation of glucose by means of ATP, the splitting of fructose diphosphate into triose phosphates and the oxidation of glyceraldehyde-3-phosphate to pyruvic acid. In these organisms, too, the oxidative degradation of pyruvic acid was superimposed on the fundamental glycolytic mechanism in the course of their evolution. Their metabolism seems to be of an aerobic nature at present but, as we have seen, it is based on glycolytic mechanisms.

Glycolytic mechanisms also form the basis of the metabolism of another large group of heterotrophic organisms, the fungi. It was, in fact, a representative of the lower unicellular fungi (yeast) which served as the classical object for the study of the chemical mechanism of alcoholic fermentation. In other groups of fungi the energy metabolism is based on glycolytic mechanisms, although many of these organisms seem, at present, to be typical aerobes. The moulds, in particular, are of the greatest interest in this connection. They are characterised by synthetic abilities peculiar among heterotrophs but they derive the energy needed for the synthesis of various specific organic substances by heterotrophic means. In them, as in bacteria and yeasts, the first stage in the breakdown of organic substances is, as J. IV. Foster rightly remarked, a system of reactions similar to alcoholic fermentation, leading to the formation of pyruvic acid which later undergoes oxidative transformation.

The researches of $\mathrm{S}$. Kostychev and others and also the more recent work of $H$. Tamiya and Y. Miwa ${ }^{12}$ have demonstrated the occurrence of alcoholic fermentation in various species of Aspergillus under aerobic conditions. Other Japanese workers (T. Takahashi, T. Asai and K. Sakaguchi, ${ }^{113,114}$ ) obtained active preparations of the zymase complex from Rhizopus and isolated carboxylase from them. J. C. Wirth and F. F. Nord ${ }^{115}$ showed that a cell-free juice obtained from the mycelium of a Fusarium contained active zymase.

According to the results of $\mathrm{S}$. Kostychev and F. Blackman, ${ }^{116}$ the systems whereby carbohydrates are broken down 
in green plants are no different in principle from those found in bacteria and fungi. H. Gaffron and H. Michels ${ }^{117}$ both showed that the unicellular green alga Chlorella forms lactic acid from glucose under anaerobic conditions. $\mathrm{H}$. Gaffron and J. Rubin ${ }^{118}$ showed that, under anaerobic conditions, pure cultures of Scenedesmus give off $\mathrm{CO}_{2}$ and accumulate non-volatile organic acids, in particular lactic acid. In connection with the extensive studies of photosynthesis carried out by M. Calvin and his colleagues ${ }^{129}$ on the one hand and by Gaffron and his group ${ }^{120}$ on the other, it has been shown that there are present in the cells of the green algae Scenedesmus and Chlorella such important products of the anaerobic breakdown of glucose as phosphoglyceric acid, phosphopyruvic acid and hexose and triose phosphates.

In recent years an enormous amount of evidence has been collected showing that the glycolytic system of Embden and Meyerhof, which is found in higher plants, takes part in the synthesis as well as in the degradation of carbohydrates. All the enzymes concerned with alcoholic fermentation have been found in higher plants and some have been isolated in a purified state. ${ }^{121}$ For example, coenzyme II (TPN) (triphosphopyridine nucleotide) has been found in various leaves and also in potato tubers. Hexokinase, an enzyme mediating the use of high-energy bonds, has been found in spinach leaves. Wheat grains and the seeds of other plants have been shown to contain oxoisomerase, and so forth. Intermediate products of glycolysis such as acetaldehyde, ethyl alcohol and lactic acid were found long ago in the tissues of higher plants when they are made to live under anaerobic conditions. ${ }^{122}$

The striking uniformity of the glycolytic mechanisms which underlie energy metabolism is found by investigation to prevail among animals from the simplest flagellates to the higher mammals and man. On the basis of studies of various zoological types, a number of scientists have expressed the opinion that the process of respiration of oxygen, which plays such an important part in the animal world, is of relatively recent phylogenetic origin. It represents a specialised mechanism which has arisen in the course of evolution on the basis of the more ancient, universal mechanism for the 
liberation of energy, namely the glycolytic breakdown of carbohydrates with the formation of pyruvic and lactic acids. This view was put forward by A. Pütter ${ }^{123}$ as early as 1905 , and, considerably later, by A. Szent-Györgyi ${ }^{124}$ who held that glycolysis represents a more ancient attempt by nature to use energy. Indeed, in all the representatives of the animal kingdom so far studied, the presence of the glycolytic cycle of degradation of carbohydrates has been established. As we saw above, glycolysis occurs in protozoa and other primitive animals. O. Harnisch ${ }^{125}$ found glycolysis in a number of groups of insects (Periplaneta, Carausius, Bombus, Apis, Eristalis). Glycolytic enzymes have been isolated from the wing muscles of the grasshopper. ${ }^{126}$ Various representative species of worms (Schistosoma mansoni, ${ }^{127}$ Neoaplectana glaseri, ${ }^{128}$ and Hymenolepis diminuta ${ }^{129}$ ) possess glycolytic systems, while molluscs can also decompose carbohydrates anaerobically. ${ }^{130}$

At the conclusion of his extensive review of glycolysis P. K. Stumpf ${ }^{131}$ writes as follows:

Since a multitude of animals have been analyzed for the presence of the cycle, it becomes impossible to itemize the activity of each animal and organ. In general all tissues of higher animals ranging from the internal organs to parts of the eye such as the cornea, the crystalline lens, and the retina have been found to contain the galaxy of glycolytic enzymes. Indeed, it would be difficult to demonstrate its absence in cell tissue.

Nerertheless, in a brief listing of the tissues in which the glycolytic system has been found unequivocally, hearts of the eel, toad, turtle, and rat, cornea of the rabbit, retinas of the guinea pig and lizard, chick embryos of different ages, leucocytes, erythrocytes, frog embryos, semen from a variety of sources, rabbit femoral and tibial bone marrow, human rib marrow, mouse melanoma, Flexner-Jobling rat carcinoma (to mention a few tumor tissues), gastric mucosa, brain and the various organ tissues of the body have the glycolytic system as a functioning unit.

A systematic survey of the evidence for the presence of glycolysis in representatives of various groups of animals may be found in a number of review works, in particular that of J. P. Greenstein and A. Meister. ${ }^{132}$ 
Consideration of the evolutionary aspect of all this material leads one to concur with the opinion of E. S. Guzman Barron $^{\mathbf{1 3 3}}$ that “. . . the complexity of the regulating mechanisms that link fermentation to respiration diminishes as the cells go down the phylogenetic scale." Analysis of the ontogenetic data leads to the same conclusion. ${ }^{134}$ In particular, a study of the ontogenesis of carbohydrate metabolism in the brain of birds and mammals shows that the metabolism of the brain has evolved from being anaerobic to being aerobic. ${ }^{135}$ This may be confirmed by the resistance of embryos and new-born animals to anoxia, a resistance which diminishes considerably as the animal becomes mature. It has also been shown that as the animal becomes older the oxidative processes in the brain become more intense while anaerobic glycolysis becomes less intense. N. Verkhbinskaya ${ }^{136}$ made a direct study of the intensity of the respiratory and glycolytic processes in the isolated brains of cyclostomes, selachians, sturgeons and bony fishes, amphibians, reptiles, birds and mammals. In this way she was able to show that in the brains of the lower, cold-blooded animals the intensity of anaerobic glycolysis is great, while oxidative respiration only occurs to a relatively slight extent. In warm-blooded animals the relationship between the intensities of respiration and glycolysis in the brain seems to be reversed. Respiration increases significantly while glycolysis decreases. This led the author to suggest that during the phylogenetic development of animals there had been a change from the predominantly anaerobic type of energy metabolism in the brain to the oxidative type.

Thus, intensive comparative study of the metabolism of contemporary organisms shows that, though the conditions of existence on the Earth are different now from what they were when life first arose, nevertheless we find, in any contemporary representative of the living world, the relics of a primitive organisation which has been inherited from the first organisms and which is, therefore, now common to all the inhabitants of the Earth. These are: in the first place, heterotrophy, the ability to use organic substances as sources of the energy and of primary structural materials needed for the synthesis of the components of protoplasm; in the 
second place, the anaerobic method of degrading these substances.

As the conditions of existence changed so, in the course of evolution, metabolism became more highly developed. Its primary mechanism became encrusted with more and more new 'accessories' which were different in different organisms, but the basic organisation common to all living matter remained as before. A study of this may therefore help us to some extent to judge of the external conditions which prevailed at the time when life first appeared, and of the ways by which it arose.

The main, and perhaps the sole sources of organic nourishment for the first living things would seem to have been hydrocarbons and their various derivatives which had been formed on the surface of the Earth. The reserves of these substances, though they may have been supplemented to some extent, were, in any case, very limited. In the meanwhile the growth and multiplication of organisms led to a greater and greater consumption of organic materials. In part they entered into the composition of living bodies, but an even greater quantity was broken down, degraded, during destructive metabolism.

Thus, the reserve of organic substances in the external medium available for the nourishment of the first organisms must, all the time, have been diminishing in quantity and becoming qualitatively simpler. This disappearance intensified the struggle for existence and was a potent factor in the later evolution of the original organisms, inducing further integration and complexity in their internal chemical organisation. But if the evolution of living things had always been confined to heterotrophic means of nutrition, then, sooner or later, the process must have attained its final conclusion with the complete annihilation of all organic nutrient material and the destruction of all living things.

This stimulated the organisms in their struggle for existence, in the process of selection and adaptation to the new conditions of life with which they were faced, to elaborate within themselves new forms of metabolism which would enable them, not merely to assimilate exogenous organic materials as rationally as possible, but also to use other means 
to obtain energy from the environment and to assimilate the simplest forms of carbon compounds.

\section{Photochemical reactions.}

The most powerful and inexhaustible source of energy on the surface of the Earth is solar radiation. As we showed above, the chief photochemical activity on the primaeval Earth must have been that of short-wave ultraviolet radiations which decompose water, in particular, to hydrogen and oxygen in the upper layers of the atmosphere. Although the hydrogen was constantly escaping from the atmosphere into space the amount of oxygen thus liberated by inorganic means was very small; in any case it was not great enough to account for the transition of the atmosphere from its original reducing state to an oxidising state. This was because the development of even small amounts of oxygen must immediately have led to the formation of an ozone screen which prevented the access of short-wave ultraviolet radiations to the lower layers of the atmosphere.

The radiations which fell in large amounts on the first organisms must therefore have been of longer wavelength, but these, as is well known, cannot by themselves bring about such reactions as the photolysis of water. Nevertheless, it was long ago established in a number of photochemical studies $^{137}$ that the energy of visible light can also be used for carrying out oxidoreductive processes in the presence of photosensitisers, especially organic pigments, capable of absorbing such light. According to A. Terenin ${ }^{138}$ the molecule of pigment which absorbs the light dissociates into two radicals and acquires a very high degree of chemical reactivity which enables it to receive or give up an electron or a hydrogen atom and thus to bring about oxidoreductive processes which could not come about spontancously in the dark without the addition of the supplementary energy of light.

If organisms possessed such sensitisers then, even without the help of complicated supplementary chemical mechanisms, they could rationalise their heterotrophic metabolism by a more complete oxidation of the organic substances available to them in the external medium. 
The pigments which assumed the role of such sensitisers in the original organisms may have been porphyrins. As we showed in Chapter V, these substances, and metallic derivatives of them, arose in the waters of the hydrosphere as a result of purely organic-chemical, abiogenic synthesis, even before the origin of living things. The first organisms could therefore obtain them ready made, directly from the surrounding medium, and it was only during the course of the further development of life that there arose the necessity to synthesise them from such simple metabolic products as succinic and oxalic acids and glycine, always supposing that the presence of porphyrins was beneficial to the organisms of that time, giving them an advantage in the struggle for existence.

If what has been suggested is true, we must suppose that porphyrins, or some similar compounds, represent one of the earliest components of living matter, along with amino acids, nucleotides, etc. This is suggested by their extremely extensive distribution in living nature, their presence in all contemporary organisms without exception.

The classical researches of M. Nencki ${ }^{139}$ on the chemical nature of haemoglobin and chlorophyll revealed a striking similarity between these important pigments of the animal and vegetable kingdoms and showed that both these kingdoms were derived from ancestors which already possessed porphyrins as necessary components of their protoplasm. This was later established for microbes with a more primitive organisation.

Contemporary data on the finding of porphyrins in the most diverse representatives of the living world are discussed in great detail in the review of R. Lemberg and J. W. Legge. ${ }^{140}$ We reproduce here a summary of the occurrence of haemoglobin in the animal kingdom borrowed from this work (Table 4). Chlorophyll is equally widely distributed in the plant world. All higher photosynthetic organisms contain it, while in the lower ones we find derivatives of porphyrin similar to chlorophyll (bacteriochlorophyll) or compounds derived from porphyrin which have a structure similar to that of the bile pigments (phycocyanin and phycoerythrin).

In tunicates, which are very ancient and primitive organ- 
Table 4. Biological Distribution of Haemoglobins

\begin{tabular}{|c|c|c|}
\hline Phylum & Pigment & Examples \\
\hline Protozoans & $\begin{array}{l}\text { Haemoglobin in } \\
\text { cytoplasm }\end{array}$ & Ciliate paramecia \\
\hline \multirow[t]{2}{*}{ Nematodes } & $\begin{array}{l}\text { Erythrocruorin } \\
\text { in body cavity }\end{array}$ & $\begin{array}{l}\text { Several species of Ascaris, intestina } \\
\text { parasitic worm in mammals. Tw } \\
\text { pigments different in character }\end{array}$ \\
\hline & $\begin{array}{l}\text { Myohacmoglobin } \\
\text { in body wall }\end{array}$ & \\
\hline \multirow[t]{3}{*}{ Annelids } & $\begin{array}{l}\text { Erythrocruorin } \\
\text { in plasma }\end{array}$ & $\begin{array}{l}\text { Scattered throughout phylum, e.g } \\
\text { Arenicola, the lug worm, or Lum } \\
\text { bricus, the earth worm }\end{array}$ \\
\hline & Erythrocruorin & $\begin{array}{l}\text { Several species of order Polychaeta } \\
\text { e.g. Glycera, the blood worm }\end{array}$ \\
\hline & $\begin{array}{l}\text { Chlorocruorin } \\
\text { in plasma }\end{array}$ & $\begin{array}{l}\text { Several species of order Polychaeta } \\
\text { e.g. Spirographis, a marine worm }\end{array}$ \\
\hline $\begin{array}{l}\text { Arthropods } \\
\text { Crustaceans }\end{array}$ & $\begin{array}{l}\text { Erythrocruorin } \\
\text { in plasma }\end{array}$ & $\begin{array}{l}\text { Found in several species, e.g. Daphnia } \\
\text { water flea, class Branchiopoda and } \\
\text { e.g., Ernoecera, parasite in fish, clas } \\
\text { Copepoda }\end{array}$ \\
\hline Insects & $\begin{array}{l}\text { Erytlurocruorin } \\
\text { in plasma }\end{array}$ & Chironomus, midges (order Diptera) \\
\hline \multirow[t]{3}{*}{ Molluscs } & $\begin{array}{l}\text { Erythrocruorin } \\
\text { in plasma }\end{array}$ & $\begin{array}{l}\text { Planorbis, fresh water snail (orde } \\
\text { Gastropoda) }\end{array}$ \\
\hline & $\begin{array}{l}\text { Erythrocruorin } \\
\text { in corpuscles }\end{array}$ & $\begin{array}{l}\text { Arca, a mussel (order Lamellibranchi } \\
\text { ata) }\end{array}$ \\
\hline & Myohaemoglobin & $\begin{array}{l}\text { Busycon, a whelk (order Gastropoda) } \\
\text { Pigment in heart and radula muscle } \\
\text { (hacmocyanin in circulation) }\end{array}$ \\
\hline Echinoderms & Erythrocruorin & Thyone, sea slug (class Holothuroidea \\
\hline $\begin{array}{l}\text { Chordates } \\
\text { Protochordates }\end{array}$ & ? & $\begin{array}{l}\text { So far, neither haemoglobin nor myo } \\
\text { laemoglobin reported present ir } \\
\text { members of this subphylum. Red } \\
\text { field reports absence of haemoglobir } \\
\text { in Amphioxus }\end{array}$ \\
\hline \multirow[t]{2}{*}{ Vertebrates } & $\begin{array}{l}\text { Haemoglobin } \\
\text { in corpuscles }\end{array}$ & $\begin{array}{l}\text { Present throughout, including Lam } \\
\text { petra (suborder Cyclostomata) }\end{array}$ \\
\hline & Myolıaemoglobin & $\begin{array}{l}\text { Probably present throughout, in lowe } \\
\text { orders, e.g. Pisces, Amphibia, and } \\
\text { Reptilia, mostly in heart muscle }\end{array}$ \\
\hline
\end{tabular}


isms, there has been found vanadium-haemochromogen which is also similar to bile pigments. ${ }^{141}$

Porphyrin derivatives are extremely widely, perhaps universally, distributed throughout the living world, especially the iron-porphyrins which play a part in the structure of living protoplasm as the prosthetic groups of various enzymes. It may be confidently asserted that there is no organism in which such catalysts have been looked for and not found.

According to Lemberg the earliest of such enzymes must have been hydrogenase, which catalyses the reaction of reduction by molecular hydrogen based on the following elementary process ${ }^{142}$ :

$$
\mathrm{H}_{2} \longrightarrow 2 \mathrm{H}^{+}+2 \mathrm{e}
$$

This enzyme participates in the metabolism of such typical heterotrophs and anaerobes as the bacteria which carry out butyric acid fermentation (clostridia). ${ }^{143}$ In them this enzyme can only manifest its activity in the complete absence of free oxygen. Hydrogenase has also been found in Esch. coli, ${ }^{144}$ in methane bacteria, in Azotobacter, in purple sulphur bacteria and in the organisms which reduce sulphur compounds to hydrogen sulphide. ${ }^{145} \mathrm{H}$. Gaffron ${ }^{146}$ established that it plays a part in the reduction of $\mathrm{CO}_{2}$ by green algae in the dark. According to E. A. Bořchenko ${ }^{147}$ this enzyme is also present in the cells of higher plants. Thus we have evidence of the participation by hydrogenase in the metabolism of the more primitive anaerobic heterotrophs as well as in that of chemo- and photosynthetic organisms.

The other porphyrin-containing enzymes are mostly catalysts activating aerobic reactions in which free oxygen and hydrogen peroxide take part. We are referring to catalase and peroxidase and also to cytochromes and cytochrome oxidase.

Naturally the role of these enzymes is especially great in living creatures which did not arise and develop until the atmosphere of our planet had been enriched with gaseous oxygen, until the respiratory process came into being.

The finding of cytochrome $a$ by M. Ishimoto and colleagues $^{148}$ in the obligate anaerobe Desulfovibrio desulfuricans is of particular interest in this connection. It allows us 
to suppose that cytochromes arose in organisms which were living under conditions in which the atmosphere was still in its primary, reducing state. In these they might have taken part in anaerobic oxidation-reduction reactions. Only after the appearance of free oxygen did they assume the character of typical aerobic mechanisms.

All the reactions listed, which are carried out by ironporphyrin enzymes, take place in the dark and therefore no use is made in them of the important property of porphyrins which is associated with their colours, with their ability to absorb light.

We can now understand this quite well, for the ironporphyrins in organisms practically never have a photosensitising effect. It is only in the case of cytochrome $c$ that there has recently been found a very weak activity which helps to explain its oxido-reductive transformations. ${ }^{149}$

Unlike the iron-porphyrin complexes, porphyrins which are not combined with metals and, especially, magnesiumporphyrin complexes, do not have the properties of ordinary catalysts acting in the dark but are able to carry out photosensitising and photocatalytic activities. The mechanism whereby iron-porphyrin complexes participate in biologically important catalytic processes is based on a reversible oxidoreduction of the central atom of iron, which takes place in the dark. The researches of A. A. Krasnovskil and his colleagues have shown that magnesium-porphyrin complexes, bacteriochlorophyll and the chlorophyll of higher plants, and even porphyrins without metals (e.g. haematoporphyrin) can be reversibly reduced (accepting an electron or hydrogen) only when they absorb a corresponding quantum of light. ${ }^{150}$ When this happens the photocatalytic transfer of an electron or of hydrogen, unlike ordinary catalytic processes occurring in the dark, leads to a raising of the energy level of the products of the photoreaction; it, so to speak, "puts into store' a part of the absorbed energy of the light in a very easily mobilised form. ${ }^{151}$

Thus, the mere presence of these porphyrin pigments in the primaeval organisms enabled them to use in their vital processes not only the readily available energy of exogenous 
organic compounds, but also a supplementary source of energy, namely light.

In the first period of the existence of life, while there were plenty of organic compounds, which had arisen primarily, in the external medium, light, as a source of cnergy, cannot have been of decisive significance for the organisms. However, as the ready-made organic materials disappeared and the deficiency of them in the external medium became more marked, so a greater and greater advantage in the struggle for existence accrued to those organisms which were in a position to use the porphyrins present in them not only as catalysts of reactions occurring in the dark, but also as photosensitisers.

In this way they were able to use light as a supplementary source of energy. The most important result of this was to enable the first coloured organisms, without undertaking any considerable reconstruction of their already existing organisation, to rationalise their heterotrophic metabolism fundamentally by using exogenous organic substances far more economically.

Ordinary heterotrophs have to transform a considerable proportion of the organic substances which they obtain from the external medium into waste products which cannot be used further. Only thus can they mobilise the energy bound up in these substances which is indispensable for synthesising the components of protoplasm. By contrast, the first coloured organisms used the 'extra' energy of light for this purpose and were thus freed from the need to waste exogenous organic substances.

This may be understood more clearly by reference to a study of the metabolism of the contemporary pigmented bacteria which were discovered quite a long time ago by T. W. Engelmann. ${ }^{152}$ It has been shown by numerous spectroscopic and chemical studies that these organisms contain considerable amounts of magnesium-porphyrin derivatives, similar in their chemical nature to chlorophyll $a,{ }^{153}$ while some of them have also been found to contain free porphyrins. By virtue of these the bacteria can absorb the visible radiations of sunlight and use their energy for metabolism. A particular example of such orgarisms is provided 
by the purple bacteria Athiorhodaceae. ${ }^{154}$ Externally, from the point of view of its over-all balance, their metabolism is of the ordinary heterotrophic type. In light they can be cultivated under anaerobic conditions but the solution in which they grow must contain organic substances (e.g. butyric acid or other analogous compounds). As the mass of the bacteria increases so the quantity of exogenous organic substances in the surrounding medium decreases correspondingly, but the bacteria also discharge a small amount of gaseous $\mathrm{CO}_{2}$ into the atmosphere.

The whole difference between the Athiorhodaceae and heterotrophs which can grow equally well in the dark or in the light, is that in the light the Athiorhodaceae can use almost all (9o per cent or more) of the exogenous substances for increasing their mass. The only 'waste product' is $\mathbf{C O}_{2}$ which forms only a few parts per hundred of the organic substances used in the growth and development of the bacteria. If we compare this with the outlay of organic substances by ordinary heterotrophs (metabolising in the dark), in which this dissipation consumes the lion's share of the nutrients, we shall see how far more rational is the use of exogenous organic materials by the Athiorhodaceae owing to their having acquired the ability to use the energy of sunlight.

As we have already said, on over-all balance, the Athiorhodaceae may be regarded as heterotrophs requiring organic substances from the external medium; but from the point of view of their internal biochemical mechanisms, these bacteria already approach the photoautotrophs. Like all other organisms, they can fix atmospheric $\mathrm{CO}_{2}$ but in doing so they make use of the increased energy of the light-absorbing pigments. Thus the Athiorhodaceae carry out a photocatalytic transfer of hydrogen, reducing $\mathrm{CO}_{2}$ and oxidising the exogenous organic substances. J. W. Foster ${ }^{155}$ succeeded in observing this in the case of the oxidation by these bacteria of secondary alcohols into ketones. As these do not enter into the general metabolism they accumulate in the external medium and can therefore easily be estimated. In other cases such waste products are not formed and the whole metabolism is directed to the synthesis of bacterial protoplasm. ${ }^{156}$ 
Other pigmented bacteria carry out their metabolism along the same lines, but in them hydrogen sulphide, rather than organic substances, acts as a hydrogen donor for the reduction of $\mathrm{CO}_{2}$. These are the so-called purple and green sulphur bacteria (Thiorhodaceae). They were discovered long ago in small bays and lagoons of sea water, well exposed to the sun, in places where the bacteria had access to hydrogen sulphide. It was later shown that they are widely distributed in the soil and also in slimy pools of fresh and salt water. ${ }^{157}$

The very interesting researches of van $\mathrm{Niel}^{158}$ on Thiorhodaceae showed that, in the light, these bacteria can oxidise hydrogen sulphide in the complete absence of free oxygen but with the simultaneous absorption of $\mathrm{CO}_{2}$ in amounts corresponding stoichiometrically to an equation, which, for purple sulphur bacteria, is as follows:

$$
\mathrm{H}_{2} \mathrm{~S}+2 \mathrm{H}_{2} \mathrm{O}+2 \mathrm{CO}_{2} \rightarrow 2 \mathrm{CH}_{2} \mathrm{O}+\mathrm{H}_{2} \mathrm{SO}_{4}
$$

That for green sulphur bacteria is:

$$
\mathrm{CO}_{2}+2 \mathrm{H}_{2} \mathrm{~S} \rightarrow \mathrm{CH}_{2} \mathrm{O}+\mathrm{H}_{2} \mathrm{O}+2 \mathrm{~S}
$$

for these latter bacteria can only oxidise $\mathrm{H}_{2} \mathrm{~S}$ as far as sulphur.

According to ran $\mathrm{Niel}^{159}$ the process occurs as follows. Owing to the presence of porphyrin pigments the Thiorhodaceae absorb sunlight and use its energy for the photolysis of water according to the equation

$$
\mathrm{H}_{2} \mathrm{O}+\mathrm{h} v \rightarrow \mathrm{H}+\mathrm{OH}
$$

The hydrogen of the water reduces $\mathrm{CO}_{2}$ and transforms it into the carbon skeletons of the substances of which the organism is composed (represented schematically in the equations by $\mathrm{CH}_{2} \mathrm{O}$ ).

According to van Niel the process of photosynthesis in green plants is analogous with that described for Thiorhodaceae. Here also the agent which directly reduces $\mathrm{CO}_{2}$ is the hydrogen of water. The only difference is that the hydroxyl radicals liberated by photolysis are not used up in oxidising some hydrogen donor $\left(\mathrm{H}_{2} \mathrm{~S}\right.$ or some organic compound) within the organism. Owing to the presence of 
specific supplementary mechanisms in green plants they are transformed into hydrogen peroxide which is broken down by catalase to liberate molecular oxygen, thus enriching the surrounding atmosphere with this gas. Van $\mathrm{Niel}^{160}$ gives the following scheme to clarify this difference between photosynthesis in bacteria and in green plants (Fig. 37).

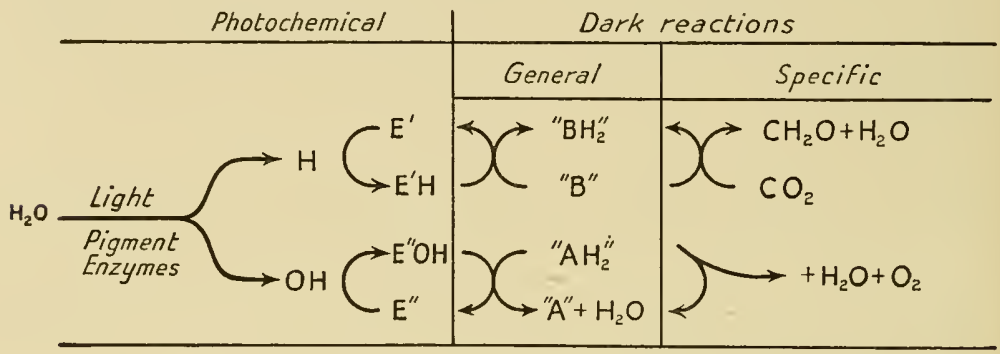

FIG. 37. Scheme of the reactions involved in photosynthesis by bacteria and green plants (after van Niel).

In this diagram the symbols $\mathrm{E}^{\prime}$ and $\mathrm{E}^{\prime \prime}$ denote factors preventing the recombination of the hydrogen and hydroxyl radicals formed during photolysis. Factor $E^{\prime}$ directs the hydrogen to the reduction of $\mathrm{CO}_{2}\left(\right.$ to $\mathrm{CH}_{2} \mathrm{O}$ ) to an equal extent in both the bacteria and green plants.

In the bacteria factor $E^{\prime \prime}$ transfers the hydroxyl radicals to the appropriate hydrogen donor, indicated by the symbol $\mathrm{AH}_{2}$, which may be $\mathrm{H}_{2} \mathrm{~S}$, thereby splitting off water from it and leading to the formation of the product of oxidation, A, e.g. sulphur. In green plants the factor $E^{\prime \prime}$ transfers the hydroxyl radicals to a special mechanism which transforms them to $\mathrm{O}_{2}$ and water via $\mathrm{H}_{2} \mathrm{O}_{2}$.

Certain doubts have been expressed by photochemists as to whether water can be photolysed directly by visible light. Nobody has succeeded in bringing about this photolysis in model experiments although various pigments have been used as photosensitisers.

However, even if we admit that, in van Niel's scheme, the photolysis of water is a somewhat speculative explanation of the reversible, photochemical transfer of hydrogen or an electron by means of the energy of the light absorbed by the 
system, this scheme will still retain its significance. It demonstrates very clearly what is the essentially new factor in the development of photosynthesis in the form in which we know it to-day in green plants. What is new is mainly concerned with the giving off of molecular oxygen into the surrounding atmosphere.

The more primitive pigmented organisms had chemical mechanisms which allowed them to use, as the primary hydrogen donors in photosynthetic reactions, only the most readily available or 'active' donors such as, for example, organic compounds, or such inorganic substances as hydrogen sulphide or molecular hydrogen. As examples of organisms which have retained this relatively simple photosynthetic organisation we may take the purple and green bacteria which were mentioned above.

However, during the progressive evolution of the earliest photosynthetic organisms their internal organisation became both more closely knit and more elaborate, tending torards the creation of mechanisms enabling them to use wider and wider selections of substances as hydrogen donors. This course of development inevitably led to the inclusion in the photosynthetic reaction of the more 'difficult', but also more ubiquitous hydrogen donor, water. The oxygen of the water was then liberated in molecular form.

Some contemporary organisms are interesting in that their metabolism retains features of a more primitive organisation of the photosynthetic processes, though the ability to give off the molecular oxygen of water is already manifest in them. They seem to be intermediate links in the chain between the earliest photosynthetic organisms and the highly organised photoautotrophs.

An example of an organism of this sort is the green alga Scenedesmus, the metabolism of which has been studied in detail from this point of view by $H$. Gaffron. ${ }^{161}$ Under normal conditions this alga, like all other green plants, carries out photosynthesis accompanied by the giving off of oxygen. However, if it is kept for an hour or more under anaerobic conditions and then placed under relatively weak illumination in an atmosphere of hydrogen or nitrogen with $\mathrm{CO}_{2}$, its metabolism will be substantially changed. Under 
these conditions it, as it were, reverts to a more primitive form of photosynthesis, reducing $\mathrm{CO}_{2}$ by means of molecular hydrogen or endogenous, organic hydrogen donors. Naturally no oxygen is given off under these circumstances.

Thus, under these conditions Scenedesmus reverts to a form of metabolism similar to that which we described above as occurring in the heterotrophic Athiorhodaceae or in the autotrophic hydrogen bacteria. In the latter case the over-all result of the photosynthesis carried out by Scenedesmus may be expressed by the equation

$$
2 \mathrm{H}_{2}+\mathrm{CO}_{2} \rightarrow \mathrm{CH}_{2} \mathrm{O}+\mathrm{H}_{2} \mathrm{O}
$$

In this reaction, which involves the oxidation of molecular hydrogen, the enzyme hydrogenase plays an important part, being adaptively activated under reducing conditions. When oxygen is present, or when the illumination is more intense, the activity of the hydrogenase is destroyed and the alga reverts to its normal metabolism, photoautotrophic absorption of $\mathrm{CO}_{2}$ and production of $\mathrm{O}_{2}$.

\section{The formation of free oxygen.}

The period when autotrophic photosynthesis was coming into being and leading to the formation in the atmosphere of ever greater and greater amounts of molecular oxygen, liberated from water by means of the energy of the long-wave components of sunlight, was one of the most remarkable periods in the whole history of our planet. It was a critical time, separating the two important epochs of the history of the surface of the Earth, the reducing and the oxidising epochs.

This period is of especial interest from the point of view of the student of the evolution of metabolism because it was just in this transitional epoch, when the external conditions of life were radically altered, that there arose numerous and diverse new forms of metabolism, there occurred what might be described imaginatively as a tense search for new paths for the process of life. Later on, when this revolutionary period of 'Sturm und Drang' had become a thing of the past, when more or less constant oxidising conditions had 
been established in the atmosphere, some of these new paths became the broad highways for the development of most of the living things on our planet, while others degenerated into narrow side alleys along which only a very few groups of specialised organisms pursue their metabolic activities.

Let us try to imagine the circumstances which prevailed on the surface of the Earth at the time which we have been describing, about 700 or 800 million years ago. The exogenous organic substances which had originally been formed, and which could serve as nutrients for the heterotrophic, anaerobic organisms which then inhabited the Earth, had largely disappeared. The atmosphere contained an abundance of carbon dioxide, hydrogen, methane and other gaseous substances, which had been formed by various fermentative processes. Dissolved in the water of the seas and oceans there were ethyl alcohol, various organic acids and the waste products of anaerobic metabolism which were of no further use. Partly in solution and partly in the deposits there were carbonates and a number of reduced inorganic substances such as ferrous oxide; some of these had remained in their original state and some, such as ammonia and hydrogen sulphide, had arisen biogenically.

All these substances were relatively inaccessible to the living things of that period in the absence of free oxygen. Only the earliest photosynthetic organisms, which had already arisen by that time, were able to make extensive use of, and almost monopolise, the diverse organic residues of fermentation and such substances as methane, $\mathrm{H}_{2}$ and $\mathrm{H}_{2} \mathrm{~S}$ as hydrogen donors for reduction of the $\mathrm{CO}_{2}$ which they fixed, and for building up their structural components. Thanks to this they must have obtained a considerable advantage in the struggle for existence at that particular time. Their rapid development and evolution, which occurred as a result of this advantage, provided a basis for the emergence of the extremely complicated and efficient metabolic mechanisms which are characteristic of present-day photoautotrophs.

However, in the very process of their development, these organisms began to enrich the atmosphere with molecular oxygen. This entailed a profound alteration in the course of the evolution of life as a whole on our planet. The appear- 
ance of molecular oxygen provided a theoretical possibility for even the colourless heterotrophs to rationalise their metabolism and to make use of substances which could not be used before by ordinary anaerobic heterotrophs. Under these circumstances the practical realisation of this possibility only required very small additions to the previously existing metabolic mechanisms of the organisms. In particular, as we pointed out on p. 430 , the transition from obligate to facultative anaerobiosis could be brought about simply by an alteration in a single link in the long chain of glycolytic degradation. This involved the replacement of anaerobic decarboxylation of pyruvic acid by its oxidative decarboxylation and the reaction whereby acetyl-coenzyme $\mathrm{A}$ is formed proceeded in accordance with the equation with which we are already familiar:

$$
\mathrm{CH}_{3} \mathrm{CO} \cdot \mathrm{COOH}+\mathrm{CoA}+\frac{1}{2} \mathrm{O}_{2} \rightarrow \text { acetyl-CoA }+\mathrm{CO}_{2}+\mathrm{H}_{2} \mathrm{O} \text {. }
$$

Thus, such facultative anaerobes as Esch. coli and Strep. faccalis can, under aerobic conditions, not only break sugar down to lactic acid, but can also oxidise it to acetic acid, which is considerably more advantageous from the point of view of acquiring energy. In the absence of oxygen they form, as well as acetic acid, reduced products such as ethyl alcohol which are useless to these organisms under the postulated conditions. On the other hand, the acetic acid bacteria, advancing even further, became confirmed aerobes; they can oxidise not only sugar, but also ethyl alcohol to acetic acid, thus putting it back into circulation in their energy metabolism and mobilising the energy of this waste product of fermentation which was previously of no use whatsoever to heterotrophs.

The line of evolution which began in this way seems to have been the outset of the development of various facultative anaerobes which effect many so-called oxidative fermentations. ${ }^{162}$

\section{Chemosynthesis.}

It is our opinion that it was in this transitional period that metabolism became differentiated, and that such special- 
ised groups of organisms as the chemoautotrophs made their appearance. It was just at this intermediate period, between the prevalence of reducing and oxidising conditions, that there first arose the possibility, in principle, of oxidising the reduced inorganic substances of the crust of the Earth on an extensive scale by means of molecular oxygen. At the period we are dealing with, when free oxygen was beginning to be formed, these oxidative reactions must have been occurring at, literally, every point on the surface of the Earth, for oxidisable substrates were present everywhere. However, when these reactions took place inorganically they proceeded, relatively speaking, very slowly and the energy which they liberated was lost, being dissipated in the form of heat.

When there was an acute shortage of exogenous organic compounds those organisms which, during their evolution, had become able to include in their metabolism those reactions whereby inorganic materials are oxidised, and which had formed in their bodies catalytic mechanisms which hastened these processes and mobilised the energy derived from them for biosynthesis, certainly had a great advantage in the struggle for existence. Their position was therefore secured by natural selection and they were later able to develop extensively.

At present we usually find organisms capable of a chemoautotrophic way of life under natural conditions in just those places where the reducing substances of the depths, emerging into the daylight, encounter the molecular oxygen of the atmosphere. For example, reduced compounds of sulphur are easily formed in nature wherever anaerobic conditions prevail. Tremendous amounts of hydrogen sulphide accumulate in the seas and oceans in places where the water is stagnant owing to differences in salinity between the surface and deep layers. Considerable amounts of hydrogen sulphide are also concentrated in the water of the petroleum-bearing strata, and also on the surface of the Earth under conditions which lead to the anaerobic decomposition of proteins. Wherever hydrogen sulphide passes from a medium where the conditions are reducing into one where they are oxidising, there we always find the development of thionic or sulphur bacteria. ${ }^{163}$ Similarly, the nitrifying bacteria carry 
out their activities at the boundary of a region where ammonia is being formed anaerobically and one where it comes into contact with the molecular oxygen of the air. This may be observed in the soil, in sea water and in bogs. ${ }^{164}$

The iron bacteria, which oxidise ferrous to ferric salts, develop especially luxuriantly where rich sources of iron emerge on to the surface of the Earth. ${ }^{165}$

At the present time very large amounts of hydrogen are given off from the depths of the Earth and from wherever the anaerobic decomposition of carbohydrates and proteins is taking place. ${ }^{166}$ Bogs, especially, produce a considerable amount of so-called marsh gas which contains hydrogen and methane. In deeper waters the oxygen which penetrates into them oxidises these gases as a result of the activities of hydrogen and methane bacteria and this often leads to the complete disappearance of oxygen from the hypolimnion. ${ }^{167}$

Nowadays the chemoautotrophs play a very important part in the circulation of materials. Practically all the processes occurring under natural conditions leading to the oxidation of reduced compounds of nitrogen and sulphur (and also of hydrogen, methane and, to some extent, iron) are associated with the vital activities of the appropriate microorganisms.

Table 5 is taken from $S$. Kuznetsov. ${ }^{167}$ It shows the reactions carried out by the chemoatitotrophs and the organisms related to them. The equations given are, of course, only those for the over-all reactions. The chemical mechanism of these reactions has, as yet, only been very little studied. At first it was believed that the metabolism of the chemoautotrophs was very primitive. ${ }^{168}$ However, as the study of this field progresses, it becomes clearer and clearer that it is far more complicated than the metabolism of ordinary heterotrophs. ${ }^{169}$

A particular illustration of the great metabolic activity and complexity of the chemoautotrophs is their ability to synthesise various vitamins and growth factors. For example, according to D. J. O'Kane, ${ }^{170} T$. thiooxidans can synthesise thiamine, riboflavin, nicotinic and pantothenic acids, pyridoxine and biotin, i.e. almost all the members of the vitamin B complex. This points, first of all, to a very great complexity 


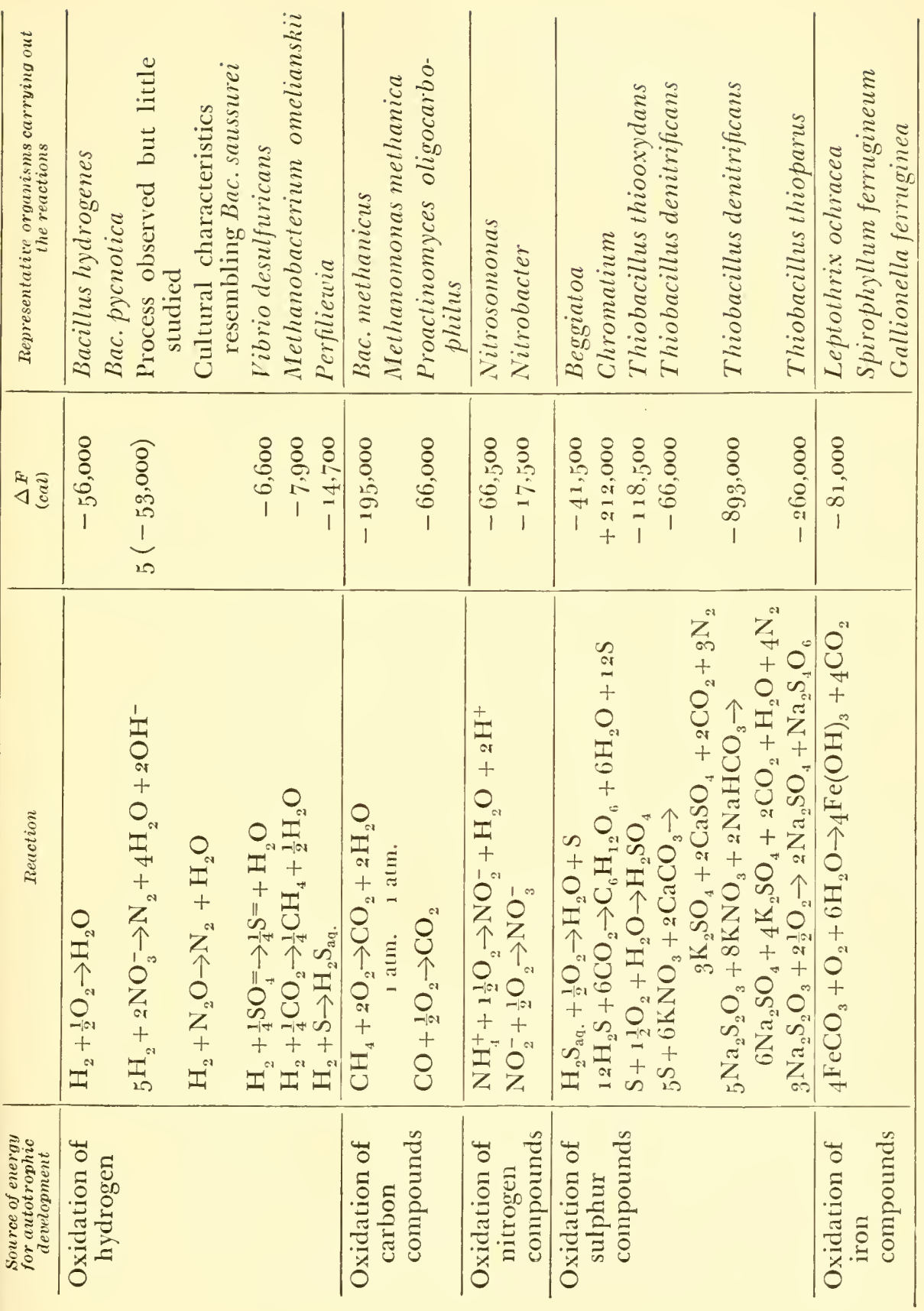


in the metabolism of these organisms, in that the synthesis of these vitamins requires the participation of a large number of strictly co-ordinated biochemical reactions. Secondly, it points to a connection between this metabolism and the glycolytic and oxidative transformations of carbohydrates, in that vitamins of the $\mathrm{B}$ group catalyse these reactions throughout the whole living world.

As we have already shown, the metabolism of the chemoautotrophs is, in fact, based on the same glycolytic mechanisms as that of the heterotrophs. In the chemoautotrophs, however, there are superimposed on these mechanisms supplementary chemical adaptations, enabling them to use energy derived from the oxidation of inorganic substances for synthetic processes. These inorganic oxidations themselves may be found in the metabolism of some ordinary heterotrophs. For example, Esch. coli can oxidise hydrogen, many mycobacteria can nitrify, typical heterotrophs oxidise sulphur, thiosulphate, etc. ${ }^{171}$

In addition, as R. Hill ${ }^{172}$ rightly pointed out, the mechanism of fixation of $\mathrm{CO}_{2}$ is identical in chemoautotrophs and in ordinary heterotrophs. The only difference is that the heterotrophs cannot use the energy and the reducing substances formed during the oxidation of mineral substances for the assimilation of $\mathrm{CO}_{2}$. They lack the necessary mechanisms for this. However, the appearance of these mechanisms on top of the finished organisation of the rest of the metabolism was not too complicated and was easily assured by natural selection in the epoch which we are considering, as they enabled the organisms to escape from the actual bitter struggle for organic substances.

The great systematic diversity of the chemoautotrophic groups and the similarity between some of their individual representatives and various heterotrophs (with which many of them are connected by transitional organisms) convinces us that chemoautotrophy arose on more than one occasion, and that its initial and exuberant development dates from a time when there already existed a great diversity of organic forms. This development was made possible by the special conditions of the period under discussion and particularly by the shortage of organic nutrients and the extensive avail- 
ability of inorganic sources of energy. Howerer, when conditions on the surface of the Earth became oxidising these sources were rather quickly exhausted and were only replenished comparatively slowly from the deeper layers of the crust of the Earth. On the other hand, the balance of organic substances in the biosphere became more and more positive owing to the appearance and quick development of photoautotrophs. Nowadays, although chemoautotrophs play an important part in the circulation of sulphur, nitrogen, etc., they have long ago been relegated to a secondary position as producers of organic substances by green plants, and only constitute a fraction of one per cent. of the general mass of living things.

\section{Photosynthesis.}

Undoubtedly the highway of autotrophic development was photosynthesis as we see it now in green plants. ${ }^{173}$ The use of water as a hydrogen donor in photosynthetic organisms was a tremendous advance in the development of biochemical systems which linked the light-induced stage of the process with the cycles of reactions and which brought about the gradual reduction of $\mathrm{CO}_{2}$ and the formation of molecular oxygen.

However, the taking of this step required the prolonged evolution of organisms which were already rather highly developed and which possessed a large arsenal of diverse metabolic mechanisms. Our knowledge of the photosynthetic apparatus of contemporary plants convinces us that this must be so. It is extremely complicated and, in spite of much research, it is still far from being fully worked out.

In order to give a general picture of what happened, we may make the following analogy although, of course, it must not be pushed too far. We may take a motor-car engine as our example of a complicated system which carries out a particular job. The work of the engine does not depend exclusively on its essential component, the cylinder block. It also depends on a number of accessory mechanisms, some of which are themselves complex, each with its own specific task, e.g. the preparation and delivery of the combustible 
mixture, the production of a high-voltage spark to explode the mixture, cooling, lubrication, transmission, the regulation of speed, etc. If the engine is to run smoothly, not only must each of these systems function well, they must also be well co-ordinated in both time and space. The spark from the plugs must occur when the piston is in a particular position in the cylinder; the mixture must enter the cylinder at the appropriate moment, etc.

Similarly, in the photosynthetic apparatus of a plant, we are not dealing with one single chain of chemical transformations but with a number of cycles of biochemical reactions, whole aggregates of catalytic and photochemical systems. Only when they are highly co-ordinated, when they are continually interacting, can their proper effect be obtained. This is achieved not only by a definite accurate co-ordination of the separate reactions in time, but also by their spatial localisation, the existence of a certain structure in the photosynthetic apparatus. The photosynthetic enzymes are 'assembled' on this structure and the products of the photosynthetic cycle move over it. Nobody has yet succeeded in reproducing photosynthesis outside the living cell, in contrast to alcoholic fermentation which may be observed in a solution if this contains all the necessary enzymes. This, in itself, indicates the extreme complexity of the photosynthetic system.

In the chloroplasts of plants the chlorophyll is concentrated in minute granules which take the form of flattened cylinders having a diameter of $0.5 \mu$ and a thickness of $0.2 \mu$. The granules consist of plates of protein combined with a chlorophyll-containing lipid layer, like a sandwich made of two slices of bread with butter inside. ${ }^{174}$ According to this view the polar, magnesium-porphyrin nucleus of the chlorophyll is associated with the protein, while its hydrophobic phytyl tail is directed towards the lipid layer of the granule.

On such a protein-lipid aggregate there occurs, first of all, the initial photochemical act which may be provisionally designated as the 'photolysis of water'. However, in addition to this 'photolytic' system, and in parallel to it, there must be, as in the motor-car engine of which we spoke, other systems or aggregates taking part in the process of photo- 
synthesis. These may be characterised as follows: (1) The formation of molecular oxygen; (2) the dark fixation of $\mathrm{CO}_{2}$; (3) the reduction of $\mathrm{CO}_{2}$ as far as carbohydrates ; (4) the synthesis of sugars from phosphotrioses; (5) the formation of 'active hydrogen' in the shape of reduced forms of diand triphosphopyridine nucleotides; (6) the formation of high-energy bonds (ATP) (Fig. 39).

We shall now give a very schematic exposition of the work of all these aggregates, using, for the most part, the data published by M. Calvin ${ }^{175}$ in his address to the Third International Congress of Biochemistry held in Brussels.

According to M. Calvin, when light falls on the laminated, chlorophyll-containing aggregate, it splits off electrons. The electrons and the remaining positive holes are quickly shared out over the structure.

According to A. Krasnovskir, V. Evstigneev and their colleagues, the photochemical transfer of electrons which underlies the action of chlorophyll occurs by means of an intermediate, reversible photoreduction of the pigment. This supposition is substantially strengthened by the recent observation in living, photosynthesising organisms, of rapid spectral variations corresponding with those which occur during the photoreduction of chlorophyll. ${ }^{175 a}$ The negative charges (electrons) which are produced in one way or another are used for the reduction of phosphopyridine nucleotides (in system 5), while the positive charges act on water, leading to its oxidation (in system 1 ).

The details of the working of system (1) have not yet been fully elucidated but there can be no doubt whatever that the molecular oxygen given off during photosynthesis is derived from water, as was asserted by A. N. Bach (Bakh) $)^{176}$ as early as 1893 , and proved experimentally considerably later by A. P. Vinogradov and R. V. Teřs ${ }^{177}$ in their experiments with isotopes of oxygen. The nearest thing to extracellular photosynthesis is the reaction obtained by Hill, who showed that, in the light, oxygen is split off from water in the chloroplast, but only when the surrounding medium contains such powerful hydrogen acceptors as quinones, organic pigments and ferric salts. This is necessary in order to prevent the reaction from occurring in the reverse direc- 
tion. It would seem that there is formed, as an intermediate product during the process of photo-oxidation of water, either hydrogen peroxide or else an organic peroxide which, on breaking down, gives rise to molecular oxygen. The oxygen which is formed in this way is mainly given off into the atmosphere, but part of it is used in the process of photosynthesis, especially in system (6).

In green plants the dark fixation of $\mathrm{CO}_{2}$ (system 2) is mainly carried out by the same mechanisms which operate in ordinary heterotrophs, namely coenzyme $\mathrm{A}$ and phosphate dehydrogenases. According to M. Calvin the primary acceptor of $\mathrm{CO}_{2}$ is ribulose disphosphate, which is obtained by the phosphorylation of ribulose monophosphate at the expense of ATP. The formation of ATP occurs in system (6) which will be discussed below, while the initial ribulose monophosphate is formed in system (4).

Ribulose disphosphate is carboxylated by $\mathrm{CO}_{2}$ with the help of the enzyme carboxydismutase and the intermediate product thus obtained, which now contains six carbon atoms, is broken down to two molecules of phosphoglyceric acid. This acid is the primary product of the fixation of $\mathrm{CO}_{2}$ by green plants and is later transformed, in systems (3) and (4), into various sugars.

In system (3) there takes place the reduction of phosphoglyceric acid to triose phosphates (glyceraldehyde phosphate and dihydroxyacetone phosphate). The carrying out of this reaction requires, in the first place, 'active hydrogen ' which is supplied in the form of reduced di- and triphosphopyridine nucleotides which are elaborated in the special system (5). In the second place it requires ATP which, as we shall see, is obtained from system (6).

The later transformation of triose phosphates takes place in system (4) and comprises, in part, their condensation to hexose disphosphate by means of aldolase (Fig. $3^{8}$ ) and partly the formation of a number of phosphoric esters of various sugars having four, five, six, seven and ten carbon atoms. This leads, in particular, to the formation of ribulose monophosphate. According to Calvin this process takes place in the following order: The hexose $\left(C_{6}\right)$, formed from triosephosphates, is broken down $\left(\mathrm{C}_{2}\right.$ and $\left.\mathrm{C}_{4}\right)$. The sugar with the 
four carbon atoms $\left(\mathrm{C}_{4}\right)$ combines with a $\mathrm{C}_{3}$ substance to give sedoheptulose $\left(\mathrm{C}_{7}\right)$. By combining with glyceraldehyde phosphate $\left(\mathrm{C}_{3}\right)$, sedoheptulose monophosphate gives rise to a phosphorylated $\mathrm{C}_{10}$ carbohydrate which is broken down by the enzyme transketolase into two phosphopentoses, ribulose monophosphate $\left(C_{5}\right)$ and ribose monophosphate $\left(C_{5}\right)$.

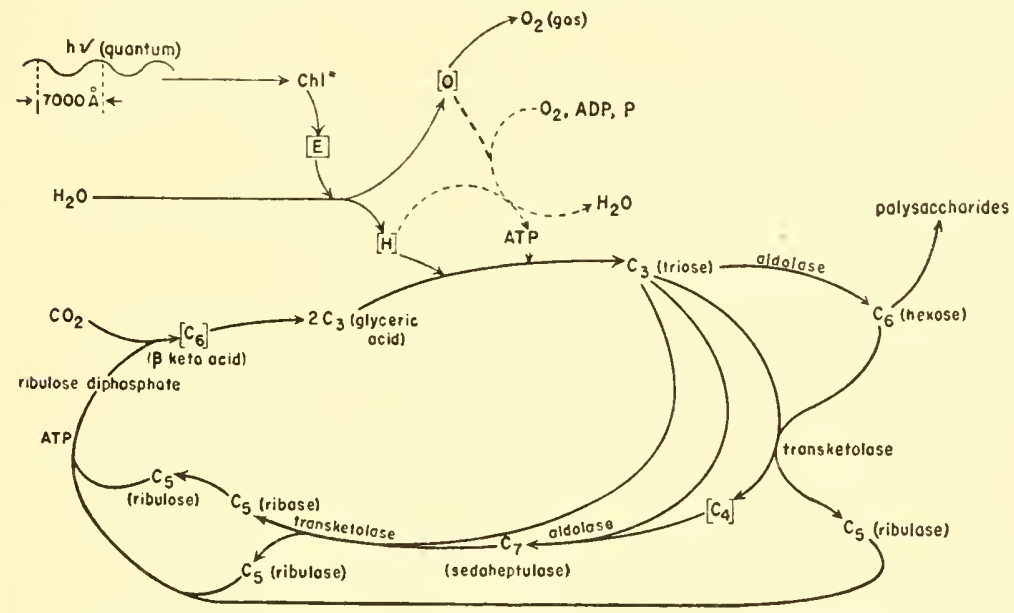

Fig. 38. Proposed cycle for carbon in photosynthesis (after Calvin).

Thus, in this process there takes place the transformation of the various sugars characteristic of the vegetable kingdom into one another. In the last analysis they are all derived from phosphoglyceric acid. However, this cycle of reactions can only run smoothly when there occurs the essential reaction of the reduction of phosphoglyceric acid into glyceraldehyde phosphate. This requires a continuous supply of reduced pyridine nucleotide and ATP, the former derived from system (5) and the latter from system (6).

The participation of reduced pyridine nucleotides in the dark fixation of $\mathrm{CO}_{2}$ in heterotrophs has been extensively demonstrated in the researches of S. Ochoa. ${ }^{178}$ The experimental material now available shows that hydrogen, which is mobilised photochemically, is transferred to pyridine nucleotides by means of pigments which act as photosensitisers. 
Thus it is probable that ' active hydrogen' enters the cycle of the assimilation of $\mathrm{CO}_{2}$ as reduced forms of pyridine nucleotides which take part in the reaction whereby $\mathrm{CO}_{2}$ is reduced as far as carbohydrate (system 3).

The elaboration in the chloroplasts (in system 5) of reduced pyridine nucleotides, using the hydrogen which was formed in the initial photochemical reaction, has also been demonstrated in model experiments. In particular, as early as 1949 A. A. Krasnovskiř and his colleagues ${ }^{179}$ succeeded in this way in showing that chlorophyll sensitises the transfer of hydrogen to pyridine nucleotides and to flavines, the energy of light being accumulated in the products of the reactions. These authors put forward the hypothesis that it is just this reaction which links the light-induced stage with the process of reduction of $\mathrm{CO}_{2}{ }^{180}$

Somewhat later W. Vishniac and S. Ochoa ${ }^{181}$ showed that, in fact, isolated chloroplasts, together with homogenates, can reduce photochemically the pyridine nucleotides which are associated with the enzymic stages of the assimilation of $\mathrm{CO}_{2}$. This is confirmed by the finding of various dehydrogenases in chloroplasts. ${ }^{182}$

The methods of formation of high-energy phosphorus compounds (system 6) in the process of photosynthesis have still been only very poorly studied, as was rightly remarked by $\mathrm{R}$. Hill. ${ }^{183}$ It is evident that the cell of the green plant has a number of mechanisms for carrying out this task, which it borrows from the metabolic arsenal of enzymes of the heterotrophs and the chemoautotrophs. Associated with these mechanisms are the specific pathways of photochemical phosphorylation. According to Hill, the energy needed for the esterification of inorganic phosphate is obtained, in green plants, by the oxidation of whatever compounds have been reduced under the influence of light. The energy obtained by such oxidation is accumulated in high-energy phosphorus compounds and in this form it enters into the photosynthetic cycle of reduction of fixed $\mathrm{CO}_{2}$.

The recent work of D. I. Arnon and colleagues ${ }^{184}$ has shown that when isolated chloroplasts are illuminated they can form ATP from ADP and inorganic phosphate; this 
reaction requires the participation of a number of co-factors, the most important of which is ascorbic acid.

It is most likely that in the formation of ATP by these reactions, 'photochemical phosphorylation' follows a similar course to oxidative phosphorylation. The initial hydrogen donor (reduced substance) is photochemically produced ' active hydrogen ' in, for example, the shape of reduced forms of pyridine nucleotides, while the oxidising agent is $\mathrm{OH}$ formed by the photolysis of water, hydrogen peroxide, or even molecular oxygen. In this reaction of photochemical oxidative phosphorylation there probably take part many of the ordinary respiratory mechanisms (e.g. cytochromes and flavines) and oxidative cycles (e.g. the tricarboxylic cycle of Krebs) with which we shall become acquainted in more detail in our exposition of the mechanism of respiration.

Calculations show that the fundamental reaction of ' raising' $\mathrm{CO}_{2}$ to the level of carbohydrates requires the participation of four electrons and three molecules of ATP, one of which is expended on the phosphorylation of ribulose monophosphate before its carboxylation by $\mathrm{CO}_{2}$.

As a synopsis we give here a greatly simplified scheme of the interactions of the separate aggregates in the general process of photosynthesis (Fig. 39).

A detailed knowledge of the photosynthetic apparatus of green plants shows that hardly any of their catalytic mechanisms or even of their whole aggregate of mechanisms show anything which is new in principle. In most cases we find the very same or analogous mechanisms in various colourless organisms or in photosynthetic bacteria.

Thus, even before the appearance of green plants, before the development of the present-day forms of photosynthesis. these chemical mechanisms existed, but they were scattered rather than being integrated into a single complex system. This unification of previously existing mechanisms took place during the development of the photosynthetic apparatus. It could only have been formed during the process of evolution of organisms on the basis of pre-existing systems and aggregates.

Continuing our analogy with the motor-car engine, we may say that, as the history of technology shows, such an 


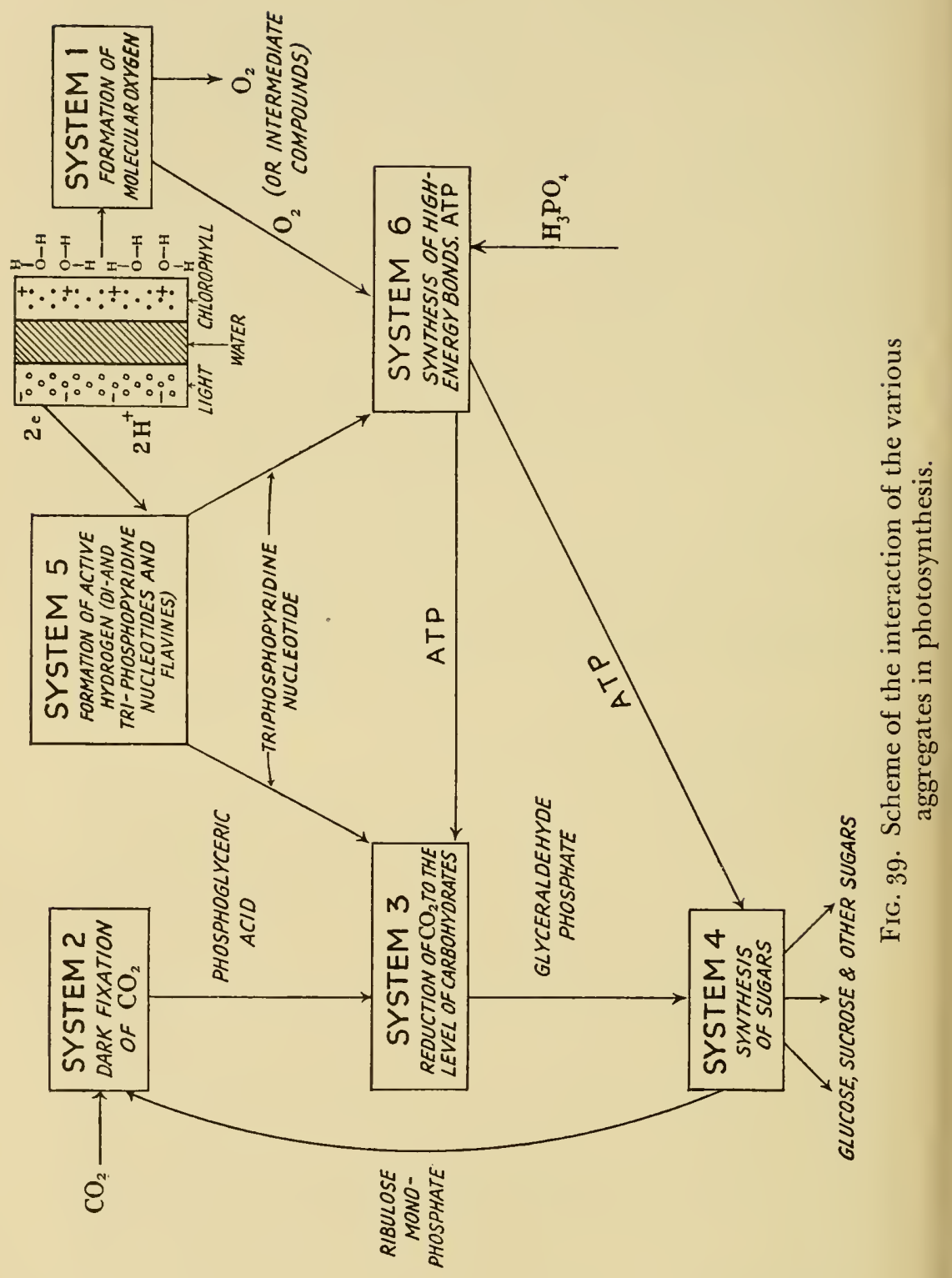


engine could only appear on the basis of pre-existing machines. Before the invention of the cylinder and the dynamo, even the most ingenious constructor could not have built such an engine.

The appearance of photosynthesis constituted an extremely important stage in the process of evolution of life on our planet. It radically changed all the relationships which had previously existed. Alongside the formation of oxygen in the atmosphere there began a rapid increase in the quantity of organic substances in the biosphere which could once more be put into metabolic circulation by the old heterotrophic methods. It allowed the main current of evolution to revert to the old channel, with the further development of organisms adapted to nourishing themselves on organic materials. The period of acute scarcity of these substances passed, and there only remained, as a souvenir of it, a small group of autotrophic organisms capable of chemosynthesis, which constituted a side branch of the main evolutionary stream.

The main channels for this stream now became the green plants (photoautotrophs) and colourless organisms, animals in particular, which were adapted to the earlier, more primitive heterotrophic habit. However, after the emergence of photosynthesis, the evolution of even those organisms which used ready-made organic substances for their vital processes took place under entirely different biochemical conditions from those which prevailed before this emergence.

The decisive condition in this regard was the presence of oxygen in the atmosphere. This allowed a considerable rationalisation and intensification of the process of mobilisation of the energy of organic substances. Naturally, this rationalisation took place on the basis of the same anaerobic mechanisms on which the energy metabolism of the earlier heterotrophs had been founded. ${ }^{185}$ However, in the process of evolution under the new aerobic conditions, natural selection guaranteed the survival and further development of those organisms in which there arose accessory enzymic complexes and systems of reactions which allowed them to obtain from the exogenous organic substances far greater amounts of high-energy compounds than had earlier been 
possible. This was made possible by the complete oxidation of the nutrients by means of atmospheric oxygen.

\section{The origin of respiration.}

The accomplishment of this task required the organisation of two new systems. First, a system for the mobilisation of the hydrogen which, under anaerobic conditions, had gone to waste, being given off from the organism in the form of reduced organic compounds which could not be used any more (e.g. acids and alcohols), or even in the form of gaseous products such as hydrogen. Secondly, a system for the activation of oxygen so that it might be possible to oxidise hydrogen to water, to carry out the reaction which occurs when a mixture of hydrogen and oxygen gases is exploded.

The individual mechanisms of the first system are very ancient. They were mostly present in the anaerobic organisms. They are the pyridine nucleotides, coenzyme A, etc., with which we are already quite familiar. On the development of aerobiosis their activity was merely extended to a number of new products which were absent from the general scheme of glycolysis. In its essence this scheme of the initial transformation of carbohydrates was retained unchanged in aerobes but, at particular places in this scheme, there were embodied new chains and cycles of reactions the individual components of which give up their hydrogen to a pyridine nucleotide or some other analogous acceptor (e.g. a flavine derivative).

Such places where new cycles have been embodied have been located exactly in rather primitive facultative anaerobes. In our earlier discussion of Strep. faecalis and other analogous microbes, we saw how aerobiosis first arose. Here we were concerned with the pyruvic acid which was formed in the process of glycolysis and which, in the absence of oxygen, underwent anaerobic dehydrogenation and decarboxylation to form acetic acid, alcohol and lactic acid. In the presence of oxygen, however, the pyruvic acid was decarboxylated oxidatively so that the formation of acetic acid was not necessarily accompanied by the appearance of reduced products (alcohol and lactic acid). In propionic acid bacteria, 
on the other hand, pyruvic acid is not decarboxylated but combines with $\mathrm{CO}_{2}$ to form oxaloacetic acid. This then undergoes anaerobic or oxidative transformations.

In higher organisms, capable of respiration, the pyruvic acid which arises in the ordinary way, by glycolysis, undergoes both oxidative decarboxylation and condensation with $\mathrm{CO}_{2}$ owing to the action of $\beta$-carboxylase. As a result of this, from every two molecules of pyruvic acid there are formed one of acetic acid (as in Strep. faecalis) and one of oxaloacetic acid (as in the propionic acid bacteria).

In higher aerobes, however, by contrast to these bacteria, this is not the end of the matter, and it is just at this point in their metabolism that there is embodied the new closed chain of transformations which has been called the Krebs cycle, or the tricarboxylic acid cycle. ${ }^{186,194}$ A diagram of this cycle is given below (Fig. 40).

As we see from the diagram, the original sugar (glucose) is first transformed into pyruvic acid (the route of this glycolytic transformation, which is common to all organisms, is not shown on the diagram). The pyruvic acid is then transformed into acetic and oxaloacetic acids as was indicated above. The oxaloacetic acid easily goes over to its enolic form (HOOC.CH:COH.COOH), which condenses with an activated molecule of acetic acid to give citric acid. This acid is converted first into cis-aconitic acid and then into isocitric acid, which then undergoes dehydrogenation (in this reaction isocitric dehydrogenase and triphosphopyridine nucleotide take part, the latter taking up the hydrogen). The oxalosuccinic acid thus formed is decarboxylated and converted to $\alpha$-oxoglutaric acid. This acid again undergoes oxidative decarboxylation to give succinic acid which loses hydrogen owing to the action of succinic dehydrogenase and becomes fumaric acid. The fumaric acid combines with a molecule of water under the influence of fumarase to give malic acid. Malic dehydrogenase acts on this, bringing about its transformation into oxaloacetic acid. This brings the cycle back to the beginning again, as the oxaloacetic acid thus formed can once more condense with a new molecule of activated acetic acid so that the whole reaction of oxidative dissimilation of pyruvic acid can be repeated. 


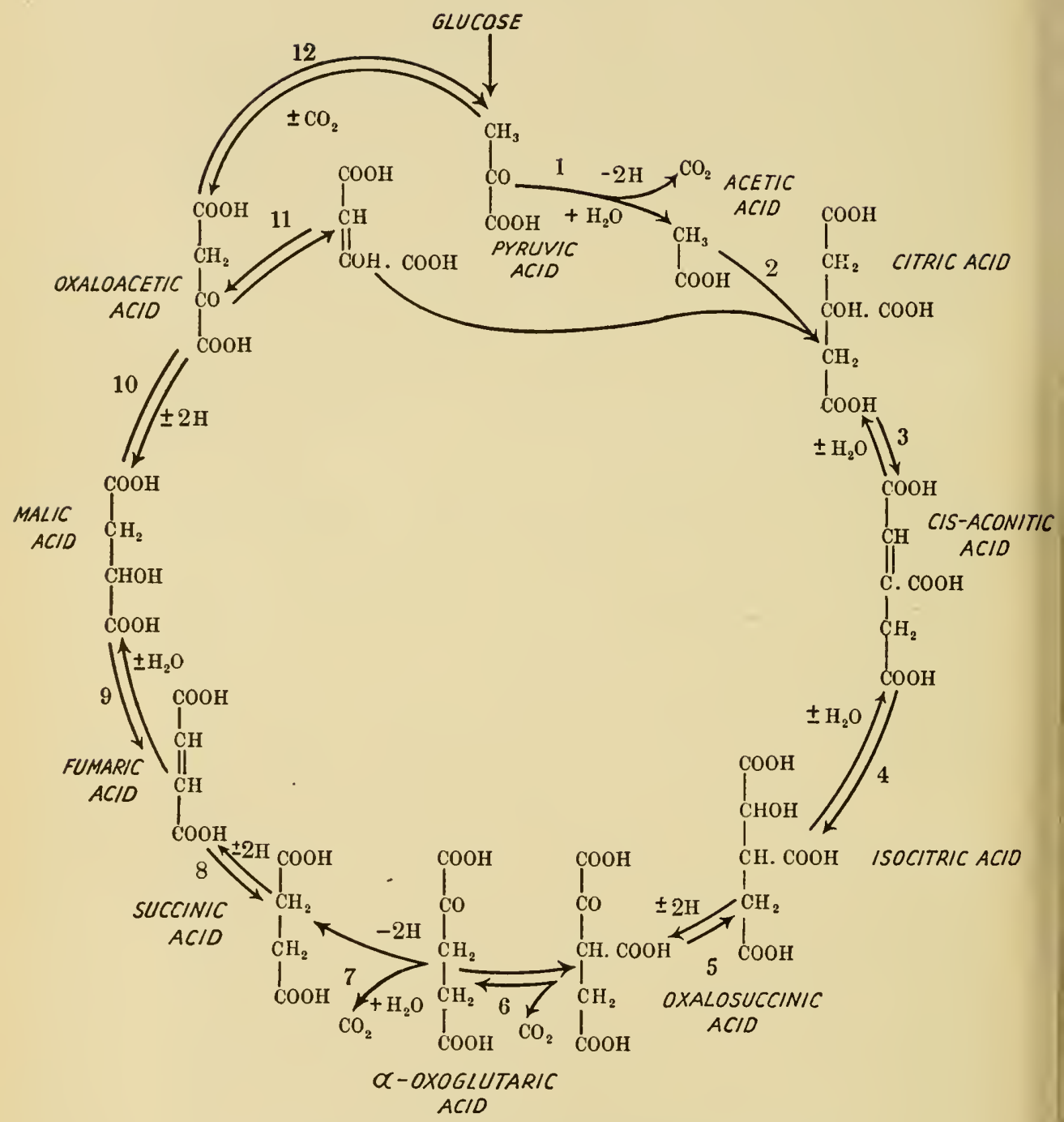

FIG. 40. The tricarboxylic cycle (after Krebs). 
In the course of this cycle all of the three carbon atoms of the pyruvic acid are oxidised to $\mathrm{CO}_{2}$ by means of the oxygen of water while, at the same time, the hydrogen leaves the cycle with the help of pyridine nucleotides and the corresponding dehydrogenases. The splitting off of $\mathrm{CO}_{2}$ is brought about directly by decarboxylases.

Thus we see that the same types of enzymic mechanisms act here as act in anaerobic metabolism, but the sequence of reactions is substantially different. An important difference is that the hydrogen which is liberated is not wasted but is used to obtain a considerable extra supply of energy by its oxidation by the oxygen of the air. The intermediate products arising in the cycle carry it over into other metabolic systems so that there is established a direct connection and mutual dependence between the metabolism of carbohydrates, fats, organic acids and proteins. A particular example is the transformation of keto acids which leave the cycle, by reacting with ammonia (i.e. by direct amination ${ }^{187}$ ) or by transamination, ${ }^{188}$ into alanine, aspartic and glutamic acids and the formation from these of various other amino acids which take part in the synthesis of proteins, hormones, enzymes, etc.

The incorporation of accessory respiratory transformations in the chain of glycolytic reactions can take place not only through the pyruvic acid at the end of the chain, but also through its first links.

As we noticed on p. $42 \uparrow$, even among anaerobic alcohol producers, e.g. Pseudomonas lindneri, the metabolism may diverge somewhat from the general scheme of alcoholic fermentation. In this case hexose-6-phosphate is not further phosphorylated but immediately enters the path of anaerobic dehydrogenation, being thereby transformed into 6-phosphogluconic acid. This is decarboxylated to a phosphorus derivative of pentose, which then breaks down to give alcohol and glyceraldehyde-3-phosphate. This glyceraldehyde-3-phosphate then enters into the general scheme of alcoholic fermentation. Among many facultative anaerobes this is used as an oxidative path. In these there takes place, alongside the ordinary glycolytic breakdown of glucose according to the scheme for alcoholic fermentation, the oxidation of glucose- 
6-phosphate to 6-phosphogluconic acid with its subsequent oxidative decarboxylation to pentose- 5 -phosphate.

As an example we may cite Microbacterium lacticum which has such an oxidative mechanism. However, in this organism the complex of glycolytic enzymes still predominates to such an extent that even in air the formation of glyceraldehyde phosphate and pyruvic acid mainly follows the scheme for anaerobic fermentation, while the contribution made by the direct oxidation of hexose is relatively small. ${ }^{189}$

According to V. A. Engelhardt and A. P. Barkhash ${ }^{190}$ yeasts, on the contrary, switch over definitely to the oxidation of hexose monophosphate under aerobic conditions. Moulds can also oxidise glucose directly and intensively. ${ }^{191}$ In particular, Aspergillus niger can, under appropriate conditions, transform glucose almost quantitatively into gluconic acid (the so-called 'gluconic acid fermentation'). In this case, however, the oxidation of glucose occurs without its preliminary phosphorylation, being mediated by the enzyme glucose oxidase. According to the evidence of P. Kolesnikov ${ }^{192}$ an analogous breakdown of hexose without preliminary phosphorylation plays a predominant part in the respiration of unicellular green algae (e.g. Chlorella).

From our point of view the obligate aerobe Pseudomonas fluorescens is of great interest. Nobody has succeeded in finding in it hexokinase, which brings about the phosphorylation of hexose before its breakdown to triose phosphates, while in addition the aldolase, which catalyses this breakdown, is only very weak in these organisms. In Pseudomonas fluorescens, therefore, the glycolytic breakdown of sugars is relegated to the background although glyceraldehyde-3phosphate and pyruvic acid, which are products of this process, figure in the metabolism of the organisms. They are formed by somewhat different means from those of the classical scheme of glycolysis. W. Wood gives the following scheme for the oxidative breakdown of glucose in this micro-organism (Fig. 41).

As may be seen from this scheme, the main means of oxidative transformation in Pseudomonas fluorescens lies through the direct oxidative dehydrogenation of glucose with its 
transformation first into gluconate and then into 2-oxogluconate. However, these products are later phosphorylated and transformed with the formation of numerous compounds, in particular $5^{-}$and 7 -carbon sugars (ribose and sedoheptulose).

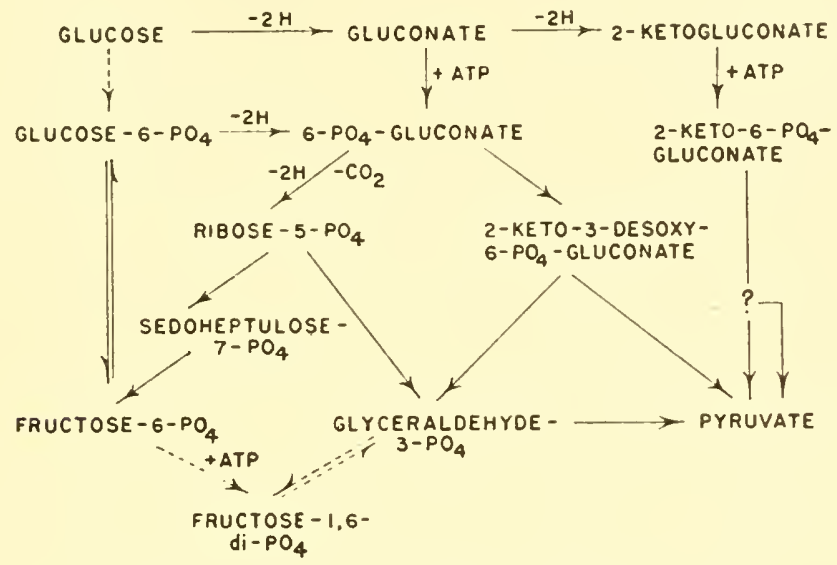

Fig. 41. Pathways in glucose oxidation by Pseudomonas fluorescens (after Wood). ${ }^{189}$

But the old metabolic pathway is retained in Pseudomonas fluorescens and, under certain conditions, this organism can transform sugar via glucose-6-phosphate, fructose-6-phosphate and fructose diphosphate.

In his communication to the Third International Congress of Biochemistry in Brussels, F. Dickens ${ }^{193}$ gave the following scheme for the interaction of the glycolytic and oxidative mechanisms in metabolism (Fig. 42).

This diagram shows where the Krebs cycle is incorporated in the glycolytic mechanism and also the connection between this mechanism and the direct oxidative degradation of glucose. This scheme was worked out for the most part with the animal cell, but Dickens considers that it is also valid for yeast. Furthermore, the fact that the appropriate sugars and enzymes are also found in higher plants (Calvin) suggests that the mechanism also operates in these organisms.

Thus, although the first system of reactions taking part in respiration varies considerably among the more primitive 
organisms, in higher organisms it has become standardised to some extent. ${ }^{194}$ There is less reason to suppose that the same is true of the second system, which is devoted to the oxidation to water of the hydrogen which is obtained during

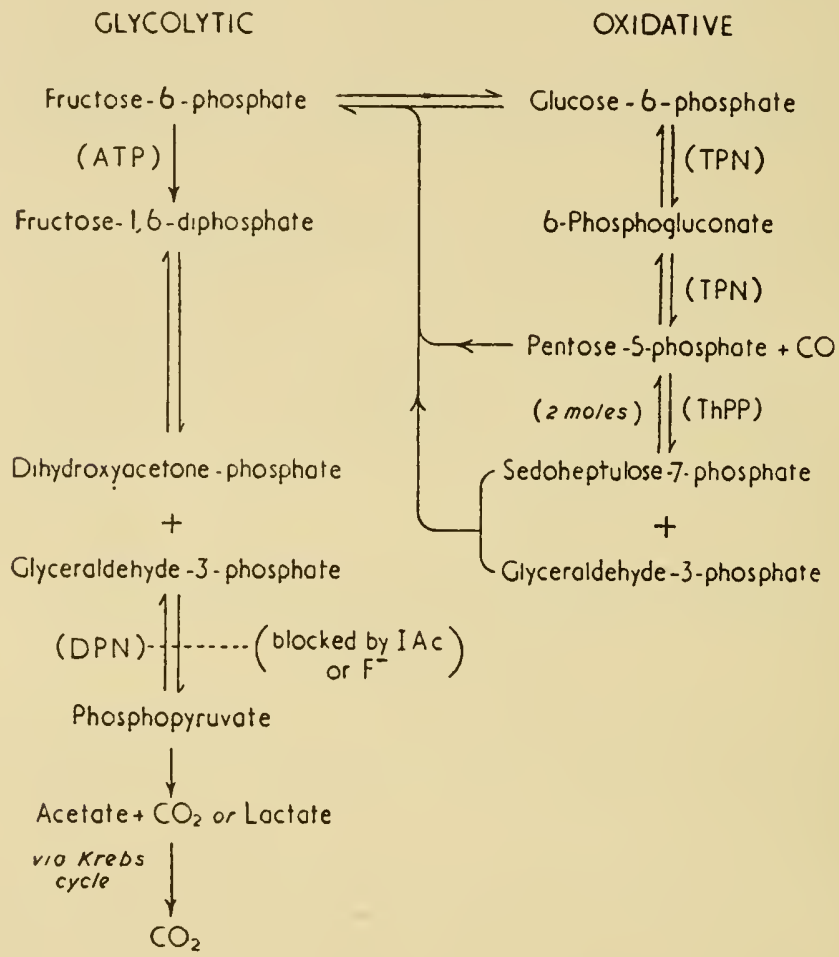

F1G. 42. Glycolytic and oxidative pathways for the breakdown of glucose (after Dickens).

dehydrogenation, by means of atmospheric oxygen with the formation of high-energy compounds at the expense of the energy liberated by this reaction.

As is well known, the combination of gaseous oxygen and hydrogen has such a high energy of activation that, at ordinary temperatures, it hardly occurs at all. Organisms overcome this energy barrier, breaking it down into a number of steps so that the hydrogen is transferred successively through a system of mediators with the help of a series of specific 
enzymes. As in the case of glycolytic degradation this allows the organism, not only to surmount the energy barrier, but also to obtain the energy in separate, easily-used portions rather than all at once, in an explosive form. At one end of this chain stand phosphopyridine nucleotides and the corresponding enzymes, dehydrogenases, which transfer hydrogen from the system which we have referred to as the first, to the second or oxidative system. At the other end of the chain are the specific respiratory enzymes, oxidases and peroxidases, the role of which, according to A. N. Bach, ${ }^{195}$ is the activation of molecular oxygen and peroxides. They complete the process of oxidation to water of the hydrogen which has been brought into the system. and are therefore sometimes called the 'terminal ' or 'finishing' enzymes. ${ }^{196}$ There is a considerable diversity in different organisms as regards the intermediate links in the oxidative chain, but flavoproteins occupy a prominent position, sometimes transferring hydrogen from pyridine nucleotides to the oxidative mechanisms, and sometimes completing its oxidation by the oxygen of the air with the formation of hydrogen peroxide. This is then broken down by catalase or used for oxidising reactions by means of peroxidases.

Recently H. Mahler ${ }^{197}$ has shown that there are to be found among living things a large number of flavoproteins having, in their prosthetic groups, such metals as iron, molybdenum and copper.

Mahler gives the following scheme for the part played by flavoprotein enzymes in the transfer of the hydrogen liberated in the first system to the oxygen of the air (Fig. 43). Under the letter A we have the case in which the substance giving up hydrogen to the flavine enzyme is reduced pyridine nucleotide which has obtained hydrogen from the substrate (from a reaction in the first system). The hydrogen is transferred by the flavine enzyme, either to a component of the cytochrome system, or to some other oxidase mechanism, but not directly to molecular oxygen. In the case designated by the letter $\mathbf{B}$ the flavine enzymes taking part obtain hydrogen directly from the substrate and transfer it to the cytochrome system. Finally, the letter $\mathrm{C}$ refers to the case in which the 
flavoproteins act as true oxidases, i.e. they transfer the hydrogen which they receive directly to molecular oxygen.

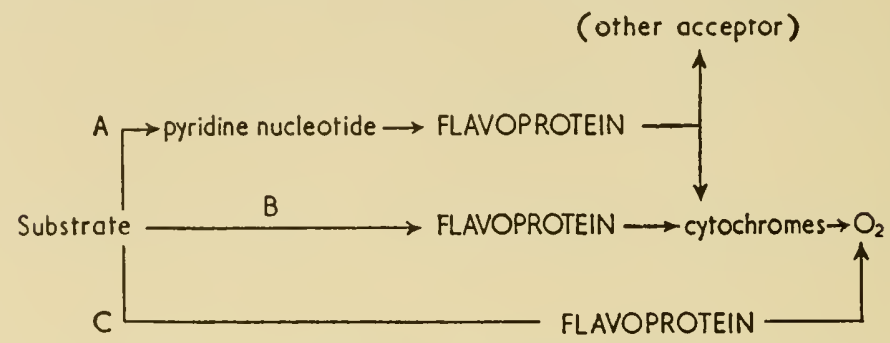

F1G. 43. Role of the flavoproteins in

electron transport (after Mahler).

A. DPNH-oxidase; DPNH-cytochrome reductase; TPNH-cytochrome reductase; xanthine oxidase; nitrate, nitrite, hydroxylamine reductases; diaphorase; old, new yellow enzymes; quinone reductases. B. Lactic oxidase; aldehyde oxidase ; xanthine oxidase; butyryl-CoA dehydrogenase ; hydrogenase; succinic dehydrogenase; sulphite oxidase. C. Amino-acid oxidases ; glucose oxidase ; amine oxidases (?).

During the transfer of hydrogen from one link of the respiratory chain to another high-energy bonds are formed. According to F. Lipmann ${ }^{198}$ this is brought about by phosphorylation which proceeds in accordance with the following scheme:

$$
\begin{gathered}
\mathrm{XH}_{2}+\mathrm{Y} \rightarrow \mathrm{X}+\mathrm{YH}_{2} \\
\mathrm{YH}_{2}+\mathrm{H}_{3} \mathrm{PO}_{4} \rightarrow \mathrm{YH}_{2}-\mathrm{H}_{2} \mathrm{PO}_{3} \\
\mathrm{YH}_{2}-\mathrm{H}_{2} \mathrm{PO}_{3}+\mathrm{Z} \rightarrow \mathrm{Y}-\mathrm{H}_{2} \mathrm{PO}_{3}+\mathrm{ZH}_{2} \\
\mathrm{Y}-\mathrm{H}_{2} \mathrm{PO}_{3}+\mathrm{ADP} \rightarrow \mathrm{Y}+\mathrm{ATP}
\end{gathered}
$$

where $\mathrm{xH}_{2}$ and $\mathrm{Z}$ are successive members of the chain of respiratory reactions and $\mathrm{Y}$ is a third substance which acts as an intermediary in the transfer of hydrogen from $\mathrm{xH}_{2}$ to $\mathrm{z}\left(\mathrm{xH}_{2}+\mathrm{z} \rightarrow \mathrm{x}+\mathrm{ZH}_{2}\right)$. As we can see, this leads to the formation of one high-energy bond by the formation of ATP from ADP.

On the basis of his work with isolated mitochondria E. Slater ${ }^{199}$ puts forward a somewhat different scheme of oxidative phosphorylation

$$
\begin{array}{r}
\mathrm{XH}_{2}+\mathrm{Z}+\mathrm{Y} \rightleftharpoons \mathrm{X} \backsim \mathrm{Y}+\mathrm{ZH}_{2} \\
\mathrm{X} \backsim \mathrm{Y}+\mathrm{H}_{3} \mathrm{PO}_{4}+\mathrm{ADP} \rightleftharpoons \mathrm{X}+\mathrm{Y}+\mathrm{ATP}
\end{array}
$$


The main difference between this system and that of Lipmann is that the high-energy bond is formed before the inclusion of the phosphate. This considerably enlarges our ideas concerning the mobilisation of energy in the respiratory process.
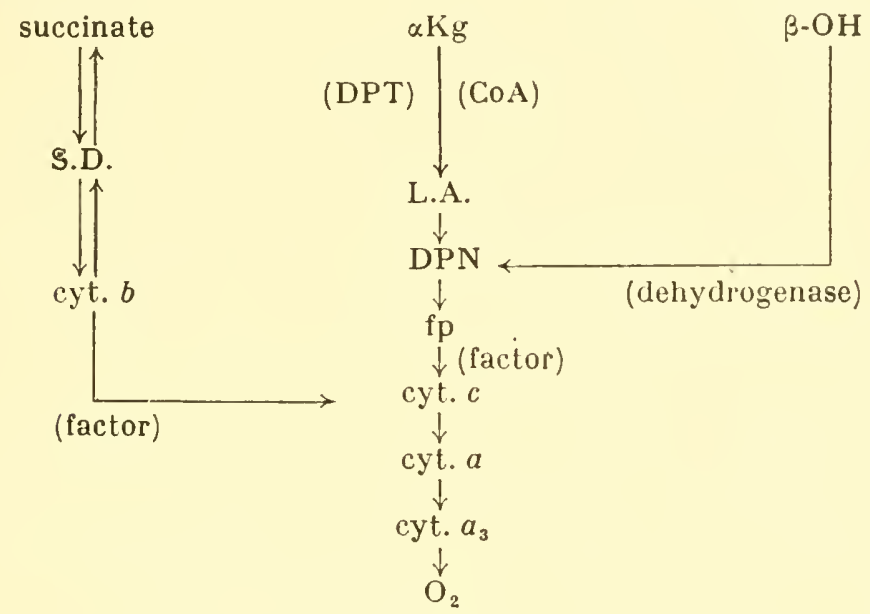

Scheme A

$(\alpha \mathrm{Kg}=\alpha$-ketoglutarate ; CoA $=$ coenzyme $\mathrm{A} ; \mathrm{DPN}=$ diphosphopyridine nucleotide; $\mathrm{f} p=$ flavoprotein; $\mathrm{cyt}$. $=$ cytochrome; S. D. $=$ succinic dehydrogenase $;$ L. A. $=\alpha$-lipoic acid; $\beta-O H$ $=\beta$-hydroxybutyrate $; \mathrm{DPT}=$ diphosphothiamine)

F1G. 44. Diagram of the oxidative transformation of respiratory substrates (after Slater).

Slater has worked out the above scheme (Fig. 44) of the links of the chain of oxidation of $x$-oxoglutarate, succinate and $\beta$-hydroxybutyrate in which he remarks on the possible ways in which phosphorylation may take part. According to this scheme phosphorylation takes place at the following stages of the process: between reduced diphosphopyridine nucleotide (DPNH) and cytochrome $c$ (here there may be two stages at which phosphorylation occurs); between succinate and cytochrome $c$; and between cytochrome $c$ and oxygen.

The great variety of the sequences of reactions in the oxidative chain in different members of the animal and vegetable kingdoms itself indicates the relatively recent origin of the system under discussion, suggesting that evolution 
followed parallel paths in different organisms even at that stage of the development of the living world when there first occurred a clear-cut differentiation into its main divisions.

One may arrive at a similar conclusion from a study of the numerous enzymes which take part in the chain of oxidative transformations in different organisms. This specially concerns the 'terminal ' group of catalysts which directly activate molecular oxygen. In organisms which are far removed from one another systematically this task is often accomplished by widely different catalytic mechanisms. The earliest of these would seem to be the cytochrome complex. ${ }^{200}$ This, clearly, owes its origin to the iron-porphyrin compounds of the primaeval living things. Thus, as we have seen, cytochromes are to be found in rather primitive anaerobic organisms.

With the appearance of molecular oxygen in the atmosphere the most diverse representatives of the living world could easily make use of the cytochromes present in them as oxidase mechanisms, adapting them to the activation of oxygen in the process of respiration.

As a result of this the cytochromes and the corresponding enzymes, the cytochrome oxidases, seem to be very widely distributed respiratory mechanisms; we find them in a wide variety of systematic groups of organisms, but their importance is especially great in the respiratory processes of a number of micro-organisms as well as in animal cells. In higher plants the most important part in this connection falls to the phenol oxidase system in which the enzymes are copper-proteins, ${ }^{201}$ and the transporters of hydrogen are the ' respiratory chromogens' of Palladin, especially chlorogenic acid. ${ }^{202}$ These mechanisms are highly specific to plants and are completely absent from members of the animal kingdom. It is evident that in the process of phylogenesis they were elaborated after the separation of organisms into the animal and vegetable kingdoms.

In the ontogenesis of a number of plants we may also observe that the cytochrome oxidase mechanism only plays a leading part during the embryonic stage of development when the plant is still leading a heterotrophic life. ${ }^{203}$ However, with the emergence of autotrophy in the plant we can 
no longer find cytochrome oxidase in it and its work is carried out, for the most part, by phenol oxiclases..$^{204}$

In the respiration of plants peroxidase, which activates the oxygen of hydrogen peroxide, is also very important, though in the animal cell it plays a comparatively small part.

Apart from cytochrome oxidase, phenol oxidase, peroxidase and the flavine enzymes, the final stages of oxidation by the oxygen of the air may be carried out by a number of other catalysts such as ascorbic acid oxidase, lipoxidase and many other mechanisms. In different living things, and at different stages in their life cycles, the parts played by each of these mechanisms may vary within very wide limits. All this indicates the relatively recent phylogenetic origin of the process of respiration, that it was elaborated considerably later than the anaerobic habit of metabolism.

We have intentionally limited ourselves to a survey of the evolution of only a few aspects of metabolism, mainly associated with the transformation of carbon, and have only touched slightly on the problems of nitrogen metabolism; but even the little which has been said about that subject in this chapter is enough to allow certain conclusions to be drawn as to the order of development of the organisation of matter.

The simplest forms of this organisation could only exist under conditions where there was a continual accession from the surrounding medium of diverse organic substances which could serve as material for the construction of the components of protoplasm and as sources of the energy needed for biosynthesis. The only method for the mobilisation of this energy seems to have been the anaerobic breakdown of exogenous organic substances.

The progressive evolution of the earliest organisms seems to have been directed towards gradually making them more and more independent of these conditions. Natural selection led to the consolidation and further evolution of those organisms in which the essential chemical reactions had become co-ordinated into integrated systems of chains and cycles which brought about the synthesis of complicated and specific components of protoplasm from comparatively simple organic molecules and their still simpler fragments. In addition the 
organisms acquired the ability to use a greater variety of sources of energy than previously. This laid the basis for the origin of autotrophy, the culminating development of which was the photosynthesis developed by green plants, which involved in the process of life that inexhaustible source of energy, sunlight.

Photosynthesis led to the creation of an abundance of organic substances and of an oxygen-containing atmosphere on the Earth. These formed the basis for the origin of the world of animals with their extremely intensive respiratory metabolism and their rapid, progressive development of organic forms which, in the long run, led to the appearance on our planet of a thinking being, man.

The contemporary process of the evolution of living things is, in principle, nothing but a series of further links in that unending chain of transformations of matter which began in the earliest stage of the existence of the Earth.

\section{BIBLIOGRAPHY TO CHAPTER IX}

1. G. Ehrensvärd, L. Reio and E. Saluste. Acta chem. scand., 3, 645 (1949).

J. Baddiley, G. Ehrensvärd, E. Klein, L. Reio and E. Saluste. J. biol. Chem., 183,777 (1950).

G. Ehrensvärd. Svensk kem. Tidskr., 66, 249 (1954); Ann. Rev. Biochem., 24, 275 (1955).

2. (V. 200).

G. R. Greenberg. Fed. Proc., 8, 202 (1949); 9, 179 (1950). (V. 203).

3. (V. 192).

4. N. H. Horowitz. Proc. nat. Acad. Sci., Wash., 3I, 153 (1945).

5. C. B. van Niel. Physiol. Rev., 23, $33^{8}$ (1943).

6. (VIII. 64).

7. R. P. Hall. Quart. Rev. Biol., 14, I (1939).

8. A. Lwoff (ed.). Biochemistry and physiology of Protozoa. New York, $195^{1 .}$

9. A. Lwoff. L'évolution physiologique. Étude des pertes de fonctions chez les microorganismes. Actualités sci. ind., no. 970 (1944); Recherches biochimiques sur la nutrition des protozoaires. Monographie d l'Institut Pasteur. Paris, 1932. 
10. K. R. Butlin and J. R. Postgate in Autolrophic microorganisms (ed. B. A. Fry and J. L. Peel), p. 271. Cambridge, 1954 .

11. V. Polyanskiľ. Priroda, 1947 , no. 2, p. 20.

12. (IV. 35 ).

13. H. Dusi. Ann. Inst. Pasteur, 50, 550, 840 (1933); 67, 340 (1940); 7o, 311 (1944); Arch. Protistenk., 89, 94 (1937); C.R. Soc. Biol., Paris, Io7, 1232 (1931).

14. K. Ondratschek. Arch. Mikrobiol., it , 89, 219 (1940).

15. E. G. Pringsheim. Pure cultures of algae, their preparation and maintenance. Cambridge, 1946.

16. V. Bukin. Personal communication.

17. P. A. Genkel' [Henckel]. Byull. Moskov. Obshchestua Ispytateler Prirody. Otdel biol., 47, 13 (1938).

18. S. V. Goryunova. Mikrobiologiya, 24, 271 (1955).

19. W. H. Schopfer. Plants and vitamins (trans. N. L. Noecker). Waltham, Mass., 1943.

20. C. Ternetz. Jb. wiss. Bot., 5I, 435 (1912).

21. O. Richter. Ber. dtsch. bot. Ges., 2 I, 493 (1903).

22. A. ARtari. $K$ voprosu o vliyanii sredy na formu $i$ razvitie vodoroslę. Moscow (Tip. M. Borisenko), 1903.

23. A. Pascher. Ber. dtsch. bot.Ges., 33, 427 (1915).

24. R. Harder. Z. Bot., 9, 145 (1917).

25. B. M. B. Roach. Ann. Bot., 4I, 509 (1927).

26. C. B. Skinner and C. G. Gardner. J. Bact., I9, 161 (1930).

27. S. V. Gorrunova. Khimicheskir sostav $i$ prizhiznennye vydeleniya sinezelenykh vodorosler. Moscow and Leningrad (Izd. AN SSSR), $195^{\circ}$.

28. B. Rubin. Fiziologiya rastenǐ. Moscow (Izd. 'Sovyetskaya Nauka '), $1954-6$.

29. J. B. Suminer and G. F. Somers. (VIII. 25).

3o. S. Winogradsky [VinogradskiǏ]. Zbl. Bakt. Abt. 2, 57, 1 (1922).

31. J. Meiklejohn in Autotrophic microorganisms (ed. B. A. Fry and J. L. Peel), p. 68. Cambridge, 1954.

32. A. Lebedev. Issledovanie khemosinteza u Bacillus hydrogenes. Odessa (Tip. Shtaba Okruga), 1910.

33. W. Ruhland. Jb. wiss. Bot., 63, 321 (1924).

34. K. Trautwein. Zbl. Bakt. Abt. 2, 53, 513 (1921).

35. R. L. Starkey. J. gen. physiol., is, 325 (1935); Soil Sci., 39, $197(1935)$.

36. P. A. Roelofsen. On photosynthesis of the Thiorhodaceae. Dissertation, Univ. Utrecht, 1935 . 
37. M. S. Cataldi. Rev. Inst. bact. Dep. nac. Hig., B. Aires, 9, 393 (1940).

38. H. Molisch. Die Eisenbakterien. Jena, 1910.

39. R. Lieske. Zbl. Bakt. Abt. 2, 49, 413 (1919).

40. M. S. Cataldi. Estudio fisiologico y sistematica de algunas Chlamydobacteriales. Doctoral thesis, Univ. Buenos Aires, 1939. See Rev. Inst. bact. Dep. nac. Hig., B. Aires, 9, 1 (1939).

41. V. O. Kalinenko. Mikrobiologiya, Io, 401 (1941).

42. C. B. Van Niel. Ann. Rev. Microbiol., 8, 105 (1954).

43. H. Bömeke. Arch. Mikrobiol., Io, 385 (1939).

44. K. G. Vogler. J. gen. Physiol., 25, 617 (1942).

45. K. G. Vogler and W. W. Umbreit. J. gen. Physiol., 26, 157 (1942).

46. K. BaAlsrud and K. S. BaAlsrud in Phosphorus metabolism: a symposium on the role of phosphorus in the metabolism of plants and animals (ed. W. D. McElroy and B. Glass). Vol. 2, p. 544. Baltimore, Md., 1952.

47. R. W. Newburgh. J. Bact., 68, 93 (1954).

48. W. W. Umbreit. J. Bact., 67, 387 (1954).

49. G. A. LePage and W. W. Umbreit. J. biol. Chem., I47, 263 (1943).

5o. H. A. Barker and A. Kornberg. J. Bact., 68, 655 (1954).

51. Yu. I. Sorokin. Doklady Akad. Nauk S.S.S.R., 95, 661 (1954).

52. Yu. I. SoRokin. Trudy Inst. Mikrobiol., Akad. Nauk S.S.S.R., 3, 21 (1954).

53. H. Lees in Autotrophic micro-organisms (ed. B. A. Fry and J. L. Peel), p. 84. Cambridge, 1954.

54. E. L. Ruban. Mikrobiologiya, 25, 103 (1956).

55. (IX. 44).

56. E. J. Russell and H. B. Hutchinson. J. agric. Sci., 3, 111 (1909).

57. V. O. TAuson. Priroda, 1934, no. 6, p. 43.

58. V. O. TAuson. Energetika sinteticheskikh protsessov $v$ kletke. Communication to General Assembly of Academy of Sciences U.S.S.R., 1940; Osnovnye polozheniya rastitel'nǒ̀ bioenergetiki. Moscow and Leningrad (Izd. AN SSSR), $195^{\circ}$.

59. C. E. Zobell. Advanc. Enzymol., Io, 443 (1950).

6o. V. O. Tauson and V. I. Aleshina. Mikrobiologiya, I, 229 (1932); 3, 523 (1934).

61. W. O. Rosenfeld. J. Bact., 54, 664 (1947). 
62. A. C. Thaysen. Congr. int. Microbiol., 3, 729 (1940).

63. H. F. HaAs. Thesis, Kansas State College, 1942. Cf. J. Bact., $48,219(1944)$.

F. H. Johnson, W. T. Goodale and J. Turkevich, J. cell. comp. Physiol., 19, 163 (1942).

64. A. Lebedev. Izvestiya Donskogo Gosudarstvennogo Universiteta, $I, 25$ (1921).

65. G. L. Seliber. Priroda, I942, no. 5-6, p. 85 .

66. I. L. Rabotnova, M. V. Ulubekova and L. V. Magnitskaya. Mikrobiologiya, I9, 401 (1950).

67. V. E. Pontovich. Izvest. Akad. Nauk S.S.S.R., Ser. Biol. 1951 , No. 5, p. 120.

M. F. Utter and H. G. Wood. Advanc. Enzymol., 12, 41 $(1951)$.

68. C. H. Werkman in Bacterial Physiology (ed. C. H. Werkman and P. W. Wilson), p. 404. New York, $195 \mathrm{I}$.

69. H. G. Wood and C. H. Werkman. Biochem. J., 32, I 262 (1938).

7o. A. L. Kursanov. Izvest. Akad. Nauk S.S.S.R., Ser. Biol. 1954 , No. 1, p. 8.

71. F. Lipmann. J. biol. Chem., I6o, 173 (1945); Bact. Rev., I 7,1 (1953).

G. D. Novelli. Fed.Proc., I2, 675 (1953).

72. D. Nachmansohn and M. Berman. J. biol. Chem., 165, 551 (1946).

73. W. Feldberg and T. Mann. J. Physiol., Io4, 411 (1946).

74. F. Lynen, E. Reichert and L. Rueff. Liebigs Ann., 574, 1 (1951).

75. K. Burton. Biochem. J., 59, 44 (1955).

76. H. Beinert, D. E. Green, P. Hele, H. Hift, R. W. von KorfF and C. V. Ramak Rishnan. J. biol. Chem., 203, 35 (1953).

77. E. J. Simon and D. Shemin. J. Amer. chem. Soc., 75, 2520 (1953).

78. B. K. Bachhawat, W. G. Robinson and M. J. Coon. J. biol. Chem., 219, 539 (1956).

79. D. D. Woods and J. LAscelles in Autotrophic microorganisms (ed. B. A. Fry and J. L. Peel), p. 1. Cambridge, 1954 .

8o. K. T. Wieringa. Leeuwenhoek ned. Tijdschr., 3, 263 (1936); $6,25^{1}(1940)$.

81. H. A. Barker, S. Ruben and J. V. Beck. Proc. nat. Acad. Sci., Wash., 26, 477 (1940). 
82. E. Pflüger. Pflüg. Arch. ges. Physiol., 10, $25^{1}$ (1875).

83. W. Pfeffer. Landw. Jb., 7, 805 (1878).

84. V. Palladin and S. Kostychev. Trav. Soc. Nat. St. Pétersb., $38,9(1907)$.

85. S. Kostychev. Issledovaniya nad anaerobnym dykhaniem rastenǐ. St. Petersburg (Tip. Shredera), 1907.

86. S. Kostrchev. Fiziologiya rasteniz. Part 1. Moscow and Leningrad (Sel'khozgiz), 1933.

87. O. Meyerhof. Chemical dynamics of life phaenomena. Philadelphia and London, 1924 .

88. G. Embden and F. Kraus. Biochem. Z., 45, 1 (1912).

89. Ya. O. [J. K.] Parnas. Uspekhi sovremennoí Biol., I2, 393 (1940).

90. (VII. 81).

91. A. J. Kluyver and W. J. Hoppenbrouwers. Arch. Mikrobiol., 2, 245 (1931).

92. M. Gibbs and R. D. DeMoss. J. biol. Chem., 207, 689 (1954).

93. B. Rosenfeld and E. Simon. J. biol. Chem., I86, 395 (1950). 94. V. Shaposhnikov. Tekhnicheskaya mikrobiologiya. Moscow (Izd. 'Sovetskaya Nauka'), $194^{8}$.

J. B. VAN DER LEK. Onderzoekingen over de Butylalkoholgisting. Delft, 1930. Quoted by K. V. Thimann (III. 1).

H. J. L. Donker. Quoted by K. V. Thimann (III. 1).

95. H. G. Wood, R. W. Brown and C. H. Werkman. Arch. Biochem., 6, 243 (1945).

96. H. A. BARKer. Leeuwenhoek ned. Tijdschr., I2, 167 (1947).

97. H. J. Koepsell, M. J. Johnson and J. S. Meek. J. biol. Chem., 154, 535 (1944).

98. S. Korkes, A. del Campillo, I. C. Gunsalus and S. Ochoa. J. biol. Chem., 193, 721 (1951).

99. I. C. Gunsalus and M. GrbBs. J. biol. Chem., 194, 871 (1952).

100. I. C. Gunsalus, L. Struglia and D. J. O'Kane. J. biol. Chem., I94, 859 (1952).

101. L. J. ReEd. Physiol. Rev., 33, 544 (1953).

102. E. A. Delwiche and S. F. Carson. J. Bact., 65, 318 (1953). 103. P. Chaix and C. Fromageot. Trav. Membres Soc. Chim. biol., 24, 1125,1128 (1942).

104. A. I. Virtanen. Acta chem. Fenn., B6, 14 (1931).

105. V. W. Cochrane. J. Bact., 69, 256 (1955).

106. E. Simon. Biochem. Z., 224, 253 (1930). 
107. N. D. GARY and R. C. BARD. J. Bact., 67, 501 (1952).

108. A. Lwoff, H. Ionesco and A. Gutmann. C.R. Acad. Sci., Paris, 228, 342 (1949).

109. H. G. Albaum, A. Schatz, S. H. Hutner and A. Hirsheeld. Arch. Biochem., 29, 210 (1950).

110. S. C. Harvey. J. biol. Chem., I79, 435 (1949).

111. R. W. MCKeE in (IX. 8), Vol. I, p. 251.

112. S. Kostytschew [Kostychev]. Ber. dtsch. bot. Ges., 25, 44 (1907).

H. Tamiya and Y. Miwa. Z. Bot., 21,417 (1928).

113. T. Takahashi, K. Sakaguchi and T. Asai. Bull. agric. chem. Soc. Japan, 3, 87 (1927).

I 14. T. Takahashi and T. Asai. Bull. agric. chem. Soc. Japan, 4,15 (1928).

115. J. C. Wirth and F. F. Nord. Science, 92, 15 (1940).

116. S. Kostytschew [Kostychev]. Pflanzenatmung. Berlin, 1924 .

F. F. Blackman. Analytic studies in plant respiration (assembled by J. Barker). Cambridge, 1954.

117. H. Gaffron. Biol. Zbl., 59, 288 (1939).

H. Michels. Z. Bot., 35, 241 (1940).

118. H. Gaffron and J. Rubin. J. gen. physiol., 26, 219 (1942).

119. M. Calvin, J. A. Bassham and A. A. Benson. Fed. Proc., 9, $5^{24}\left(195^{\circ}\right)$.

120. E. W. Fager, J. L. Rosenberg and H. Gaffron. Fed. Proc., 9, $535\left(195^{\circ}\right)$.

121. P. K. StumpF in Phosphorus metabolism: a symposium on the role of phosphorus in the metabolism of plants and animals (ed. W. D. McElroy and B. Glass), Vol. 2, p. 29. Baltimore, Md., $195^{2}$.

122. S. Kostytschew [Kostychev]. Pflanzenatmung. Berlin, 1924 .

123. A. Pütter. Z. allg. Physiol., 5, 566 (1905).

124. A. vov Szent-György in Perspectives in biochemistry (ed. J. Needham and D. E. Green), p. 165. Cambridge, 1937.

125. O. Harnisch. Biol. gen., is, 30 (1944).

126. G. F. Humphrey and L. Siggins. Austr. J. exp. Biol. med. Sci., 27, 353 (1949).

127. E. Bueding. J. gen. Physiol., 33, 475 (1950).

128. W. P. Rogers and M. Lazarus. Parasitology, 39, 302 (1949).

129. C. P. Read. Proc. Soc. exp. Biol., N.Y., 76, 861 (1951). 
130. G. F. Humphrey. Austr. J. exp. Biol. med. Sci., 28, 151 (1950).

131. P. K. StumpF in Chemical pathways of metabolism (ed. D. M. Greenberg), Vol. 1, p. 67. New York, 1954.

132. J. P. Greenstein and A. Meister in The enzymes (ed. J. B. Sumner and K. Myrbäck), Vol. 2 (part 2), p. 1131. New York, 1952.

133. E. S. Guzman Barron. Advanc. Enzymol., 3, 149 (1943).

134. H. E. Himwich. Brain metabolism and cerebral disorders. Baltimore, Md., 1951.

135. Z. D. Pisareva and D. A. Chetverikov. Doklady Akad. Nauk S.S.S.R., 78, 393 (1951).

136. N. VerkHBINSKAYA in Materialy po evolutsionnol fiziologii (ed. L. A. Orbeli). Vol. 1, p. 59. Moscow and Lenin$\operatorname{grad}($ Izd. AN SSSR), 1956.

137. F. Weigert. Z. phys. Chem., 106, 313 (1923).

138. A. Terenin. Fotokhimiya krasitelei. Moscow and Leningrad (Izd. AN SSSR), 1947.

139. M. Nentskil̆ [Nencki]. Arch. Sci. biol., St. Pétersb., 5, 254 (1897).

M. NentSkiľ and L. MARKhlevskiř [MARChLEWSKi]. Ibid., 9, 387 (1902).

140. R. Lemberg and J. W. LegGe. Hematin compounds and bile pigments. New York, 1949 .

141. D. A. Wевв. J. exp. Biol., 16, 499 (1939).

142. D. E. Green and L. H. Stickland. Biochem. J., 28, 898 (1934).

143. (VI. 65).

144. M. Stephenson and L. H. Stickland. Biochem. J., 25, 205, $215(1931)$.

145. S. B. LeE, J. B. Wilson and P. W. Wilson. J. biol. Ghem., I44, 273 (1942).

146. H. Gaffron and J. Rubin. J. gen. Physiol., 26, 219 (1942). H. GafFron. Biol. Rev., 19, I (1944).

147. E. A. Boĭchenko. Biokhimiya, 13, 219 (1948).

148. M. Ishimoto, J. Koyama and Y. Nagai. J. Biochem., Japan, $4 I, 763$ (1954).

M. Ishimoto and J. Koyama. Bull. chem. Soc., Japan, 28, 231 (1955). 
149. A. A. Krasnovskiľ. Doklady Akad. Nauk S.S.S.R., 6o, 421 $(1948) ; \quad 103,283$ (1955).

A. A. Krasnovskiľ and K. K. Voǔnovskaya. Biofizika, $I$, $120(1956)$.

150. A. A. Krasnovskir. Zhur. fiz. Khim., 30, 968 (1956).

151. A. A. Krasnovskiň in Voprosy khimicheskol kinetiki, kataliza i reaktsionnol sposobnosti (ed. V. N. Kondrat'ev and N. M. Emanuel), p. 92. Moscow (Izd. AN SSSR), 1955 ; Izvest. Akad. Nauk S.S.S.R., Ser. biol., 1955, No. 2, p. 122.

152. T. W. Engelmann. Pflüg. Arch. ges. Physiol., 30, 95 (1883).

153. H. Fischer and J. Hasenkamp. Liebigs Anu., 519, 42 (1935).

154. F. M. Muller. Arch. Mikrobiol., 4, 131 (1933).

155. J. W. Foster. J. Bact., 47, 355 (1944).

${ }_{15} 6$. J. W. Foster in Bacterial physiology (ed. C. H. Werkman and P. W. Wilson), p. 361 . New York, $195^{1 .}$

157. C. B. van Niel. Arch. Mikrobiol., 3, 1 (1931).

158. C. B. van Niel. Arch. Mikrobiol., 7, 323 (1936).

159. C. B. van Niel in Photosynthesis in plants (ed. J. Franck and W. E. Loomis), p. 437. Ames, Iowa, 1949.

16o. C. B. van Niel. Amer. Scientist, 37, 371 (1949).

161. H. Gaffron. Amer. J. Bot., 27, 273 (1940).

162. K. Bernhauer. Ergebn. Enzymforsch., 3, 185 (1934).

163. M. Miyoshi. J. Coll. Sci. Tokyo, 1o, 143 (1896).

B. L. Isachenko and A. G. Salmovskaya. Izvest. gos. gidrolog. Inst., 21, 1 (1928).

164. A. G. Salimovskaya. Izvest. gos. gidrolog. Inst., 36, 43 (1931).

B. L. Isachenko. Mikrobiologiya, 6, 964 (1937).

C. L. Corey. J. mar. Res., I, 291 (1938).

165. N. Cholodny [Kholodnyй]. Die Eisenbakterien: Beiträge zu einer Monographie. In series Pflanzenforschung (ed. R. Kolkwitz), Heft 4. Jena, 1926.

R. L. Starkey. Science, 102, 532 (1945).

166. G. E. Zobell. Bull. Amer. Ass. Petrol. Geol., 3I, 1709 (1947).

167. S. I. Kuznetsov. Mikrobiologiya, 3, 486 (1934); 16, 429 (1947); 17,307 (1948).

168. O. Jensen. Zbl. Bakt. Abt. 2, 22, 305 (1909).

169. C. B. van Niel. Physiol. Rev., 23, 338 (1943).

B. A. Fry and J. L. Peel (ed). Autotrophic micro-organisms. Cambridge, 1954 .

17o. D. J. O’Kane. J. Bact., 4I, 441 (1941).

171. Yu. Sorokin. Dissertation. Moscow, 1954. 
172. R. Hill and C. P. Whittingham. Photosynthesis. London, 1955 .

173. E. I. Rabinowitch. Photosynthesis and related processes. Vols. 1 and 2 (Parts 1 and 2). New York, 1944, 1951, 1955 .

174. E. I. Rabinowitch. Sci. Amer., I89, November, p. 8o (1953).

175. M. Calvin. Conférences et Rapports. 3-ème Congrès international de Biochimie, Bruxelles, I-6 Août 1955, p. 211. Liège, 1956 .

175 a. A. A. Krasnovskiľ and L. M. Kosobutskaya. Doklady Akad. Nauk S.S.S.R., 104, 440 (1955).

L. M. Vorob'eva and A. A. Krasnovskiľ. Biokhimiya, 21 , 126 (1956).

L. Bell. Doklady Akad. Nauk S.S.S.R., 107, 329 (1956).

B. L. Strehler and V. H. Linch. Science, 123,462 (1956).

176. A. Bach. C.R. Acad. Sci., Paris, II6, 1145 (1893); Arch. Sci. phys. nat., 1898 , Vol. 5, pp. 287, 401 ; [A. N. ВАкH]. Sbornik isbrannykh trudov., No. 1. Moscow (ONTI), 1937 .

177. A. P. Vinogradov and R. V. TeǏs. C.R. Acad. Sci., U.S.S.R., 33, 490 (1941); 56, 59 (1947).

178. S. Ochos in Currents in biochemical research (ed. D. E. Green), p. 165 . New York, 1946.

179. A. A. Krasnovskiř and G. P. Brin. Doklady Akad. Nauk S.S.S.R., 67, 325 (1949).

A. A. Krasnovskiľ and K. K. VoǏnovskaya. Doklady Akad. Nauk S.S.S.R., 87, 109 (1952).

180. A. A. Krasnovskiň. Uspekhi biologicheskol Khimii, I, 473 (1950).

181. W. Vishniac and S. Ochoa in Phosphorus metabolism: a symposium on the role of phosplorus in the metabolism of plants and animals (ed. W. D. McElroy and B. Glass), Vol. 2, p. 467. Baltimore, Md., $195^{2}$.

182. (VIII. 39).

183. R. Hill. Conférences et Rapports. 3-ème Congrès international de Biochimie, Bruxelles, I-6 Août 1955, p. 225. Liège, 1956 .

184. D. I. Arnon, M. B. Allen, F. R. Whatley, J. B. Capindale and L. L. Rosenberg. Ibid., p. 227.

D. I. Arnon. Science, I22, 9 (1955).

185. Y. OdA. Kagaku, 25, 455. (cf. Chem. Abstr., 50, 14825 (1956)). 
186. H. A. KREBs. 2-ème Congr. intern. biochim. Symposium sur le cycle tricarboxylique, p. 42. Paris, 1952.

S. Оснол. Ibid., p. 73.

187. (VIII. 49).

188. (VIII. 50).

189. W. A. Woon. Conférences et Rapports. 3-ème Congrès international de Biochimie, Bruxelles, I-6 Août 1955, p. 179. Liège, 1956 .

19o. V. A. Engel'Gardt [Engelhardt] and A. P. Barkhash. Biokhimiya, 3, $500(1938)$.

191. H. R. V. Arnstein and R. Bentley. Biochem. J., 54, 493 (1953).

192. P. KolesNikov in Sbornik nauchnykh rabot komsomol'tseybiologov. (ed. I. I. Shmal'gauzen), p. 75. Moscow and Leningrad (Izd. AN SSSR), 1940.

193. F. Dickens. Conférences et Rapports. 3-ème Congrès international de Biochimie, Bruxelles, I-6 Août 1955, p. 170 . Liège, 1956 .

194. H. A. KREBS in Chemical pathways of metabolism (ed. D. M. Greenberg). Vol. 1, p. 109. New York, 1954.

195. A. N. Bakн [Bach]. J. Russ. phys.-chem. Soc. (Chem. Section), 44, div. 2, 1 (1912).

196. D. M. Mikhl.IN. Uspekhi souremennož Biol., 33, 1 (1952); Biologischeskoe okislenie. Moscow (Izd. AN SSSR), 1956 .

197. H. R. Mahler. Conférences et Rapports. 3-ème Congrès international de Biochimie, Bruxelles, I-6 Août 1955, p. 252 . Liège, 1956 .

198. F. Lipmann. Advanc. Enzymol., 6, 231 (1946).

199. E. C. Slater. Conférences et Rapports. 3-ème Congrès international de Biochimie, Bruxelles, I-6 Aout I955, p. 264. Liège, 1956.

200. D. Keilin. Ergebn. Enzymforsch., 2, 239 (1933).

201. F. Kuвоwitz. Biochem. Z., 292, 221 (1937); 299, 32 (1938).

202. A. Oparin. Biochem.Z., IS2, 155 (1927).

203. D. M. Mikhlin and K. V. Pshenova. Biokhimiya, I6, 5 (1951).

204. A. I. Oparin and T. A. Shubert. Biokhimiya chainogo Proizvodstva. Sbornik no. 6 (ed. V. V. Potemkin, M. I. Leont'eva, A. V. Blagoveshchenskiǐ and A. I. Oparin), p. 82 (1950). Cf. Chem. Abstr., 46, 2631 (1952). 



\section{O N C L US I O N}

T $\mathrm{N}$ Conclusion I should like to spend a little time on a question which is very often put to me concerning the 1 origin of life, the question as to the possibility of life originating now, in our own time. In the scientific literature, and especially in the literature of popular science, there is rather a lot of confusion on this subject. This seems to be due to the fact that the problem itself is commonly construed in the most diverse ways. It would therefore be worth while to consider all its possible variants.

Does life arise now, at the present time? Yes, it undoubtedly does. Life, as one of the forms of the motion of matter, must arise every time suitable conditions for it occur at any place in the Universe. Contemporary astronomical evidence shows convincingly that even now, in various parts of our galaxy, there are being formed new stars and new planetary systems. No doubt on many of these planets the process of development of matter is following a course analogous to that which it followed on the Earth, and thus the development of life must be proceeding on them.

However, the people who put the question are usually concerned with a more limited aspect of the matter, being interested in whether life is coming into being now on the Earth, and not in the Universe in general. This is another aspect of our problem, but even when the question is understood in this way we must still give a positive answer. Every day we observe the birth of living things. Living things arise now, but only through the agency of other living things.

The origin of living things by these means can only take place at a very high stage in the development of matter. With the origin of life, i.e. metabolism, there arose synthetic paths and new and extremely effective methods of building up living material. Obviously this could not take place before the origin of life and therefore the development of matter from the lifeless to the living stage took place at that time by very slow and involved means as we have shown 
above. At first organic materials developed over the course of many hundreds of millions of years. Then they were transformed into polymers of high molecular weight which formed individual open systems, and only as a result of the directed evolution of these systems did there arise the first, primitive organisms, the simplest forms of life.

However, when this happened the origin of living from lifeless material began to take place on a gigantic scale with extraordinary thoroughness, as we can see every day and everywhere at the present time.

The people who put the question are not, however, usually interested in the origin of living material through the agency of living things (this seems to them very trivial), but in whether living material can now arise on our Earth primarily, directly in a lifeless natural medium. This is yet a third aspect of our question.

Many people give a purely theoretical answer to this, being convinced that when once any form of the motion of matter has arisen, then it must still go on arising now. This assumption, however, is only valid for the Universe as a whole and not for some particular limited system such as the Earth. In this case such a presentation of the problem can lead to a completely unwarrantable inference.

To clarify this I shall give the following simple example. The origin of man was undoubtedly one of the most important stages in the development of matter. This stage is wholly comparable with the origin of life. If the origin of life involved the appearance of a new, biological form of the motion of matter, so man is the culmination of this biological development and his origin involved the transition to a still higher, social form of the motion of matter. We do not doubt that man arose on the Earth during the process of the development of life but there can hardly be anyone who would maintain that he arises nowadays on our planet without being born from another like himself, but in some other way.

Let us imagine some sterile tank of water, free from living things, with various organic substances dissolved in the water. If it were left to itself, the processes of transformation of substances which we described above would come about slowly in it. Finally, during many millions of years, this would lead 
to the origin of life. However, if we were to introduce into our tank ready-made organisms, e.g. bacteria, the course of events would be quite different; in that case the more highly developed form of the motion of matter would come to the fore and take the lead. At once the transformation of lifeless to living material would cease to follow the old slow paths and would proceed in the new way, based on metabolism, converting the organic substances in the solution into the ingredients of living protoplasm with colossal rapidity. The origin of life from lifeless material simply could not occur under these conditions. It would, in fact, be completely ruled out, as Darwin pointed out long ago and as, indeed, we can see everywhere in nature.

Of course, in some out of the way parts of our planet where, for some reason, there are no organisms, but where the circumstances are suitable, it might be that the process of the primary formation of life is, even now, taking place. However, if we are to accept this possibility as a fact, the process must first actually be found taking place under natural conditions, but nobody has yet succeeded in doing this. A far more rational approach to a solution of the problem of the origin of life would seem to be the study of the ways in which lifeless material is transformed into living material as manifested in metabolism. A detailed study of the processes of metabolism is the very thing which can lead towards a solution of the problem of reproducing it artificially. By studying this high form of the organisation of matter which is characteristic of living bodies we shall be able to proceed far more efficiently than nature and shall be able to synthesise life at a far greater rate. One may rest assured that this is a matter for the not so distant future. 



\section{N D E X}

Abiogenesis of organic compounds nitrogenous, $170,172,178-84,188$, $192,196,202-5,207,213-6$ phosphorus-containing, 205-9 sulphur-containing, $171,184,188$ 196,214

oxygen-containing, $153-4, \quad 162-6$, $170-2, \quad 174, \quad 177^{-82}, \quad 189, \quad 198-$ 200

\section{Adsorption}

on inorganic catalysts, 188, 195 , $214,304,339$

in coacervates, $311,314,353,371$, 385

Albertus Magnus, 10

Amino acids ( $c f$. Polypeptides, Proteins)

abiogenesis, 96, 100, 108, 179-81 , $203,211,214,216$

biosynthesis of, 401, 413

common, $237-9$

uncommon, 240

Amino acid radicals, $23^{8-42}, 250$, 252

arrangement in peptides, 236, 241-5

arrangement in proteins, 234, $236-60,267-8,37^{\circ}$

Ammonia

cosinic distribution, 119-20, 137-40

on primitive Earth, 97, 141-3, $172,178-83,201$

Anabiosis, 60-1, 67, 187, 312

Anaerobiosis

anaerobic metabolism, 413,416 29

primitiveness, $400,4^{02}$

transition to aerobiosis, $430-8$

Antibiotics, 108, 19o, 240, 243 , $251,282,361,403$

Aquinas, Thomas, 10

Aristotle, 5-10
Arrhenius, S., 57-9, 63

Astronauts, 68

Asymmetry, 48-9, 100, 189-96

asymmetric synthesis, $183,192-6$, 216, 388-9o

Atmosphere of Earth

enrichment with oxygen, 143, $156-9,44^{6-50}, 4^{63}$

primaeval ( $c f$. Evolution, chemical), $81,94-5,14^{1-3}, 155^{-6}, 15^{8-}$ 62

radiations, absorption by, $63,161-3$

Atmospheres

of planets, 95, 118-20, 125, 142

of stars, $115^{-7}, 125$

Augustine of Hippo, St., 9-10, 44

Autocatalysis (cf. Self reproduction)

Bacon, Francis, 16

Basil the Great, St., 8-9, 11

Borodin, I., 32, 35

British Association, 73, 92

Bruno, Giondano, 15, 51

Buffon, G. L., 21

Carbides, 123, 125-9, 140-2, 159-61 , $167-8$

Carbohydrates (cf. Glycolytic systems)

abiogenesis of, $189,198-201$

laboratory synthesis, 108, 162-5

Carbon dioxide, fixation of, 110 , $407,411-2,414-5,417-8$

Catalysts ( $c f$. Enzymes)

analogous to enzymes, $245-6,371-3$ in stationary open systems, 331, $333-5,379$

simple, 170-4, 188, 195-6, 199, $211,214-5$ 
Chain reactions, catalytic ( $c f$. Fermentation, Tricarboxylic cycle), $336,33^{8}$

prebiological evolution of, $359^{-}$ 85

Cluain reactions, ionic, $335^{-9}$

Chemoautotrophs

metabolism, 110, 263, 408-12, 450-5 not primitive, $113,408-10$

Chlorophyll, 360-1, 408, 442-3

Christianity, 8-13

Coacervates, 303-21, 340-1, 351-9, $363,371-3,376,385,390$

Coenzyme A, 201, 208, 265, 334, $361,415-7,428-9,464$

Comets, $124-5$

Core of the Earth, 121, 125, 128, $140,142,168$

Cosmic dust, 52-3, 56-9, 117-8, 124-5, 132-7

Cytoplasm, 86, 271-2, 312-4, 379-80

Darwin, Charles, $32-3,75,79,289$

Democritus, 3-4

Descartes, 16

Dimitriǐ Rostovskiǐ, 11

Dusch, T., 26, 28-9

Electric discharges, $79-80,97,163-4$, $166,175-80,183-5,197,203$, 205, 333, 335

Empedocles, 3, 260-1

Energy of activation, $175,365-8$, $3^{8} 7,4^{21}, 470$

Energy metabolism ( $c f$. Glycolytic systems), $3^{81-3}, 3^{86-8}, 39^{1-2}, 399^{-}$ $404,409-13,419-37$

Engels, F., 33-4, 46, 92, 230-1, 348-9

Enzymes

abiogenesis, 93-7, 217, 261-2

active centres of, $247,250-3,372$

co-ordination, $364-6,374-85$

enzyme-substrate complex, 237 , $25^{0-1}, 336,368-70$

evolution, 261, 369-73, 401-2

localisation of, $3^{80-1}$

prosthetic groups, $245^{-7}, 366,369$, $372,403,439-43,454,471$

protein nature, $233-5,245-52$, $255,259,366-7$

specificity, $367-83$

in stationary systems, $327-9,331$
Epicurus, 3, 4

Evolution, biological, 114, 239-40, $260-1,285,35^{0-1}, 363,373,388$, $397-476$

Evolution, chemical

in the atmospluere, $153,162-4$, $175^{-8}-335^{-6}$

in the hydrosphere, $97-8,153$, $166-7,185-8,195^{-217}, 259^{-61}$

in the lithosphere, $165-75$

Evolution, prebiological, 24, 74-5, 78-9, 92-102, 260-1, 287-90, $301-2,319-20,33^{8-41}, 347-93$

Fermentation, 263, 364, 398

alcoholic, 337, 375-6, 383, 386, $420-8$

butyric, 417,428

extracellular, $375^{-7}, 3^{8} 3$

lactic, 420, 428-9, 434

other forms, 428

Gay-Lussac, J. L., 25, 30

Genes, 95-6, 99, 339

Germinal plasm, 85

Glycolytic systems

mechanisms, 263-4, 386-7, 420-31

in various organisms, 114, 263, 414, 431-6

oxidative, $467 \cdot 70$

universality, 388,426

Goose trees, 12-3

Haeckel, E., 34, 77-8, 82

Haemoglobin, 439-40

Harvey, 16

Hegel, 24

van Helmont, $15^{-6}, 35,44$

Heterotrophic metabolism

in various organisms, 406-11, 414, 444-5

primitiveness, 113-5, 399-400, 402, 418

High-energy compounds

abiogenic synthesis of, 207-9

localisation, $271-2,381$

in metabolism, 100, 114, 264-6, $3^{8} 7,39^{1}, 411,416,421-6,457$, $460-1$

Homunculus, 12-5

Hormones, 233-5, 243-5, 252, 255, $259^{-60}$ 
Huxley, T. H., 73-4

Hydrocarbons ( $c f$. Polymerisation)

abiogenesis of, 67, 94-5, 109, $129-30,159,165-9$

abiogenic transformation of, 142-3, $153,161,164-85,205$

in atmosphere, 166, 175-9, 185

cosmic distribution, $54^{-5}, \quad 116$ $27,137-41,153$

in hydrosphere, $167,175,186$

in lithosphere, 167-9, 173-7

saturated, $118-20,130,137-9,143$, 170,182

unsaturated, $67,119-20,143,170-1$, $182,184,202-3,215$

in volcanic gas, $160,167,175$

Hydrocarbon-using organisms, 412-4

Hydrosphere ( $c f$. Evolution, chemical, prebiological)

catalysts in, 371

coacervates in, 319-21, 340, $35^{6}$

open systems in, 339-41, 356

primaeval, $97-8,141,153,155-6$, 206, 449

Hylozoism, 44-6

Idealism, 6, 23, 31-3, 43, 45-7, 73, 107.347

Insulins, 235, 243-4, 252, 257

Isotopic composition of elements, $49-50,111,116,122,128,143$

Joblot, Louis, 20

Kant, I., 23-4, 132-3

Kircher, Athanasius, 44

Lamarck, 74-5

van Leeuwenhoek, 19

Leibnitz, 20, 44

Liebig, 46-7

Lipids

abiogenic formation, $189,200-1$

biosynthesis, 391, 413, 415

laboratory synthesis, 108

Lithosphere, 121, 141-2, 155-6, 159 , $165-77,184,188$

Materialism, 3, 16, 31-5, 44-7, 5o, $73-4,92,339,347-8$
Meteorites, $5^{2-7}, 120-5,127,140$

Microsomes, 269, 271-2, 380-2

Mitochondria, 98, 266, 268-72, 380-1

Needliam, J. T., 21-2, 25, 27, 36, 44

Nitrogen compounds, inorganic (cf. Ammonia), 74, 84, 116, 138, $142,178-82,203$

Nucleic acids

abiogenesis, 208-9, 211

biosynthesis, 208-10, 216, 271, 286-8, 391-2

in coacervates, 310

in protein synthesis, $265,267-8$, $272-90,362$

structure, $280-4$

Nucleoproteins

abiogenesis, 217

self-reproduction, 232

viral, $275-9$

Nucleosides

abiogenesis, 203-5

biosynthesis, 205

Nucleotides

abiogenesis, 189, 203, 205, 319

in nucleic acids, $275,279-85$

in peptide synthesis, $282-3$

Nucleus, 86, 93, 271-2, 312, 314

Oken, L., 24, 75

Oxygen (cf. Atmosphere, Photosynthesis)

Ozone screen, $63-6,16_{3}, 181,43^{8}$

Panspermia, 43, 52-6o, 64, 69, 77, 93. 112

Paracelsus, 14-6, 44

Pasteur, Louis, 28-31, 37, 45, 48, $50,55,375,3^{88}$

Pentoses

abiogenesis, 199

in alcoholic fermentation, 428

in nucleosides, 205, 208

Peptide formation, 208-16, 232, $259-60,264-7,302$

Petroleum

in nutrition of micro-organisms, 412-3

origin, 49, 110-1, 127-30, 173-4, 201 porphyrins in, $111,201-2$

Pflüger, E., 82-4, 419-20 
Phosphorus compounds, inorganic, 205-6, 209

Photoautotrophs

evolution, $442-5,449$

metabolism, 162, 263, 445-8, 455-64 not primitive, $111,406-7$

Photosynthesis (cf. Photoautotrophs)

effect on atmosphere, $15^{6-9}, 44^{6-}$ 5o, 463

production of organic compounds, $109-13,130,156-9$

Planets, $51-3,56,59^{-60}, 69$ carbon compounds on, $117-22,125$ origin of, 131-4, 136-42

Plasteins, 266

Plastids, 269, 272

Plato, 4-5

Plotinus, 8

Polarised light, $185,194-5$

Polymerisation of acetaldehyde, 177

amino acids, $211-3,216,266$

formaldehyde, $163,198,211$

glycolic aldehyde, 164

hydrocarbons, $67, \quad 119, \quad 169-70$, $174,176,182-3$

hydrocyanic acid, 213

mercaptans, 184

nitriles, 213-5

other organic compounds, 97, $153,163,177,180,186,216,266$

Polynucleotides, 100, 203, 209, 288, 302,341

Polypeptides

abiogenesis, 96, 208-17, 302

structure, 231, 236, 241-2, 245

Porphyrins

abiogenesis, 189, 201-2

biosynthesis, 201-2, 334, 361, 391-2

in enzymes, $37^{2}, 439,44^{1}$

in petroleum, 111

as photosensitisers, $439,443-6$

Pouchet, F., 26-8, 37, 44

Prokopovich, Theofan, 11-2

Proteins

amino acid composition and sequence, $232-52$

biosynthesis, $86,259^{-9}$ o, 36o, 391-2, 399,413

in coacervates, $305^{-11}$

conjugated, 237, 245-7

denaturation, $67-8,254-5,378$
Proteins-cont.

'living' and 'dead', 82-4

meaning of word, 229-33, 348-9

three-dimensional structure, 252 -

60

$\mathrm{X}$-protein of tobacco mosaic virus, $276-7,279$

\section{Protoplasm}

asymmetry in, 196

destruction by radiation, $67-8$

models of, 88-91

organisation, $37,317-23,331-2,379$

origin, $74,85-6,97$

proteins of, $68,82-4$

structure, $76,87-9,231,311-21$

use of term, $230-1$

vitrification, 61

Purine and pyrimidine bases

in nucleotides, $279^{-80}, 282-3,401$

synthesis, 203-5, 216

Radioactivity, $79,81-2,94,155^{-6}$, $165^{-6}, 168-9,174-5,333$

Redi, 17, 37

Respiration

a co-ordinated process, $364-5,377^{-8}$ glycolytic systems in, $114,467-70$ integration in metabolism, 386 , $400,420,422$

ontogenesis, $43^{6}$

origin, $464-76$

oxidative mechanisms in, $470-5$

Schäfer, E. A., 92-4

Schelling, F., 24

Schorlemmer, C., 108, 230

Schröder, H., 26, 28-9

Schulze, F., 25-6

Schwann, T., 25, 29

Self reproduction of

living systems, $33^{8-9}, 35^{0}, 360,362$

molecules, $97-9,3^{89}$

'moleculobionts', 96-7

nucleic acids, $284-9$

nucleoproteins, 217,232

proteins, 231-2, 259, 261-3, 278

viruses, 274

$\mathrm{X}$-protein, 276

Solar radiation (cf. Ultraviolet radiations), $161-2,180,197,43^{8}$ in metabolism, $43^{8}, 44^{2-3}$

Spallanzani, 22-3, 36 
Spontaneous generation, 1-46, 69, Timiryazev, K. A., 35, 93

$73,77-8,80$

Standardisation

of amino acids, $239-40$

of energy metabolism, 434

of metabolic materials, $39^{\mathrm{I}}$

Stationary open systems, 101, 321-35, $337 \cdot 8,35^{2}, 35^{6-60}, 371,389-90$

Sulphur compounds, inorganic, 141-3, $184,205,213-4,45^{1-5}$

Symbiogenesis, $85^{-6}$

Terekhovskiř, M., 23, 37

Tricarboxylic cycle (Krebs), 337,380 , $386-7,392,465-7$

Tyndall, J., 73-4

\section{Ultraviolet radiations}

and chemical evolution, 79, 94, $97,143,162,175,180-5,188$, $194-5,202,205,209,333,335$ effects on organisms, $62-8,188$

Virus, $37,96-8,259,273-9$

Vitalism, 32, 44, 46-7, 109

Thomson, W. (Lord Kelvin), 45 54

Volcanic effects, $49,58,81,112$, $129-30,142,160,168,175$ 




